\title{
Long Lives and Untimely Deaths
}




\title{
Brill's \\ Tibetan Studies \\ Library
}

\author{
Edited by \\ Henk Blezer \\ Alex McKay \\ Charles Ramble
}

VOLUME 27 


\section{Long Lives and Untimely Deaths}

Life-span Concepts and Longevity Practices among Tibetans in the Darjeeling Hills, India

By

Barbara Gerke

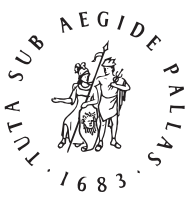

B R I L L

LEIDEN - BOSTON

2012 
Cover illustration: Woman with child turning prayer-wheels during a long-life empowerment in Ghum near Darjeeling, 2005 (photo by the author).

This book is printed on acid-free paper.

Library of Congress Cataloging-in-Publication Data

Gerke, Barbara, 1966-

Long lives and untimely deaths : life-span concepts and longevity practices among Tibetans in the Darjeeling Hills, India / by Barbara Gerke.

p. cm. - (Tibetan studies library ; v. 27)

Includes bibliographical references and index.

ISBN 978-90-04-21703-4 (hardback : alk. paper) 1. Tibetans—India—Darjeeling (District)—Social conditions. 2. Tibetans-India—Darjeeling (District)—Religion. 3. Longevity-India—Darjeeling (District) 4. Life span, Productive-India-Darjeeling (District) 5. Old age-India—Darjeeling (District) 6. Darjeeling (India : District)—Religious life and customs. 7. Darjeeling (India : District)-Social life and customs. I. Title.

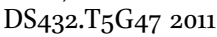

$305.895^{\prime} 4105414-\mathrm{dc} 23$

2011035141

Brill has made all reasonable efforts to trace all rights holders to any copyrighted material used in this work. In cases where these efforts have not been successful the publisher welcomes communications from copyright holders, so that the appropriate acknowledgements can be made in future editions, and to settle other permission matters.

This publication has been typeset in the multilingual "Brill" typeface. With over 5,100 characters covering Latin, IPA, Greek, and Cyrillic, this typeface is especially suitable for use in the humanities. For more information, please see www.brill.nl/brill-typeface.

ISSN $1568-6183$

ISBN 9789004217034 (hardback)

ISBN 9789004217485 (e-book)

Copyright 2012 by Koninklijke Brill NV, Leiden, The Netherlands.

Koninklijke Brill NV incorporates the imprints Brill, Global Oriental, Hotei Publishing, IDC Publishers, Martinus Nijhoff Publishers and VSP.

All rights reserved. No part of this publication may be reproduced, translated, stored in a retrieval system, or transmitted in any form or by any means, electronic, mechanical, photocopying, recording or otherwise, without prior written permission from the publisher.

Authorization to photocopy items for internal or personal use is granted by Koninklijke Brill NV provided that the appropriate fees are paid directly to The Copyright Clearance Center, 222 Rosewood Drive, Suite 910, Danvers, MA 01923, USA.

Fees are subject to change. 
For my parents

with gratitude for their love and support throughout my journeys 
Barbara Gerke - 978-90-04-21748-5 Downloaded from Brill.com๑4/26/2023 $\odot 2: 47: 13 \mathrm{PM}$ via free access 


\section{CONTENTS}

Note on Previous Publications .................................................................. xi

Acknowledgements ................................................................................ xiii

List of Maps and Illustrations $\quad$....................................................................... X. $\mathrm{xV}$

List of Abbreviations ................................................................................. xix

Notes on Tibetan Terms and References ............................................... xxi

Maps .................................................................................................. xxii

PART ONE

ETHNOGRAPHIC SETTINGS AND ANALYTICAL FRAMEWORKS

$1 \quad$ Introduction ..............................................................................................

1. Outlining the Argument ...................................................................... 3

2. Organisation of the Book .................................................................. 10

3. Some Notes on Important Terms ……………………………..... 15

4. Ethnographic Encounters …............................................................... 17

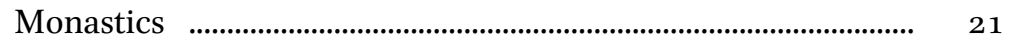

The Lay Community ....................................................................... $\quad 23$

Tibetan Medical Practitioners, Astrologers, and Diviners ..... $\quad 25$

5. Documentation Methods and Challenges ................................... 28

6. Analytical Frameworks: The Anthropology of Time ................ 32

\section{PART TWO}

THE FIELD SITE AND TIBETAN AREAS OF KNOWLEDGE

2 Tibetans in the Darjeeling Hills: The Socio-Political and

Historical Background

1. Historical and Political Climates ….............................................. 45

2. Demographic Data of Tibetans ....................................................... 56

3. The Reinvention of Ethnicity: Creating 'Cultural Vibrancy' $\quad \ldots . . \quad 58$

4. What Does it Mean to be a Tibetan in the Darjeeling Hills? ... 61

5. Tibetan Refugees ........................................................................... 66

6. Being Tibetan Without Speaking Tibetan ................................... 71

7. Tibetan Buddhist Monasteries ......................................................... 75

8. Tibetan Medical Healthcare .......................................................... $\quad 79$ 
3 Contextualising Tibetan Longevity Practices ……………………... 84

1. An Exposition of Pertinent Tibetan Areas of Knowledge ...... 84 Tibetan Medicine ........................................................................... 84

Tibetan Astrology …………………………………………………... 92

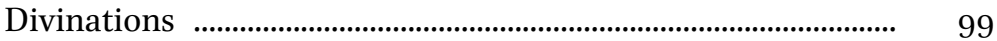

Tibetan Vajrayāna Buddhist Longevity Rituals $\quad$......................... 105

2. Knowing about the Life-span $\quad$....................................................... 111

PART THREE

THE LIFE-SPAN AND LIFE-FORCES IN TIBETAN MEDICAL CONTEXTS

4 Temporal Dimensions of Life-forces ………………………………… 119

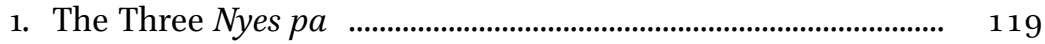

2. Temporal Frameworks of the Three Nyes pa …………………. 122

3. Temporalities and Treatment Schemes .................................... 127

4. Appropriating the Auspicious: The Best 'Life-force Days' and 'Life-essence Days' ...................................................................... 131

5 Detecting the Life-forces in the Body and the Life-span in the Pulse

1. Bla and Its Places in the Body in Tibetan Medical Texts and Clinical Practice

2. Divinatory and Temporal Aspects of Pulse Diagnosis ............ 154

3. Rhythm of Pulse, Rhythm of Life ............................................. 157

4. Distilling the Supreme Radiance of Vitality $\quad$............................... 162

PART FOUR

\section{THE LIFE-SPAN IN ASTROLOGICAL AND DIVINATORY CONTEXTS}

6 Merit, Karma, Liberating Animals, and the Five Astrological Factors

1. Merit and Karma ...……………………………………………... 169

2. The Longevity Practice of Liberating Animals ......................... $\quad 174$

3. Astrological Calculations Involving the Five Factors ……....... $\quad 176$

The Tibetan Almanac ...................................................................... 179

The Life-force \& the Body ............................................................ 181

Power, Prosperity, and Presence ................................................. 182 
Generating Good Fortune .......................................................... 184

'Bla is the Mother of Srog' $\quad$......................................................... 186

4. Jigme Lost His Bla $\quad$............................................................................ $\quad 187$

7 Untimely Deaths, Remaining, and Maximum Life-spans $\quad$......... 191

1. The 'Timely' Death of Samden .................................................. 193

2. A Family Story of Short Lives ...................................................... 197

3. Controlling Breath and the Maximum Life-span ................. 201

4. The Life-span is Completed ......................................................... $\quad 205$

8 Divining the Life-span $\quad$..................................................................... $\quad 207$

1. Your Life-span is Exhausted': Momola's Rosary Divination 208 The Notion of Bar chad ............................................................... $\quad 213$

2. Throwing the Dice: Textual Divination on Tshe and Srog ....................................................................................... $\quad 215$

The Palden Lhamo Divination ................................................... $\quad 216$

The Certainty of Uncertainty: Divinations on 'Whether

Srog is Stable or Unstable' ........................................................ $\quad 219$

3. Life-span Divination and Issues of Accuracy ......................... 221

\section{PART FIVE}

\section{TIBETAN BUDDHIST LONG-LIFE EMPOWERMENTS}

9 Ritual Layers of Long-life Empowerments $\quad$.................................... 229

1. The Notion of Byin rlabs ............................................................. 231

2. Tshe dbang Literature Review ................................................... $\quad 234$

3. Ritual Layers and Multiple Voices ............................................ 239

The Lama ............................................................................... 240

The Monks ................................................................................... 243

The Organisers .................................................................... $\quad 25^{2}$

The Sponsor .............................................................................. $\quad 253$

The Interpreter …................................................................... $\quad 256$

The Public ............................................................................... $\quad 257$

Individual Buddhist Practitioners $\quad$............................................... $\quad 258$

4. The Importance of Visualisation in relation to Byin rlabs ........................................................................................... $\quad 263$

10 The Sakya Tshe dbang: An Ethnographic Account of a Long-life Empowerment ................................................................ $\quad 269$ 
Appendices

1. Overview of the Terminology of the Life-span and Lifeforces and Their Meanings in Various Contexts

2. List of Monasteries Mentioned in the Book

3. The Thirty Places of Bla in the Body

4. Mtk Table of the Monthly, Weekly, and Daily Movement of Bla according to Three Different Traditions, with English Translation 308

Glossary of Recurrent Tibetan and Sanskrit Terms

List of Tibetan Proper Names

Bibliography

Index 


\section{NOTE ON PREVIOUS PUBLICATIONS}

Parts of this book have appeared, in revised and edited versions, in the following publications:

Gerke B. 2010a. Tibetan treatment choices in the context of medical pluralism in the Darjeeling Hills, India. In Studies of Medical Pluralism in Tibetan History and Society. PIATS 2006: Proceedings of the 11th Seminar of the International Association for Tibetan Studies, Königswinter 2006, eds. M. Schrempf, S. Craig, F. Garrett, M. Cuomu, pp. 337-376. Andiast, Switzerland: International Institute for Tibetan and Buddhist Studies GmbH.

. 2010b. The multivocality of ritual experience: long-life empowerments among Tibetan communities in the Darjeeling Hills, India. In The Varieties of Ritual Experience. Section IV of Ritual Dynamics and the Science of Ritual. Volume II - Body, Performance, Agency, and Experience (eds. A. Michaels et al.), eds. J. Weinhold, G. Samuel, pp. 423-441. Wiesbaden: Harrassowitz.

. 2011. Correlating biomedical and Tibetan medical terms in amchi medical practice. In Medicine Between Science and Religion: Explorations on Tibetan Grounds, eds. V. Adams, M. Schrempf, S. Craig, pp. 127-152. Oxford, New York: Berghahn Books.

— in press. Allegiance to whose community? Effects of Men-Tsee-Khang policies on the role and identity of amchi in the Darjeeling Hills. In Healing at the Periphery: Ethnographies of Tibetan Medicine in India, ed. L. Pordié. Durham: Duke University Press. 
Barbara Gerke - 978-90-04-21748-5 Downloaded from Brill.com๑4/26/2023 $\odot 2: 47: 13 \mathrm{PM}$ via free access 


\section{ACKNOWLEDGEMENTS}

A book involves many people, and its creation touches the lives of many. To write the acknowledgements after the work is done is a very enjoyable part of a book's creation. I deeply thank everyone involved in the process of researching and writing this book, even if I cannot list all the names here.

This work reflects the voices of many people in India whom I feel honoured to have met. I thank everyone listed below, and also those who contributed material that could not be included in this book but will appear in other publications:

Ama Tsamla, Amchi Jamyang Tashi, Amchi Kartsokyi and her husband Sangye Gyatso, Amchi Künga, Amchi Tsering Wangdue, Anmole Prasad, Anna Balikci, Anthony Fidler, Daniela Zinsmeister, Diki Choeden and Choeyang Lhamo, Dr. Pema Dorje, Dr. Tashi Namgyal, Heera Sharma, Jampa Kalsang, Jampel and Jigme Kaldhen, Lama Kunzang Dorje at the Jangsa Gompa, Lama Sonam in Ghum, Lama Tsewang at Tharpa Chöling, Lama Tsültrim at the Segyu Gyumed Datsan, Lyse Lauren, Mataji Kumari Cinturi, Niraj Lama, Prof. Samten Norbu, Ratna Vajra Rinpoche, Sangye and Norbu Dekeva, Shedup Tenzin, Sherab and Könchok Peljor, Sonam, Tanya Zikovic, staff and students of the Central School for Tibetans in Kalimpong, the amchis and teachers of Chagpori Tibetan Medical Institute and the late Dr. Trogawa Rinpoche, the lamas and monks of Durpin Gompa, the late Ang Purbu Sherpa, the late Khen Rinpoche, the late Momola, the late Penpa of the Yolmo Buddhist Association in Darjeeling, the Tibetan Welfare Officers, Tsering Dorje, the owners of Tsongzar Restaurant, and others.

Special thanks go to Adelheid Herrmann-Pfandt, who first inspired me to pursue a doctorate; David Gellner and Elisabeth Hsu for encouraging me to apply to Oxford University; my parents, Alfons and Ursula Gerke (1938-2011), who supported me throughout; all colleagues and friends who read through this work at various stages and made inspiring comments; and especially my D.Phil. supervisors Charles Ramble and Geoffrey Samuel, who skilfully steered me through the ups and downs of academia.

This book was written at many different places in four countries, and I want to thank those who provided welcoming living spaces to work: in the USA Hank and Vivien Shor, the late Adeline Altman, Julie Roberts, and Bonia Kovek; in the UK Geoffrey Samuel and Santi Rozario, Theresia 
Hofer, and Elizabeth de Michelis; in India the late Lama Chimpa and Tsering Dolma; and in Germany Jürgen and Renate Aschoff.

In India, I especially wish to thank my academic guide Suresh Sharma, former Director, Centre for the Study of Developing Societies (CSDS), Delhi, for inspiring talks and for granting my research affiliation with the CSDS; Madhulika Bannerjee and Jogendra Yadav with Gunu and Pele for their friendship and support in Delhi; all old friends who have known me since I first lived in Darjeeling and who supported me at many different stages; in Kalimpong, the International Trust for Traditional Medicine (ITTM), its staff, trustees, well-wishers, and all voluntary research coordinators, who creatively managed ITTM during my absences (especially Alicja Rucinska, Brenda Foran, Dalia Iskander, Elsa Lamiel, Emily Esmaili, Frank Müller, Laura Dorantt, Pamela Naymark, Renate Parasoglou, Anthony Ryan Haeseley, and Susanne Strässle); Sapna, Sabina, and Shankar for enriching my life in many ways; Shova Pradhan and Kalpana Prasad for caring for them when I could not, and Anne and Norman Pettigrew for their long-term support.

I gratefully acknowledge the financial support from various funds, organisations, and individuals, who made this research possible: Dr Susil Kumar and Jamila Mitra Charitable Trust, London; the Green College Travel Fund and the Anthony Storr Bursary Fund, Green Templeton College, Oxford; Oxford University Society Travel Award; Radcliffe-Brown Fund for Social Anthropological Research; The Khyentse Foundation; the late Dr. Gerhard Mentzel, Germany; Swati and Arun Iyer, India, and my parents.

Special thanks go to Edward Henning in London and Tenzin Tsewang Jamling for their valuable comments on the astrology-related sections of the book; Jampel Kaldhen in Kalimpong for sharing his time and knowledge on astrology and the Palden Lhamo divination; Amchi Tsering Wangdue, Anne Pettigrew, Florian Ploberger, Mona Schrempf, Stephan Kloos, and Tsering Gonkatsang for reading through various sections of the book and offering comments and suggestions; Johannes Schneider in Munich for first making available his unpublished Habilschrift and then providing the page numbers to my citations of his published work (Schneider 2010); Hermann Kreutzmann in Berlin for his cartographic expertise; the editorial team and the anonymous reviewer from Brill Academic Publishers for guidance and valuable comments.

To end, I warmly thank my husband Thomas K. Shor, who entered my life unexpectedly one day in the middle of Darjeeling at the end of fieldwork, for his love and support ever since, and all the patience it takes to share the daily life of research and writing. 


\section{LIST OF MAPS AND ILLUSTRATIONS}

\section{Maps}

1. The location of Darjeeling district in India

xxii

2. The geographical setting of the field site, Darjeeling and Kalimpong, in West Bengal, India

\section{Tables}

4.1. Characteristics and temporalities of the three nyes pa according to the Rgyud bzhi

4.2. 'Vitality table' indicating the best 'life-essence' days, 'life-force' days, and 'inauspicious' days

6.1. Interpretation of pebble calculations in the Tibetan almanac

\section{Plates}

All photos in this book are by the author except plate 1.2, which is by Thomas K. Shor.

1.1. The fieldwork base, the centre of the International Trust for Traditional Medicine, Kalimpong 2005

1.2. The author with her Nepali foster children, Kalimpong 2005

1.3. Jangsa Gompa, the Bhutanese monastery following the Dudjom gter gsar school, Kalimpong 2005

1.4. Amchi Tsering Wangdue feeling the pulse of a patient, Kalimpong 2006

1.5. Lama Tsewang, a senior longevity practitioner at the Tharpa Chöling Monastery, Kalimpong 2004

2.1. View of Darjeeling with Mount Kanchenjunga, 2004 ................ 46

2.2. View of Kalimpong with the Kanchenjunga Range, 2005 ........ 47

2.3. The Tenth Mile area, Kalimpong 2005 
2.4. The famous Tibet Mirror Press, Tenth Mile, Kalimpong 2007

2.5. Tsering Dorje at his shop in Tenth Mile, Kalimpong 2006

2.6. Monks in front of the Zangdok Palri Monastery (Durpin Gompa), Kalimpong 2005

2.7. View of Kalimpong from the Zangdok Palri Monastery (Durpin Gompa), Kalimpong 2005

2.8. Tharpa Chöling, the Geluk monastery at Tirpai, Kalimpong 2005

3.1. A mo pa performs $m o$ at the Jangsa Gompa, Kalimpong 2004

3.2. The dice and mo text used by the mo $p a$ at the Jangsa Gompa, Kalimpong 2004

3.3. Ama Tsamla, a Tibetan diviner, in her shrine room,

Kalimpong 2005

3.4. The Gesar mo temple at the Tharpa Chöling Monastery, Kalimpong 2004

3.5. The three long-life deities on a wall painting at the Mani Lhakhang, Kalimpong 2005

4.1. A pre-printed MTK brown paper bag used to distribute Tibetan pills, Kalimpong 2005

5.1. Amchi Jamyang Tashi in his consultation room at the MTK branch clinic, Kalimpong 2004

5.2. Amchi Künga with Amchi Jamyang at the opening ceremony of the new MTK building, Salugara 2004

5.3. Amchi Kartsokyi at the MTK branch clinic, Kalimpong 2007

5.4. Dr. Pema Dorje at the opening ceremony of the new MTK building, Salugara 2004

6.1. Inauguration of the fishpond at the Jangsa Gompa, Kalimpong 2005

6.2. Rlung rta flags in the five colours, Kalimpong $2005 \quad$................... 185

8.1. The Tibetan diviner Momola, Ghum 2004 ................................... 209

8.2. Wooden dice used in the Palden Lhamo divination, Kalimpong 2004

8.3. Jampel Kaldhen explains the Palden Lhamo divination text, Kalimpong 2004

9.1. Long-life pills at a tshe dbang, Ghum 2004 238

9.2. Two bowls of long-life nectar and other offerings, Ghum 2004 
9.3. Lama Kunzang Dorje at a seven-day sman sgrub sgrub chen ritual, Kalimpong 2004

9.4. Elaborate offerings for a tshe dbang at the Mani Nyungne Kidu, Ghum 2004

9.5. Long-life pills and long-life nectar that were consecrated during a tshe sgrub, Kalimpong 2004

9.6. A monk prepares the offerings during a tshe sgrub, Kalimpong 2004

9.7. Lama Karma, Lama Sonam, and a young novice during a tshe sgrub, Kalimpong 2004

9.8. Lama Karma circulates the long-life arrow during a tshe sgrub, Kalimpong 2004

9.9. The monk Phuntsok explains the various offering gtor ma, Kalimpong 2004

9.10. The long-life arrow on the tshe sgrub altar, Kalimpong 2004 250

9.11. The official sponsor of a tshe dbang receives his blessings, Pedong 2005

9.12. A monk distributes long-life water to participants during a tshe dbang, Gangtok 2004

9.13. Monks distribute long-life nectar and long-life pills to the crowd during a tshe dbang, Pedong 2005

9.14. A monk distributes protective cords during a tshe dbang, Gangtok 2004 261

9.15. Tibetan women pray during a mandala offering at a tshe dbang, Gangtok 2004

262

10.1. Ratna Vajra Rinpoche gives a White Tārā tshe dbang, Ghum 2005

270

10.2. The crowd in front of the Sakya monastery and temple during a tshe dbang, Ghum 2005

10.3. The crowd settling on balconies and roof tops during a tshe dbang, Ghum 2005

10.4. Family picnics on roof tops during a tshe dbang, Ghum 2005

10.5. A scene behind the temple during a tshe dbang, Ghum 2005

10.6. A long-life initiation gtor ma with an image of Amitāyus, Ghum 2004

10.7. A scene inside the temple during a tshe dbang at the Sakya monastery, Ghum 2005

10.8. Young teenage participants receive byin rlabs during a tshe dbang at the Sakya monastery, Ghum 2005 
Figures

5.1. Excerpt of a Tibetan medical thanka: The loss of bla tshe when stolen by a demon

5.2. Excerpt of a Tibetan medical thanka: Bla tshe personified by a human being

5.3. Excerpt of a Tibetan medical thanka: The case of an inconstant bla pulse

5.4. Excerpt of a Tibetan medical thanka: A person who has lost the bla tshe

8.1. Photo of a manuscript folio: Divination to see whether srog is stable or unstable, folio $7 \mathrm{~b}$ and folio $8 \mathrm{a}$

8.2. Photo of a manuscript folio: Divination to see whether srog is stable or unstable, folio $31 \mathrm{~b}$ and folio $32 \mathrm{a}$

8.3. Photo of a manuscript folio: Divination on tshe and skyid sdug, folio $3 \mathrm{~b}$ and folio $4 \mathrm{a}$

8.4. Photo of a manuscript folio: Divination on tshe and skyid $s d u g$, folio $11 \mathrm{a}$ and folio $1 \mathrm{~b}$

\section{Appendices}

3. The thirty places of bla in the body

4. MTK table of the monthly, weekly, and daily movement of bla according to three different traditions, with English translation 


\section{LIST OF ABBREVIATIONS}

$\begin{array}{ll}\text { CCTM } & \text { Central Council of Tibetan Medicine } \\ \text { CIBS } & \text { Central Institute of Buddhist Studies } \\ \text { CTA } & \text { Central Tibetan Administration-in-exile } \\ \text { CTMI } & \text { Chagpori Tibetan Medical Institute } \\ \text { CTRC } & \text { Central Tibetan Relief Committee } \\ \text { CTSA } & \text { Central Tibetan Schools Administration } \\ \text { CUTS } & \text { Central University of Tibetan Studies } \\ \text { DGHC } & \text { Darjeeling Gorkha Hill Council } \\ \text { DLLS } & \text { Drepung Loseling Library Society } \\ \text { GNLF } & \text { Gorkha National Liberation Front } \\ \text { IAS } & \text { Indian Administrative Services } \\ \text { IDP } & \text { International Dunhuang Project } \\ \text { ITBCI } & \text { Indo-Tibetan Buddhist Cultural Institute } \\ \text { ITTM } & \text { International Trust for Traditional Medicine } \\ \text { MPT } & \text { Most Primitive Tribe } \\ \text { MTK } & \text { Men-Tsee-Khang, Dharamsala, India and Mentsikhang, Lhasa, } \\ & \text { Tibetan Autonomous Region } \\ \text { NGO } & \text { Non-governmental organisation } \\ \text { NSWC } & \text { Nyingmapa Student's Welfare Committee } \\ \text { OBC } & \text { Other Backward Classes } \\ \text { RC } & \text { Refugee Certificate } \\ \text { SC } & \text { Scheduled Castes } \\ \text { ST } & \text { Scheduled Tribes } \\ \text { STSS } & \text { Sambhota Tibetan Schools Society } \\ \text { TAR } & \text { Tibetan Autonomous Region } \\ \text { THL } & \text { Tibetan and Himalayan Library }\end{array}$


Barbara Gerke - 978-90-04-21748-5 Downloaded from Brill.com๑4/26/2023 $\odot 2: 47: 13 \mathrm{PM}$ via free access 


\section{NOTES ON TIBETAN TERMS AND REFERENCES}

Tibetan terms are presented in their Wylie transliteration (Wylie 1959). The phonetic renderings of all recurrent terms appearing in Wylie can be found in the appended glossary. Tibetan common names (e.g. Tashi) names of historical figures (e.g. Desi Sangye Gyatso), high lamas (e.g. Ratna Vajra Rinpoche), and names of places (e.g. Lhasa) and monasteries (e.g. Jangsa Gompa) are reproduced in a simple phonetic rendering. The Tibetan orthographic forms of common names and historical figures are given in a separate glossary in the appendix, using the Wylie system of transliteration. Names are not italicised. Other Tibetan terms, longer quotes in Tibetan and titles of Tibetan texts are italicised and only given in their Wylie transliterations. Titles of Tibetan texts are additionally capitalised.

References for the Tibetan medical standard text Rgyud bzhi are indicated as follows: I, II, III, and IV refer to the respective four main treatises. These are followed by the chapter and page numbers. For example, 'Rgyud bzhi II, 5: 45' denotes the second treatise, fifth chapter, page 45. Page numbers refer to the Chagpori edition (Darjeeling 1992).

Plural forms of Tibetan terms are not indicated. Exceptions are popular Tibetan terms, which are written in their anglicised form (e.g. amchi, gompa, lama, rinpoche). Only in case of the more familiar anglicised Tibetan words, such as 'lama,' is the plural -s directly attached, for example, amchis, gompas, lamas, rinpoches. Those words are also not italicised. The same applies to the anglicised Indian or Nepali terms for different population groups, such as Biharis, Marwaris, Tamangs, etc.

Although I am usually consistent in using the Tibetan terms, in a few cases I use the Sanskrit term, both because of its relative familiarity in English and because a majority of Tibetans in India use the term, for example, karma (las) and dharma (chos). Sanskrit terms are listed separately in the glossary. The names of Buddhist deities are given in their more familiar Sanskrit forms (e.g. Buddha, Amitāyus, Tārā), except where the Tibetan forms are more in use (e.g. Palden Lhamo), or where a speaker has used the Tibetan form in a direct quote. 
MAPS

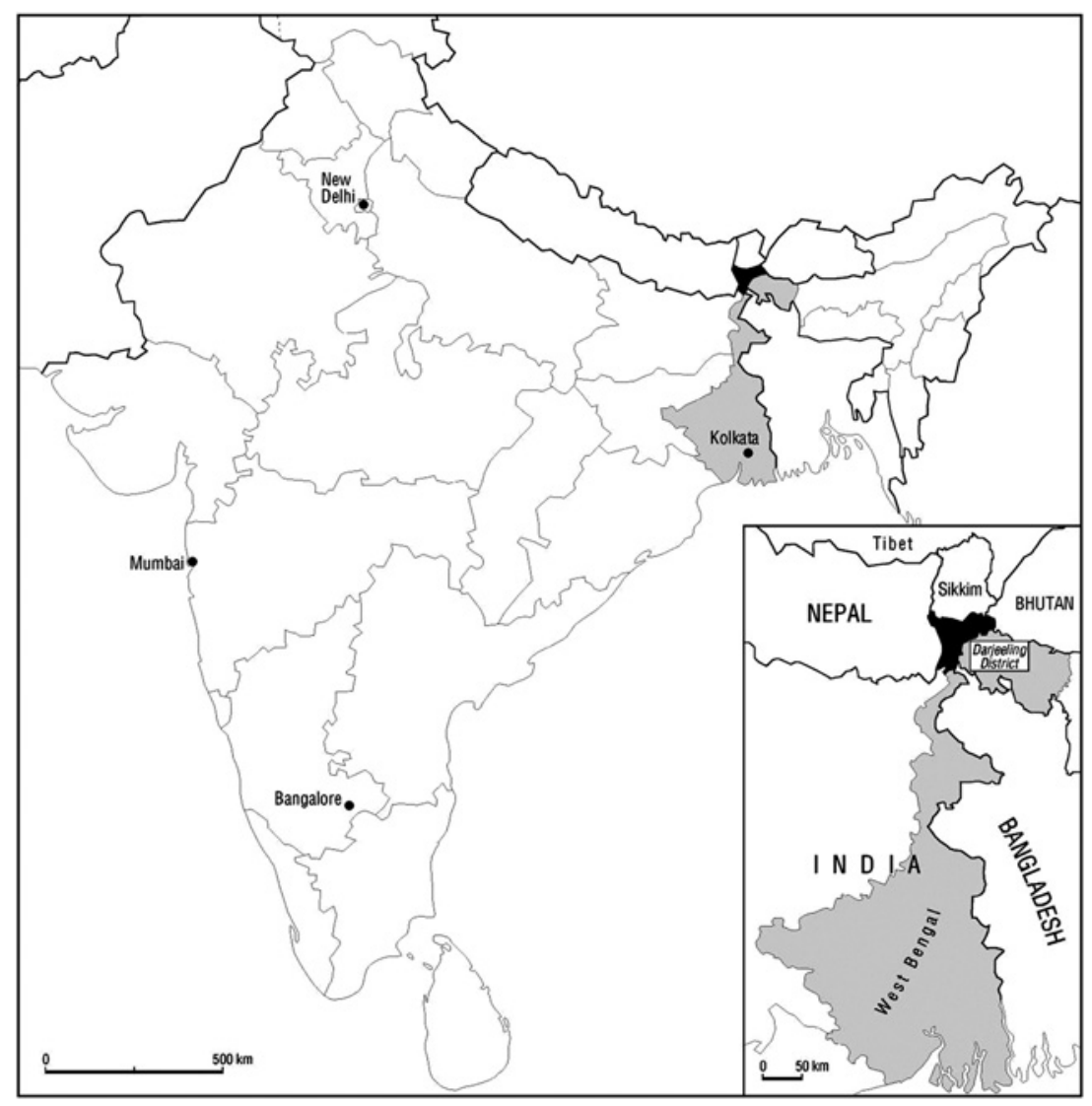

Map 1. The location of Darjeeling district in India. 


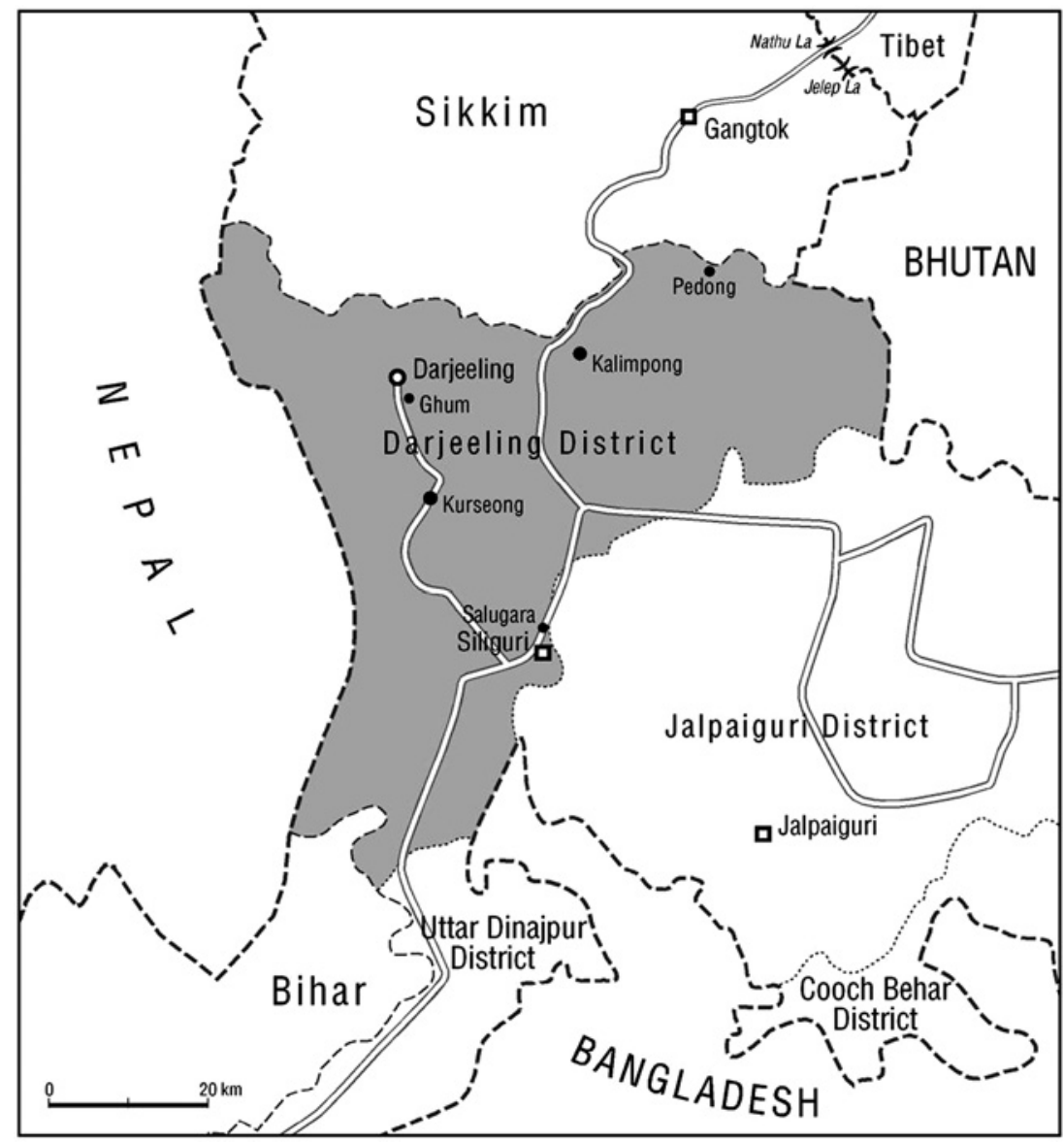

Map 2. The geographical setting of the field site area in West Bengal, India. 
Barbara Gerke - 978-90-04-21748-5 Downloaded from Brill.com๑4/26/2023 $\odot 2: 47: 13 \mathrm{PM}$ via free access 
PART ONE

ETHNOGRAPHIC SETTINGS AND ANALYTICAL FRAMEWORKS 
Barbara Gerke - 978-90-04-21748-5 Downloaded from Brill.com๑4/26/2023 $\odot 2: 47: 13 \mathrm{PM}$ via free access 


\section{INTRODUCTION}

\section{Outlining the Argument}

This book presents a study of how Tibetans in the Darjeeling Hills, India, understand the life-span and various life-forces that influence longevity. Based on a significant corpus of new ethnographic material from this Tibetan context, it emerges that the life-span is not necessarily conceived of as a linear concept of years lived, but implies more the idea of a reservoir, of an oil-lamp filled with oil that can, for example, be refilled to a certain extent when the oil runs low. Interestingly, the various factors that exist to strengthen or 'fill' this reservoir are intrinsically linked to temporal frameworks connected to various systems of vitality and their reckoning. This book discusses how Tibetans use these temporal frameworks in medical, astrological, divinatory, and ritual contexts to locate and reckon various life-forces influencing their life-spans.

Ethnographic accounts show, for example, that temporal ideas influence the ways Tibetans choose auspicious days for medical treatment, avoid the injury of specific places in the body that embed a vital essence, use almanacs to establish the status of annually-changing factors that determine their fortune and vitality, and interpret divinations concerning the life-span in wider contexts of Buddhist ideologies. Tibetans also engage in Vajrayāna Buddhist long-life empowerments (tshe dbang), ${ }^{1}$ which grant special blessings that counteract karmic obstacles that could lead to an 'untimely death.' In all these events, temporality and agency are deeply interlinked in the ways in which Tibetans enhance their vitality and prolong their life-spans.

The main argument I bring forth in this book is that Tibetan concepts of various life-forces and the life-span are linked to temporal frameworks that emerge from specific physiological and cosmological ideas. These temporal frameworks are required to map out and govern the inherently changing nature of the life-span and life-forces, which go through periods

\footnotetext{
${ }^{1}$ For phonetic renderings of recurrent Tibetans terms see the glossary on page $317 \mathrm{ff}$.
} 
of ups and downs, illness and health in day-to-day life. Since they keep changing, they need to be known. I argue that it is through a variety of what I call practices of temporalisation, in which professionals and lay people mediate between temporal frameworks and the situation of individuals or of social groups, that Tibetans strengthen their life-forces and create a sense of increased vitality. In this process they map out medical, astrological, divinatory, and ritual activities throughout their lives in the pursuit of protecting, negotiating, and prolonging their life-spans. I discuss these practices of temporalisation in their wider contexts involving ideas of karma, obstacles, auspiciousness, and 'blessing.'

In what ways is temporality of crucial importance in understanding longevity among Tibetans? How do Tibetan lay people and professionals (traditional Tibetan doctors, diviners, astrologers, and Buddhist teachers) mediate between these temporal frameworks and their personal and professional situations? In answering such questions this book draws on recent studies concerning the anthropology of time and emphasises situational agency. It presents a substantial body of ethnographic data from seventeen months of fieldwork (2004-2007) among Tibetan communities in the two urban centres of Kalimpong and Darjeeling, situated on the hilly slopes of the northeastern Himalayas in the Indian state of West Bengal. I lived in this area for long periods of time between 1992 and 2008. My own translations of relevant sections from two influential Tibetan medical texts from the twelfth and seventeenth century $\mathrm{CE}$, which are used by contemporary Tibetan medical practitioners, supplement my ethnographic accounts.

The various knowledge systems through which Tibetans - who mostly follow Tibetan forms of Vajrayāna and Mahāyāna Buddhism² ${ }^{2}$ encounter the life-span have been accumulated over many centuries, and draw on historically and ideologically unrelated systems of thought. These knowledge systems have become deeply interlinked, and in daily life their boundaries are often blurred. Medical knowledge is ritualised, and rituals are linked to health and well-being; astrology and divination are interconnected with the medical and ritual realms and vice versa. Taken as a whole, they all contribute to the extension of life and the well-being of Tibetan societies. Therefore, even though I present my ethnographic

\footnotetext{
${ }^{2}$ Mahāyāna (lit. 'Great Vehicle') is one of the major branches of Buddhism. It has a strong focus on the motivation to achieve Buddhahood out of compassion for all beings (bodhicitta). Vajrayāna (lit. 'Diamond Vehicle') or tantric Buddhism employs additional tantric techniques, such as the self-identification with a Buddha form.
} 
data within four areas of knowledge - medicine, astrology, divination, and ritual - I do not draw clear lines between them. The separate introductions to these knowledge systems in chapter 3.1 make sense, however, because each exists as a specialised field of knowledge with a large body of literature and expert educational training. Despite their interrelationships and blurred boundaries, each of these knowledge systems offers specialised practices and professional expertise concerning longevity. Since I look at the different domains of these professionals and their engagement with longevity, my differentiation between them intends to provide a clearer structure for the reader to understand this rather complex material. This arrangement is also applied to the three main ethnographic parts of the book, which present the material within the contexts of the knowledge systems of medicine (part III, chapters 4 and 5), astrology and divination (part IV, chapters 6 to 8), and Vajrayāna Buddhist rituals (part V, chapters 9 and 10).

Medicine here refers to the corpus of classical Tibetan medical knowledge, including its textual and oral traditions, and contemporary practices. Astrology, although often taught side by side with medicine in Tibetan institutions, is a body of knowledge in its own right and includes astronomy, calendar making, astrological charts, death calculations, and almanacs. Divinatory knowledge can be textual, but is also practised by illiterate diviners. Both, astrology and medicine can be of divinatory character. By ritual knowledge, I mainly refer to the vast area of Tibetan Vajrayāna Buddhist practices involving the recitation of mantras, the visualisation of deities, the transfer of 'blessing' (byin rlabs) through empowerments (dbang), and meditation practices.

Tibetans generally do not know about all the different life-forces that are mentioned in their various knowledge systems. Rather they make varied use of the numerous vitality factors and their related methods of diagnosis, prognosis, or treatment that these systems provide them with depending on their life situation. Lay Tibetans often have a popular understanding of the specialised knowledge, and technical terms can acquire a range of meanings in different contexts (see summarised overview of the different interpretations of technical terms in appendix 1).

During my fieldwork, it was noticeable that in dealing with different life-forces professionals as well as lay people gave significant importance to temporality. Therefore, my discussions of the data raise several interesting questions that contribute to current studies in the anthropology of time (see chapters 1.6 and 11). Rather than focusing on time per se and arguing that there is a uniquely Tibetan understanding of time that can 
be contrasted with other Asian or with western understandings, I look at practices of temporalisation.

In my ethnographic accounts, I use the term practices of temporalisation to indicate those activities in which professionals and lay people mediate between temporal frameworks and the individual (e.g. a patient or client) or the social group (e.g. the community at the time of a death). I define temporal frameworks as those Tibetan ideas that are characterised by temporal dimensions and follow a reckoning system: for example, the seasons or times of the day, astrological parameters in almanacs, 'vitality tables,' the movement of a life-force in the body following the moon cycle, and the rhythm of the pulse indicating the life-span. Some of these frameworks relate to astrological or calendrical parameters (e.g. the moon cycle), some to physiological rhythms of the body (e.g. the pulse beat or breath), others involve larger cosmological ideas. Temporal frameworks are often used as 'time-markers' and set certain events in time and mark them with (in)auspicious qualities. In Tibetan traditions, these temporal frameworks are embedded in sophisticated and complex bodies of textual and oral knowledge systems. By linking life-forces to temporal frameworks these concepts receive meaning and are more easily calculated, known, and manipulated by both professionals and lay people.

With this approach of practices of temporalisation I intend to emphasise what actually happens between actors and existing temporal frameworks. I show how professionals as well as lay people have what I term here situational agency in their selective ways of dealing with temporal frameworks in their day-to-day lives. By situational agency ${ }^{3}$ I mean the engaged response of professionals as well as lay people to situational circumstances, in which existing temporal frameworks are selectively used and modified. It implies that actors not only have selective choices in their ways of using these frameworks, but that they feel empowered through active engagement with these existing temporal frameworks in an attempt to mediate their life-spans at a point in time. I address my use of situational agency again at the end of this chapter. As I will show, the interactions between temporal frameworks and people's situational agency generates a variety of practices of temporalisation.

Throughout this book I use practices of temporalisation as a generic term to group together the various activities of professionals and lay

3 I want to thank Mona Schrempf for pointing me in this direction and for suggesting relevant literature. 
people in different contexts that involve temporal frameworks to manage life-forces. The varying quality and strength of the life-forces in time are established through divination, astrological calculations, and medical diagnosis. Most of these life-forces can be strengthened ritually on auspicious dates and involve concepts of 'blessing.'

In Tibetan, the life-span is generally called tshe, tshe tshad (lit. 'duration of life'), or tshe lo (lit. 'life years'). Tshe lo means the maximum lifespan and is also a colloquial term for 'age.' The term tshe will appear throughout this book in numerous contexts. Tshe encompasses a number of different ideas that have a temporal dimension: notions of a maximum life-span that can be cut short; ideas of an 'untimely death,' in which case the remaining life-span can be lived in another lifetime; factors of auspiciousness, merit, and blessing, all of which can prolong tshe; and karmic obstacles that can cut short the life-span. Overall, tshe is linked and interconnected to various vital factors. In Tibetan there is no single word that encompasses all these concepts. In this book I label them 'life-forces,' defined for this purpose as an umbrella term for Tibetan concepts that relate in one way or the other to tshe and influence ideas of longevity. They include large variations of interpretations, as already indicated, and exist in parallel and overlapping knowledge systems.

Two of the life-forces that are given considerable significance among Tibetans are called srog and bla. Srog is life itself. It indicates the key vitality of a person, and I translate it as vital force. Its decline leads to a loss of tshe; its loss leads to death. The stability of srog can be astrologically calculated (see chapter 6.3) or divined (see chapter 8) and it can be ritually strengthened. Astrological annual 'vitality tables' include favourable srog and bla days (see chapter 4.4). Bla in the astrological and medical contexts is a subtle life-essence that supports srog. It is sometimes translated as 'soul,'4 or 'spirit' (Desjarlais 1992: 64). Bla can be lost through shocks and accidents or stolen by demons. ${ }^{5}$ It can only be regained through rituals, not

\footnotetext{
4 The notion of 'soul' is strongly rooted in a Western philosophical context. Bla has most commonly been translated as 'soul,' probably because the European connotation of a vital force that is capable of leaving the coarse body has survived most prominently in the idea of the 'soul.' Lopez argues that the original meaning of bla as a life-force was lost in the Buddhist term bla ma, where bla was translated as 'high' and bla ma as guru or spiritual teacher (Lopez 1997a: 20-21).

5 The Tibetan world knows of a variety of demons (srin) and spirits (gdon) that can cause harm to humans. People protect themselves from demonic attacks through rituals, mantras, and amulets, by ingesting or wearing consecrated substances, and by reserving important activities for auspicious days.
} 
through medical treatment, although its loss can be diagnosed by Tibetan medical practitioners through pulse diagnosis. A medically diagnosed loss of bla is usually confirmed by a divination and also by astrological calculations (illustrated in the story of Jigme losing his bla in chapter 6.4). The loss of bla weakens srog and if untreated cuts short tshe. In medicine, bla receives a special significance since it is said to travel through the body through various vital points (bla gnas, lit. 'places of bla'), ${ }^{6}$ following the moon cycle (see chapter 5.1). The special bla pulse itself is also used to diagnose and prognosticate the life-span.

Sometimes, the three, tshe, srog, and bla are treated as a trinity (tshe srog bla gsum). All of them support the idea of the life-span being a reservoir of vitality that will eventually be exhausted, like an oil-lamp running out of fuel. A Tibetan simile reveals the nature of this trinity: "tshe is like oil in a lamp, srog is like the wick, and bla is like the flame" (Tibetan and Himalayan Library, hereafter THL 2009). The life-span itself (tshe) is the oil. The flame (bla) cannot exist without the wick (srog). If the wick $(s r o g)$ is weak, the flame (bla) will go out. The temporary loss of bla would be represented by a blown out lamp. This simile shows that tshe itself requires a certain amount of fuel (oil in a lamp), which can run out, but can also be refilled, which opens the possibilities of actively managing one's tshe (refilling the lamp with oil).

The ethnographic accounts presented in this book show that many of the life-forces are mapped out using various temporal frameworks, which allow for a certain diagnosis of their location in the body. Their movements and strengths follow daily, monthly, and annual cycles. The 'vitality tables,' divination, and medical prognosis of the life-forces are widely but varyingly used by Tibetans to forecast difficult periods in their lives. Preventive methods, which are embedded in ideas of merit and karma, include merit-generating activities, such as saving animal lives (srog bslu and tshe thar), conducting longevity attainment practices (tshe sgrub), or attending long-life empowerments (tshe dbang). All these activities are also of a therapeutic nature, for example, when obstacles to tshe have been divined.

Most Tibetans regularly attend Buddhist long-life rituals throughout life as preventive measures to avoid 'untimely deaths.' Empowering and enhancing tshe is not merely an issue of extending life, but also of protecting tshe, srog, and bla. Many Tibetans bring their children to these very popular events to protect them from accidents and 'untimely deaths.'

${ }^{6}$ These bla gnas have different meanings in other contexts; see appendix 1. 
Longevity practices, however, also involve personal meditative practices, passed on from teacher to disciple, that employ breathing techniques and visualisations of various life channels in the body in combination with mantras and deity practices, all of which are meant to enhance the life-forces.

The Tibetan context is apt for a study of practices of temporalisation with regard to the life-span and life-forces because the life-span, tshe, exists as a negotiable entity that people have and can manipulate. As I suggested above, $t$ she is primarily not understood as a time-span, a durational allotted time that one passes through and that ends with death. It exists within the dynamic field of various life-forces that can strengthen or weaken tshe, and that require constant management. Tshe maintains a certain amount of flexibility in the way that it includes opportunities to reckon and modify the various life-forces that influence it. Tshe can be exhausted, cut short, ritually modified, or snatched away by demons or spirits. It is a reservoir of vitality that requires constant vigilance to last for the maximum time possible and not to become prematurely exhausted.

A basic understanding prevalent in Tibetan societies is that there is no concept of lengthening life at all costs because the life-span does not necessarily terminate at death and death is not seen as terminal. When death is inevitable, long-life practices change over to death-preparation practices. When death is approaching, a different set of practices is applied to prepare for the transition of consciousness (rnam shes $)^{7}$ into the intermediate state (bar do) and into the next incarnation. What does it mean for Tibetans when a divination states that "the life-span is finished and nothing can be done?" What does it mean in terms of their temporal ideas of tshe and in terms of their treatment-seeking behaviour? To answer such questions, some ethnographic examples of how divinations have been employed during times of terminal illness and sudden deaths are presented in chapter 7 . In order to contextualise such examples within the wider picture of the medical pluralistic societies of the Darjeeling Hills, various medical facilities and ideas that guide decision making behaviour among Tibetans at times of illness are introduced in chapter 2.

The following sections outline the chapters of the book, explain complex terms, introduce the types of ethnographic encounters I had in the field, discuss the methodology used in my ethnographic research,

\footnotetext{
7 Consciousness is the technical meaning of rnam shes in Buddhist philosophy. In colloquial contexts the concept of rnam shes can become blurred and overlap with other concepts, such as bla (see, for example, Millard 2002: 152; Diemberger 1993: 104-106, 113).
} 
and explain why the anthropology of time is significant to the material I collected.

\section{Organisation of the Book}

This book is comprised of eleven chapters in five parts. Part I, a single chapter, introduces the main ideas of the book, defines its most important technical terms and contextualises their usage. It outlines the different kinds of ethnographic encounters I had in the field and critically reflects on the positions I held during fieldwork and how this affected the study. It also presents the key authors of the anthropological literature on time that inspired me to develop the analytical framework on practices of temporalisation.

Part II, comprising chapters 2 and 3, introduces the field site and the various knowledge systems that Tibetans draw from in their understanding of longevity. Chapter 2 begins with a socio-political history of the people in the Darjeeling region, or the Hills - as the region is locally called - and especially Tibetan communities. Tibetans in the Darjeeling Hills are a heterogeneous group of people with contrasting histories, depending on whether they came to the area as traders, refugees, or were born there. The chapter explores how - given the complex social world within which Tibetans have lived in the Hills - their expression and sense of 'Tibetanness' ${ }^{8}$ has changed with time. I discuss how they have learnt to utilise the power and agency that comes with the creation of new categories of 'ethnicity' and 'identity' in a multi-ethnic society as a tool that allows them to define themselves and each other as 'Bhutias,' 'old' or 'new' 'Tibetans,' or 'newcomers.' All these categories are explained in the chapter and put into context of the particular political situation of the Darjeeling Hills up until 2007, just after I completed my fieldwork. ${ }^{9}$ The Hill politics are marked by the uncertainties of a long-term Nepali nationalist movement, involving a violent agitation in the 1980s. The movement has marginalised Tibetans, as well as other non-Nepali groups, ${ }^{10}$

\footnotetext{
8 The term 'Tibetanness' is explained in the next section (1.3).

9 I did not include the political upheavals after 2007, since they happened after my fieldwork was completed. See the doctoral thesis by Middleton 2010 for details on these events.

${ }^{10}$ The situation is different in Sikkim, where the Sikkimese Bhutias, who ruled under the Choegyal, still hold substantial power and are in conflict with Tibetans, who often
} 
and has crippled the creative development of individuals and the region as a whole.

I sketch Tibetan identity in a different light than what has been described in other Tibetan identity studies based mainly in or near Dharamsala, the base of the fourteenth Dalai Lama Tenzin Gyatso and about ten thousand Tibetans in the Indian state of Himachal Pradesh (for example, Diehl 2002; Klieger 2002; Kloos 2010; Korom 1997; Prost 2004, 2008). The Dharamsala area is dominated by the administration of the Tibetan government-inexile and a massive Tibet tourism. I present Tibetan identity outside the Dharamsala enclave. How Tibetans express their 'Tibetanness' allowing for 'modern' interpretations of a Tibetan Buddhist culture in the heterogeneous structure of the Darjeeling Hill societies is shown in local interpretations of a long-life empowerment, described in chapter 10.

Chapter 3 introduces the major sources of the material - both textual and ethnographic - that are presented in chapters 4 to 10 of this book. In four sections, I outline the main bodies of Tibetan areas of knowledge from which my ethnographic data derives: medicine, astrology, divinations, and Vajrayāna Buddhist rituals (3.1). Over time, Tibetans have attempted to develop their numerous longevity concepts into a consistent body of theory drawing on various areas of knowledge. Without artificially segregating the medical from the religious or the divinatory from the astrological, this chapter outlines these areas of knowledge in four units of analysis. I describe these four areas of knowledge from two angles: first, as a general introduction with a focus on longevity issues, and second, as a brief outline of the local contexts in which I encountered professionals trained in these areas of knowledge. This chapter also presents popular myths of enlightened beings that are believed to have the power to control their own life-spans and asks how Tibetans today know about the life-span (3.2).

Chapters 4 and 5 in part III of the book take the reader into the medical reasoning of individual Tibetan physicians. How do they apply temporal frameworks mentioned in their medical texts in clinical practice in order to enhance the efficacy of their therapies and to strengthen life-forces? Here, I also approach the question of where temporal frameworks are found in the Rgyud bzhi and the Baidürya sngon po (the principal Tibetan medical text and its standard commentary; see chapter 3.1), and how they

display their perceived 'superior' Buddhist education. Non-Nepali groups, such as the Lepchas, who have a protected status, are nevertheless marginalized. 
are related to theoretical knowledge in Tibetan medicine. In chapter 4, I discuss how the life-forces are linked to cosmological and bodily rhythms mentioned in the Rgyud bzhi, as well as to the three basic physiological principles of Tibetan medicine, called nyes $p a$, which are known as rlung, mkhris pa, and bad kan (4.1). In emphasising the importance of the seasons in relation to the three nyes $p a$, I show that the connections between the nyes $p a$, the seasons, and the times of the day provide a temporal framework for Tibetan medical practitioners, indicating when and by what means to treat a nyes $p a$ disorder and when to prescribe medicines (4.2). Ethnographic examples show how such temporal frameworks are actually utilised in contemporary Tibetan medical clinics in the Darjeeling Hills (4.3), and how Tibetan doctors choose and apply these frameworks varyingly to enhance their medical practice (4.4).

Chapter 5 analyses the ways in which Tibetan physicians have utilised temporal frameworks in the body (e.g. the pulse beat) to locate various non-homogenous life-forces in the body and consequently calculate and manipulate them with the intention of reckoning and prolonging the life-span. In this chapter, I introduce the life-essence bla, which has an ambiguous existence in many different cultural contexts. In Tibetan medicine it is linked to the thirty places of bla, called bla gnas, which for most Tibetan medical practitioners are significant because it allows them to locate the exact place of bla in the body following the moon calendar (5.1). This temporal (and spatial) framework can guide clinical efforts of practitioners to avoid injury and loss of bla. The quality of bla can be felt in the life-essence pulse (bla rtsa, 5.2), in which each year of the life-span is represented by one pulse beat (5.3). A supreme vital essence called mdangs mchog, which is created through a process of refined digestive activity is also linked to this pulse (5.4). I also outline the difference between local lay and professional understandings of bla. This topic is taken up again in chapter 6 with ethnographic examples on the astrological and ritual conceptualisation of bla.

Part IV of the book has three chapters that take the reader into Tibetan areas of knowledge related to astrology and the divination of the life-span. Chapter 6 commences with an outline of the meanings of merit and karma (6.1). How do these concepts influence people's ideas of longevity and guide their motivations to take part in long-life enhancing practices, such as the animal liberation practices (6.2)? I then show that five particular astrological factors provide cyclically reoccurring codes for the annual almanac that follow specific, although varying, cosmological ideas, which 
are calculable, and thus knowable (6.3). Through them lay Tibetans and professionals determine periods of illness and misfortune. In the same way that they map out good and bad times, they also map out daily activities that are carried out to counteract the effect of negative predictions.

The five factors are not limited to astrology. They have different meanings in various Tibetan contexts. The story of Jigme losing his bla (6.4) shows that they are not only parameters for astrological calculations; they also encompass wider ideas of social importance and provide temporal frameworks for a plethora of medical and economic activities, which usually - although not necessarily - remain ethically linked to ideas of merit, karma, and 'blessing.'

Chapter 7 discusses ethnographic accounts of 'timely' and 'untimely' deaths, the 'remaining' and 'maximum' life-span, and yogic breath control practices. The often multi-layered temporal frameworks of the five factors and time cycles of the calculations, explained in chapter 6 , as well as the ideas of a 'remaining life-span' (tshe lhag) and a 'maximum life-span' (tshe lo) provide Tibetans with an arena of possible personal interpretations that can be tailored to individual life-situations, such as the failure of a medical or ritual treatment ('The "timely" death of Samden'; 7.1), or the death of a family member ('A family story of short lives'; 7.2). Breath control practices related to longevity reveal that the act of controlling the breath requires a temporal framework to exert control, which is achieved by employing time-spans of breath retention or the counting of inhalations and exhalations (7·3).

The idea of a 'remaining life-span' offers psychological and emotional support to deal with short life-spans through tshe being temporalised across many lives. The 'timeliness of death,' which is important in astrological death calculations, shows that the multilayered methods of the calculation itself allow for adjusting the interpretation to the social situation. Tibetans also take the help of diviners to allocate their limited resources. If a divination by a high lama says 'the life-span is completed' (tshe tshar ba) and 'nothing can be done,' the family will not spend money on often expensive life-extending medical treatments or life-extending rituals $(7 \cdot 4)$.

Chapter 8 shows how Tibetan professional astrologers and diviners arrive at predictions concerning the life-span and certain life-forces. I present two types of divinations of the life-span. Momola, an illiterate female diviner, maps out tshe in terms of periods of 'exhaustion' (tshe 'dzad $p a$, chapter 8.1). The textual Palden Lhamo divination provides answers 
concerning the strength of the life-force and the duration of the life-span (8.2). A pattern of ambiguity about the life-force emerges from certain divination answers, which I argue leaves room for personal interpretation. Paradoxically, the divination responses concerning the life-span are surprisingly detailed with regard to how many years a person would live and when and how death would occur, which often prove to be 'wrong,' but are rarely seen as 'erroneous' by Tibetans (8.3). I take up the issue of 'accuracy' in such divinations again in my conclusions in chapter 11.

Part V of the book takes the reader over two chapters into the ritual world of Vajrayāna Buddhist longevity practices, their various ritual layers of lay and monastic participants, and the hierarchies of long-life empowerments. Chapter 9 introduces the concept of 'blessing' or byin rlabs (9.1), summarises the existing literature on tshe dbang rituals (9.2), and presents multiple voices from various ritual participants from ten longevity rituals I documented (9.3). It also discusses the interface of visualisation and byin rlabs in the perception of efficacy of empowerments (9.4). Chapter 10 presents a detailed ethnographic description of one such longevity empowerment and shows how lay people and monastics negotiate tshe through such rituals.

I show that ideas of 'blessing' can be expanded and projected onto all kinds of ritual objects as ways of communication. For the public attending the ritual, prolongation of tshe is only possible through the transmission of byin rlabs from the lama conducting the ritual. These 'blessings' flow unconditionally and limitlessly and can add several years to one's lifespan, depending on personal belief.

In chapter 11, I summarise the main points in the development of the argument and present my conclusions.

The table in appendix 1 summarises the main terms used for the various life-forces and the life-span discussed in this book. It is meant as an overview and provides an outline of the various contexts in which the terms are used. It becomes clear in the course of this book that these terms are sometimes contradictory and at times their relationships seem confusing or even paradoxical. Not all Tibetans know of them or make sense of them in the same way. Some of the life-forces appear more prominently in medicine, others in astrology, divination, or popular ritual. Therefore, this table has been added as a simplified overview of Tibetan terminology of the life-span and life-forces, the meanings of which in daily life are not at all that straightforward. The translations into English are equally provisional and only meant as a support for the reader. Personally, I prefer to use the Tibetan terms. 


\section{Some Notes on Important Terms}

It is necessary to briefly explain a few terms that keep appearing in this book in various contexts and are difficult to define. What, for example, do I mean when I say 'the Tibetans' or talk about 'Tibetanness'? Why do I use the terms 'Tibetan medicine' and 'amchi' and what do these terms encompass?

Tibetans in the Darjeeling Hills themselves vary in their definition on who is a Tibetan, based on such factors as when and from where they or their forebears migrated to India and whether they still speak Tibetan. There is no clear-cut definition of who is a Tibetan in the Hills, and any attempt to impose one would inevitably be an oversimplification. However, the term 'Tibetan' is frequently used in this book, but in the widest sense of the term, which includes several different local identities: 'old' and 'new' Tibetans, 'newcomers,' 'Bhutias,' and also Nepali-speaking Tibetans. All these distinctions are explained in the course of chapter 2.

The people I label under the umbrella term 'Tibetan' in this book have in common their Tibetan ancestry, which may be recent or several generations old. Even this ancestry is heterogeneous in character since Tibetan religious and language affinities vary greatly across the vast Tibetan plateau and the Himalayas, where Tibetans settled over time. We have to consider that there is nothing like a traditional Tibetan identity, since "right up until 1959, the Tibetans had very little sense of being one group" (Shakya 1993: 9). Tibetan identity was largely based on Buddhist faith and sharing Tibetan language and culture, which has many localised variants. We know that later developments have used the 'historical memory' of Tibet's past to revive Tibetan religion and identity (see, for example, Goldstein and Kapstein 1998).

With 'Tibetanness,' I refer to numerous cultural, social, political, linguistic, and religious forms through which Tibetans express their sense of a Tibetan identity and what it means to them to be a Tibetan in the Darjeeling Hills. Klieger in his edited volume Tibet, Self and the Tibetan Diaspora aptly states that "Tibetan-ness is quite a concrete thing, but very difficult to conceptualise and describe" (Klieger 2002: 9). Tibetanness in exile encompasses among other things an 'imagined' identity, which is constructed from Tibetans' own imaginings of the homeland as well as western projections of Tibetan identity (Klieger 2002; Diehl 2002). For Lhasa, Adams compels us to "rethink categories of authentic Tibetanness" (Adams 1996: 529) and analyse what constitutes being an 'authentic Tibetan' and who constructs these categories of Tibetanness. In Lhasa, 
Tibetanness is blurred and encompasses characteristics scripted "by others in search of an 'authentic Tibetan,' " which are in turn internalized by Tibetans, as well as mechanisms created by Tibetans themselves in the intermingling of western, Chinese, and Tibetan lifestyles in modern Lhasa contexts (Adams 1996: 537-538). In other words, Tibetanness in Lhasa can be constructed by western tourists, and Chinese versions of Tibetanness might be internalized by Tibetans as much as Tibetans create their own sense of Tibetanness based on all of those aspects as well as their own ideas and lifestyles.

The varying identities surrounding Tibetanness as found among Tibetan refugees and Tibetan(ised) communities across the Himalayas shows that being Tibetan is not a result of belonging to a unified nation (Gyatso L. 1990: 15), even though Tibetans have shown developments of forms of religious nationalism (Dreyfuss 2002). In the Darjeeling Hills, Tibetanness is a fluid concept, since the multiethnic character of the region has led to a diffusion of Tibetan cultural distinctiveness.

My encounters with Tibetans in the different social arenas exemplify that in the Darjeeling Hills we deal with multi-identities and cross-border cultural affiliations among Tibetans and Tibetan groups. The often effortless and unconscious assimilation of intercultural environments have led to an ability of many Tibetans (and other ethnic groups for that matter) to move between various social and political settings with considerable ease. This makes the term Tibetanness quite ambiguous and I use it with this recognition. Chapter 2 will further explain and contextualise the nuances of Tibetanness.

While referring to 'Tibetan medicine' in this book, I am aware that the definition of Tibetan medicine is itself problematic. Since its boundaries are and have in the past never been clearly demarcated, we cannot talk about a unified system. Pordié even talks about Tibetan medicines (Pordié 2008: 4) and characterises their modern globalised forms as a newly emerging 'neo-traditional' form of Tibetan medicine with an urbanised and institutional character (2008: 10-17).

Tibetan medical practitioners across the Himalayas and at the first and foremost Tibetan medical and astrological institute in Indian exile, the Men-Tsee-Khang (sman rtsis khang, hereafter MTK) ${ }^{11}$ in Dharamsala, often use the Tibetan term Sorig, or Sowa Rigpa (gso ba rig pa), which means

${ }^{11}$ The MTK will be introduced further in chapter 3.1. For details on its history and recent developments in exile see Kloos 2010. 
'science of healing,' to describe what they view as distinctly Tibetan medical traditions. This does not include the many other forms of healing and divinations that Tibetans draw on (Schrempf 2007: 3). In 2010, Sowa Rigpa was officially legalised as a system of Indian medicine through an amendment to the Indian Medical Central Council Act of 1970 (MTK 2010c). ${ }^{12}$ In the Darjeeling Hills, the term Sowa Rigpa was hardly used; people used either bod sman, the Tibetan term for Tibetan medicine, or simply the English term 'Tibetan medicine' to distinguish it from the wide variety of healing practices available in the region. In this book, I use the term Tibetan medicine, but in its widest sense, acknowledging its heterogeneous nature with its intraregional variations and terminologies.

Tibetan medical practitioners often call themselves amchi (am chi) or emchi (em chi). It is the Mongolian-derived word for a Tibetan medical practitioner and is widely used across the Himalayas. In Nepal, amchi is a politically more neutral term than 'Tibetan doctor' and has helped medical practitioners of various Tibetan ethnic groups practising numerous forms of Tibetan medicine to organise themselves and gain recognition at the centre in Kathmandu (Craig 2008). In India, one often finds the title 'Dr.' followed by the name of the amchi printed on the name board above the medical consultation rooms at the MTK clinics. For various reasons, some Tibetan medical practitioners prefer to be called 'doctor' or sman $p a$, the Tibetan term for physician, others find it more unique to be called amchi. In this book, I use the terms amchi and doctor interchangeably.

\section{Ethnographic Encounters}

My fieldwork situation grew out of a long-term involvement with the region and its people. I lived in the Darjeeling area for long periods of time between 1992 and 2008, and pursued intensive fieldwork there from May, 2004 until August, 2005, and from March, 2006 until May, 2006. I revisited the area for several months in 2006 and 2007, and eventually left in July 2008. During fieldwork, I relied on my own previously established networks but also explored new contacts. My long-term involvement in

\footnotetext{
12 The official website of the MTK defines Sowa Rigpa as "the Tibetan system of medicine, astronomy and astrology" (MTK 2010b). This definition differs from the official Indian legalised definition of Sowa Rigpa as 'amchi system of medicine' (Department of AYUSH 2010), which does not mention Tibet but emphasises the sub-Himalayan region as its main area of practice. The absence of reference to Tibet in this definition can certainly be seen as a concession by the Indian government to the Chinese government.
} 
the region was as a student of Tibetan medicine at the Chagpori Tibetan Medical Institute (hereafter CTMI ${ }^{13}$ in Darjeeling (1992-93), as a student of Tibetan language and literature at two Indian universities in West Bengal (1993-94) and as the co-founder and research coordinator of a nongovernmental organisation (NGO), the International Trust for Traditional Medicine (hereafter ITTM), in Kalimpong (1995-2008).

During my fieldwork in Kalimpong, I stayed in a flat annexed to the ITTM centre (see plate 1.1), and living there involved an ongoing exchange with an international community of visiting students and researchers. When in Darjeeling, I stayed with a Tibetan family I had known for many years or in a hotel. In Kalimpong, I shared my flat with two Nepali girls, Sapna and Sabina, whom I had fostered since 1998, when they were seven and five years old. Administering the ITTM centre and raising the two girls, as well as a Nepali boy, Shankar (aged fourteen in 2005; see plate 1.2), who was a student at a boarding school and stayed with me during his school holidays, enlarged my network of people in the area. Local Nepalis mostly knew of me through my engagement with the children, ${ }^{14}$ and most Tibetans in Kalimpong knew the two Tibetan women who were employed by ITTM. My image as the 'employer' of the Tibetan women was both helpful and at times disconcerting - helpful in terms of opening doors to new contacts in the community and being offered front-row VIP seats during overcrowded longevity rituals in Kalimpong, but distancing in terms of being treated with exaggerated politeness. Often, I preferred to spend informal time with Tibetans who did not know this particular role of mine, but felt comfortable talking to me knowing that I had been living in the area for many years and was interested in Tibetan medicine.

My complex circumstances situated my fieldwork somewhere between 'autobiography' and 'anthropology' (Hastrup 1990), and not all roles I held were as an ethnographer. My presence in the area was in one way or the other influenced by my roles as a coordinator of the research institute, a guardian of three children, an ex-student of CTMI, and an Oxford doctoral student. I considered it an advantage in most encounters not to be labelled as an anthropologist, since it allowed me closer contact with people who often felt either shy or distanced when hearing of a 'doctoral' research project in a locality where only two Tibetans held PhDs. The

\footnotetext{
${ }^{13}$ For details on the CTMI see chapter 3.1.

${ }^{14}$ In total, nine underprivileged children in our village received schooling with the support of foreign sponsors. My old primary school in Germany has supported the education of four girls since 1998 .
} 


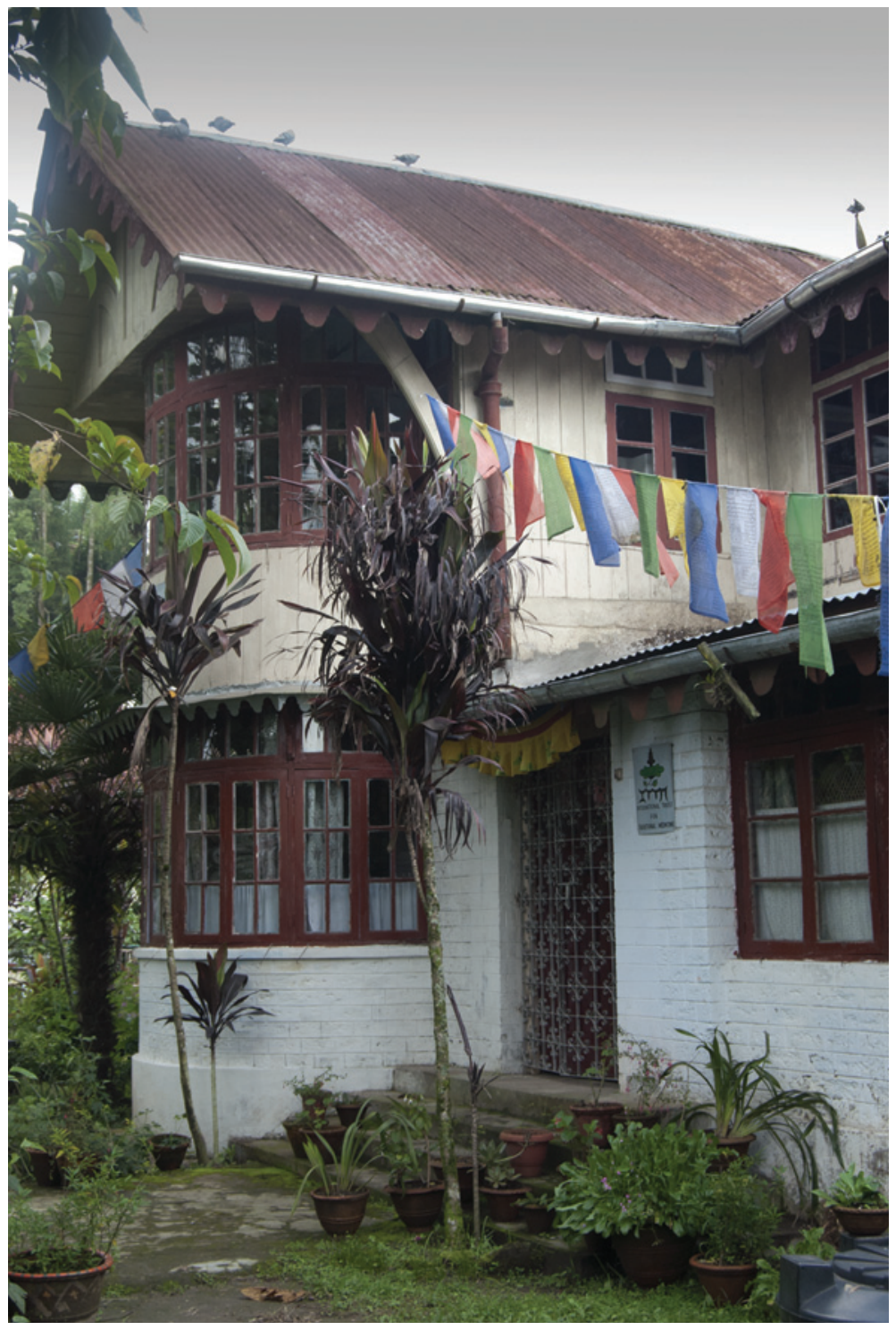

Plate 1.1. The author's fieldwork base, the centre of the International Trust for Traditional Medicine, Kalimpong 2005. 


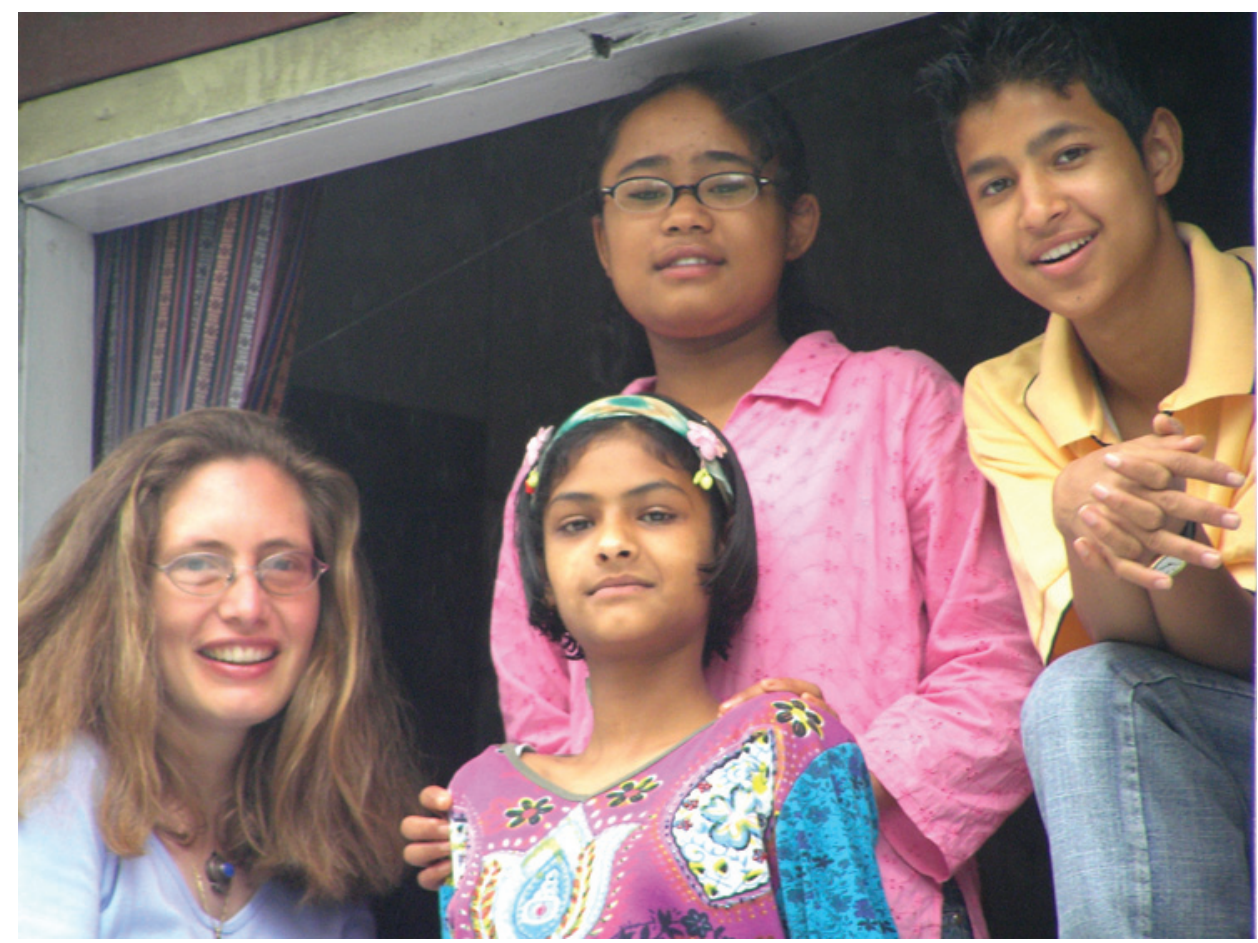

Plate 1.2. The author (left) and her Nepali foster children, Sabina (centre), Sapna (top), and Shankar (right), Kalimpong 2005.

authority attributed to 'knowledge' in Tibetan communities played a role here, which I discuss further in section 5 of this chapter.

I have chosen the past tense to describe ethnographic events that occurred at a certain time during fieldwork and the present tense to describe ongoing patterns that I observed over the years of living in the region. I do this with a certain inconsistency, which reflects my own changing standpoint as an ethnographer living in the field within shifting time-spaces, carved out by the interrelationship between the personal histories of the people I encountered, ongoing, long-term socio-political trajectories, and my own place in them.

This book weaves many people's views and information together. Many of them would not meet or engage with one another in their daily lives, even though they live in the same locality. In the following, I lay out the various relationships I had with people in the field. I engaged with Tibetans from all age groups across the entire range of economic and educational backgrounds, from illiterate poor Tibetans to middle and upper 
class, educated Tibetans, monastics, lay people, and professional astrologers, diviners, and Tibetan medical practitioners.

\section{Monastics}

Since monasticism plays a significant role in most Tibetan communities and their ritual activities, almost half of my fieldwork relationships were with monastics, but I also maintained many relationships with lay Buddhist practitioners. My encounters with Buddhist monastics involved celibate monks (grwa pa) and spiritual teachers, called lama (bla ma), from four schools of Tibetan Buddhism. ${ }^{15}$ There are no nunneries in the region, and I only met three nuns during fieldwork. Consequently, female monastic views are under-represented. Local people often refer to ordinary monks respectfully as 'lama,' which can be confusing. I distinguish between grwa pa and lama. Grwa pa refers to an ordained, celibate monk, ${ }^{16}$ and I prefer to use the term monk throughout this work. The term lama refers both to a qualified monastic teacher, who has completed a traditional three-year retreat, and to a tantric lay-practitioner (sngags pa, lit. 'one who practises mantra').

I met lamas of the Geluk, various Kagyü schools, as well as a few noncelibate lamas of the Nyingma order. I also spoke with one sngags pa, who mostly conducted rituals at his home for Buddhist Tamang and Sherpa communities in Darjeeling. These were all both new and old contacts. Since longevity and long-life practices are pan-Tibetan phenomena and are found across all schools of Tibetan Buddhism, I did not focus on a specific tradition. Local people and even monks would attend any long-life empowerment given by a 'great lama' (bla ma rtsa chen po, lit. 'a valuable lama'). ${ }^{17}$ It was not important whether he belonged to any specific school of Tibetan Buddhism; it was his reputation and status as a high lama that were important.

Conversations with monastics took place mostly in colloquial Tibetan. I used the help of an interpreter (usually an English-speaking monk at the

${ }^{15}$ The four main schools of Tibetan Buddhism are Nyingma (rnying ma), Sakya (sa skya), Kagyü (bka'brgyud), and Geluk (dge lugs). For a good summary on the four schools see Kapstein 2006: 231-237. When I talk about people of these Buddhist schools I add the Tibetan suffix $-p a$, indicating a person of that particular school, for example, Nyingmapa, Sakyapa, Kagyüpa, or Gelukpa. There are no monasteries of the Bon (bon) school in the Darjeeling area but there are monasteries of the Drukpa Kagyü ('brug pa bka' brgyud) school, the predominant Buddhist school of Bhutan and a sub-school of the Kagyüpa.

${ }^{16}$ For a detailed discussion of the various types of grwa pa see Samuel 1993: 286.

${ }^{17}$ Rtsa chen po can also mean 'full of blessings' (Diemberger 2005: 125). 
same monastery) only for the translation of more complicated Buddhist teachings. All my talks with the older Tibetan monastics were held within the traditional Buddhist framework of a teacher-student relationship. It was challenging to explain the purpose of doctoral research to them. In their world, the only perspective from which to ask questions about meditation practices was as a dharma practitioner. Since I had attended numerous teachings on Tibetan Buddhism in various capacities since 1991 and was familiar with the methods of knowledge transmission in Tibetan Buddhism, taking on this role did not cause conflict.

Getting access to leading Buddhist teachers, called rinpoche (rin po che, lit. 'precious one'), before or after long-life initiations was almost impossible, since these teachers have busy schedules and are shielded carefully from the rest of the monastic and the lay communities. My requests for interviews were not always granted, and if a private meeting took place it was usually very brief or involved special teachings or blessings in a small group situation. Although the rinpoches' perspective is therefore underrepresented in my data, the effects of the strict monastic hierarchy and the lack of direct communication between the rinpoches and local people are addressed in chapters 9 and 10 of the book.

I felt fortunate to befriend the head lama of the local Bhutanese gompa $(\text { dgon } p a)^{18}$ Jangsa Dechen Chöling, locally known as Jangsa Gompa (see plate 1.3). Lama Kunzang Dorje (see plate 9.3) was in his early thirties, spoke English, and was extremely helpful in answering detailed questions on longevity rituals. He had spent time in retreat and studied with high lamas of the Nyingma tradition of the late Dudjom Rinpoche Jigdral Yeshe Dorje (1904-1987), who lived in Kalimpong the last decades of his life and built the Zangdok Palri monastery, locally known as Durpin Gompa. He not only gave me permission to join a six-day tshe sgrub ritual that was conducted during the first visit to Kalimpong of the teenaged reincarnation of the late Dudjom Rinpoche, Kyabje Dudjom Yangsi Rinpoche (1990-), but he also spent considerable time with me after the events to explain the ritual intricacies and the symbolism of ritual objects. He also went through the Tibetan ritual texts with me. I had known him since he took over the gompa after the death of his father Lama Pema Longdrol in the mid-199os. We had an exchange over many years on various occasions. This was facilitated by the fact that the monastery's retreat centre, which he supervised, was located next to the ITTM centre.

\footnotetext{
${ }^{18}$ A gompa is a Tibetan term for a monastery or other religious establishment.
} 


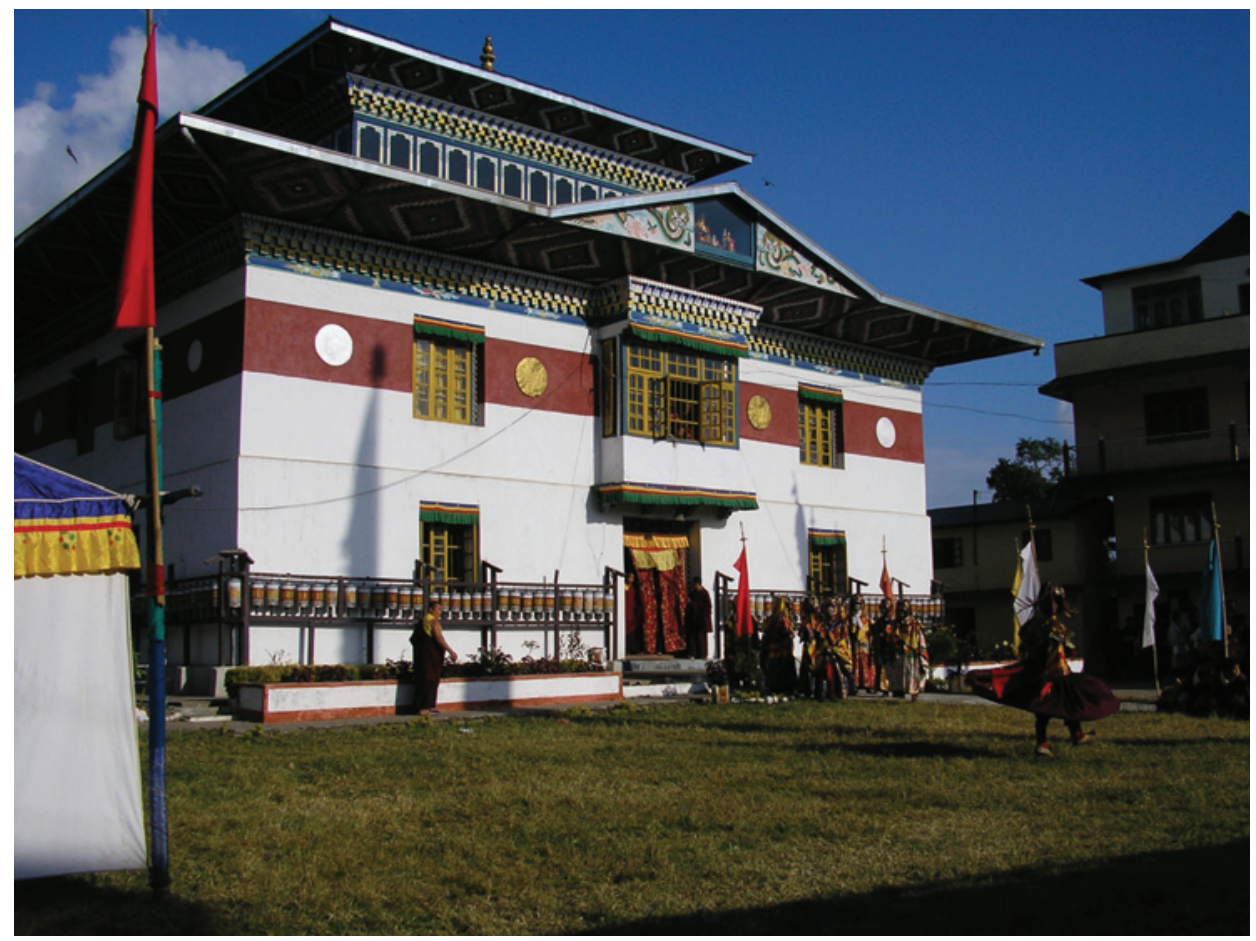

Plate 1.3. The Jangsa Gompa, the Bhutanese monastery following the Dudjom gter gsar school, during a ritual mask dance event, Kalimpong 2005.

I also interviewed some monks who were not related to any local monastery, but who had recently arrived from Tibetan monasteries in Amdo and rented places to live in Darjeeling. These monks provided valuable contextual information, although I have not referred to them directly here. The Tibetan family with whom I lived when visiting Darjeeling had a son who was a married Nyingma sngags pa. He and his father told me the stories of several of their family members who had had short life-spans (see chapter 7.2).

\section{The Lay Community}

My involvement with Tibetan lay people was largely built on previous acquaintances. Many Tibetans in Darjeeling knew me from my time at CTMI in 1992-93. It was easy to talk with them about their personal views on the life-span and longevity. Our talks were always informal and occurred during occasional visits to their homes, or when we met by chance on the 
road. In Kalimpong, I often walked around the shops of the Tibetan area known as Tenth Mile and had informal talks with Tibetan shop and restaurant keepers, some of whom were newcomers, and some of whom had been there for generations. These newly-formed relationships added an original freshness to my fieldwork.

Over time, I also met lay practitioners, mainly educated middle and upper class Tibetans in Kalimpong, only two of whom were dedicated longevity practitioners, but all of whom had personal experiences and views regarding the life-span and its extension through rituals. Tibetans working as teachers or school principals were mostly long-term acquaintances. Informal discussions with them were mostly held in English at the Tibetan schools on weekends or late afternoons when classes were over. Among these educators, my longest and most intense exchange, which also involved translations of Tibetan texts, was with Jampel Kaldhen (see plate 8.3), the principal of the Indo-Tibetan Buddhist Cultural Institute, known as the ITBCI School, in Kalimpong. At the time of my fieldwork, my Tibetan language teachers of 1992-94, the late Khen Rinpoche, also known as Prof. Ngawang Jinpa (see plate 2.8), who passed away in 2007, and Prof. Samten Norbu, were all retired in Darjeeling and in their seventies. They both had taught Tibetan language at colleges and institutions in Darjeeling for many years, were generous with their time and expertise, and helped me with translations and other questions. Khen Rinpoche also held a Geshe Lharampa degree from the Drepung monastery in Tibet, and was the abbot of the Tharpa Chöling monastery in Kalimpong from 1958 to 1963 , before he married and became a Tibetan language teacher in Darjeeling. His insights into Tibetan rituals were invaluable.

The shortest encounters were with people during long-life empowerments. These are mostly mass events with several hundred or even thousands of people. Between 2004 and 2007, I attended eight tshe dbang and two brtan bzhugs (a specific longevity ritual conducted for the long life of high lamas). These were performed by and for different lamas in various monasteries or temples in Kalimpong, Pedong, Darjeeling, Ghum, and Gangtok (see map 2 on page xxiii). During each of the longevity rituals I focused on a different perspective. Either I sat with the monks and focused on the texts and ritual events, or I was with the crowd of people outside the temple, gaining glimpses of their motivations and understandings of the ritual. It would have been inappropriate in such settings to ask questions about ethnic backgrounds or use any kind of questionnaire. But people freely spoke about the ritual and why they attended it, what expectations they had from it, and how they believed it would affect them. 
I filmed one tshe dbang at Lama Kunzang's request, but felt that the camera distanced me from the people. I preferred to document the tshe dbang rituals with a small digital still camera and record the recitations with a digital audio recorder. I was able to photograph the ritual texts of three of the eight tshe dbang, one brtan bzhugs, and one tshe sgrub. In the process of the analysis I have focused less on the translations of these texts and more on how people used them and what role they played in the creation of hierarchies during rituals.

Several times I was able to talk to the organisers of a tshe dbang and also once to an interpreter, who had translated a rinpoche's teachings from Tibetan to Nepali during a tshe dbang in Ghum (chapter 9.3). Once, I used a formal questionnaire in Tibetan with a group of eleventh grade students at the Central School for Tibetans in Kalimpong to assess their knowledge, interest, and ideas on longevity issues and Tibetan medicine. The questionnaire was followed up by a discussion with the students, which was unproductive because of gender conflicts. Despite being a coeducational school, girls would not talk in front of boys and I discovered the reasons for their shyness only after the discussion was over. The questionnaire thus provided some general information, but no follow-up details. ${ }^{19}$

\section{Tibetan Medical Practitioners, Astrologers, and Diviners}

During fieldwork, I re-established connections with several of my former colleagues from the CTMI, who were by then all practising Tibetan doctors. This was a rewarding experience since we were familiar with each other and could discuss topics in detail without much introduction. Most relationships I had with Tibetan amchis spanned years, but the MTK rotation scheme ${ }^{20}$ also brought new amchis to Kalimpong. It required time and several visits to establish a good contact with them. Knowing their teachers or colleagues helped to establish a collegial relationship.

Some interviews with Tibetan medical practitioners were more structured and organised because of their brief visits to the region and timeconstraints. Interviews with amchis were held either in English or Tibetan

\footnotetext{
19 I published some results of this questionnaire in the paper "Tibetan treatment choices in the context of medical pluralism in the Darjeeling Hills, India" (Gerke 2010a).

${ }^{20}$ Since the late $1990 \mathrm{~s}$ the MTK policy has been to rotate the increasing number of amchis among their branch clinics across India and Nepal every two to three years. Amchis with families are able to extend their stay, but short postings are frequent and have affected the role of amchis in the Darjeeling Hills (Gerke, in press).
} 
depending on their English language skills. If they were fluent in English we spoke English using Tibetan mostly for technical medical terms.

My research did not focus on patient perceptions of the life-forces or of medical diagnosis. Therefore, I did not sit through long clinic hours observing patient encounters. From my previous studies of Tibetan medicine, which involved many hours of clinical encounters between 1989 and 1993, I had, however, a clear understanding of what was involved in the doctor-patient relationship during diagnosis and treatment procedures.

Dr. Pema Dorje, currently one of the most senior doctors at the MTK in Dharamsala, told me about his clinical experience with the life-essence pulse (chapter 5) during an interview in Salugara. This interview took place on the occasion of the inauguration of the MTK staff building at the main MTK branch clinic in Salugara, a settlement with about one hundred Tibetan families at the fringes of Siliguri, a large city in North Bengal. We had known each other for ten years and had met every couple of years. In the past, Dr. Pema Dorje had spent five years in the region as Chief Medical Officer. He stayed several days seeing about eighty patients a day, who had signed up already weeks before his arrival. As a senior doctor he was treated with great respect. I use excerpts of this recorded interview, which was held in English, along with comments by Amchi Künga, a resident Tibetan physician at the Salugara MTK.

Amchi Jamyang Tashi was my main informant at the MTK clinic in Kalimpong in 2004/2005 (see plate 5.1). Like many contemporary Dharamsala MTK-trained amchis, he also had a general knowledge of astrology (rtsis). Amchi Jamyang privately studied astrology with a senior monk and applied this knowledge in his clinical practice (see chapter 4.4). I mostly visited him during his late afternoon clinic hours, when there were less patients and more time to discuss Tibetan medical texts and astrology. Sometimes I took foreign researchers in residence at ITTM to him for consultations.

Amchi Tsering Wangdue (see plate 1.4), who nowadays is a lecturer at the MTK in Dharamsala, worked as an amchi in the MTK branch clinics in Gangtok, Sikkim in 2005 and in Kalimpong in 2006. Being a friend and long-term colleague, he also read through sections of the final manuscript.

Amchi Kartsokyi is a female Tibetan physician trained at the Lhasa MTK and worked at the Dharamsala MTK branch clinic in Kalimpong in 2007 (see plate 5.3). I only met her towards the end of my fieldwork, when she had just arrived. Her medical training in Lhasa was definitely different from the training that amchis in Dharamsala receive. The contrast 


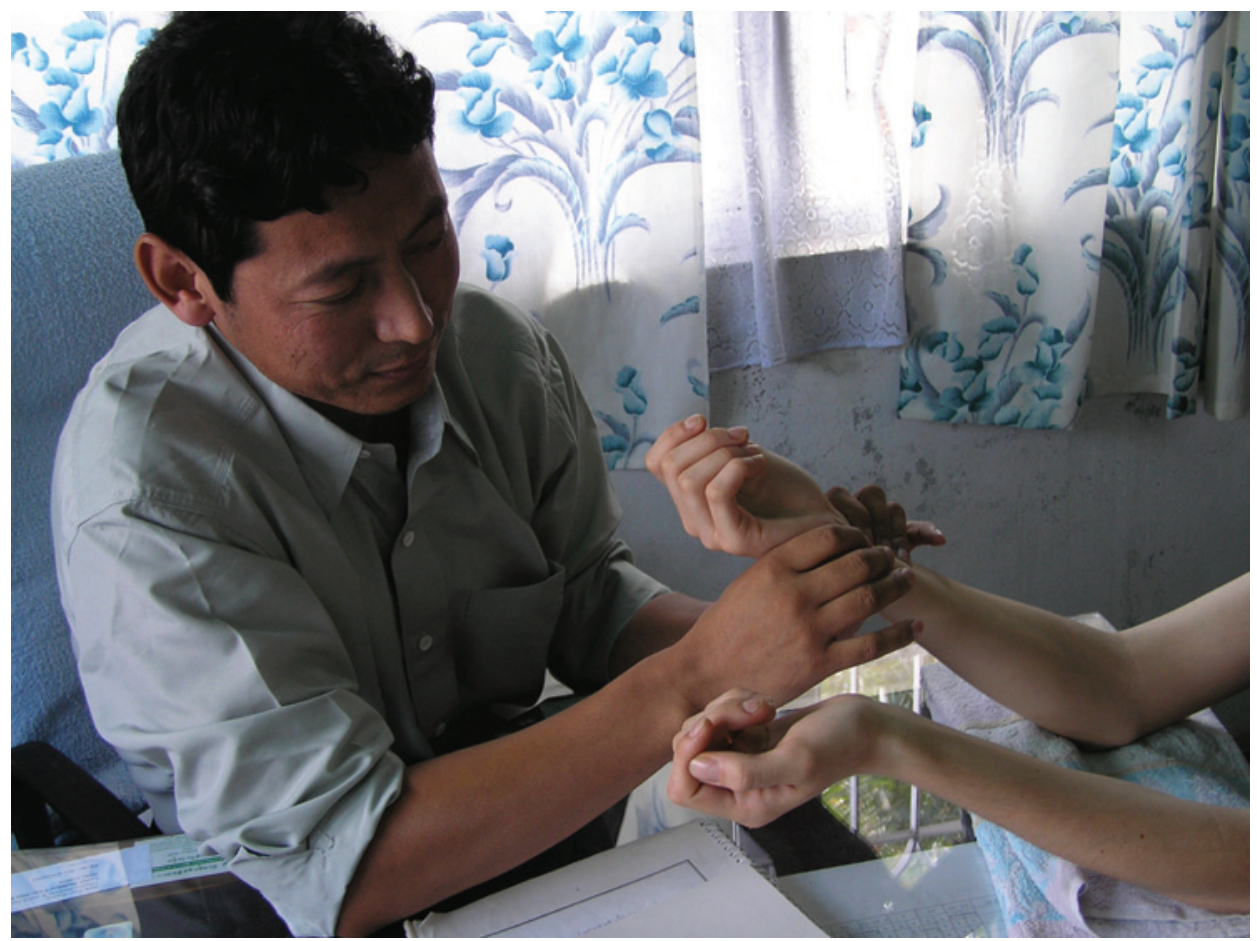

Plate 1.4. Amchi Tsering Wangdue feeling the pulse of a patient, Kalimpong 2006.

became obvious when discussing medical terms, such as the bla, which does not fit easily into the 'scientific' approach often taken by institutionally trained Tibetan doctors in urban Tibetan areas of China (see, for example, Adams 2002 a, 2002 b; Janes 1995, 2001).

For the astrological parts of this book, I mainly consulted - apart from Amchi Jamyang - Jampel Kaldhen, the principal of the ITBCI School in Kalimpong, whom I already introduced. He was well versed in astrology and the Palden Lhamo dice divination that the late Dhardo Tulku Rinpoche (1917-1990), the founder of the ITBCI School, used to perform (see chapter 8.2). He occasionally offered his astrological services to the community. When his son Jigme lost his bla, I was able to document the story including Kaldhen's astrological interpretations (see chapter 6.4). After I moved to Himachal Pradesh in 2008, I established contact with Tenzin Tsewang Jamling, an astrologer at the MTK in Dharamsala, who kindly read through and added useful comments to the astrological sections of this book. 
Between 2004 and 2007, women formed the majority of Tibetan diviners $(m o p a)$ in the Darjeeling region. They worked as professional diviners and were largely illiterate. They were still outnumbered by lamas who also performed divinations $(\mathrm{mo})$. In Kalimpong, I knew of five lamas who regularly performed mo for the public; in the Darjeeling Hills, I knew of three Tibetan female and two male mo pa. I met four of them and will introduce the most famous one in chapter 8.1. I met these diviners either alone or when they were performing divinations and will introduce them further in the context of my introduction to divinatory knowledge in chapter 3.1.

\section{Documentation Methods and Challenges}

I generally taped all interviews with a digital audio recorder if people had no objections. Apart from participant observation, I preferred unstructured, informal interviews as a method, especially at the beginning of fieldwork, in order to discover and explore the wider range of topics people themselves would bring into our open discussions on longevity. Towards the end, when I had more specific questions on certain topics, the encounters - especially with amchis - were guided more by my specific questions. For brief and pre-arranged meetings with Tibetan medical practitioners, who were not available for long discussions - for example, the senior Tibetan physician Dr. Pema Dorje - I prepared a list of questions but kept the interviews open-ended and semi-structured to leave space for serendipities. My long-term encounters involved the translation of Tibetan medical texts (with Amchi Jamyang), the reading of ritual texts and the understanding of ritual symbolism (with Lama Kunzang), and the translation of medical and divinatory texts (with Jampel Kaldhen). I showed them print-outs of my translations of texts, to which they responded in the course of several meetings, or by e-mail.

Those aspects of Tibetan knowledge systems that are based on tantric or oral traditions, commonly involve issues of secrecy. I had no access to secret oral teachings of Tibetan medical texts, which are passed on from teachers to their selected disciples. One practitioner shared with me detailed instructions on tantric longevity practices, but did not want this to be included in my written work. An example of a similar limitation was when Lama Kunzang requested me not to publish any of the photos in which the young reincarnation of Dudjom Rinpoche appeared during the rituals to avoid negative karma that could befall the rinpoche if the publications were in any way misused. 
Whenever recording was not possible, I took detailed field notes after the event or recorded my own summaries on the way home from a meeting and wrote them down the same evening. Taking notes was not always an option. One of the older longevity practitioners at the Tharpa Chöling monastery, Lama Tsewang (see plate 1.5), who was in his early seventies in 2004, did not allow me to take any notes, nor record any of his teachings. He pointed out that it was not in conformity with the Tibetan way of teaching to write or record without having understood the practice. I accepted his method, which was to sit cross-legged opposite him and memorise his explanations of the meditation practice of the long-life deity Amitāyus, the Buddha of Boundless Life. I had to practise the visualisation from memory at home. His view that only accomplished masters write about dharma practice, although detrimental to my documentation methods, had to be respected in our encounters.

Doing fieldwork with Tibetan doctors is impossible without considering their medical literature. Every amchi I met referred to published material in Tibetan during our discussions. They all had copies of the Rgyud bzhi and the Baidūrya sngon po on their clinic desks.

MTK consultation rooms often have a bookshelf or a cupboard with Tibetan medical texts, and many times when I entered a consultation room I found the amchi reading. All Tibetan doctors I met readily cited from these texts during our informal discussions and interviews. For some physicians "the Rgyud bzhi is like the Bible" (to quote Dr. Pema Dorje), which they read during mornings and evenings, continuously refreshing their knowledge. Since a large number of medical texts are memorised in medical education (Millard 2002), daily recitations form an integral part of amchi life.

The use of texts in Tibetan societies poses an ethnographic challenge. Apart from conveying specialised knowledge, texts often acquire additional meanings involving ideas of authority, which influence their contemporary use and interpretations. For example, Mills points to the difficulties in studying Tibetan Buddhism when dealing with the enormous corpus of historical literature. He explains two particular manifestations found in the study of Tibetan Buddhism and monasticism as

[...] the 'objective' histories of the archaeologist and secular historian on one hand; and the interpretative histories of Buddhist self-representation on the other. Generally, these two are seen as at odds, with the former acting to progressively deconstruct and disprove the pious and post hoc reconstructions of the latter, unearthing the 'true' history of Buddhism to its (presumably conservative and indignant, but ultimately 'enlightened') proponents (Mills 2003a: 7). 


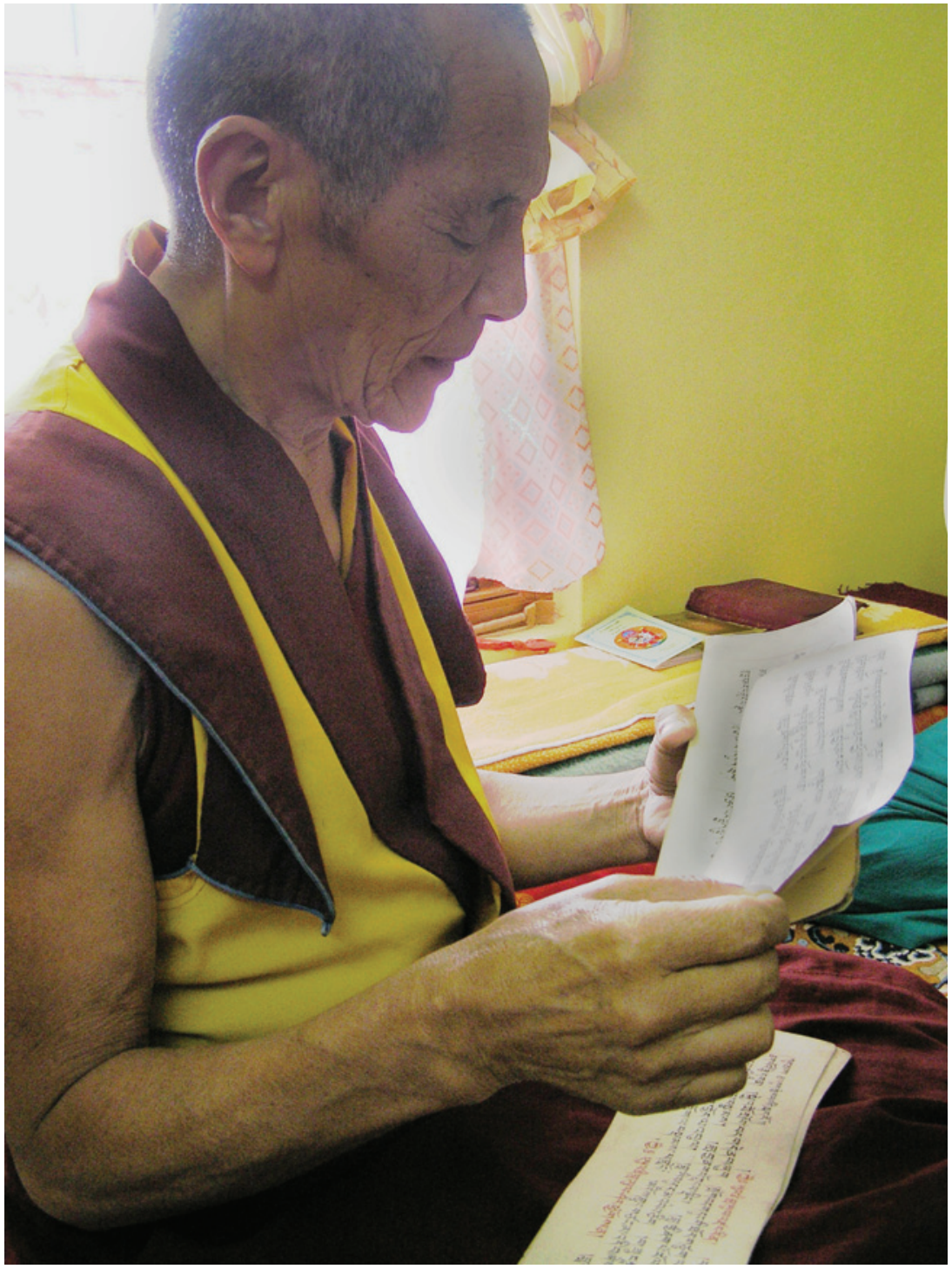

Plate 1.5. Lama Tsewang, a senior longevity practitioner at the Tharpa Chöling Monastery, Kalimpong 2004. 
These two approaches to history are also found in Tibetan medical contexts. Medicine is not free from religious interpretation. Since from its beginning literacy in Tibet was associated with ideas of spiritual enlightenment, these notions pervaded other areas of textual scholarship, including medicine. During fieldwork it became obvious that Tibetan medical literature was inherently linked to Tibetan debates on authority and texts. This has influenced my research methods and needs to be highlighted briefly.

It is characteristic of Tibetan societies that knowledge systems derive their authority from 'authentic' sources. The understanding of what authenticity entails is often linked to the word of the Buddha or a revered Buddhist saint and does not necessarily depended on chronology or antiquity. In discussions with amchis about the 'origin' of Tibetan medical knowledge, I often observed a heated debate whether their main medical text, the Rgyud bzhi, is considered the work of the Medicine Buddha (sangs rgyas sman bla, Skt. Bhaișajyaguru), or was authored by the twelfth century physician Yuthok Yönten Gonpo the Younger (1126-1202), who is revered by some as a manifestation of the Medicine Buddha. The Rgyud bzhi presents itself as a religious text in the sense that it is written in the form of a revelation by the Medicine Buddha. During my training at CTMI in Darjeeling in 1992, secular medical history was not taught and all questions pertaining to the authentic origin of the medical texts were eventually answered with the accepted explanation, "The Medicine Buddha said so" (sangs rgyas sman gyi blas zhes gsungs so). In this context it is understandable that historical questioning is often met with resentment, since "innovation if not actual deviation from the authoritative was always a risky business in Tibetan literary culture" (Gyatso J. 2004: 86).

This understanding of how Tibetans deal with the authority of knowledge influenced my ways of referring to texts during informal interviews and talks with amchis. During discussions with amchis in ethnographic encounters it was important to understand their sense of history when asking questions concerning the origins of concepts or texts. For the westerntrained historical eye, things become dangerous when 'origin' implies "a beginning with complete explanations" (Bloch 1992 [1954]: 25). Regardless of its 'historical accuracy,' however, people's re-telling of their history provides material for the ethnographer. What I want to stress here is that when combining texts with ethnography we need to consider the ways in which Tibetan medical practitioners currently view their medical past and refer to authority and text to establish the authenticity of medical knowledge. The same applies for most religious, divinatory, and astrological 
texts, but in the case of my research the text-authority question arose mainly in encounters with amchis.

Textual knowledge itself, however, never suffices - despite its great authoritative power - and oral instructions from a lama or teacher are regarded as crucial in the understanding of the Rgyud bzhi. This interplay of text and oral explanations manifested in most of my discussions with amchis. Often, the amchi would recite a passage from the Rgyud bzhi from memory and then added explanations, or we looked at Tibetan medical commentaries - largely the Baidūrya sngon po - together and discussed their deeper meaning. Therefore, I usually quote both the Rgyud bzhi and the Baidūrya sngon po when using medical texts.

Working with texts had several advantages. First, it allowed me to take part in the text-based interactions that were so familiar and essential for amchis themselves. I translated sections from the Rgyud bzhi and the Baidürya sngon po, which steered conversations with amchis. Second, it was an expression of my own deep interest in Tibetan medicine, which Tibetan doctors responded to by sharing their time and knowledge. Third, it added a textual dimension to my ethnographic data.

Within these multiple voices of texts and people, it is methodologically important to point out carefully to the reader who is speaking when, and whether we are dealing with the Tibetan text itself (in my translation), the amchi interpreting its meaning, or the ethnographer observing a practice. However, not all the textual excerpts in this book are paired with their contemporary interpretations. In some cases, I still chose to include the texts to add a literary dimension to the ethnographic accounts and to show how, when, and where these concepts appear in Tibetan medical writing, knowing well enough that their contemporary interpretation might differ. There is often a conflict between interpretations by western academics, which may be largely determined by their knowledge of what the texts 'should' say, and the amchis' interpretations, which often have a practical clinical approach. An example here is the frequently repeated 'western' interpretation of the three nyes pa as 'humours,' which is derived from the Latin word 'humor' (lit. 'fluid' or 'moisture'). This eurocentric translation has been critiqued by several authors, which I discuss in more detail in chapter 4.1.

\section{Analytical Frameworks: The Anthropology of Time}

As my fieldwork progressed, I came to realise that Tibetan knowledge systems that address the issues of longevity and the various life-forces 
were extremely diverse. Life-forces were interpreted by different people in different ways and had specialised meanings in medicine, astrology, and Buddhism. Not only were lay Tibetans unfamiliar with all the lifeforces, but the understanding of these forces amongst specialists (amchis, astrologers, diviners, and lamas), while overlapping, was not uniform.

Within these landscapes of diverse views I noticed a common theme. Practices of temporalisation emerged as a palpable pattern that appeared to me repeatedly in Tibetan activities surrounding longevity. To understand these key aspects of my discoveries, notably the significance that people give to certain practices of temporalisation, some reference needs to be made to relevant existing literature on the anthropology of time.

The study of time-reckoning systems in different societies has been popular among anthropologists through all stages of the discipline. Some famous studies that come to mind here are, for example, Hubert, who early on showed that the "purpose of the calendar is not to measure, but to put rhythm into time" (Hubert 1999 [1905]: 6-7); Malinowski's functionalist approach stressing the activity-coordinating aspects of time-reckoning in the Trobriand Islands (Malinowski 1927); Evans-Pritchard's 'oecological' and 'structural' time, where cycles of activities are linked either to natural cycles among the Nuer or span several generations through lineages (Evans-Pritchard 1939); and Geertz's cultural-interpretative approach to 'depersonalised time' in Bali (Geertz 1973). But only a few studies consider what happens when existing reckoning systems 'fall out of time,' become 'disjointed,' or get it 'wrong' from the perspective of our sense of time. I will address these studies later in this section.

Tibetan medical and astrological knowledge developed around cosmologies that involve seasonal rhythms, the time of day, month, and year, the position of the stars, etc. - in brief, the quality of time. Nevertheless, there is no unitary Tibetan measurement of time. A study on Tibetan timereckoning systems would range from movements of herds among Tibetan nomads to various Buddhist doctrines of time. A discussion of 'time' as an independent category in Buddhist philosophy, which is embedded in the notion of life being transitory and impermanent (Baatz 2002), would already form a separate project. In this book, I therefore avoid any philosophical and metaphysical analysis of the category of time per se. The specific focus of this work is on practices of temporalisation surrounding the life-span and on how people utilise existing temporal frameworks in their management of tshe.

The author who first inspired me to develop my argument along the lines of temporalisation was Johannes Fabian, specifically his influential work 
Time and the Other (2002 [1983]). To Fabian, I owe the idea of temporalisation and a practical anthropological approach to time, which emphasises the agency of people and their ways of encoding and structuring time. I apply his idea in a very different context, but acknowledge his contribution to my thought process.

The anthropology of time is not a new field, and Munn's seminal review essay (1992) lists a large amount of anthropological literature on time that was published throughout the twentieth century. Rather than presenting another review on the anthropology of time - something Munn has already done in great detail - only recent developments and debates in the anthropology of time are summarised here.

My analysis has been influenced by the overall movement away from time-based dichotomies (for example, cyclical versus linear time), which is often found in anthropological literature. The often repeated misconception here was that linear time is a product of literate and advanced societies while the ordering of the past in cycles is somehow 'primitive' and typical for traditional societies. More nuanced and reflective positions have developed, which, for example, Adam's works on time demonstrates (Adam 1994, 1995, 2004). She shows that "cyclicality and irreversible linearity are not the dominant time perceptions, respectively, of traditional and modern societies, but are integral to all rhythmic and structured phenomena" (Adam 1994: 510-511). Even though we talk about time cycles (for example, birth, life and death, or agricultural cycles), "within each cycle the changes are unidirectional" (Adam 1994: 510). The same would apply to other dichotomies of time, such as 'ritual, non-durational time' versus ideology-free 'practical, durational time' (e.g. in agriculture), to take an example from Bloch (1977).

Despite an increased awareness of these issues, the literature on the anthropology of time does not present a unified position. The debate has become more nuanced, still encompassing universalist as well as cultural relativist approaches. Each position offers valuable arguments, of which I want to sketch a few that are pertinent to my data.

Gell's seminal work The Anthropology of Time (1992) offers a universalist approach to time perception and an objectivist theory of time cognition, critiquing previous cultural-relativist perspectives on time. His argument is that time is always one and the same, even though it can be studied within many different analytical frameworks. Gell sees no contradiction in this. He does not believe in the distinction of different species or varieties of time (Gell 1992: 315). I agree with Gell that calendrical festivals and auspicious days neither create time nor modify it, except rhetorically or 
symbolically. Ritual representations of time do not provide a 'world-view' but a series of special commentaries about the world, which can only be understood in context and practically, not metaphysically (Gell 1992: 326). Therefore, none of the temporal frameworks presented in this book should be interpreted as a proof for the existence of a particular Tibetan variety of time, or as the base for an argument on the autonomy of 'cyclical time' compared to 'linear time.'

Gell turns more structuralist and dichotomous with his model of A-series and B-series time. The purpose of his model is to distinguish between the phenomenological orientation in time, where time is experienced as dynamic and becoming (A-series), and situations where time is objective, linear, and measurable (B-series). He makes a strong distinction between our inward sense of time as a dynamic process and the outside 'real world,' which we inhabit, arguing that perceptual images of A-series are mapped onto B-series belief-inscriptions, which form the basis of mental maps of time. From there he concludes that A-series time perceptions are actually encapsulated in B-series contexts (Gell 1992: 238). Gell himself is a moderate B-series supporter. While he is right in suggesting that progress would be made in the anthropology of time by bridging the gap between extreme B-series studies - for example, time-budget studies by social geographers - and phenomenological A-series ethnographies (more commonly favoured by anthropologists), his model in itself creates a further dichotomization of time studies. This is not helpful in bridging these gaps.

Wendy James and David Mills, the editors of the recent volume The Qualities of Time: Anthropological Approaches (2005), are quite critical of Gell. They envision an “'anthropology of time,' which can engage with history and the work of historians" (James and Mills 2005: 14), something Gell admittedly does not consider. The editors want to move away from seeing "timekeeping as cultural representation" and "even from everyday practice as a temporally patterned process" and focus more on "the relevance of these anthropological concerns to history in the social or even political, historian's sense" (James and Mills 2005: 1), which requires an interdisciplinary approach.

A point they emphasise and which matters to me is the 'timing' of action in social life, in other words "the timing of how things are done" (James and Mills 2005: 2), an important point they share with Gell, and which offers a refreshing perspective on time studies. This perspective includes the occurrence of unexpected events and the consequent interplay between "conventional representations of time" and "the way that 
things are actually done" (James and Mills 2005: 9). This often overlooked gap between how representations of time structure social life and how people work with and around them opens the ethnographic gaze towards the situational agency of people, something I refer to at several stages in this book. Martin Mills' paper on 'fractured temporalities' in Buddhist Ladakh in the aforesaid volume is exemplary in this regard and of relevance to my argument. It also takes place in a Tibetan Buddhist milieu culturally related to my field site and deserves some attention.

Mills' main point is that people's agency is stronger than the timereckoning systems they use, a fact that he feels - and I agree - should be given attention in the anthropology of time. My ethnographic examples in parts III and IV of this book go in this direction since they show that despite maps, time-markers, calendars, and predictions, there is considerable flexibility in how people deal with them in daily life. Mills argues that the temporal map is not primary, but that the agency of people is the essential factor in constructing temporalities in daily life. My data contributes to his argument in that it shows that the same temporal maps are used by different professionals (e.g. doctors, astrologers, lamas) and are selectively and differently interpreted in various contexts (e.g. therapeutic, astrological, or ritual events). This leads to a polysemous situation in which life-forces known under the same name receive different meanings in various contexts, something that is not at all clear from the onset, especially when one is taking a mere textual approach to the various 'vitality tables' and astrological factors in almanacs that are in circulation. ${ }^{21}$

Mills mentions two aspects that he thinks the anthropology of time needs to consider. First, "why people represent time in a particular way," by which he means, "the intellectual expression of a particular temporal ideology (cyclic, linear, or whatever) as a general valid way to interpret the world." Second, "the embodied practices by which people do time," which means how people use the calendars and "thereby integrate themselves into wider ideologically structured communities" (Mills 2005: 350, 360 ). In elaborating these points, he stresses those times when social agents become dislocated from the established cycles that are embedded within ritual, for example, during birth or death. His ethnographic example here refers to the idea of pollution (grib, lit. 'defilement'), and

${ }^{21}$ Hsu offers a similar example on the polysemous nature of medical terms in the context of Chinese medicine (Hsu 2000a). 
how people who become 'polluted' at certain times in their lives cannot partake in the usual rituals, and are consequently "placed 'outside' ritual time" (Mills 2005: 356).

My focus on practices of temporalisation includes both aspects mentioned by Mills in that it emphasises how Tibetans in the Darjeeling Hills utilise temporal frameworks that they are exposed to within their societies' cosmological ideologies, and at the same time have individualised ways of interpreting them in their daily lives. Like Mills, I also observed that in this process of reinterpretation "the actor does not reject the values of the temporal system, he just redefines it for his personal situation" (Mills 2005: 351), something I refer to as situational agency in this book, for example, in chapters 4 and 5 , where the actor simplifies the temporal system or uses it selectively.

In chapter 8, I ask how this plays out in life-span calculations and divinations, considering that these are presented in a style that sounds quite deterministic. The unequivocal nature of such predictions is illustrated in the following example:

Your life-span will last for fifty-nine years. Ultimately, on a Tuesday on the twelfth day in the month Antares (snron), you will die in the morning from the secondary cause (rkyen) of a benign tumour (an example from the Palden Lhamo divination text; see chapter 8.2).

Often, these predictions do not come 'true.' Interestingly, I came across Tibetans doubting their reckoning or divinatory system only occasionally. ${ }^{22}$ It is more a matter of style and interpretation, in which actors are quite free to interpret the given temporal outline of the prediction within their larger cosmological frameworks, involving karma, merit, blessing, (in)auspiciousness, as well as obstacles.

With their use of various calendars and two sets of elements (Indian and Chinese), ${ }^{23}$ Tibetans follow a logic of indeterminacy - for example, skipping and adding days and months as required - with 'practical coherence' rather than what we would understand as 'logical coherence.'

How can we link this to existing anthropological time studies that account for events when things 'fall out of time'? There are some examples

\footnotetext{
${ }^{22}$ Concerning Tibetan calendars, Henning (2007, chapter 6) points out the astronomical errors that have crept into Tibetan calendrical calculations over several hundreds of years. There have also been recent attempts among Tibetans to reform their calendar (Henning 2006, 2007: 271-274).

${ }^{23}$ I explain these sets of five elements in more detail in chapters 3.1 and 6.3.
} 
in the literature I wish to point out that indicate that although temporal gaps are sometimes 'illogical,' they serve a purpose.

For example, Gell makes an interesting observation in his description of the lunar months of the Mursi in Ethiopia (Gell 1992: 301). It has been ethnographically observed (Turton and Ruggles 1978) that the Mursi do not commit themselves to the rigid views of their calendar and remain vague about what month it is. If they were to follow their calendar, their seasonal activities would fall out of step before long. Rather than arguing that their calendars are simply 'wrong,' Gell suggests that the occurrence of calendrical gaps is not merely "evidence of a 'practical' or A-series dominated attitude to time, but is in fact essential to the functioning of the system" (Gell 1992: 301).

In Thailand, both Davis (1976) and Tannenbaum (1988) have pointed out that contradictions in calendars are more problematic for the anthropologist than for the people themselves, especially, "when a single person uses different methods of determining a kind of day at different times" (Tannenbaum 1988: 15). Taking the example of astrological and divinatory life-span predictions, I show that the indeterminacy of the results is actually an intrinsic part of the system. In chapter 8.3, I highlight that 'accuracy' has not been the foremost consideration in Tibetan calculations and divinations on the life-span.

Jacqueline Hobbs' M.Phil. thesis $(2006)^{24}$ is the first attempt of an anthropological analysis of Tibetan time-reckoning debates. Hobbs argues "for an analysis in terms of the living practices of Tibetan Buddhists (what they actually 'do') and the 'gap' which exists between the empirical observation of nature and the Tibetan calendar's textual tradition" (Hobbs 2006: 1). She introduces 'the gap' to indicate the difference between the empirical observation of nature and the Tibetan textual tradition's account of it (Hobbs 2006: 11). Discrepancies between these observations and the calendar systems are not new and had to be overcome in the past. She looks at how Tibetans bridged these gaps with examples covering several centuries and how these decisions were influenced by politics and power. She argues that the Kālacakra calendar was adopted for political as well as practical reasons; it helped to oppose Chinese rule and was at the same time more practical than the Indian Hindu calendar (Hobbs 2006: 21).

${ }^{24}$ All page numbers refer to an unpublished, electronic version Hobbs kindly shared with me. 
It is necessary for anthropologists to investigate ethnographically and historically how the 'gap' between empiricism and textual accounts is bridged. In this context, Ramble (2002) offers a suitable ethnographic example from the Tepa in Mustang. The Tepa calendar does not coincide with the Tibetan Buddhist calendar and has to be adjusted annually. But instead of proclaiming that the calendar is 'wrong,' Tepa successfully employ their 'erroneous' calculations in expressing their political distinctiveness. Since the day of the official 'adjustment' of their calendar is marked by a ceremony, the formalised error also "determines the timings of people's activities over the course of a year" (Ramble 2002: 81).

Similar 'errors,' though of a different kind, not only appear in calendarmaking but also in Tibetan astrological calculations and divinations. In chapter 7.1, I analyse an ethnographic account of Tibetan death calculations from the literature (Mumford 1989) to show how the calculation techniques are designed in layers that allow for several results to appear, which in turn can be interpreted according to what is socially appropriate in the given situation. Here we find flexibility for 'errors' that allow for situational agency and can be re-interpreted to coincide with what is socially appropriate using different layers of the calculation.

Tibetan calendar systems, astrology, and astronomy are also linked to ideas of auspiciousness and power. In chapters 9 and 10, I discuss longevity empowerments (tshe dbang), which are organised regularly as mass events for various reasons. Since they 'add auspiciousness' to any event and thus function as time-markers in themselves, they also have a dimension of power. In the Darjeeling Hills, where Tibetans are now a minority and politically not very active, this element of power refers largely to the strengthening of local identities. Here, a tshe dbang is often organised to attract larger crowds, to easily pass on a political message to the Tibetan community, and to add auspiciousness to local events.

However, what constitutes 'auspicious' events in the Tibetan world is often closely linked to a combined employment of temporal ideas with political power. The New Year celebrations in Lhasa provide a good example of the link between calendars and political power. Throughout the 169os, the New Year celebrations in Lhasa were used by the regent Sangye Gyatso (1653-1705) to extol the role of the fifth Dalai Lama Ngawang Lobsang Gyatso (1617-1682) and the Ganden government (Schaeffer 2006: 190). In his work Tales for the New Year, Sangye Gyatso published astrological calculations that provided evidence that the New Year in the Tibetan lunar calendar coincided with events in the life of three major Buddhist figures: the Buddha himself, Tsongkhapa (1357-1419, the founder of the 
Geluk school of Tibetan Buddhism), and the fifth Dalai Lama. He argued that the New Year was therefore "an auspicious occasion on which to celebrate the reign of the Ganden Government through festivals around the Potala," the Dalai Lama's palace in Lhasa (Schaeffer 2006: 190). In this innovative political move Sangye Gyatso was keen to show that "the New Year's festivities are part of an unbroken ancient tradition" (Schaeffer 2006: 194), which established the necessary authority to strengthen the Tibetan Ganden government.

Auspiciousness is not always linked to political power. It also plays out in what people do in time in their daily lives. During my fieldwork I came across several Tibetan astrological reckoning tables that employ various life-forces and link them to existing calendar systems and cosmological ideas. Rituals and therapeutic events are scheduled using 'vitality tables' that follow weekly cycles indicating the weekdays where srog and bla are strongest (see chapter 4.4). Tibetan calendars and almanacs are filled with information on auspicious and inauspicious days, based on temporal rhythms of various factors that influence life-forces and longevity. One of their main purposes is in fact to lay out the times that mark auspicious events and activities throughout the year and predict times of obstacles that have to be counteracted by rituals.

To mark (in)auspicious days is the purpose of many Buddhist calendars and almanacs (for example, Davis 1976; Mills 2005: 352-354; Tannenbaum 1988). Mills is right in pointing out that the "interlocution of time and agency [...] was often highly explicit" on auspicious days (Mills 2005: 353). People become more active on auspicious days, begin important projects, receive treatment, conduct rituals, etc. Mills articulates this rather well in that time is envisioned more as a "legitimation (or auspiciousness) that must be 'sought out' by the ritual practitioner (whether astrologer, monk or farmer) through particular ritual practices and disciplines" (Mills 2005: 354).

I noticed that lamas, monks, lay people, and amchis generally all derive their interpretations from the same almanac (lo tho $)^{25}$ and 'vitality tables,' but may interpret them differently in various contexts. It is interesting to draw a line of comparison here with Tannenbaum, who points out that the use of Shan calendars among Theravāda Buddhists in lowland Thailand varies with age, gender, and the general interest of the individual and

\footnotetext{
${ }_{25}$ The official almanac of the Tibetan government-in-exile follows the phug pa tradi-
} tion. See chapter 6.3 for details. 
focuses on how experts use calendar knowledge and why people consult experts (Tannenbaum 1988: 14). The calendar is mainly used to find the quality of days and determine the appropriate time to schedule treatments. In this practice "the level of expertise consulted is directly related to the importance of the event," which is similar to the Tibetan context.

Interestingly, there is never just one particular expert. The 'vitality table,' for example, is used by lay people, monks, and amchis alike, but in the process of interpretation the life-forces bla and srog receive different meanings and are linked to different areas of life. This brings us back to what I mentioned above, that the situational agency of professionals and lay people is an essential factor in constructing and interpreting temporalities in varied contexts of daily life.

Using the term situational agency in this book immediately brings up thoughts about the varied (mis)use by anthropologists of the ubiquitous term 'agency' and needs to be briefly clarified. 'Agency' in anthropology has been critiqued and defended extensively; consequently its use is a charged call. There is no need here to go into the details of how agency is used in anthropology or how it evolved from 'practice theory' and has influenced history. ${ }^{26}$ I rather want to define situational agency the way I use it in this book and why it plays a part in the analysis.

A general workable definition of agency is that it "refers to the socioculturally mediated capacity to act" (Ahearn 2001: 112, 130). However, it has its fallacies. Ahearn cautions that,

For anthropologists in particular, it is important to avoid treating agency as a synonym for free will or resistance. One fruitful direction for future research may be to begin to distinguish among types of agency - oppositional agency, complicit agency, agency of power, agency of intention, etc. while also recognizing that multiple types are exercised in any given action (Ahearn 2001: 130).

Following her suggestion on further distinguishing types of agency, I use the term situational agency in the context of practices of temporalisation in this book to highlight how people deal with their temporal systems in given daily situations and adjust, use, and manipulate them according to a given context. The social actor here is not understood to be a free individual. Social agents "are always involved in, and can never act outside of,

${ }^{26}$ For good overviews of the use of 'agency' in anthropology see Ortner 2006, in linguistics see Ahearn 2001, in sociology see Barnes 2000, and in relation to history see Comaroff and Comaroff 1992. 
the multiplicity of social relations in which they are enmeshed" (Ortner 2006: 130).

It is understood that this is a complex affair, in which the social actors with their intentionality and agency are not just individual players but part of larger issues involving collective histories, politics, and power. The fear of the loss of complexity when obsessed with agency (for example, Comaroff and Comaroff 1992) is a valid point taken. Nevertheless, I consider situational agency a valuable angle to better understand the material presented in this book along with my main focus on practices of temporalisation, since it adds the changing perspectives of individual actors in their application of existing temporal structures. I think that both angles help us to understand Tibetan ideas of longevity within the wider context of complex Tibetan Buddhist worldviews involving numerous concepts, such as auspiciousness, karma, and blessing. How varied these practices of temporalisation play out on the platforms of individual actors and their interrelationships with temporal structures is an ongoing theme in the chapters to come. 
PART TWO

THE FIELD SITE AND TIBETAN AREAS OF KNOWLEDGE

Part II of this book provides substantial background information that will help the reader contextualise the ethnographic accounts of parts III, IV, and V. Chapter 2 introduces the socio-political background of the Darjeeling Hills with its multi-ethnic communities and specific Tibetan refugee situation, its Buddhist monastic establishments, and pluralistic health care settings, which are all part of the contemporary landscape in which Tibetan longevity beliefs and practices are played out. Longevity practices are also deeply embedded in various professional knowledge systems that are laid out in chapter 3 . 
Barbara Gerke - 978-90-04-21748-5 Downloaded from Brill.com๑4/26/2023 $\odot 2: 47: 13 \mathrm{PM}$ via free access 


\section{TIBETANS IN THE DARJEELING HILLS: THE SOCIO-POLITICAL AND HISTORICAL BACKGROUND}

To begin the introduction to the field site, ${ }^{1}$ I want to first sketch the two most prominent socio-political factors that have shaped life in the Darjeeling Hills since the beginning of the twentieth century. These are (1) the immigration of people to the area from a variety of multi-ethnic groups and (2) the political violence during a long-term Nepali regional nationalist movement. Since these two factors have impacted and changed the lives of Tibetans in the region considerably, they strongly influence what it means to be Tibetan in the Darjeeling Hills.

There is little previous ethnographic research on Tibetans in the Darjeeling Hills. In the 1950s, Beatrice Miller studied the mutual aid societies, called skyid sdug (Miller 1956), and lay and monastic relationships (Miller 1958). More recently, Tanka Subba worked on the adaptation of Tibetan refugees in Darjeeling and Kalimpong (Subba 1988a, 1990). His research deals with five percent of the refugee population and specifically emphasises ethnicity and socio-economics (Subba 1990). Between Miller and Subba lie three decades without any published anthropological studies on Tibetans in the Darjeeling Hills. Sikkim, in comparison, has been better studied by anthropologists, ${ }^{2}$ although with little emphasis on Tibetan communities.

\section{Historical and Political Climates}

Darjeeling (altitude 2,134 m or 6,982 ft.; see plate 2.1) and Kalimpong (altitude 1,249 m or 4,100 ft.; see plate 2.2) are fast-growing urban areas situated in the foothills of the Himalayas in the Darjeeling District in the Indian state of West Bengal. Both towns offer majestic views of

\footnotetext{
${ }^{1}$ This chapter draws on published literature, interviews with contemporary Tibetans and Nepalis, as well as my own personal long-term observations.

${ }^{2}$ Some of the seminal anthropological studies on Sikkim include Arora 2004, 2006a; Balikci 2002, 2008; Gorer 1984 [1938]; Macdonald 1982; Nakane 1966; Shneiderman and Turin 2006; Siiger 1967; Steinmann 2001; Vandenhelsken 2003.
} 


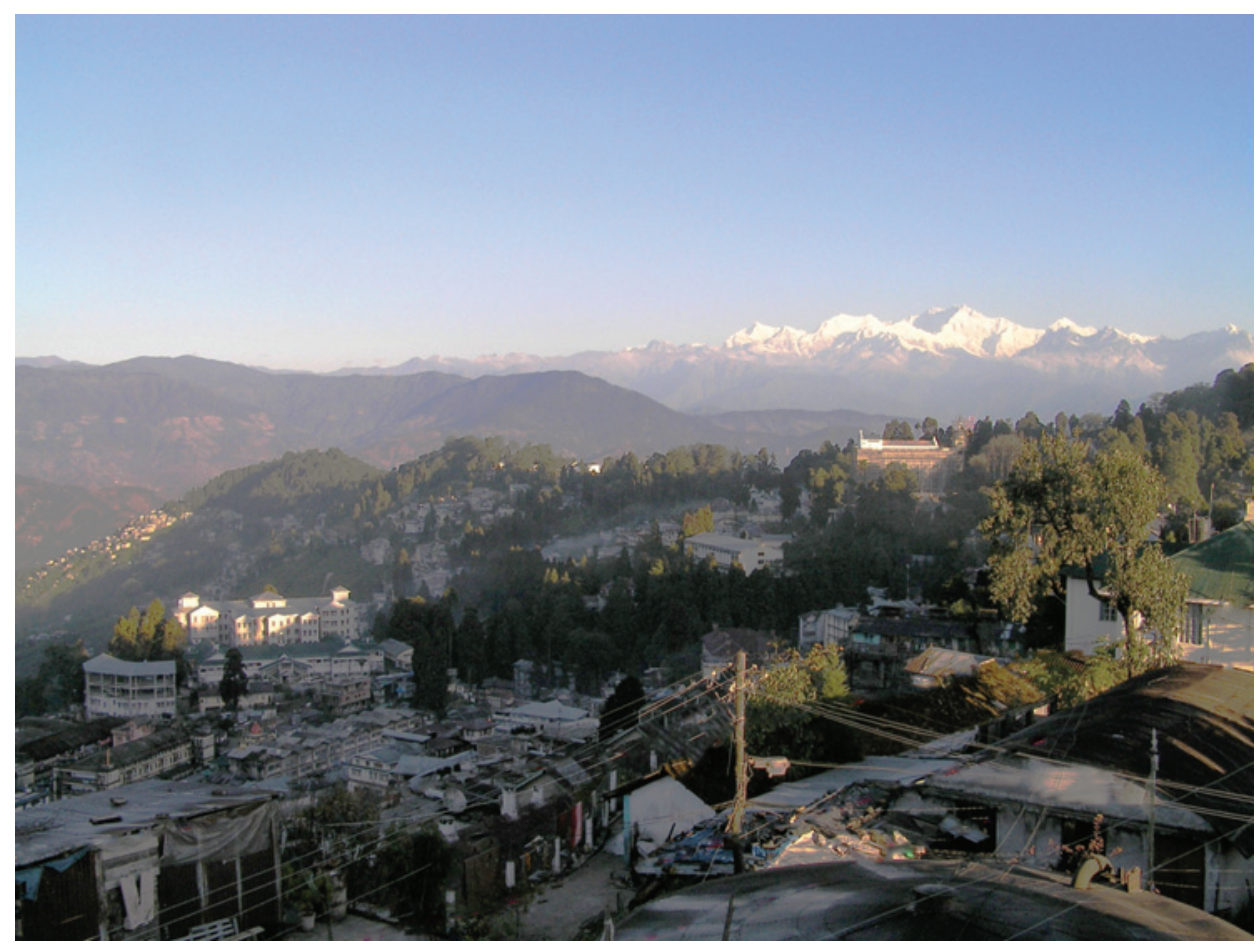

Plate 2.1. View of Darjeeling with Mount Kanchenjunga, 2004.

Mount Kanchenjunga, the third-highest mountain in the world (altitude $8,585 \mathrm{~m}$ or $28,169 \mathrm{ft}$.). North of the Darjeeling Hills lies the Indian state of Sikkim - an independent kingdom until $1975 ;^{3}$ to the east the Kingdom of Bhutan; to the south the divisions of Jalpaiguri and Uttar Dinajpur in West Bengal; and to the west what was the Kingdom of Nepal and since 2008 is the Federal Democratic Republic of Nepal. The area has always been strategically important and has changed rulers several times in the course of history.

Before the British annexed various parts of the Darjeeling Hills during the mid-nineteenth century, the region was sparsely populated by Lepchas, Bhutias, Limbus, and Magars (Subba 1988b: 357). The Lepchas, in Tibetan known as mon $p a$, however, are considered the original inhabitants of the Kalimpong-Darjeeling-Sikkim region. ${ }^{4}$

3 Sikkim became a British protectorate in 1890 .

4 The Lepchas have been fairly well studied; see, for example, Arora 2004, 2006b, 2007; Awasty 1978; Das and Banerjee 1962; Gorer 1984 [1938]; Lepcha and Balikci-Denjongpa 


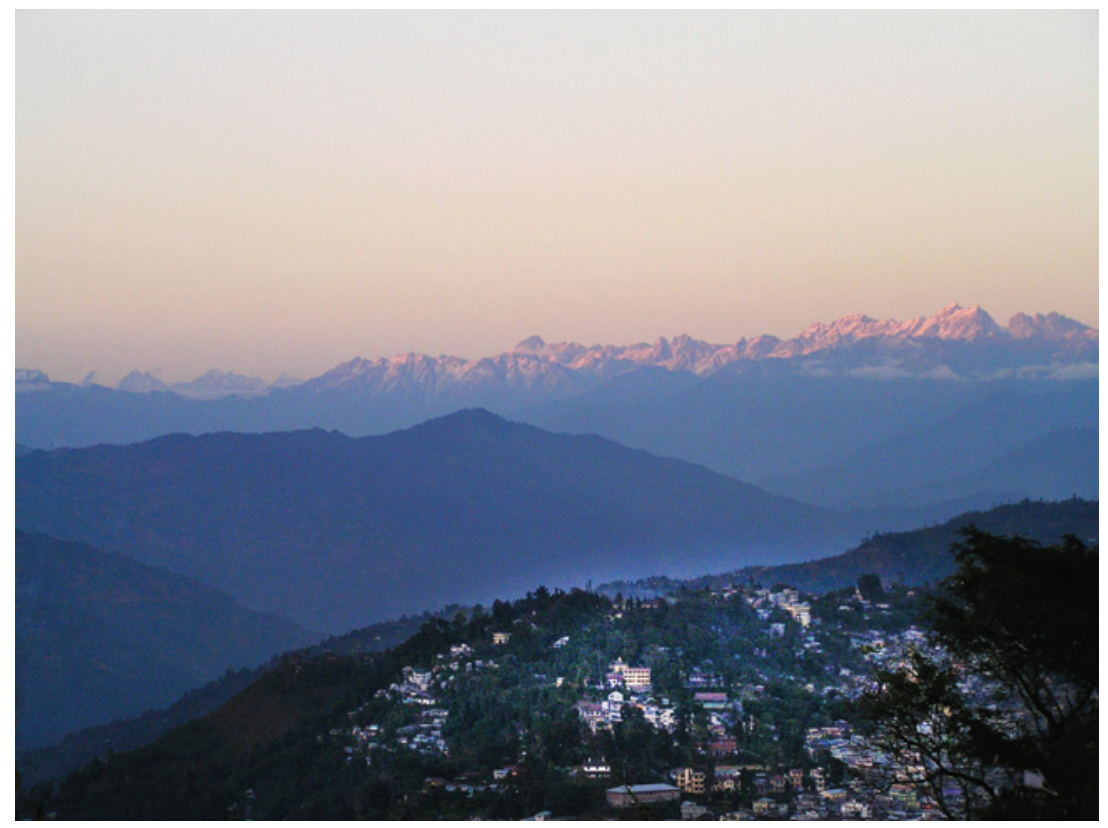

Plate 2.2. View of Kalimpong with the Kanchenjunga Range, 2005.

Bhutan annexed Kalimpong from Sikkim in 1706 and held it until the British-Bhutanese Sinchula treaty of 1865 absorbed the area into British India. In 1879, the British paved a road through Kalimpong and Pedong to Jelep La, ${ }^{5}$ the pass into Tibet on the Kalimpong-Lhasa trade route. They were interested in the trade route and the defence of Darjeeling, which they managed to receive as a 'gift' from the Choegyal of Sikkim in 1835, turning it into an elite hill station surrounded by tea gardens. After India's independence in 1947, Kalimpong and Darjeeling became a part of the state of West Bengal.

Kalimpong has always had a very different ambience from Darjeeling. Whereas Darjeeling was shaped by the tea industry and British colonial tourism, Kalimpong achieved prominence during the 1930s and 1940s as a junction on the Lhasa trade route. Sir Charles Bell, a British political officer for Sikkim, Bhutan, and Tibet, noted in 1924 that half of the entire

2005; Morris 1938; Nakane 1966; Plaisier 2007; Siiger 1967; Sprigg 2005; Steinmann 1996; Torri 2010. See Plaisier 2010 for an online "selected bibliography of works concerning Lepcha language or culture."

${ }_{5}$ The Tibetan term $l a$ indicates a high pass. 
trade between Tibet and India came through the Lhasa-Kalimpong trade route (Bell 1992 [1924]: 19).

Kalimpong and Darjeeling both attracted missionaries who established private anglophone boarding schools from the turn of the twentieth century onwards (McKay 2007b: 67-74). Boarding schools have remained a major contributor to the Hill economies together with tea, tourism, and plant nurseries. While Tibetan economic activity in Kalimpong centres on small incense and noodle factories as well as family-owned retailing, in Darjeeling, tourism has been the largest source of income for Tibetans. The influx of Buddhist lamas from Tibet since 1959 has led to a reinforcement of Buddhism and the construction of numerous Buddhist monasteries in the region.

The route to Tibet via Kalimpong and Jelep La became important after the Younghusband Expedition of 1904, which marked a period of an increasingly British-controlled trade with Tibet through the Chumbi Valley route via the Nathu La (14,440 ft.) into Sikkim. Many of the Bhutia traders who were in charge of the northern Nepal-Tibet trade shifted towards the east, settling in Kalimpong and Darjeeling. The Kalimpong-Lhasa yak wool trade peaked in the 1930 s and 1940 s but was closed abruptly during the Indo-China war in 1962.

The merchants of Kalimpong were members of age-old trading communities, such as Kashmiris and Newars, who had been patronised by Lhasa and the Dalai Lama's Ganden government since the seventeenth century, as well as Tibetan trading families, mostly from Kham, who monopolised the wool trade across the central Himalayas (Spengen 2000: 143). Most of the wool buyers were American companies, and this trade was actively supported by the thirteenth Dalai Lama in the otherwise anti-foreign atmosphere of Tibet. World War II increased the Kalimpong trade when the Burma Road to China was closed. In 2006, the Nathu La was reopened for limited trade with China via Sikkim, forty-four years after its closure.

Since the early Kalimpong-Lhasa trade period the busiest part of Kalimpong town has been known as Tenth Mile. Even today, the Tenth Mile area is predominantly Tibetan with small Tibetan restaurants and shops selling noodles, handicrafts, prayer flags, dried cheese, Buddhist statues, the Tibetan staple of roasted barley flour (rtsam pa), and brocades (see plate 2.3).

Many people have migrated to the Darjeeling Hills; this has led to a socially heterogeneous character of the entire region. ${ }^{6}$ From the later

\footnotetext{
${ }^{6}$ See Subba $1988 \mathrm{~b}$ for a discussion on the early migration into the region.
} 


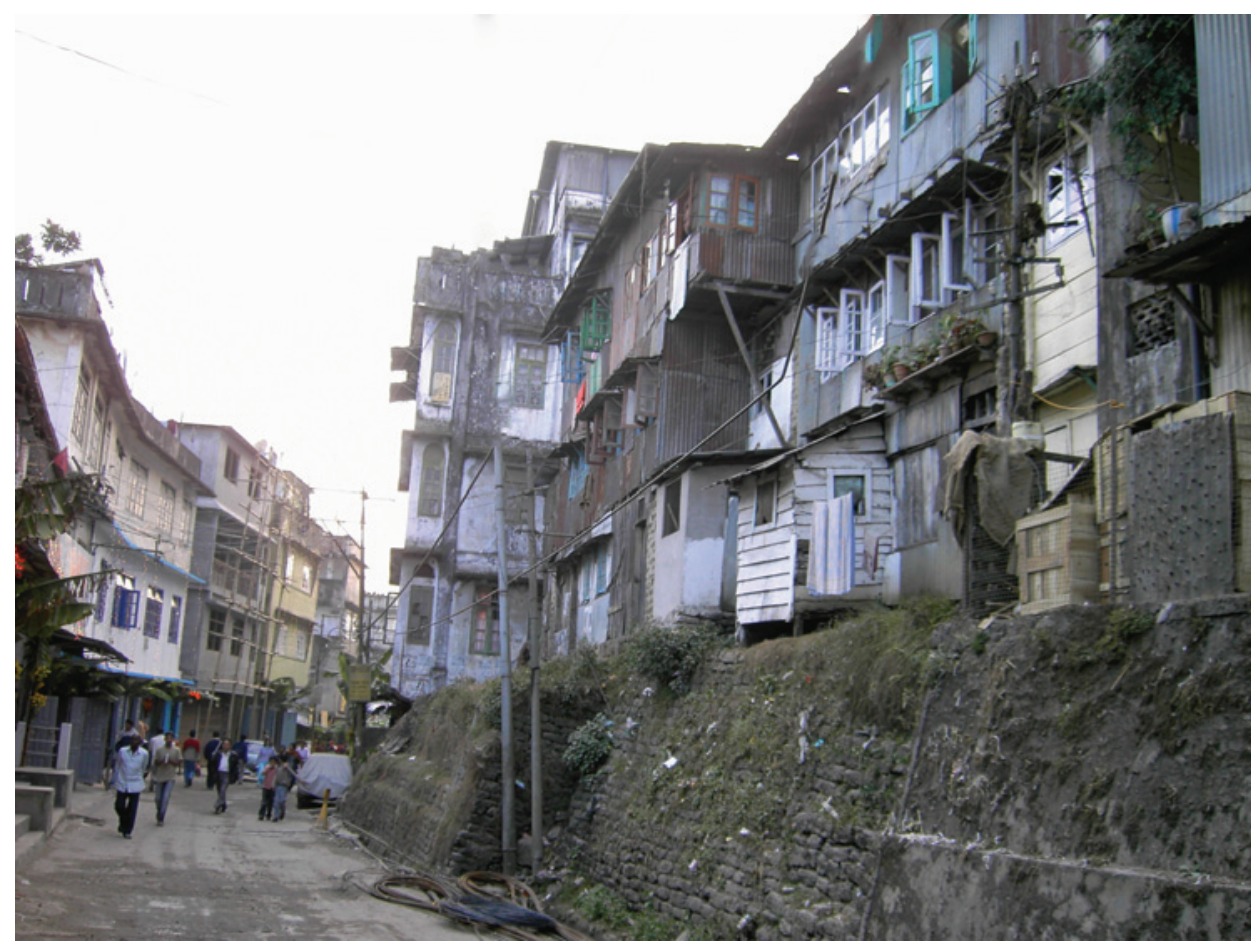

Plate 2.3. The Tenth Mile area, Kalimpong 2005. The Tenth Mile in Kalimpong was part of the Kalimpong-Lhasa trade route during the first part of the twentieth century.

part of the nineteenth century, Tibetans came as traders along the trade routes. Tibetan refugees arrived from the 1950s onwards. Nepali migrant workers, the culturally Nepali Ghorkas, came into the Darjeeling region from the early nineteenth century onwards, leading to the 'Nepalisation' of the entire Hills. In 1941, ninety-six percent of Darjeeling's tea garden workers were Nepali (Kennedy 1996: 189). Although Nepali migrant workers continue to come to the area, ${ }^{7}$ the majority of Nepalis in the area are now Indian citizens.

Ethnic groups originating in Nepal - such as the Gurungs, Limbus, Magars, Rais, Newars, and Thamis, as well as the high-caste Nepalis such

7 An example here are the Thamis or Thangmis (thang mi), a group of approximately 40,00o people, who live in areas of the Dolakha and Sindhupalcok districts in eastern Nepal as well as in bordering areas of the Tibetan Autonomous Region (TAR). Many of them are migrant workers, and some earn their living as seasonal porters in Darjeeling (Shneiderman 2006: 11, note 5; see also Shneiderman and Turin 2006). 
as the Chetris and Bahuns (Brahmins) - form the majority of the population in the Darjeeling Hills and dominate local politics. ${ }^{8}$ Nepali Buddhist groups, such as the Yolmos, Tamangs, and Sherpas, some of whom have close resemblance to Tibetans, have lived in the Darjeeling Hills for over a century. ${ }^{9}$ The Tamangs are one of Darjeeling's largest ethnic groups and have long held considerable political power; the political leader Subash Ghisingh, who ruled the Darjeeling Hills from 1988 to 2007, is a Tamang.

People of Indian provenance settled in the region from the mid-nineteenth century onwards: Marwaris came from Rajasthan to Kalimpong for the wool trade and have remained as clothes and hardware merchants; Biharis work mainly as carpenters, bakers, cobblers, and barbers; Bengalis came with the British and have taken over administration and teaching positions. These groups comprise a growing entrepreneurial class in the region, which contributes to increasing ethnic stratification.

Christian missionaries - both Catholic and Protestant - were instrumental in setting up most of the boarding schools in the Hills from the early twentieth century onwards. A Tibetan preaching hall was built in Kalimpong at the end of the nineteenth century but is no longer used. Still, a small Tibetan Christian community exists. In the twentieth century, Gergan Dorje Tharchin (1890-1976), locally known as Tharchin Babu, was the most famous Tibetan Christian in Kalimpong. He founded the Tibet Mirror, the first-ever newspaper printed in Tibetan, which was regularly sent to Lhasa (see plate 2.4). Muslims form about one percent of the entire population and have active mosques in Kalimpong as well as in Darjeeling. There are even a few Tibetan Muslims living in Kalimpong.

Ethnic identities in the Darjeeling Hills have to be considered in the light of both Bengali governance and an increasing Nepali nationalism. Since Nepalis have progressively populated the region, now form the majority, and have been engaged in a long-term struggle for their own political independence from West Bengal, the weaker ethnic groups among them Tibetans, who were politically quite active until the 1970 s have only marginal political influence.

\footnotetext{
${ }^{8}$ For details on the caste structure of the Nepalis in the Darjeeling Hills see Subba 1985; Nepali ethnic groups in the Darjeeling Hills are discussed in Subba 1989.

${ }_{9}$ Ortner discusses the migration of the Sherpas to Darjeeling in the late nineteenth and early twentieth century, where they supported British infrastructure and mountaineering expeditions through various labour tasks (Ortner 1989: 159-163).
} 


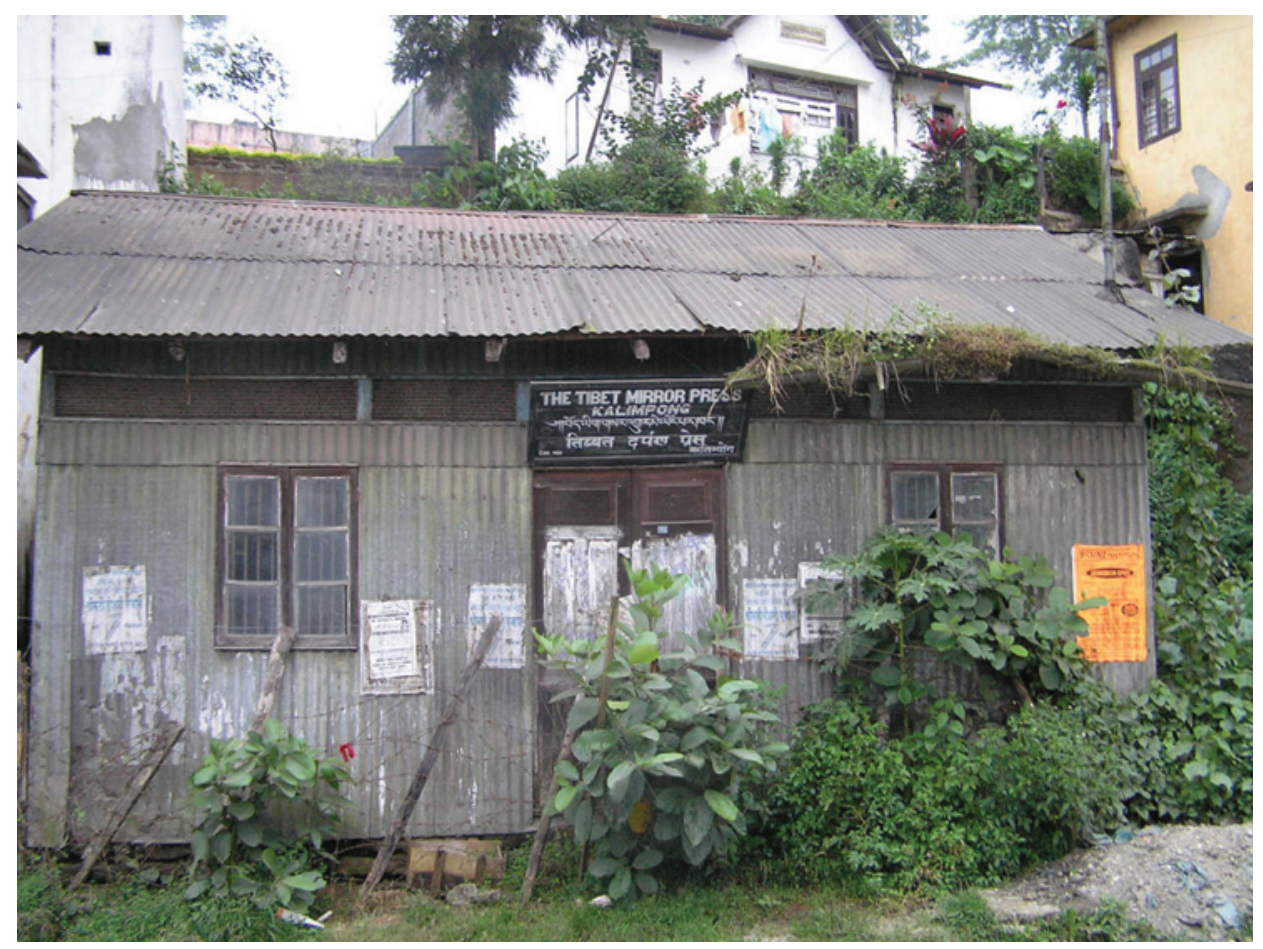

Plate 2.4. The famous Tibet Mirror Press, Tenth Mile, Kalimpong 2007. The Press operated from 1925 to 1962 . From here the Tibet Mirror, the first-ever newspaper printed in Tibetan, was regularly sent to Lhasa.

The Nepali nationalist movement is, however, not Hindu-dominated, since many Nepali groups are Buddhist or have only partial allegiance with Hinduism (Subba 1990: 70). The movement has its origins in a longterm Nepali-Bengali conflict. Bengalis have controlled the area through elite positions in education and government since the incorporation into Bengal of Darjeeling in 1835, Siliguri in 1850, and Kalimpong in 1865 . Nepalis, to the current day, are fighting marginalisation through the Gorkhaland movement, which seeks a self-governing state independent of West Bengal. This movement, its leadership, and its violent methods have left a long-lasting imprint on life in the area, which is marked by corruption (Middleton 2010; Subba 1992a; Wangyal 2002).

The Nepali demand for independent statehood goes back to 1906 and is based on the massive ethnic, cultural, linguistic, and political differences between Nepalis and Bengalis. Partial political autonomy was achieved through the establishment of the Darjeeling Gorkha Hill Council 
(DGHC), but only after two years of a violent movement from March 1986 to August 1988, known as the Agitation, during which there was a complete loss of both basic human rights and state control. Fear of violence swept the Hills as people were killed randomly. The Agitation, which was steered by the Gorkha National Liberation Front (GNLF), did not attack minority communities such as Tibetans directly, but the trauma caused by political violence and injustice has paralysed local communities irrespective of their ethnic background. The level of corruption has made it difficult for some Tibetan newcomers to identify with and adjust to such local strategies, and this in turn has hampered their process of acculturation.

The political activities of Tibetans in the Hills have changed over time. One can observe several phases: a strong political involvement in Kalimpong from the trade route times through the 1970s, a retreat during the Agitation in the 1980s, a period of Nepali-Tibetan clashes in the mid-1990s, and a low political profile until 2007/2008.

Earlier, Kalimpong was more important to Tibetans than Darjeeling because of the Tibetan trade route. Consequently, Tibetan involvement in local politics was more prominent in Kalimpong than in Darjeeling, as is exemplified by the story of Penpa Yeshi. ${ }^{10}$ Penpa Yeshi was a Tibetan Bhutia, with a Newar mother and a Tibetan Bhutia father. The family had humble beginnings, but Penpa's mother made a fortune with homemade liquor sales and bought a lot of property in Kalimpong. Among Nepalis, she was known as the 'Iron Lady' of Kalimpong, and Penpa Yeshi became known as the 'Uncrowned King of Kalimpong.' He was among the first Tibetans to receive an English education at the prestigious Protestant boarding school Dr. Graham's Homes. He entered the political arena in the early 196os, surrounding himself with a group of strong-willed - and at times violent - characters. Penpa Yeshi had a talent for bringing people together. He was an extremely good networker, and very flamboyant. He entertained army commanders at his place and shook hands with Indira Gandhi and with the president of India. No major political decision in the area was made without him. He and his supporters basically ruled the town.

\footnotetext{
${ }^{10}$ Anmole Prasad, a local Nepali lawyer, told me this story. Tibetan perspectives of this story would probably differ.
} 
Penpa Yeshi held the chair of the municipality for many years. His wealth was his most influential asset. By the mid-196os he had secured the financial support of the Marwaris, who were known as the bankers of Kalimpong and who financed the Tibet trade as well as trade-sympathetic politicians. The Marwaris made a political statement against Nepali nationalism by supporting Tibetan politicians. Penpa Yeshi's position was similar to the one held by the Nepali political leader C.K. Pradhan in the 1990s - a single leader of Kalimpong town, supported by a local mafia. Penpa Yeshi's downfall came with the rise of Nepali nationalism in the 1970s. Thereafter, he only exerted limited influence as the vice-patron of Dr. Graham's Homes.

With the rise of the Nepali nationalist movement and Nepalis taking over local politics, Tibetans withdrew from the political scene, keeping a low profile during the Agitation. Tibetans are known to 'mind their own business' and have not been taking part in local politics since the 1970s. Most Tibetans left Kalimpong during the Agitation, or stayed indoors. The Tibetan schools closed during the forty-day strike in 1987, but otherwise remained open. Some Nepalis I spoke with did not think of the Agitation as being traumatic for Tibetans (some Tibetans, who came in the 1950s, confirmed this). The reasons mentioned for this were that they were not targeted by the Agitation, and also had not really put down their roots in Kalimpong apart from some property in Tenth Mile. It was relatively easy for those Tibetans who had come as refugees to leave for some time because of their earlier experiences of being displaced. They were, however, affected economically, since a lot of their businesses relied on foreign tourists, who were not allowed to visit the Darjeeling Hills for several years. I did not interview older generations of Tibetan Bhutia trading families, who own larger property, on the Agitation. Subba claims that "many of them [Tibetans] got unnecessarily harassed both by the supporters of the movement and the brutal paramilitary forces like the Central Reserve Police Force deployed by the state government to contain the violence" (Subba 1990: 119). During my fieldwork, I met one Tibetan who exemplifies this. Tsering Dorje was an ex-Khampa soldier, who had come to Kalimpong in the 1970s and was arrested during the Agitation, falsely accused of having killed a policeman. When we met, he was in his seventies and stitched Tibetan bags on an old sewing machine in a shop in Tenth Mile (see plate 2.5 ).

While his case is exceptional, it illustrates a tragedy experienced by a Tibetan during the Agitation in Kalimpong. Tsering Dorje narrated his story: 


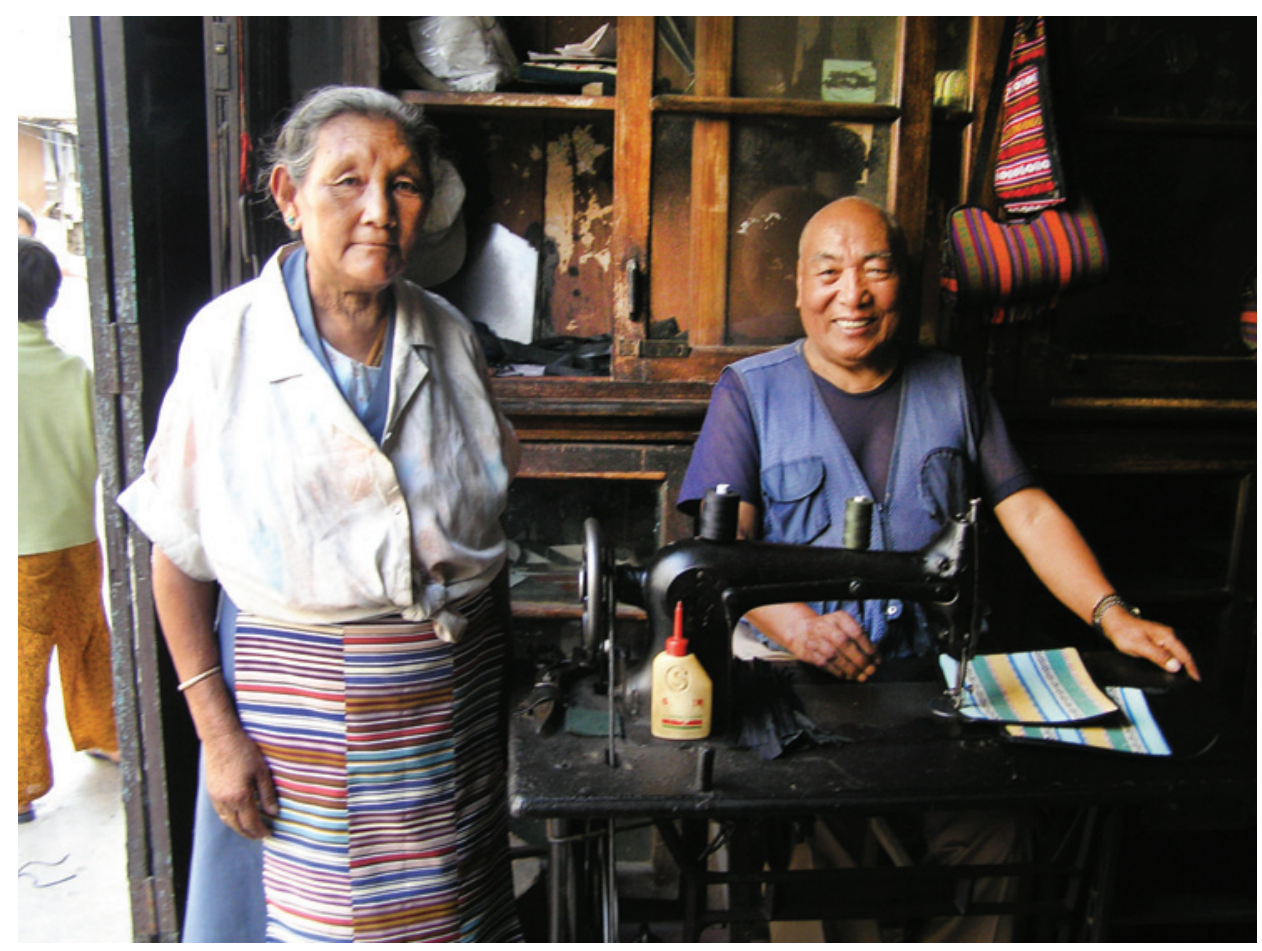

Plate 2.5. Tsering Dorje at his shop in Tenth Mile, Kalimpong 2006.

One night, we were sleeping; they [Indian paramilitary police forces] banged on the door. There was no electricity, and I saw in the light of the butter lamps on our altar that three policemen came in with their guns. We said we were Tibetans and had nothing to do with politics; they did not understand. I said, 'We are people of the Dalai Lama'; they did not know who the Dalai Lama was. I wanted to show them my Tibetan passport and turned around to reach under the blanket. It was then that they shot me in my leg, and I was arrested. I spent several days in hospital and then in jail and would still be there without the help of Tibetans who eventually got me out.

Whether or not Tibetans were personally affected by the Agitation, it is important to understand how the Agitation shaped the way in which they came to relate to local Nepalis. The medical anthropologist Eric Jacobson observed in the 1990s that Tibetan hotel owners in Darjeeling treated their Nepali staff with caution and did not react to their extensive demands for holidays because of a lingering fear that they would complain to the local party if they felt in any way treated with disrespect (Jacobson 2000: 268).

By the mid-1990s, across India and Nepal, a growing resentment against Tibetans exploded in violent clashes in Kathmandu, Dharamsala, and 
Darjeeling." In Darjeeling and Kalimpong, this anti-Tibetan resentment was based on several issues. First, by the 1990 it became clear to the larger local community that Tibetans had ensured key positions for themselves in the Indian administration and police services through their Bhutia status. ${ }^{12}$ They had bought property, owned shops and hotels, and thrived in their businesses. Second, the international interest in Tibetan Buddhism and the large-scale support of Tibetans caused jealousy among Nepalis. Third, outdated prejudices, such as the belief that Tibetans were involved in illegally selling liquor - which they did during the rather lawless trade route times - were dredged up in statements insinuating that Tibetans were conspiring to 'demoralise the Nepali community.' Such anti-Tibetan resentment contributed to Tibetans withdrawing from public political expression in the Hills.

At the time of my fieldwork, Tibetans kept a low public political profile and were active only in their own associations, such as the Tibetan Women's Association, the Tibetan Youth Congress, and the Indo-Tibetan Friendship Society. Their network of economic and social support is organised through their self-sufficient social welfare skyid sdug system, ${ }^{13}$ to which most Tibetans are connected. Skyid sdug provide them with a secure community aid network and social contacts in the absence of an effective governmental system of social welfare. Even though skyid sdug are known as welfare organisations, they also offer an indirect political platform to establish connections and utilise networks in an otherwise politically dormant situation.

During my fieldwork, although the older generation of Tibetans made their political statements on Tibet publicly, they kept them low key. On March 10, Tibetans remember the Tibetan Uprising Day of 1959, when Tibetans surrounded the Dalai Lama's Norbulingkha Palace in Lhasa to protect him from an anticipated Chinese abduction. China's military response resulted in the violent death of tens of thousands of Tibetans. On March 10, 2005, I saw a small group of older Tibetans who had gathered for a few hours in the morning on the Chowrasta, the main square in Darjeeling. There were no young people. Young Tibetans told me that

\footnotetext{
${ }^{11}$ Jacobson was in Darjeeling at the time and wrote about such clashes in some detail (Jacobson 2000: 269).

${ }^{12}$ The Bhutia status will be explained in detail in one of the following sections of this chapter.

${ }_{13}$ For studies on this social welfare system, see, for example, Daniels 1994 and Miller 1956.
} 
they did not have much of a relationship with that day. The Nepali journalist Niraj Lama told me:

Tibetans are not very active politically. Whenever Tibetans take out a political procession, it is always remarkable that seventy percent of those people are old Tibetans; the young people don't turn up. I did not even know about the event on March 10. I just saw people walking on Chowrasta. They did not inform the press about it. It was not covered.

Subba reported from his fieldwork in Kalimpong in the mid-1980s that Tibetan refugees in Kalimpong burnt Chinese clothes publicly on March 10 (Subba 1990: 116). Tibetan political activities have again resurfaced since 2007, when the Tibetan Uprising Day in Darjeeling was a surprisingly large event with public candle processions and news coverage. The Tibetan Youth Congress was suddenly keen to raise awareness of Tibet's past among young Tibetans. In 2008, with the Beijing Olympics and the demonstrations leading up to the events, the protests in the Darjeeling Hills also increased drastically, with hundreds of young and old Tibetans taking part in demonstrations, hunger strikes, and public prayer vigils.

How can we understand people's sense of being Tibetan, which I call 'Tibetanness,' within this political climate? Before analysing further what it means to be a Tibetan in the Darjeeling Hills, I briefly describe the demography of the Tibetan population.

\section{Demographic Data of Tibetans}

Available demographic data concerning Tibetans and other ethnic groups in the Kalimpong-Darjeeling region are limited and mostly unreliable. Demographic data on ethnic groups in the region dates back to the gazetteers of British colonial times (Dash A.J. 1947; O'Malley 1989 [1907]; Risley 1894). With India's independence, it was anticipated that the caste system would be abolished. Consequently, ethnic groups were ignored in data collection, a fact that has led to a lack of census data over the past fifty years. Thus we know little of the demographic development of all ethnic groups.

Kalimpong has a total population of 42,980 and Darjeeling of 106,257 (2001 census, quoted in Fareedi and Lepcha 2002/2003: 4). These figures are low estimates, focus on urban centres, do not include villages, and keep changing with intense and uncontrolled migration into the area. The first detailed Tibetan demographic survey in India and Nepal was conducted in 1998 by the Planning Council of the Central Tibetan 
Administration-in-exile (hereafter CTA). ${ }^{14}$ It was a multi-sited survey, using English and Tibetan questionnaires, to account for age, sex, fertility, mortality, and education of Tibetans in ninety-three settlements in India, Nepal, Bhutan, and in international communities around the world (CTA 2000: 4-6). According to this survey, the Indian state of West Bengal has a total Tibetan population of 6,455 . Darjeeling $(2,455)$ and Kalimpong $(2,141)$ are the urban areas with the largest groups of Tibetans (CTA 2000: 36). Smaller Tibetan communities of a few hundred people are located near these main urban centres.

The survey does not define who a Tibetan is, or whether, for example, Tibetans and their children from mixed marriages were included or not. It presents an image of a 'unified Tibetan community,' which the CTA in Dharamsala is keen to promote. The term 'refugee' is avoided; instead the focus is on the 'settlements' and 'Tibetans in exile.' The surveyors admitted that it was difficult to locate Tibetans living outside the settlements in cities and those not in touch with the CTA in Dharamsala (CTA 2000: 38). The figures also do not include Tibetan traders who settled in Kalimpong in the earlier decades of the twentieth century. Even though they hold Indian citizenship, many of them feel 'Tibetan.'

The area of Kalimpong known as Tenth Mile, once part of the Lhasa trade route, remains predominantly Tibetan, but there are no figures of how many Tibetans came before or after 1959. Darjeeling has a Tibetan Refugee Self-Help Centre with six hundred and fifty refugee residents, but most Tibetans live elsewhere in the town and are not distinguishable as such. Affluent Tibetan families live outside the settlements and often run large businesses. The survey covers the economically more disadvantaged settlement Tibetans, and thus depicts a 'poorer' image of Tibetans than the urban situation reflects. Taking into account these grey zones of who may count as a 'Tibetan,' the population figures are probably much higher than the 1998 census suggests.

Demographic data on Tibetan life expectancy also has to be viewed critically. The surveyors argue that they could not determine the correct age of older Tibetans, since most older Tibetans do not celebrate their birthdays and thus do not remember them (CTA 2000: 40). In fact, for most divinatory, astrological, and ritual purposes Tibetans need to know

${ }^{14}$ A follow-up survey, entitled the 'Socioeconomic Survey,' was conducted in 2001 (Childs 2008: 20). For a detailed study of Tibetan demography and population regulating mechanisms in traditional Tibetan societies see Childs 2008. For a social and demographic study of Tibetan refugees in India see Bhatia, Dranyi, and Rowley 2002. 
the year of their birth according to the twelve year signs (lo rtags bcu gnyis), and many also know the element that is attached to it. With some effort their correct age could have been established. The surveyors avoided this, and consequently the life expectancy of woman ( 78.8 years) and men (66.3 years) are but crude estimates (CTA 2000: 33).

\section{The Reinvention of Ethnicity: Creating 'Cultural Vibrancy'}

I have always found it challenging to grasp the intricacies of the extremely kaleidoscopic relationships between the various ethnic groups, their languages, and the cultural, religious, and political practices that collide in the Darjeeling Hills. Ethnicity ${ }^{15}$ is situational and influences social interactions and personal self-identification. The focus on boundaries among ethnic groups has contributed to the understanding of discrimination and exclusion of 'others,' but has also depicted ethnicity as a static concept. In the Darjeeling Hills, I found ethnicity highly politicised for gaining personal benefits. It is not spoken of much otherwise, even though it underlies many daily interactions.

Consumerism - which has made deep inroads into India since the opening of the markets in the early 1990s - appears as a distraction from dealing with a deeper confrontation with the traumas of the past. The urban market scenes seem to reflect blurred identities in the wake of 'globalisation' reaching the Hills. However, ethnicity has been politicised and ethnic groups have been re-proclaiming their identities in order to draw financial gain from government benefit schemes, as I will explain in the course of this section.

Since the 1990s, there has been a palpable development towards strengthening individual ethnic groups rather than focusing on their unifying aspects. This is quite different from the situation when the Nepalis first came to the region and their togetherness as a work force in a new land forged a common 'Nepaliness.' The Nepali nationalist movement tried to depict itself as a non-communal movement, an agenda it has mostly managed to adhere to, until recently.

Since 1990, with the introduction of new benefit schemes by the Indian government, there has been an increasing competition among all ethnic

${ }^{15}$ Ethnicity is a much-contested and debated term, reflected in a large amount of literature that cannot be addressed here. See Middleton 2010 for a more detailed discussion on ethnicity in the Darjeeling Hills. 
groups to be part of those groups that receive governmental and educational advantages through this reservation system. Categories under which ethnic groups can be officially classified are: 'Other Backward Classes' (hereafter OBC), ${ }^{16}$ 'Scheduled Tribes' (hereafter ST), ${ }^{17}$ 'Scheduled Castes' (hereafter SC), ${ }^{18}$ and, since 2005, 'Most Primitive Tribes' (hereafter MPT). ${ }^{19}$ Most groups try to achieve the ST status. 'Cultural distinctiveness' is a prerequisite to receiving this ST status. This distinctiveness has to be publicly demonstrated and assessed by government officials (see Middleton 2010). Nepalis in the Darjeeling Hills, who had grown up in the postindependence era with a feeling of being 'Nepali' rather than 'Tamang,' 'Gurung,' or 'Sherpa,' had to 'learn' and often 'invent' such distinctiveness. For Bhutia groups, such as the Yolmowa, who received ST status just after independence, it meant facing new and tough competition. For those groups who were newly applying for the ST status, like the Tamangs and the Thamis, it involved the creation of a culture that demonstrated unique traditions, language, and distinctiveness. ${ }^{20}$

The sudden ethnic differentiation is largely a matter of semantics and is presented on public holidays, during festivals, and political speeches. For many, it serves the purpose of getting government benefits. It matters little in day-to-day life, since all these groups live in a Nepali-dominated society, adopt Nepali as their lingua franca, hardly speak Tamang or Gurung, mostly receive education in the English language in one of the private schools, and embrace urbanised, modern Indian lifestyles. It is precisely to such middle-class people that the educational benefits (such as college admission, job reservations, educational grants) are important.

For Tibetans, the only option has been to acquire the ST status under the category of 'Bhutia.' This is often done under cover and through

${ }^{16}$ On the OBCs Shneiderman and Turin note: "Members of Other Backwards Classes have access to a smaller number of reserved seats, but do not qualify for the direct financial support available to ST and SC individuals. This has created a situation where those groups currently classified as OBC - such as the Magar, Rai and Thami - see their position as only a temporary stepping-stone to the more desirable category of ST" (Shneiderman and Turin 2006: $\left.5^{8}\right)$.

${ }_{17}$ Lepchas, Bhutias, Sherpas, and Doptapas were classified as ST in 1978 (Bhasin 2007: 62).

${ }_{18}$ Nepali Kamis (smiths), Damais (tailors), and Sarkis (shoemakers) are classified as SC. Indians from Bihar and Bengal who work in the same trade are also included in this category.

${ }_{19}$ MPT is an upgrade of the ST status and was granted to the Lepchas of Sikkim in January 2005 (Shneiderman and Turin 2006: 58).

${ }_{20}$ Shneiderman and Turin provide a good example of the reinvention of Thami culture and language (2006). These issues are also discussed in detail by Middleton (2010). 
connections, especially for the newcomers, who see more opportunities in India as Indian nationals and need the ST certificate to apply for an Indian passport and eventually travel abroad. The Tibetan administration does not always like to admit this. A Tibetan welfare officer in the region was proud to express during an informal interview what Tibetans sacrifice for remaining 'Tibetan':

Taking on Indian citizenship would be easier for us in many ways, it would allow us to travel easily, and also to buy and own land in India. The RC or refugee certificate, which all Tibetans get, is only the permission to stay in India. ${ }^{21}$ Even His Holiness has such an RC. As a Tibetan I have a Green Pass [voluntary contribution pass]. As a Tibetan refugee I have the Blue Pass [refugee pass]. I will register my son for the RC when he is 18 , he won't get Indian citizenship. We might be richer, but what kind of life is this? What about our race, our cause?

If I would choose ST and work in the IAS [Indian Administrative Services], I would earn, but what is this life and what about our race? The majority of Tibetans think that way and will not join ST. If we take Indian citizenship the Tibetan people in Tibet will lose their morale. Despite economic problems, Tibetans keep their identity with their RC. Therefore, most of their land here is owned or built in the name of societies or trusts.

I was aware that this was the stand he had to take as a welfare officer, and he also knew that many Tibetans applied for Indian citizenship, which he acknowledged to some extent later during our talk.

Tibetans do not have to prove any 'cultural vibrancy' to obtain their ST status as Bhutias, since 'Bhutia' has been an ST category since India's independence. Identifying themselves as Bhutias does not necessarily represent a denial of their national feelings as Tibetans. Tibetans are well known for preferring to express their distinctiveness as Tibetans. The ST status is often just a pragmatic choice that opens the door for a better life in India. Moreover, the 'Bhutia' ST status also removes them from their 'refugee' status, which Tibetans in the Darjeeling Hills do not like to identify with, as I explain later in this chapter. However, after having lived several generations in India and after having lost touch with their Tibetan roots, being a 'Bhutia' can also involve an emotional identification distinct from those Tibetans who are 'newcomers' (gsar 'byor ba) or who show strong nationalist feelings of 'Tibetanness.'

${ }^{21}$ The RC has to be renewed every year and only allows Tibetans to work and travel within India; it does not permit foreign travel. For international travel, Tibetan refugees resident in India require an additional 'identity certificate.' 
How can we then understand the arbitrary term 'Bhutia,' the Tibetan refugee situation, and how Tibetans relate to these issues? The following sections provide further answers to these questions.

\section{What Does it Mean to be a Tibetan in the Darjeeling Hills?}

There is no single answer to the question of what it means to be a Tibetan in the Darjeeling Hills. 'Tibetanness' in the Hills is not an essential imperative but is changeable. People are social actors who continuously change boundaries. For anthropologists it has become important to look at what ethnicity means for the individual, acknowledging that "ethnic groups are categories of ascription and identification by the actors themselves" (Barth 1969: 10).

Tibetans in India do not constitute a single unified community. This is not a new situation for Tibetans. Even in the past, the culturally Tibetan world was actually never united as a single nation. Some scholars even argue that the attempted religious unity in Tibet that began during the reign of king Songtsen Gampo (617-649/650 CE) "was actually detrimental to national sentiment" (Ramble 1997: 384 , original emphasis) and that allegiance to local mountain gods was stronger in forming identities than abstract Buddhist teachings (Ramble 1997: 398). The argument here is that Buddhism introduced an image of the Tibetan environment as dangerous, full of demons and negativities that constantly had to be pacified as compared to the exalted home of Buddhism, India. This negatively affected the sense of a Tibetan national identity (Ramble 1997:384). However, later developments have used the 'historical memory' of Tibet's imperial past for a revival of Tibetan religion and identity, also in exile (Goldstein and Kapstein 1998).

The 'Tibetanness' we find among Tibetan(ised) communities across the Himalayas differs greatly from the 'Tibetanness' in the Tibet of preand post-1959. We have to consider that there is nothing like a traditional Tibetan identity, since "right up until 1959, the Tibetans had very little sense of being one group" (Shakya 1993: 9). This is reflected in the Tibetan use of the term bod pa, which is generally translated as 'Tibetan,' but actually denotes different people for different groups of Tibetans: for a Changthang nomad it refers to a Tibetan from Lhasa, and for people of Amdo and Kham it signifies a Tibetan from Central Tibet (Shakya 1993: 9). When I asked Tsering Dorje in Tenth Mile whether he was a Tibetan (bod pa red pas), he replied, "No, I am Khampa" (ma red khams pa red). 
So, how do Tibetans create their identities and sense of 'belonging' or 'not belonging' to one or the other group or category? The context is different from Dharamsala, where the Dalai Lama and Tibetan refugees received permission from the Indian government to settle in the hill station Mc Leod Ganj, where they established a unique exile community. ${ }^{22}$ What makes the study of Tibetans in the Darjeeling Hills kaleidoscopic in outlook is the fact that one has to deal with several generations of Tibetans who settled in this region at different points in history and under very different circumstances. In this context, the term 'Bhutia' is important and needs some clarification.

The terms 'Bhoe' or 'Bhutia' as such are derived from Bhoțah, a Sanskrit rendering of the Tibetan word for Tibet, bod (Ramble 1997: 391); so 'Bhoe' indicates someone from Tibet. Tibetans who lived in India at the turn of independence received the ST status under the category 'Bhutia,' which was adopted in the Indian constitution to support marginalised groups. As an ST status, the category includes also many other ethnic groups. ${ }^{23}$ The term can also refer to ethnic characteristics that people of various origins have adopted over time while living in the area. Those Bhutias can be from Sikkim, Tibet, or Bhutan. Unfortunately, there are no population figures available that would give us demographic details about the different types of Bhutias in Kalimpong and Darjeeling.

Early Tibetans migrated to the Sikkim region as early as the thirteenth century CE (Balikci 2008: 6). Their descendants are generally called Bhutia or 'Bhotiya.' ${ }^{24}$ In this case, Bhutia is an Anglicized variant of 'Bhotiya,' the name conventionally used to designate the indigenous Tibetan-speaking people of Sikkim (Ramble 1997: 141, note 5). But in the Darjeeling Hills, these Bhutias are called 'Sikkimese Bhutias' to distinguish themselves from 'Bhutanese Bhutias' and 'Tibetan Bhutias.' 25

Until recently, Bhutia indicated a person of Tibetan speech and culture who dwelled outside the frontiers of Tibet proper. Nowadays, the term

${ }^{22}$ For a discussion of the uniqueness of Dharamsala as a place for researching Tibetans in exile see, for example, Prost 2008: 7-12.

${ }^{23}$ The Kagatey Bhoteys (Yolmowas), Sherpas, Doptapas, Tromopas, Chumbipas, and Drukpas (Bhutanese) are all classified along with the Tibetans under the ST category 'Bhutia' (Subba 1988b: 359).

${ }^{24}$ In Sikkim, they also call themselves Lhopo (lho pa, lit. 'people from the south'; Balikci 2008: 6).

${ }_{25}$ Ramble analyses the meaning of the term 'Bhot' in the Nepal Himalayan context (Ramble 1997: 391; 2008: 29-30). See Arora 2006a for a study of self-identification of Lhopo or Bhutia groups in Sikkim. 
often indicates someone's ancestry, since many Bhutias do not speak Tibetan and have adopted Nepali culture. Local people in the Darjeeling Hills tend to use the term 'Bhutia' for all Tibetans in general. The term is so fluid that even Hindus who traded with Tibet were alluded to as 'Bhotiyas' (Awasty 1978: 46).

In the Darjeeling Hills, the Nepali view of Tibetan Bhutias has changed over time. For quite a few years after 1959 - before the Tibetan refugees were organised into settlements or managed to establish themselves within existing towns - life for the majority of Tibetan refugees was marked by hardship and survival through alms collection. In the 196os, the 'Bhotey' was considered a 'wandering beggar' (Subba 1990: 41). The status of these early Tibetan refugees was only slightly raised when they were employed in road construction after the Indo-China War of 1962. By 1970, the image of the Tibetan refugees had definitely changed in the society at large. Shedding their image as beggars, they slowly established themselves, many of them becoming rather affluent (Subba 1990: 41-42).

Based on his research in the early 1980s, Subba remarked that the term 'Tibetan' "refers to those 'Bhutias' who are not naturalised as yet" (Subba 1990: 61). This distinction did not last. During my fieldwork, I found that all Tibetans in the region are generally referred to as Bhutias, whether they came before or after 1959, are Indian citizens, or have retained their refugee status. There is, however, a clear difference in their legal status. The term 'Bhutia' nowadays denotes a recognised ethnic category as much as an essentialised feeling of belonging to one particular, though heterogeneous, group. Despite ethnic differences between the Bhutia groups, there is a certain communal identity bringing together people under that umbrella term. Buddhism is certainly a strong unifying aspect that links all these Bhutia groups.

Tibetans born in India cannot hold dual citizenship. For the children of Tibetan refugee families born in India, it is the choice of the parents whether to register their child as a Tibetan refugee and receive a Tibetan refugee certificate (RC), or apply for the ST status as 'Bhutia' and become an Indian citizen. Some Tibetans have managed to be absorbed into the 'Sherpa' or 'Yolmo' sub-category of 'Bhutia.' In privately run schools, some Tibetans added 'Bhutia' to their second name to indicate their ST status.

Even though there are ethnic differences within the various groups classified as Bhutias, in schools and public spaces they mingle easily with each other. They all speak Nepali, and from their features are not always distinguishable. Walking around the public spaces of the Hills one cannot easily 
make out who is a Tibetan, Sikkimese, or Bhutanese Bhutia, a Yolmowa, or a Sherpa. Public space, in fact, is an area of commonality and ethnic immunity, especially with younger generations wearing western and nontraditional clothes, and Bhutia women also wearing Indian kurtas or saris instead of their traditional phyu pa. Tibetans often speak a mix of Nepali and Tibetan. Even elderly Tibetans often replied to my Tibetan questions in Nepali. Young Tibetans frequently do not understand Tibetan; some Bhutias said they are Tibetan but cannot speak Tibetan and have 'lost touch with their roots.' Quite often when I initiated a conversation in Tibetan, people would respond in English, explaining that they are Bhutias and not Tibetans. Their obvious embarrassment at not knowing their language in front of a foreigner who spoke to them in Tibetan belied an internal conflict which I think made them 'choose' to identify themselves as Bhutias under these circumstances. In the monasteries, young monks mostly speak Nepali with each other, and technical 'Dharma Tibetan' has a function similar to the Latin of the Church.

Towards the end of my fieldwork, the newly arrived Tibetan physician to the Kalimpong branch clinic of the MTK, Amchi Tsering Wangdue, who was a young bachelor and a 'newcomer' (he had come to India about ten years previously and graduated from MTK in Dharamsala), had difficulties finding friends in the local Tibetan community. He complained, three months after his arrival, "When I go to the market, I cannot make out who is Tibetan. They all look the same; they all speak Nepali. It is difficult to make new Tibetan friends here." I noticed this kind of isolation often, especially among the MTK amchis who worked on a rotation scheme and were regularly transferred between the MTK branch clinics (Gerke, in press).

Despite the extent to which Tibetans meld into the local Nepali community, they do publicly display their distinctive culture during regular programmes at the Tibetan schools. These public functions often provide the only opportunities for young Tibetan men to look for a prospective marriage partner within their own group. I knew of a Tibetan bachelor who was keen to marry a Tibetan girl, but had no chance to meet one except at those Tibetan functions, where he could identify the unmarried girls as the ones wearing their phyu pa without the apron (pang gdan). He was assisted by two local married Tibetan women, who would initiate conversations with prospective brides and research their family backgrounds. Intermarriages with Nepalis occur, but not as frequently as one might expect, probably because of Nepali-Tibetan tensions. Tibetans who 
have not intermarried make a point of this, distinguishing themselves from those who have intermarried.

To understand the expression of 'Tibetanness' and Tibetan distinctiveness, one has to differentiate between the generations of Tibetans. Tibetans who experienced their flight in the 1950s and early 196os are described by local Nepalis as being very nationalistic and proud of their Tibetan culture. The older families from the trade route times do not feel such a need to display their 'Tibetanness,' and most of the younger generation, who have grown up quite removed from their Tibetan language and culture, also do not express such distinctiveness unless they are attending schools that organise Tibetan cultural school programmes. The presence of the Dalai Lama, however, seems to bridge these generational gaps, and his annual birthday celebration is always an occasion to express 'Tibetanness' across age and status barriers.

In 2005, his seventieth birthday was honoured with three-day cultural programmes at the two Tibetan schools in Kalimpong, including a day of longevity prayers at the Mani Lhakhang ( $m a$ ni lha khang, lit. 'jewel temple'), which is both a Tibetan temple and a community-cum-marriage hall in the centre of Kalimpong. ${ }^{26}$ Both Tibetan schools presented a public programme with Tibetan prayers, songs, dances, jokes, exhibitions, and many speeches. At the Central School for Tibetans some of them were of political character with the local Nepali party councillor as the chief guest, who declared a holiday for the Tibetan school children and distributed sweets after his speech. Outside these occasional annual events, Tibetan culture is not expressed distinctively in public and usually remains in the domain of the homes, monasteries, and schools.

In summary, 'Bhutia' is an ambiguous term with several connotations for Tibetans: it denotes a legal status that gives Tibetans a place in the Indian setting; it also provides a sense of belonging for those Tibetans who have lived in India for a long time, or for refugees who want to identify themselves with local people. Being a Bhutia sets them apart from the Tibetan refugees or newcomers. It also provides an umbrella to unite the various Tibetanised Himalayan Buddhist groups, if and when required. The category is so fluid that it still allows for a distinctive 'Tibetanness' that people express as Tibetans if or when they wish to. Their

\footnotetext{
${ }^{26}$ When compared to a monastery, a Mani Lhakhang does not provide living quarters to monks but functions as a public prayer hall.
} 
membership in flexible categories such as 'Bhutia' is situational and negotiable. Tibetans, who have lost touch with their language and customs after having lived for several generations in the Hills, also identify as Bhutias to differentiate themselves from those Tibetans, often newcomers, who still strongly adhere to their language and religious affinities. In such cases, Bhutia becomes a group identification within its own - individually defined - ethnic boundary, which is quite different from the recognised ST category of 'Bhutia.'

So far, my discussions have shown that with growing 'globalisation' and migration, contemporary Tibetans in the Darjeeling Hills belong to various groups at the same time, shifting between them depending on what kind of 'belonging' they wish to express, or which benefits they would be entitled to. To further understand 'Tibetanness' in the Hills, one also has to look at the refugee groups and how the status of being a 'refugee' has been modelled and applied.

\section{Tibetan Refugees}

The acculturation of Tibetan refugees in the Darjeeling Hills has to be viewed in the context of both the multi-ethnic communities that surround them and have influenced their lives in the region and the interfaces between Tibetans who are refugees and those who are not.

Tibetan refugees in India have been studied by various scholars. ${ }^{27}$ Among them only Subba worked in the Darjeeling and Sikkim region (Subba 1988a,b, 1990).

One can roughly distinguish between four groups of refugees: (1) those who came from the early 1950 s until the Dalai Lama fled Tibet in March, 1959; (2) those who came with him (over 80,00o) and who followed his lead; (3) those who came in another wave of refugees between 1986 and 1996 (about 25,000); (4) and those who came in the 199os, and thereafter. The first group had more time to organise their move and tended to bring more financial resources to India (Subba 1990: 28). The second group experienced more horrific flight situations and could hardly bring any belongings. The third group came when Tibet opened up to trade and

${ }^{27}$ Examples for Tibetan refugee studies are Arakeri 1998; Bernstorff and von Welck 2004; Diehl 2002; Fürer-Haimendorf 1990; Goldstein 1978; Klieger 2002; Norbu D. 2004; Nowak 1984; Saklani 1984; Subba 1988a, 1992b, 2002. For a brief review of existing literature on Tibetan refugees in India see Prost 2008: 8-11. 
tourism, peaking after the clashes in Lhasa, in 1989. The fourth group were predominantly monks and nuns from Amdo, who sought the presence of the Dalai Lama and higher education in India, as well as Tibetan children seeking religious and secular education in India. ${ }^{28}$

The government of India set up thirty-five settlements for Tibetan refugees in ten states across India (Norbu D. 2004: 188; Prost 2004: 17). ${ }^{29}$ Refugee settlements in the Hills have all been non-agricultural and have few landholdings. This is unlike the Tibetan settlements in Bhutan, Ladakh, and Arunachal Pradesh, where more than fifty percent engage in agriculture. ${ }^{30}$ The Darjeeling and Sikkim region has only four settlements: Darjeeling, Sonada, Ravangla, and Pokhriabong. The larger settlements and urban centres also established Central Schools for Tibetans, ${ }^{31}$ which offer education in the Tibetan language for refugees. How does the process of acculturation differ between Tibetans staying in the settlements and Tibetans living in towns? How is it different in Darjeeling, which has the Tibetan Refugee Self-Help Centre, and in Kalimpong, which does not have a settlement?

Clearly, it has been easier for the Tibetans outside the settlements to intermingle with Indian society, to receive their 'Bhutia' ST status, intermarry, and build up independent lives. In Darjeeling, they own hotels or have stalls on the main shopping road. In Kalimpong, they are less affluent because the town has fewer tourists. Here, business in the Tenth Mile area consists of only a few little restaurants, hotels, and shops, but taking advantage of the warmer climate - more family-owned noodle and incense factories. Many of the early refugees received good positions through the 'Bhutia' ST status and occupy posts in the police and government offices and also work as teachers and lecturers in local schools and

\footnotetext{
${ }^{28}$ The Tibetan Reception Centre in Dharamsala states that from 1991 to June 2004, the Centre hosted a total of 43,634 new arrivals from Tibet. Out of these, $59 \cdot 75 \%$ were found to be children below the age of thirteen and youths between the age of thirteen and twentyfive (CTA 2009).

${ }_{29}$ The numbers of settlements vary in different sources. The Central Tibetan Relief Committee (CTRC) lists thirty-nine settlements for India also including urban Tibetan welfare offices without designated settlements, such as Gangtok and Kalimpong (CTRC 2010).

${ }^{30}$ Tibetan Under Chinese Communist Rule 1976, appendix V: 206-207, quoted from Subba 1990: 132-133.

${ }^{31}$ The Central Schools for Tibetans are Indian government schools that were set up mostly along with the larger Tibetan settlements (CTSA 2009). In the Darjeeling Hills, there are three Central Schools for Tibetans, in Kalimpong, Darjeeling, and Sonada. Additionally, the Sambhota Tibetan Schools Society (STSS) runs sixteen schools for Tibetans in India; one of them is in Gangtok, Sikkim, and one in Pokhriabong near Darjeeling (STSS 2010).
} 
colleges. In contrast, Tibetans in settlements cannot easily find well-paid jobs, or receive the ST status, which would help them gain educational benefits; their salaries tend to be lower than the local average. Tibetans who have the money settle in town. Many of them received their 'Bhutia' ST status within a few years of arrival.

The Tibetan Refugee Self-Help Centre just outside Darjeeling looks almost like an enclave, with its own biomedical clinic, kindergarten, printing press, temple with a head lama and resident monks, old people's home, carpet factory, handicraft centre, and sales shop where tourist buses stop during their tours of Darjeeling. It is evident that the 'refugee' status of the Tibetan Refugee Self-Help Centre has helped attracting customers, as well as Indian and foreign aid (for example, the X-ray machine and the German-made printing press), which has been more difficult to attain for other local groups. The Tibetan Refugee Self-Help Centre provides valuable help for the weaker sections of the Tibetan community, such as single parents with children and the elderly, who would not easily receive social protection and free health care in town. It is thus like a 'social housing complex,' a place for Tibetans who 'did not make it' in the eyes of the town dwellers.

The Tibetan settlement policy is clearly non-assimilative and has been designed to recreate Tibetan society in exile. Keeping Tibetans in settlements certainly makes cultural and linguistic preservation easier, but cannot stop the inevitable intermingling with mainstream Indian society. Settlements have led to both more isolation from the local communities and fewer communal tensions when compared with Tibetans living outside (Subba 2002: 140-142). This policy worked in the 1960s, but has been increasingly criticised. Norbu argues that the new generations of Tibetans in exile "have reached their limits of educational levels and economic choices offered in the settlements" (Norbu D. 2004: 209). This has been reflected in the trend of young Tibetans leaving the settlements.

When Tibetans came to India, being labelled 'refugee' (btsan byol pa) gave them a kind of identity; it also attracted international support. Knowing that Tibetans have often taken advantage of this status (see, for example, Frechette 2002), I wondered why in both Kalimpong and Darjeeling the term 'refugee' was avoided in talks amongst or with Tibetans. In Darjeeling, they use the terms 'old Tibetans' (bod pa rnying pa) and 'new Tibetans' (bod pa gsar pa). The 'old Tibetans' settled there before the Chinese occupation of Tibet, whereas 'new Tibetans' are the refugees who came after 1959. The meaning of the terms has even shifted along with history, when the newcomers of the $1986-1996$ period became the 
'new Tibetans' and the refugees of the post-1959 period turned into 'old Tibetans.' The later arrivals were ranked progressively lower down the social ladder. It is well known that the treatment of the 'newcomers' by the earlier Tibetan settlers has not always been cordial (see, for example, Prost 2004: 61-66, 2008: 61-72; Diehl 2002: 64, 87).

Tibetans in Kalimpong have not adopted these terms, probably because they settled within existing Tibetan (trading) communities, such as Tenth Mile, and had no refugee settlement like in Darjeeling. Thus 'old' and 'new' Tibetans mixed freely in town. Although they tend to use the term 'Bhutia' for all Tibetans, when asked in informal interview situations they use the term gsar 'byor ba for 'newcomers' as in Dharamsala. ${ }^{32}$ The traders who came before 1959 are locally known as Gyakar Khampa or Bhutias. Subba suggests that many Tibetan refugees did not want to be called 'refugees,' because in India the term 'refugee' assumes a disparaged sense of a 'beggar' (Subba 1990: 5). This is probably true and may have influenced the choice of terms, avoiding the label 'refugee.' Moreover, the fact that Tibetans already lived in the region before the refugees arrived led to further stratification within their own society between the 'old' and 'new' Tibetans, or the 'Bhutias' and 'newcomers.'

Tibetans in Tibet were commonly divided according to their ranks as commoners, monks, and aristocrats. Even though in India the power relations between these ranks changed considerably, their prejudicial way of dealing with each other is based on their earlier pattern of creating ranks among themselves. This may have influenced the creation of the new divide between 'old' and 'new' Tibetans, or 'Bhutias' and 'newcomers,' especially also because the 'old' Tibetans, or Bhutias, were much wealthier, more educated, and influential. Subba also discusses class differences among Tibetans as one of the reasons for their internal tensions (Subba 2002: 138-139). It is certainly important to avoid stereotyped images of a homogeneous Tibetan refugee community in the Indian exile context.

In my interactions with Tibetans I found that for them there is a clear difference between Tibetans living outside the settlements and those living within, even though they are not called 'refugees.' Moving out of the settlement is seen as economically climbing the ladder of modernity. Tibetans from the Darjeeling Tibetan Refugee Self-Help Centre try to

$3^{2}$ Diehl defines gsar 'byor ba as "recent escapees born and raised under Chinese rule in Tibet" (Diehl 2002: 64). For further discussions on 'newcomers' in Dharamsala see Prost 2004, 2008; Diehl 2002. 
improve their status by marrying Tibetans outside, preferably 'old' Tibetans who are already Indian citizens and have the right to buy property. The position Tibetans hold within their own community is negotiated both in terms of socio-economic status and their degree of Indianisation, or perhaps more accurately Nepalisation.

Since the Tibetan status is not defined from a sense of being a 'refugee,' we need to ask the question: Are there still Tibetan refugees in the Hills if Tibetans themselves do not think and feel in such categories? When I asked a welfare officer how many Tibetans in Kalimpong were refugees and how many came before 1959, he replied,

We do not look at this difference at all, because people here do not feel the difference (my emphasis). Even I did not ask the old woman who just came into my office and took the letter for her medical supplies. I did not ask for her refugee certificate. They are all Tibetans; it does not matter when they reached, and if they came before 1959 or after.

He seemed keen to promote the same unified image of Tibetans that the Tibetan government-in-exile in Dharamsala tries to portray. In the context of his own work, he only made the distinction between Tibetans who lived in the 'settlements' and those who lived 'scattered.' For him it was a mere difference in administration, not between the status of being a refugee or not.

Subba observed in the 1980 s that refugees in Darjeeling and Sikkim settlements were usually accepted as 'local people,' and "seldom get to experience the feeling of being a 'refugee' in this region" (Subba 1990: 75). Twenty years after Subba's initial research, I found that the term 'refugee' was scarcely heard except in the name of the 'Tibetan Refugee Self-Help Centre' in Darjeeling.

My conclusion is that the experience of having a refugee status has changed for almost all Tibetans in the Hills, and that in daily life their inter-community and socio-economic rank differences are more important to them than the 'refugee' or 'non-refugee' status. I think we have to look more at effects of 'globalisation' on Tibetan (even Tibetan virtual) communities to make sense of their identity in India. Daily life in the Hills over the past decade has been increasingly shaped by 'globalisation' and open markets. As for the Tibetans, many of them have begun considering the Hills as a place of transition, and keep migrating to other areas, or abroad, where they have better job opportunities. Jacobson rightly emphasises the "high values which Tibetans place on mobility and independence" and points out the swiftness and ability with which they move around, may it be for pilgrimage, new jobs, better climates, or to 
go abroad (Jacobson 2000: 351-352). I often looked at them as nomads in search of better pastures.

\section{Being Tibetan Without Speaking Tibetan}

As long as those Tibetans who experienced the flight from Tibet are still alive, there are enormous differences in experience between the generations. The generational gaps are so large that an individualised anthropological approach to Tibetan identity is essential.

Samuel explicitly mentions several underlying principles that have marked Tibetanised groups, such as the significance of continuity (in terms of lineage and household) and the maintenance of the gompa (Samuel 1993: 149-154). Here is an example of how the significance of a gompa has changed for young Tibetans. In Kalimpong, I often met young Tibetan men with their girlfriends going for an outing to the Durpin Gompa (see plate 2.6). ${ }^{33}$ From the top of the gompa one had a beautiful view over the town and the surrounding hills and valleys (see plate 2.7). The gompa's quiet ambience made it a natural choice for young couples to meet. Rather than a symbol of ancestry, it was a suitable place to go for a picnic and take one's girlfriend. One day, I saw a Tibetan boy explaining the statue of Padmasambhava, reading out his mantra from the signboard to a Nepali girl. We started talking casually. Dorje was nineteen and from a Tibetan Nyingma Buddhist family in Pedong, a small township fourteen kilometres from Kalimpong with three Buddhist gompas. Dorje had not heard the mantra before nor did he know anything about Padmasambhava. Considering that Padmasambhava is the founding figure for the Nyingma School of Tibetan Buddhism and his mantra, om ah hum vajra guru padma siddhi hung, is one of the most commonly recited mantras among Tibetans, this was surprising. Dorje went to a Christian school, where he was taught in English. His parents were Tibetans and Buddhists, his grandmother still did the rituals at home, but he had never developed any interest in Buddhism and rarely visited gompas. His brother had married a Nepali and the family spoke Nepali at home. Still, he went for longevity rituals, and as chapter 10 will show, a lot of young Tibetans attend long-life rituals for various, often modernised, reasons.

\footnotetext{
33 Durpin is the Nepali term for 'binoculars,' and Durpin Gompa is the local name of the Zangdok Palri monastery, which follows the Dudjom gter gsar tradition.
} 


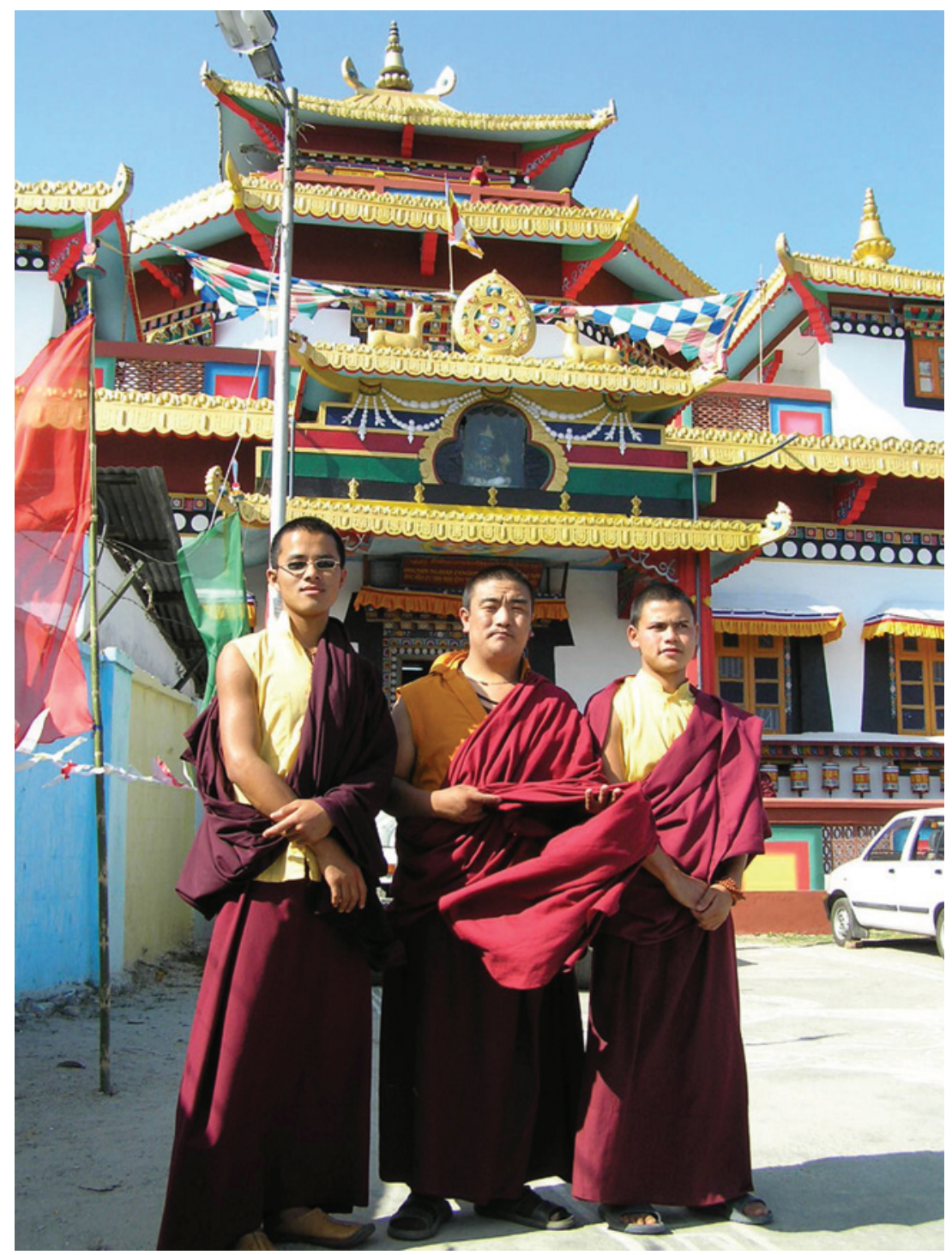

Plate 2.6. Monks in front of the Zangdok Palri Monastery (Durpin Gompa), Kalimpong 2005. 


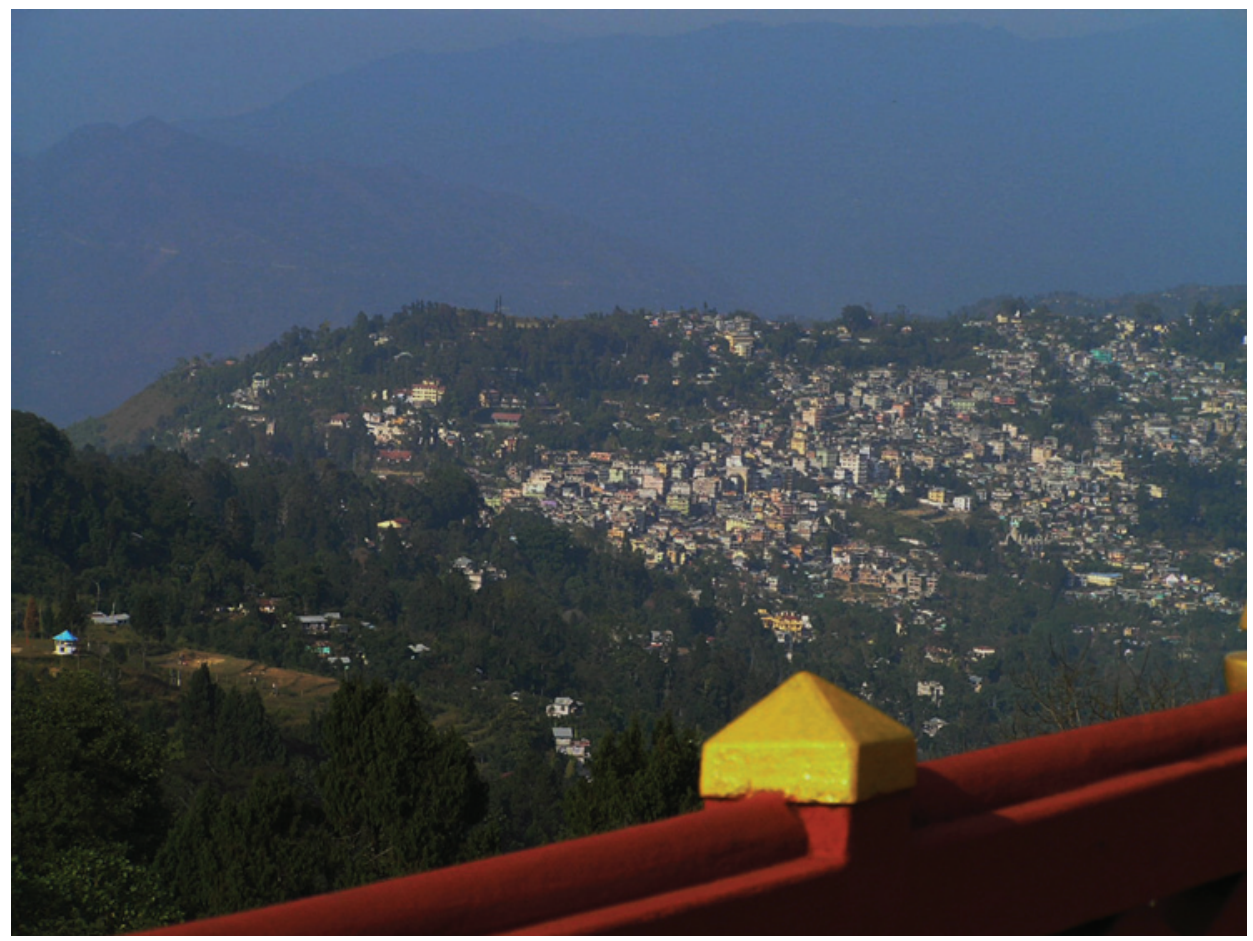

Plate 2.7. View of Kalimpong from the Zangdok Palri Monastery (Durpin Gompa), Kalimpong 2005.

Dorje's situation is typical of second- and third-generation Tibetans born in the Hills, and I encountered many similar situations during fieldwork. When I asked a young Tibetan from Ghum, Tashi, what it meant for him to be a Tibetan in the Hills he replied, "I don't know, [silence] ancestors." It was his past that made him refer to himself as a Tibetan, not his present. The question arises: what constitutes the experience of being a Tibetan in the Hills if language, religion, and relationships are increasingly 'nonTibetan,' and if daily life does not directly reflect 'Tibetanness'?

If identity "must mean something to the individual before it can be said to 'exist' in the social world" (Jenkins 1997: 166), Tibetan identity would have to be considered as "a state of mind rather than a unified nation," a view which some Tibetans support (for example, Gyatso L. 1990: 15). So far, a national sentiment of 'being Tibetan' has been based mostly on Buddhist faith (Ramble 1997: 380-381). For Dorje's generation it may be just the atavistic memory of that. 
What role does the Tibetan language play in upholding Tibetan identity in the Hills?

Until the 1970s, almost ninety-nine percent of the Tibetans in Kalimpong and Darjeeling sent their children to the Central Schools for Tibetans, which teach in the Tibetan language. Today, almost all Tibetan families who can afford it send their children to more expensive private schools where subjects are taught in English.

One of the reasons for the decline of admissions to the Central Schools for Tibetans is the requirement of the Tibetan refugee certificate (RC). I mentioned above that most Tibetans born in the Darjeeling Hills choose Indian citizenship and adopt the ST status under the category 'Bhutia.' Since dual citizenship is not possible, the Central Schools for Tibetans are not an option for many Tibetan children. The ITBCI School in Kalimpong is the only Tibetan school in the Darjeeling region where Tibetan Bhutias can enrol. Established as a trust in 1954 and directed by Jampel Kaldhen, a Tibetan scholar from Lhasa, the medium of instruction is Tibetan, but all students also learn English. Fees are subsidised by the trust, and a boarding student pays as much as a day scholar in a private school. Fifty to sixty percent of the students are Tibetan; the others are Tamangs, Lepchas, Bhutanese, and Indians from the plains. The school also educates children as boarders from Tibetan families in Assam and Arunachal Pradesh, who want their children to learn the Tibetan language and remain in touch with Tibetan culture.

The second and major reason for the decline of admissions to the Central Schools for Tibetans is that Tibetan as a language has no economic value for most Tibetans who are business people and have expanded their trade into the Indian plains and abroad. Miller already observed in Kalimpong in the 1950s, when the trade route was still open, that the Tibetan language "has no - or very - little economic value" (Miller 1958: 219). The English education provided by privately run schools is seen as economically more advantageous for Tibetans. Only one of the English-medium higher-secondary missionary schools (Dr. Graham's Homes) has Tibetan as an elective subject. Second and third languages offered at local schools are usually Nepali, Hindi, Bengali, or Sanskrit. However, on the college level Tibetan is available as an elective subject. Most of the Tibetan school principals and language teachers with whom I spoke pointed out that young Tibetans no longer speak proper Tibetan because they speak Nepali at home and attend schools in which classes are conducted in English.

Most of the renowned private schools were started by missionaries and still have Christian agendas. Tibetan parents value the quality of 
education and do not mind the religious influence and show a large degree of inter-religious tolerance. At times this renders them oblivious to the effect Christian teaching has on the way Tibetan children view Buddhism. ${ }^{34}$

So, what we find among Tibetans in the Darjeeling Hills is an increasing separation between 'language,' 'culture,' and 'identity.' Tibetan identity and a sense of 'Tibetanness,' especially for the India-born Tibetans, have to be established in a multi-lingual, Nepali-dominated, mostly non-Tibetan environment. Being Tibetan no longer necessarily implies knowing the Tibetan language. Efforts made by Tibetan schools teaching in Tibetan do not meet with large success because they do not correspond to the needs of modern Tibetan families for whom English and the ST status are economically more valuable than a school education in the Tibetan language at one of the Tibetan schools.

\section{Tibetan Buddhist Monasteries}

In order to understand the monastic contexts in which the longevity rituals described in this book take place, a brief outline of the Tibetan Buddhist monasteries in the Darjeeling Hills is necessary.

There have been no anthropological studies on the monasteries and monastic communities in the Darjeeling and Kalimpong region with the exception of Miller's doctoral thesis on Lamas and Laymen (1958) and the recent doctoral thesis by Zivkovic (2008). ${ }^{35}$ By 2004-06, the relationships of power between the monasteries and lay people had changed drastically from Miller's pre-1959 descriptions. The monasteries have lost their political influence, as well as their land. ${ }^{6}$ For Tibetans, political power has shifted from the monasteries and the head lamas to the local politicians. Tibetans need to see a (Nepali or Bengali) politician and not the head lama of a monastery to get things done. This has changed the economic and social purpose of the monasteries.

\footnotetext{
34 The documentary film We Homes Chaps by Kesang Tseten, a Tibetan educated at Dr. Graham's Homes in Kalimpong, quotes a Tibetan student who says that because of the Christian education in the hostel he used to look at his gods at home as demons.

35 Zivkovic (2008) presents a study of the 'posterior forms' of the body of lamas (corpses, relics, reincarnations) and how these extend the biographical process of the lamas' lives for their devotees in lay and monastic settings in the Darjeeling Hills.

${ }^{36}$ Previously, the oldest monastery in Kalimpong, Jangsa Dechen Chöling, locally known as Jangsa Gompa (first consecrated in $1680 \mathrm{CE}$ ), had about four acres of land, which has been encroached on by town dwellers, leaving less than an acre to the monastery.
} 
All four branches of Tibetan Buddhism have constructed monasteries in the Darjeeling Hills. There is not a single nunnery in the region and ordained women are rare. ${ }^{37}$ Some monasteries were built in the nineteenth century, or earlier, to cater to the influx of Bhutias into the region, who came largely from Sikkim and Bhutan; some were built during the trade route times, and others after 1959. There is little published literature on the monasteries, their history, or monk population - apart from old gazetteers and contemporary local tourist brochures. The monasteries certainly have shaped the outlook of the towns in terms of the sometimes grand and colourful Tibetan architecture, standing out from the general view of badly constructed concrete buildings on the steep slopes of the Hills.

Darjeeling, including Ghum and Aloobari, has twelve larger monasteries representing all Buddhist schools. Kalimpong has ten Buddhist monasteries and temples: three Geluk, one Bhutanese monastery following the Dudjom gter gsar school, one Nyingma, one Kagyü, one small Lepcha, a Tamang gompa, and a Nepali Buddhist temple. The famous two-storey Mani Lhakhang in the middle of town is used for high lamas' visits, public functions, weddings, the annual birthday celebrations for the Dalai Lama, and many of the public long-life initiations.

While I lived in Kalimpong, none of the monks worked in town as taxi drivers, bar tenders, or cinema ticket sellers, as Miller reported for Kalimpong in the 1950s when "even the ordinary celibate monk must turn to other activities to supplement his income" (Miller 1958: 224). From informal talks I had with monks on various occasions it became clear that all of the large monasteries were dependent on foreign donors, known as sbyin bdag. This was in line with the traditional role of the patron-priest relationship (mchod yon), and "ideologically compatible to historical forms" (Klieger 1992: 16).

The foreign donors have considerably changed monastic life. Monks have new quarters with single or double rooms, good sanitary facilities, and elaborate kitchens. Lama Tsewang, the senior Gelukpa monk at the Tharpa Chöling monastery in Kalimpong (see plate 1.5), whom I already mentioned in chapter 1.5, had his own two-room apartment with linoleum

\footnotetext{
${ }^{37}$ During fieldwork, I only spoke with four nuns; two of them were Tibetan doctors. Nuns are in a minority as the 1998 census of Tibetans in India shows: 9,838 monks and only 797 nuns (CTA 2000: 12). In 2005, twenty-two nuns from Ladakh were in their second year of medical studies at CTMI in Takdah, near Darjeeling, but left after the demise of Dr. Trogawa Rinpoche. I relied on my earlier acquaintances with Chagpori and MTK amchis who were already practising physicians.
} 
floors, refrigerator, and gas-cooking facilities. The head lamas of the larger monasteries often have a luxurious flat on the top floor above the gompa with a large bathroom, tiled kitchen, computer, Internet, and a television set. Similar to Prost's 'modern monks' in Dharamsala (2004: 102-110), it is common to see monks with mobile phones, and even laptops are not a rarity.

Although the local community needs the monasteries for conducting rituals, the monasteries cannot survive on their contributions. The form of economic exchange previously described in Tibetan societies (for example, Samuel 1993) has changed to a triangular relationship between the community, the monastery, and the foreign sbyin bdag. Miller still described monasteries as 'belonging' to the community, because the community had raised the money for their construction (Miller 1958: 213-218). The local community now feels less responsible since the lamas, many of whom teach abroad, and the foreign sbyin bdag are expected to take care of the gompa. At the Tharpa Chöling monastery (see plate 2.8), long-life rituals were performed regularly for the foreign sbyin bdag, since without their long life and continuous patronage the monasteries would not survive.

It is true that "Buddhism continues to be the main vector of nationalist, anti-Chinese sentiment both in Tibet and among the diaspora community" (Ramble 1997: 380), but contemporary urbanised Tibetans of Kalimpong and Darjeeling rarely regard a Tibetan Buddhist monastic education as valuable. At the Tharpa Chöling monastery I was told that nowadays novices are recruited from rural areas, mostly from Sikkim, and do not know a word of Tibetan when they enter the monastery. By the time they are around fifteen to eighteen, eighty percent of them leave monkhood and start a family life. The elder monks, who still received their training in Tibet, know this and are not interested in investing their time and effort in teaching the younger ones; they often complain about their lack of interest in studies and Buddhist practice. For many, monkhood is a time spent in childhood and youth. It is an economically viable way of receiving some education for children of families that cannot afford paying school fees, or live in remote villages without educational facilities. At the Tharpa Chöling monastery, for example, parents only have to pay a one-time admission fee of one thousand five hundred Indian rupees (approximately twenty-six euros in 2007) to the monastery. In comparison, privately run schools (or even free government schools considering books, uniforms, etc.) are more expensive.

Monks do not receive a salary and, apart from sbyin bdag support, 'earn' through 'donations' given for performing rituals in people's houses or for 


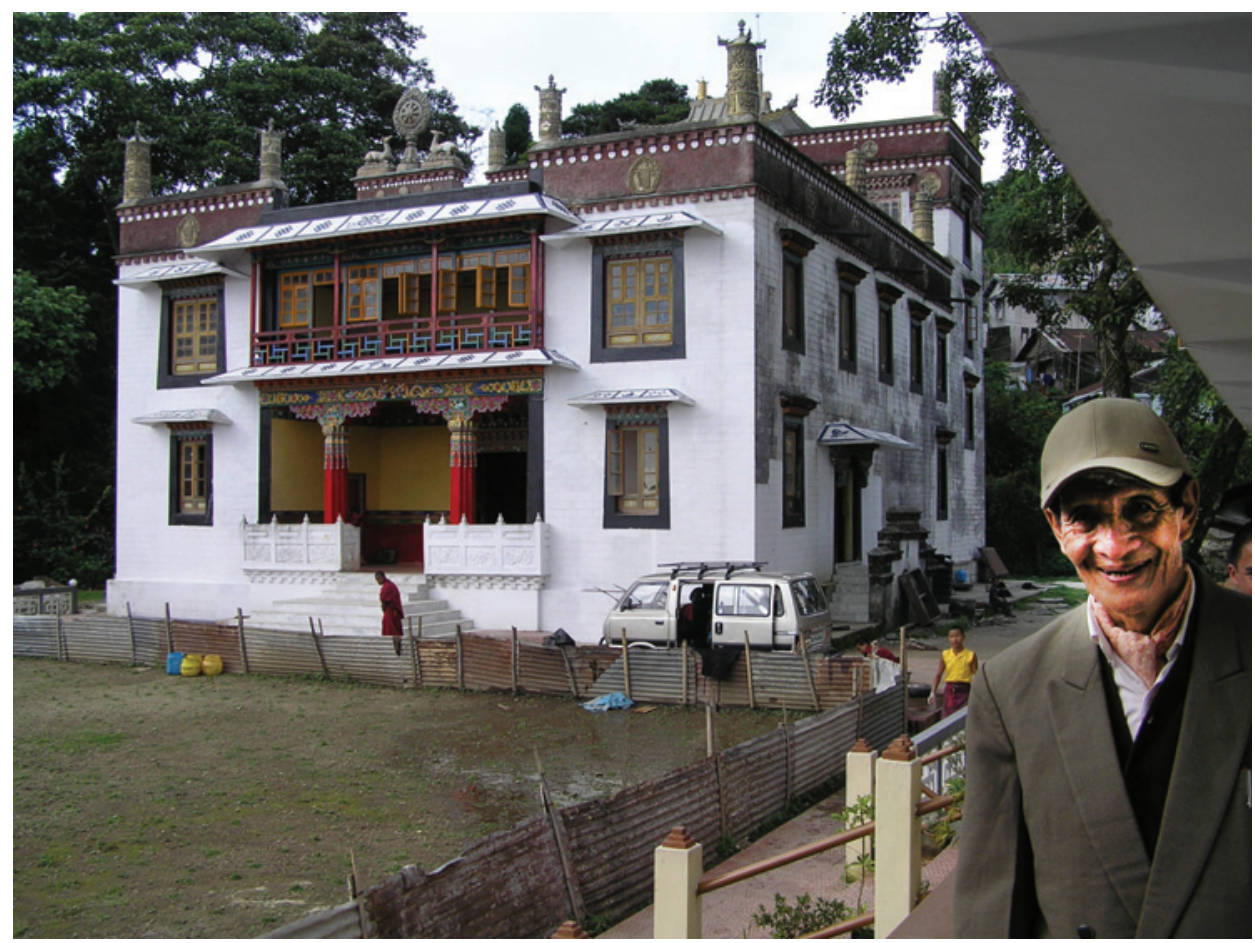

Plate 2.8. Tharpa Chöling, the Geluk monastery at Tirpai, Kalimpong 2005. The late Prof. Ngawang Jinpa (right), known as Khen Rinpoche, was the abbot of this monastery in the 1950 s.

people at the gompa. Those donations are often at 'fixed prices.' In 2007, a three-day long-life tshe sgrub ritual performed by two hundred monks at a monastery outside Gangtok cost eleven thousand Indian rupees (approximately one hundred ninety euros in 2007 , which was then equivalent to a local monthly salary of a higher secondary school teacher). The prices rise with the number of mantras recited. I heard local Tibetans complaining about the high prices asked by monks to come to their house to perform rituals (approximately three hundred Indian rupees per day per monk, which was about five euros in 2007), but some Tibetans and monks assured me that it was still done on a donation basis and people could give what they could afford.

The monasteries provide the space for public gatherings of Tibetans, especially during empowerments. Each monastery has its own annual ritual calendar that the monks adhere to. Some of the rituals last several days and involve a lot of discipline and skills. Several-day-long rituals 
usually end with one or two days of ritual mask dances ('cham) for the public and often conclude with a long-life empowerment.

During popular rituals the monastery becomes a meeting place for families and entire communities, linked by their common faith, even though many of the participants belong to different ethnic Buddhist groups and do not speak Tibetan. The ritual practices described in this book are not an analysis of the textual ritual traditions but an attempt to sketch ethnographically the nuances and local interpretations of the varying lived traditions and how they shape Tibetans' views on longevity in the Darjeeling Hills.

\section{Tibetan Medical Healthcare}

In order to understand contemporary Tibetan medical practice in the Darjeeling Hills, it is necessary to briefly describe the local contexts into which these practices are embedded.

Tibetan medicine is part of the medical syncretism in the Darjeeling Hills. Heterogeneous structures of multi-ethnic societies promote medical pluralism and influence perceptions of efficacy among Tibetans.Overall, the Kalimpong/Darjeeling situation seems not unusual for a multi-ethnic community with access to pluralistic medical health care. Biomedicine, ${ }^{38}$ Tibetan medicine, religious practice, ritual healing, and divinations are deeply interrelated and in practice do not necessarily oppose or compete with each other. ${ }^{39}$

When it comes to health care, Tibetans in the Darjeeling Hills use a plurality of approaches. When making medical decisions, Tibetans are not necessarily concerned with epistemological conflicts between medical systems, but rather focus on utilising and combining medical and ritual

${ }^{38}$ I avoid the term 'Western medicine' because of its ethnocentric character and use the term 'biomedicine' in its widest sense, being aware that it is not a unified medical system and is open to local interpretations. Tibetans do not look at biomedicine necessarily as 'Western' medicine, but call it 'Indian' medicine or rgya gar gyi sman (lit. 'medicine from India'). This is a widespread term among Tibetans in India, and is used in Dalhousie (Samuel 2001: 250) and in Dharamsala (Prost 2004: 115); in Dharamsala the term also includes Indian Āyurvedic medicine (Prost 2004: 115). In China, Tibetans often call biomedicine rgya sman, where rgya refers to rgya nag ('China'), or tang sman, a combined Chinese-Tibetan word meaning 'party medicine' alluding to the political dimensions of biomedicine in China's Tibet (Schrempf 2007: 4).

39 I describe this situation in more detail in a separate paper (Gerke 2010a). See Strässle 2007 for a study on medicine and 'plural modernities' in the Darjeeling Hills. 
knowledge that is available in the pluralistic setting of the Darjeeling Hills. Providers of medical care from various systems are seen as experts and can be amchis, biomedical practitioners, as well as Hindu, Buddhist, or other ritual specialists. Amchis themselves use an eclectic mix of biomedical and Tibetan diagnostic methods. They selectively use sphygmomanometers and blood tests, prayers and mantras; they also send patients to the monasteries for divinations and rituals. Thus, the boundaries between ritual and prayer, biomedical and amchi medical practice are often fluid.

Tibetans use both western and Tibetan frameworks to explain their illness events, and it is not always clear which is predominant in any given instance (see, for example, the story of Jigme losing his bla in chapter 6.4). Amchis also freely interpret biomedical test results through the lens of Tibetan medical concepts (Gerke 2011). For certain illnesses, the MTK clinics in the Darjeeling area give out Tibetan medicines, correlating particular disease categories with particular drugs ${ }^{40}$ however, in other cases, amchis treat patients according to nyes pa disturbances, involving specific ideas of temporalities (see chapter 4).

Tibetans make choices between a variety of available healing modalities, freely mixing biomedicine with Tibetan pills, and consulting Hindu as well as Buddhist diviners and performing rituals at Buddhist monasteries as well as in Hindu temples. There are, of course, also Tibetans who avoid the Hindu healers, and even shun the female Tibetan diviners and consult only 'high lamas' for divinations. The entire picture, however, suggests that people's sense of efficacy is often established independently from the substances they take and is influenced by a variety of factors that combine notions of 'blessing' (byin rlabs), ${ }^{41}$ ritual healing, and medication. As I show in chapters 6.4 and 7.4, divination plays a considerable role in the way people decide to allocate resources and direct health-seeking behaviour, which can consist of one or a combination of biomedical, ritual, or Tibetan medical therapies. In practice, all these therapies are interlinked and form part of a larger body of healing.

Apart from medical decision-making through divination, an additional blessing is usually essential before taking biomedical treatment. I saw and recorded several cases of illness in which the patient was first taken to a

\footnotetext{
${ }^{40}$ This is similar to what Samuel describes for Dalhousie in northwestern India (Samuel 2001: $250-251$ ).

${ }^{41}$ See chapter 9.1 for a discussion of byin rlabs.
} 
Hindu mata $^{42}$ and then to the hospital in order to rule out the influence of spirits. "Otherwise, the medicines won't work and the patient may even die if we don't do the required rituals," is a common view among Tibetans and Nepalis alike.

The economics of making medical choices is complex. Monks, diviners, and matas are not in economic competition with biomedical practitioners and amchis. Economics does play a major role in medical choices, but does not necessarily determine which system to choose from. Even rituals can be simple and affordable or very elaborate and expensive. Invasive biomedical treatment is usually very expensive (except in lowstandard government hospitals). In general, Tibetans I spoke with considered Tibetan medicine to be cheaper than biomedicine, partly because the amchi's consultation fees were generally included in prescription fees. Tibetan medical health camps were free and organised regularly by the MTK. In the Hills, ordained monks and nuns, as well as school children, paid only half price at the MTK, and people above seventy received free medicines.

Prost reports from Dharamsala that Tibetan medicine is subsidised for poorer Tibetans (Prost 2004: 136; see also Kloos 2010: 172-174 and Samuel 2001: 251). Tibetan medicine can be an inexpensive alternative to invasive and costly biomedical procedures, but since long-term treatment is often required, it frequently works out to be more expensive than a quick biomedical fix (McKay 2007a: 25).

The use of Tibetan medicine to demonstrate 'Tibetanness' or to strengthen Tibetan nationalist feelings in the exile community has not been a major and palpable concern of Tibetans in the Darjeeling Hills. This seems different at the centre in Dharamsala, where Tibetan identity, Tibetan nationalism, Buddhist ethics, and promoting Tibetan medicine are more closely interwoven (Kloos 2010). This Dharamsala agenda was not evident in the way the MTK clinics were set up and operated in the Hills (Gerke, in press). However, the efficacy of Tibetan medical and ritual treatments was interpreted by some - mostly older - Tibetans according to their sense of 'belonging.' For some Tibetans, the non-Tibetan

\footnotetext{
${ }^{42}$ Strässle describes matas in the Darjeeling Hills as Hindu mediums who channel goddesses who then diagnose and heal through the matas. They live ascetic lives, mostly refrain from marriage, and have their own temples or shrine rooms (Strässle 2007: 55).
} 
surroundings in exile can be an underlying reason why healing rituals do not work anymore. ${ }^{43}$

Local Tibetans perceive Tibetan medicine and its efficacy in different ways. Most people think Tibetan medicine works very slowly, is good for chronic ailments, and has no side effects. For some, the bitter taste of the pills is hard to adjust to. Precious pills (rin chen ril bu ${ }^{44}$ and other types of 'empowered medicine' (sman sgrub) are very popular and are used as tonics for all kinds of diseases. Tibetan medicine is often the last choice - unless people are firm believers in Tibetan medicine, or a divination has specifically recommended it. Amchis often complain that they receive "the hopeless cases, where western medicine does not work."

Free medical camps organised by the MTK are common. In 2005, on the Dalai Lama's seventieth birthday, ten-day medical camps were organised by all MTK branch clinics in India "for the long life of His Holiness." "How would the medical camps affect his life-span?" I asked one amchi. "Through merit (bsod nams)," ${ }^{45}$ he replied, indicating that the merit collected through this good deed of supplying free medicines would be dedicated to the Dalai Lama and thus increase his life-span. This kind of merit transfer that can be turned into an extension of someone's life-span is a common Tibetan Buddhist practice.

I also came across this kind of practice in the Tibetan campaign for vegetarianism, where people, including school children, committed themselves for a lifetime of vegetarianism by signing a list. This list was later sent to the Dalai Lama and the merit collected through saving animals' lives was dedicated to his long life. The Tibetan welfare officer in Kalimpong promoted this vegetarian campaign. It had nationalistic, medical, and religious connotations, and the boundaries between them were blurred.

In the practice of Tibetan medicine and its interface with Tibetan Buddhist rituals, 'faith' ( $\mathrm{dad} p a$ ) features prominently. This is especially true when medical decisions are made by means of divination and when the cause of an illness is attributed to spirits (gdon), or the loss of a life-force.

\footnotetext{
${ }_{43}$ Prost makes a similar observation in Dharamsala, where many Tibetans view the exile environment as pathogenic, endangering health (Prost 2008: 43-53).

${ }^{44}$ Rin chen ril bu are multi-compound Tibetan medicines containing herbs, minerals, metals, and precious stones. They are used in severe illnesses, but also as regular rejuvenating tonics. They are generally taken on auspicious days, i.e. the $15^{\text {th }}$ (full moon) or 3 oth day (new moon) of the Tibetan calendar, or are worn as talisman. They are controversial since many of them contain mercury sulphide in the form of 'purified ash' known as btso thal (Aschoff and Tashigang 1997, 2001, 2004).

${ }^{45}$ I discuss merit and karma in more detail in chapter 6.1.
} 
Patients request monks to conduct rituals at a gompa or at home after determining the appropriate ritual by means of a mo. Amchis also refer patients to monasteries for healing rituals, especially if they think the bla has been lost or a gdon is involved. If the amchi is an ordained monk or nun, he/she performs prayers and mantra recitations during therapies.

For Tibetans in the Darjeeling Hills, the boundaries between the medical and ritual systems are 'osmotic' and at times even collapse. Lay people utilise specialists for health and ritual purposes in their search for practical solutions; they are not interested in detailed underlying explanations. However, the roles of amchis and lamas remain clearly defined.

In conclusion, it is important to note that biomedicine is not seen as contradictory to or competing with Tibetan medicine, Buddhist healing rituals, or the various modes of divination, even though their underlying systems of thought seem to be strange allies. Medical choices are not directed by governmental or monastic superstructures, or by nationalistic feelings of 'Tibetanness,' but primarily by family economics, local medical concepts, and religious faith, played out within the large healthcare market available in Indian urban centres of the Hills.

With this background of the field site in mind, the following introduction of relevant Tibetan areas of knowledge will open the avenue for the ethnographic accounts in the chapters to come. 


\section{CONTEXTUALISING TIBETAN LONGEVITY PRACTICES}

\section{An Exposition of Pertinent Tibetan Areas of Knowledge}

This chapter focuses on the specific epistemological contexts from which the various life-forces and longevity practices addressed in this book derive their meaning and application. In the following, I introduce the four areas of knowledge that the textual and ethnographic material presented in this book draw from: Tibetan medicine, astrology, divination, and Vajrayāna Buddhist rituals. Garrett cautions to be careful when applying contemporary classificatory systems of knowledge to ancient bodies of knowledge and history in Tibet (Garrett 2006: 207). Being aware of this, I want to emphasise that the framework of knowledge areas presented in this chapter is understood to be a lose guideline rather than a set classificatory system.

\section{Tibetan Medicine}

As explained in the introduction, Tibetan medicine is largely a heterogeneous body of knowledge and encompasses more than the textual Rgyud bzhi medicine taught at medical institutions. The basic physiological principles found in the Rgyud bzhi will be introduced in chapter 4. In the present section, I briefly outline the contemporary institutionalised forms of Tibetan medicine in India and some key aspects of the history of Tibetan textual knowledge, both of which have shaped the types of Tibetan medical knowledge I came across during fieldwork.

The Tibetan exile situation in India is dominated by increasingly standardised forms of Tibetan medical practice and institutionalised education carried out by four institutes that are registered with the Central Council of Tibetan Medicine (hereafter CCTM), ${ }^{1}$ an apex body that was founded in Dharamsala in 2004 to oversee and control the education and practice of Tibetan physicians in exile. Among these four the oldest, largest, and

${ }^{1}$ As of October 2010, three hundred eighty-three Tibetan medical practitioners have registered with the CCTM (CCTM 2010a). 
most important institute is the Men-Tsee-Khang (MTK) in Dharamsala. ${ }^{2}$ With a medical and astrology college, a pharmacy, a museum, various translation and research departments, and fifty-five branch-clinics (as of September 2010), the MTK serves the Tibetan exile community across India and Nepal as well as a large Indian clientele, and some foreigners. Between 1961 and 2006 thirteen classes totalling about two hundred twenty-seven amchis graduated from the MTK with the degree of sman pa $d k a^{\prime} b c u p a$, out of which about one hundred forty-five amchis ${ }^{3}$ currently work at the MTK (others passed away, left, or work in private clinics). Almost thirty of them are non-Tibetan from various Himalayan regions and other countries. ${ }^{4}$ The more textual research-oriented Department of Tibetan Medicine at the Central University of Tibetan Studies (CUTS) in Sarnath near Varanasi (U.P.), which comes under the Indian Department of Higher Education and is thus independent from the Tibetan government-in-exile, was opened only in 1993 and graduated twenty-six doctors by 2008 (Kloos 2008: 32). The CTMI was founded in Darjeeling in 1992 and graduated more than thirty students by 2010. The Department of Sowa Rigpa at the Central Institute of Buddhist Studies (CIBS) in Choglamsar, Ladakh, was founded in 1989 (CCTM 2010b). These last two largely follow the MTK syllabus.

In the Darjeeling Hills, Tibetan medical practice has been shaped by two of these institutions, the Dharamsala-based MTK and the Chagpori tradition of the late Samphel Norbu Trogawa Rinpoche (1932-2005) at the CTMI. The only family lineage of amchis spanning many generations that I came across in the vicinity is the Dopta family in Gangtok, Sikkim. ${ }^{5}$ All amchis basically follow the same textbooks, but have different traditions of clinical practice. This specialised knowledge, known as lag len, refers

${ }^{2}$ Stephan Kloos' doctoral thesis (2010) is the first extensive work on the history of Tibetan medicine in Indian exile and focuses on the history and current role of the MTK by looking at the nexus of medicine and culture and how it shapes Tibetanness and nationhood in exile.

3 Kloos mentions that in March 2010 the MTK had one hundred and twenty doctors, several hundred staff members and fifty branch clinics in India and Nepal (Kloos 2010: 12); see also MTK 2010a.

${ }^{4}$ I am grateful to Amchi Tsering Wangdue, Dharamsala, for providing these details.

5 The late Amchi Tashi Namgyal (1938-2010), also known as Dopta Amchi (rdo bkra means multi-coloured stones) was from a family lineage of amchis southwest of Lhasa. The lineage began with Amchi Penpa (1822-1901). The third Dopta Amchi treated the Choegyal of Sikkim and was exempt from paying taxes. Amchi Tashi Namgyal was the fifth amchi of the lineage and was specialised in gtar bsreg (a term that means both bloodletting and moxibustion). His son continues the lineage. 
to the experience of medical practice gained through apprenticeship with a senior amchi and varies widely, since it depends on the availability of internships with senior amchis after students have completed their fiveyear theoretical training.

The history of the MTK and the CTMI can only be briefly summarised here. The Mentsikhang ${ }^{6}$ institution was established in Lhasa in 1916 and developed out of an early twentieth century movement to modernise health care in Tibet. This was presumably partly inspired by the thirteenth Dalai Lama's encounter with British public health measures during his exile in India (Samuel 2001: 262). The MTK in Dharamsala was founded in $1967^{7}$ under the name of 'gro phan sman rtsis khang (lit. 'Institute for Medicine and Astrology for the Benefit of all Beings'; Kloos 2008: 20). The name was later changed to Tibetan Medical and Astrological Institute (TMAI), and in the 1990s it was changed to Men-Tsee-Khang (lit. 'Medicine Astrology House').

For a long time, Tibetan medicine in Tibet was transmitted and practised through numerous lineages (rgyud) with geographical affiliations; five of the most famous were the byang pa, zur mkhar, gong sman, 'bri gung, and brang ti lineages. ${ }^{8}$ The institutionalisation of medicine took place only in the seventeenth century as one of many attempts "to exert direct influence over the development of learning and culture on the part of the newly formed Tibetan theocracy" (Schaeffer 2003: 621). Beginning in 1643, the fifth Dalai Lama attempted to institutionalise Tibetan medicine four times through establishing medical colleges in the areas of Drepung, Shigatse, and Lhasa, but all these attempts failed (Meyer 2003: 103). The success of institutionalisation came in the form of the Chagpori Medical College, ${ }^{9}$ established in 1696 in Lhasa, which emphasised the combination of medicine (sman) and dharma (chos). Political influence by the Ganden government was a part of Tibetan medical institutions since their beginning. The charter of Chagpori was drafted by the regent Sangye Gyatso

\footnotetext{
${ }^{6}$ The spellings are according to their local use: Mentsikhang for Lhasa, Tibetan Autonomous Region (TAR), and Men-Tsee-Khang for India. Both are abbreviated as MTK.

7 The first medical centre was established in 1961. The medicine and astrology sections were merged in 1967. For details on the establishment of the MTK see Kloos 2008.

${ }^{8}$ For more details on some of these lineages see, for example, Gerke 1999a; Hofer 2007, in press 2011; Taube 1981; Yontan 1989.

${ }_{9}$ The college is known by its Tibetan name Icags po ri rig byed 'gro phan gling (lit. 'Iron Hill - Abode of Instruction for the Benefit of all Beings') since it was built on the Iron Hill (lcags po ri) opposite the Potala. For more details on the history of this college see Gerl and Aschoff 2005 and Meyer 2003; for interviews with three Chagpori amchis see Gerl and Aschoff 2005.
} 
himself, who also appointed the main teachers (Meyer 2003: 111). Being a prolific writer, he also furthered the publication of numerous medical works.

At that time, this approach of institutionalisation corresponded with the diffusion of the Mahāyāna Buddhist ideal within the medical arena, which was propagated by the Ganden government of the fifth Dalai Lama. The Chagpori Medical College provided trained amchis for over two hundred years to "religious hierarchs and lay sovereigns, in central Tibet and the eastern provinces, in Mongolia and even in the entourage of the emperor of China" (Meyer 2003: 117). It was destroyed by the Chinese Red Army during the Tibetan revolt of 1959. In 1992, the late Dr. Trogawa Rinpoche, himself trained in Lhasa by the Chagpori lineage holder Rigzin Lhundrub Paljor Nyerongshar (1898-1997), founded the CTMI in Darjeeling in commemoration of the Chagpori Medical College in Lhasa. Initially, the Chagpori amchis from Darjeeling were required to sit their final examinations in Dharamsala and were technically treated as MTK graduates. Currently, they are under the control of the Health Department of the Central Tibetan Administration, and the CCTM in Dharamsala is issuing the certificates (CTMI 2010). Students received additional instructions on medicine and dharma from Dr. Trogawa Rinpoche until his passing in 2005 .

I found that the relationship between amchis from the MTK and the CTMI was collegial and not marked by competition. Many of the CTMI amchis had their practical training with MTK amchis; both followed the same medical text books and, at the time, sat for the same examinations. MTK-trained amchis also taught at the CTMI. Dharma practice among Chagpori amchis was encouraged, but was a free choice. Lay as well as ordained men and women were admitted to the course. During fieldwork, I spent time with amchis from both institutions, but since I was based in Kalimpong, I mostly talked with amchis who worked at the MTK branch clinic in Kalimpong.

Tibetan medical literature as a body of written knowledge requires a brief introduction. For the understanding of the close link between Tibetan medicine and Buddhism it is important to realise that "Buddhism and medicine grew up together in Tibet in a shared universe of institutions, conceptions, and modes of discourse" (Gyatso J. 2004: 84). The introduction of literacy and Buddhism into Tibet in the seventh century CE and the establishment of the Tibetan empire were all intricately linked. The translations of Sanskrit literature into Tibetan - which were mostly Buddhist works but also included numerous medical texts - took place 
over two historic periods (seventh to ninth and late tenth to around the thirteenth centuries) and were state controlled. The genres of texts corresponded to the Indian model of the 'ten cultural sciences' (rig pa'i gnas $b c u$ ), in which Buddhism, medicine, and astrology are included (Cabezón and Jackson 1996: 18). ${ }^{10}$

One of the most interesting but also difficult aspects one must consider when analysing Tibetan medical texts concerns the multicultural origin of this body of literature. While Tibet itself had its indigenous medical knowledge, it was open to foreign influence. The Tibetan empire in Central Asia at various times included the regions of Khotan, the Tarim basin, Lop Nor, and other places with Iranian and Turkic populations (Kapstein 2000: 59). Medical knowledge was derived largely from Greece, Persia, China, and India and was incorporated into indigenous Tibetan ways of healing over many centuries." Medical texts are also found among the Tibetan sources from Dunhuang. ${ }^{12}$ Those manuscripts represent the earliest extant sources on Tibetan medicine, divination, and astrology and are generally dated between the mid-eighth to the early eleventh centuries (Yoeli-Tlalim, 2008: 228). These texts also mention an apparently preBuddhist medical system from Zhang zhung (Karmay 1998) probably linked to the Bon tradition. ${ }^{13}$

During the later propagation of Buddhism in Tibet, from the mid-tenth to the twelfth century $\mathrm{CE}$, major medical literary works were introduced from India and subsequently translated from Sanskrit into Tibetan. A substantial part of this knowledge was incorporated into the core compen-

${ }^{10}$ The 'ten cultural sciences' include arts, grammar, medicine, logic, Buddhism, astrology, poetics, prosody, synonymics, and drama (THL 2009). In a further division of these sciences as 'major' (che ba) and 'minor' (chung ba) medicine and Buddhism are rated as 'major' and astrology as a 'minor' science.

"Beckwith 1979 analysed four Tibetan historical texts with regard to the Chinese, Indian, and Greek physicians who visited the royal court of the Tibetan king Songtsen Gampo (617-649/650 CE). The Graeco-Arabic influences on Tibetan urine analysis have been studied by Yoeli-Tlalim 2010.

${ }^{12}$ The Dunhuang manuscripts were found at the beginning of the twentieth century in caves near the oasis town of Dunhuang in western China. Since 1994, the International Dunhuang Project (IDP) has worked for the preservation and worldwide access to the several thousand artifacts through a database (IDP 2010).

${ }_{13}$ We should keep in mind that the label Bon, which is often applied to pre-Buddhist Tibetan traditions, "refers not to an illusory unity, but to a complex series of historicallyspecific phenomena" (Samuel 2005: 140), and anything pre-Buddhist in Tibet is not necessarily Bon. 
dium of Tibetan medicine, The Four Medical Treatises, ${ }^{14}$ well-known by its brief Tibetan title Rgyud bzhi. Emmerick (1977: 1136) argues that some chapters of the present version of the Rgyud bzhi are based on Indian sources, mainly the Aștāingahrrdayasamnhitā by Vāgbhața (seventh century $\mathrm{CE}$ ), which was translated into Tibetan by Rinchen Zangpo (958-1055). ${ }^{15}$

We know that the eleventh century Tibetan translation of the Aștāingahrdayasaṃhitā was the most influential medical text until the Rgyud bzhi took prominence during the course of the thirteenth century (Martin 2007: 312). There is little doubt that the Rgyud bzhi remains the most influential medical text among contemporary Tibetans, but there are regional variations. For example, Garrett's study (forthcoming) of the Situ Panchen (1700-1774) tradition of medicine in eastern Tibet in the eighteenth century questions the dominant role of the Rgyud bzhi. Garrett emphasises "the need to understand Tibetan medical knowledge and practice as being as widely diverse as we know religious traditions in Tibet to be" (Garrett, forthcoming), which points again to the heterogeneous nature of Tibetan medicine as described earlier.

There has been a dispute concerning the origin of the Rgyud bzhi, dating back to the fourteenth century, which hinges on the question of whether the Rgyud bzhi is the original word of the Medicine Buddha, a translation of an Indian work, a revealed treasure or gter ma going back to the famed master and physician Yuthok Yönten Gonpo the Elder (708-833), or was compiled by Yuthok Yönten Gonpo the Younger in the twelfth century. ${ }^{16}$ I alluded to this topic already in chapter 1.5 in the context of authority and texts.

Over the centuries, Tibetan medical literature was enriched by numerous commentaries on the Rgyud bzhi as well as by textbooks on compounding

\footnotetext{
${ }^{14}$ The full Tibetan title reads Bdud rtsi snying po yan lag brgyad pa gsang ba man ngag gi rgyud. I refer to a reprinted version of the first, second, and fourth treatises of the Rgyud bzhi - those memorised by medical students - from the CTMI in Darjeeling (Yuthok Yönten Gonpo 1992). This version was copied from the MTK Dharamsala edition (Yuthok Yönten Gonpo 1984), which was prepared from a seventeenth century edition and is said to be based on a twelfth century, or even eighth century, version (Gene Smith, personal communication 2005).

${ }_{15}$ The Aștāñgahrdayasamhitā is available in its original Sanskrit (Emmerick and Das 1998) and in Tibetan (Vāgbhața, no date), German (Hilgenberg and Kirfel 1941), and English translations (Murthy 1996). The title of the Tibetan translation reads Yan lag brgyad pa'i snying po bsdus pa (Vāgbhața, no date).

${ }^{16}$ For details about the debate concerning the authorship of the Rgyud bzhi see Czaja 2005/o6; Emmerick 1977; Fenner 1996; Gyatso J. 2004; Karmay 1989; Meyer 1981; Yang Ga 2010.
} 
medicines that adopted the materia medica of the flora and fauna of various Tibetan areas. In the sixteenth century, the tradition of 'writing from experience' (nyams yig) developed and added a literary genre of practical medical experience, which the Rgyud bzhi could not fulfil, and which stressed the transmission of practical medical knowledge from teacher to student (Gyatso J. 2004: 86).

The most famous commentary on the Rgyud bzhi, which is still studied today, is the Blue Beryl or Baidürya sngon po, ${ }^{17}$ compiled by Sangye Gyatso, the regent of the fifth Dalai Lama, and completed in 1688. A series of medical paintings was created in Lhasa between 1685 and 1703 under the aegis of Sangye Gyatso as a visual aid for the study of the Baidürya sngon po. ${ }^{18}$ The idea developed over discussions concerning materia medica and delicate questions on anatomy (gnas lugs) ${ }^{19}$ involving the subtle channels (Meyer 2003: 108). Because of its scope and originality of conception, the series constitutes an exceptionally rich document, not only for Tibet, but for the history of medicine in general (Meyer 1992: 12).

Since the twelfth century, Tibetan medical texts have been linked to Buddhism in the sense that medicine as a discipline is presented as being an essential part of Buddhism (Garrett 2006: 208; Karmay 1998: 231). This has led to numerous debates spanning centuries, especially concerning how Buddhist perceptions of a tantric body can be integrated into empirical medical knowledge of the body (Gyatso J. 2004; Garrett and Adams 2008; Gerke forthcoming).

A large part of the Rgyud bzhi, which consists of 156 chapters and 5900 verses, is written in poetic verse form. Therefore a literal translation would not convey the full meaning of its content, an issue that has slowed the translation process of this work. To date, only parts of the Rgyud bzhi

${ }^{17}$ The full title reads Gso ba rig pa'i bstan bcos sman bla'i dgongs rgyan rgyud bzhi'i gsal byed bai dūr sngon po'i ma lli ka zhes bya ba bzhugs so. In this book I refer to the Lhasa reprint of 1982 (Sangye Gyatso 1982). The authorship is generally attributed to Sangye Gyatso, who should, however, be considered more as the compiler than the actual author. For more details on this work see Czaja 2007.

${ }_{18}$ The publication of the set of medical paintings (Parfionovitch, Dorje, and Meyer 1992) is not a complete English translation of the Baidūrya sngon po, but a translation of the paintings' captions and a summarised commentary that refers to the corresponding chapters in the Baidūrya sngon po.

19 'Anatomy' is a loose translation of the Tibetan lus kyignas lugs (lit. 'the natural condition of the body'). The term 'anatomy' derives from the Greek anatome (lit. 'dissection'); the Tibetan view of the 'natural conditions of the body' also involves subtle and invisible aspects that have not been detected through dissection (see Garrett and Adams 2008: 98, note 17 ; Gerke, forthcoming). 
have actually been translated into English or German: ${ }^{20}$ for example, Badaraev et al. 1981 [III: 49];" Clark 1995 [I; II]; Clifford 1984 [III: 77-79]; Donden 1977 [I, II: 1-15]; Donden and Hopkins 1986 [IV: 1-8];22 Dorje and Richards 1981 [I: 1-2]; Emmerick 1975 [I: 3], 1990 [III: 9o]; Jäger 1999 [III: 71-72]; Kelsang 1977 [I; II: 1-15]; Meyer 1990 [IV, 1]; MTK 2008 [I; II], MTK 2011 [IV]; Ploberger, forthcoming [I; II]; ${ }^{23}$ Seitelberger $2010[\mathrm{I}] .^{24}$ The first complete English translation of a Tibetan medical work is Kilty's translation of Sangye Gyatso's treatise on medical history, the Gso rig sman gyi khog 'bugs (Kilty 2009). This means that there are far fewer translations of Tibetan medical texts in modern languages when compared to available translations of Chinese and Āyurvedic seminal medical texts. There has also been very little textual research on how amchis have interpreted anatomical ideas in their clinical practice in the past. ${ }^{25}$

Large parts of the Rgyud bzhi are still memorised as an integral part of medical education. ${ }^{26}$ The interpretation of the memorised medical texts adds another dimension to Tibetan ways of knowing, since many passages of the Rgyud bzhi are incomprehensible in themselves. As just mentioned, the text is largely written in verse, and words are often omitted or entire medical technicalities are at times represented by only one syllable. This aids memorisation, but the teacher's explanations are essential in understanding the meaning of the root text. A deeper comprehension is only possible with the help of specialised commentaries. As I already

\footnotetext{
${ }^{20}$ There exists a large amount of Tibetan medical literature in Russian, which I did not consult. See Aschoff 1996 for an annotated bibliography.

${ }^{21}$ The Roman numeral here refers to the four parts of the Rgyud bzhi and the Arabic numeral to the chapter. For example, [III: 49] refers to the 49th chapter of the third treatise of the Rgyud bzhi. If no chapter is mentioned, the entire part has been translated.

${ }^{22}$ Donden's book is not a literal translation, but is based on lectures and translations of various chapters of the Rgyud bzhi (Donden and Hopkins 1986: 9).

${ }^{23}$ Ploberger's forthcoming work is a revised German translation of the English publication by the MTK (2008).

${ }^{24}$ Vaidya Bhagwan Dash reconstructed a Sanskrit version of the Rgyud bzhi, from which he translated and annotated parts I, II, III 1-11 in English (Dash V.B. 1994-2001).

${ }_{25}$ Garrett researched the history of embryology in Tibet at various times between the eleventh and seventeenth century CE (Garrett 2005, 2007, 2008). Janet Gyatso analysed the medical perception of channels as understood in Tibetan anatomy in the fifteenth century CE (Gyatso J. 2004: 88).

${ }_{26}$ At both the MTK in Dharamsala and the CTMI in Darjeeling, fifty per cent of students' exam marks depend on the correct oral recitation from memory of hundreds of pages from the Rgyud bzhi, which students commit to memory during their five-year training. See Millard 2002 for a discussion of the importance of memorisation in Bon medical education.
} 
mentioned in chapter 1.5 , this interplay between text and contemporary interpretation marked my encounters with amchis.

\section{Tibetan Astrology}

This section highlights some basic features of Tibetan astrology, namely its relationship to divination and medicine, and introduces the key Tibetan astrological systems. The boundaries of these disciplines are not clearly defined and often overlap. Tibetan astrological and divinatory calculations (rtsis kyi rig gnas, lit. 'science of calculation'), also simply called rtsis, are commonly referred to as 'Tibetan astrology,' which does not really convey its divinatory content. Rtsis is one of the five minor sciences (rig gnas chung ba lnga), which traditionally have been taught together with medicine (sman), which is one of the five major sciences (rig gnas che ba lnga). ${ }^{27}$ Initially, sman and rtsis were even taught as a single eight-year course at the MTK in Dharamsala; this link is still expressed in the current name of the institute itself (sman rtsis khang, lit. 'medicine-astrology-house') ${ }^{28}$ The fact that sman and rtsis are still taught together at one institute is very significant. It demonstrates how closely linked these two knowledge systems have been since the seventeenth century, when Sangye Gyatso unified these two disciplines into a hegemonic system that went hand in hand with the centralisation of power.

The link between medicine and astrology is, however, an old one. Tibetan Buddhist accounts maintain that both medicine and astrology were taught by Buddha Śākyamuni himself (Yoeli-Tlalim 2008: 225). Wallace also comments that "throughout the history of Buddhist Mahāyāna monastic learning in India, astronomy and astrology were treated as ancillary to medicine" (Wallace 2009b: 288). Linguistically, the fluidity of this boundary between medicine and astrology is exemplified in the Tibetan term kha dmar gdags (lit. 'clear view'), which refers to prediction, both in the contexts of divination (including divinatory astrology) and medicine (Drungtso and Drungtso 2005: 37-38, quoted in Yoeli-Tlalim 2008: 235). Such interrelationships are not unusual for Tibetans, even though

${ }_{27}$ The ten sciences are listed in footnote 10 in this chapter.

${ }_{28}$ Astrological practices are also taught at the MTK in Lhasa (Dorje 2002: 20-21). In 1998, the late Amchi Sonam Wangdu (1955-2000), a former senior amchi trained at the MTK in Dharamsala, told me that in India in the mid-196os the eight-year medicine and astrology course was split into two five-year courses because the Tibetan exiled community required medical doctors quickly. Moreover, students found it too difficult to memorise both the medical and astrological texts. 
not all of them are found in practice today. Tibetan urine analysis, for example, can serve as a diagnostic tool for nyes pa imbalances as well as a method of prognostication regarding influences of evil spirits (Parfionovitch, Dorje, and Meyer 1992: 139-148; Yoeli-Tlalim 2010). The same applies to the general pulse diagnosis and the bla rtsa described in chapter 5 .

The relationship between astrology and divination is quite porous. In the seventeenth century, Sangye Gyatso treated astrology and divination as one body of knowledge, which his main work on astrology, the White Beryl or Baidūrya dkar po ${ }^{29}$ (Sangye Gyatso 1972 [1685]), clearly shows. The Baidūrya dkar po as well as the Baidūrya sngon po (Sangye Gyatso's commentary on medicine) both emphasise the divinatory and prognostic character of astrology and medicine. The Baidūrya dkar po includes astrological as well as divinatory practices concerning such important issues as birth, health, illness, and death. The Baidürya sngon po clearly has a strong divinatory focus in sections concerning pulse and urine diagnosis. Dorje, who translated an illustrated manuscript on 'elemental divination' (nag rtsis, lit. 'black calculation') from the Baidūrya dkar po, interprets rtsis kyi rig gnas as 'astrology-cum-divination' (Dorje 2002: 15).

The introduction of various Indian and Chinese astrological systems into Tibet took place at different times in history. The Chinese influence is generally traced to the mid-seventh century CE and the Indian influence to the introduction of the Indian Buddhist Kälacakratantra into Tibet in the eleventh century. The two main lineages of calendrical calculations in Tibet, mtshur phu and phug pa, were both linked to Buddhist schools and developed over the centuries with various Tibetan authors reworking Chinese, Indian, and indigenous sources into several distinctive Tibetan traditions. ${ }^{30}$ In the following, I introduce the main Tibetan astrological systems that are in use today and are pertinent to life-span and other vitality calculations.

The astrological system of nag rtsis is also known as 'byung rtsis (lit. 'elemental calculation'). ${ }^{31}$ It is related to the Chinese I Ching and is based on, among other parameters, nine numeric squares (sme ba) and eight

\footnotetext{
${ }^{29}$ The Tibetan title of the 1972 Delhi reprint reads Phug lugs rtsis kyi legs bshad mkhas pa'i mgul rgyan baidūr dkar po'i do shal dpyod ldan snying nor. Gene Smith points out that the actual author was without doubt Dumbu Döndrub Wangyal (Smith 2001: 243).

$3^{\circ}$ For details on the history of astrology in Tibet see Berzin 1991, 1996; Cornu 1997; Dorje 2002: 14-21. For the link between astrology and medicine in the Kälacakratantra see Wallace $2008,2009 b$.

${ }^{31}$ Nag is a geographical expression for China, the 'black' region (Schuh 1973: 17).
} 
trigrams (spar kha). ${ }^{32}$ In contrast, the system called dkar rtsis (lit. 'white calculation') $)^{33}$ refers to calendrical calculations, astronomy, and astrology that entered Tibet from India through the Kälacakratantra (Schuh 1973: 15).

Dorje only differentiates between $d$ kar rtsis and nag rtsis and translates them as 'Indian astrological tradition' and 'Chinese elemental divination' respectively (Dorje 2002: 16), which leads one to believe that the Indian influence on the Tibetan system was more linked to astrology, and the Chinese influence more to divination. This is not fully the case. Schuh offers more details on this issue, referring to the division of the Chinese rtsis system into rgya rtsis and nag rtsis. Rgya rtsis includes Chinese astrology and astronomy. This material has been translated into Tibetan and has been compared with other sources by Tibetan authors but is not used in the Tibetan calendars. ${ }^{34}$

Nag rtsis is not astrology per se, but a set of divination techniques based on temporal intervals and their determinants, which formed the base of calendrical calculations (Schuh 1973: 16). Nag rtsis divinations are part of a larger body of practices, which include those rituals that are necessary to counteract negative outcomes of divinations, in Tibetan known as gto (Schuh 1973: 16). Nag rtsis and gto were apparently so popular in Tibet that in the course of time, Buddhist mantra and prayer recitations became as much a part of these counteracting rituals as non-Buddhist practices (Schuh 1973: 17).

Another Tibetan astrological system is known as dbyangs 'char gyi rtsis (lit. 'calculation of arising vowels'). This system derives its symbolism from vowels and consonants. These vowels are ciphers or categories for changes in time and are based on Hindu astrology. ${ }^{35}$ The syllables that are linked to the places of bla in the body (see chapter 5.1 and appendix 3)

${ }^{32}$ Mills mentions sparkha as a life-force in Ladakh (Mills 2003a: 77, 148 and passim). I have not come across this elsewhere. The local Ladakhi interpretation of sparkha as a lifeforce is probably related to the Arabic term barakah, which means 'blessing, benediction' (Wehr 1979: 67) and indicates an Islamic influence in Ladakh (thanks to Charles Ramble and Ronit Yoeli-Tlalim for pointing to this link and reference). Gellner mentions that the term baraka is in use throughout North Africa by Arabs and Berbers. Among central Moroccan Berbers it can mean "plenitude, and above all blessedness manifested amongst others by supernatural means" (Gellner E. 1970: 43, and note 1).

${ }_{33}$ Here, dkar (lit. 'white') refers to rgya dkar or gar, the Tibetan term for India (Schuh 1973: 14-15). In some contexts $d$ kar rtsis is also spelled skar rtsis and translated as 'calculation of the stars' (Schuh 1973: 16).

34 Edward Henning, personal communication, December 2007.

35 Edward Henning, personal communication, December 2007. 
are probably related to this system. The 'calculation of breaths' (rlung rtsis) is a part of dbyangs 'char gyi rtsis, ${ }^{36}$ but also appears in other astrological, medical, as well as tantric texts (see, for example, Wallace 2oogb: 289). Here, the time it takes to breathe once in and out is considered a temporal unit called dus tshod, which in one solar day amounts to 21,60o breaths. ${ }^{37}$ Later in the book (chapter 7.3) I explain how during meditation the control of breath is related to the control of the life-span.

Another related system called dbyangs 'char gza' dgu (lit. 'arising vowels and nine planets') combines nag rtsis and dkar rtsis astrology and is used in natal chart calculations. With this method the optimal or maximum lifespan (mchoggitshe tshad or tshe lo), which according to the Kälacakratantra is one hundred years (Wallace 2008: 215), is calculated and distributed to the nine planets, each of the planets receiving a certain allocation of years of the total life-span..$^{38}$ It is interesting to note that in this type of calculation the maximum life-span, which is the first parameter calculated based on the time of birth and the constellation on the day of birth, is a necessary methodological tool to arrive at detailed information on difficult phases in life. However, knowing the actual life-span is less important for the astrologers than knowing about dangerous phases in the life of their clients - for example, potential causes for an 'untimely death' - for which they need to prescribe certain ritual antidotes. ${ }^{39}$

Yet another Tibetan rtsis system, which produced a considerable amount of literature, is called 'bras rtsis (lit. 'result calculations'), which is the Tibetan system of horary and electional astrology. This type of 'interpretative astrology' (Henning 2007: 117) refers to the results of the other systems of rtsis. Just as Tibetan medicine synthesises features from Indian and Chinese medical systems, all these astrological systems employ both Indian and Chinese classifications of the five elements. In the Tibetan tradition derived from India, the five elements are water, earth, fire, wind, and space; in the Tibetan tradition derived from China, the five elements

\footnotetext{
${ }^{36}$ Tenzin Tsewang Jamling, personal communication, August 2010.

37 Six dus tshod equals one chu srang; sixty chu srang equals one chu tshod; sixty chu tshod equals one solar day of 21,60o breaths (Tenzin Tsewang Jamling, personal communication, August 2010).

${ }^{38}$ The allocation of years based on a maximum life-span of one hundred years is as follows: Sun: 6, Moon: 10, Mars: 7, Rahu: 18, Jupiter: 16, Saturn: 19, Mercury: 17, Ketu: 7, and Venus: 20. If the maximum life-span calculated in the natal chart is less than one hundred years, the respective percentage is allotted to each of the nine planets. In this way difficult phases in life can be predicted (Tenzin Tsewang Jamling, personal communication, August 2010).

${ }_{39}$ Tenzin Tsewang Jamling, personal communication, August 2010.
} 
are water, earth, fire, wood, and iron. ${ }^{40}$ In classical Tibetan medical texts, the pulse and urine diagnoses utilise the five Chinese elements; the physiology of the body, the six tastes, and the foundations of pharmacology are based on the Indian Âyurvedic tradition of the five elements. To complicate things further, the divinatory aspects of Tibetan pulse diagnosis are not necessarily of Chinese origin (Yoeli-Tlalim 2008), and the development of Tibetan urine analysis - which also includes divinations - has Arabic influences (Yoeli-Tlalim 2010).

Among contemporary Tibetans in India, the profession of 'astrologer' (skar rtsis $p a$, lit. 'the one who calculates the stars,' or dus shes $p a$, lit. 'the one who knows time') is not as popular as that of 'doctor' (sman pa). An indication of this is the fact that the astrology course at the Dharamsala MTK has fewer students than the medicine course. ${ }^{41}$ English-speaking Tibetans use the term 'astrologer' for rtsis pa. I have not heard rtsis pa calling themselves 'diviners' in English, even though they clearly engage in divinatory calculations. Tibetans use the term 'diviner' only for a mo $\mathrm{pa}$, which is the common Tibetan name for a diviner (see next section). There is usually a difference in prestige, status, and income between a rtsis pa and a mo $\mathrm{pa}$. Nevertheless, exceptionally skilled and popular mo $\mathrm{pa}$ might easily have a higher income, which they receive through donations from their clients, whereas a rtsis $p a$ at the MTK draws a monthly salary with various other benefits. Janes mentions that in rural Tibet astrology was considered 'a lucrative sideline to medicine' (Janes 1995: 34, note 4). In India, $r t s i s ~ p a$ who work outside the MTK institution accept donations. There is no significant competition between rtsis pa and mo $p a$, since the latter are often illiterate and usually do not use texts or calculations, and each profession has its respective specialities.

Rtsis pa working at the MTK in Dharamsala are consulted by Tibetans, Indians, and foreigners for natal charts and for astrological predictions on marriage, death, obstacle years, and ill health. They recommend auspicious dates for important government-in-exile events and predict annual obstacles for the Dalai Lama. They also prepare the popular

\footnotetext{
$4^{40}$ 'Iron' is the literal translation of lcags; sometimes 'metal' is used as well, which refers to the Chinese wu xing (Hobbs 2010).

${ }^{41}$ Medical courses run in two batches (of approx. twenty-five students each) over five years, whereas the astrology course runs only once every five years (with five to twelve students per batch). By 2006, two hundred and thirty students had been educated at the MTK with forty-six medical and twelve astrology students still enrolled (MTK 2006).
} 
annual almanac (lo tho) and teach at the MTK astrology college. ${ }^{42}$ During my fieldwork, I did not meet professional astrologers trained at the MTK, but mainly learned about longevity and astrology in the medical context from Amchi Jamyang (chapter 4) and in the popular context from Jampa Kaldhen (chapter 6).

This book presents only a few examples of life-span calculations that are found within the various systems of rtsis. These calculations differ widely and engage different kinds of life-forces. The calculation of the life-span involving the counting of breaths (rlung rtsis) is part of the dbyangs 'char gyi rtsis system; calculations surrounding longevity using the five factors (explained below) follow the Chinese nag rtsis system. Calculations of an 'untimely death' are part of the nag rtsis system and are calculated at the time of death. As already mentioned, the life-span is also calculated when preparing a natal chart, which is often done for children. Unfortunately, an ethnographic study of natal chart calculations was beyond the scope of my research.

The five factors are well-known parameters that appear in popular almanacs, and most Tibetans know about them. They came up in many conversations during fieldwork and require explanation. They are listed here in the sequence of their importance: the life-force (srog); the body (lus); power (dbang thang); good fortune (rlung rta, lit. 'wind horse'); and the subtle life-essence (bla). ${ }^{43}$ In the absence of a common Tibetan term for all of them, I follow Henning (2007: 172) and call them 'five factors.' Dorje (2002) calls them 'elements,' which I find too confusing, having to deal already with two sets of the five elements.

The five factors "derive from pre-Buddhist material reworked to some extent in Buddhist terms" (Samuel 2001: 250) and involve ideas of vitality, success, auspiciousness, and good luck. They are also linked to another range of concepts, such as obstacles (bar chad), pollution (grip), and spirit-affliction (gdon; Samuel 2001: 250), the first of which will be covered in later chapters of this book.

The fact that the five factors are not known under a common Tibetan term may point to their various origins. They are sometimes just called srog lus dbang klung ${ }^{44}$ bzhi (lit. 'the four: life, body, power, and wind horse'; THL 2009), leaving out the fifth one, bla. This is interesting because

\footnotetext{
${ }^{42}$ Tenzin Tsewang Jamling, personal communication, August 2010.

43 These five factors are explained in more detail in chapter 6.3.

44 Sometimes, rlung rta is also spelled klung rta.
} 
it hints at the unusual place that bla holds in Tibetan areas of knowledge, something that will become more obvious in later sections of the book. There have been no studies so far of the manner in which popular knowledge of bla entered Tibetan medical and astrological texts. What is apparent is that bla has a special status, in both Tibetan astrological as well as medical contexts. We find some indication for this in the sections on 'elemental divination' in the Baidūrya dkar po (Dorje 2002). The four factors recur throughout the text, but bla as the fifth factor is mentioned only in some of the death calculations (Dorje 2002: 346-347). The rituals to summon the bla, however, are mentioned several times as suitable measures to deal with negative results, which were calculated using only the four factors (Dorje 2002: 296-297, 301, 330, and passim).

These are my initial observations concerning the five factors, and at this stage it seems too speculative to say when and how bla became the fifth factor. Bla might have been significant without having been mentioned specifically as the fifth factor, or bla rituals might have been part of popular practices that were known to counteract loss of vitality and were eventually included in astrological texts.

To sum up this section, astronomy, calendrical calculations, astrology, and divinatory calculations of both Indian and Chinese origin are all part of the Tibetan area of knowledge called rtsis (Schuh 1973: 12). What links these topics together is the fact that they all involve some sort of calculation, which can, however, be of a divinatory character. Rtsis knowledge is deeply linked to temporal rhythms. A variety of almanacs, 'vitality tables,' and specialised calendars point to reoccurring auspicious dates that support human action. As Mills points out succinctly,

The astrological systems (of which there are several) thus encapsulate an understanding of events which is both profoundly periodical, but at the same time largely non-deterministic. Rather than stating that particular events would occur (although this does happen), Tibetan astrological systems emphasise the relative ability to carry out particular kinds of action successfully (Mills 2003a: 171).

My examples in chapter 4 show how this plays out in clinical practice in relation to strengthening the life-forces and making use of the times of the day, week, and month when life-forces are at their peak. Chapter 8 discusses in more detail certain life-span divinations, their interpretation, and issues of accuracy.

In order to comprehend Tibetan attitudes towards astrological predictions and divinations, which are not seen as deterministic but as cautionary, it is imperative to understand the notion of rten 'brel (lit. 'arising in 
mutual connection,' Skt. pratityasamudpāda). An important theme in all of these Tibetan areas of knowledge is the idea that everything - animate and inanimate - is interconnected, an idea that is expressed in Tibetan Buddhism as rten 'brel. This fundamental early Buddhist idea "asserts that nothing exists independently of other factors since things and events come into existence only by dependence on the aggregation of multiple causes and conditions" (Dorje 2002: 415).45

In Tibetan usage, rten 'brel has acquired additional meanings that are linked to ideas of 'omen' and 'divination' (Samuel 1993: 448-449).46 In Tibetan medicine, the idea of rten 'brel is used to illustrate the interconnections between the times of the day or annual seasons, the five elements, and three nyes $p a$, which are explained in chapter 4.1. In an astrological context, rten 'brel is more of an 'auspicious coincidence' that causes certain things to happen on the relative level of existence, which is contrasted to the absolute level of enlightenment (Dorje 2002: 15).

Negative predictions can be nullified through a variety of ritual practices (Dorje 2002: 15). The Kālacakra astrological tradition also provides "a system of practices designed for counteracting negative predictions," but acknowledges that "ultimately it is one's own karma that determines one's physical and mental conditions and one's lifespan" (Wallace 2009b: 294). The ethnographic examples of the forthcoming chapters will elucidate these points further.

Divinations that do not involve calculations, but rely on chance, such as the throwing of dice, are specifically known as mo rtsis (Schuh 1973: 12, note 43), also simply called $m o$, which is the topic of the next section.

\section{Divinations}

In this section, I introduce types of divinatory knowledge that are not related to calculations, but employ elements of chance. Divination is only an approximate translation of the Tibetan $m o$, and to avoid confusion

${ }^{45}$ The translation of rten 'brel as 'interdependent origination' is a Buddhist textual one. The popular usage of $r$ ten 'brel differs from Buddhist interpretations. For example, Clarke (1990: 177-178), on the basis of his fieldwork in Helambu, Nepal, describes rten 'brel (he calls it tendil) as connected to blessings that are received, whereas for Daniels (1994: 272), among Tibetan pilgrims in Kathmandu, rten 'brel is created through virtuous striving.

${ }^{46}$ Clarke also points to the popular meaning of tendil as 'good fortune,' 'omen,' and 'matters of direct material prosperity' (Clarke 1990: 177). In Kalimpong, Jampel Kaldhen translated rten 'brel as 'omen' as well as 'causality.' 
with other types of divination I mostly use the term mo.47 Most Tibetans make use of a mo when they become seriously ill, embark on a journey, or have to make a major life decision. Among Tibetans, it is widely accepted that predictions can easily cross conventional boundaries of past, present, and future. Mo predictions may even span several lifetimes. They are very popular among Tibetans, and are performed by lamas and incarnates (sprul sku) in monasteries or at their homes, "almost as a daily occurrence" and "quite gratuitously as a part of the normal events" (Chime Radha Rinpoche 1981: 5-6).

Casting a $m o$ is a pan-Tibetan practice that is not bound to a specific profession or method. ${ }^{48}$ Even lay people learn how to do simple rosary $m o$ at home to guide their daily decision making. In the Darjeeling Hills, Tibetans largely rely on mo done by ordained Buddhist monks, lamas, or high rinpoches across all Buddhist schools and economic status, as well as mo done by illiterate - mostly female - diviners. Men or women who professionally practise $m o$ are both called $m o p a$, but the majority of them are female. ${ }^{49}$ Lamas and rinpoches who do mo are not called $m o p a$, but some monks are professional mo pa. Mo pa perform mo at their homes or within a monastery compound. The two male mo $\mathrm{pa}$ I knew in Darjeeling and Kalimpong were monks and poor, but literate. They were not directly part of a congregation of monks in a monastery but practised on monastery compounds (see plate 3.1). Mo $p a$ in the Darjeeling area use dice (sho) or a rosary (phreng ba) to perform a mo. Dice mo usually come with a text that provides guiding answers to the diviner (see plate 3.2), whereas rosary $m o$ are interpreted without the help of texts.

$M o p a$ are often associated with their poor and dirty living conditions. This was not true for every mo pa I met. Ama Tsamla, a Tibetan illiterate female diviner in Kalimpong (see plate 3.3), was married and had several children. She kept to a strict diet and purification practices in her little temple, which was always clean. However, Momola - the single illiterate

\footnotetext{
47 Other Tibetan terms that carry meanings related to divination, prognostics, fate, and chance are rten 'brel and phya. A mo diviner is also called a phya pa.

${ }^{48}$ Ekvall (1963: 34-35) describes various types of mo using dice, rosaries, songs, pebbles, butter lamps, or scapulas of sheep; Chime Radha Rinpoche (1981: 3-37) mentions Tibetan divinations employing visions, arrows, rosaries, dice, butter-lamps, and bird behaviour. There are several studies on Tibetan divination, for example, Laufer (1914) on Tibetan bird divination, Mortensen (2003) on raven augury, Orofino (1994) on divination with mirrors, and Róna-Tas (1956) on divination with dice.

49 Róna-Tas, referring to A. H. Francke, points out that the very term mo also means 'female' (Róna-Tas 1956: 161).
} 


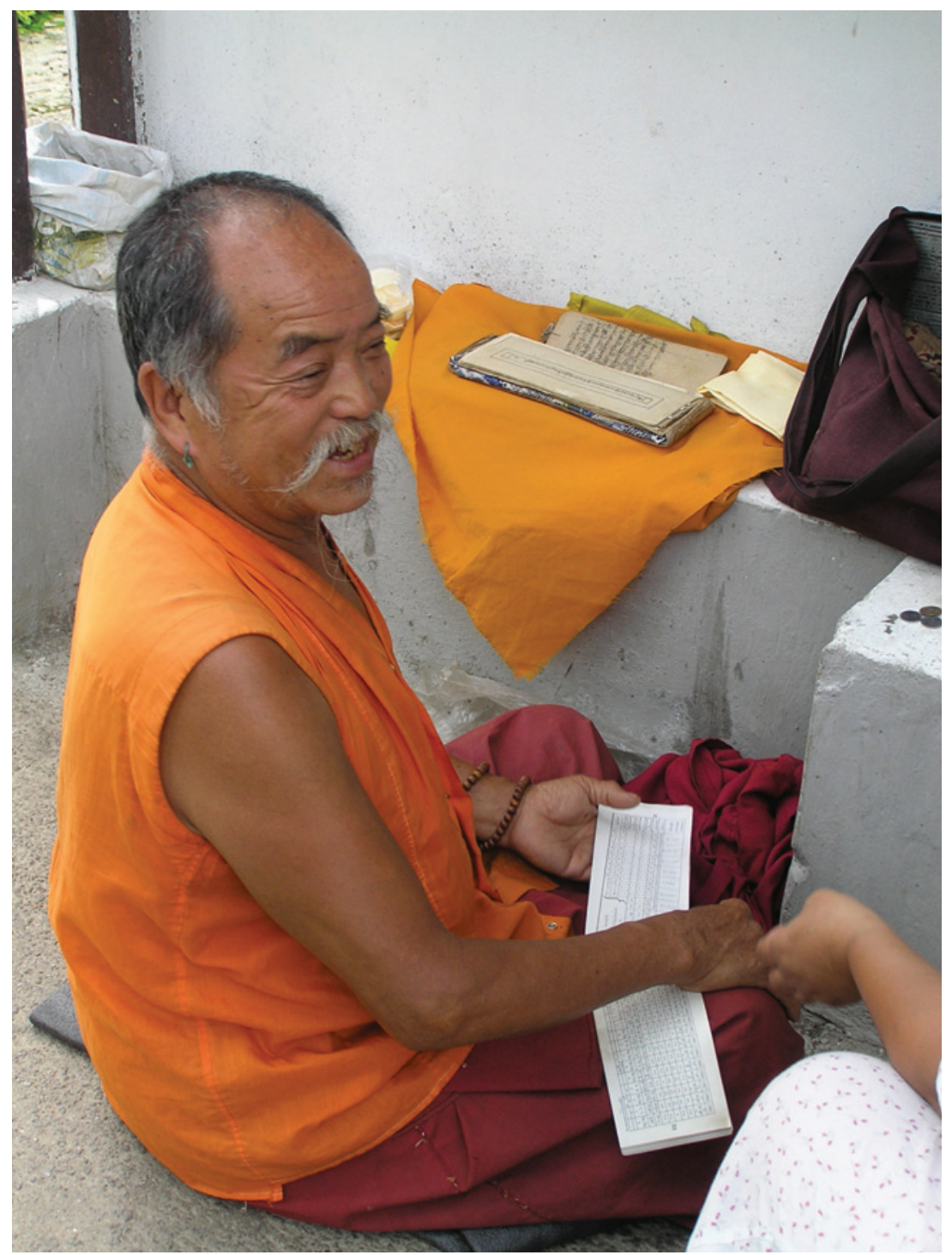

Plate 3.1. A mo pa performs a mo at the Jangsa Gompa, Kalimpong 2004. 


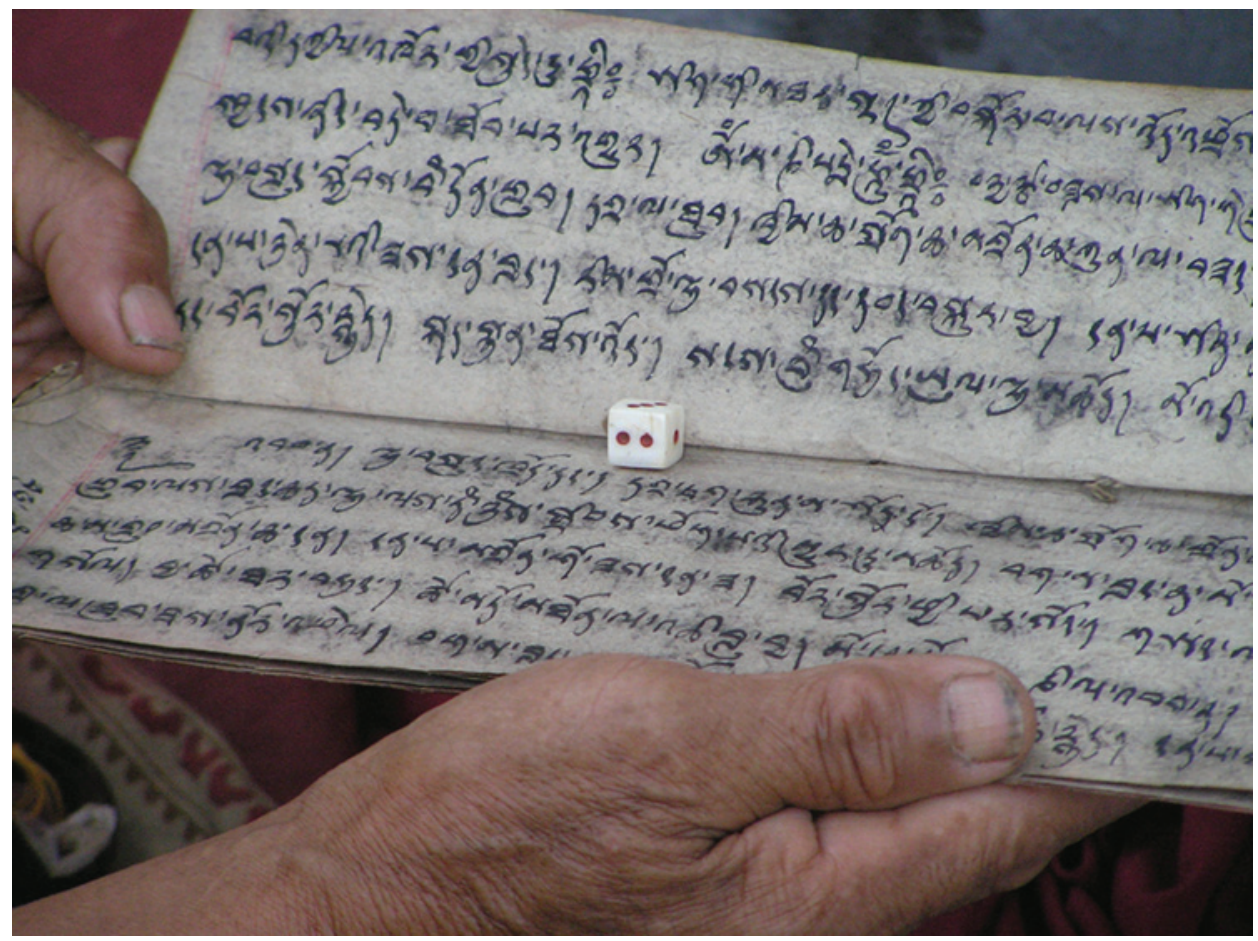

Plate 3.2. The dice and mo text used by the mo $p a$ at the Jangsa Gompa, Kalimpong 2004.

female mo pa of Ghum - whom I introduce in chapter 8.1, lived in the filthiest and most run-down conditions I had ever seen among Tibetans in the Hills.

People in Tibetan societies also seek divinations from spirit mediums (dpa' bo and dpa' mo), such as those described by Berglie in Nepal (1976, 1992) and Diemberger (2005) in the Tibetan Autonomous Region (hereafter TAR), or the lha pa as described by Bellezza (2005) in Upper Tibet. I only knew of one spirit medium in the region, a Bhutia woman who lived in Gangtok. Whereas spirit mediums fall into trance and generally do not remember their divinatory actions, mo $p a$, for the most part, do not go into states of trance, ecstasy, or possession. Elements of 'possession,' however, have been documented for Tibetan Vajrayāna practices and are not uncommon among Buddhist diviners (Samuel 2005: 233). In Tibetan societies (pre- and post-1959), women constituted the majority of the non-monastic spirit mediums (Diemberger 2005: 118). Such mediums divine and heal, but are not called mo pa. 


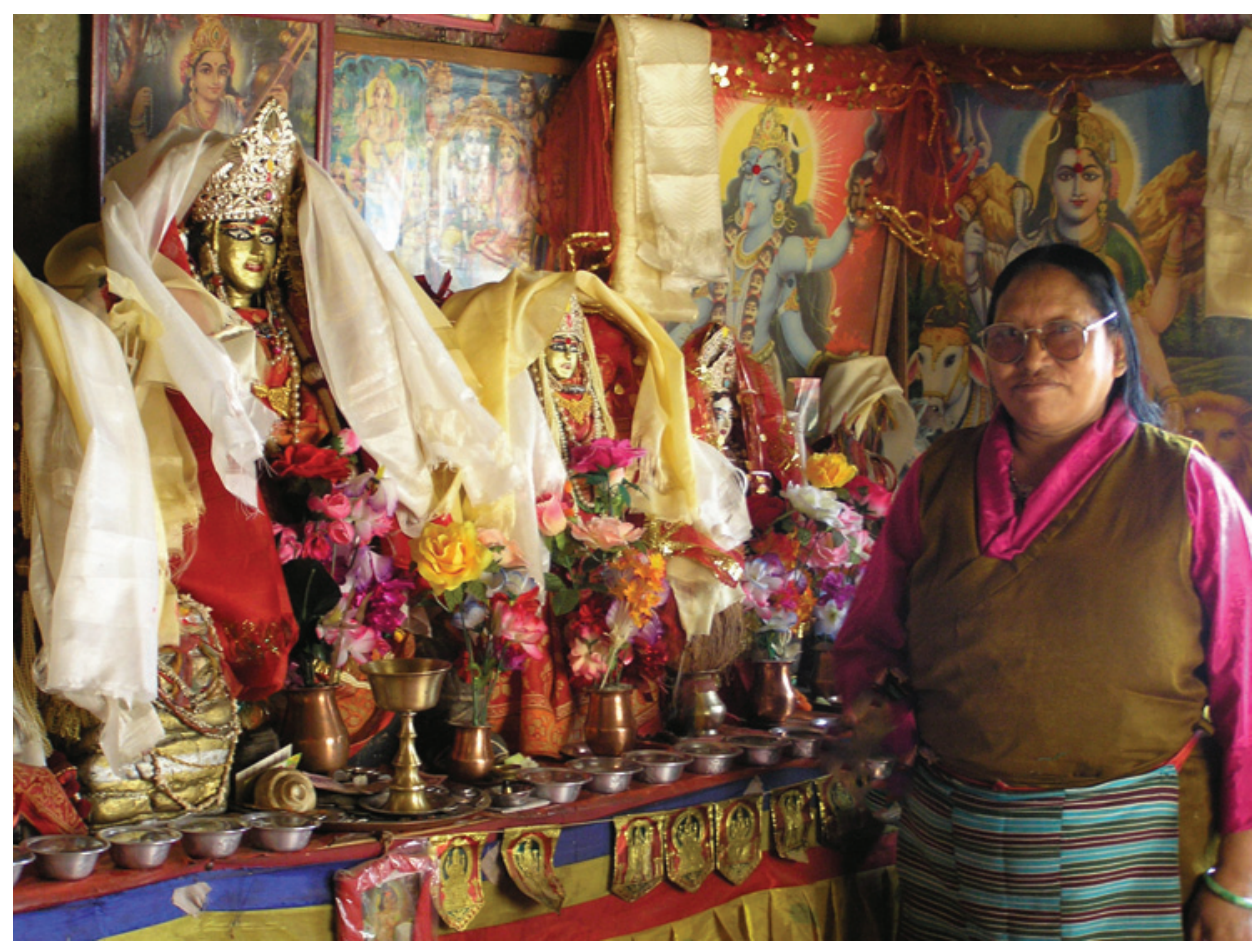

Plate 3.3. Ama Tsamla, a Tibetan diviner, in her shrine room filled with Buddhist and Hindu deities, Kalimpong 2005.

Mo pa were judged by the local people according to the success of their predictions or healing ceremonies, not by whether they were recognised by a lama or not, something Diemberger described as significant for spiritmediums in the TAR (Diemberger 2005: 117-118). In fact, of the six nonmonastic Tibetan diviners known to me in the region, only the Gangtok spirit-medium had been trained and recognised by a lama.

For illiterate single Tibetan women, becoming a $m o p a$ is a way to survive without family support. This is similar to the 'profession' of the Hindu mata, who are often single, uneducated women from lower castes. In the Darjeeling Hills, to be a mata gives these women a respectable position in society, and is an accepted way to remain 'single' (Gerke 1999b: 157; Strässle 2007: 59). The multi-religious situation in the Darjeeling Hills allows a Tibetan woman to become a mata, practise Buddhism, and still be married and have children. An example of such a joint Buddhist-Hindu practitioner is Ama Tsamla, the Tibetan diviner mentioned above. She was called mata by local Nepalis and mo pa by Tibetans. She performed 
rosary $m o$, typical for a $m o p a$, and also fell into trance, which is common for a mata. She performed mo for Indian, Nepali, and Tibetan clients, including monks, fell into trance, channelled Hindu and Buddhist deities (who spoke through her in either Hindi, Tibetan, Nepali, or even Bengali), and recited prayers in Sanskrit as well as in Tibetan. However, the central theme in the work of all these diviners, even if their methods and religious frameworks differed, was the same: the curing of illness and the detection and counteraction of harmful forces.

As mentioned above, divinations are linked to a complex body of ritual practices that counteract negative outcomes of divinations. Diviners basically detect which of these practices are appropriate for the client. Most of the practices are directly linked to the monasteries and are performed partly or fully by the monks and lamas. These can be rituals, the filling and consecration of deity statues, or the preparation and blessing of protective amulets. There are exceptions. Some amulets are prepared by diviners. Practices like raising prayer flags (rlung $r t a)$ or making small clay or plaster miniature conical figures filled with wheat (tsha tsha) and offering them on sacred grounds, are done by lay Tibetans themselves, although the lamas are usually involved in these activities through blessing these objects.

My observation is that because of the link between mo done by the diviners and rituals performed by the monks, the diviners and the monasteries have a symbiotic relationship; both reap economic rewards. The diviners provide the monastery with clients and detailed instructions on what kind of practices to perform, and the monasteries provide the body of sophisticated religious practices. The client usually 'pays' for the services in the form of donations. If a lama prescribes certain rituals, they can be either performed in his own monastery or in any other monastery that might be specialised in or have a local reputation for certain skills, such as the filling of deity statues with blessed substances. These skills are usually linked to individual specialists. People freely use their services, which can cross the boundaries of the different Buddhist schools. For example, the Geluk monastery Tharpa Chöling, which was avoided by many Tibetans because of the Dorje Shukden controversy (the monastery had a small Dorje Shukden temple), ${ }^{5^{\circ}}$ had a monk skilled in performing

${ }^{50}$ Dorje Shukden ( $r$ do rje shugs ldan) has been revered by some Gelukpa followers as a protective deity. This practice has been explicitly discredited by the current Dalai Lama. This controversy, which first became a public issue in India in 1975, has split Tibetan 


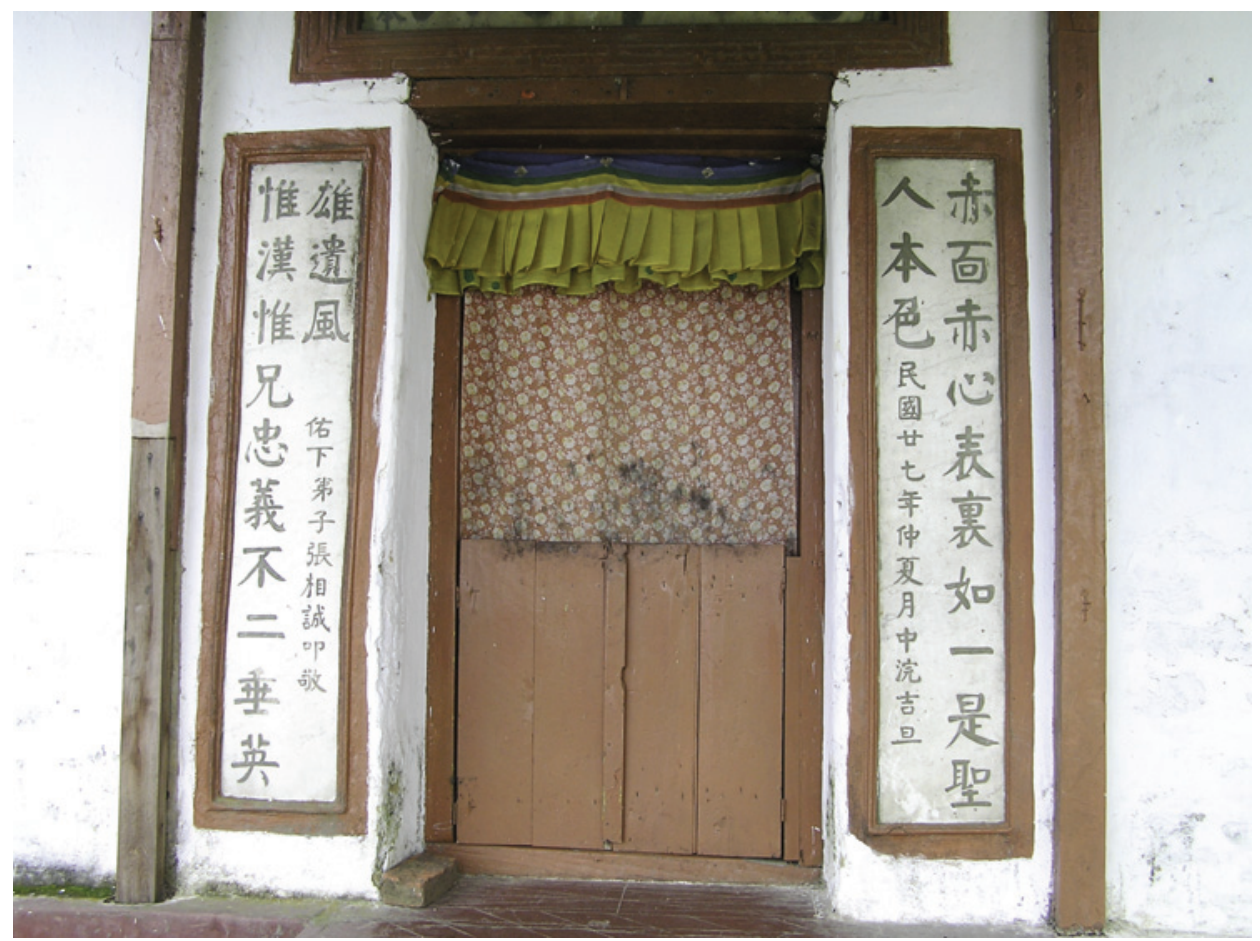

Plate 3.4. The entrance to the Gesar mo temple at the Tharpa Chöling Monastery, Kalimpong 2004.

a Chinese Gesar mo in a small shrine room on the monastery compound (see plate 3.4). This mo remained popular throughout the time I lived in Kalimpong.

\section{Tibetan Vajrayāna Buddhist Longevity Rituals}

The body of Tibetan Buddhist ritual knowledge is vast, and even an outline would be beyond the scope of this book. ${ }^{5^{1}}$ Therefore, in this section I only introduce some general aspects of ritual practices among Tibetans in the Darjeeling Hills. Moreover, I outline some of the longevity rituals that relate to monastic rituals presented in chapters 9 and 10.

communities throughout India and Nepal. See Dreyfus 1998 and Mills 2003b for good summaries of the issue.

${ }^{51}$ For a succinct introduction to Tibetan ritual see Cabezón 2010: 1-34. 
While Tibetan Buddhism is the overarching religious framework for the majority of Tibetans, ${ }^{5^{2}}$ the religious values and practices that affect their daily lives vary considerably, and the textual understanding of Buddhist rituals often contradicts popular beliefs. Ritual is all-pervasive in the hierarchical world of Tibetan Buddhism. The ritual field is not welldemarcated and not confined to the monasteries; practices of the abovementioned areas of knowledge - medicine, astrology, and divination - are also often ritualised. Most meditation practices are ritualised as well, as are the making of daily offerings and the recitation of prayers, thus making ritual involvement an integral part of Tibetan daily life. Nevertheless, monastic Tibetan Buddhist ritual knowledge involves highly specialised skills requiring long-term training.

A few words on empowerments (dbang) need to be said here in order to contextualise the longevity empowerments (tshe dbang) presented in part $\mathrm{V}$ of this book within the enormous corpus of Tibetan Buddhist tantric initiations. The term dbang indicates "the conferring of power or authorization to practice the Vajrayāna teachings, the indispensable entrance door to tantric practice" (THL 2009). They are regularly performed with the aim of keeping the lineages and practices alive and to pass them on to the next generation of practitioners (Beyer 1973: 399). Initiations and empowerments also mark the start of an intimate relation with the practitioner's 'personal' deity (yi dam), and often include vows. Beyer remarks,

The primary signification of 'initiation' in Tibet is as a guarantor of lineage of authenticity of doctrinal transmission - and as a preliminary and proper authorisation of practice; only secondarily is it considered as a means in itself to genuine realisation (Beyer 1973: 399).

Usually, receiving a dbang involves a series of commitments from the side of the lama as well as the disciple. How these empowerments and related commitments are perceived by monks and the attending public will be discussed in chapter 9. I now give a brief orientation of the types of longevity rituals performed in the Darjeeling Hills by monks and lamas for individual clients and the public.

Longevity rituals include longevity empowerments, called tshe dbang, ${ }^{53}$ and longevity practices, known under the generic term tshe sgrub. A particular type of these practices is known as longevity attainment practices

$5^{2}$ As I mentioned in chapter 2, only a few Tibetan Christians and Muslims live in the Darjeeling Hills.

${ }_{53}$ I explain tshe dbang rituals in greater detail in chapter 9, where I also review the existing literature. 
(tshe sgrub thabs or longevity sādhana). ${ }^{54}$ All of these are meditative and ritual practices to strengthen tshe and accomplish long life. Some of the tshe sgrub practices form part of a tshe dbang itself, and others are recited as part of individual Buddhist practices with vast regional variations, which to date have not been studied in detail. ${ }^{55}$ One of these practises that has recently been studied textually as well as ethnographically is the 'chi med srog thig of the Dudjom tradition, which is performed in Kalimpong every Tibetan New Year (lo gsar) at the Jangsa Gompa (Cantwell and Mayer, 2008, 2010; Samuel 2008a, b, 2010a, b, c, d; Samuel and Cantwell forthcoming). It is a revealed treasure practice (gter $\mathrm{ma}$ ) related to Padmasambhava. The 'chi med srog thig is a cycle of several practices, many of which contain the generic term tshe sgrub in their title, but are not longevity sādhana in the strict sense of the term..$^{56}$ Tshe sgrub rituals follow a number of standard sequences:

Typically, they include one in which the principal deity or deities generates healing and life-restoring nectar which pervades the practitioner's body, and one in which a series of secondary deities is sent out into the surrounding universe to recover one's depleted energy. These are often combined with specific breathing practices. Another common sequence involves the building of elaborate protective barriers to protect one from further loss of lifeenergy, assault by hostile supernaturals, or both (Samuel 2010b: 308).

Longevity requests specifically performed for a high lama are known as brtan bzhugs (lit. 'abiding with stability'). Gzungs (Skt. dhāraṇi) is a ritual formula similar to a mantra; in the case of a tshe gzungs, these formulas involve long-life prayers and mantras (for example, DLLS 1994: 573577). Long-life poetic prayers are called zhabs brtan (lit. 'firm feet'), but in the Darjeeling Hills the term zhabs brtan has a contemporary popular meaning as 'ritual.' I found that these practices can be highly technical and textual, meditative and secret, and/or popular and open to personal interpretation.

\footnotetext{
${ }_{54}$ Sädhana is a general term for a spiritual practice with the goal of attaining a siddhi (spiritual accomplishment). Sädhana is related etymologically to siddha and involves the visualisation of deities (Gellner D. 1992: 287-292). It is a central practice in Buddhist Tantra involving the evocation of deities and their entourage with the aim of achieving enlightenment (see Cozort 1997: 331-343). Kongtrul mentions numerous longevity sādhana in his autobiography (Barron 2003: 41, 108, 111, 125, 146, and 230).

${ }_{55}$ For a sketch of the possible history of the tshe sgrub practices see Samuel 2008b.

${ }^{56}$ Geoffrey Samuel, personal communication, September 2010. A typical sādhana structure "involves a preliminary part including the taking of refuge and arousing bodhicitta, a main part involving visualization of a buddha and recitation of the mantra, and a concluding part with dedication of merit to all sentient beings" (THL 2009).
} 
Whereas longevity dhäranī date back to the tenth century $\mathrm{CE}$, the brtan bzhugs rituals developed only in the sixteenth century, and the poetic zhabs brtan appeared only during the eighteenth century and are a direct descendant of brtan bzhugs rituals (Cabezón 1996: 350). The idea of requesting a spiritual teacher to live a long life is, however, much older and dates back to the time of the Buddha (Cabezón 1996: 351).

Tshe dbang rituals are very popular and draw large crowds who believe that this empowerment protects them from accidents and 'untimely deaths,' and also extends their lives by several years. They are attended from early childhood onwards, and I met Tibetans who had attended forty or more long-life empowerments during their adult lives. Sometimes, they are consciously avoided by old people who have no desire to live any longer. On the other hand, I also attended a tshe dbang where specifically the oldest Tibetan people of the community gathered, because, as the organiser explained, "they can still do manis7 and prepare for their next life." For lay Tibetans, longevity in old age does not imply physical immortality, but ideas of a good life in their next incarnation that can be achieved through practising dharma in this lifetime.

Tshe dbang rituals are also designed to protect the interrelationships between the individual and the community. Lamas have combined the popularity of both tshe dbang and the ritual mask dance, 'cham, into one festival, in which both 'blessing' and entertainment are offered to the community. Rituals, often spanning several days, are frequently concluded with a public tshe dbang. Tshe dbang ritual performances mostly involve large crowds and usually have religious and socio-economic dimensions. For various reasons, participants of tshe dbang rituals do not necessarily engage in the required meditation techniques, which involve visualisations of long-life deities, but are largely motivated by ritually achieving this-worldly aims.

Between 2004 and 2007, I attended eight tshe dbang, two brtan bzhugs, and participated in a six-day tshe sgrub. These were performed by and for different lamas in Nyingma, Geluk, and Sakya monasteries and temples in Kalimpong, Pedong, Darjeeling, Ghum, and Gangtok. The two brtan bzhugs rituals differed significantly in outlook. One derived from a Sakya tradition, the other was a Kagyü brtan bzhugs linked to Padmasambhava. Both were expensive and elaborate rituals, performed for the purpose of

57 'Doing mani' is a common expression for reciting the mantra of Avalokiteśvara, om mani padme hung. 
requesting a high lama to live long. This material is not included in this book. I focused on tshe dbang instead, since they were performed frequently in the area and I had more opportunities to study them.

In chapter 9, rather than focusing only on the ritual structure and content of a tshe dbang, I analyse how ritualised ways of communication between the different participants (lamas, monks, and lay people), who are socially segregated through strict hierarchies, affect people's ideas of longevity. On the one hand, the lack of communication between these participants preserves the hierarchy within the system, and on the other hand, it allows the introduction of individually created ritual layers that reflect the needs of a fast-changing Tibetan society confronted by problems of modernity in India.

To understand what longevity practices mean to individual practitioners, I talked with two ordained Gelukpa monks who had chosen Amitāyus as their main deity (yi dam) and performed the longevity practice associated with this deity on a daily basis. Some of this data is integrated into chapter 9. Amitāyus is considered a specialised manifestation of Amitābha, and both deities are often conflated (Samuel 2008b: 14). Originally from India, the Amitāyus practice first spread in Tibet exclusively in the Kagyü tradition; it was later adopted by all schools of Tibetan Buddhism and was promoted by the first and second Dalai Lamas as well as the first Panchen Lama (Mullin 1986: 154)..$^{8}$ Amitāyus is one of the 'three long-life deities' (tshe lha rnam gsum, see plate 3.5); the other two are White Tārā and Ușnīṣavijayā. ${ }^{99}$

The Amitāyus and Tārā practices "go back in some sense to the early Mahāyāna Sütras, but they have undergone a progressive transformation and specialisation in these contemporary Tibetan forms, taking on a health-giving role that appears to have been only a secondary element within their initial context" (Samuel 2008b: 3). Longevity practices connected to the deity Tārā were mainly introduced from India to Tibet by Atiśs ${ }^{60}$ around $1042 \mathrm{CE}$, although Tārā images existed prior to this in Tibet, possibly dating back to the mid-seventh century (Beyer 1973: 10). The date

\footnotetext{
${ }^{8}$ Mullin has translated an Amitāyus practice by the second Dalai Lama into English (Mullin 1986: 155-172).

${ }^{59}$ For a study of White Tārā longevity practices see Beyer 1973; for Ușnīṣavijayā see Shaw 2007: 291-305.

${ }^{60}$ Atiśa also translated Vāgīśvarakīrti's work on 'cheating death,' which is mentioned in chapters 1 and 7. Schneider states that the spread of Buddhism in Asia was successful in part because of these popular practices that addressed concerns of day-to-day life, including the prevention of 'untimely death' (Schneider 2010: 70).
} 


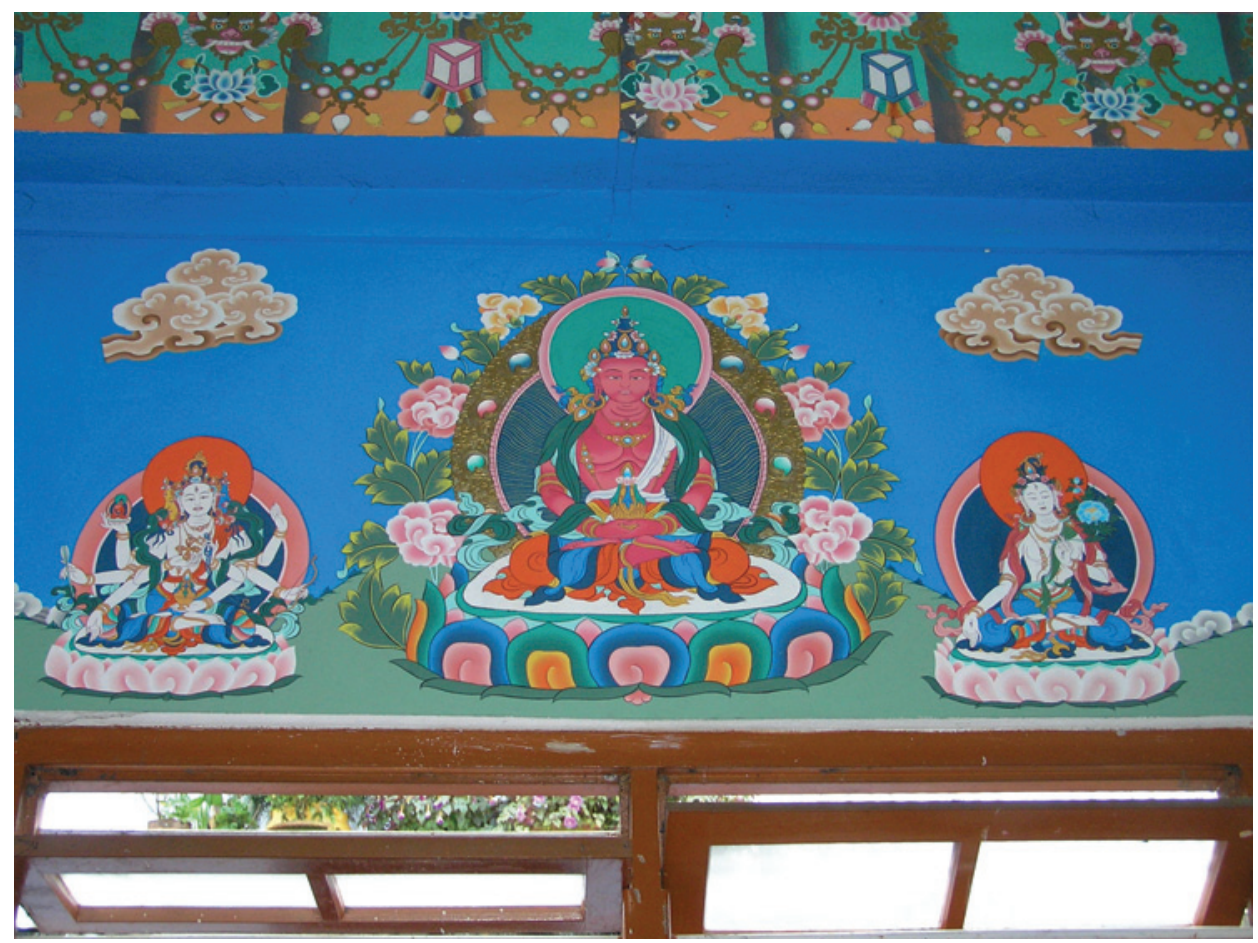

Plate 3.5. The three long-life deities Ușnīṣavijayā (left), Amitāyus (centre), and White Tārā (right) on a wall painting at the Mani Lhakhang, Kalimpong 2005.

of the Indian origin, however, cannot be ascertained (Beyer 1973: 6). White speculates on a Chinese origin, mentioning Tārā as the goddess of navigation (White 1996: 64).

In the Darjeeling region, tshe dbang rituals mostly involve either Amitāyus or White Tārā. The deity Ușṇiṣavijayā is the least prominent among the three long-life deities in the area and is occasionally offered one thousand oil lamps, which is a practice to promote longevity and remove obstacles to the life-span. My Tibetan language teacher in Darjeeling, the late Khen Rinpoche, told me in 2004 about a tshe sgrub called rnam rgyal tshe chog, where they offer one thousand oil lamps to Uṣnịṣavijayā on the 8 th, $15^{\text {th }}$, or 3 th day of each Tibetan month. This tshe sgrub was sometimes performed at a branch monastery of Tharpa Chöling near Darjeeling. Shaw mentions a similar ritual called rnam rgyal stong mchod with offerings made in sets of thousands (Shaw 2007: 297).

Tantric practitioners combine the visualisation of one of the longlife deities and the recitation of its specific mantra with internal yogic 
breathing exercises. Since tantric practitioners are not supposed to talk about their practice, they were cautious about what they revealed, and therefore their practices are discussed only marginally in this book.

Another ritual related to longevity is the ritual to retrieve a lost bla (bla 'gugs tshe 'gugs). There are many versions of rituals ransoming the bla, performed by shamanic practitioners and Buddhist lamas across the Himalayan and Tibetan regions. ${ }^{61}$ In Kalimpong, Buddhist lamas and also the female diviner Ama Tsamla performed bla retrieving rituals. Unfortunately, I was able to document only one such ritual, at the Tharpa Chöling monastery towards the end of my fieldwork. Bla rituals were, however, mentioned by Tibetan lay people, amchis, and monks in various contexts and appear at several places in the book.

In the following section, I explore the questions of how Tibetans have known about their life-span over time, and why longevity is such a panTibetan idea.

\section{Knowing about the Life-span}

We can gain an understanding of the importance of longevity practices among Tibetans over time from recorded stories and myths concerning longevity, mostly found in the biographies of lamas, heroes, or royals. These stories generally share the same motif, which is common in Mahāyāna Buddhist texts, that enlightened beings have a 'supernatural power' to control their life-span (Schneider 2010: 56 ). One of the key stories of the Tibetan royal mythology concerns the rejuvenation of the Tibetan king Lha Totori, who assumes the appearance of someone half his age and receives a 'second life,' thanks to his worship of the Buddhist texts: "He became [like] a sixteen year old youth; his life-span was extended by a further sixty years, and he lived to the age of $120 .{ }^{\prime 62}$

Another story tells how the Indian tantric Padmasambhava extended the life of the Tibetan king Tri Songdetsen (790-844 CE) by thirteen years (Tsogyal 1999: 121). The extension of life in these royal contexts is generally linked to the conversion to Buddhism, the performance of Buddhist

\footnotetext{
${ }^{61}$ Millard, for example, describes a Bonpo version (2002: 276-279), which is similar to the one documented by Karmay (1998). Bawden (1962) and Lessing (1951) present textual versions. I mention pan-Himalayan bla rituals briefly in chapter 5.1 and in detail in another paper (Gerke 2007).

${ }_{62}$ This is a quote by Pawo Tsuklak Trengwa (ca.1504-1566), 1986, vol. 1: 169. I am grateful to Charles Ramble for sharing this reference.
} 
rituals, or the accumulation of merit, all of which leads me to assume that the human wish to live long played a role in the conversion of Tibetans to Buddhism. I regularly heard these heroic stories being told to the public during long-life empowerments; they are also sometimes included in the empowerment ritual text itself (see chapter 9.3).

There are also stories of lamas whose lives are cut short because they violated their teachers' instructions (Ramble 1984: 365 ), or because of the inappropriate behaviour of their students. A current example of the latter concerns the worship of Dorje Shukden. The statement by the cabinet of the Tibetan government-in-exile, Dharamsala, of May 31, 1996, reveals that one burning issue around worshipping Shukden is that the life-span of the Dalai Lama is at stake. The understanding is that his life-span can be cut short by followers who worship Shukden and at the same time attend empowerments given by the Dalai Lama. ${ }^{63}$

The point I want to make here is that longevity is an important and recurrent theme in the lives of Tibetans. Longevity is not only a phenomenon of contemporary Tibetans living in exile, but has been an enduring theme in Tibetan culture, including in medicine, astrology, divination, and ritual life. It is a topic that authors wrote about at length over several centuries.

It is also reflected in another important area of study, called the 'signs of death' ('chi ltas). This topic involves a large amount of literature. It is based on the understanding that the skill to live long also requires the skill to interpret signs of 'untimely' or 'timely' deaths and counteract them where necessary (Schneider 2010: 69). These signs of death correlate to periodically reappearing times, usually linked to the moon cycle, during which they might occur (Schneider 2010: 69). The vast Buddhist literature on 'cheating death' also points to a pattern in which people's direct fear of death, coupled with the desire to live long, was tailored into long-life practices, which indirectly supported the spread of Buddhism in Tibet.

${ }_{63}$ “[...] it would not be appropriate for those who propitiate Dolgyal [Shukden] to attend this empowerment. When the protector concerned is disloyal to its commitments, the person concerned becomes disloyal in turn. [...] this gives rise to a breach of commitments which carries with it a definite threat to the life of a Lama [...]. If any among you here are determined to continue propitiating Dolgyal, it would be better for you to stay away from this empowerment [...]. It will not benefit you. On the contrary it will have the effect of reducing the life span of Gyalwa Rinpoche (The Dalai Lama), which is not good. However, if there are any among you who hope that Gyalwa Rinpoche will soon die, then you can stay" (Cabinet of the Tibetan government-in-exile 1996). Thanks to Cathy Cantwell for pointing me to this reference. 
Schneider offers an example with his translation of a north-Indian Buddhist work by Vāgīśvarakīrti on 'cheating death,' which was translated into Tibetan by Atiśa (982-1054) and Rinchen Zangpo (958-1055). Most of the practices mentioned in Vāgīśvarakīrti's work involve the deity White Tārā. They aim at lengthening the life-span through strengthening the lifeforces (Schneider 2010: 68). The text also shows that long-life practices and their efficacy were linked to the intention of practising Buddhism (Schneider 2010: 68, my emphasis). It was legitimate in Indian Hindu longevity ritual practices to have this-worldly aims - including avoiding an 'untimely death' and achieving a long life (Schneider 2010: 52). Indian Buddhist authors, such as Vāgīśvarakīrti, shifted their interpretation of Buddhist practice in the sense that dharma practice itself would already accumulate enough merit to lengthen life and consequently 'cheat death' (Schneider 2010: 53).

Thus, the introduction of these sets of practices into Tibet, including the White Tārā longevity practices, was less the introduction of new ritual techniques than an expression of a leitmotif of Buddhism that could accompany almost every form of religious expression (Schneider 2010: 68). This might explain to some extent why longevity is such a pan-Tibetan concern.

How do Tibetans today know about life-forces that impact their longevity?

I already mentioned that Tibetans are more concerned with medical or ritual practitioners being 'experts' and having a good reputation, than with questioning the epistemological framework of the available systems and how they relate to each other. This situation is based on the fact that amchi and rtsis pa knowledge, as well as monastic ritual knowledge, is generally viewed as being specialist knowledge, which lay people are not supposed to know or understand. A lot of the knowledge is even kept secret, such as certain Buddhist tantric practices or the recipes for medicines.

In the context of medicine, on one level, amchis know about the lifeforces from texts and from their institutional education. On another level, they know about them through oral instructions, clinical interpretation, and spiritual practice, which can vary from amchi to amchi. One can draw a parallel to styles of knowing in Chinese medicine here, where Hsu offers a useful observation in this regard:

Chinese medical terms will show to vary to such an extent in connotation, language use, and performative significance in different social contexts 
that one hesitates to assume that they refer to one and the same concept. These variations will be shown to depend on different styles of knowing (Hsu 1999: 20).

Hsu focuses on the social contexts of medical reasoning in specific settings that goes beyond the understanding based on textbooks. She concludes that modes of verbal reasoning and styles of (non-verbal) knowing have been shown to vary in different learning situations (Hsu 1999: 225). The same is found in Tibetan contexts. For example, the term indicating the subtle life-force bla is found in medical, astrological, divinatory, ritual, and popular contexts, but is variously interpreted by professionals and lay people, depending on how they know about the bla (for example, through oral instructions, astrological calculations, pulse diagnosis, ritual texts, or popular knowledge).

How interpretations of life-forces can vary significantly in different contexts will be elucidated throughout the book. In the following chapters, where I discuss temporal frameworks in medical, astrological, and divinatory contexts, I show that Tibetans often make selective choices of these 'expert' areas of knowledge and interpret them according to their individual situations. As will become clear, they have considerable agency in doing so.

Popular knowledge of life-forces in medicine, astrology, divination, and ritual among contemporary Tibetans in India does not necessarily correspond to the theoretical understanding of the scholarly textual traditions in these areas of specialised knowledge. The widely varying interpretations of the life-forces show that Tibetans have multiple ways of knowing about these life-forces, their places in the body, and their influence on the life-span. Lay Tibetans are not necessarily concerned with what they mean, as long as they can be modified to their advantage. Ethnographically, a great variety of practices can be observed in Tibetan societies that are structured around questions of knowing about the life-span. Will it be shortened through accidents or 'untimely death'? Is it exhausted? Can it be prolonged? Are the life-forces strong enough to sustain tshe until the maximum life-span is achieved?

One reason I have chosen to look at these concepts through the lens of time is that these life-forces are linked to cosmological and physical temporal frameworks (seasons, calendars, pulse beat, amounts of breaths). Through these frameworks they receive temporal characteristics and, along with this, social importance and medical or ritual significance. 
In the body, life-forces are linked to existing anatomical temporal rhythms of various systems, for example, the respiratory system. Bla as usual - falls out of place here, following the moon cycle and moving through locations in the body that are not linked to any particular physiological system, but rather to body concepts that appear in 'anatomical' charts alongside the tantric channels (see Parfionovitch, Dorje, and Meyer 1992: 40; appendix 3). The physiological systems, however, not only give the life-forces a physical location but also a temporal rhythm. All these physiological systems are marked by a specific way of time-reckoning: the time it takes to digest food; the time it takes for the blood to flow through the channels and for the heart to beat; the time it takes the moon to wax and wane; the time it takes to inhale and exhale. These rhythms imply the experience of duration.

I argue that for amchis the life-forces are easier to diagnose in connection with time-reckoning systems. While linked to temporal rhythms in the body and in their ecological environment they receive attributes of duration. They become countable as well as socially accountable through certain practices of temporalisation that allow for them to be diagnosed, measured, and negotiated. How exactly this plays out in various areas of daily life among Tibetans in the Darjeeling Hills is the topic of the chapters to come. 
Barbara Gerke - 978-90-04-21748-5 Downloaded from Brill.com๑4/26/2023 $\odot 2: 47: 13 \mathrm{PM}$ via free access 
PART THREE

THE LIFE-SPAN AND LIFE-FORCES

IN TIBETAN MEDICAL CONTEXTS

The central question that guides part III of this book is how temporal processes in the body are medically organised by amchis to make sense of the life-span and various life-forces. In chapter 4, I introduce temporal frameworks that guide medical assessment utilising the seasonalities of the five elements and the three nyes pa. The clinical application of calendars and 'vitality tables' exemplifies how auspiciousness and effectiveness augment therapeutic events using these temporal frameworks. Chapter 5 shows how the subtle life-essence bla is temporalised in the circular movement through thirty places in the body following the moon cycle. It also offers an analysis of the diagnostic and prognostic aspects of feeling the quality of both bla and mdangs mchog (a vital force that influences the radiance of an individual) in the pulse through a special method of pulse diagnosis that is also used to prognosticate the life-span. 
Barbara Gerke - 978-90-04-21748-5 Downloaded from Brill.com๑4/26/2023 $\odot 2: 47: 13 \mathrm{PM}$ via free access 


\section{TEMPORAL DIMENSIONS OF LIFE-FORCES}

Tibetan medical physiology links life-forces to cosmological as well as bodily rhythms. This takes place in several ways. The elements of the body are understood to change according to the season and time of day. Certain times have certain qualities, which reflect back on the life-forces. For example, the life-force srog and the subtle life-essence bla have certain auspicious days for each individual. In practice, this translates into selecting auspicious times for treatments and the intake of medicines. In the following four sections, I explain how the interconnections of the five physical elements ('byung ba lnga) and the three basic physiological principles (nyes pa gsum) link to the temporalities of hours, days, and seasons, and how this affects treatment schemes. How are these temporalities employed in clinical practice and guide ideas of treatment efficacy?

First, I want to introduce the principles of physiology as found in the Rgyud bzhi, the five elements, the three nyes $p a$, and related time cosmologies. It is important to outline these ideas because they influence how amchis understand the relationship between the nyes $p a$ and the life-span.

\section{The Three Nyes pa}

Tibetan cosmology explains the body as a micro-organism in terms of the five elements - earth (sa), water (chu), fire (me), wind (rlung), and space (nam $m k h a$ ') - which primarily determine the mind-body organism. "The characteristics and therefore the nature of all matter then results from the qualities of these elements individually or in combination" (Tokar 2008: 232). These elements form three basic physiological principles, collectively called nyes $p a$. The three principles are rlung (predominated by the element wind), mkhris $p a$ (predominated by the element fire), and bad kan (predominated by the elements earth and water). Debatably, the three nyes pa have often been translated as the 'three humours,' which are translated as 'wind,' 'bile,' and 'phlegm' respectively, further discussed below. 
There are five types of each nyes pa. Each is connected to a specific location in the body and has its own functions. Very briefly, the five types of rlung organise all functions related to movement, for example, blood, muscles, breath, food, thoughts, etc.; the five types of mkhris $p a$ are mainly responsible for the digestive process and for regulating body temperature; the five types of bad kan lubricate the joints, make the tissues soft, and give stability to the whole body. ${ }^{1}$

The cosmological framework of the Tibetan nyes $p a$ is derived from Indian Âyurveda. The temporal links between the nyes $p a$ and the seasons refer to Indian seasonal cycles ${ }^{2}$ and relate to the three doșa in Âyurveda, vāta, pitta, kapha. ${ }^{3}$ These were reworked in Tibetan Buddhist contexts but adhere to fundamental Indian cosmological premises, the main one being that the individual and the cosmos are both composed of the same five elements.

There is an ongoing debate whether these technical terms can actually be translated into English, which needs to be addressed briefly. In this book I avoid the terms 'humour,' 'wind,' 'bile,' and 'phlegm' altogether and use the Tibetan terms, since these are complex concepts that cannot be pinned down by any single word in a European language. The term 'humour' literally means 'fluid' or 'moisture,' deriving from the Latin 'humor,' and is linked to Galenic concepts of the four humours 'blood,' 'phlegm,' 'black bile,' and 'yellow bile' and their respective sanguine, phlegmatic, melancholic, and choleric temperaments. Despite some early Greek influences on Tibetan medicine (Beckwith 1979), ${ }^{4}$ these translations remain eurocentric since they miss the polysemous nature of the Tibetan terms. This has even been critiqued by practitioners of Tibetan medicine

${ }^{1}$ Their physiological functions have been explained in detail in numerous publications (for example, Clark 1995; Donden and Hopkins 1986; Drungtso T.T. 2007, 2008; MTK 2001).

${ }^{2}$ These cycles involve six seasons, i.e. early winter (dgun stod), late winter (dgun smad), spring (dpyid dus), late spring (sos ka), summer (dbyar dus), and autumn (ston dus), each corresponding to two months of the Tibetan calendar (Rgyud bzhi II, 14: 112). They cannot easily be converted to European climatic conditions. The Rgyud bzhi devotes one chapter to seasonal behaviour counteracting seasonal fluctuations of the nyes $p a$ with certain foods (Rgyud bzhi II, 14: 112-115). The seasons used in pulse diagnosis are different, i.e. spring, summer, autumn, winter, and the remaining eighteen days of each season (MTK 2001: 25, 43).

${ }^{3}$ Zimmermann 1987 describes the ecological themes in Hindu medicine and the relationship between doṣa and the seasons.

${ }^{4}$ Beckwith discusses various Greek and Arab physicians and lists the works which they wrote while in Tibet, but not the influence of the four Greek humours on the nyes pa. However, he traces tenets of the Hippocratic Oath in Tibetan medical texts (Beckwith 1979: 304). 
themselves (for example, Gyatso Y. 2005/06; Tokar 2008). Here, I want to look briefly at the critique brought forward by Gyatso.

Amchi Yönten Gyatso argues that nyes pa is both a vernacular and technical term with two very distinct sets of meanings. As a vernacular term it simply means 'fault' - which is also the literal translation of the Sanskrit doșa - whereas as a technical medical term nyes pa can indicate 'disease,' 'a cause of a disease,' 'a force or energy in the body that has a physiological function,' as well as 'a gross or subtle component of the body' (Gyatso Y. 2005/06: 111).

Western authors have often simplified the meanings of nyes pa, giving preference to definitions that stress the understanding of health and illness as balance or imbalance of the 'humours.' While the Rgyud bzhi itself uses terms expressive of the idea of balance (see footnote 5 below), I agree with Samuel that the overemphasised ideas of holism and balance might be a projection of what westerners like to see in their idealised view of 'Tibetan medicine' (Samuel 2001: 248). Gyatso argues that the understanding that nyes pa are "causes of diseases only when they are unbalanced" (for example, Winder 1981: $5^{-6}$, quoted in Gyatso Y. 2005/06: 113) is "essentially wrong" (Gyatso Y. 2005/06: 113). Gyatso rightly argues that the three nyes pa are also "causes of diseases when they are in a state of balance. But when disturbed and rendered imbalanced they are the characteristic entities of diseases, for they harm and bring suffering to body and life" (Gyatso Y. 2005/06: 113). ${ }^{5}$ In line with his argument I use the Tibetan term.

The literal English renderings of the three nyes pa as 'wind,' 'bile,' and 'phlegm' carry only a trace of what these nyes pa mean in all their broad aspects (Tokar 2008: 234). One could argue that by now, for instance, 'wind' is a widely accepted and fairly well studied notion in anthropology in general, ${ }^{6}$ and using the English translation would be less problematic because it would be received by a sensitised readership, well aware of the different guises 'wind' can take. Nevertheless, since there is no uniform agreement on how to translate these terms, authors are continuously challenged to address the issue and justify the position they take.

${ }^{5}$ This is Gyatso's translation of a quote from the Rgyud bzhi (II, 8: 86): rnam par ma gyur nad kyi rgyur 'gyur la/ rnam 'gyur ma snyoms nad kyi ngo bo yin/ lus dang srog la gnod cing gdung bas so/.

6 The special issue of JRAI edited by Hsu and Low 2007 on the anthropology of 'wind' offers a range of papers dealing with 'wind' in scholarly medical traditions as well as hunter and gatherer societies. The overall approach emphasises the anthropology of the senses and the phenomenology of 'wind.' 
In various Tibetan contexts some studies on rlung and the 'life-wind' one of the five types of rlung called srog rlung - have stressed not so much the phenomenological aspects but the social and political significance of rlung illnesses. ${ }^{7}$ These authors vary in their translations of rlung, mainly using the Tibetan term, interchanging both wind and rlung, or placing their English translations in quotation marks, arguing that the "concepts to which they refer are not the same as those invoked by the same words in medical or everyday" English (Jacobson 2002: 274). One of the arguments brought forth is that the complex epistemologies of Tibetan medicine are "very unlike those found in Western epistemology" (Adams 1998: 83).

While I find 'wind' useful to describe the subtle differences or characteristics of rlung in the various contexts, ${ }^{8}$ I prefer to use the Tibetan term when it comes to the medical meanings of the nyes pa. In the following, I show how the three nyes pa are linked to temporal frameworks that exist in Tibetan medical literature and that provide an outline for amchis to understand illness.

\section{Temporal Frameworks of the Three Nyes pa}

The three nyes $p a$ are not static substances. They are subject to change at different hours of the day, seasons of the year, and even periods of life. They are not stable but in a constant flow, subject to fluctuating inner and outer conditions of the elements. Therefore, their link to temporal ideas deserves closer attention. ${ }^{9}$

7 For such studies on rlung illnesses see, for example, Adams 1998, 2002a, 2002b; Bassini 2006, 2007; Gutschow 1997; Jacobson 2000, 2002, 2007, 2009; Janes 1995, 1999a, 1999b; Millard, 2007; Prost 2006; Rucinska 2007.

${ }^{8}$ In Tibetan tantric contexts, for example, rlung does not refer to a nyes pa but more to the movements of a 'subtle wind' or prāna.

9 The way I explain the nyes $p a$ in this and the following sections is based on explanations from the Rgyud bzhi (I, 3, 4; II, 5, 6) and the way it is generally taught at the MTK. I personally went through this curriculum during my year at the CTMI in Darjeeling in 1992-93 and have discussed these aspects with Tibetan doctors on many occasions. The sources I use in this chapter are the Tibetan version of the Rgyud bzhi, two available English translations (Clark 1995; MTK 2008), and the Baidūrya sngon po commentary by Sangye Gyatso in its Tibetan (Sangye Gyatso 1982) and illustrated English version (Parfionovitch, Dorje, and Meyer 1992). 
The times of the day, year, or periods of life are understood to expose certain defining characteristics, in Tibetan known as mtshan nyid (lit. 'own sign'), which are similar to the attributes of the nyes $p a$ mentioned below..$^{10}$ Tibetan amchis rely on certain temporal frameworks by which they recognise balances and imbalances and which are based on these mtshan nyid (see table 4.1 on page 126). The Indian Buddhist Kälacakratantra, which had considerable influence on Tibetan medical ideas, explains the underlying logic of such correlations in a way in which "the individual and the cosmos are seen as two closely related mechanisms of time that perfectly correlate to each other in terms of their structures and modes of operation" (Wallace 2009b: 289). I explain such mechanisms of time and related Tibetan time markers further below. First, I want to illustrate the relationship between the nyes $p a$ and various temporalities.

The first of the three nyes $p a$ is rlung. As a technical term it serves to denote subtle forces in the organism that manifest themselves physically with a characteristic of the element wind. But their meaning cannot be confined to the sensation of wind, such as gas in the intestines or breath in the lungs. All movements in the organism - including the flow of everything from blood to thoughts, all nerve activity, and the movement of the muscles and bowels - are governed by this nyes pa. Six key mtshan nyid describe rlung as coarse (rtsub pa), light (yang ba), mobile (g.yo ba), subtle (phra $b a$ ), cold (grang $b a$ ), and hard (sra ba). These mtshan nyid are not only found in certain climates, environments, and foods, but also in specific time periods both of one's life and of the day. Rlung is said to predominate in old age ${ }^{\text {n1 }}$ because the body in old age takes on more of the mtshan nyid of rlung. The mtshan nyid of rlung also link up with the quality of the early morning and late afternoon, and the summer rainy season. These times of the day, year, or life are understood to inherently expose those characteristics - coarse, light, mobile, subtle, cold, and hard - that are known to increase rlung. This means that rlung disorders can more easily occur during times that have the same mtshan nyid as rlung.

\footnotetext{
${ }^{10}$ The characteristics of the three nyes $p a$ are the same as in Āyurveda, since they have been translated from Sanskrit into Tibetan. One of the seminal Sanskrit texts that influenced the compilation of the Rgyud bzhi is the Aștāngahrdayasamnhitā by Vāgbhața, in Tibetan Yan lag brgyad pa'i snying po bsdus pa.

"In the Rgyud bzhi, 'old age' is defined as above seventy years of age (Rgyud bzhi II, 6: 77).
} 
Anthropologists have observed social manifestations of such links between the nyes $p a$, age, and seasons. Prost mentions that younger Tibetan exiles in Dharamsala attended the annual summer teachings by the Dalai Lama in order to 'cool down' rlung, which peaks during the rainy season (Prost 2006: 123). Bassini describes that "ordinary people in Golok and Tsholho, who talked about rlung disorders only refer to a condition that befalls the elderly, which was described as loss of vigour" - which conforms to the traditional medical view. However, she also reports that rlung-related heart distress is also found among young people in Amdo who suffered traumatic experiences during the Cultural Revolution (19661976; Bassini 2006: 9). Janes also presents an ethnographic example from the TAR, where rlung diseases increasingly occur among young people (Janes 1999a).

How exactly the mtshan nyid are manifested in the body depends on the individual nature (rang bzhin) of each person, which usually appears in single, dual, or triple combinations of the nyes pa (Rgyud bzhi II, 6: 77). The mtshan nyid also appear as parameters in pulse and urine diagnosis, where certain pulse characteristics as well as the colour and odour of the urine are described using the same or similar terms. Successful treatment depends on the skill of the amchi in diagnosing the predominance of certain mtshan nyid and nyes pa over others and to balance them through diet and medication that are of the opposite nature.

Mkhris $p a$, the second nyes $p a$, is dominated by the element fire. It dominates adulthood, ${ }^{12}$ midday and midnight, as well as the autumn, because the mtshan nyid of mkhris pa express the nature of these time periods. The mtshan nyid of mkhris pa are hot (tsha ba), sharp (rno ba), light (yang ba), foul-smelling (dri mnam pa), purgative ('khru ba), moist (gsher $b a$ ), and oily (snum pa). Mkhris pa's aspects of sharpness, lightness, and heat reflect in the intellect, decision making, and physical activity of an active adult person. These mtshan nyid also make this nyes pa responsible for the digestive process and for regulating body temperature. People with a mkhris $p a$ constitution are said to have a hot temper and sharp intelligence.

\footnotetext{
${ }^{12}$ In the Rgyud bzhi, 'adulthood' is defined as between sixteen and seventy years of age (Rgyud bzhi II, 6: 77).
} 
Bad kan, the third nyes $p a$, is mainly produced by the combination of the water and earth elements. Peak times of bad kan are childhood, ${ }^{13}$ midmorning and evening, as well as spring, when the mtshan nyid of bad kan are strongest. These mtshan nyid are cool (bsil ba), heavy (lci ba), blunt (rtul ba), oily (snum pa), smooth ('jam pa), firm (brtan pa), and sticky (sbyar bag can). Bad kan, promoting firmness and growth with characteristics of oiliness, smoothness, and firmness, outweighs the other nyes pa in the body during childhood. Due to these mtshan nyid, bad kan lubricates the joints, makes the tissues soft, and gives stability to the whole body. People with a bad kan constitution are known for their softness and gentleness, but can at times be lazy and dull.

Regarding the relationship of the nyes pa and the life-span, the Rgyud bzhi (II, 6: 77-78) follows the general three-fold pattern. The text states that people with a rlung constitution have a short life-span, mkhris $p a$ constitutions have a medium life-span, and bad kan constitutions have a long life-span, acknowledging that this varies for people with constitutions of dual or triple nyes pa combinations (Rgyud bzhi II, 6: 78). Amchi Jamyang explained the relationship between the nyes $p a$ and the life-span as follows:

Rlung is not visible and therefore weak, 'without power' (shugs med), and therefore causes a short life-span. Mkhris $p a$, with a strong fire element, is visible, but still weak because it is 'light' (yang ba), so it causes a medium life-span. Only the 'firm' (brtan pa) quality bad kan is strong enough to produce a long life-span.

He said one has to understand the mtshan nyid of the elements and the nyes $p a$ to understand these life-span classifications. Arguably, this interpretation is open to a certain flexibility and association with only some of the several characteristics. Not all mtshan nyid have to 'fit' the description. Moreover, most individuals combine two or three nyes $p a$ in their nature.

The following table summarises the nyes $p a$ and their temporalities.

\footnotetext{
${ }^{13}$ In the Rgyud bzhi, 'childhood' is defined as below sixteen years of age (Rgyud bzhi II, 6: 77).
} 
Table 4.1. Characteristics and temporalities of the three nyes pa according to the Rgyud bzhi (I, 3: 45; II, 6: 77-78; II, 14: 112-115).

\begin{tabular}{|c|c|c|c|c|c|c|c|}
\hline nyes pa & $\begin{array}{l}\text { Element } \\
\text { 'byung ba }\end{array}$ & $\begin{array}{l}\text { Characteristics } \\
\text { mtshan nyid }\end{array}$ & $\begin{array}{l}\text { Life Period } \\
\text { tshe dus }\end{array}$ & $\begin{array}{l}\text { Season of } \\
\text { Accumulation } \\
\text { gsog pa'i dus }\end{array}$ & $\begin{array}{l}\text { Season of } \\
\text { Manifestation } \\
\text { dus }\end{array}$ & $\begin{array}{l}\text { Temporal } \\
\text { Relations } \\
\text { to Day and } \\
\text { Night } \\
\text { nyin mtshan } \\
\text { dus }\end{array}$ & $\begin{array}{l}\text { Life-span } \\
\text { tshe }\end{array}$ \\
\hline rlung & $\begin{array}{l}\text { wind } \\
\text { rlung }\end{array}$ & $\begin{array}{l}\text { coarse (rtsub pa) } \\
\text { light (yang ba) } \\
\text { mobile (g.yo ba) } \\
\text { subtle (phra ba) } \\
\text { cold (grang ba) } \\
\text { hard (sra ba) }\end{array}$ & $\begin{array}{l}\text { old age } \\
\text { rgas pa }\end{array}$ & $\begin{array}{l}\text { late spring } \\
\text { sos } k a\end{array}$ & $\begin{array}{l}\text { summer } \\
\text { dbyar dus }\end{array}$ & $\begin{array}{l}\text { evening } \\
\text { and dawn } \\
\text { dgong dang } \\
\text { tho rangs }\end{array}$ & $\begin{array}{l}\text { short life- } \\
\text { span } \\
\text { tshe thung }\end{array}$ \\
\hline $\begin{array}{l}\text { mkhris } \\
p a\end{array}$ & $\begin{array}{l}\text { fire } \\
m e\end{array}$ & $\begin{array}{l}\text { hot }(\text { tsha ba) } \\
\text { sharp (rno ba) } \\
\text { light (yang ba) } \\
\text { foul-smelling } \\
(\text { dri mnam pa) } \\
\text { purgative } \\
\text { ('khru ba) } \\
\text { moist (gsher ba) } \\
\text { oily (snum pa) }\end{array}$ & $\begin{array}{l}\text { adulthood } \\
\text { dar ma }\end{array}$ & $\begin{array}{l}\text { summer } \\
\text { dbyar dus }\end{array}$ & $\begin{array}{l}\text { autumn } \\
\text { ston dus }\end{array}$ & $\begin{array}{l}\text { noon and } \\
\text { midnight } \\
\text { nyin dgung } \\
\text { mtshan } \\
\text { dgung }\end{array}$ & $\begin{array}{l}\text { medium } \\
\text { life-span } \\
\text { tshe 'bring }\end{array}$ \\
\hline bad kan & $\begin{array}{l}\text { earth and } \\
\text { water } \\
\text { sa dang } \\
\text { chu }\end{array}$ & $\begin{array}{l}\text { cool }(b s i l \text { ba) } \\
\text { heavy (lci ba) } \\
\text { blunt (rtul ba) } \\
\text { oily (snum pa) } \\
\text { smooth ('jam pa) } \\
\text { firm (brtan pa) } \\
\text { sticky (sbyar } \\
\text { bag can) }\end{array}$ & $\begin{array}{l}\text { childhood } \\
\text { byis pa }\end{array}$ & $\begin{array}{l}\text { winter } \\
\text { dgun }\end{array}$ & $\begin{array}{l}\text { spring } \\
\text { dpyid dus }\end{array}$ & $\begin{array}{l}\text { dusk and } \\
\text { morning } \\
\text { srod dang } \\
\text { snga dro }\end{array}$ & $\begin{array}{l}\text { long life- } \\
\text { span } \\
\text { tshe ring }\end{array}$ \\
\hline
\end{tabular}

The above presentation is based on classical Tibetan medical textual knowledge. Individual interpretations in clinical practice might differ from the text. There has been no research so far on the phenomenological aspects of amchis' perceptions of these mtshan nyid, which are closely linked to taste in pharmacology and touch in pulse diagnosis, and deeply influence Tibetan medical gaze. A detailed study involving the anthropology of the senses, similar to the study by Hsu and Low (2007) concerning 'wind,' would enlarge our way of thinking about these complex ways of medical theorising. My observations in this section are limited to the temporal mapping of the nyes $p a$, which appears repeatedly as a pattern in Tibetan medical texts and links Tibetan physiology to larger cosmologies. 
The point I wish to make here is that it is characteristic of Tibetan medical texts to divide the period of the life-span - considering age, times of the day, and annual seasons - according to the nyes $p a$ into rlung, mkhris pa, and bad kan intervals. ${ }^{14}$ This is not surprising when one looks at the general pattern of medical epistemologies in the Rgyud bzhi, which categorises phenomena according to the three nyes pa in numerous contexts.

It is important to note that lay Tibetans do not use these nyes pa categories to classify the life-span. When lay Tibetans and diviners talk about tshe, they talk in terms of whether tshe is exhausted (see chapter 8.1). In an astrological context it is calculated whether the death was 'untimely' and if there is a remaining life-span that will be lived in a future life (see chapter 7 ). None of these ideas are related to the predominance of a nyes $p a$. This confirms my earlier point that Tibetan medical knowledge is specialised knowledge; it has its own temporal categories classifying the life-span. In the next section, I answer the question of how temporalities influence Tibetan medical treatment schemes.

\section{Temporalities and Treatment Schemes}

The way a disorder can be treated successfully also depends on the season and the time of day. The seasons of the nyes pa are very important since they indicate the best time when a disorder of a nyes $p a$ can be treated most successfully. The Rgyud bzhi mentions that a disorder of a nyes pa should be eliminated at its 'own location' (rang gnas) and in the 'season of its accumulation' (gsog pa'i dus), since it is difficult to treat a nyes pa disorder once its 'season has past' (dus 'das; Rgyud bzhi II, 27: 176). The temporal links between the nyes pa and the seasons provide a clear framework for amchis, indicating when to treat a nyes pa disorder, and at what time of day to prescribe the medicines.

Tibetan diurnal time-slots are described in various contexts and are based on the five elements, the twelve year signs, and the three nyes pa.

${ }^{14}$ In comparison, the Kālacakratantra divides the maximum life-span into three sets of thirty-two years and three-and-a-half months and into a period of decline of the remaining three years, three fortnights, and three days. "This division of the human life-span of ninety-six years and ten-and-a-half months corresponds to the length of time it takes eight planets altogether to move through the circle and a half of twenty-seven constellations" (Wallace 2009b: 291; see also footnote 16 in this chapter on the twenty-seven constellations, which are also called lunar mansions). 
Astrology and medicine are deeply linked in this regard. The Tibetan lunar year has three hundred and sixty days and cycles of sixty and one hundred and eighty years. ${ }^{15}$ Since a year is longer than three hundred and sixty days, adjustments are made by adding extra days and skipping days, or introducing an extra month. To understand the temporalities in Tibetan medicine we have to understand the origins of their intricate cosmologies, summarised by Wallace:

Already in the Atharva Veda one finds the earliest indication to time ( $k \bar{a} l a)$ as an efficient factor that links together the cosmos and the individual on the grounds that it is time that creates and governs heavenly spheres and living beings. [...] These and other ancient allusions to the relation between the individual and the cosmos through the efficacy of time, eventually developed into full-fledged theories concerning definite relationships between the circulation of the humors (tri-dosa) and vital energies (pränas) in the body and the positioning of constellations and movements of planets (Wallace 2009b: 288).

These ideas entered Tibet through the Kälacakratantra and were integrated into medical thought. The division of 'inner' and 'outer' time in the Kälacakratantra is found in Tibetan astrology as well as medicine. The twenty-seven lunar mansions or twenty-seven constellations ${ }^{16}$ along the zodiac belt provide units of external circular time (yul gyi chu tshod). The internal, embodied aspect of time are measured in the units of inhalation and exhalation (dus tshod), which add up to 21,60o breaths a day (see chapter 7.3).

The day itself is divided into twelve two-hour periods, also called dus $t_{s h o d,{ }^{17}}$ each of which refers to one of the twelve year signs. The twelve year signs thus relate to hours, days, months, and years. In medicine, the various periodisations of time involve the subdivisions of the day and year according to the nyes $p a$, which are in turn based on the five elements. The twelve year signs are accompanied by one of the elements in a combination that repeats itself every sixty years. At twelve-year intervals, the obstacle year (lo skag or lo skeg) is believed to bring loss, difficulty, and suffering to the individual. Longevity practices are often performed during such skag years. The 'obstacle year' as a time marker for the interpretation

\footnotetext{
${ }^{15}$ For details on Tibetan time measurements see Schuh 2010.

${ }^{16}$ The lunar mansions are a division of the ecliptic into twenty-seven sections similar to the twelve divisions of the signs of the zodiac. The twenty-seven lunar mansions are listed in Henning 2007: 356-357.

${ }^{17}$ These twelve two-hour periods are listed in appendix 4, section 4, indicating the movement of bla.
} 


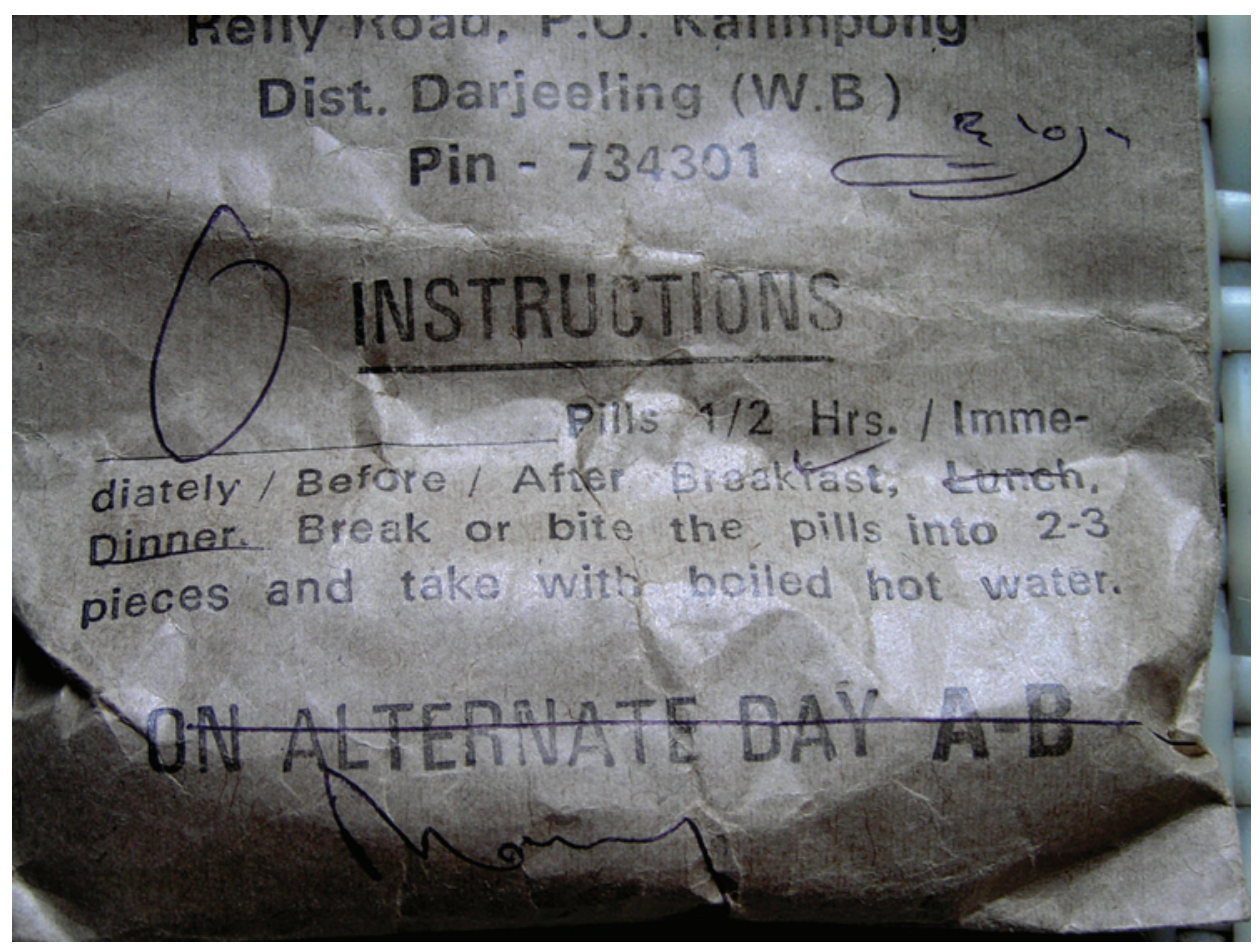

Plate 4.1. The pre-printed MTK brown paper bag used to distribute Tibetan pills at the MTK clinic, Kalimpong 2005.

of misfortune will be discussed in more detail in chapter 6.3. Here, I just wish to point out that periodicity and seasonality in Tibetan medicine are predominantly linked to astrological time markers, the five elements, and the three nyes pa.

The question of how far this (many-centuries-old) theoretical knowledge of these intrinsic temporalities, which forms part of the five-year medical course at Tibetan medical institutions in India, is actually applied in clinical practice today is certainly interesting.

During my fieldwork, I observed how the prescribed timings of medications are structured in a way that is more simplified than those mentioned in the Rgyud bzhi. Tibetan pills are given out in pre-printed MTK brown paper bags (see plate 4.1). They are labelled as ' $1 / 2$ hour/immediately, before/after, breakfast, lunch, dinner,' and options are crossed out as required. These account for the usual 'three times a day' medication. If four different medications are given, a ' 3 p.m.' label is added to one of the paper bags. 
The Rgyud bzhi (II, 27: 176) mentions ten different times at which medication can be taken:

(1) On empty stomach, (2) just before a meal, (3) half way through a meal, (4) just after a meal, (5) (between) mouthfuls of food, (6) in meal intervals, (7) in small doses at no (specific) time, (8) mixed with food, (9) immediately after a meal (lit. 'covered with food'), and (10) at night. ${ }^{18}$

The text even warns that,

Administering [medicines] at a time not related to the illness and when everything has been digested is a foolish system, and it will be difficult to strike at the core of the illness. ${ }^{19}$

In practice, amchis seem to be mainly concerned with administering medicines at the times of the nyes pa. If the illness relates to a single nyes pa disorder, for example, $m k$ hris $p a$, and all three or four medications given are specific $m k$ hris pa medicines, they are distributed across the day in the MTK-prescribed forms. If a combined nyes pa disorder is diagnosed, for example, mkhris $p a$ and rlung, the mkhris pa medicine is given at lunch time - the peak time for mkhris $p a$ - and the rlung medicine either at 3 p.m. or in the evening - around the peak time for rlung. Bad kan medicine is preferably given in the morning or evening. I have not seen any amchi following the detailed times for administering medicines as described in the Rgyud bzhi. The answers I received when asking amchis about the importance of time when it comes to the intake of medicine relate to the nyes $p a$ and their peak times. The digestive heat is also of concern. Amchi Kartsokyi at the Kalimpong MTK clinic explained in 2007:

When I treat a mkhris $p a$ disease, I give the main medication at lunch time, when mkhris $p a$ is highest. The morning is best for giving pho ba sman (lit. 'stomach medicine'), to stimulate the digestive heat and to reduce bad kan. In the evening rlung increases, so I give rlung medicine.

Amchi Jamyang followed the same scheme, but he especially stressed the importance of the morning medication:

In the morning the digestive heat in the stomach is very powerful and the digestive channels are not disturbed and blocked by mucus from food. The stomach channel is clear and open during that time, so the medicines will

\footnotetext{
${ }^{18}$ zas ma zos dang zas sngon dbus dang mthar/zas kham zas mtshams dus med tse gur dang/zas bcas zas mnan mtshan mo btang ba'o/ (Rgyud bzhi II, 27: 176).

${ }^{19}$ nad dang mi sbyor kun la zhu dus gtong/rmongs pa'i lugs te nad thog 'bab pa dka'l (Rgyud bzhi II, 27: 176).
} 
reach to all the channels of the digestive system and then to the entire body and treat the disease. Patients have their best health in the morning, when they can better absorb the medicines. Therefore, the morning is the best time to give bad kan medicines.

I now turn to ethnographic examples that show practices of temporalisation in the context of the life-forces. My argument presupposes what I have outlined above, i.e. that Tibetan medicine arranges medical knowledge around cosmologies that attribute quality to time, by involving the five elements and three nyes pa in relation to seasonal rhythms, times of day, month, and year, etc. I now move on to the central question of this chapter, which is how such temporal frameworks are medically organised. How do amchis clinically relate to the life-forces that are embedded in these temporal frameworks? I suggest that the ways in which amchis engage with and utilise these temporal frameworks that link life-forces to various physiological rhythms in the body can be considered practices of temporalisation. Within these practices, amchis have agency to selectively chose, manage, and negotiate such temporalities and their link to vital forces. In effect, these vital forces become more temporal and thus more accessible to medical diagnosis and treatment.

The following section shows how certain 'vitality tables' that indicate the favourable days for bla and srog set therapeutic events in time, add auspiciousness to clinical practice, and influence notions of efficacy. Chapter 5 then takes the example of the vital essence bla and analyses its temporal movement through the body following the moon cycle and its link to the pulse-beat as a temporal framework to reckon the life-span through the pulse.

4. Appropriating the Auspicious: The Best 'Life-force Days' and 'Life-essence Days'

In Kalimpong, the MTK annual almanac is sold out shortly after the Tibetan New Year (lo gsar). Most Tibetans have a copy at home and can read it and know how to find auspicious and inauspicious days. To determine the quality of the life-forces bla and srog, there is a particular table that monks, astrologers, amchis, as well as Tibetan lay people use. I have seen variations of these 'vitality tables' in many MTK clinics, each containing the same information and used by amchis to look up the auspicious day for certain treatments or the intake of precious pills (rin chen ril bu). They detect the best time for treatment by choosing what they 
call the 'nectar-hour' (bdud rtsi thun mtshams), which is an 'auspicious conjunction of time' (THL 2009). Nectar-hours are important time-markers to set the time for any special treatment, such as bloodletting and moxibustion, collectively called gtar bsreg, ${ }^{20}$ or the golden needle therapy (gser khab). ${ }^{21}$ Monks in the monasteries use this particular table to set the date for longevity and other rituals (see chapter 8.1).

This material is not strictly speaking part of the Tibetan calendar. It is part of "a large amount of symbolic information that is overlaid on the structure formed by the calendar" (Henning 2007: 141). It is nevertheless included in the almanac and used by many Tibetans in all kinds of circumstances. One particular 'vitality table' (see table 4.2) determines favourable days for people according to their year sign. There are three options: (1) the 'life-essence day' (bla gza'), (2) the 'life-force day' (srog $g z a^{\prime}$ ), and (3) the days of 'inauspicious planetary configuration' (gshed $\left.g z a^{\prime}\right)$. The favourable days are determined according to the twelve year signs and their relationship to the days of the week. For example, a person born in the year of the pig has his/her strongest srog on a Tuesday and his/her best bla on a Wednesday. Saturdays are considered inauspicious for people born in a pig year.

Long-life rituals are generally conducted on srog gza' days when srog is the strongest; bla rituals are held on bla gza' days when bla is the strongest. Nevertheless, a clear demarcation between bla and srog is not possible since the rituals usually involve the strengthening of both, bla and srog. In medical practice, since many Tibetans know their specific bla gza' and $\operatorname{srog} g z a^{\prime}$ days, they themselves request amchis to conduct special treatment accordingly. Tibetans also consider these days when setting a date for surgery (other than during emergencies).

Amchi Jamyang, who had a particular interest in astrology, used a 'vitality table' from his almanac, containing the same information as in table 4.2 in combination with other astrological parameters. He made a clear distinction between which of this information was medically relevant and which lay outside his discipline and belonged to astrology:

${ }^{20}$ I have not seen bloodletting practised by MTK or Chagpori amchis in India. During a moxibustion treatment dried plant material of Artemesia vulgaris is burnt just above the skin on specific points.

${ }^{21}$ During this treatment a golden needle is placed on the top of the cranium and dried plant material of Artemesia vulgaris is burnt on the top of this needle. The warmth is channelled through the needle into the central channel and is said to strengthen memory and cure rlung disorders. 
Table 4.2. 'Vitality table,' translated and modified from a page of a Tibetan calendar at the Sakya Guru Gompa in Ghum, October 2004. The table was also used by amchis and indicates the best 'life-essence' days, 'life-force' days, and 'inauspicious' days depending on one's year sign.

\begin{tabular}{|c|c|c|c|}
\hline $\begin{array}{l}\text { Twelve } \\
\text { Year Signs } \\
\text { lo rtags bcu gnyis }\end{array}$ & $\begin{array}{l}\text { Life-essence Days } \\
\text { bla gza' }\end{array}$ & $\begin{array}{l}\text { Life-force } \\
\text { Days } \\
\operatorname{srog} g z a^{\prime}\end{array}$ & $\begin{array}{l}\text { Inauspicious Days } \\
\text { gshed gza' }\end{array}$ \\
\hline $\begin{array}{l}\text { Pig phag } \\
\text { Mouse byi ba }\end{array}$ & Wednesday & Tuesday & Saturday \\
\hline $\begin{array}{l}\text { Ox } \\
\text { glang }\end{array}$ & Saturday & Wednesday & Thursday \\
\hline $\begin{array}{l}\text { Tiger stag } \\
\text { Hare yos }\end{array}$ & Thursday & Saturday & Friday \\
\hline Dragon 'brug & Sunday & Wednesday & Thursday \\
\hline $\begin{array}{l}\text { Snake } s b r u l \\
\text { Horse } r t a\end{array}$ & Tuesday & Friday & Wednesday \\
\hline Sheep lug & Friday & Monday & Thursday \\
\hline $\begin{array}{l}\text { Monkey sprel } \\
\text { Bird bya }\end{array}$ & Friday & Thursday & Tuesday \\
\hline Dog khyi & Monday & Wednesday & Thursday \\
\hline
\end{tabular}

From this table I only check the $\operatorname{srog} g z a^{\prime}$, bla gza', and gshed gza' to find the good and bad days for medical treatment. The other information is only used by astrologers. For me srog $g z a^{\prime}$ and bla $g z a^{\prime}$ are almost the same. They are both good days for treatment. If you go to a monastery or start a journey it is different. You do the rituals on a srog $g z a$ ' day, and you start important work on a bla gza' day. Anything you do on a bla gza' day will work out well. On the obstacle days you should avoid new projects.

I did not have the opportunity to discuss this particular table with an astrologer, but want to point out that the astrological information given in almanacs is selectively used by different experts. For Amchi Jamyang's medical practice the almanac was of importance because it indicated good and bad days for special treatments. He also used two other parameters: the five elements that rule each day, as well as the special 'nectar-hours' of the day. Amchi Jamyang very selectively combined all three of these timemarkers to find the best time for medical treatment, which the following ethnographic encounter illustrates.

One morning in October 2004, about six months into fieldwork, I went with a twenty-four-year-old German woman to the MTK amchi in Kalimpong for a medical check-up. I acted as guide and interpreter. At the time, two amchis 
were working at the MTK clinic: a nun, whom we generally called Anila, and a monk, Amchi Jamyang. I had been meeting them regularly over several months now and they were used to me bringing foreign patients once in a while. Since Anila was busy with a patient, we saw Amchi Jamyang. The German patient complained of a decade of menstrual disorders with severe blood flow, which back home could only be treated by stopping her menses altogether through special hormone medication. She also complained of a vaginal fungus.

The amchi took her pulses and explained that she had a strong disturbance in the life-wind (srog rlung). Her kidney pulses revealed a cold disorder and an excess of bad kan. The vaginal fungus was interpreted at as a chu ser ${ }^{22}$ disorder. A treatment was recommended that aimed at drying up the chu ser through medication (at lunch time), warming the kidney and digestive heat through medication (in the morning), and reducing the srog rlung through medication (in the evening). He explained that the kidneys are linked to the power in the body (lus stobs). Weak kidneys would result in a weak digestive heat (me drod) and frail bodily constituents (lus zungs bdun), as well as reduced sexual power (ro tsa).

Two moxibustion treatments were scheduled for the coming two weeks, each on a Tuesday, which was the patient's srog gza' day. Since the patient had a chronic srog rlung imbalance, which was considered severe, the time to conduct the moxibustion was carefully chosen. First, Amchi Jamyang checked the year sign of her birth year in his almanac. She was born in the year of the pig (1983). Then he looked up the almanac and the 'vitality table' on his wall and said, "Today is 'earth fire' (sa me), which is unfavourable for moxibustion. Monday would be good, but not for pigs. Tuesday at 11 a.m. is the best time for a moxibustion, because Tuesdays is the srog $g z a^{\prime}$ for pigs, and 11 a.m. is marked as the 'nectar-hour' in the almanac." He concluded the discussions by mentioning that, "In cases of a weak rlung disorder we could do it any day, but since her srog rlung is severe, I have to check the date, not to make things worse."

The moxibustion was carried out accordingly by Anila, who was considered the most suitable therapist, since she was a woman and as a nun also well versed in reciting the mantras and prayers during the moxibustion. Amchi Jamyang continued to supervise the medication given over a period of three months, after which the patient subjectively felt considerably better.

I am aware that the above encounter would probably have been different with a local patient and in the absence of an anthropologist. Tibetans

${ }^{22}$ Chu ser (lit. 'yellow water') is generally translated as 'serum' or 'lymph,' but is based on a different physiology. In the process of distilling the lus zungs bdun (see chapter 5.4), chu ser is the waste product of 'blood,' which is refined in the gall bladder and eventually channelled throughout the body. It is red and light yellowish in colour and is primarily linked to skin and joints (MTK 2008: 18-19). 
certainly ask fewer questions, but they do have a keen sense of the auspiciousness of time and often know their favourable bla and srog days and insist on special treatments being conducted on those days. Not only Tibetans, but also Tamangs and Sherpas who visit the Tibetan amchi, generally know their best bla gza' and srog gza' days.

This ethnographic encounter shows that the amchis regards certain aspects of the calendar as more important than others. Amchi Jamyang only used those time-markers that were useful for his medical practice. To argue here that Tibetans have a different sense of time from what we have, would be oversimplistic and fall back into temporal dichotomies discussed in chapter 1.6. Using the idea of temporalisation in the above example makes sense since it does not single out one viewpoint on the 'quality' of time in the almanac, but provides a wider ethnographic gaze and takes into account the way the 'therapeutic event' is situated in time. This includes the overlapping and selective use of the different knowledge systems and stresses the agency of the amchi. His effort to avoid making 'things worse' implies that there could potentially be a 'wrong' time for the moxibustion that could inflate the srog rlung problem to an extent that would make treatment even more difficult. Thus, the time-markers not only provided Amchi Jamyang with the best time for treatment, but also influenced his idea of efficacy. It was not merely the medical skill involved in the treatment that made it work; the way the event was situated in time supported the treatment to work well. 'Inauspicious days' would make 'things worse.' This points to the popular notion among Tibetans that things can always go wrong and therefore need to be done at the 'best time' (dus yag shos). The patient will also feel more comfortable, knowing he/she is treated at the 'best time,' something that adds to individual perceptions of efficacy.

The selective use of the almanac shows the interconnection between medicine and astrology. A recent Tibetan astrological commentary on the almanac mentions specifically that, "if making medicines and conducting medical treatments, etc., are made to coincide with these moments [referring to 'nectar-hours'] it is said to be very beneficial"23 (Tsewang Lhamo 1997: 56).

On the above-mentioned occasion, the amchi did not check the bla table, which shows the movement of the subtle life-essence through

\footnotetext{
${ }^{23}[. .$.$] sman sbyor nad bcos sogs kyi rigs la dus tshod 'di dang 'khel na shin tu bzang bar$ bshad/.
} 
the body, because, as he explained to me later, the moxibustion was not carried out near one of the thirty places of the bla, called the bla gnas. How the movement of bla matters to amchis and how its movement through the body exemplifies a practice of temporalisation is discussed in chapter 5 .

What I wanted to point out in this chapter is that 'vitality tables' and astrological time markers are selectively used in Tibetan clinics to improve the efficacy of drugs and other treatment schemes through timing therapeutic events around favourable nyes pa times, bla and srog days, and 'nectar-hours.' I showed that the almanacs combine a number of different types of information, some more astrological in nature, some more symbolic. The 'vitality tables' belong to the symbolic information that nevertheless is mapped onto calendar structures using the same cosmological framework. In this case, medical professionals draw from them selectively depending on what suits them for their purposes, which might be ritualistic, therapeutic, or both. This process of selectively choosing from an existing multi-layered temporal system shows that the situational agency is stronger than the time-reckoning system, something I showed in chapter 1.6 giving Mills' example from Ladakh.

My ethnographic example links up with Mills' point concerning the way people actually use existing temporal systems (e.g. calendars, 'vitality tables') and "thereby integrate themselves into wider ideologically structured communities" (Mills 2005: 350). I view the selective use of calendars by amchis and monks as a certain practice of temporalisation through which they connect in an engaging way with the wider calendrical and astrological ideologies that guide Tibetan communities at large. Their selective or even simplified use of rather complicated knowledge systems does not question the systems as such, but creates niches in which certain aspects make practical sense and support them in their therapeutic and ritual endeavours.

In the following chapter, I introduce two other temporal aspects of Tibetan medicine that are linked to longevity: the movement of the subtle life-essence bla through the body and the diagnostic method of detecting the life-span in the pulse beat. 


\section{DETECTING THE LIFE-FORCES IN THE BODY AND THE LIFE-SPAN IN THE PULSE}

\section{Bla and Its Places in the Body in Tibetan Medical Texts and Clinical Practice}

Bla beliefs and practices are complex and ambiguous, and to date have not been researched well enough to provide a clear overview. There is no single Tibetan idea of bla, but rather a conflation of concepts sharing the same name. Historical origins are multiple and difficult to assess. This section traces some of the possible origins of the Tibetan medical understanding of bla and, particularly, of the places where bla moves through the body, known as bla gnas. I combine a textual analysis with ethnographic research on the contemporary clinical practice surrounding these ideas and show how, in medical texts, bla has been linked to the temporal rhythm of the moon cycle in the body, and how, in clinical practice, this temporal framework is used by amchis to avoid harming the bla.

Anthropological studies on bla among different ethnic groups in the Himalayas have emerged since the 1980s (for example, Desjarlais 1991, 1992, 1996; Diemberger 1993; Holmberg 1984, 1989; Mumford 1989; Sagant 1996; Steinmann 2001). Textual materials on Tibetan bla rituals are scarce (Bawden 1962; Karmay 1998; Lessing 1951; Norbu N. 1995). This means that we are still dealing with a fairly unexplored topic and that my conclusions remain preliminary, but nevertheless suggest topics for further research. My discussions leave aside pan-Himalayan ideas of bla. ${ }^{1}$

Bla gnas appear in classical Tibetan medical texts, some astrological texts (for example, Dorji, no date; Dorje 2002), and in some Tibetan works on hippology (Maurer 2001). ${ }^{2}$ Dorje in his work on Sangye Gyatso's

\footnotetext{
${ }^{1}$ I have discussed pan-Himalayan ideas of bla previously (Gerke 2007).

${ }^{2}$ Maurer translated excerpts of a manuscript belonging to Jigme Senge Palbar, a king of Mustang. The last chapter on diseases in horses describes the bla gnas in horses. The bla movement follows the moon cycle, starting on the right hoof in females and at the left hoof in males. Similar to the Rgyud bzhi, the text indicates that on such days where the bla resides in one of the bla gnas, cauterisation and bloodletting should not be performed (Maurer 2001: 39-40).
} 
astrology text, the Baidūrya dkar po, distinguishes between an inner and outer meaning of bla gnas. Internally, bla gnas refer to "seminal points (thig le) or subtle generative fluids within the body that support or sustain the life-essence $[b l a] . . . "$ (Dorje 2002: 416). Externally, Dorje links bla gnas to "a sacred object, a semi-divine animal or a sacred power place imbued with the ability to protect a given individual..." (Dorje 2002: 416). Locations of an external place for bla, such as trees, lakes, or mountains, are found in Tibet and among many Tibetanised communities across the Himalayas (for example, Diemberger 1993: 113-114; Huber 1999: 79-80; Mills 2003a: 161).

These examples point to the ambiguous existence and polysemous nature of bla and bla gnas in many different cultural contexts. My main focus in this section is on the Tibetan medical understanding of bla and bla gnas, how the moon cycle provides a temporal framework for the movement of bla, and how amchis actively engage with this temporal framework in clinical practice.

In Sangye Gyatso's seventeenth century medical commentary, the Baidūrya sngon po, bla gnas correspond to thirty places in the body. These are mostly joints, such as toe and finger joints, wrists, elbows, shoulders, knees, etc., but also other body parts (for example, the throat, the big fontanel, the heart, etc.). As long as bla remains in the body, it is bound to a specific movement in connection to these thirty places. This movement follows the moon cycle and differs in men and women (Parfionovitch, Dorje, and Meyer 1992: 39-40; see appendix 3).

The notion of life-forces moving through the body is not an idea specific to seventeenth century Tibet. There might be some similarities between bla and the 'spirit' shen in ancient China, which inhabits specific landscapes as well as the area of the heart in the body (Hsu 2007: 120). Moreover, Chinese texts from Dunhuang describe a movement of a 'human spirit,' renshen, which flows through the body in a very similar way as bla (Yoeli-Tlalim 2008: 231). Although the idea of renshen moving through the body following the moon cycle is similar to bla, the places of renshen do not correspond with the bla gnas mentioned in the Baidürya sngon po, apart from day one (the large toe). ${ }^{3}$

There must have been regional variations, since there are several bla tables in circulation with different bla gnas. For example, the bla gnas

${ }^{3}$ On the movement on renshen see Arrault 2010: 292-299, 306-309, 312-332; Lo 2001: 82-83; 2005: 239; 2010: 256, 258-260. 
in the Baidūrya sngon po differ from the bla gnas mentioned by the contemporary Dzogchen teacher Chögyal Namkhai Norbu Rinpoche (Cornu 1997: 101). The MTK bla table presents three different versions of monthly rotation schemes in humans and cattle (see appendix 4), and a contemporary calendar by the Dzogchen community mentions three traditions of bla movements - zur mkhar, dar mo, and mi pham. ${ }^{4}$ Further translations of the Dunhuang manuscripts may reveal closer similarities between bla and renshen, since some manuscripts on renshen show both Chinese and Tibetan inscriptions (Kalinowski 2003: 149).

Interestingly, in the seventeenth century Tibetan medical paintings, the bla gnas were sketched on the same anatomical chart that shows the three main channels and the five chakras, which are of Indian tantric origin (Parfionovitch, Dorje, and Meyer 1992: 40; see appendix 3). The painting shows that during the waxing fortnight (1st to $15^{\text {th }}$ day of the Tibetan month) bla travels through the left side of the body in men and the right side in women. During the waning fortnight (15th to 30 th day of the Tibetan month), bla travels through the right side of the body in men and the left side in women. The reason given in the Baidūrya sngon po for the female cycle moving from right to left, and the male from left to right is that masculinity is represented by the left, white channel (rkyang ma), and femininity by the right, red channel (ro ma; Parfionovitch, Dorje, and Meyer 1992: 39). The seats of bla during full moon (the crown of the head) and new moon (the sole of the feet) are the same for men and women.

The bla gnas within the body give a location and a calculable rhythm to the ambiguous notion of bla by linking it to common ideas of the daily movements of the moon through which it can be calculated and consequently also protected. The movement of bla can thus be 'known'; for example, on the third day of the Tibetan month the bla resides in the third joint of the big toe, on the left side in men and the right side in women.

Each of the bla gnas also has a syllable attached to it (Parfionovitch, Dorje, and Meyer 1992: 39-40). None of these have any medical significance in contemporary Tibetan medicine whatsoever, and amchis could not tell me why and how bla is linked to these specific syllables and bla gnas. Kālacakra expert Edward Henning pointed out that these syllables are a form of Hindu numerology and categorise time, the short syllables

${ }^{4}$ Geoffrey Samuel, personal communication, April 2011. Zur mkhar here probably refers to the medical tradition of Zurkhar Lodrö Gyalpo (1509-1579), dar mo to Dharmo Mänrampa Lobsang Chödrak (b. 1638), and mi pham to Jamgön Mipham Gyatso (1846-1912). 
referring to days in the calendar that fall into the waxing fortnight and the long syllables relating to the waning fortnight. In the Kälacakratantra, these syllables are also associated with physical characteristics and provide correspondences between the inner and outer world. ${ }^{5}$

Amchis need to know about the bla gnas in order to locate the exact place of bla in the body in an attempt to avoid its injury. Any invasive medical treatment in the location of a bla gnas on the day when bla resides there, as well as the day before and after, could lead to a loss of bla. Invasive therapies should also be avoided on new or full moon days, when the bla is said to pervade the entire body for a short period of time.

When did bla and bla gnas become prominent in Tibetan medical texts? In a preliminary attempt to trace their medical history, I look at their appearance in the Rgyud bzhi and in two medical commentaries.

In the Rgyud bzhi, bla is only mentioned in the context of the three life channels (Rgyud bzhi II, 4: 68) and as a part of the life-essence pulse, bla rtsa (Rgyud bzhi IV, 1, section 13). In the 'anatomy' chapter of the Rgyud $b z h i$, the term bla is brought up only once. The respective quote in the poetic root text of the Rgyud bzhi is brief, and so is Sangye Gyatso's seventeenth century commentary of that passage:

Root text of the Rgyud bzhi: gcig ni bla dang 'dra ste 'khyam pa yin/ (Rgyud bzhi II, 4: 68)

Commentary to the Rgyud bzhi: gcig ni bla 'khyams pa zhes 'jig rten na grags pa de dang 'dra ste/ (Sangye Gyatso 1982: 108-109; see also Zurkhar Lodrö Gyalpo 1991: 173)
One [i.e. the third life channel] ${ }^{6}$ is like the life-essence (bla) and irregularly wanders around.

One of these [life channels] is like the so-called wandering bla, which is widely known.

Bla in both the root text and the commentaries is mentioned in the form of a simile (de dang 'dra ste, 'it is like that [bla]'), not as an integral part of the life channels and their function. This implies that a known medical concept, the life channel, is compared to a known phenomenon outside of medicine, bla. The adjective that is used to describe bla is the word 'wandering' ('khyams pa). The little information we get on bla suggests

\footnotetext{
${ }^{5}$ Edward Henning, personal communication, December 2007; see also Wallace 2009 a.

${ }^{6}$ For details on the three life channels see Garrett and Adams 2008 and Gerke, forthcoming. Millard mentions that the third life channel relates directly to certain forms of illness and the use of ritual in healing (Millard 2002: 153, and chapter 8).
} 
that bla did not really have a place in medicine, but was part of popular knowledge. It was 'widely known' and 'wanders around.'

The notion of 'wandering around' is found among the nomads of Tibet, the 'brog pa and 'khyams pa. 'Brog pa are pastoralists and have fixed seasonal abodes across large areas, which they journey to; 'khyams pa are vagrants and wander around without any fixed seasonal abode. The bla is like the 'khyams pa, vagrant - it wanders around.

There are several types of 'khyams pa across the Nepal Himalaya that provide an interesting analogy here. Rauber describes the Humli Khyampa in western Nepal as nomadic traders who base their subsistence on an annual round of salt and rice trade between Tibet and the lowlands of southern Nepal and the Ganges plain. "They move in a yearly fixed cycle [...] using about thirty camp-sites one way" (Rauber 1980: 61). Jest mentions the rgya 'khyam pa, who are very mobile trading families, wandering from village to village selling foreign goods bought in India (Jest 1975: 255, quoted in Rauber 1980: 74). 'Khyams pa are usually ethnic Tibetan immigrants and, when settled, belong to the lower strata of the society they attach themselves to (Rauber 1980: $75^{-76}$ ). The notion of 'khyams $p a$ seems to involve some sort of mobile temporalisation, either cyclical along an annual route, or errantly from place to place. It bears some similarity to the principle of the bla wandering along the route of the bla gnas, following the moon cycle, but also - when lost - straying like a vagrant.

The bla gnas are only mentioned once in the Rgyud bzhi in the context of bloodletting. "Do not perform bloodletting in the places of lumps, meeting points of channels, ${ }^{7}$ and bla gnas!" ${ }^{8}$ As Yoeli-Tlalim points out, a Tibetan text on moxibustion from Dunhuang (Pelliot tib. 1044) mentions in the colophon: "one needs to calculate the time, determine where the brla $a^{9}$ is residing [at that time] and not apply [moxibustion] there" (YoeliTlalim 2008: 231). This bears a resemblance to some Chinese 'prohibition literature' (texts which prohibit acupuncture and moxibustion on certain days). In the Tibetan medical texts I consulted I did not come across any mention of a Chinese origin for bla or bla gnas, although more textual research is necessary to confirm this point.

\footnotetext{
7 Depending on the context, rtsa mdud can indicate blockages in subtle channels but also a junction of channels, i.e. a cakra.

${ }^{8}$ dog dang rtsa mdud bla gnas sar mi gtar/ (Rgyud bzhi IV, 20: 331).

9 The term brla here is a variation of the classical Tibetan term bla (Yoeli-Tlalim 2008: 231).
} 
A Chinese influence seems, however, quite likely, since the Chinese notions of shen and renshen mentioned above show close resemblances to bla. The idea of spirits residing in organs is found in various Chinese traditions across many centuries (Lo 2001: 84). For example, Lo mentions that shen resides in nine distinct sectors of the body every twelve years, where any inappropriate cautery might prove fatal (Lo 2001: 82-83).

Chinese Han dynasty texts speak of the movement of the life-force $q i^{10}$ around the body. This circulation of $q i$ is "an embodiment of celestial movement" and an attempt to correlate "the sky with human society made flesh and blood" (Lo 2001: 62). The places where qi lodges - usually the acupuncture tracts - are prohibited for cautery and piercing on that day. Injury of these points on the day when qi resides there "will result in symptoms of varying degrees of ferocity" (Lo 2001: 62). This is similar to Tibetan amchis avoiding invasive treatment on or near the bla gnas on days when the bla resides there.

Lo points out that it is specific to the 'prohibition literature,' "to envisage the human shen or the $q i$ as a smaller, more self-contained, discrete entity taking up residence around the body rather slowly, day by day" (Lo 2001: 88). Lo interprets the existence of the popular prohibition texts in the historical context of the time. She writes:

Since we know ... that the prohibition texts were part of a written tradition used in far-flung places with no formal medical provisions, they may represent a formalised response to the shared perception of acupuncture and moxibustion as a widespread, undocumented, potentially unorthodox practice that existed beyond the range of literate healers and the penetration of state patronized medical literature and training (Lo 2001: 86).

Shen has had numerous meanings in a variety of contexts and across time, which makes it difficult to draw parallels to bla, which is equally ambiguous. Hsu shows that shen has various meanings that differ in institutional and private clinical contexts. She argues that "the meaning of the technical terms that evolved in those scholarly medical traditions ${ }^{11}$

10 $Q i$ is defined as "breath or 'basic stuff' that makes things happen" and "in which things happen" (Sivin 1987: 46-47, quoted in Hsu 1999: 19). Shen and $q i$ are two of the lifeforces mentioned in Chinese texts.

${ }^{11}$ Here, with 'scholarly medical traditions' Hsu refers to Bates 1995. The main Asian medical traditions, including Tibetan medicine, can be considered 'scholarly medical traditions,' since they all constitute a literate tradition of medical theory and practice, are mostly taught in institutions, and evolved in highly stratified societies. It is a characteristic 
is notoriously polysemous and dependent on the context in which they occur" (Hsu 2000a: 219; see also Hsu 1999: 116).

The same applies to Tibetan concepts, such as bla and bla gnas, which have had popular and professional interpretations. In the following, I want to look in more detail at the mention of bla gnas and at illustrations of bla in medical texts.

By the sixteenth century, the Tibetan physician Zurkhar Lodrö Gyalpo (1509-1579) discusses the bla gnas in the 'anatomy' chapter of his Mes po' $i$ zhal lung, a commentary on the Rgyud bzhi compiled between 1560 and 1570 (Zurkhar Lodrö Gyalpo 1991: 167-173). About one hundred and twenty years later, Sangye Gyatso does the same in his commentary Baidūrya sngon po (Sangye Gyatso 1982: 107; Parfionovitch, Dorje, and Meyer 1992: $39-40)$. His section is copied verbatim from the Mes po' $i$ zhal lung. ${ }^{12}$ In both works, the section on bla gnas begins with the statement, "The bla gnas in the tradition of medical examination are certainly in conformity with the principal meanings elucidated in the Kälacakratantra." ${ }^{13}$ This is followed by a detailed description of the movement of bla through thirty places, mentioning the day of the months, the place, and the respective syllable of the bla gnas (see appendix 3). The bla table that amchis use today at MTK clinics is only partly based on these commentaries (see appendix 4). Nevertheless, all amchis I met that used this bla table referred to the Kälacakratantra as the origin of bla gnas pointing to the respective section in Sangye Gyatso's Baidūrya sngon po.

The fact that Tibetan authors argue that the bla gnas are in conformity with the Indian Buddhist Kälacakratantra does not necessarily prove their origin. We know that with the introduction of Buddhism to Tibet, the focus on India was intensified in an attempt to stress the authority of Buddhist knowledge (Kapstein 2000: 17-18). This also applied to medicine, where the Buddha himself was seen as the 'supreme physician' and as the primary source of the medical teachings (Meyer 2003: 203).

of scholarly medical traditions that there are different interpretations of medical terms in texts and in practice (Hsu 2000a: 217).

${ }^{12}$ For a detailed assessment of these works it has to be considered that the Mes po' $i$ zhal lung was revised and completed in the seventeenth century by two physicians under the instructions of the fifth Dalai Lama (Meyer 2003: 103). The actual authorship of the section on bla gnas in the Mes po'i zhal lung still has to be ascertained.

${ }^{13}$ sman dpyad lugs kyi bla gnas dang nges par mthun pa ni/ dus kyi 'khor lo ste de'i dgongs don bkrol ba ni/ (Zurkhar Lodrö Gyalpo 1991: 170; Sangye Gyatso 1982: 107). 
A detailed search in the extensive Kālacakra material might reveal Sanskrit equivalents for bla and bla gnas. So far, my initial attempts to find these Sanskrit equivalents have remained unsuccessful. Wallace's translation of the second book of the Kälacakratantra does not mention bla or bla gnas. She mentions syllables that are connected to joints (Wallace 2004: 100), but they do not correspond to the syllables of the bla gnas mentioned in the Mes po'i zhal lung and the Baidūrya ngon po. Linking syllables to ideas of the Indian Buddhist tantric body, she points out that in the Kālacakra tradition the

tantric body is constructed on a specific linguistic model, on the taxonomic order of syllables. This suggests that Indian Buddhists considered linguistic structures of the embodied tantric texts to be important and powerful. Consonants are referred to as the presiding deities of the nādis and the lords (nātha) of the chakras (Wallace 2009a: 184).

Henning's comment above that these syllables categorise time, points to a temporal dimension. Nevertheless, it is still unclear when and why these Indian tantric syllables were linked to Tibetan perceptions of bla. YoeliTlalim concludes, based on the Dunhuang reference on bla mentioned above, that this material "reflects a very early Tibetan adoption of the Chinese notion of the movement of the vital force through the body," which was apparently "later synthesised with the Kälacakra idea of the syllables ascribed to the different parts of the body in each day, so as to form the concepts as described by Zur khar in the fifteenth century and Sangs rgyas rgya mtsho in the seventeenth century" (Yoeli-Tlalim 2008: 231). As will become clear in the course of the following chapters, the popular concepts of bla are different from the medical or astrological bla and cannot simply be conflated into a single concept.

In Sangye Gyatso's medical paintings we find, apart from the bla gnas, iconographies on bla in the chapter on the life-essence pulse (Parfionovitch, Dorje, and Meyer 1992: 139-140). These images portray bla along with tshe as a little human-like figure (see figures 5.1 to 5.4). The Tibetan titles indicate an intricate relationship between bla and tshe. They are used almost synonymously and both terms occur together as bla tshe, which is translated as "the life-essence [which supports] the life-span principle" (Parfionovitch, Dorje, and Meyer 1992: 295). This relationship of 'support' is not explicitly mentioned in the related section of the Baidürya sngon po (Sangye Gyatso 1982: 1204-1205). I prefer to keep both Tibetan terms together as mentioned, since this shows the interrelated but not specified relationship between bla and tshe. 
I now want to look more closely at these images of bla in the medical paintings. In the case of bla being stolen by a demon, bla is depicted in a small upright figure leaving the body of a wild, almost possessed-looking man, clad in an animal skin with loose flowing hair (figure 5.1). Bla might leave the body through the ring finger ${ }^{14}$ of the right hand at night and can be stolen by a demon if srog is weak (Parfionovitch, Dorje, and Meyer 1992: 139). In a healthy person, who is depicted as a well-posed, half-robed man, bla tshe is illustrated as a small human being sitting in meditation posture at the area of the heart (figure 5.2). In the case of an inconstant bla pulse, bla tshe is interpreted as unstable, which is indicated by a small figure appearing without a head (figure 5.3). The loss of bla tshe is illustrated by a figure sitting in mid-air behind the back of the body of a distressed-looking man (figure 5.4). The commentary states that in such a case the life-span will come to an end unless longevity rituals are conducted (Parfionovitch, Dorje, and Meyer 1992: 295).

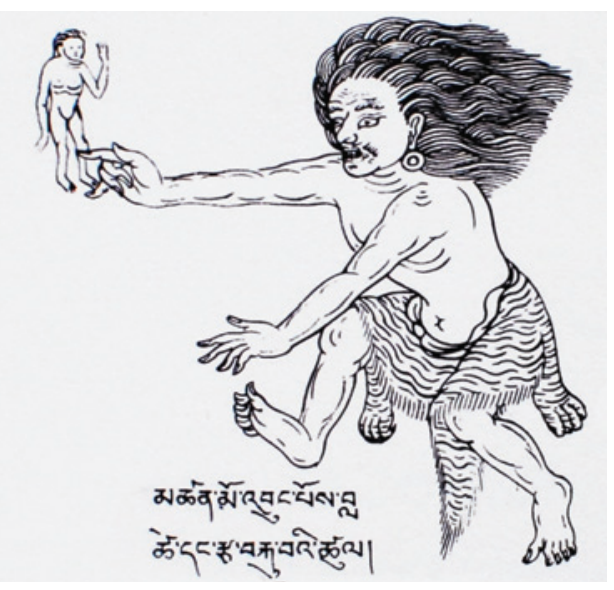

Figure 5.1. This image depicts the loss of bla tshe through a finger when stolen by a demon (Parfionovitch, Dorje, and Meyer 1992: 140).

\footnotetext{
Translation of Tibetan caption: "The theft of bla tshe and its pulse by an elemental demon at night" (mtshan mo 'byung pos bla tshe dang rtsa brku ba'i tshul).
}

${ }^{14}$ This finger is known as the srin $m d z u b$. It is considered the 'pure finger' because it is believed to be kept inside the nostril while in the womb and thus remains pure from the mother's liquids. Spirits enter and leave the body through this finger. It is also used to make offerings (Charles Ramble, personal communication, November 2006). Even though the painting does not clearly depict bla tshe leaving through the ring finger, the commentary mentions it (Parfionovitch, Dorje, and Meyer 1992: 139). 

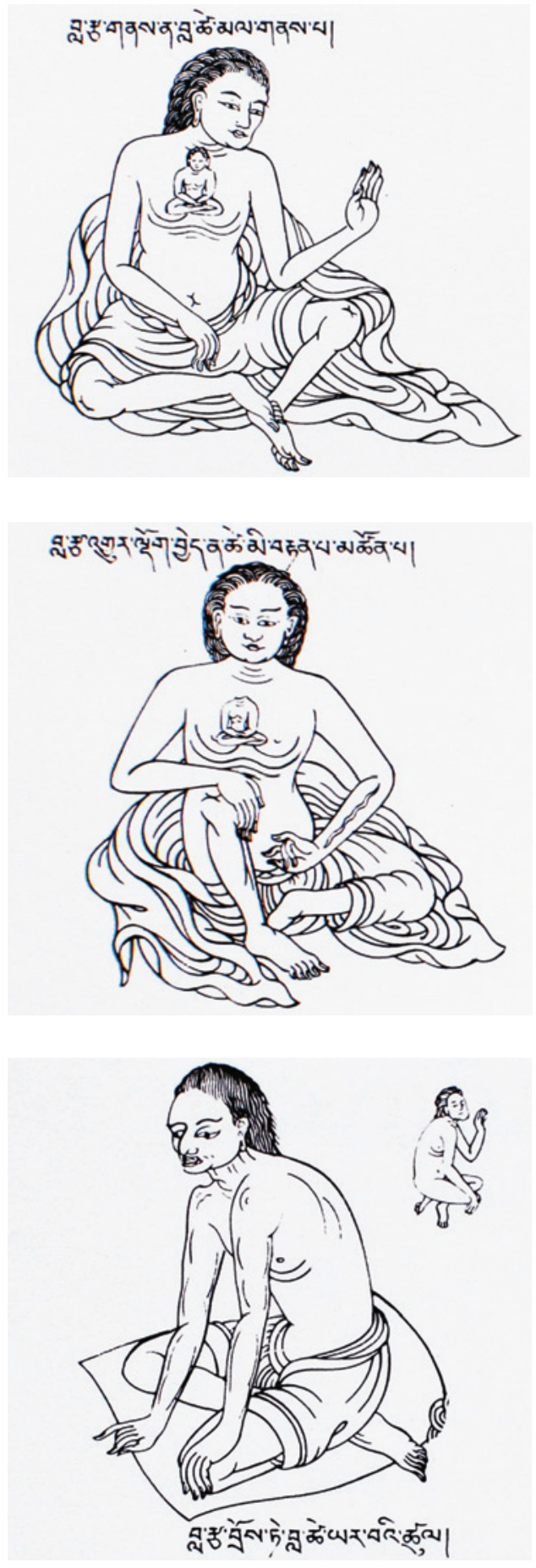

Figure 5.2. This image depicts bla tshe personified by a human being sitting crosslegged in the heart centre of a healthy person (Parfionovitch, Dorje, and Meyer 1992: 140).

Translation of Tibetan caption: "If the bla pulse remains calm, bla tshe abides in its proper place" (bla rtsa gnas na bla tshe mal gnas pa).

Figure 5.3. In the case of an inconstant bla pulse, sketched as a pulse wave at the place of the arteria ulnaris at the left arm of the person, the figure in the heart is shown without its head (Parfionovitch, Dorje, and Meyer 1992: 140).

Translation of Tibetan caption:

"If the bla pulse is inconstant, tshe will be unstable, as illustrated here" (bla rtsa 'gyur ldog byed na tshe mi brtan pa mtshon pa).

Figure 5.4. In the case of the loss of bla tshe the figure is shown behind the person, who seems weak, bending forward and supporting himself with his arms (Parfionovitch, Dorje, and Meyer 1992: 140).

Translation of Tibetan caption: "Consequent to the escape of the bla pulse, bla tshe is lost"

(bla rtsa bros te bla tshe yar ba'i tshul). 
The personification of life-forces, as well as the illustrations of the bla gnas in anatomical charts, also have to be interpreted in the context of the political milieu of the time these paintings were made. I alluded to this already in chapters 1.6 and 3.1, and want to further elucidate this point here in the context of the bla illustrations.

Schaeffer emphasises the political aspects of the interrelationship between medicine and authority in seventeenth century Tibet (Schaeffer 2003). He argues that Sangye Gyatso, who commissioned the medical paintings, used the Baidūrya sngon po to proclaim the political rhetoric of his government. Sangye Gyatso linked ideas of what constituted authority and the 'proper' use of texts with Buddhist ideals, also in the medical discipline. In doing so, "medical books and the areas of expertise associated with them were utilized as symbols in the construction and maintenance of authority" (Schaeffer 2003: 636). Schaeffer concludes that,

the authority of tradition (the medical lineage stemming from Yuthok Yontan Gonpo to Sangye Gyatso himself), the propriety of a privileged mode of learning (textual scholarship) and a privileged body of knowledge (scholarly medicine), and the authority of the government of which Sangye Gyatso was leader were all linked and maintained by a rhetoric that argued for the inseparability of philology and exegesis from altruism, enlightenment, and 'healing' conceived in bodily, soteriological, and political terms. (Schaeffer 2003: 637-638).

According to Schaeffer, Tibetan authors were communicating a workable concept of the human body that was 'designed' to convey Buddhist concepts. This historical process has also been studied by Garrett taking the example of Tibetan embryology texts. Garrett exposes this process, which went on for several centuries, and interprets "the resurgence in interest in theorising about the human body in Tibetan medicine by the fourteenthfifteenth centuries [as] a sign of the 'Buddhification' of Tibetan medicine" (Garrett 2007: 422). Further research could investigate if the medical and popular knowledge of bla and bla gnas underwent a similar 'Buddhist' transformation.

To elucidate the Tibetan clinical context of bla gnas further, I now turn to ethnographic examples which show how amchis today relate to bla and bla gnas.

All MTK clinics I visited in the Darjeeling region had a bla table in the consultation room, usually clipped under the glass protecting the amchi's desk. Amchi Jamyang told me that they received this table from the MTK in Dharamsala. This table presents three different traditions of bla gnas: (1) the tradition of the famous Tibetan astrologer Phugpa Lhundrup 
Gyatso, $^{15}$ (2) the Kālacakra tradition of Sangye Gyatso as laid out in the Baidūrya sgnon po, and (3) the tradition of the bla gnas of horses and cattle. ${ }^{16}$ The English translation of the entire bla table can be found in appendix 4 .

I have seen amchis in the Darjeeling Hills mostly considering the bla gnas in the body. There was no particular mountain or geographical point in the area that was considered a place of bla. The fact that the Darjeeling Hills is a society of immigrants probably plays a role here. The only external manifestations of bla were turquoise stones, known as bla g.yu. Tibetans who had lost their bla in the past often wore a turquoise stone, which is one of the ritual objects used during bla retrieving rituals to protect their bla from being lost again (see chapter 6.4).

Amchi Jamyang considered the movement of bla before conducting any invasive treatment on or near bla gnas, such as the golden needle therapy or moxibustion. When we discussed bla in his consultation room in August 2004, Amchi Jamyang (see plate 5.1) pointed to the bla table on his desk and explained,

Even the day before, and the day after, the particular bla gnas is still affected by the bla. Thus the three bla gnas around the current place of bla should not be touched. If they are injured, bla can be lost through those injuries.

He also showed me a book published by the MTK that warns amchis that they can cut short the life-span and even kill a patient if the places where bla resides are injured (Lobsang Wangyal, no date: 177).

Most amchis I met tended to know only enough about bla not to cause harm to it. They distinguished between (1) harming the bla through conducting treatment in the 'wrong' place and (2) losing the bla altogether, which can be diagnosed through the pulse. The loss of bla, however, was more often diagnosed by a lama than by an amchi. Even if amchis did notice the loss of bla through irregularities in the bla pulse, they would typically send the patient to a lama to confirm the diagnosis through a $m o$ and treat its loss through rituals. Contemporary practices surrounding bla link medical and ritual domains; amchis and lamas collaborate in negotiating its existence inside and outside the body.

\footnotetext{
${ }_{15}$ Phugpa Lhundrup Gyatso is one of the Three Illustrious Gyatsos (rgya mtsho rnam gsum du grags pa), who authored the astrological treatise entitled Pad dkar zhal rlung, which forms the basis of the phug pa calendar tradition (Edward Henning, personal communication, December 2007; see also appendix 4).

${ }^{16}$ It is not specifically mentioned to whom this tradition refers to, but it could also be by Phugpa Lhundrup Gyatso.
} 


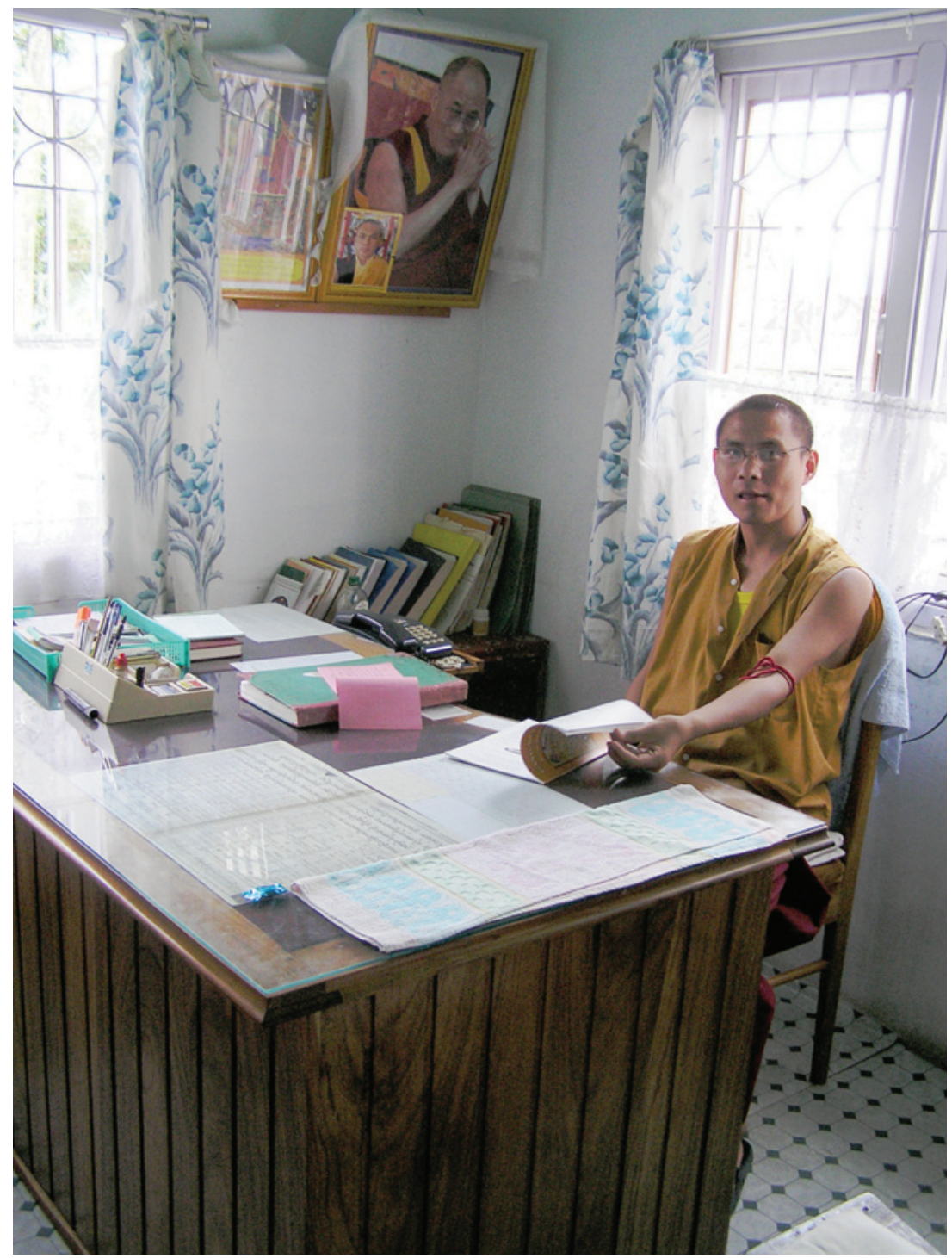

Plate 5.1. Amchi Jamyang Tashi in his consultation room at the MTK branch clinic, Kalimpong 2004. The bla table is visible on his desk. 


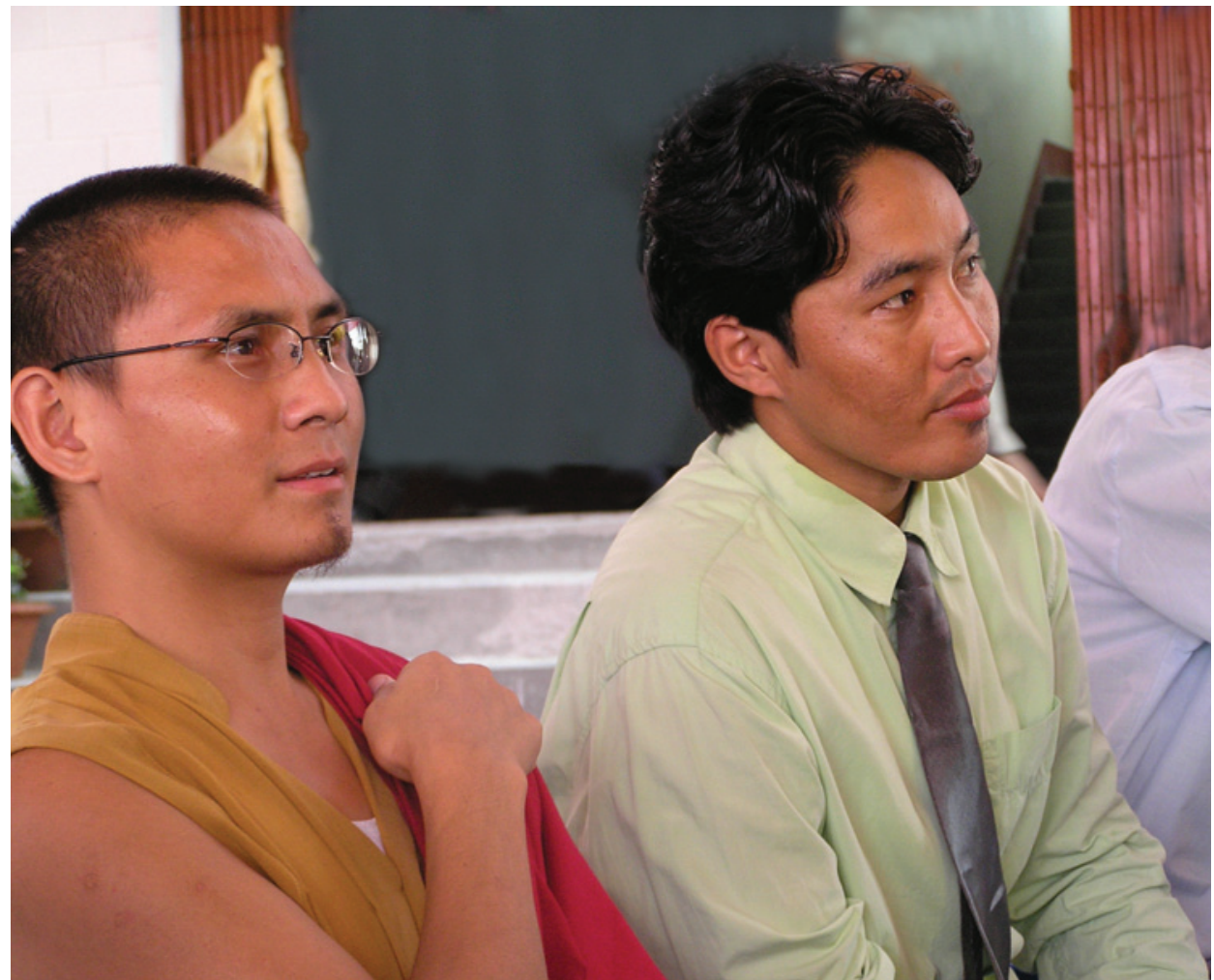

Plate 5.2. Amchi Künga (right) with Amchi Jamyang (left) at the opening ceremony of the new MTK building, Salugara 2004.

Especially to young amchis bla seems a confusing and strange concept. Amchi Künga (see plate 5.2), who was in his late twenties when he worked at the MTK branch clinic in Salugara, alluded to this during an informal discussion in August 2004:

$B l a$ is very complicated because it differs in the medical, astrological, and religious traditions, and we are confused about the different explanations. In medicine we do not study it extensively, just enough to avoid harming it. We have the chart [he refers to the bla table]. We translate it as 'inner energy' or 'soul,' mostly because westerners won't understand it otherwise. We use the translations of previous authors and rely on our senior teachers. Bla is not so important in Tibetan medicine, but it is very important in Tibetan society.

Amchi Künga's last sentence is quite significant. Although bla stands outside the general medical framework of health and illness - presumably 
because it has no direct link to the five elements and the three nyes paamchis respect bla as a popular vital force that could negatively affect the health of the patient if harmed accidentally. Amchis are not involved in treating the loss of bla, and there is no medication that could rebuild the bla if it were to be lost. Bla is something that a person either has or loses. Amchis are thus helpless in this regard, because bla is a life-force that they cannot treat or strengthen through medication. Therapeutically, it lies outside their professional realm.

The bla table makes it easier for amchis to place bla in a medical and temporal framework. They can relate to the moon cycle because it follows the same rhythm than their calendar. The rhythm of the moon provides a common sense of temporality and duration to understand bla. They can relate to the thirty bla gnas because they form a part of their anatomical training.

Their understanding of bla also depends on where they received their medical education. My experience with Amchi Kartsokyi, trained at the Lhasa MTK and working at the MTK clinic in Kalimpong in 2007, was very enlightening in this regard, and showed that these concepts are bound to the ways in which Tibetan medicine is taught and linked to Buddhist ideas.

Amchi Kartsokyi was visibly embarrassed talking about the concepts of bla and bla gnas, which did not form a part of her curriculum back in Lhasa. She framed her answers to my questions in quotes like "they say it is like this." With 'they' she meant the authors of the medical books mentioning the bla gnas. When asked directly, she admitted that she did not really know or believe in the bla gnas and never used the bla table. The bla table Amchi Jamyang had used before her was still under the glass top of her desk in the consultation room. She had placed her sphygmomanometer, which she used in every consultation I witnessed, on top of the bla table (see plate 5.3). She said that the bla table "was left behind by the previous amchi." Then she said apologetically, "bla is connected to chos [dharma], but we did not study chos."

She did, however, pay some attention to the bla gza' days for certain therapies, but only because the Tibetan patients coming to her knew their best bla gza' days and insisted the therapy should be conducted on that particular day. I realised that my fieldwork experience would have been very different with her than with Amchi Jamyang in 2004/05.

A more careful look at the caption of the bla table distributed by the Dharamsala MTK (see appendix 4) also reveals a potential conflict in the ways amchis might deal with bla. It gives an indication that the ritual 


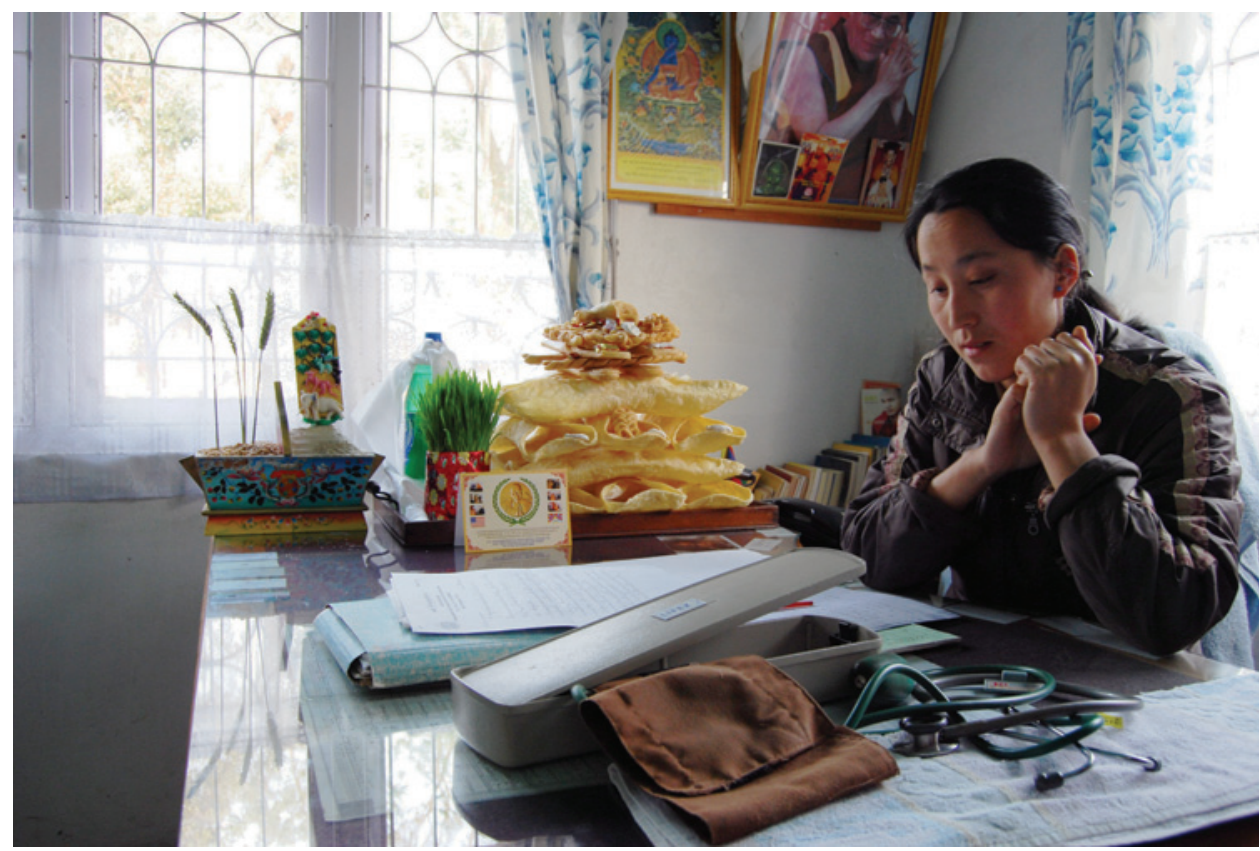

Plate 5.3. Amchi Kartsokyi at the MTK branch clinic, Kalimpong 2007. A folder and her sphygmomanometer are placed on top of the bla table.

aspect of bla is downplayed, but that the potential injury of bla through moxibustion cannot be ignored by amchis. The caption reads:

On the day before new moon [3oth day of the Tibetan lunar month] and the day after new moon [the 1st day of the Tibetan lunar month], [the bla] appears under the foot sole taking the characteristic (lit. 'form') of the letter

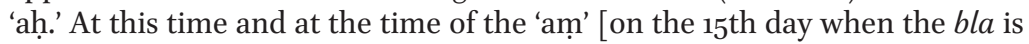
on the crown of the head], the 'consciousness principle' (byang chub sems) $)^{17}$ pervades the entire head and body. This is a very sensitive time. The intelligent person should realise this.

This is also compatible with the science of healing. This [time] is also effective to perform destructive rituals (mngon spyod) such as striking a ritual dagger ( $p$ hur ba), and so forth, into the bla. Do not strike or alter the places of bla in the body of humans and cattle through bloodletting and moxibustion. Even though there may be a limitless number of people who maintain that they can change the position of the bla through ritual objects, mantras,

${ }^{17}$ Here byang chub sems might perhaps be a synonym for bla; it is also a synonym for sperm in tantric practices. 
or circular magic diagrams (rdzas sngags 'khor lo) in order to deceive foolish people (blun rnams), the essential issue is merely for practical purposes. ${ }^{18}$

The demarcation between the 'intelligent person' who realises this and 'foolish people' who still believe that the bla can be influenced through 'ritual objects, mantras, or circular magic diagrams' (which would probably also include bla retrieving rituals), shows that there seems to be an attempt by the MTK to deal with bla only medically and 'for practical purposes.'

Bla is clearly a vital force that has been crossing all boundaries of medicine, divinations, astrology, and ritual for a long time. Among contemporary amchis in India, the gulf between these knowledge systems seems to produce conflicting ideas of how to deal with bla. On a practical level, amchis employ these systems in various ways, not necessarily following the MTK guidelines.

Nevertheless, some concepts surrounding the life-forces are apparently sidelined in some modern Tibetan medical curricula or are even omitted from medical studies. They tend to enter medical practice through the personal interest and beliefs of individual amchis, especially of those with an additional monastic or Buddhist training or through patients who have a popular knowledge of temporalities of life-forces and insist on them being used for their personal treatment.

Amchis create a diverse hybridisation of medical practice, negotiating between 'modern' and 'traditional' ways of diagnosis and treatment. Placing the sphygmomanometer on the bla table is just one expression of how amchis themselves choose to act in this process. Amchi Jamyang's and Amchi Kartsokyi's diverse ways of dealing with the bla presents a glimpse into the variations that can be found in contemporary Tibetan medical practice.

To sum up this section: bla does not hold a prominent status in Tibetan medical texts; in medical practice it is mainly given importance as a lifeessence moving through certain places in the body that could potentially be harmed through invasive therapeutic methods. Contemporary amchis

${ }^{18}$ gnam stong dang ni tshes gcig mtshams/ / rkang pa'i mthil du 'ah' yig gzugs/ /'di dang 'am' gi dus kyi tshe/ byang chub sems gyis mgo lus kun//khyab phyir shin tu gnyan pa ste/ /blo ldan skye bos de rtogs bya/ / gso ba rig pa dang yang mthun/ / de la bla phur brdeg pa sogs/ /mngon spyod las rnams shis yin/ /mi phyugs lus kyi bla gnas sur//gtar sreg la sogs bcos brdeg spang / blun rnams mgo skor bslu ba'i ched/ /rdzas sngags 'khor lo la brten nas/ /bla gnas 'pho bar'dod pa sogs/ /mtha' klas rnam grangs mang yod kyang / dgos don snying po de tsam $\mathrm{mo} / /$ (see appendix 4 for the translation of the complete bla table). 
in the Darjeeling Hills are largely aware of these dangers and apply a bla table distributed by the Dharamsala MTK. Amchis may not know much about the origins of bla, but they have a sense of responsibility not to harm it, since they cannot treat it. The bla tables help them to place and reckon bla within their known calendar system. The interpretation of bla also depends on the education of amchis; the amchi trained at the Lhasa MTK had a different take on bla.

The next section explores in more depth practices of temporalisation surrounding the 'life-essence pulse' (bla rtsa) and its relation to ideas of longevity and the life-span.

\section{Divinatory and Temporal Aspects of Pulse Diagnosis}

In the course of this and the following section I look at one specific form of Tibetan pulse diagnosis that combines both diagnosis and prognosis: the feeling of the life-span through the life-essence pulse, called bla rtsa. In particular, my focus is on how amchis utilise the pulse beat as a temporal framework to map out and reckon the years of the life-span.

Pulse diagnosis is the main diagnostic method in Tibetan medicine. It is extremely complex, and I shall not discuss it here in detail. The first chapter of the fourth treatise of the Rgyud bzhi is devoted to the different types of pulses, which according to most amchis take many years to master in practice. Tibetan pulse diagnosis has so far not been studied in detail by anthropologists. There have been some attempts to analyse Chinese pulse diagnosis, which are promising because they offer new approaches emphasising body techniques, touch, and the anthropology of sensory experience (for example, Hsu 2000a, 2000b, 2005b; Kuriyama 1999). Daniel's work is the only example of an anthropological analysis of South Indian Siddha pulse diagnosis (Daniel 1984).

Literature in European languages on the bla rtsa is principally limited to brief descriptions of medical methods and interpretations of sphygmology, mostly relating to the relevant sections in the Rgyud bzhi (Donden and Hopkins 1986: 104-105; Meyer 1990: 249-251; Parfionovitch, Dorje, and Meyer 1992: 123-139). Yan and Jingfeng offer a comparative study with a focus on the locations in the body where pulses are felt in Tibetan and Chinese medicine. These authors mention that "for estimating one's life span, feel the pulsation of the heart (over the chest)" (Yan and Jingfeng 2007: 331). They do not label this particular pulse reading bla rtsa. I have neither seen nor heard about this method among amchis in India, who 
feel the bla rtsa at the ulnar artery, arteria ulnaris. The place of palpation gives it a special status since the pulse diagnosis is usually done at the radial artery, arteria radialis.

Meyer presents a brief note on the bla rtsa and the life channels (Meyer 1990: 249, note 184). He studied the section on pulse diagnosis in the ninth century Tibetan medical text Sman dpyad zla ba'i rgyal po, one of the earliest extant texts of Tibetan medicine of probably both Indian and Chinese origin (Nāgārjuna 1989). This text also shows a Graeco-Arabic (Khrom) influence on Tibetan medicine, for example, in the section on urine diagnosis (Yoeli-Tlalim 2008: 232-236). Apparently, pulse diagnosis had a divinatory significance in Tibet. Meyer concludes that the divinatory aspects of Tibetan pulse diagnosis found in the Sman dpyad zla ba'i rgyal po were not practised in China (Meyer 1990, quoted in Yoeli-Tlalim 2008: 233).

Apart from diagnosing the life-span, prognostic pulse diagnosis felt at various arteries, includes, for example, predicting the gender of an unborn child or diagnosing the illness of a patient through feeling the pulse of a relative. The so-called 'seven astonishing pulses' (ngo mtshar rtsa bdun) use the relationship between the seasons and the organ pulses in a sophisticated way to predict household matters, travel, wealth, and family interrelationships (Parfionovitch, Dorje, and Meyer 1992: 125). The bla rtsa itself is not only used to diagnose the life-span but also to predict the health and life-span of a relative, the loss of wealth, or spirit attacks (Donden and Hopkins 1986: 104-105; Parfionovitch, Dorje, and Meyer 1992: 139). Among these prognostic methods, the pulse reading predicting the life-span and the pulse diagnosis establishing the gender of an unborn child are still practised, the second albeit rarely. I have not seen the other types of pulse prognosis in practice, since most young MTK amchis consider this divinatory method of pulse reading too difficult.

The prognostic dimension of pulse diagnosis would potentially also enlarge a practitioner's social position from an amchi who treats diseases to one of an amchi-cum-diviner, which can lead to a great deal of publicity (see the example of Dr. Pema Dorje in the next section). Contemporary Tibetan amchis in India do not often make use of this dimension of diagnosis, and its knowledge largely comprises a part of their memorisation of the Rgyud bzhi and their theoretical examinations. If asked, they refer to the old, senior amchis in Tibet, who 'knew,' the attitude seeming to be that 'the best physicians are always elsewhere.' None of the young MTK amchis I met claimed to have mastered divinatory pulse reading; some of them, such as Amchi Künga, said they would feel the bla rtsa, "just to make sure the beat is there." Senior Tibetan physicians in the Darjeeling 
region, such as Dr. Trogawa Rinpoche and Dr. Pema Dorje, who used prognostic pulse reading techniques, were careful with their statements. I have seen Dr. Trogawa Rinpoche detecting the gender of an unborn baby through feeling the kidney pulse and discussing his results with his students but not revealing his prognosis to the mother, subtly indicating that a wrong statement would harm his reputation as a physician. Amchi Jamyang, when detecting a spirit possession or the loss of bla in the pulse, would always send the patient to a lama to confirm the diagnosis through a $m o$, thus sharing the responsibility of such a diagnosis.

In chapter 4, I showed that it is a common feature of Tibetan medicine to link the five elements and the three nyes $p a$ to various temporal frameworks (seasons, times of the day, stages of life, etc.); this is sustained by the logic of the cosmological idea of interrelatedness (rten 'brel), explained in chapter 3.1. Feeling the pulse also makes use of a temporal framework. One section of the Rgyud bzhi (IV, 1, ninth section: 216) interprets the frequency of the pulse beat in relation to the physician's own breath. This is not unusual and presents a link between medicine and time computation in astrology, where one inhalation and exhalation is considered a single temporal unit (dus tshod), which I already explained in chapters 3.1 and 4.3 .

When giving me an introduction to pulse diagnosis, amchis generally started with this distinction and how one could find out whether the pulse was of 'hot' or 'cold' quality by counting one's own breath. They then often pointed to the Baidūrya sngon po, which states in its annotated English commentary:

$[T]$ he normal pulse rate is five beats during one respiratory cycle of the physician [...]. A pulse rate of six beats and more per respiratory cycle indicates a disease of hot nature, $[\ldots]$ a pulse rate of four and lower indicates a disease of cold nature (Parfionovitch, Dorje, and Meyer 1992: 133).

In this case, temporalising two physiological rhythms - breath and pulse - allows for a categorisation of illness between 'hot' and 'cold.' The parameter of measurement is the physician's own breath, which is supposed to be calm and regular. Breath and the pulse beat are both used as existent physical temporal frameworks that allow a reckoning and consequent medical interpretation. All amchis I knew used this method to detect the 'hot' and 'cold' nature of a disease. This is just one example to show that temporal frameworks are common in Tibetan pulse diagnosis. In the next section, I present the temporal aspects of the bla rtsa diagnosis. How can the amchi tell the life-span through the pulse? 


\section{Rhythm of Pulse, Rhythm of Life}

The technique of diagnosing the life-span through feeling the bla rtsa is mentioned in the Rgyud bzhi (IV, 1: 221). The interesting point for our discussion on temporalisation is that the amchi translates the rhythm of the pulse beat into years of the life-span, and that irregularities in the quality of the pulse beat are interpreted as years of ill health, obstacles, or chances of dying. In this method, one regular pulse beat corresponds to one year of life and a hundred healthy pulse beats to a life-span of a hundred years. A hundred years here are seen as the optimal life-span (Parfionovitch, Dorje, and Meyer 1992: 295, caption 62; Rgyud bzhi IV, 1: 222).

In clinical practice, I only saw some amchi using the technique of feeling the bla rtsa. It was mostly applied when a patient was very ill, but some doctors also used it to predict difficult years for the patient so they could give precautionary advice. In India, Dr. Pema Dorje (see plate 5.4) was the most senior MTK physician with whom I was able to discuss the bla rtsa. For him, the prognostic aspect of the bla rtsa was an integral part of his diagnostic skills. The interview took place during the inauguration of a new building at the MTK branch clinic in Salugara, in September 2004 .

BG [myself ]: Do you use this pulse diagnosis frequently?

PEMA DORJE: Yes, of course. I have so many incidences about feeling the life-span pulse. For example: When I was in Bihar, during a MTK medical camp, there was one gentleman who had a jerk at the fourteenth pulse rate, always. So I told him, 'When you were fourteen years old, you had a very bad time in your body and mind, in your life.' He told me it was true and that he had fallen from a horse. He called the Bihar chief minister, telling him, 'This doctor told me I fell from the horse,' which I had not done, but that's how he told the story. The next day, I had to go to the airport to check the pulse of the chief minister.

In another case, I checked the life-span pulse. I started counting several times, about four times, and the beginning of the pulse was missing. I asked how his birth was; it must have been very hard. He told me that he was born nearly dead.

BG: Can you predict the end of a life?

PEMA DORJE: One beat indicates one year. If you check the pulse, and if there is no beat - count yourself, one, two, three, four, five - and at six you can feel a beat. This means, from his year of birth until the age of six he had a problem. From the sixth year onwards he was ok, the pulse beat was there. Then, you count from fifty until one hundred.

BG: What if it stops at fifty-five? Does it indicate only a health problem, or that he could die? 


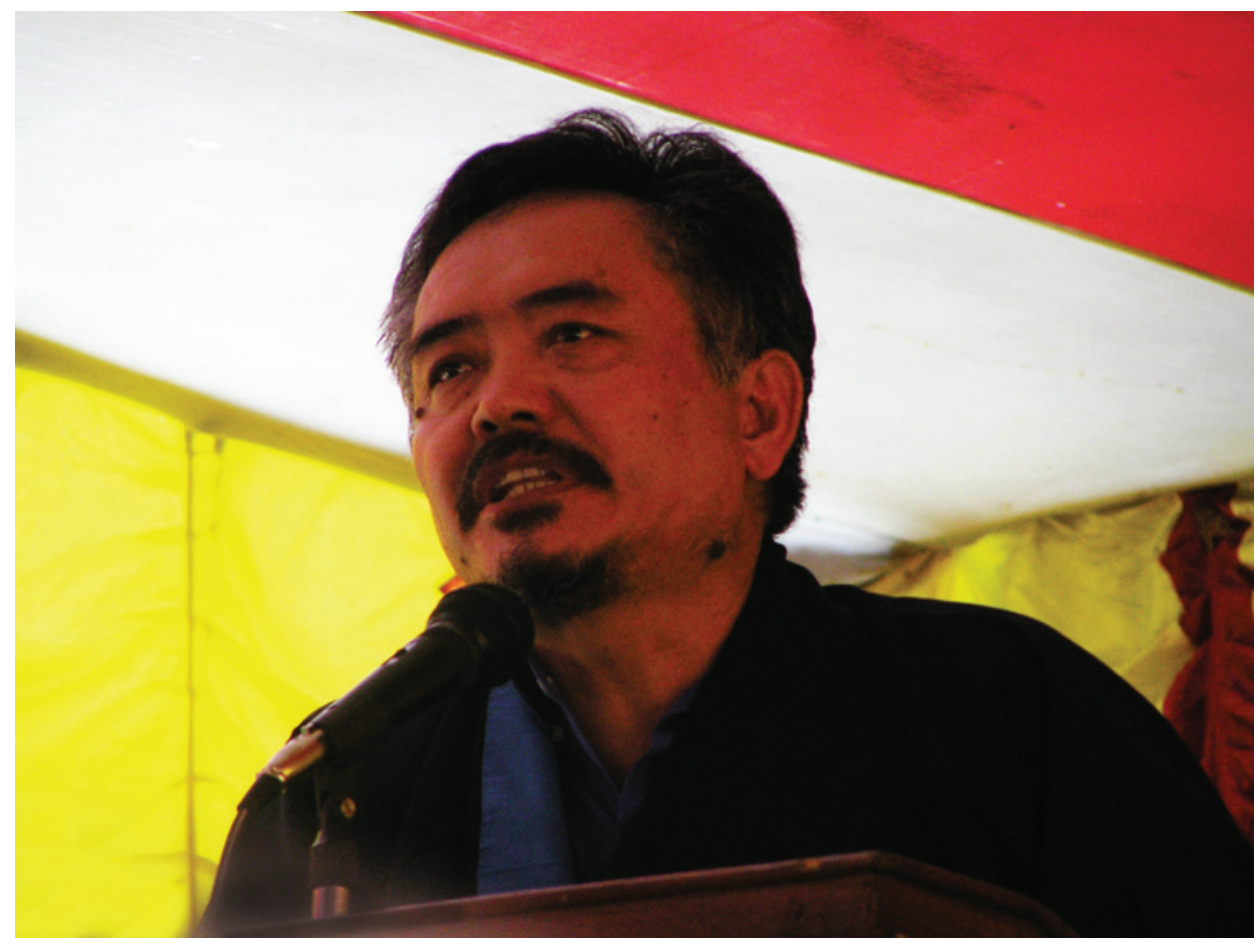

Plate 5.4. Dr. Pema Dorje giving a speech at the opening ceremony of the new MTK building, Salugara 2004.

PEMA DORJE: If he is fifty years old now, and I can feel a problem at the fifty-sixth or sixtieth pulse beat, I will tell him to be careful at that age, since the pulse beat indicates a problem in the life-force. Sometimes we find that from seventy there is no beat at all.

BG: If the pulse shows that your life-span is short, can you change that? If so, how?

PEMA DORJE: We do the ritual to retrieve the bla (bla 'gugs tshe 'gugs), save lives of animals, or buy fish and release them. We also take long-life initiations or do long-life deity practices.

The longevity practices that Dr. Pema Dorje mentions are explained in later chapters. My question here is how the temporal nature of the life-span is transported into the pulse beat. How is it that when the amchi starts to count the pulse beat, it always corresponds to the first year of the patient's life? There is a sense of synchronicity. It does not happens that he touches the pulse 'before' or 'after' the beginning of the life-span count. It is never doubted that he might miss 'the first year of life.' The act of 
touching the patient and the intention to count the life-span now marks the beginning of the prognostic diagnosis. To take a moment as a starting point for a diagnosis is not uncommon in divinatory and astrological traditions. Both Indian and Tibetan astrology emphasise horary astrology, where the time the question is asked is used to determine the answer, and electional astrology, where the time of an event provides the basis for the calculation.

In the case of Tibetan divinatory pulse diagnosis, the moment in time that marks the beginning of the divinatory event is determined by touch. Tactility is the key mode of perception in pulse diagnosis in Asian medical systems. The importance of touch in feeling the pulse (Hsu 2005b) adds an important point to my temporal perspective. The act of touch as part of the pulse diagnosis sets an interval to the rhythmic continuum of the pulse beat. The moment the Tibetan physician touches the patient's ulnar artery, a new event commences within this continuum: the feeling of the life-span pulse. The pulse beats are temporal representations of the years of life of the patient. The duration of the life-span corresponds to a number of pulses before a missed beat. This number is given a prognostic meaning. The pulse beat here acquires the special meaning of representing the life-span. It does so only during the specific duration that the doctor touches the patient's wrist and - with the intention of making a prognosis of the life-span - counts the pulse beat.

This method presupposes that the pulse beat of the bla rtsa embodies the life-span. The years of the life-span are being mapped onto the temporal rhythm of the pulse beat. In such a temporal framework, the first felt and counted pulse beat 'automatically' corresponds to 'year one' of the patient's life. To set the time for the counting of the years essentially requires a conscious, intended focus within a set temporal framework. The bla rtsa is a diagnostic method in the sense that one temporal system (the pulse beat) is translated into another (the years of life). This translation of the pulse beat into years of life was avoided by some - mostly young amchis - who felt that because of lack of experience they were not able to predict the life-span from the bla rtsa. They preferred to use the bla rtsa simply to diagnose if the bla is there or not. Amchi Künga at the MTK branch clinic in Salugara said in 2004:

I use the bla rtsa only sometimes. It requires many years of experience to feel and interpret the bla rtsa correctly. I feel and count the beats; if there is an interruption, I ask the patient if during that year there was an obstacle. One needs many years of experience to diagnose the life-span correctly. For me, as long as the beat of the bla rtsa is there, it is enough. 
Whereas young Dharamsala-trained MTK amchis studied the divinatory technique but did not necessarily engage in bla rtsa due to lack of experience, Amchi Kartsokyi, who was trained at the MTK in Lhasa, had not even studied the divinatory aspects of bla rtsa. She used the bla rtsa only to see "whether the bla is there or not." Amchi Jamyang said that he feels the bla rtsa only when the patient is seriously ill. He said irregularities can give hints on the reduced life-span of the patient, but he would then send the patient to a lama to confirm the diagnosis with a mo and treat it through rituals, which would be determined by the mo not by his pulse diagnosis.

The interface between the amchi and the lamas in this context is interesting. If the amchi is not entirely sure or able to interpret the bla rtsa, the lama provides a second opinion. Reasons for a disturbed bla rtsa could be accidents and sudden obstacles, the loss of bla, or interference by spirits (gdon). The astrologer, lama, or diviner provides the necessary details, and ritual is usually then seen as a more powerful antidote than medication.

Amchi Jamyang welcomed having the option of taking a second opinion from a mo practitioner, or an astrologer. Because of the geographical distance between MTK clinics, young amchis often have no senior amchis with whom they can discuss difficult cases. The largely theoretical MTK training lacks long-term practical experience when it comes to sophisticated pulse readings. Therefore, it gives amchis a sense of professional security to have other options of confirming their diagnoses locally, especially if it concerns opaque concepts such as the loss of bla, or spirit affliction.

I generally found that amchis who actively practised Buddhism had a greater interest in the life-span pulse and astrology, and used these notions more often in medical practice. Other amchis mentioned bla rtsa, bla gza', and bla gnas only if the patients expressed a belief and special interest in these systems.

In sum, the divinatory diagnosis of the bla rtsa is arrived at through temporalising the pulse-beat. The method situates an event in time. This means, the first pulse beat that is consciously counted by the physician is translated to 'year one' of the patient's life, similar to horary and electional astrology.

The question now arises as to how people receive predictions about the life-span, may it be through pulse diagnosis or through astrological calculations. While I was not present during a bla rtsa diagnosis and could not ask a patient directly, I discussed this topic with both amchis and 
astrologers, who had to deal with their client's varied reactions. Dr. Pema Dorje had the experience that Tibetans seemed to be more at ease about life-span predictions than foreigners. He said,

I have done bla rtsa with many people. It really comes correct. I can't say if you fell from a horse, but I can see if the life-force has been disrupted or not. For Tibetans it is OK to predict, but for foreigners it is difficult. I found many incidents where foreigners got very scared about these predictions. So I stopped telling anything. They will not accept the prognosis the way Tibetans do. Many people tell me not to tell them about the future because they are scared of that.

Dr. Pema Dorje's experience demonstrates how predictions of the lifespan are perceived and interpreted with large cultural differences. Tibetans have their own ways of dealing with such predictions. This was also confirmed to me by Jampa Kalsang, a senior MTK-trained astrologer in Dharamsala now living in the US, whom I have known since 1990. He expressed his views to me in 2006:

Normally, Tibetan people are more interested to know about their lifespan, so they come to ask the astrologer. I find westerners don't like to hear about their life-span; they always ask me not tell them when I do a reading. I personally tell the life-span to my clients. At the beginning westerners feel uncomfortable hearing it, but I always say that it also depends on one's lifestyle and how you deal with it. If, you want to live longer, you can prolong your life through practices, like yoga and controlling the life-sustaining wind' (srog rlung; e-mail communication, October 2006).

The fact that the prediction of the life-span is not considered definite is characteristic of how Tibetans deal with prophecies in general. Tibetans know that it is negotiable when an obstacle is detected for a certain year of life. It can be counteracted through Buddhist long-life empowerments, saving animals' lives, and other longevity practices. The life-span, whether prognosticated in medicine or astrology, is always stated literally with a definite number of years. But it is obviously not meant literally. I take up this discussion further in chapter 8 and in the conclusion.

The feeling of the bla rtsa is not only linked to the life-essence, bla, but also to another vital force called mdangs mchog (lit. 'supreme radiance'), which is of Āyurvedic origin and part of a different physiological system, which in the medical text is unrelated to the bla rtsa. Nevertheless, Tibetan physicians make sense of these ideas of vitality and reinterpret them in terms of their own experience. Before discussing this, the concept of mdangs mchog requires a brief introduction. 


\section{Distilling the Supreme Radiance of Vitality}

In Tibetan medical texts, mdangs mchog is described as a person's radiance and lustre; it is also called the 'supreme quintessential vital-essence' (Clark 1995: 62). Mdangs mchog is the translation of the Sanskrit word ojas. Alter describes it in the context of north Indian wrestlers as 'the lustre of vitality or virility' (Alter 1992: 269) and in his paper on Āyurveda and 'good health' as "the physiological analogue of the divine shakti and the manifestation of power, vigor, fitness, and ultimate vitality" (Alter 1999: 53). Other translations of ojjas are 'life-force' or Lebenskraft (Hilgenberg and Kirfel 1941: 66), 'life warmth' or Lebenswärme (Schneider 2010: 35), and 'vital energy,' 'strength,' or 'power' (Wujastyk 1998: 29).19

In Tibetan medicine mdangs mchog is considered a distillate of the seven bodily constituents (lus zungs bdun). They are the equivalent of the seven dhātus ${ }^{20}$ in Āyurveda. Ōjas, in fact, is a Vedic concept and was later attached to the dhätus when Āyurveda became more systematised. ${ }^{21}$ Notably, in bla as well as in mdangs mchog, we find ideas of vitality that are much older than the systematised bodies of medical knowledge that present them today as part of their physiology. Nevertheless, in the Rgyud bzhi, mdangs mchog only appears in the chapter on physiology and is not linked to bla (Rgyud bzhi II, 5: 72-73).

The Rgyud bzhi (II, 5: 72) describes the physiology of the digestive process of the seven bodily constituents as a continuous process of refining essences from the five elements and six tastes (sweet, sour, salty, bitter, hot, astringent) taken in the form of food. The Tibetan understanding of this process is almost identical with the descriptions in the seventh century Indian Āyurvedic work Aștāingahṛdayasaṃhitā by Vāgbhața (Hilgenberg and Kirfel 1941: 2ff; Murthy 1996: 9). According to the Rgyud $b z h i$, the digestive process takes six days ${ }^{22}$ and is as follows: the essence of food is refined through six stages from the organic food sap, or chyle,

\footnotetext{
19 Āyurvedic texts describe ōjas as cold, oily, solid, and cooling (Wujastyk 1998: 322), as well as watery in nature, clear and slightly reddish yellow in colour (Hilgenberg and Kirfel 1941: 66, Murthy 1996: 163). I have not come across these descriptions for mdangs mchog in the Tibetan medical texts.

${ }^{20}$ The Sanskrit dhätu is often translated as 'tissues' (Zimmermann 1987: 162), which is misleading, since one of them is semen (Langford 1995: 336). Alter mentions dhātu in his glossary as 'primary substance of the body; semen; mineral' (Alter 1992: 267).

${ }^{21}$ Dominik Wujastyk, personal communication, 2005.

${ }^{22}$ Alter, for example, mentions that it takes twenty-eight days for the food to become semen (Alter 1999: 53). I have not found an explanation why in Tibetan medicine this cycle has only six days.
} 
into blood, flesh, fat, bone, and bone marrow, finally becoming the regenerative fluids, mentioned as semen (khu ba; Rgyud bzhi II, 5: 72). Mdangs mchog is the essence of khu ba. The Baidurrya sngon po mentions that it is characteristic of this process that the essence of one stage is transformed entirely ('ba' zhig tu) into the constituent of the next stage, expelling all impurities that are created during this distilling process in the form of excretions (Sangye Gyatso 1982: 120). Therefore, mdangs mchog has to be understood not as an organ-related idea ${ }^{23}$ but as an expression of healthy lus zungs, which becomes visible in the radiant complexion of a person and influences the quality of health and long life. This radiant complexion can be lost, a condition which is also symptomatic for the loss of bla.

I have observed Tibetan physicians linking both these concepts together, concluding that mdangs mchog can be lost along with bla. This also explains why Dr. Pema Dorje, for example, described bla to me as "an umbrella for mdangs mchog." Millard in his ethnographic account of a Bonpo medical school in Nepal mentioned a senior medical student correlating bla with "the most refined nutrient of the metabolic process" (Millard 2002: 154), which is a description of mdangs mchog.

Nevertheless, mdangs mchog has a very different physiological nature than bla. It is created from food through digestion, whereas bla does not undergo any physiological process in the body to be 'made.' People have it and can lose it. Despite the difference in origin and physiology, in the contemporary Tibetan medical practice in India, the Ayyurvedic notion of mdangs mchog has been integrated into the plethora of life-forces and linked to bla and bla rtsa.

Amchi Jamyang explained that bla and mdangs mchog share the same pathways in the body and that both move along the third of the three types of life channels (tshe'irtsa). As I have shown in the previous section, the third life channel is not clearly defined in the Tibetan medical texts. "The third [life channel] is like the life-essence (bla) and irregularly wanders around [the body]" (Rgyud bzhi II, 4: 68). A channel that 'irregularly wanders around' seems devoid of spatial and temporal order. Its irregularity in the human body makes it an opaque concept that seems open to re-interpretations. Mdangs mchog might be associated with this channel because of similar temporal and spatial representations. The Rgyud bzhi describes mdangs mchog as "the supreme radiance, [which] is the final

\footnotetext{
${ }^{23}$ Zimmermann also points out that "the very idea of an organ makes no sense in Âyurvedic physiology" (Zimmermann 1987: 163).
} 
[essence] of the [seventh] lus zungs, [which is] semen. It resides in the heart, but it pervades the entire body." ${ }^{24}$

Through which pathways does it pervade the entire body? The third life channel ${ }^{25}$ here seems to be providing an anatomical framework for amchis to locate both bla and mdangs mchog, even though the text does not explicitly say so.

I found that in medical practice some Tibetan physicians relate the mdangs mchog to bla and the bla gnas. Dr. Pema Dorje, for example, explained during our interview:

PEMA DORJE: You cannot see anything, but mdangs mchog actually covers the whole body. But the main seat is in the heart, and it moves through the body and has the main energy points, which are called the bla gnas.

BG: Is mdangs mchog related to bla?

PEMA DORJE: Mdangs mchog is a part of bla. The bla is like an umbrella.

This shows that originally unrelated concepts, such as bla and mdangs mchog, have been linked together by Tibetan physicians because of certain similarities. These similarities between bla and mdangs mchog also extend to emotional experiences of the patients. Dr. Pema Dorje explained that mdangs mchog can be lost in an instant through stress and anxiety, which is similar to bla, which can be lost through accidents and sudden frights, especially in children. For Amchi Jamyang, bla and mdangs mchog are so interwoven that they are 'almost equal' (gcig pa dang 'dra bo red). Amchi Jamyang explained:

The mdangs mchog is a very important concept and almost equal to bla since it also moves through the body and can be lost along with bla. If the bla is lost, people also lose their radiance, so mdangs mchog also gets lost.

Even the diagnosis of mdangs mchog is more linked to bla and the bla rtsa than to the lus zungs bdun, which are assessed with the general pulse diagnostic methods at the radial artery. Dr. Pema Dorje diagnosed the quality and strength of mdangs mchog in the bla rtsa, as he told me during our interview:

${ }^{24}$ lus zungs khu ba'i mthar phyin mdangs mchog ste / snying la gnas kyang lus kun khyab pa dang / (Rgyud bzhi II, 5: 72).

${ }^{25}$ Medical perceptions of the life channel have been debated among amchis in the past. For discussions on this channel debate see Garrett 2008, Garrett and Adams 2008, Gerke forthcoming, and Gyatso J. 2004. 
BG: What about the life-span pulse? Can you feel each beat corresponding to one year of life?

PEMA DORJE: The bla rtsa has the influence of the mdangs mchog [...], it flows very smoothly and once you get a kind of jerk, abnormal strength, in the body or mind, it means there will be a break in the pulse. That abnormal break indicates a change in the longevity of life.

BG: Can you feel the quality of the lus zungs bdun and mdangs mchog through the bla rtsa?

PEMA DORJE: You can diagnose the quality of the lus zungs bdun from the normal pulse. Now, mdangs mchog can be detected from the bla rtsa, because that is the power in your body. If the mdangs mchog is declining in the body it is shown in the bla rtsa, you can see the weakness in the pulsation in the irregularity.

Dr. Pema Dorje saw a link between the vitality of mdangs mchog and of bla, which made him utilise the same diagnostic framework, even if this meant detaching mdangs mchog from its general place in physiology, the lus zungs bdun. Seeing bla and mdangs mchog both as vital forces with similar characteristics, he diagnosed the quality of mdangs mchog by feeling its weakness in the irregularity of the pulse beat of the bla rtsa, not the general pulse. I understand this as a practice of temporalisation in the sense that through this practice the Tibetan physician links temporal frameworks with certain representations of vitality. In doing so he is able to medically assess the quality of those vital forces. In this particular case, the practice is based on personal clinical experience and the way how Tibetan physicians themselves interpret their medical texts. 
Barbara Gerke - 978-90-04-21748-5 Downloaded from Brill.com๑4/26/2023 $\odot 2: 47: 13 \mathrm{PM}$ via free access 
PART FOUR

THE LIFE-SPAN IN ASTROLOGICAL AND DIVINATORY CONTEXTS

Part IV of this book sketches various aspects of how the life-span is assessed in divinatory and astrological contexts, employing various concepts, such as the 'five factors' and the 'obstacle year,' 'untimely' and 'timely' deaths, as well as 'maximum,' 'remaining,' and 'completed' life-spans. I look at astrological and divinatory predictions concerning such notions of the life-span, which reveal various temporal frameworks along which Tibetans understand and negotiate tshe. These concepts are all embedded in Tibetan ideas of causation, such as merit and karma, and influence numerous merit-generating practices aimed at strengthening and prolonging tshe. My ethnographic examples show that astrological calculations and divinations help people make sense of illness and death in general, but specifically sudden death (through accidents), or those that occur early in life (death of children). The subsequent discussion leads to the question of how 'accurate' certain prognostications of the actual duration of the life-span are, since factually speaking they often turn out to be 'wrong.' 
Barbara Gerke - 978-90-04-21748-5 Downloaded from Brill.com๑4/26/2023 $\odot 2: 47: 13 \mathrm{PM}$ via free access 


\section{MERIT, KARMA, LIBERATING ANIMALS, AND THE FIVE ASTROLOGICAL FACTORS}

Merit and karma are ideas of causation that belong to Tibetan value systems. They necessitate some initial discussion because they reappear in the chapters to come. Why do things happen when they happen? How to make sense of misfortune and understand difficult phases in life? This chapter explores Tibetan ideas of causation in relation to the life-span. Animals are involved in some of these practices that are all aimed at combating negative karma and strengthening tshe. Animal liberation practices are popular and are believed to strengthen the tshe of the person who liberates the animals from death.

In this chapter, I also return to the five factors (briefly introduced earlier in the book), which provide a temporal framework for repeatedly and rhythmically recurring prognostications for individuals concerning the loss or weakening of vital forces. These factors are also used to explain personal experiences of symptoms such as mental stress or nightmares, which could not be treated biomedically. Tibetans sometimes understand these symptoms in terms of the weakness of the five factors and the loss of bla. The ethnographic account of Jigme losing his bla elucidates the interconnectedness of the five factors and their influence on longevity as a whole. I suggest that while the five factors are technical astrological terms in themselves, they do not necessarily have the same meaning in their popular usage and are often reinterpreted in an effort to adapt them to the needs of an individual's circumstances.

\section{Merit and Karma}

The ethnographic accounts presented in this and the following chapters are embedded in the Tibetan value system of merit, called bsod nams or dge $b a$, and karma, known as las (lit. 'action'). ${ }^{1}$ Both ideas basically imply

\footnotetext{
${ }^{1}$ I use the equivalent terms bsod nams and merit interchangeably since both terms are frequently used by Tibetans in the Darjeeling Hills. Karma is more often used than las, and I use las only in direct quotes by Tibetans who themselves used the term.
} 
one and the same concept, merit being 'positive karma.' They belong to a complex Tibetan value system that can affect tshe either in a prolonging or shortening way.

Karma and rebirth are central ideas in all Buddhist societies (Samuel 1993: 199). They connect a sense of time (rebirth) with an ethicised universal authority (karma) and the individual self. Karma "implies the effect of actions in a past life on one's present existence, and (more especially) on one's present actions on future existences within a continuing cycle of rebirth" (Samuel 1993: 200). Tibetans' understanding of karma often follows a rather pragmatic approach assuming a universal validity in that the law of cause and effect influences previous, current, and future lives. It is therefore not surprising to find that ideas of tshe, which are linked to karma and merit, can stretch over several lifetimes in the form of a 'remaining life-span' (see chapter 7). Apart from a deep interest in thisworldly concerns, past and future lives are understandably subjects of great curiosity among Tibetans, which are partly satisfied by divinations and astrological calculations.

There are a vast number of publications on the topic, of which a few have informed my discussions. Keyes and Daniel (1983) present anthropological essays on karma, of which Lichter's and Epstein's paper refers to a Tibetan context. Clarke (1990) offers a case-specific ethnographic account from a village in Helambu, Nepal, and discusses merit in terms of virtue and blessing, which shows how local interpretations of Buddhist terminology can differ from standard textual interpretations. Gombo (1985) presents a Tibetan account of the socially competitive merit-making activities of Tibetans at the pilgrimage place of Buddha's enlightenment, Bodh Gaya, in India. Samuel (1993) speaks of the 'karmic orientation' of Tibetan societies as a part of the Tibetan value system.

Merit is closely linked to blessing (Tib. byin rlabs, Skt. adhișthāna). In the Tibetan context, byin rlabs has acquired a wider range of meanings than the Sanskrit adhișthāna. It has significant pre-Buddhist associations, such as involving "the quality of invincibility in battle" (Samuel 1993: 450). This interconnection of bsod nams and byin rlabs is common throughout Asia, and appears to be a local version of the relationship between 'merit'and 'blessing'-type vocabularies that have been analysed for a number of Southeast Asian societies (for example, Durrenberger and Tannenbaum 1989; Kammerer and Tannenbaum 1996). I discuss byin rlabs in more detail in chapter 9.1 in the context of long-life empowerments and Buddhist visualisation practices. 
Since Tibetans have considerable power and agency in this karma ideology, the accumulation of merit (bsod nams kyi tshogs) is of great importance to them. Astrology and divination are often utilised to detect the suitable means to accumulate merit and counteract negative karmic consequences. Merit is collected through various dharma practices. Popular ideas of such accumulations are, however, often linked to practical economic ideas; accumulating meritorious actions is like saving money in a bank account that can be drawn when times become difficult. I observed this pragmatic idea of bsod nams, for example, in formalised acts of generosity, such as the MTK's free medical camps that are dedicated to the long life of the Dalai Lama as well as in local animal liberation practices (see next section). Public acts of accumulating bsod nams also enhance the social status of Tibetans within their community (Gombo 1985: 240) and have been institutionalised in the role of the ritual sponsor (see chapter 9.3).

Tibetans apply these merit- and karma-related approaches to longevity in various ways. For instance, many Tibetans with whom I spoke said that collecting merit produces positive karmic results, which are reflected in a healthy and long life, whereas a lack of merit might lead to a short life-span or a premature death through an accident or a sudden severe illness. Some felt that merit and karma can influence any form of ritual and medical efficacy: on the one hand, a long-life empowerment would not be effective without having merit; on the other hand, through attending the empowerment, merit would also be collected 'automatically.' Amchi Jamyang thought that ingesting the ritual long-life pill, called tshe ril, which is distributed during long-life empowerments, would increase the life-span because of the byin rlabs it contained. But apart from the ingredients, whether it would actually increase tshe depended on karma. He said,

Long life does not happen automatically just by taking a tshe ril. A tshe dbang increases the life-span only if you have the right las with the lama and your [dharma] practice, just like medicine only works if you have las with your amchi.

Apart from merit and karma, Tibetans have several other mechanisms to explain causation, such as the concept of retribution related to 'suffering of change' (layogs; Lichter and Epstein 1983: 254-257) and divine intervention, for example, in the form of 'pollution' (grib; Lichter and Epstein 1983; Mills 2003a, 2005; Samuel 1993). These value concepts are often vague and cannot always be clearly separated from each other (Mills 2005: 224); they 
are nevertheless frequently explained in terms of karma. Vagueness seems to be part of these value systems, and case-specific analyses might be useful to uncover their meaning and their interrelationships.

Lichter and Epstein point to the significance of the underlying concepts of 'happiness' and 'the good life' that motivate Tibetan merit-making activities. Tibetans attribute events that have no apparent cause to Buddhist ideas analogous to karmic categories - an apparent paradox to outsiders. Tibetans themselves have developed the concept of retribution, la yogs, to build this apparent paradox into their cosmic world view (Lichter and Epstein 1983: 223-225). La yogs does not operate according to moral principles and can be an innocent, well-meant action that nevertheless leads to suffering (Lichter and Epstein 1983: 255). Since I was unfamiliar with Lichter and Epstein's work when I conducted my fieldwork, I did not ask questions specifically about la yogs and its causal effects on longevity.

However, my ethnographic observations contribute to the understanding of two other causal factors mentioned by Lichter and Epstein: (1) the material or primary cause (Tib. rgyu, Skt. hetu) and (2) the cooperating or secondary cause (Tib. rkyen, Skt. pratyaya). The Tibetan meanings are again quite broad compared to their Sanskrit equivalents. Rkyen, which might include any misfortune from a demonic attack to an accident, is generally linked to supernatural events in this lifetime that occur by chance; however, Tibetans do not necessarily exclude the possibility of rkyen also being linked to karma (Lichter and Epstein 1983: 248).

The dual causality of rgyu and rkyen is also found in Tibetan medicine. The Rgyud bzhi describes rgyu as the primary cause of illness, linked to the three nyes pa, and rkyen as the contributing cause of illness, linked to environmental or dietary influences, a demonic attack, or a case of 'pollution' (Rgyud bzhi I, 2: 40; IV, 27: 389; see also Tucci 1980: 173).

The meaning of $r$ kyen is not at all straightforward among Tibetans. Daniels describes Khampa pilgrims around Boudhanath in Kathmandu using rkyen as a synonym for 'obstacle' or bar chad (Daniels 1994: 291). Lichter and Epstein do not mention bar chad but hold that "any misfortune can be labelled rkyen" (Lichter and Epstein 1983: 246, 248), something Daniels critiques for presenting a pan-Tibetan view that does not hold ethnographically (Daniels 1994: 292). As with so many other concepts in the Tibetan world, there is probably no pan-Tibetan view on rgyu and rkyen. These are concepts that can be used according to situation in a wide variety of ways. In Kalimpong, I came across rgyu and rkyen in the context of Lama Kunzang Dorje, the head lama of the Jangsa Gompa, explaining the effectiveness of longevity practices. Lama Kunzang explained the benefits of animal-liberation practices in terms of rgyu and rkyen: 
Regarding longevity practices we distinguish between rgyu and rkyen. Saving other's lives belongs to rgyu and is more effective than attending tshe dbang and long-life rituals, which come under rkyen. Saving others' lives extends one's own life-span. That's why lamas prescribe methods of saving animals from slaughter when obstacles to one's life-span arise.

The division between rgyu and rkyen here is not made primarily to interpret the causes of misfortune, but to evaluate the effectiveness of longevity practices. In terms of life-span extension, the active practice of freeing animals is rated more effective (rgyu) than the more passive receiving of a long-life blessing during a tshe dbang (rkyen). In sum, rgyu and rkyen operate as a pair of concepts that can be used in a variety of ways. In this way, multiple layers of causes can be dealt with so that decisions can be made as to which causes are to be tackled first in order to obtain the best results.

Another major point to be considered for the understanding of Tibetan longevity practices and their relation to karma and merit is the importance given to the precious human body (mi lus rin chen). The Buddhist view that enlightenment can only be achieved while incarnating in a precious human body is a central part of the Buddhist teachings. A typical motivation for long-life practices according to Buddhist practitioners I spoke with (for example, the monk Sherab, who will be introduced in chapter 7.2), is to generate more obstacle-free time for dharma practice. This is the reason why longevity practices are integrated into the schedule of Buddhist meditation retreats.

A reincarnation as a human being becomes more likely through the collection of bsod nams. Non-meritorious actions may lead to rebirths in one of the lower realms (that of animals, hungry ghosts, or hell beings). Even rebirths as gods or demi-gods, although pleasurable, are not seen as particularly useful in the advance towards enlightenment. Consequently, human individuals are seen as active agents responsible for their actions and therefore able to determine their life-spans. Accumulating bsod nams then means creating positive karma for long lives and favourable rebirths, and is one of the main incentives for Tibetans to make offerings and to pursue a large variety of Buddhist practices. One of these are the 'cheating death' practices that encourage the accumulation of bsod nams and mention long life as one of the benefits (Schneider 2010: 53).

Even though Buddhist teachings say that wanting to prolong one's own life is not the 'right motivation' for pursuing longevity practices, among lay Tibetans this is often clearly the motivation. "Long-life practice is a selfish practice," a Tibetan lay practitioner told me. "We practise for selfish reasons, just to extend our own life-span. The lamas do it for others." 
This confirms Samuel's observation that "concerns for the proper use of magical power for this-worldly ends nevertheless remain at the basis of the Tibetan approach to reality" (Samuel 2005: 70). This does not imply that the other, more altruistic concerns, are less meaningful.

Overall, longevity has permeated the popular ideas of merit and karma. Tibetans are keen to find out through divinatory and astrological methods whether their life will be good, whether their srog is weak and their life-span is about to be exhausted (a condition known as tshe 'dzad pa), or whether tshe is endangered by other obstacles. On special occasions or when facing sudden illness and misfortune, Tibetans ask the diviner and astrologer for advice on what kind of rituals and meritorious actions they could perform to strengthen srog and prolong tshe. Divinatory and astrological texts on srog and tshe typically mention a series of dharma practices aimed at accumulating merit and prolonging life.

I suggest that in this process both astrologers and diviners should be recognised as powerful social actors who steer and influence people's religious and health-seeking behaviour. They not only have a considerable influence on how people view and deal with the death of family members, but also determine the course a family takes to invest money in further medical treatment or rituals. If the outcome of the divination is that 'nothing can be done,' this can lead to the family not investing in any further treatment (see chapter 7.4). As I mentioned earlier, both biomedicine and longevity rituals can be very expensive, and life-span divinations can potentially save a family a large expenditure that would otherwise deplete their financial resources.

In the following section, I briefly summarise longevity practices involving the freeing of animals, which have been on the rise in the Darjeeling region and are also connected to the widespread movement for vegetarianism among Tibetans in India mentioned earlier.

\section{The Longevity Practice of Liberating Animals}

Animal liberation practices are widespread throughout Buddhist Asia. ${ }^{2}$ In Tibetan they are known as tshe thar (lit. 'life-liberation') or srog bslu

\footnotetext{
${ }^{2}$ Holler (2002: 207, note 1) lists various publications on animal liberation practices in Buddhist Asia.
} 
(lit. 'life-ransom') depending on who possesses the animal. ${ }^{3}$ Holler (2002) provides the only detailed research to date on various Tibetan rituals of liberating animals. His research is based on fieldwork in Namtso, northeast of Lhasa, as well as on textual sources. Holler suggests that animal liberation practices were introduced as a substitute for animal sacrifices and fed into a strong psychological need of Tibetans to reconcile their daily reality (hunting, fishing, murder, war, death penalty) with the Buddhist doctrine (Holler 2002: 210). His research suggests that these practices entered Tibetan literature around $1000 \mathrm{CE}$, during the second spread of Buddhism. They also became popular among the Tibetan Ganden government, and it has been documented that the fifth Dalai Lama not only released prisoners from captivity, but also ransomed the lives of one hundred yak and sheep and one hundred thousand fish to overcome an obstacle and prolong his life (Holler 2002: 211).

In the Darjeeling Hills, freeing animals is also a common Buddhist practice. Lama Kunzang recently institutionalised this practice to some extent in the form of the 'Jangsa Animal Saving Trust' (Lama Kunzang Dorje 2006). On his website, the accumulation of merit through animal liberation practices is explained by Chatral Sangye Dorje Rinpoche (1913-), the most revered tantric lama in the Darjeeling region, in relation to the 'sin of taking life' (srog gcod kyi sdig pa). Chatral Rinpoche was famous for his journeys to Kolkata, where he used to release many trucks of living fish into the Hooghly River every year. Unfortunately, he was too old at the time to be interviewed. An excerpt of the website reads:

Behind all these teachings there is one single fact of cardinal importance: that on this earth a human being can commit no greater sin than taking the life of another living being. By implication, there is no greater source of accumulating merit than saving life (Chatral Sangye Dorje Rinpoche 2006).

Following Chatral Rinpoche's teaching, and in order to give local devotees the chance to save lives and accumulate great amounts of merit, Lama Kunzang constructed a fish pond next to the Jangsa Gompa in 2005 (see plate 6.1). Here devotees set free living fish bought from the market. Later the monks would set the fish free into the Teesta River. Ironically, the pond had to be fenced and kept under lock and key to avoid the

${ }^{3}$ In the case of tshe thar the animal that is set free belongs to oneself, while in the case of srog bslu the animal is bought from another person for the purpose of being set free (Holler 2002: 218). 
stealing and killing of the fish by the surrounding impoverished nonTibetan neighbourhood.

During the inauguration of the pond, Lama Kunzang told me that a Bhutanese woman bought live fish worth three thousand Indian rupees (roughly equivalent to a labourer's two month salary) and freed them in order to lessen the severity of her mother's illness and to strengthen her life-force. Tibetans also freed pigeons and bought bulls from the slaughterhouses to accumulate merit for themselves and others. Later, we will come across some of these animal liberation practices in the Palden Lhamo divination text, where they are prescribed to combat negative divinatory results of a weak or fading life-force or life-span (see chapter 8.2).

Animals are not only involved in the methods to combat negative karma, but can also be the subjects of divinations. In Tibet, where nomad life was centred on livestock, divinations concerning cattle and calculations of the movement of bla in horses were commonplace (Dorji, no date; Maurer 2001). The Palden Lhamo mo also provides readings on the quality of srog in animals (Yogini Kachö Deden Wangmo, no date, folio 37b). These methods seemed useful back in Tibet, where people depended economically on livestock. In the Darjeeling Hills, where Tibetans are not engaged in agriculture or animal husbandry, I did not come across any divinations conducted specifically for animals.

The following section introduces in more detail the five astrological factors and the 'obstacle' year, mentioned earlier in the book, and analyses how these parameters are used as time-markers to indicate the changing quality of life-forces.

\section{Astrological Calculations Involving the Five Factors}

Tibetan astrological predictions are periodical and non-deterministic in nature. They map out cyclically recurring ups and downs in life by calculating various parameters using several techniques that are quite complicated to learn (one should keep in mind here that the astrology course at the MTK takes five years to complete). ${ }^{4}$ This section discusses one of the simpler and more commonly used sets of astrological parameters. These are the five factors (mentioned briefly in chapter 3.1). The methods of

\footnotetext{
${ }_{4}$ For example, the nine numeric squares (sme ba) are used to calculate the life-span and vitality, but the calculations are quite complicated and lie outside popular astrology. Consequently, I did not study them in detail.
} 


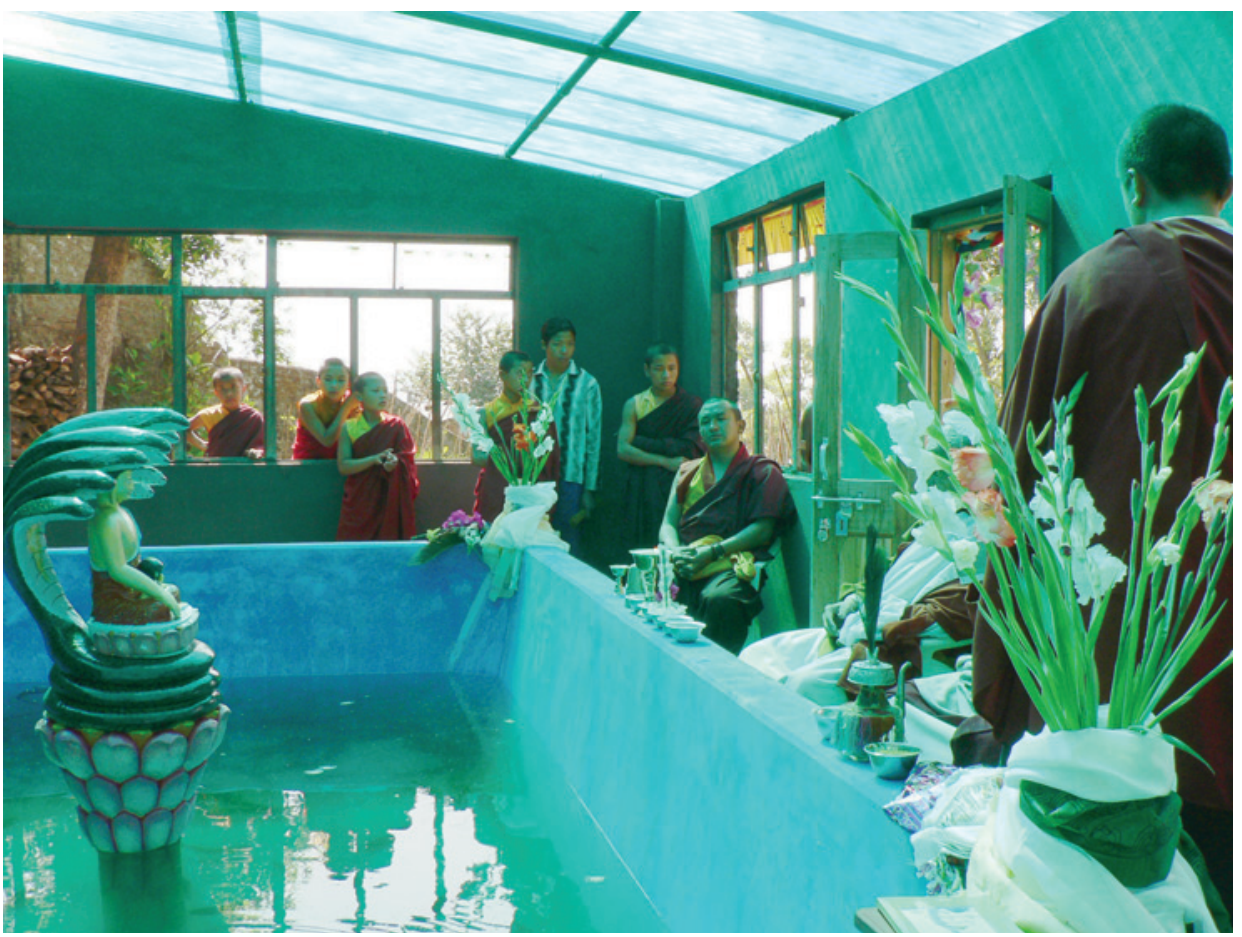

Plate 6.1. Inauguration of the fishpond at the Jangsa Gompa, Kalimpong, May 2005.

divinatory astrology are quite different from mo divinations discussed in chapter 8 , in the sense that they are annually calculated by professional astrologers and published in popular almanacs.

To repeat, the five factors in the sequence of their importance are: the life-force (srog), the body (lus), power (dbang thang), good fortune (rlung $r t a$ ), and the vital-essence (bla). Tibetan almanacs present these five factors every year with their annual changes. As mentioned earlier, even though the five factors are non-Buddhist in origin (Samuel 2001: 250), their astrological interpretations have been embedded in the Buddhist karma theory.

My analysis focuses on how these five factors provide temporal frameworks for Tibetans who use them to map out auspicious and inauspicious times in their lives. My aim here is to explore how longevity is understood and negotiated through these five factors. I show that longevity in this particular context means more than just the length of the life-span. It also involves personal power, economic achievement, and the ability to deal with illness successfully. 
I avoid going in great depth concerning the actual calculation methods, since they have already been published elsewhere (Berzin 1996; Cornu 1997; Dorje 2002; Drungsto 2002; Henning 2007). For my analysis, it suffices to know that all the attributes recur invariably and with periodic consistency during astrological time cycles, and that the calculations of the five factors are all based on the five Chinese elements (water, earth, fire, wood, and iron) and the twelve year signs (mouse, ox, tiger, rabbit, dragon, snake, horse, sheep, monkey, bird, dog, pig) and their changing relations to each other. The calculation follows a certain principle, described by Henning:

Each year has a specific element associated with each factor, and when an astrological examination is performed, those elements from the natal year are compared with those in the year under consideration (Henning 2007: $172)$.

The annually changing strengths of these five factors are calculated according to the so-called 'mother-son-enemy-friend' cycle ( $m a$ bu dgra grogs). This is an astrological method to determine the beneficial or harmful interrelationships between the elements and year signs, which relate to each other in 'friendly' or 'unfriendly' ways (Dorje 2002: 63). "These relationships are the basis of most of the calculations and prognostications of elemental divination" (Henning 2007: 169).

For instance, since water extinguishes fire, it is regarded as the 'enemy' of fire. The year signs that are linked to water are considered harmful to the year signs linked to fire. The relationships between the year signs are traditionally marked by pebbles $(\mathrm{rdel}) \mathrm{.}^{5}$ In the almanac, white pebbles are symbolised by ' $o$ ' and black pebbles by ' $x$.' Three white pebbles mean 'excellent,' two 'very good,' one 'good,' one white pebble with one black pebble 'neutral,' one black pebble 'bad,' and two black pebbles 'very bad.' The meanings of the pebble calculations are all based on these relationships and are summarised in the following table.

5 Dorje (2002: 296ff) explains various types of divinatory pebble calculations. Ekvall (1963: 34) mentions 'pebble divinations' (rde'u mo). 
Table 6.1. Interpretation of pebble calculations in the Tibetan almanac (according to Henning 2007: 170)

\begin{tabular}{|c|c|c|c|}
\hline $\begin{array}{l}\text { Relationship between } \\
\text { Elements }\end{array}$ & Number of Pebbles & $\begin{array}{l}\text { Pebble Symbol } \\
\text { in the Almanac }\end{array}$ & Interpretation \\
\hline Mother $(m a)$ & three white pebbles & $\therefore$ & excellent \\
\hline Friend (grogs) & two white pebbles & 00 & very good \\
\hline Son $(b u)$ & $\begin{array}{l}\text { a pair of white and } \\
\text { black pebbles }\end{array}$ & $o x$ & $\begin{array}{l}\text { neither good } \\
\text { nor bad }\end{array}$ \\
\hline Enemy (dgra) & two black pebbles & $x \times$ & very bad \\
\hline $\begin{array}{l}\text { When element earth } \\
\text { meets earth, or water } \\
\text { meets water }\end{array}$ & one white pebble & ○ & good \\
\hline $\begin{array}{l}\text { When element fire meets } \\
\text { fire, iron meets iron, or } \\
\text { wood meets wood }\end{array}$ & one black pebble & $x$ & bad \\
\hline
\end{tabular}

\section{The Tibetan Almanac}

During fieldwork, I came across three different almanacs (lo tho). ${ }^{6}$ All three differ slightly in their dates, ${ }^{7}$ which indicates that there is no uniform system of calendrical calculations among Tibetans. ${ }^{8}$ In Kalimpong, I mostly saw the MTK almanac in use.

Many Tibetans keep an almanac at home to identify auspicious and inauspicious days on a day-to-day basis and to check their annually changing five factors. In the almanac, the five factors appear in a 'sexagenary table' and are marked by white and black 'pebbles' (summarised in table 6.1). The table is called sexagenary because it describes a sixty-year cycle made up of the five elements in combination with the twelve year

${ }^{6}$ These almanacs are published by the MTK in Dharamsala, by Khunu Dhatho Gyespa in Kinnaur, and by the Palpung Sherabling monastery in the Kangra Valley in Himachal Pradesh. The MTK almanac follows the phug pa tradition and is the standard Tibetan almanac approved by the Tibetan government-in-exile (Tenzin Tsewang Jamling, personal communication, July 2010). The common almanacs are almost certainly from the phug $p a$ tradition (Henning 2007: 9).

7 The differences are minimal and refer mainly to 'skipped' and 'extra' days (Tenzin Tsewang Jamling, personal communication, July 2010).

${ }^{8}$ For a detailed discussion of these discrepancies in calculations see Henning 2007, chapter 6. 
signs. Jampel Kaldhen, the educator and lay astrologer in Kalimpong, explained to me that all these pebble results are based on detailed astrological calculations, but that they are shown in the form of pebbles to make the reading easier for lay Tibetans.

One day, I discussed the almanac with Amchi Jamyang. He had a keen personal interest in astrology and took private classes once a week with a senior monk astrologer in Kalimpong. He explained the 'sexagenary table' in an old almanac of 1999, which he was using for his studies.

For a person born in 1965, in this year [1999] the following calculation applies: srog has three white pebbles [ $\because 0]$, which means that the life-force is very good that year; lus has one white, one black pebble $[0 \times]$, which indicates that the physical strength is neither good nor bad. One white and one black pebble means that there could be illness or not. Dbang thang has two white pebbles $[0 \circ]$ to show that there is a very good chance to attract money. Two white pebbles [0o] for rlung $r t a$ means there will be good luck. Bla with three white pebbles $[\%]$ is extremely good this year. Even if there is illness, it will be easy to deal with since there will be enough money, good luck, and a strong life-force.

Each of these five factors will be explained in detail in the following sections. Apart from the annual pebble calculations of the five factors, 'vitality tables' for srog and bla are also widely used. They have already been explained in chapter 4.4 .

Tibetan astrology holds that every twelve years throughout a human life-span - i.e. at the Tibetan age of $1,13,25,37,49,61,73,85$, etc. $^{9}$ - a so-called 'obstacle year' (lo skag, lo keg, or lo skeg) occurs when the natal year-sign coincides with the calendar year (gcig pa rang keg) $\cdot{ }^{10}$ During a skag year an individual can easily fall ill or even die an 'untimely death.' Tibetans are very conscious of their skag year. Even the year preceding the skag year is already considered inauspicious. The obstacle year is a reoccurring cyclical time-marker that calls for special rituals and meritgenerating activities to lessen potential obstacles. I have observed Tibetans making all sorts of adjustments during their skag year, such as shifting their residence, changing jobs, or going into retreat (see the example of Könchok Peljor in chapter 7.2).

\footnotetext{
9 One has to be aware here that Tibetans use 'inclusive counting,' which reckons the actual birth as the first birthday. When a Tibetan says, 'I am eighty-five,' it means that he/ she is in her eighty-fifth year, but that the age by our reckoning is eighty-four.

${ }^{10}$ Skag year calculations are quite complicated (see Dorje 2002: 224ff); some of them use forty-seven pebbles (Dorje 2002: 417-418).
} 
The following sections now briefly introduce the five factors, which are also summarised in the table in appendix 1.

\section{The Life-force \& the Body}

The life-force, srog, is considered the most important of the five factors since it directly determines the life-span. Without srog there can be no life. Srog and tshe are so deeply interlinked that it is not surprising that some astrology books use them as synonyms (Drungtso T.D. 2002: 101). Henning argues that srog is concerned not only with life itself but also with risks to it, such as accidents, danger, and natural causes, whereas the factor lus (lit. 'body') refers to physical health and well-being. Consequently, if both factors are weak at the same time, the person would perhaps be considered "to be in mortal danger through ill health" (Henning 2007: 172).

Srog is the first of the five factors mentioned in the almanac, followed by lus. Srog and lus involve both the quantity of years and the quality of life. Srog sustains the life-span, but not necessarily the body. What is the use of a long life if one's health is weak? Some elderly people mentioned this issue and refused to attend a tshe dbang because they did not want to live longer than necessary in their frail bodies. Some elderly Tibetan women, among them my Sikkimese Bhutia landlady in Kalimpong, even warned me not to go to too many long-life empowerments, since becoming too old would be undesirable because of the hazards of old age. According to them, a tshe dbang could be harmful since each tshe dbang was believed to add a few years to the individual's life-span. In contrast, one sponsor of a tshe dbang in Kalimpong said that the old people requested the tshe dbang because "even a few extra days would allow them some more time to collect merit for a better rebirth by reciting mantras." I am aware that this might have been just the culturally-appropriate explanation given to an inquiring foreigner, but this particular empowerment was well attended by the elderly.

Physical well-being might not be caused directly by a strong srog. In astrology, the 'body' is considered a separate category, which is linked to srog but not synonymous with it. This view differs from that found in Tibetan medical texts, where the life channels and srog are very much a part of the physical body (Rgyud bzhi II, 4). Both types of bodies are called lus but, while the 'astrological body' is more a parameter indicating the quality of health, the 'medical body' is the physical form prone to balance and imbalance caused by disturbed nyes pa. The existence of two different types of lus here shows that we are not dealing with a unified concept of 
the body in astrology and medicine, and that one and the same Tibetan term can receive different meanings in different knowledge systems.

Even within the astrological context, the categories of srog and lus are used in various types of calculations referring to all aspects of daily life. They are thus not only technical parameters used to calculate the quality of the life-span but also determine issues beyond tshe, such as death and rebirth. For example, during death calculations they give indications of the realm in which the person will be reborn (Dorje 2002: 330). Tibetans can also influence the lus factor. For example, there is a popular practice of changing lus through wearing odd, funny, and colourful clothes.

\section{Power, Prosperity, and Presence}

The factor dbang thang relates to personal power and peoples' capacity to achieve goals and attract money. It does not necessarily include the moral concept of merit, and "can be misdirected and result in illegitimate status acquisition" (Calkowski 1993: 33). It also relates to rlung rta, as well as to notions of auspiciousness. Norbu translates dbang thang as 'ascendancy-capacity' (Norbu N. 1995: 62). If dbang thang is strong, it is easy for a person to accumulate merit and perform good deeds, if his/ her motivation is ethical. A weak dbang thang leads to loss of prosperity, power, vitality, and good fortune. Dbang thang considerably expands the understanding of life-forces into the ethical frameworks of society as well as into political control and economic power. Dbang thang signifies "both the ascendancy and charisma a person can exercise over others and the capacity to perform activities of the first order in any field such as government or conquest" (THL 2009). Henning suggests that, "control could also be a good translation for this in the sense that we talk in English of the resources a person controls" (Henning 2007: 172). Jampel Kaldhen talked of dbang thang and all five factors as relevant to health and longevity (see chapter 6.4).

In a Tibetan medical context, knowledge of dbang thang is considered important in the organisation of treatment strategies, particularly expensive surgeries. One day in 2005, when I discussed the remaining life-span with Amchi Jamyang, he started talking about his latest astrology class. He had just studied the five factors and spontaneously talked about them.

Dbang thang is the most important - equal to money. Without money you cannot buy good food, medicines, and look after your health needs. If the dbang thang is low, you won't get money for an operation. For example, if you do not go for the surgery, you may die a premature death through heart failure. Many Tibetans go to the astrologer to calculate the auspicious day 
for a successful surgery (except during emergencies), and also to see the quality of their dbang thang, which will tell them if they will get the money together for the surgery. If your tshe is sixty, but at forty you develop a heart disease, you may die if you do not undergo surgery. In India, this costs lakhs of rupees [several thousand euros], and if you do not have dbang thang to pay for it, you will have an untimely death.

Many Tibetan patients not only checked astrologically whether they would survive an illness by getting a prognostication of their life-span, but, as Amchi Jamyang explained, they also felt the need to ascertain whether they were able to handle the economic side of the illness event and afford the treatment. Tshe involves economics; long life needs financial security, especially in the absence of any organised health insurance in the Indian exile situation.

Having the dbang thang to be able to contribute financially to rituals also plays an important part in Tibetan societies. Since the sponsors are believed to receive the primary merit of the ritual (Clarke 1990: 174), dbang thang and merit accumulation are closely linked. I discuss the role of the sponsors in relation to longevity empowerments in more detail in chapter 9.3.

Karmay suggests that the four factors (bla is excluded here) are connected to Tibetan ritual contexts. He mentions a ritual ${ }^{11}$ that strengthens the four factors, and especially dbang thang. In one particular part of the ritual, dbang thang is represented by "a vase with four sides likened to four doors. In the east, it has merit, in the south, the gift of oratory, in the west fame and in the north wealth" (Karmay 1993: 152; emphasis added). This image represents the accomplishments that a person with a strong dbang thang can achieve, which can be ritually supported. Karmay's example points to some interesting issues. First, employing personal influence combined with economic and political power can in itself be seen as potentially meritorious. Second, Tibetan ritual ideas easily involve power, wealth, and politics, i.e. this-worldly activities. Third, dbang thang, just like the other four factors, is more than a technical term used in astrological calculations and has wide-ranging popular and ritual meanings. An example for a popular interpretation of dbang thang is its power to win consistently in gambling situations as compared to rlung rta (the factor

"The Tibetan title reads Dbang thang bskyed pa'i thabs (lit. 'The method of generating dbang thang'). The text was published in Bskyed pa bzhi ldan gyi gto chog, Gto chog skor, Thimpu 1987 (quoted in Karmay 1993: 157). 
explained in the next section), which could cause a one-time sudden lottery success (Calkowski 1993: 35).

\section{Generating Good Fortune}

The fourth factor, rlung $r t a$, is about good luck and happiness in thisworldly existence. In a popular context, rlung rta certainly encompasses more than the meaning ascribed to it as an astrological factor. In the astrological pebble calculations of the sexagenary table, rlung rta is one of the five factors and indicates "the progress of one's activities and work. Will there be obstacles, or will things flow smoothly?" (Henning 2007: 172). Lichter and Epstein point out that rlung rta refers to a person's worldly luck, which undergoes cyclic alterations and can be astrologically calculated, unlike bsod nams, which is cumulative and affects various lifetimes (Lichter and Epstein 1983: 240). Calkowski, in the context of Tibetan gambling, stresses the 'unpredictability' of rlung rta (such as winning a lottery) and its flow down from deities to humans, "who cannot, in turn, accumulate it, direct it to any specific purpose, or transfer it" (Calkowski 1993: 32).

Rlung rta, obviously, is not part of the Buddhist karma and merit duo of causality - even though it might be explained in those terms. Rlung rta is also not always linked just to the individual. 'Untimely deaths' caused by a low rlung rta can badly affect not only the deceased person but also other family members. A 'timely death,' in comparison, is ascribed to the individual's karma, and not to his/her rlung rta (Lichter and Epstein 1983: 240). I discuss these ideas of timeliness further in chapter 7.1.

Rlung rta can be strengthened through a variety of rituals, which are specifically designed for crisis intervention and to counteract dangerous supernatural influences, in other words to avert secondary causes of misfortune (Lichter and Epstein 1983: 241). Rlung rta rituals are preferably conducted in the morning during the waxing moon and are often accompanied by a fumigation ritual (bsang; Cornu 1997: 97).

During fieldwork, I heard that the practice of raising prayer flags (dar lcog, lit. 'cloth attached to the pinnacle or turret'; Karmay 1993: 150) was commonly known as 'practising rlung rta,' the motivation being to generate good fortune and auspicious circumstances, mostly for thisworldly events. In Kalimpong, prayer flags are nowadays increasingly manufactured by the Indian Marwari community around Tenth Mile and printed on cotton or synthetic cloth in the colours of the five elements (earth-yellow, water-blue, fire-red, wood-green, iron-white) with designs 


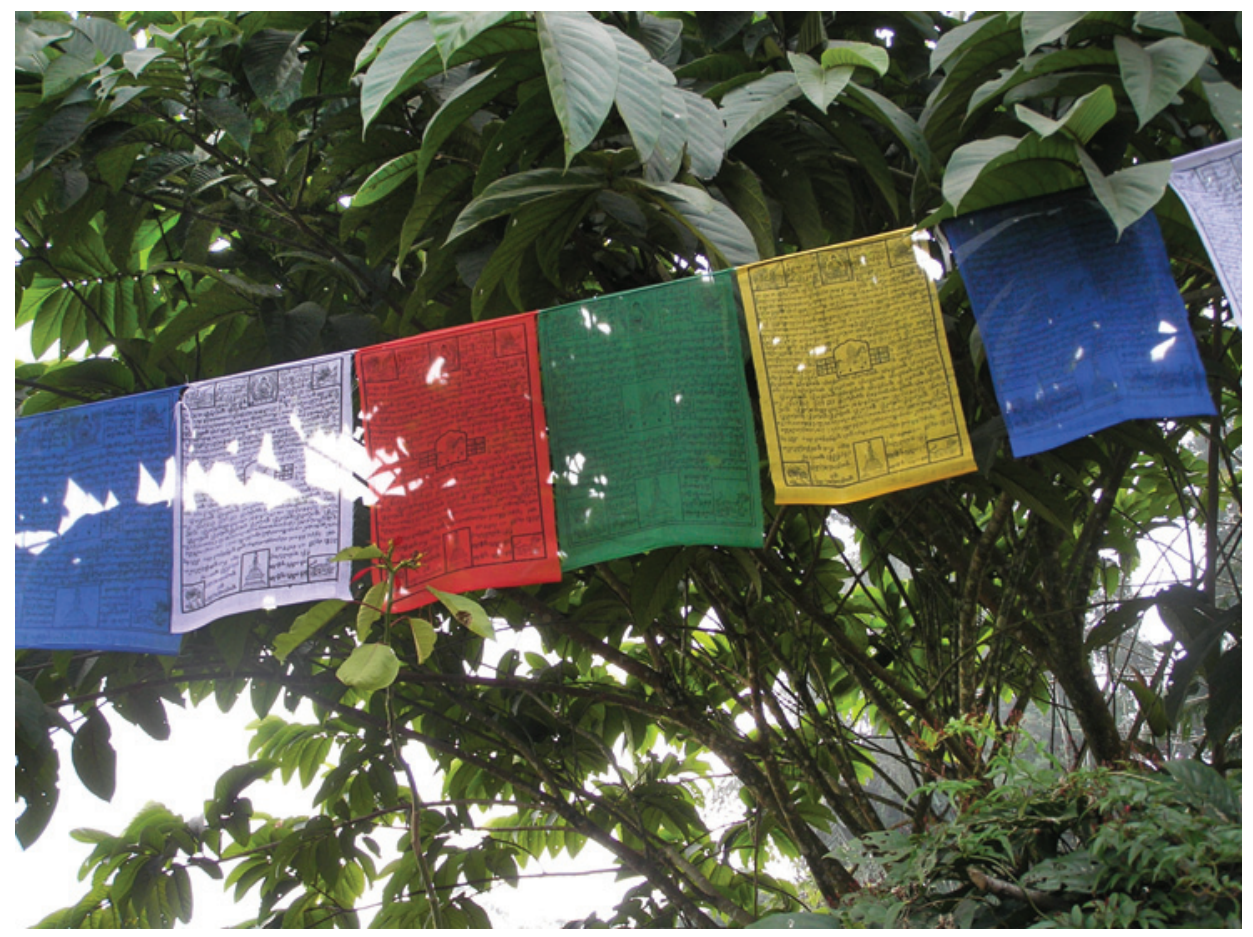

Plate 6.2. Rlung rta flags in the five colours of the five elements with printed mantras and symbols, Kalimpong 2005.

of mantras and animal symbols (see plate 6.2). ${ }^{12}$ Tibetans from the entire region buy them there for further trade or personal use. These prayer flags, although called rlung rta, cover only part of the concept of rlung rta. As Karmay observes, "the word is still, often mistakenly, taken to mean only the actual flag planted on the roof of a house or on a high place near a village. In fact, it is a symbol of the idea of well-being or good fortune" (Karmay 1993: 151).

Prayer flags are raised periodically on auspicious days at monasteries, on bridges spanning rivers, on mountain tops, and other auspicious places. Tibetans often follow astrological and divinatory advice and select only those colours that would raise their personal rlung rta or any of the other factors during that year. For example, the fourteenth Dalai Lama's

${ }^{12}$ Cornu (1997: 100-101) and Karmay (1989: 152-156) describe such animal symbols on prayer flags in more detail. 
birth element is wood and therefore Tibetans preferably raise green rlung $r t a$ on his birthday. This is often combined with raising the number of flags that corresponded to the age of the person. Raising flags in all five colours is considered helpful in strengthening all five factors. ${ }^{13}$ Rlung rta should not be raised on inauspicious days or without having been blessed through prayer.

Tibetans take an active part in strengthening their five factors, especially through raising rlung rta. In Kalimpong, the Durpin Gompa was the most preferred location for raising prayer flags. Rlung rta is also closely related to the individual's bla. Good fortune involves finding and restoring the bla of a person (Mumford 1989: 175-178; Samuel 2005: 232). In astrology, bla is one of the five factors, and as I show next, not necessarily synonymous with the individual bla.

\section{'Bla is the Mother of Srog'}

The MTK almanac includes bla as the fifth factor. Some almanacs only mention four, leaving aside bla (Henning 2007: 172). In Tibetan astrology, the bla is called 'the mother of srog' (srog gi ma ni bla ru grags; Drungtso T.D. 2002: 111), mainly because astrologically, using the ma bu dgra grogs cycle, the relationship between bla and srog is that of a mother to a son, which is said to be very favourable. ${ }^{14}$ I was told by amchis that without the protective shield of bla, srog would deteriorate very fast. Therefore, any loss of bla has to be diagnosed and treated, since a long-term loss could weaken srog to such an extent that the person could die an 'untimely death' (an example here is Mumford's ethnographic account of Samden's death; see chapter 7.1).

As already mentioned, bla concepts are rather fluid, and the popular understanding differs from the astrological and medical meanings. The popular understanding among Tibetans is that bla only affects one's present life and does not affect ones subsequent reincarnations (Lichter and Epstein 1983: 241). In Kalimpong, I documented a story of a Tibetan man

${ }^{13}$ Lopez mentions the practice of writing one's year of birth on the flag before hoisting it, which I did not see in practice in the Darjeeling Hills, where Tibetans use readymade printed flags. The benefit of raising the flag in Lopez' example is reflected in the text printed on the flag: "May lifespan, merit, power, energy, glory and fame of the person born in _ year increase” (Lopez 1997b: 550).

${ }^{14}$ For example, the element of srog of someone born in a horse year is 'fire.' According to the ma bu dgra grogs cycle, 'wood' is the mother of 'fire.' Astrologically, 'wood' would be the element of this person's bla (see also Drungtso T.D. 2002: 112). 
suffering from terminal stomach cancer. About two months before he died, he himself felt that the bla left him, and he told his family about it. In this case it was clear that the patient would not survive his illness and no ritual efforts were made to bring back the bla.

Bla in the pebble calculations is a technical factor and an index of a person's state of bla. For instance, it provides amchis with information on the quality of bla during the particular year, which indicates how successful or unsuccessful their treatment might be. Amchi Jamyang explained, "If the bla [factor] is weak, say with a result of two black pebbles, the patient may die during that year." On the other hand, if bla has three white pebbles - as was the case in his example given at the beginning of this section - illness "will be easy to deal with."

While the pebble calculations on bla may provide information to amchis and their patients on the seriousness of an illness, the manner in which lay Tibetans and astrologers themselves interpret these calculations shows that they adjust the readings to personal circumstances. The following ethnographic account of Jigme losing his bla illustrates such a case.

\section{Jigme Lost His Bla}

The ethnographic example presented in this section points to the interconnectedness and temporality of the five factors explained above and exemplifies how astrological calculations concerning the five factors are interpreted by Tibetans and guide health-seeking activities. By interconnectedness I mean that the five factors influence each other in such a way that one weak factor may weaken another and the strengthening of one factor may strengthen another. They are temporal in the sense that some of their leading elements and their interrelationships, and therefore their effects on the individual's life, undergo cyclic alterations.

With the following account I suggest that a reading of the five factors and their interconnectedness provides a wide platform with many options for experience-related interpretations to explain illness events. Tibetans do not necessarily take the yearly calculation of a single factor as an equivalent for the actual state of the corresponding life-force of a person. They might choose multiple diagnostic methods (astrological, divinatory, medical) and interpret the results according to their situation. The interconnectedness of the five factors provides them with the opportunities to make adjustments where necessary. In other words, the bla of a person 
can be lost even though the astrological bla factor still shows one white pebble, which is actually not a bad result. Reasons for a loss of bla might instead lie in the weakness of one or more of the other factors, which show black pebbles for that particular year.

One day in July, 2004, during one of our discussions on astrology, which usually took place at his residence after school hours, Jampel Kaldhen explained that to understand longevity in astrology, one needed to study all five factors.

Longevity is related to all five, you have to study all of them [...]. If your rlung rta falls, your bla 'betrays.' You feel stress and depression. We call it bla 'khyams pa, the bla is wandering around [...]. We say srog and lus have the combination of the five elements. One is related to another. Lus means your health. If something goes wrong with bla or rlung rta, your health deteriorates. A weak bla usually also causes ill health. Some people feel something is lost; their energy and strength leaves them.

During our discussion, he told me that three weeks earlier his son Jigme, who was in his late twenties, had lost his bla. When Jigme later came into the room, I asked him to join our conversation and requested him to talk about his loss of bla. He agreed but was quite shy, and his father dominated the conversation, which was held in English and which I recorded. The conversation elucidates some interesting points.

JIGME: Three or four times I had nightmares, really bad; I felt like being strangled, and in the morning my body felt really heavy.

KALDHEN: It was stress-related and could not be cured with medicine. First we went to Dr. X [he mentions the name of a biomedical practitioner in Kalimpong], but medicine did not help. We sent a note with a request for a mo, money, and a kha btags [a Tibetan ceremonial scarf] to two monasteries, Durpin Gompa and the Segyu Datsan [a Gelukpa Tantric College in Kalimpong]. Mostly, they do the Palden Lhamo dice $m o$, but a different version from the one I have here. You have to send the message before noon. In the afternoon the mo cannot be done clearly. You also have to consider astrology.

JIGME: Both divinations showed that my bla had been lost, and I had to do the bla 'gugs tshe 'gugs ritual. I had to take two shirts to the püjā [the popular Sanskrit term for ritual], one I had previously worn, and a fresh one. I also had to take a real turquoise stone, a bla g.yu, which I have been wearing since the $p \bar{u} j \bar{a}$ [he showed me a sealed amulet he was wearing around his neck].

KALDHEN: You need a bla g.yu, not a good one, but make sure it is not artificial. It has to be from Tibet. Three years ago, I also did this. It is said that the bla g.yu should be kept for several months. If you don't lose it you can keep it forever [he shows me his bla g.yu which he was wearing on a string around his neck]. If possible, you should always wear it. 
JigmE: The püjā started with a bowl of water, in which a sheep (bla lug) made of dough was placed. When the sheep drowns it is a very bad sign. In my case, they stirred the water and the sheep made a full circle until it faced me. It took only about half an hour. It can take two to three hours until the sheep finally faces the patient. The night after the $p \bar{u} j \bar{a}$ I felt better; I did not have any nightmares.

KALDHEN: For the bla 'gugs püjā your presence is very much needed. If the sheep takes hours and hours to face the patient, that means bad luck. If it goes fast, it means it is not too bad. Many lamas know this ritual; they need to have done a three-year retreat to perform this pūja. Especially, if a disease cannot be cured by medicine, you do the bla 'gugs tshe 'gugs. ${ }^{15}$

BG [Tо JiGME]: What do you think bla is?

JIGME: I don't know, but I had very bad nightmares, felt like being strangled, and after the püja I became better, my body felt much lighter. When I had the nightmares, the next morning I had a very heavy body.

BG [ASKING KALDHEN]: Did you check the almanac?

KALDHEN: His bla was not so favourable, only one white pebble. We did another püjā for this with about four monks [he opens the almanac]. Jigme was born in 1969, an earth-bird year (sa bya). This year his srog has one black pebble, lus, that is health, has one white pebble, dbang thang has two black pebbles. Bla has one white pebble, not so bad, but his dbang thang is bad [two black pebbles]. Dbang thang is the main force, so if dbang thang is not good, everything else will be affected. Then we have to see the sme $b a$ [nine numeric squares] and spar kha [eight trigrams] as well.

You can also change your lus by changing your clothes. You wear odd shirts and funny clothes, and people will say, 'that is good.' Jigme did not do this. They say you can wear very colourful clothes to change your lus.

Jigme's story is a good example for the interpenetration of western and Tibetan approaches to illness among Tibetans in the Darjeeling Hills and highlights the medical syncretism in the area, which I outlined in chapter 2. Jigme's father had no difficulty in giving a 'western' interpretation of bla ('It was stress-related and could not be cured with medicine'). They first tried biomedicine, which did not work. Jigme and his father were then able to understand the experience with the help of their astrological system as well as in a divinatory and ritual context. It is difficult to say which of these frameworks was of primary concern for their interpretation. Kaldhen seemed to be able to use all four - biomedicine, astrology, divination, and ritual - quite freely.

The partly conflicting results that appeared using different Tibetan diagnostic frameworks (astrology, divination) were overcome by interpreting

${ }_{15}$ Towards the end of fieldwork, I was able to document a bla 'gugs tshe 'gugs ritual at the Tharpa Chöling monastery in Kalimpong, which was similar to Jigme's description. 
all the five factors in relation to each other and matching them to the divinatory result. Even though the astrological factor bla was not too bad [o], Jigme's bla could still be still lost - as the two divinations had revealed since his dbang thang was very bad $[x x]$, and his srog was weak $[x]$. What becomes clear here is that the astrological factor bla is clearly not the same bla a person has, but it can indicate a weakness of the person's bla, the loss of which is usually confirmed by a divination and then ritually treated.

When I met Jigme again three months later, he was still fine. "No more nightmares," he said, showing me two turquoise stones he was wearing, one around his neck and the other one on a cord tied around his upper arm. 
This chapter explores the concepts of 'untimely death,' as well as the 'remaining' and 'maximum' life-spans with ethnographic examples from the anthropological literature and my fieldwork. I also discuss how breath is used as a temporal framework in yogic practices to manipulate the life-span.

Among Tibetans, 'untimely death' (dus min 'chi ba) is an important component of astrological death calculations. The Baidürya dkar po bases such calculations mostly on the five factors, the nine numeric squares, the eight trigrams, and the year sign of the deceased (Dorje 2002: 312). An 'untimely death' implies the idea that the life-span was not lived to its full length, but was cut short through sudden illness or an accident, generally understood as caused by the ripening of previous negative karma and the lack of merit. Longevity practices have been known for not only prolonging lives but also for preventing 'untimely deaths.' Some Buddhist ritual practices go as far as claiming that not only an 'untimely death' but also a 'timely death' can be 'cheated' (Schneider 2010: 56). Moreover, Mahāyāna Buddhism has developed the view that enlightened beings have extraordinary control over their life-spans (Schneider 2010: 56), something I discuss later in this chapter.

The notion of 'untimely death' appears frequently in Tibetan Buddhist texts and is linked to the merit and karma ideology. For example, the first Dalai Lama mentions three reasons for an 'untimely death': (1) the exhaustion of the life-span, (2) the exhaustion of merit, and (3) the exhaustion of karma (Mullin 1986: 150). There are countless texts in Tibetan traditions on 'death omens' ('chi ltas) and ritual practices that involve the strengthening of the life-forces to avoid an 'untimely death' (Beyer 1973: 367-375). Schneider mentions that ideas of 'untimely death' were widely spread in India and influenced the development of a religious terminology along those lines (Schneider 2010: 82).

'Untimely deaths' are thought of as occurring suddenly and unexpectedly, mostly through accidents. Among Tibetans, the state of mind at the point of death is seen as crucial for the subsequent rebirth. An 'untimely death' is understood as potentially creating an unfavourable rebirth since 
one's state of mind is most likely to be disturbed through a sudden death. The perception of 'untimely death' may differ widely between common people and dharma practitioners. The fear of accidents, for example, motivated young Tibetans, who had to drive around the steep, curved roads of the Darjeeling Hills, to attend a tshe dbang (see chapter 10).

In Tibetan popular religion and also, to some degree, in astrology there is the idea that if a death was 'untimely,' the 'remaining life-span' (tshe lhag) can still be lived in another lifetime. Tibetans enact ideas of 'timeliness' through the notion of a 'remaining life-span.' The idea of a death being 'timely' allows for lives to be short and still meaningful. If a death is 'untimely,' the 'remaining life-span' can be of comfort to the grieving family, because either the current short life was a remnant of a past life, or the remaining years of the current life-span that was cut short can still be lived in another future human incarnation. ${ }^{.}$Through the idea of tshe lhag Tibetans temporalise the life-span across more than one lifetime. I have not come across an explanation of exactly how tshe lhag is transferred to the next life. It does not fit into the Buddhist teaching of the transfer of consciousness (rnam shes) through the intermediate state between death and rebirth (bar do). But I often observed that Tibetan popular religion is not concerned with such technical details.

Tshe lhag is not mentioned in the Tibetan medical texts Rgyud bzhi and the Baidurrya sngon po. According to Mumford, it appears in astrological death calculations among Tibetans and other Buddhist communities, such as the Gurungs in Nepal (Mumford 1989: 196ff). ${ }^{2}$ The tshe lhag can only be calculated when the person has died, because the astrologer requires the particular time of death for the calculations. One cannot calculate the tshe lhag while the person is still alive. The tshe lhag implies an interesting notion of temporality because it crosses the boundaries of birth and death into another lifetime. Tshe lhag is not about how many years a person has still left to live, but how many years of the deceased's maximum life-span were not lived in this lifetime.

In the following, I present and analyse ethnographic accounts of 'short lives' and 'untimely deaths' and show that the notion of tshe lhag is about

\footnotetext{
${ }^{1}$ The life-span is also transferable between beings. In the Phur pa sgrol ba rituals, the left-over life-span of the liberated being gets transferred to the Buddhist practitioner (Cathy Cantwell, personal communication, November 2007).

${ }^{2}$ Mumford here might refer to specific texts; Dorje 2002 does not mention tshe lhag as part of the death calculations in elemental astrology.
} 
making sense of 'timely' or 'untimely' deaths. Tshe lhag helps Tibetans comprehend why a person died when he/she did. It allows for the lifespan to be placed in a temporal framework that supports people who are encountering deaths in their families. As I show below, especially in the case of sudden death in children, tshe lhag helps to some extent to make sense of a short life-span, although coping with the grief of losing one's child is clearly a more complex issue. Amchi Jamyang saw the purpose of calculating the tshe lhag as a support for the grieving family and said, "I think that the calculation of the tshe lhag at the time of death has the sole purpose of causing some relief and peace of mind for the grieving family members."

Jampel Kaldhen told me that he would not necessarily tell the family of the deceased about the tshe lhag when he was asked to calculate it as part of the death calculations. He thought that knowing that a death was 'untimely' would increase the grief; he would therefore rather keep quiet about these calculations.

The following section presents a case from the available anthropological literature on the timeliness of death and tshe lhag.

\section{The 'Timely' Death of Samden}

Mumford's account on the sudden death of the twenty-three-year-old woman Samden among the Gurungs in Gyasumdo, Manang District, Nepal, is the only ethnographic account I came across that deals with the 'remaining life-span' (Mumford 1989: 196-204). ${ }^{3}$ The death of Samden describes the coming together of a Gurung shaman and a Tibetan lama, neither of whom could expel the spirits that had befallen Samden when she had accepted some milk from an old lady on her way back to the village. When the government health assistant was called, he ascertained that she had been bitten by a dog three months previously, and left with comment that she was dying of rabies. This was of no relevance to the lama and the shaman, who both diagnosed a spirit attack. However, none of their rituals was successful, and the girl died.

\footnotetext{
3 During Mumford's fieldwork (1981-83), Tibetans in Gyasumdo commonly attended Gurung rituals, and Tibetans called both Tibetan lamas and Gurung shamans for exorcism rites.
} 
The Tibetan lama, who was also a skilled astrologer, was responsible for calculating Samden's death horoscope. Socially, the situation demanded that the death was 'timely' since no ritual means, neither shamanic nor Buddhist, had been able to treat the girl. Both lama and shaman had failed. The family had to be reassured that 'nothing more could have been done.' The socially acceptable explanation would be that her death was 'timely.'

The astrological calculations described by Mumford consisted of three time cycles, utilising (1) the five factors, (2) the year signs, and (3) a day calculation (Mumford 1989: 199-204). The lama made a calculation and prediction for each of these cycles, which left the option of final interpretation to him. The first time cycle utilised the five factors, which were explained in the previous chapter. The calculation showed one black pebble for Samden's bla and srog factors, which indicated that her bla had already been lost a year previously and had not been recovered ritually. Her srog was weak and thus death was 'timely.' Both factors having one black pebble also indicated that she was prone to spirit attacks at the time of her death. Lus, dbang thang, and rlung rta all had white pebbles, which were interpreted as good omens for the surviving family. If lus had been black, she would have remained attached to her family possessions, and a black rlung rta would have brought malicious talk against the family.

This example shows that the five factors are also used to interpret the situation for the remaining family members who could potentially be harmed by the daughter's death. Lichter and Epstein point to a similar case. If a low rlung rta and not the individual's timely karma caused the death, the survivors would have to conduct specific rituals to avoid being harmed themselves by the low rlung rta factor (Lichter and Epstein 1983: 240). Here, in the widest sense, life-span interpretations are not only of individual but of social importance, since they affect the entire group.

The second time cycle calculation was considered the most important one and involved the twelve year signs. The result was that her death was 'untimely,' and that she had actually six more years to live. Mumford documents this as follows:

The text stated that she had been a nun in her previous life. The nun had had an untimely death, and Samden's recent life had been given so that she could 'use up' the unlived years of that nun, which should have taken her life up to age twenty-nine instead of age twenty-three (Mumford 1989: 199).

The third time cycle was based on a day calculation, which showed that 'nothing could have been done.' Moreover, her death occurred in the year 
prior to her 'obstacle year,' which was considered inauspicious and susceptible to demonic attacks.

Mumford points out that the technique of these calculations itself allowed for a choice between conflicting statements; there was no need to manipulate or cheat on the reading. The interpretations followed two principles of selection:

[F]irst, statements that are consistent with others have more weight than isolated, deviant assertions. Second, statements are selected that have the most consistency with known experience (Mumford 1989: 202).

It is common in Tibetan divinations that predictions are open to interpretation and can be adjusted to the current experience of the person requesting the divination. Some diviners experience a certain pressure "to express their predictions with some degree of ambiguity and inexactitude, in order to minimise the possibility of error" (Chime Radha Rinpoche 1981: 7). Apart from this professional 'error' technique, the divining method itself also involves intuition. This intuition is a spiritual ability that is sharpened through meditative practice and then applied to the divination technique. The primary answers suggested by the divination, and the accompanying text in some cases, are combined with an intuitive feeling for the situation. In the words of Chime Radha Rinpoche: "It is in this operation that something that might be called creation or inspiration enters the process of divination" (Chime Radha Rinpoche 1981: 16).

I have not come across a divinatory practice among Tibetans in which the diviner arrives at the interpretation of the divination results by discussing them together with the people asking the questions, such as in Mongolian divinations described by Swancutt (2006). Among Tibetans, the diviner, lama, or astrologer has the authority to present the final divinatory result, which remains unquestioned, even when the divination is a public event.

In Mumford's ethnographic account, the lama admittedly preferred to say that the death was 'timely.' "It is psychologically appropriate, it explains the failure of exorcism, and it teaches the karma doctrine," is Mumford's conclusion (Mumford 1989: 203). While Mumford is certainly right, it is interesting to analyse what his ethnographic account tells us about how people engage in practices of temporalisation in dealing with tshe? Three points come to light.

First, 'timeliness' as an attribute of death is skilfully employed to place tshe in a temporal framework that extends across lifetimes. The astrological methods themselves are designed to allow for an encoding of the 
life-span in a way that seems acceptable and appropriate to all concerned. The notion of tshe lhag is brought into play in an attempt to make sense of a sudden death. In that effort, tshe itself is stretched across a timespan that encompasses past, present, and future lives. Tshe is mapped out across lifetimes so that the current life-span, which has come to an end in a sudden death, can be made sense of in a socially appropriate way.

Second, the interpretation of 'timeliness' is given a powerful place in the situation. The time cycles of the calculation methods themselves consist of layers and various techniques. The technique itself includes several possible results and offers space for individual interpretation. It does not come as a surprise that the lama also functions as the astrologer at that time, and thus has a fair amount of control over the situation. The entire event is not only a matter of astrological calculation but also a matter of social skill and interpretation. The interpretation of 'timeliness' is a crucial factor to make things 'look right.'

Third, the person who does the calculations has the power to determine the death rituals. Mumford's example enables us to detect a nexus between tshe and the situational agency of the lama-cum-astrologer. As I showed in chapter 1.6, calendrical calculations are deeply linked to issues of power. In the Tibetan example, those who have the skill to apply astrological calculations have influence in guiding peoples' ritual performances in socially acceptable ways. In Mumford's example, the lama-cum-astrologer basically provides the temporal map for the people who have to organise ritual activities at a time of great emotional distress. Death events in Gyasumdo and among Tibetans in general are elaborate. Mumford describes the details of these events: how the corpse had to be dealt with, how the death demon had to be exorcised, how the surrounding villages had to be fed, how forty-nine days of rituals to be performed, and so on. The lama not only determined the 'timeliness' of death but also provided the time schedule for these events and carefully calculated who could touch the body and who could not, in which direction the corpse had to be moved, and on which day it had to be burnt (Mumford 1989: 200-205).

In chapter 1.6, following Mills (2005), I pointed out that the agency of professionals and lay people is stronger than the time-reckoning systems they use. Mumford's example shows that in the context of Tibetan death calculations, the reckoning system itself is designed in a way that allows for the situation to be interpreted by the professional lama-cum-astrologer in a socially appropriate way, while at the same time being truthful to the reckoning system. In this case, the lama's statements were critical for the villagers to make sense of the tragic death of a young woman that 
neither he nor the shaman could successfully treat. He had the agency to utilise the temporal frameworks available to him in a skilful way in order to pronounce her death as 'timely.' The temporal framework itself with its multiple layers of time cycles allowed the lama to exert his power and interpret the results according to what the situation demanded socially.

What he did is an example of what I call a practice of temporalisation. In this case, the temporal framework is the astrological calculation of the 'timeliness' of death. The concept of the 'remaining life-span' is part of the knowledge system the lama used to explain the sudden death to the people. This ethnographic example shows that it is through such practices of temporalisation that people are able to make sense of quite fluid concepts of the life-span and life-forces as well as complicated knowledge systems and then link them to their experiences and ritual practices.

Unfortunately, during my fieldwork I did not witness an astrological calculation of tshe lhag, but I came across the following case of a family history of short lives. This case study elucidates how the temporal ideas of tshe lhag and the 'timeliness' of death might affect the lives of Tibetans in a more encompassing way, influencing their own ways of negotiating tshe on a daily basis throughout their lives.

\section{A Family Story of Short Lives}

I had known Sherab ${ }^{4}$ (born in 1961) for almost ten years and sometimes stayed with him and his father when in Darjeeling. They lived alone and rented some rooms to long-term visitors. I knew Sherab as an active dharma practitioner with some monastic training and deep devotion to his lama. Sherab had become a monk in response to the last wish of his paternal uncle, who had died at the age of fifty-one of pneumonia in Darjeeling when Sherab was around twenty-one. The uncle had been a monk in his youth, but left the monastery to become a trader later in life. He was in his mid-forties when he felt his death was approaching. He gave up everything and went into a three-year retreat, followed by another twoyear retreat, and practised Tibetan Buddhism until he died at the age of fifty-one. The uncle expressed his last wish: that Sherab become ordained, even if it were for one day. Consequently, Sherab, who was very fond of

${ }^{4}$ All names in this ethnographic account have been changed to protect the family's privacy. 
his uncle, became a monk (he had also been advised by other lamas to become ordained).

None of Sherab's father's family members lived long. His father's parents and relatives all died before the age of fifty. Sherab and his father, Könchok Peljor, aged sixty-eight at the time, were keenly aware of the fact that everyone in their family had died early. Sherab's eldest sister died seven months after her birth. The lamas said at the time that every girl born to this family would have a short life. The family was advised to invite monks to recite a sacred text one hundred thousand times. Thereafter, Sherab was born as the only son. Another girl was born later, but died at the age of three. Sherab recalls,

When my sister died at the age of three, my father and uncle asked Rinpoche for an explanation. He said that she had three years of tshe lhag left from her previous life, which helped her to be reborn as a human and live for those three years. That in itself was auspicious. Her death was timely, and this helped my father to understand and accept her death.

Könchok Peljor never mentioned to me the death of his two daughters, nor his wife who had left him years ago, but recalled the death of his parents, two brothers, and a sister. Their early deaths led him to go for a longevity pilgrimage and to practise dharma. One morning in March, 2005, after he had completed his morning prayers, we sat in his kitchen in Darjeeling having breakfast. He narrated his story in Tibetan. It shows how he made sense of his own, longer life-span:

I am from a small place in Kham. My parents were farmers. They owned a lot of land. We had to pay taxes to China as well as to the Tibetan government. We had a hard life. My parents died at fifty-two and fifty-one from illness. I had two brothers and two sisters. Before my parents died, one of my brothers died at the age of twenty-eight. One of my sisters died at thirtyseven. We could not look after the land after my parents, brother, and sister had died, and so we left (my uncle, sister, brother, and I). So, at the age of thirteen, I came to Lhasa together with my uncle, who was around twenty, and stayed near the Jhokhang for two years working as a porter. Around 1952, I went with my uncle for pilgrimage to India, Sikkim, and Nepal. We went again back to Lhasa and were told by our lama to go back to India because the Chinese had already started to take over Tibet. So we went back to India.

My brother died when I was forty-four. Four years later, I went to Nepal to the Maratika long-life cave with my son, who at the time was around twenty-five and a monk. Inside the cave, I made the prayer that I would live up to the age of seventy-seven. I was praying as if I were talking to a person, requesting long life. I will be sixty-nine this year [2005], so I have possibly eight more years to live. 
Some people pray that they will live one hundred years. There is no benefit in getting too old. You cannot hear, your eyes get weak, you have no taste, can't eat, can't walk. It is useless to stay like that. The most important is your mind (sems). If you have many lamas it does not help, you need one lama you have total faith in, that's enough. This is very important.

When we die we do not know where we will be reborn - in a body of a human, an animal, insect [...] we do not know. Human life is really very short, we never know when death comes, we are like guests on this planet; we have to go.

I think my relatives' lives were so short because of their previous karma. It all depends on our karma, if we get sick, when we die [...] it's all our karma; we have to accept it. But life can be extended through bsod nams. Negativity can be purified with dharma practice. If there are obstacles (bar chad), the [prayer] bar chad lam sel ${ }^{5}$ helps; we do that. We can also do the tshe sgrub; that helps to clear the obstacles. If we practise dharma, we can go to the Buddha's pure land (sangs rgyas kyi zhing khams). If we really practise dharma, we can also attain enlightenment.

Later that day, Sherab, who spoke English well, showed me some photographs of their longevity pilgrimage to eastern Nepal, to the sacred cave of Maratika ('chi ba mthar byed, lit. 'to destroy death,' in Nepali halesi). The events of the story surrounding this pilgrimage site go back to the eighth century CE, when the Indian tantric Padmasambhava, founding figure for the Nyingma school of Tibetan Buddhism, and his female consort Mandarava are said to have gone to this cave to meditate. They received a blessing directly from Amitāyus, the Buddha of Boundless Life, and achieved the siddhi (spiritual attainment) of longevity and immortality ('chi med tshe yi dngos grub; Tsogyal 1999: 45). ${ }^{6}$ For a long time, pilgrims have been visiting this cave to practise dharma and offer prayers to prolong their lives. ${ }^{7}$

Sherab believed that his father had reached the age of sixty-eight, despite all family members dying around fifty, because of this pilgrimage, the blessings of Padmasambhava, and because of his lama.

When Könchok Peljor was sixty-one, he was passing through his obstacle year (lo skag). Many Tibetans request a special tshe dbang from their

5 The bar chad lam sel (lit. 'Clearing the obstacles of the path') is a very popular prayer addressed to Padmasambhava, published in the popular Nyingma prayer book Snga 'gyur rnying ma'i chos spyod (lit. 'Religious practices of the Nyingma tradition'; Nyingmapa Student's Welfare Committee [hereafter NSWC] 2002: 98-103). It is a 'treasure' text (gter ma), which was discovered by several treasure revealers (gter ston) across several centuries (THL 2009).

${ }_{6}$ This narrative is also central to the 'chi med srog thig longevity practice (Samuel 2008b).

7 See Berg 1994 and Buffetrille 1994 on pilgrimage to the Maratika cave. 
lama for their skag year. Könchok Peljor did not receive such a tshe dbang, but stayed the entire year with his lama as his personal attendant in his monastery, which was about seventy kilometres away from his home in Darjeeling. Sherab said the obstacle year was thus passed under the protection of the rinpoche and nothing life-threatening occurred.

Könchok Peljor recited prayers at sunrise and sunset at their home altar or sitting on his bed, spinning his prayer wheel, and burning incense outside his house. To clear bar chad, he recited the bar chad lam sel prayer from his daily prayer book, which I had seen in many Tibetan households (NSWC 2002). He also did the Amitāyus longevity ritual entitled tshe sgrub rgyun khyer with the Amitāyus mantra om amarani dzvawanti ye svo ha (NSWC 2002: 276-277). As with other Tibetan deities, there is no uniform Amitāyus mantra; it has many variations. Sherab recited by heart the tshe mdo tshe gzungs, a popular Tibetan Buddhist longevity dhäranī, which includes the long-life Amitāyus mantra of Padmasambhava om a hung benza guru pema ayurkye hinenza. Sherab said that most Tibetans recite this prayer daily and that it generates blessings to purify and prolong life itself.

Sherab said that because of his family situation and his Buddhist training, he thought about death a great deal. For him death was certain, and dharma practice was of the utmost importance. Like his father, Sherab performed a long-life Amitāyus practice daily. For him it was not only a practice to prolong his life-span, but also a kind of purification, protection, and blessing.

Sherab also did a five-year retreat in the Nepal Himalaya. He explained that the greatest fear of a Buddhist practitioner is to die an 'untimely death,' one of the reasons why White Tārā or Amitāyus practices are an integral part of every long-term retreat. For twenty-one days during Sherab's five-year retreat, all the practitioners did four sessions of long-life practices a day, each lasting three hours. The practice was meant to avoid 'untimely deaths' and prolong the practitioners' lives. Sherab said:

For practitioners, it is important to prolong their lives because every day of practice is important. Prolonging life is not always good; if you do more bad deeds you can accumulate more bad karma by living longer. There are even instances in which life was cut short to protect a person from accumulating bad karma. ${ }^{8}$

${ }^{8}$ An example of this is the usual justification given for the assassination of the last Tibetan king Lang Darma by Lhalung Palgyi Dorje in the ninth century CE. The king was accused of withdrawing his patronage from the Buddhist clergy, the reasons of which are still debated (Kapstein 2006: 80-81). 
Living in a family of short-lived members made Sherab more aware of the possible limitations of his own life-span. After he turned forty, he started to meditate on Amitāyus more seriously; he had come close to the age where many of his relatives had died. I asked him how he thought he could attain a longer life. He mentioned a list of things:

You can extend your tshe with your yoga practice, with daily Amitāyus longlife prayers, tshe dbang empowerments, good habits, the way you live, such as diet [his lama promoted vegetarianism], lifestyle, with collecting merit through protecting life, even the life of plants, as well as animals. Everything depends on your karma and increases or decreases your own life-span. If you kill someone, your own life will be shortened, in this lifetime or any other future lifetime. Every action has a reaction.

In Sherab's family, the early deaths of his two sisters were a very personal matter and were only discussed within the family and with their lama. Nevertheless, Sherab explained why one of his two sisters died so early using the idea of tshe lhag, which made her death 'timely' in the sense that she just lived out a few remaining years from a previous lifetime, which was even considered auspicious.

Looking at Sherab's and Könchok Peljor's narratives, it becomes clear that both of them were actively involved in several practices aiming at prolonging their own life-span beyond the average life-span of their family members. They went for a pilgrimage and recited daily Amitāyus prayers. Könchok even shifted his residence for his entire skag year to his lama's monastery. He felt the obstacle year was the most predictable and most vulnerable time for any negative karma that could surface and cut short his life. Both of them took up preventive measures that were available to them and made longevity practices a part of their daily lives.

\section{Controlling Breath and the Maximum Life-span}

So far we have seen that Tibetans generally distinguish between two temporalities when it comes to death: 'untimely' and 'timely' death. While 'untimely deaths' are perceived as premature and can have all kind of reasons, a 'timely death' simply means that the individual's full life-span has been completed (Sogyal Rinpoche 1993: 244).

Among Tibetans, the full completion of the life-span is expressed in the idea of the 'maximum life-span' called tshe lo or tshe mthar phyin pa (lit. 'fully completed life-span'). Tshe in general is not seen as fixed, since merit can always be collected and negative karma be purified. It appears to be easier for the family and relatives to accept the inevitable death when 
the 'maximum life-span' has been achieved, and a divination states that 'nothing can be done' to extend life. The tshe lo is usually not extendable, except in the case of yogic or tantric masters, who are said to control their tshe lo by controlling their breath.

There are many stories among Tibetans of how high lamas were able to extend their tshe lo by a few years through their spiritual practice (for example, Sogyal Rinpoche 1993: 244). I was told quite a few such stories during fieldwork. When talking to Tibetans about tshe lo, they often explained it in terms of the life-span being 'fixed' or 'flexible.' The monk Sherab from Darjeeling, who was introduced in the previous section, said,

The point of death is flexible for realised beings. High masters can choose their moment of death by redirecting their life-force through their inner practices. They can die the moment they want to die. Masters have a flexible life-span, but our maximum life-span is fixed, we cannot prolong it since we do not have the yogic power to do it.

In this section, I discuss how manipulating the tshe lo involves a temporal framework to exert the necessary control over tshe. It was very difficult to collect ethnographic material on this issue, since these spiritual practices are kept secret. Therefore, my explanations are mainly based on texts. In most of these practices we find that $t s h e$ is linked to the rhythm of breath, and control is exerted on the breath itself. Breath here is divided into stages of inhalation, retention, and exhalation, which provides a temporal framework through which tshe can be measured and controlled.

Breath (which is one of the meanings of the Tibetan term rlung, also sometimes called dbug; Skt. prāna or vāyu) has been related to vitality since very early times. ${ }^{9}$ In ancient India, the outer wind, vāta or vāyu, and the inner breath, prāna, were considered the same thing (Zysk 2008: 99-100). The main concerns of ascetic disciplines involving breath control, which emerged from a process of 'ritual interiorisation,' were longevity and immortality (Zysk 1993: 202). The duration of one breath was divided into three intervals, or three 'winds': inhalation (prāna a), breath retention (vyāna), and exhalation (apāna); all three constituted the technique of yogic breath control (Tib. srog rtsol rlung, Skt. prānayāma; Zysk 1993: 202; 2008: 100). The Upanișads (800-200 BCE) document the earliest attempt to codify breath in certain anatomical locations and link them to physiological features that eventually led to the codification of the five types of $v \bar{a} t a$

9 For an overview of seminal literature on prāna see Zysk 1993: 198, note 1. 
in Âyurvedic medical literature (Zysk 1993: 205-207; 2008: 101). Counting the breath was developed as a means to control its life-force. The notion of breath control was thus linked to the idea of controlling the life-span. The amount of breaths in a day was calculated in Indian yogic texts as 22,736 , $^{10}$ "which by modern standards is approximately accurate" (Zysk 1993: 210).

In his translation of the Tibetan version of a north-Indian Buddhist work on 'cheating death' by Vāgīśvarakīrti,' already mentioned in chapter 3.2, Schneider adds an interesting perspective on how this knowledge was expressed in Tibet. Vāgiśvarakīrti defines breath or $v \bar{a} y u$ as a 'collection of nectar, able to avert death' (Schneider 2010: 65). In his work, the notion of breath control is clearly linked to the idea of controlling the life-span."

Tibetan authors translated and took up these ideas and concluded that since the life-span could be measured by breaths, fast and uncontrolled breathing would shorten the life-span, whereas deep-flowing, slow breathing would lengthen it. Vāgīśvarakīrti as well as Sangye Gyatso mention 21,600 breaths for twenty-four hours $(1,136$ breaths less than the Indian yogic texts) as a balanced measure to achieve one's maximum life-span (Schneider 2010: 66; Sangye Gyatso 1982: 108-109). Sangye Gyatso writes in the Baidūrya sngon po, referring to a type of 'wind' called 'awareness wind' (yes shes kyi rlung):

If the awareness wind itself, having the nature of the life-force, is exhaled in more than a measured manner, the life-span will be shortened. In the case of the 21,60o [winds/breaths] moving through one solar day (twenty-four hours), the life-span will be fully completed. ${ }^{12}$

There are two techniques of breath control described in Vāgiśvarakīrti's text: (1) 'unrestricted breathing' (rgya yan), and (2) a specific method of holding the breath while forming a vase within the body (Tib. bum pa can, Skt. kumbhaka). ${ }^{13}$

10 This is quite similar to the breath count of 21,6oo per day mentioned in Tibetan medical texts.

${ }^{11}$ It is important to note that there is no longevity practice in Tibetan Buddhism that aims at physical deathlessness (Schneider 2010: 70). Even though life can be prolonged with longevity practices, the Tibetan understanding of deathlessness ('chi med) is a state of consciousness.

${ }^{12}$ srog gi rang bzhin can ye shes kyi rlung de nyid phyi rol du tshad las mang bar brgyus pa na tshe thung ngur 'gyur zhing/gal te nyis khri chig stong drug brgya nyin zhag gcig gi khongs su rgyu na de'i tshe mthar phyin pa dang/ (Sangye Gyatso 1982: 108-109).

${ }_{13}$ Germano describes the bum pa can as an "important yogic technique of 'vase breathing.' In this practice, the meditator presses down the body's upper currents of energy and pulls up its lower ones, thereby penning them up in a spot around the navel in a 'vase.' 
The first technique of 'unrestricted breathing' involves consciously counting one hundred thousand breaths, which is said to prolong one's life for five years (Schneider 2010: 66). The conscious counting of breath, which can be accompanied by mantras and visualisations of colours, is said to balance the breathing and fixes the ambrosia, which is the nectar that the breath carries, inside the body. In contrast, the ambrosia is lost through unconscious breathing (Schneider 2010: 67).

The second technique describes holding one's breath for up to five minutes. This technique might also involve certain yoga postures. The text describes various time-spans, in Sanskrit called mātrās, according to which the holding of breath can be reckoned (Schneider 2010: 66). The accumulation of such time-spans of breath retention gives the practitioner the assurance that death will not occur for a certain period of time, for example, six months or one year (Schneider 2010: 66). Schneider points out the ambivalent logic behind these ideas: on the one hand, breath is seen as the carrier of life. On the other hand, through normal unconscious breathing the life-giving potency of breath is lost, and only through breath control is a practitioner able to increase and draw from the life-giving potency of prāna (Schneider 2010: 66-67).

Some of these yogic exercises are still practised today by Tibetans as part of longevity practices in combination with mantras and visualisation. Bum pa can is a very important breathing technique, forming part of tshe sgrub longevity practices. During fieldwork, I spoke to a practitioner who practised a type of bum pa can technique in relation to a White Tārā tshe sgrub, but he did not want me to write about it, since the mantra and visualisation aspects of this practice are meant to be kept secret. ${ }^{14}$ This particular practitioner had maintained this specific practice on a daily schedule of twenty minutes each morning for the past twenty years. He said that this practice had given him a sharp intellect and that he did not suffer from any serious illnesses.

Although not mentioned in the Rgyud bzhi, I found a quote on this breathing technique in the commentary Baidūrya sngon po by Sangye Gyatso, where he writes in the 'anatomy' chapter that,

\footnotetext{
Thus, rather than the winds functioning in diverse ways throughout the body, their energy is restrained and concentrated in a single spot, such that they become 'nonmanifest' or concealed" (Germano 1997: 296).

${ }^{14}$ Loseries-Leick (1997: $583^{-584}$ ) researched similar tantric practices in Tibet and describes the difficulties she underwent as a researcher to get in touch with such practitioners.
} 
If one has the ability to gradually hold [the breath] inside the bum pa can, this is one reason for attaining deathlessness ('chi med). All the yogis by means of breathing have extended or shortened their life-span, etc.; also all those who know, relied on and examined this [method]. ${ }^{15}$

Unfortunately, I did not have the chance to receive detailed instructions on this breathing technique by a lama, nor did I study any Tibetan tantric texts that describe this practice. Further research on this topic might reveal more details on how the 'maximum life-span' can be extended.

\section{The Life-span is Completed}

Cases in which the life-span is fully completed (tshe tshar ba or tshe mthar phyin pa) and the person is going to die, a divination can help the family make choices about last-minute, often expensive life-extending medical procedures, or death preparation rituals. During a tshe dbang in Pedong in 2005, I met an elderly Sikkimese Bhutia man, whose wife had died a few years earlier. He said,

My wife died a few years ago. When she was very ill, I went to Mungpoo Rinpoche ${ }^{16}$ for a $m o$, and he said that her tshe was completed and that she would only live another seven days. He said there was nothing more that could be done; her life could not be extended through any tshe dbang. She died, as he had predicted, seven days later.

The divination indicated the completion of his wife's life-span. What did the divination accomplish for the man who lost his wife as predicted? He said,

The $m o$ really helped to accept the inevitable. I did not feel pressured about deciding to take her to Siliguri for further biomedical treatment, which was expensive. Also requesting any more long-life rituals would have been useless. They would not have helped her anyway. When Mungpoo Rinpoche told me that her tshe was completed, I could focus on her last wishes and the death rituals.

Although I could not find out if her death calculations revealed a 'timely death,' this example shows that negotiations of the life-span continue until death. Extending life does not mean to extend life by all possible

\footnotetext{
${ }_{15}$ bum pa can gyi rim pas nang du 'dzin nus pa na 'chi med 'grub pa'i rgyu mtshan yang de ltar yin te/ rnal 'byor pa rnams kyis rlung gi sgo nas tshe ring thung la sogs pa'i ltas shes pa rnams kyang 'di nyid la brten nas brtags pa yin no/ / (Sangye Gyatso 1982: 109).

${ }^{16}$ He refers to the late Dinchen Rinpoche of Mungpoo, near Darjeeling.
} 
means, at any cost, and in any circumstances. Accepting the end of the life-span as a point where 'nothing can be done ${ }^{{ }^{17}}$ provides time and space for family members to support the dying process. It certainly helps people allocate their often-limited financial resources and make decisions about higher quality health care, which involves expensive travel and is only available at high-priced private hospitals in developed urban areas on the Indian plains.

Chapter 8 now looks in more detail at divinations of the life-span and the issue of 'accuracy' of such predictions.

${ }^{17}$ The Baidūrya skar po mentions in the section on astrological death calculations for the negative result: "Nothing will help even if hundreds and thousands of Bon priests are present, and the living should not grieve because the lifespan is exhausted" (Dorje 2002: 315$)$. 


\section{DIVINING THE LIFE-SPAN}

Divinations $(m o)$ of the life-span among Tibetans are carried out in various ways. They can be oral and/or textual. Momola, a Tibetan illiterate female diviner in her eighties, who will be introduced in this chapter, makes predictions concerning the life-span in terms of its state of exhaustion and obstacles that may cut life short. In contrast, the textual Palden Lhamo divination on the strength of the vital force srog and the life-span tshe show that vagueness is a major characteristic of predictions concerning srog. A notable exception to this vagueness are the predictions found in the section on tshe, which gives the exact number of years that a person is going to live and the day of and reason for his/her death. Most of these predictions do not come 'true.' This leads to the question of what 'accuracy' in Tibetan divination and astrology is really about. In this chapter, I argue that divining the life-span is less about specifying a certain amount of years, even though divinatory texts may say so, than about mapping out possible times of strengths and weaknesses of life-forces and consequently giving Tibetans the opportunity to prevent obstacles through ritual means. As we will see, life-span divination does not provide an unalterable prediction of the time of death, instead it is part of a process of negotiation in which ritual counter-measures, merit-accumulating activities, and other Buddhist practices can be utilised to avert or postpone illness and death.

First, I examine the ethnographic account of an illiterate Tibetan diviner, Momola, and her methods of divining the life-span. Momola's story shows that she mainly thinks of tshe in relation to whether tshe has been exhausted; in Tibetan this condition is known as tshe 'dzad pa. Mullin offers a good explanation of what is meant by the term ' $d z a d p a$ in relation to tshe:

['Dzad pa] has the implication not of depletion but of weakness or proneness to a break or lapse. Our lifespan, creative energy or karmic power has a weak link that is manifesting. These factors are not depleted or spent; they are in a crucial phase, or suffering from a temporary lapse of sustaining energy (Mullin 1986: 150). 
Tshe 'dzad pa is not a medical condition; it neither appears in the Rgyud bzhi nor in the Baidūrya sngon po, and I have not heard of amchis diagnosing or treating an 'exhaustion of the life-span.' Tshe 'dzad pa typically appears in divinatory and ritual contexts. There might be a similarity to the state of a 'weakened life-span' (tshe nyams pa) described by Desjarlais among the Yolmos in Nepal (Desjarlais 1992: 63-64). In the Darjeeling Hills, I observed tshe 'dzad $p a$ as a condition diagnosed through a divination that does not necessarily imply impending death in the sense that the end of the life-span has been reached. Rather, tshe is temporarily depleted, which could lead to an 'untimely death,' if not treated ritually.

\section{Your Life-span is Exhausted': Momola's Rosary Divination}

Momola (rmo mo lags, lit. 'grandmother'; see plate 8.1) lived in Ghum, ten kilometres from Darjeeling, in a small wooden room of about three metres square with two tiny windows. Plastic rugs were fixed underneath a roof that did not look waterproofed. The milk pot on her kerosene stove, which she kept next to her bed, had the crusts of months of daily milk supply sticking to its rim. She had no running water or bathroom, and she urinated between two wooden planks in the dark walk-way that led to her room. Her hands and face were black from handling her smoky kerosene stove, and when I presented her with a photo (she allowed me only twice to photograph her), she burst out laughing, commenting on how dirty she looked. She could barely move and used a walking stick. She said her legs pained her; she had a breathing problem (dbugs mi bde ba) and heart disease (snying gi na tsa). She did not eat fruits or solid foods, just tea with the traditional tsampa (roasted barley flour) and dried rice flakes. Her chronic cough reminded me that tuberculosis was still rampant in the Hills. The cat on her lap looked healthy and well-fed and was her only friend, she said, stroking her tenderly.

Momola was eighty-three years old when we met in 2004. She had walked from Tibet to India in the early 1950s and had been a diviner ( $m$ o pa) since the age of eight. She divined a safe route through Chineseoccupied territory and across the passes into India for the small group of refugees she was walking with. She never married and never learnt how to read or write. Doing $m o$ for people was her only source of income. She had always lived alone. She said her home made her feel ashamed (ngo tsha), but at the same time she liked it and had refused an offer to move into a nearby house. 


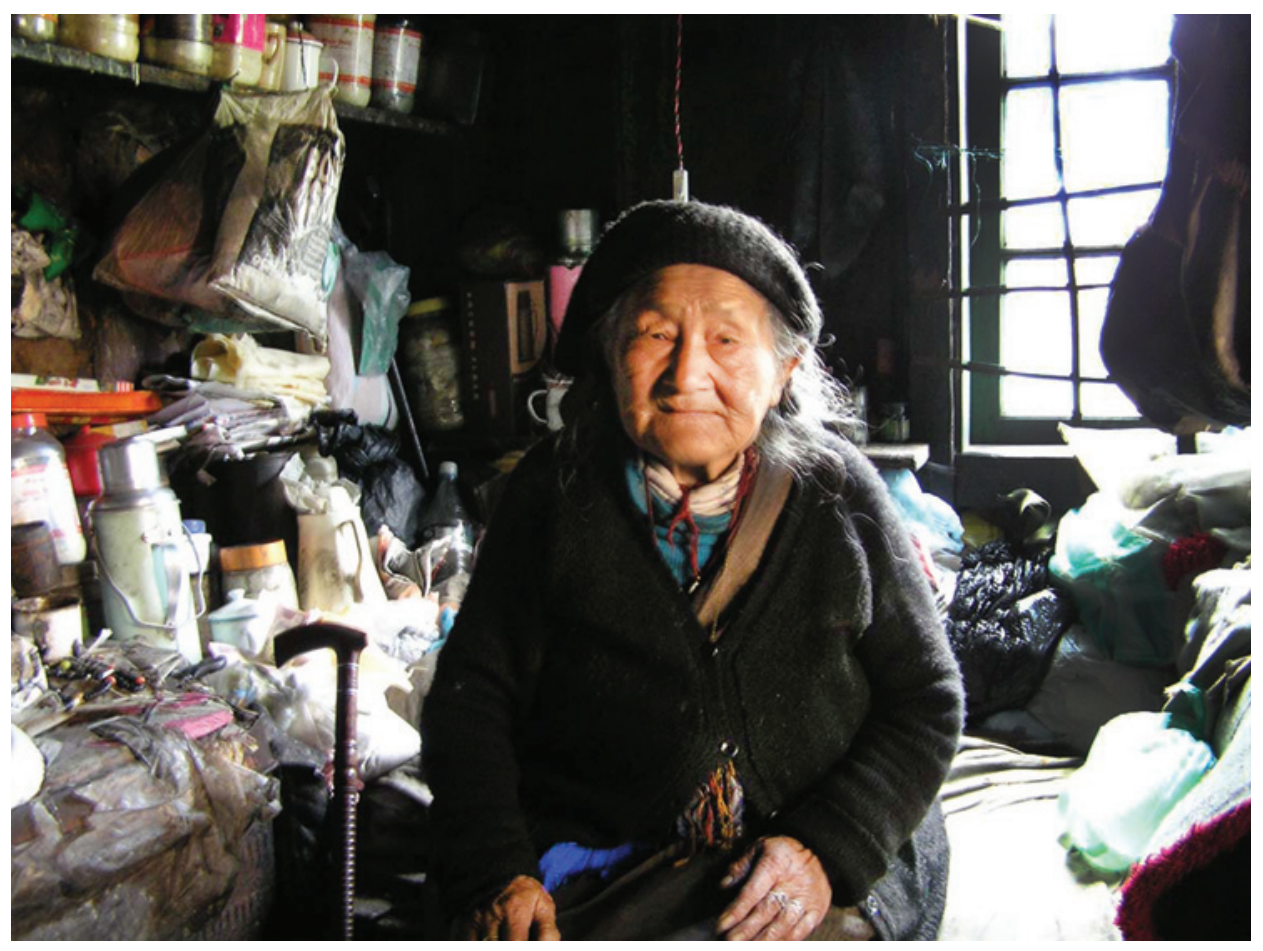

Plate 8.1. The Tibetan diviner Momola, Ghum 2004.

Whenever she was not engaged in conversations she recited mantras, her fingers moving across the 108 wooden beads of her rosary. Opposite Momola's bed was a small bench, covered with old rugs for her clients to sit on and ask their questions. At the top end of her bed a framed picture of Padmasambhava adorned a simple altar.

It was not easy to ask her questions about herself. She only knew mo questions and on hearing a question immediately counted beads from both ends of her rosary, in sets of three, meeting up at the centre, leaving either one or two beads, or none between her fingers, which then determined her answer. No 'left-over' beads were considered 'very good,' two were 'medium,' and one was 'really bad.' This simple result was the foundation for her reading, which she would then interpret according to her meditative intuition and the situation.

She had a good reputation in the region, and people from all walks of life came to seek advice for their health, family matters, and financial investments. Even Tibetans living abroad sent money and mo questions 
through monks living in Ghum. Questions being asked were 'Should I buy this car?'; 'My four-year old son saw his departed grandmother in his dream; what did it mean?'; 'Will this marriage between my daughter and this family's son be successful?'; 'Do we have to take her to the hospital?' Her answers were clear and to the point.

If there were obstacles, she would prescribe prayers and rituals, which she termed zhabs brtan. ${ }^{1}$ She sent a lot of her clients to the local Sakya Guru Gompa, situated on the hill, a five minute walk above her hut. She advised them to do zhabs brtan and 'to practise dharma' (chos byed pa). Her view of 'practising dharma,' to me seemed similar to what Clarke describes for people in Helambu, Nepal. It had a sense of 'morality' and 'correctness' as "the proper order which stands behind all aspects of nature and culture" (Clarke 1990: 172). It was more than just following the 'Buddhist doctrine.' It was the remedy for all maladies and bar chad in general and constituted the continuous recitation of prayers and mantras, and making offerings at the monasteries. Momola's ritual instructions were simple, since she was illiterate and knew only a certain number of rituals. Her most common prescriptions of zhabs brtan were the longevity rituals tshe gzungs and tshe sgrub, and the prayer bar chad lam sel (NSWC 2002: 98-103). She also prescribed specific rituals linked to the Buddhist deities Tārā and Avalokiteśvara, as well as to Padmasambhava.

She exuded confidence in her art, which was very much outside the monastic establishment and authorised textual knowledge, even though she referenced it. The only knowledge she had was 'her own,' derived from her personal spiritual experience. "How did you become a mo pa?" I asked. "I had faith ( $d a d p a)$, in Tārā, Padmasambhava, and Avalokiteśvara," she replied. It was her own wish to be a mo $p a$ and she figured out the skill herself. "It is my own mo from my own practice," she said, "without any dbang (empowerment) or instruction from a lama. I prayed to Padmasambhava and Tārā and learnt how to do mo myself." Her source of knowledge was her faith, and she kept in close contact with her deities through her incessant recitations of their mantras. They appeared to become some sort of personalised figures that advised her.

${ }^{1}$ In this context, Momola used zhabs brtan as a popular term for a ritual or prayer. In a more literary context, zhabs brtan is a type of Tibetan religious poetry that is specifically conducted for the 'stability of life.' The recitation of zhabs brtan has, however, "become so popular in modern times that the word has almost become a synonym for ritual itself" (Cabezón 1996: 353). 
One day while we sat together in her room, a Tibetan woman in her mid-twenties entered along with two elderly women. Only the elder women spoke; the younger one looked ill and tired and was clearly the patient. Momola asked where she was from and what her year sign (lo rtags) was. They were Tibetans from a small trading township at the Nepal border about an hour drive from Ghum, and she was born in a bird year (bya lo). The complaints were stomach ache and that she could not conceive a child. Momola took her rosary and did the divination, three times. She said there was no disease in her body (na tsa ma red), so no doctor was required. However, a zhabs brtan, especially a tshe gzungs, had to be done to clear off bar chad. "Your life-span is exhausted (tshe zad pa red)," Momola said.

The young woman said nothing, and looked down at her knees. The two elderly women were not convinced. "Shouldn't we take her to a doctor?" they asked for the second time. Momola laughed. "If there is no disease, why spend money on a doctor? Give it to the monastery and do zhabs brtan. This will be much more effective." The divination result was followed by advice to practise dharma and to recite mantras continuously. The three women offered a kha btags (a Tibetan ceremonial scarf) and some money to Momola and left. The young woman never uttered a word.

When we were alone, I asked Momola again about this case and she repeated, even more directly than before, "Her life-span is finished, and if she does not do the zhabs brtan she will die." This sounded serious, and I was curious about what would happen up at the monastery. I bade Momola farewell and hastened up the hill to the Sakya Guru Gompa. When I reached, the three women had just come out of the monastery office. I talked to them a bit in Tibetan, but felt immediately that they did not want to communicate with me. I felt awkward in my role as the inquiring anthropologist. We all entered the temple; they offered their prostrations and walked around, praying in front of every altar. They ignored me and left, walking down the hill. I stood aside; participation was not an option.

It was, however, clear that this divinatory act was not an isolated event, but part of a whole process of dealing with the woman's weakness, misfortune, and illness. To at least understand more about the monastic context of Momola's divination, I went to the monastery office hoping to find out more. A friendly monk, named Jampa, offered me tea and I sat down at a big table, while he continued his work at the counter. I told him about my visit to Momola and the patients. He knew Momola well saying this was 
the custom (lugs tshul), first to do the mo and then the zhabs brtan. He said the three women requested a tshe gzungs, a dhäraṇi for longevity.

He explained in Tibetan that the tshe gzungs was performed in the morning during the general morning prayers. The chant master $(d b u$ mdzad) would announce the name and the year sign of the patient, and all the monks would recite one hundred and eight mantras of each of the three long-life deities, Amitāyus, White Tārā, and Uș̣ị̄savijayā (see plate 3.5). Three times one hundred and eight mantras recited by forty monks would result in 12,960 recitations. That was supposed to be quite a large amount, enough to revive her tshe. The patient did not need to be present. To know her name and year sign would be enough. Jampa explained that the year sign was mentioned in combination with the name, because Tibetan names were often the same for many people. In combination with the year sign it was more precise, he said. Jampa did not treat the ritual request as an urgent situation. For him it was a daily routine, and since the patient was not deadly ill - the diagnosis tshe 'dzad pa apparently did not imply any emergency - one could wait a few days with the ritual until the day was auspicious.

To show me the most auspicious day for the ritual, Jampa took out a worn-out, much-used Tibetan calendar. It was the same 'vitality table' that I had seen amchis use at the MTK clinics to set the right date for a moxibustion or golden needle therapy (see table 4.2 in chapter 4.4). Since the young woman needed to strengthen her tshe, the zhabs brtan was performed on a favourable life-force day $\left(\operatorname{srog} g z a^{\prime}\right)$, which for people born in a year of the bird was Thursday. After I had finished my tea, I bed farewell to Jampa and left. Unfortunately, it was impossible to follow up on the woman's story.

A few weeks later, I saw Momola again. This time I asked her how she could know tshe through her mo. She was very clear in her response and said,

I can't. Only the astrologer can calculate tshe. With the mo I can only detect if tshe is exhausted or if there are obstacles to the life-span. Then I prescribe tshe gzungs and other zhabs brtan to strengthen tshe and to remove the bar chad.

Momola clearly separated her divinatory skills from those of the lamas and astrologers. I still wondered about her personal link to life-span divinations, and asked her about her own tshe. Momola had a personal connection with long-life rituals and had herself felt the effect of strengthening tshe through zhabs brtan. On her own life-span, Momola said: 
I do not have much tshe left now. Actually, I only had a life-span of fifty years, one lama told me. But because of tshe dbang and tshe sgrub rituals performed by many lamas I got another thirty years. When I was fifty, I gave all my money, which was 50,00o Indian rupees, to the monasteries, because I thought I would die. They performed many tshe gzungs, tshe sgrub, bar chad lam sel, and Tārā rituals. Therefore, I have lived another thirty years.

Momola passed away shortly after I completed fieldwork. Her own experience reflects a popular understanding among Tibetans, who feel that lamas can extend lives through special rituals.

This ethnographic account shows that for Tibetans life presents itself with intervals of weakness, illness, and misfortune and tshe 'dzad pa refers to a temporary period during which the life-span is weakened and vulnerable. In the above example, the weak interval in a particular individual's life was counteracted with a ritual in which 12,96o longevity mantras were recited and dedicated to the patient. The tshe gzungs was enhanced by conducting it at an auspicious moment, the idea being to increase the benefit and to accumulate the necessary power to strengthen tshe through scheduling the ritual on an astrologically auspicious day. This is similar to the amchis selecting the date for the moxibustion treatment in chapter 4.4. Here, too, working with the auspiciousness of time is used to enhance the efficacy of things done in time.

To understand how Tibetans view the crucial phase of an obstacle arising that could cut short their life-span, we need to look at the notion of bar chad in more detail.

\section{The Notion of Bar chad}

The notion of bar chad, or obstacle, deserves a closer look since it presents a very common aspect of Tibetan popular understanding of misfortune. It is part of the package of causation strategies, explained in the previous chapter. Most Tibetan Buddhist rituals focus on the removal of individual bar chad. Bar chad are believed to come up in everyone's life, from time to time. Their existence is generally explained by 'previous karma,' or astrological circumstances, such as the 'obstacle year' (see chapter 6.3). Whatever the reason may be, the fact is that bar chad have a cause, which can be linked to an event in the past, following the karma doctrine, and they can be treated. The type of bar chad can be established by a mo or astrology. There is even an emergency mo that lay Tibetans perform at home when they cannot go to a skilled astrologer. The lay astrologer Jampel Kaldhen explained, 
If someone falls ill on a Sunday, we use a particular mo, called the tha mo brgyad kyi rtsis (lit. 'Calculation of eight goddesses'). We calculate based on the day and time when someone falls ill. This mo is part of astrology as well as religious practice and involves eight deities. Even a lay person can do this mo. You need a cause. Without a cause nothing can be.

Once the cause has been established, the action to counteract the cause can be prescribed. Rituals remove bar chad either through creating merit (for example, by making offerings), through reciting prayers and mantras, or through pacifying certain spirits and deities during rituals. Bar chad encompass a whole series of distinct concerns that can easily be linked to the broader concept of 'auspiciousness,' a general label used to indicate favourable and unfavourable circumstances. In the Indian Hindu context, auspiciousness marks processes that involve "outcomes which are desired - health, success, prosperity - or feared - death, disease, poverty, misfortune" (Samuel 2005: 262-263).

Among anthropologists working on Tibetan issues, Mills makes an interesting point on bar chad in relation to the notion of 'pollution' (grib) in Buddhist Ladakh. In Ladakh, 'pollution' is seen as an obstacle to certain kinds of social and ritual action, causing a vulnerability to misfortune (Mills 2005: 356). Grib can be caused by "things being upside down," such as placing your sleeping mattress or shoes on your head (Mills 2005: 355). It cannot be removed by removing the cause (for example, the mattress); once caused, grib remains and - as with every kind of bar chad - has to be purified by ritual means (Mills 2005: 357). Grib is not similar to a disease that disappears when the causes are removed. It is seen as an obstruction, a type of bar chad. How then can we understand the significance of bar chad in the context of tshe?

In his comprehensive summary on anthropological approaches to divination, Peek points out that it is important to look at which form of divination correlates with which kind of problem and to understand the typologies used by the diviners themselves. He argues that anthropological studies of divinations must also be placed in the larger context of decision making in daily life (Peek 1991: 13). Momola's divination on tshe is related to two typologies, tshe 'dzad pa and bar chad. Momola was not concerned with divining the actual life-span of the client. By means of her mo, she could detect any weakness or obstacles that affected tshe and could potentially cut short the life-span.

Divinations are essential in determining causes of illness, which in the above case was the 'exhaustion of the life-span.' If $t$ she is exhausted, no medication will help since first, an exhaustion of tshe is not considered 
a disease, and second, medication is not believed to be able to clear bar chad. "If there is no disease, why spend the money on a doctor?" was Momola's view. This understanding locates possible causes and cures for the exhaustion of the life-span in a realm unreachable by medical science. I could not follow up this specific case, but have seen other cases in which Tibetans in the Hills see ritual treatment as primary to other forms of treatment, thinking that medicines will not work without taking care ritually of, for example, possible spirit causations. Tshe 'dzad pa and bar chad do not have to be linked directly to spirit causation, but follow similar therapeutic procedures, in that rituals are seen as the primary choice of treatment.

I wanted to know more about the differences between Momola's mo and divinations done by lamas using texts when it came to knowing about tshe. Why could lamas and astrologers tell the actual life-span, something Momola could not? Could they really? The next section will contrast the ethnographic account of Momola with a lama's mo based on texts.

\section{Throwing the Dice: Textual Divination on Tshe and Srog}

In 2004, I came across a divination text linked to one of the many forms of Palden Lhamo, the Palden Lhamo Magsor Gyalmo. ${ }^{2}$ Palden Lhamo (dpal Idan tha mo, lit. 'glorious goddess') is a wrathful goddess and one of the principal protectors of Tibet. She appears in both divination and many other ritual contexts. This particular Palden Lhamo divination text was a dice $m o$, and both dice and manuscript belonged to the late Dhardo Tulku Rinpoche at the ITBCI School in Kalimpong. After his death in 1990, the mo objects and text were given to the current director of the school, Jampel Kaldhen, with whose assistance I translated several excerpts of the text (see figures 8.1 to 8.4). He told me of several versions of the Palden Lhamo mo and that it was practised in at least two monasteries in Kalimpong. In this section, I present translated excerpts of this divination text and analyse how temporal frameworks are employed in the answers on the qualities of srog and tshe.

Palden Lhamo is depicted on wall paintings riding a white mule. She is often shown as the consort of the Lord of Death, Yamāntaka. The deity's iconography shows a pair of dice with five or six dots hanging down the

\footnotetext{
${ }^{2}$ Volkmann (1995: 202) provides a detailed description of this raging and revengeful transfiguration of Palden Lhamo.
} 
side of her mule (Róna-Tas 1956: 170). Palden Lhamo is not only revered as a protector deity at many Tibetan Buddhist monasteries, especially of the Geluk school, but is also closely linked to dice divination (Róna-Tas 1956: 173). Róna-Tas shows that dice divination was attached to Palden Lhamo as a person as well as to acts of healing (Róna-Tas 1956: 173).

Róna-Tas suggests that healing practices of female fortune tellers were widespread in Tibet as early as the ninth to twelfth centuries and were bound up with Palden Lhamo (Róna-Tas 1956: 175). ${ }^{3}$ The link between divination and healing is also visible in contemporary Tibetan contexts. Chapter 5 already showed that diagnosis and prognosis are closely knitted together in Tibetan medicine. Based on my observations, I would say that the divinatory aspect of diagnostic methods is in itself a part of the healing process, as much as a detailed prognosis is an integral part of therapy in the West. Anthropologists have looked at this overlapping link between diagnosis and therapy; it is found, for instance, in the context of African and Chinese medical diagnostic processes (Hsu 2005a). Hsu maintains that diagnosis itself can constitute an integral part of treatment and does not necessarily follow a linear temporal process of, first, the diagnosis and, second, the treatment (Hsu 2005a: 155). I suggest that when it comes to divining tshe, the divinatory event itself may be considered part of the entire therapeutic process (ritual or otherwise) of Tibetan life-span negotiations.

How did Dhardo Tulku Rinpoche's Palden Lhamo dice divination work? What kind of divinatory results were presented concerning srog and tshe?

\section{The Palden Lhamo Divination}

This particular Palden Lhamo mo is performed with two dice (see plate 8.2), which are treated as units of meaning represented by a specific section in the manuscript. The dice are made from dark wood and kept in a special box. Only the rinpoche who uses the set is allowed to touch them. Kaldhen said that some types of divination have three dice but are used only by high lamas. The dice are unlike the ones which Tibetans commonly play with. The opposite sides add up to either six or nine: one and five, two and four, and three and six.

\footnotetext{
${ }^{3}$ Female oracles were probably around even earlier (mid to late eighth century $\mathrm{CE}$ ), following the account that the wicked uncle of king Tri Songdetsen (790-844) was buried alive at the recommendation of a female oracle (Wangdu and Diemberger 2000: 37-38).
} 


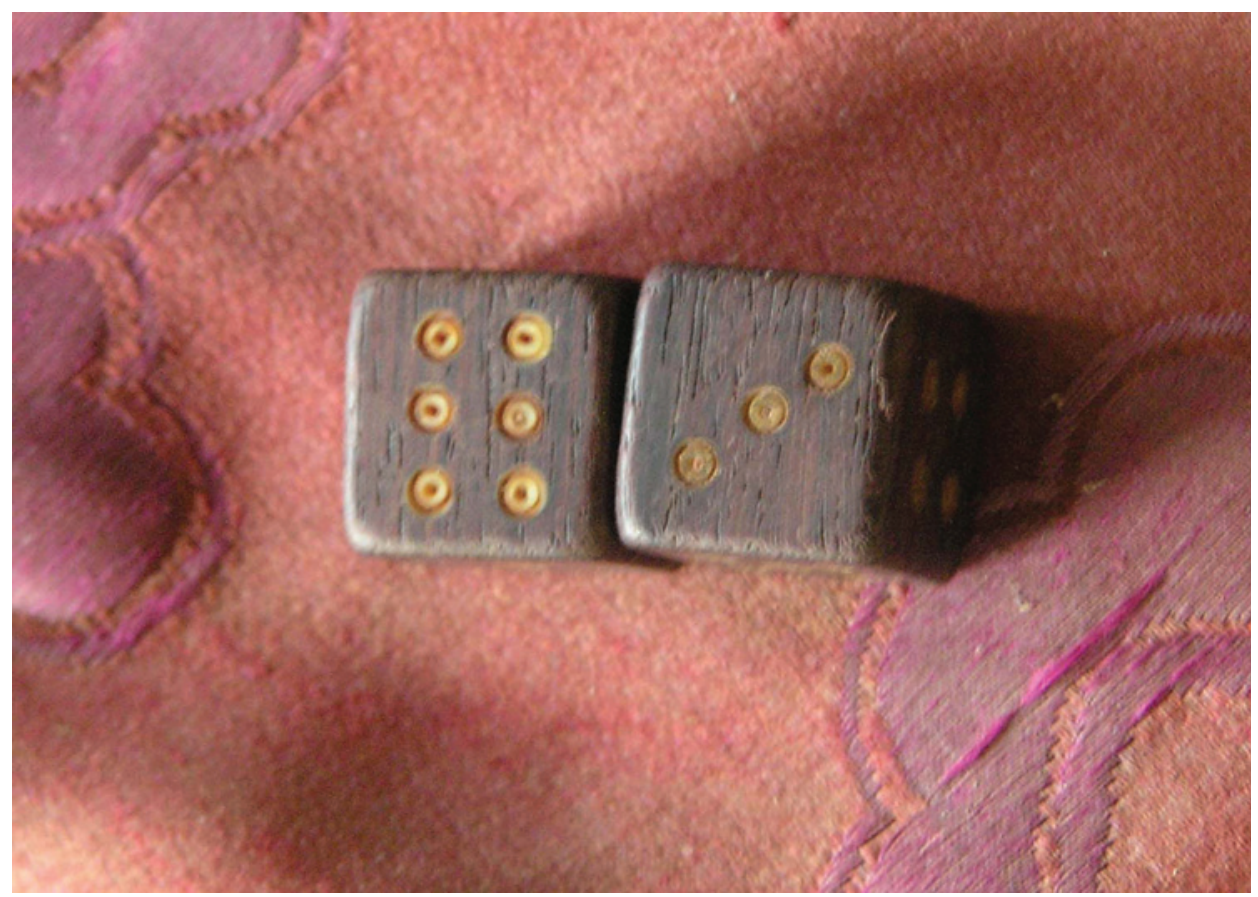

Plate 8.2. Wooden dice used in the Palden Lhamo divination, Kalimpong 2004.

Kaldhen always kept the mo manuscript carefully wrapped in a piece of burgundy-coloured brocade (see plate 8.3). The colophon mentions that the author is a female Buddhist practitioner named Yogini Kachö Deden Wangmo. The seventy-five folio manuscript is handwritten in two colours. ${ }^{4}$ The section headings are written in red ink and the text in black (see figures 8.1 to 8.4 ). The meditation practice is explained at the beginning of the manuscript and involves numerous visualisation and mantra practices. The practitioner is instructed to visualise him/herself as the deity Palden Lhamo while reciting her mantra in order to achieve the meditative state necessary to perform the divination, which has two stages: (1) the throwing of the dice that determines the section in the text, and (2) the interpretation of the text for the client. The author mentions in the colophon that she had performed the recitations and mantras involved in this practice ten million times ('bum brgya).

${ }^{4}$ The manuscript title reads Dpal ldan lha mo'i blang dor gsal ba'i me long sho mig grangs ldan (lit. 'The [divination of] Palden Lhamo: numerable dots on dice, the clear mirror of moral choice'). No date of composition is mentioned in the colophon. 


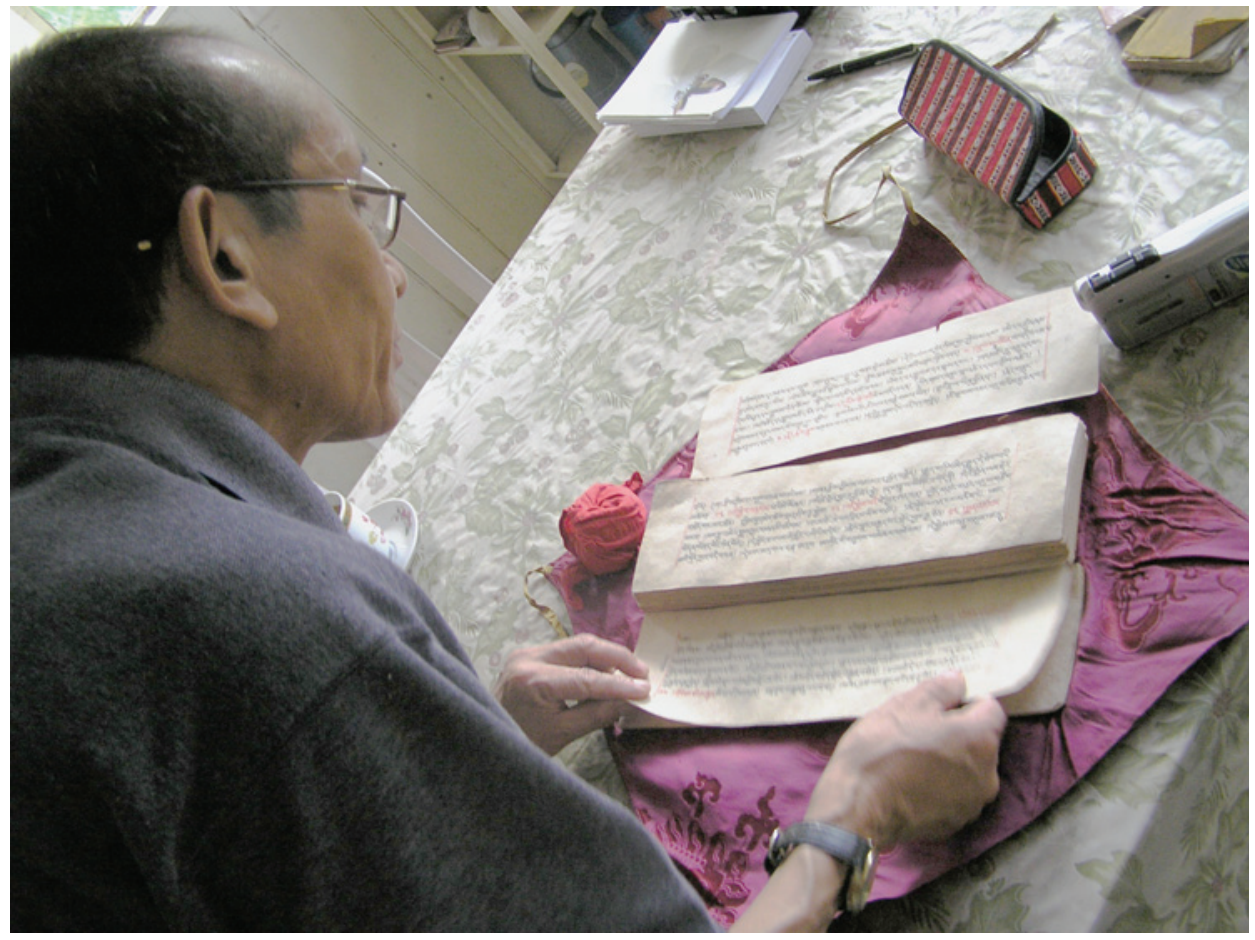

Plate 8.3. Jampel Kaldhen explaining the Palden Lhamo divination text, Kalimpong 2004.

Unfortunately, I could not see this mo being practised and only know about it from Kaldhen's narrative. He saw the mo performed over many years while Dhardo Tulku Rinpoche was living at the ITBCI School. When I asked him about the circumstances in which Tibetans would come to specifically divine srog and tshe, he said, "When patients were very ill someone used to come for the mo in order to check the strength of srog and whether the patient would die or not."

The manuscript has eleven chapters, each corresponding to a throw of the dice, with the smallest sum of the two dice being two, and the highest, twelve. Each chapter has the same thirty-four subheadings, each dealing with a different aspect of life for which the mo gives a reading. These subheadings, written in coral red ink, include among others: the household, the selection of a spiritual teacher or a doctor, the appropriate deity for one's practice, women's daily life, friendship, business, shifting residence, gambling, animal husbandry, sickness, obstacles, why the protector deity might be annoyed, spirit affliction, and whether a long journey will be safe or not. 
The two headings that concern us here are 'If you threw [the dice to see] whether the vital force is stable or unstable' (srog e brtan mi brtan btab pa $n a)$ and 'The duration of the life-span and its ups and downs' (tshe tshad dang skyid sdug skor). This textual divination is clearly about making choices in daily life, and knowing about the life-span is a part of it. In the following, two examples of each of these two sections will be analysed.

\section{The Certainty of Uncertainty: Divinations on 'Whether Srog is Stable or Unstable'}

If the sum of the dice thrown is 'two' and the question is about the strength of srog, the divination result in chapter five of the manuscript reads (in excerpts):

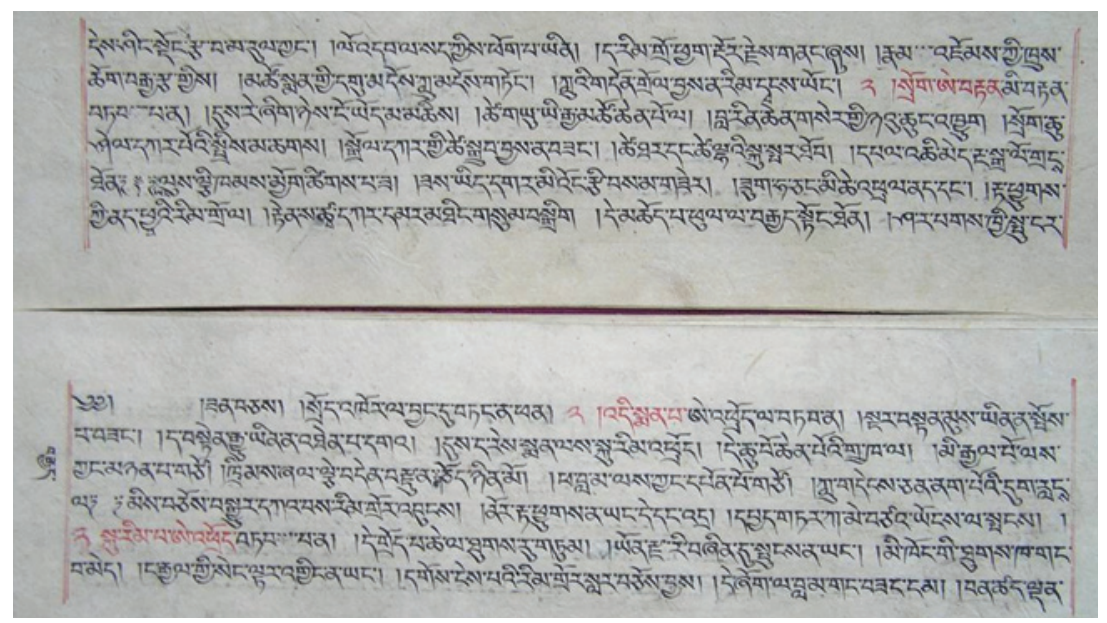

Figure 8.1. Divination to see whether srog is stable or unstable, folio $7 \mathrm{~b}$ (top, line 2ff) and folio 8a (bottom, first line).

2. [folio $7 \mathrm{~b}$, see figure 8.1] srog e brtan mi brtan btab pa na/

dus re zhig nyes ngo yod ma mchis/ tshe g.yu yi rgya mtsho chen po la/ bla rin chen gser gyi nya'u chung 'khyug

srog chu shel dkar po'i spris ma chags/

sgrol dkar gyi tshe sgrub byas na bzang/

tshe thar dang tshe lha'i sku spar thob/

dpal 'chi med rnga sgra lo grangs thon/ [...]
2. If you threw [the dice to see] whether the vital force is stable or unstable:

For the time being there is not much risk. Your life-span is like a great ocean of turquoise. Your bla is like a precious golden little fish flashing by [full of life but transient]. Your vital force is not obstructed with the cream of the white crystal. It will be good to perform a tshe sgrub of White Tārā. Free living beings and acquire or print [images, for example, tsha tsha] of a long-life deity. Recite the 'Drum of deathlessness' [a longevity dhäraṇī] as many times as your age [...]. 
If the sum of the dice is 'six,' the result on srog reads:

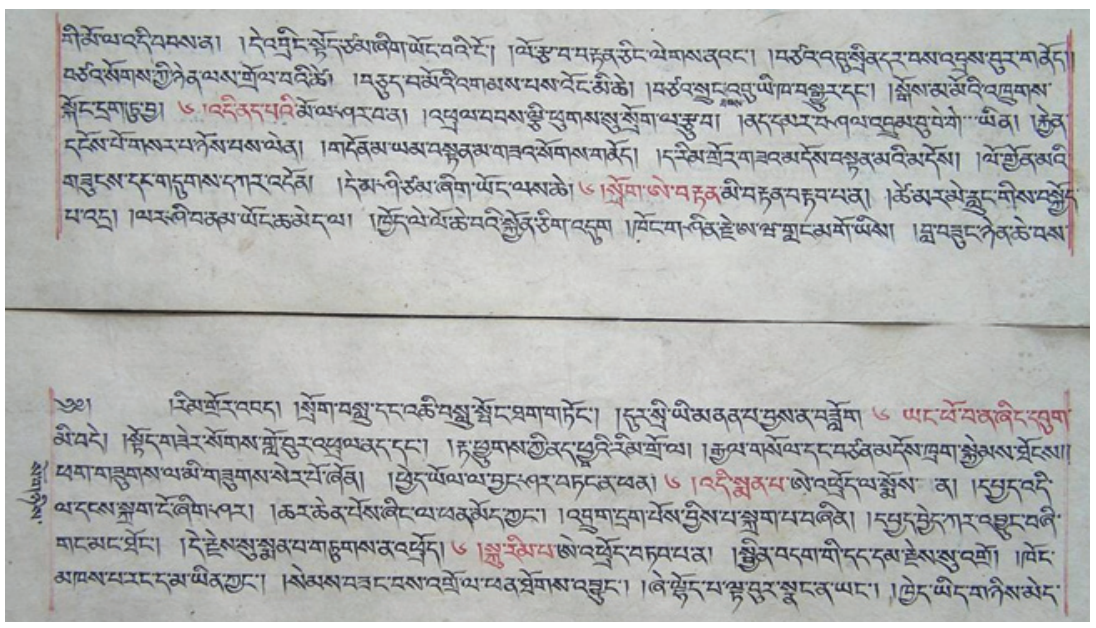

Figure 8.2. Divination to see whether srog is stable or unstable, folio $31 \mathrm{~b}$ (top, line $5 \mathrm{ff}$ ) and folio $32 \mathrm{a}$ (bottom, first line).

6. [Folio $31 \mathrm{~b}$ and $32 \mathrm{a}$, see figure 8.2] 6. If you threw [the dice to see] whether srog e brtan mi brtan btabs pa na/ the vital force is stable or unstable:

tshe mar me rlung gis bskyod pa 'dra/

lar shi ba nam yong cha med la/ khyod le lo che ba'i skyon cig dug/ khong gshin rje a wa glang mgo yis/ bla bzung nyen che bas rim gror 'bad / srog bslu dang 'chi bslu spong thag gtong / dur sri yi mnan pa byas na bzlogl
Your life-span is like a butter lamp flickering in the wind. There is no certainty when death will come to you. You have one fault of being very lazy.

As there is great danger of your bla being snatched by the Lord of Death [Yamāntaka], who is in the form of the bull-headed Chögyal, make efforts to perform the rituals to ward off the negativities!

Perform the rituals to 'ransom srog' and 'ransom death' and give things away to the dharma!' If you perform a subjugation of the charnel-ground spirits (sri), you will [successfully] repel them.

\footnotetext{
5 This refers to a Buddhist practice that prescribes freeing oneself from illness by giving away what one likes most. Most of the time, this is a full set of one's clothes, which is offered to a lama (Tenzin Tsewang Jamling, personal communication, July 2010).
} 
These two excerpts show that mo answers typically follow a pattern of ambiguity. Answers such as 'there is no certainty when death will come to you' or 'for the time being there is not much risk,' both express vagueness. There is no indication for how long 'for the time being' will last. It is vague and leaves space for the personal interpretation and spiritual intuition of the lama.

Nevertheless, each answer involves clear instructions on certain dharma or ritual activities to be carried out by the client. In the first example, the reading on bla is relatively good, whereas in the second one, bla is endangered. In both cases, the advice is given to perform certain rituals, recite mantras, or obtain deity statues, reflecting the same mode: everything about the life-forces is uncertain. Bla is 'flashing by' and transient, and thus can be stolen at any time. Srog can be 'flickering,' and even its strength is only temporary.

The $m o$ answers also make use of similes, which are equally vague and are open to personalised interpretation. 'Your tshe is like a great ocean of turquoise,' 'your bla is like a precious golden little fish,' or 'your srog is like the cream of a water crystal' are all positive attributes of tshe, bla, and srog, but provide no definite details on temporal or spatial dimensions.

Even if the reading is positive, nothing is really certain, and strategies are made available to involve the client actively in dharma practice and to clear any type of obstacles that could suddenly surface and cut life short. As a result, the client becomes an active agent in shaping his/her vital force and life-span, and the community and local monasteries become involved in performing the remedial tasks. Thus, the mo itself is already an integral part of the subsequent ritual and therapeutic process.

I already mentioned earlier that it is an important aspect of Tibetan divination to leave room for interpretation. It seems easy to come to a general conclusion on the structure of ambiguity in $m o$ answers and argue that the answers are designed to leave space for the diviner's intuitive interpretation concerning the client's personal situation. Although this may hold true for most divinations, the next example of tshe divinations show that such a conclusion misses an important point.

\section{Life-span Divination and Issues of Accuracy}

The Palden Lhamo mo text devotes one section to the 'duration of the lifespan' (tshe tshad) together with 'happiness and misery,' called skyid sdug (lit. 'joy suffering'), which Kaldhen interpreted as "ups and downs in life, whether life will be good or unhappy, successful or full of difficulties." The 
fact that the life-span divination is coupled with predictions concerning happiness shows that for Tibetans a long life alone is not enough; they want to know if it will be a happy life as well. I already alluded to the importance of happiness and Tibetan concerns for this-worldly success in relation to karma and merit (Lichter and Epstein 1983; see also Gombo 1985: 238) and the five factors in chapter 6.

Here are two typical examples of the eleven possible answers on tshe and skyid sdug. When the sum of the two dice thrown is 'two,' the answer to any question relating to the life-span reads (in excerpts):

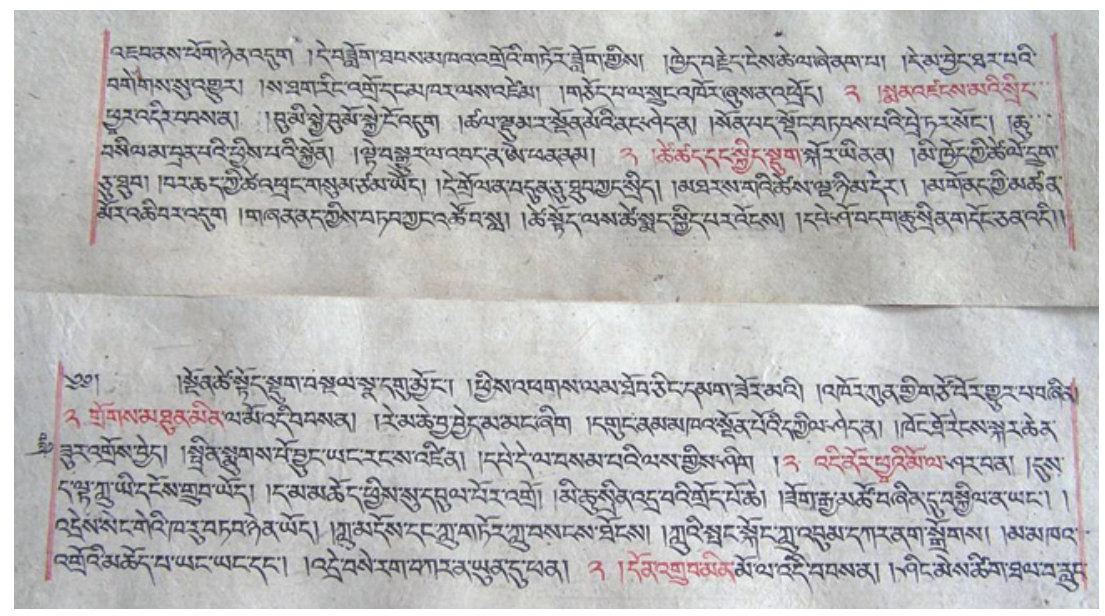

Figure 8.3. Divination on tshe and skyid sdug on folio $3^{\mathrm{b}}$ (top, line $4 \mathrm{ff}$ ).

2. [folio $3 \mathrm{~b}$, line $4 \mathrm{ff}$, see figure 8.3 ]

tshe tshad dang skyid sdug skor yin nal

mi khyod kyi tshe lo drug cu thub/ bar chad kyi tshe 'phrang gsum tsam yod/

de grol na bdun cu thub kyang srid/ mthar sa ga'i tshes lnga nyi ma der/ mgo nad kyi mtshan mor 'chi bar 'dug

gzhan nad kyis btab kyang 'tsho ba slal

tshe stod las tshe smad skyid par 'ongs $/[\ldots]$
2. If [the question] concerned the duration of the life-span and happiness or misery:

Your life-span will last for sixty years. Only three times there will be obstacles to the life-span. If you pass those three dangerous stages, you might possibly (srid) even last (thub) up to the age of seventy. Eventually, during the fourth month, sa ga, [Saka Dawa, sa ga zla ba, an auspicious month] on the fifth day, at that time you will die ('chi bar'dug) during the night of headaches. Otherwise, you will easily survive any kind of illness that may strike. The later part of life will be happier than the first part of life $[\ldots]$. 
If the sum of the dice is 'three,' the result on the 'duration of the life-span' reads:

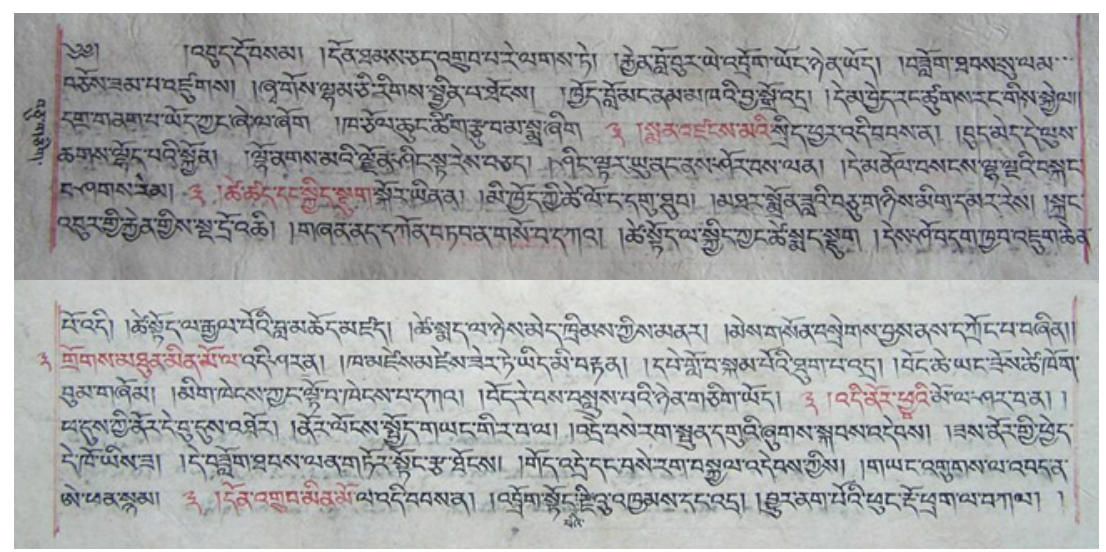

Figure 8.4. Divination on tshe and skyid sdug on folio 11a (top, line $5 \mathrm{ff}$ ) and folio 11 b (bottom, first line).

3. [folio 11 a, line $5 \mathrm{ff}$, and folio $11 \mathrm{~b}$, line 1 , see figure 8.4]

tshe tshad dang skyid sdug skor yin nal

mi khyod kyi tshe lo nga dgu thub/ mthar smron ${ }^{6}$ zla'i bcu gnyis mig dmar res/

skrang 'bur gyi rkyen gyis snga dro 'chil

gzhan nad dkon btab na gso ba $d k a^{\prime} /$

tshe stod la skyid kyang tshe smad sdug

des sho bdag khyab 'jug chen po 'dil tshe stod la rgyal po'i bla mchod mdzad/

tshe smad la nyes med khrims kyis mnar/

me gson bsregs byas nas dkrong pa bzhin//
3. If [the question] concerned the duration of the life-span and happiness or misery:

Your life-span will last for fifty-nine years. Ultimately, on a Tuesday on the twelfth day in the month Antares (snron), you will die in the morning from the secondary cause (rkyen) of a benign tumour. Otherwise, illness will be rare. In case you get sick, it will be difficult to recover. Although the first part of life will be happy, the later part will be full of suffering.

Because of that, the 'omni-present lord of the dice' [i.e. Vishnu] [says]: Just like someone who is exalted to the position of the chief priest of the king in the earlier part of life, in the later part of life he will suffer injustice through no fault of his own, just as if killed by being burnt alive.

${ }^{6}$ Smron is a spelling mistake in the manuscript and should read snron. Snron refers to the fifth month called Antares, which is the brightest star in the constellation Scorpio (Tenzin Tsewang Jamling, personal communication, July 2010). 
I want to point out two issues in these examples.

First, the duration of the life-span is mapped out by pointing out certain patterns that will occur in an individual's life. Those are helpful to label problematic phases in life that can thus be marked, named, and dealt with. I now point out these patterns.

The divinatory results generally divide tshe into two temporal denominators, called 'the first half of life' (tshe stod), and 'the latter half of life' (tshe smad). Stod and smad are common denominators in Tibetan that can indicate temporality as well as - usually downward-bearing - verticality (Ramble 1996: 151). In the Palden Lhamo mo results, stod and smad indicate a chronological sequence in time. Typically, the first part of life is different from the second part.

As in Momola's divination, bar chad, which can periodically occur in the form of illness and suffering, is another factor employed to map out tshe. The text indicates that it is up to the lama to interpret exactly when periods of bar chad will take place. Another interesting observation is that the Tibetan verb used to describe the duration of the life-span is thub (lit. 'to last'). Tshe 'is going to last for $\mathrm{x}$ years,' indicates a strong sense of durability. Thub here is a textual indicator that supports the previously mentioned Tibetan understanding of tshe as a reservoir (the oil in the lamp) that lasts for a certain amount of time.

The second and more interesting point for my discussion is that the time of death is given with an astonishing exactitude, "Tuesday on the twelfth day in the month of Antares' or 'during the fourth month, sa ga, on the fifth day, on a Sunday, at night.' The Tibetan verb 'chi bar'dug (lit. 'will die') indicates that this statement is certain. This does not fit the pattern of vague answers commonly found in divinations, particularly in textual forms. Divinatory texts are especially and typically opaque and open to interpretation, since the same verse has to be variously interpreted for different questions (Zeitlyn 2001: 227). For the western eye it seems paradoxical that answers about the life-span as such can be so specific - giving the exact age, time, and cause of death - while, with only eleven possible answers, the answers perforce will be 'inaccurate,' and will certainly be proven 'wrong,' since people die at times other than those specified.

\footnotetext{
7 Stod and smad are also used for the geography of upper and lower Tibet, for the grading of upper and lower tantric colleges, for texts that appear in two volumes, or for body typologies in Tibetan medicine. Denominators of vertical classifications seem to be of special importance in Himalayan societies, grammatically as well as geographically, as discussed, for example, by Allen 1972; Bickel and Gaenszle 1999; Ramble 1996.
} 
In various other astrological calculations of the life-span that generally appear in Tibetan horoscopes we also find definite dates that do not prove to be "correct.' ${ }^{18}$ Childs offers us an example from Nubri, where he describes that after the tshe dbang the astrologer was called to prepare a natal chart, in which the life-span of the child was calculated, of which an example is given: "he will live to be 78 . He will have seven setbacks in life and many grandchildren [...]. Death will come quickly in the end [...]" (Childs 2004: 46-47). This shows that the 'style' of presenting the life-span can be very similar in astrological and divinatory texts, even though the methods to obtain such results differ widely.

Western scholars have tried to 'explain' the 'inaccuracies' of the calculations with Buddhist ideas. Berzin comments on this problem:

Sometimes, when you calculate a person's life-span, you discover that according to the mathematical formulas he or she should have died years ago. Another calculation reveals that if the person does a great deal of positive things, he or she can extend the life-span by a certain percentage. Even then, many people should be dead already. Moreover, how many positive things do you need to do to extend your life-span? [...] Astrological information describes samsāra - rebirth and the course of each life occurring uncontrollably under the influence of karma. To liberate ourselves from this vicious cycle, we need to understand voidness - the fact that everything, including our personalities and the events in our lives, are devoid of impossible ways of existing. [...] The fact that the information we gain from Tibetan-Mongolian astrology is often inaccurate is actually helpful. It shows us that life is not solid and fixed (Berzin 1996).

Berzin 'solved' the problem of 'inaccurate' calculations by looking at them from the Buddhist perspective of 'karma' and 'voidness.' Ethnographically, this may not hold. There are deeply faithful Tibetans who take these predictions at face value. My account of Momola shows that she took the predictions concerning her own life-span entirely seriously. At age fifty, she really thought she would die. Nevertheless, she felt that tshe was negotiable through certain efforts, which in her case were successful. She felt that the additional thirty years were granted because of the rituals, blessings, and her spiritual practice. Her 'faith' in her deities was certainly more enduring for her than any Buddhist explanations of 'voidness.' Still being alive in her eighties justified and validated the effectiveness of those

${ }^{8}$ Tibetan natal astrology involving the lunar mansions at birth also uses a similar style citing the age the person is going to achieve (Henning 2004b). 
practices she had been doing and motivated her to prescribe them for others.

Apart from Momola, I mostly got the sense that neither the amchis, nor astrologers, lamas, diviners, or the clients took a life-span prognosis at face value, as we seem to do. We came across this already in chapter 5.4, where Dr. Pema Dorje thought that westerners "will not accept the prognosis the way Tibetans do," and the astrologer Jampa Kalsang found that "westerners don't like to hear about their life-span." This reminds me of Tannenbaum's experience with Shan calendars mentioned in chapter 1.6, where she noticed that contradictions in the calendar trouble the anthropologist, but not the people who use them. Literal life-span predictions seem to confuse westerners, not the Tibetans.

The question that needs to be asked is how do Tibetans accept lifespan prognoses? Henning argues that although life-span calculations in astrology are literal in style, they "are not to be taken literally," and that "the astrological charts and so forth would be used as guides for intuitive interpretation" (Henning 2004a). When Henning asked Khempo Tsündru about the literal meaning of life-span predictions, "the Khempo was surprised at hearing that westerners were even asking that question" (Edward Henning, personal communication, December 2007).

Jampel Kaldhen, himself a respected lay astrologer, admitted that accuracy in astrology was actually impossible. He said: "Suppose your astrology chart gives eighty years as the life-span, it can also be sixty or seventy. In astrology you cannot be one hundred percent accurate." This did not make him think that something was 'wrong' with his system or that it was not worth being an astrologer. He had no problem acknowledging that calculated life-spans often do not turn out to be correct. Unlike other textual divination results, life-span divinations are stated literally but they are not meant literally. Something precise is given, but most people do not take it as a precise piece of information. This seems to follow a principle where something specific denotes something general. We obviously cannot dismiss this phenomenon out of hand because of its logical inconsistencies. To me, the interesting question is why, given the inaccuracies, these practices occur so widely in Tibetan societies. Obviously, they fulfil a purpose. I will take up this point of discussion again in chapter 11. 
PART FIVE

TIBETAN BUDDHIST LONG-LIFE EMPOWERMENTS

Until now little has been said about the actual long-life empowerments that Tibetans attend, often en masse, to receive blessings of longevity, believed to extend their life-span. So far, the book has provided individual vantage points on the life-span and life-forces - by amchis, diviners, and astrologers. Part V now deals with crowds of people and their public engagement in long-life empowerments (tshe dbang). Even though I base my discussion on individual views concerning tshe dbang, the entire ritual event presents a fairly regulated, institutionalised religious expression of collective, popular ideas of longevity. In taking up the issue of crowds, I show how tshe dbang have been used as an accepted mode of collective assemblage, which allow Tibetans in the Darjeeling Hills to gather in large groups and make subtle public statements, both to strengthen their status as a minority and to gain support for other activities (for example, establishing a skyid sdug, or financing monasteries).

Chapter 9 illustrates the different perspectives of the various participants of these empowerments, their motivations for attending such rituals, and their beliefs concerning their life-prolonging efficacy. The ethnographic account of the Sakya tshe dbang in Ghum in chapter 10 demonstrates how Tibetans in the Hills project their own health needs onto rigid and hierarchical ritual structures and give them a new meaning, which often lies outside the conventional Buddhist paradigm adhered to by the lamas. At the same time, I also show that the lamas who conduct these rituals have to make concessions to the public, who are rarely trained in Vajrayāna practices and who often no longer speak or study the Tibetan language, let alone understand ritual texts. 
Barbara Gerke - 978-90-04-21748-5 Downloaded from Brill.com๑4/26/2023 $\odot 2: 47: 13 \mathrm{PM}$ via free access 


\section{RITUAL LAYERS OF LONG-LIFE EMPOWERMENTS}

Long-life empowerments, called tshe dbang, are popular ritual events that attract large crowds of people in Tibetan Buddhist communities. They have been a part of Tibetan monastic festivals for hundreds of years. Originally from India, long-life empowerments were initially a one-to-one transmission, passed on from a teacher to a disciple. In contemporary Tibetan communities one still finds one-to-one tshe dbang transmissions, ${ }^{1}$ but the empowerment is mostly a public event.

I already mentioned the three main longevity deities - Amitāyus, White Tārā, and Ușṇịṣavijayā. How exactly these deities were propagated in the institutionalised and structured ritual forms of a tshe dbang is still open to research. Most of the tshe dbang rituals I attended in the Darjeeling Hills and in Sikkim were devoted to Amitāyus or White Tārā. The Ușnīṣavijayā tshe dbang was not as popular as the tshe sgrub of this deity. Apart from the three long-life deities there are also local variants of longevity deities, probably related to mountain cults. For example, Kohn in his work on Mani Rimdu ritual in Nepal mentions five auspicious long-life goddesses that have their own specific longevity ritual practice and a corresponding local mountain peak (Kohn 1988: 838-866). In the Darjeeling region, I did not come across any local longevity deities. Perhaps this is because it is a community of immigrants.

Tshe dbang are to be found in all schools of Buddhism with regional and sectarian variations. In 2004, the tshe dbang given by Dzongsar Jamyang Khyentse Rinpoche (1961-) in Sikkim was linked to the treasure teaching of Lhatsün Namkha Jigme (1597-1650), who converted the indigenous Lepchas of Sikkim to Buddhism by integrating their beliefs concerning sacred landscape into his interpretation of Sikkim's sacred geography. ${ }^{2}$ Long-life empowerments of the Nyingma School of Tibetan Buddhism usually link up to Padmasambhava, although they may still be centred on Amitāyus

\footnotetext{
${ }^{1}$ I documented, for example, one event where a Tibetan man who was in a car accident went to a rinpoche who gave him a tshe dbang as 'first aid.'

${ }^{2}$ Balikci (2002, 2008) and Arora (2004, 2006b), for example, discuss Sikkim's sacred geography, also in ritual contexts.
} 
(see the Maratika cave story in chapter 7.2). The text of the tshe dbang performed by Kyabje Dudjom Yangsi Rinpoche in Kalimpong in 2005 was composed by his previous incarnation, the late Dudjom Rinpoche Jigdral Yeshe Dorje. The father of another Nyingma lama from Kalimpong told me that Sakya Trizin Rinpoche Ngawang Künga (1945-), the present throne holder of the Sakya school, would preferably give the tshe dbang of Thangtong Gyalpo (1361?-1485), ${ }^{3}$ whereas the fourteenth Dalai Lama would mostly bestow the White Tārā tshe dbang.

While there are certain variants of tshe dbang within the different schools of Buddhism, ordained monastics and the public freely attend all types of tshe dbang in the region, especially when they are given by a high lama. For the public it matters if the lama is considered powerful, since the efficacy of the tshe dbang is based more on the lama's level of spiritual realisation than on his textual tradition.

A tshe dbang can be located at the periphery of the corpus of tantric empowerments for two reasons. First, a tshe dbang is relatively easy to perform and does not require long preparatory retreats on the part of the lama. Second, Tibetans - at least in the Darjeeling Hills - admit that tshe dbang do not involve a daily commitment of practice. For them tshe dbang is a 'blessing without practice.' This perception is so widespread and unchallenged that it is part of 'local knowledge,' even though it contradicts the texts.

Jampel Kaldhen, who was also a dedicated lay practitioner of Tibetan Buddhism, would attend a dbang only when he wanted to become involved in a particular practice. He considered a tshe dbang not to be a 'real empowerment.' He said,

Tshe dbang is a general public initiation which everyone can attend. No practice or obligations are necessary. Just a blessing is given. Real empowerments include the promise and obligation to practise.

Lay Tibetans had their own views on tshe dbang and gave them a different level of importance than the lamas did. The president of a skyid sdug in Pedong, a Sikkimese Bhutia, told me during an informal conversation while attending a tshe dbang, in May 2005:

3 Thangtong Gyalpo was a Tibetan Mahāsiddha, architect, and artist and is said to have lived to the age of one hundred and twenty-four. See Stearns 2007 on the life and legacy of this Tibetan master. 
BHUTIA: There is tshe dbang and ordinary dbang.

BG: Is a tshe dbang not ordinary?

BHUTIA: Lamas told me that any lama can give it, no samaya has to be kept, no three-year retreat to be done. It is an easy dbang to give for the lama, but for the lay person it is special, because it reduces the obstacles of your life and avoids premature death. That is special.

Lamas' and lay people's views on tshe dbang differ, and in some cases have led to the lamas making certain adjustments in their interpretation of dbang. In the Darjeeling Hills, I observed a certain re-interpretation of the transmission of Vajrayāna dbang and the importance of promises linked to $d$ bang, which are reflected in the thoughts of Lama Kunzang, who told me when we met after the tshe dbang given by Dudjom Rinpoche at the Durpin Gompa in Kalimpong, in April 2005:

Every dbang has a promise, a samaya, in Tibetan called dam tshig. A tshe dbang has a certain dam tshig. Dam means 'bond' and tshig means 'to burn.' It expresses the bond between the teacher and the disciple. Receiving a teaching and then breaking the rules will have you burn in hell [he laughs while quoting the text in Tibetan].

Tshe dbang can be related to Amitāyus, White Tārā, Padmasambhava, or others. They belong to the Vajrayāna teachings. Actually, when taking a tshe dbang, you have to practise all the dam tshig of Vajrayāna. In particular, you have to practise the tshe dbang tshe sgrub mantra as often as you can. One of the dam tshig is not to kill. Then you try to save lives. This is written clearly in the longer tshe dbang texts.

During the tshe dbang, the teacher has to explain the samaya. But nowadays it has changed, and many lamas would rather put the seed into the people for receiving liberation in another lifetime. This happens with a lot of the Vajrayāna teachings these days. People still have pure faith in the Vajrayāna teaching, pure motivation; they want to receive the tshe dbang. That also benefits them. If people practise, it is better, but if they do not know the practice, they still get a blessing.

'Getting a blessing' is a lot of what tshe dbang are about, since only a few people attend a tshe dbang to 'get permission to do the practice.' But what does this 'blessing' involve? How is it transferred to such large crowds? How do people understand it and link it to their life-span? The next section analyses the notion of 'blessing' in more detail.

\section{The Notion of Byin rlabs}

In order to understand people's ideas on tshe dbang, the Tibetan concept of byin rlabs, which is often translated as 'blessing,' deserves a closer look. 
Byin rlabs is central to Tibetan Buddhist rituals in general and is an intrinsic aspect of the Tibetan experience of receiving an empowerment.

Byin rlabs (Skt. adhisthāna) is quite complex, probably of pre-Buddhist origin, and involves concepts of power. Byin is one of the attributes associated with the old Tibetan kings. The pre-Buddhist divine king possessed byin as "a personal property or quality of his physical body" in the sense of 'splendour' and 'glory' (Huber 1999: 90). Byin rlabs literally means 'wave of byin' (Samuel 1993: 450). In Tibetan dictionaries, we find byin translated as "pomp, splendour, magnificence, blessing, and resplendence" (THL 2009).

Byin rlabs is generally understood as the blessing-power inherent in sacred sites, objects, landscapes, and deities, which can be exploited through a ritual engagement by a lama. Byin rlabs is in fact one of the prerequisites for a lama to "claim to be an effective supplier of magical power" (Samuel 2005: 70-71). Its underlying relationship with power makes it a source of protection from harm and increases auspiciousness. Moreover, byin rlabs is considered important in the transmission of a lineage. ${ }^{4}$ Huber translates byin gyis rlabs as 'empowerment' in the sense of 'flooded with power' or 'suffused with power,' arguing that Tibetans have a broad understanding of byin in terms of a 'field of power' in terms of both place and space, especially in the context of pilgrimage (Huber 1999: 91). Byin affects the sacred environment, which in turn produces 'the empowered' (byin can), which can be any substance of that place, that is passed on to the pilgrim circambulating such places (Huber 1999: 90-91). Byin is also expressed in terms of social status and ritual hierarchy, which will be elucidated in chapter 10.

Daniels points out that byin rlabs can be received from a distance, and it can also be very material and placed in bottles and plastic bags, thus overlapping the invisible sacred and the material profane (Daniels 1994: 145, 147). Byin rlabs is thus not solid but can be absorbed into the body through a substance, through touch, or across distance psychically. This will become clear in the course of this chapter when the ritual implements of a tshe dbang, such as the consecrated water and pills that carry the byin rlabs of long life, are discussed.

\footnotetext{
${ }^{4}$ Tibetans have conceived of three types of lineages: the family lineage ( $\left.g d u n g ~ r g y u d\right)$, the transmission of tantric teachings or empowerments to disciples (slob rgyud), and lineages of 'emanations' of incarnate lamas (sku rgyud; Mills 2003a: 125).
} 
The interpretation of byin rlabs shows local variations. In Helambu, Clarke defines byin rlabs by contrasting it with tendil (rten 'brel) and dbang (Clarke 1990: 177-178). He discusses dbang not as an empowerment but as a blessing, as well as a substance. Consecrated pills are locally called $\mathrm{dbang}$ as well as byin rlabs. He relates byin rlabs to the Sanskrit prasād, which in Helambu refers only to certain kinds of blessing, relating to health and general well-being. The blessing of 'good fortune' is linked to notions of tendil explained earlier. ${ }^{5}$

Ideas of byin rlabs also extend to other notions of spiritual realisation, known as siddhi in Sanskrit and dngos grub in Tibetan. One of these dngos grub that can be achieved and for which the byin rlabs of a tshe dbang and other longevity practices is essential, is the 'siddhi of longevity and immortality' ('chi med tshe yi dngos grub). As mentioned earlier, immortality here is not understood as physical immortality.

In understanding diverse ritual meanings, I am inspired by the anthropologist Michael Jackson and his approach to take 'things as they are' (1996). Jackson advocates that,

$[\mathrm{r}]$ ather than examine the epistemological status of beliefs it is more important to explore their existential uses and consequences. Our emphasis is thus shifted from what beliefs mean intrinsically to what they are made to mean, and what they accomplish for those who invoke and use them (Jackson 1996: 6).

Especially when it comes to a complex idea, such as byin rlabs, it seems important to see what byin rlabs actually accomplishes for the different participants of a tshe dbang and how byin rlabs is invoked and transferred to extend the life-span. Based on my data, I argue that the concept of byin rlabs is central to how people develop temporal ideas of the life-span in longevity rituals. At the same time, byin rlabs also remains embedded in the larger framework of merit and karma.

I now present a brief literature review on tshe dbang. I then introduce the various participants of a tshe dbang (lama, monk, organiser, sponsor, interpreter, the public, and individual Buddhist practitioners) and sketch their roles in the ritual. The data used in this section is based on all eight tshe dbang I attended between 2004 and 2007. In chapter 10, I then present a

5 Tendil (rten 'brel) was mentioned by Clarke with its popular meaning of 'good fortune,' 'omen,' and 'matters of direct material prosperity' (Clarke 1990: 177; see chapter 3 , footnote 46 ). 
vignette of one tshe dbang event (Ghum, March 2005). The overall picture that emerges from the data is discussed in chapter 11.

\section{Tshe dbang Literature Review}

Since we know very little about the history and origins of tshe dbang and since there are hardly any published works on this topic, in this section I present an overview of the existing literature. A historical study of tshe dbang is difficult and may prove that rituals can be disseminated in ways similar to the ones found in the Mani Rimdu festival in Nepal, which was studied by Kohn (1988). He traced some of the steps "that took a small private cult from a monastery in Central Tibet and made it the focal point of a rural festival in Nepal," a historical development that he describes as being led by 'logic' as much as by 'random elements' (Kohn 1988: 956). Such trajectories are difficult to sketch.

There is no up-to-date study on tshe dbang, but Samuel has summarised the existing anthropological literature succinctly (1993: 261-265). He emphasises the 'pragmatic' aspects of a tshe dbang, pointing to it affects on the contingencies of everyday life. Waddell in his early description of a tshe dbang draws strong Christian parallels (Waddell 1978 [1895]: 444448), which are "more apparent than real" (Samuel 1993: 261-262).

The tshe dbang performed on the first day of the Mani Rimdu ( $m a n i$ pill practice) at Tengboche in Nepal has been described several times with more or less detail (Fantin 1976: 163-164; Fürer-Haimendorf 1964: 214; Jerstad 1969: 102-106; Kohn 1988). However, as Samuel explains, from the lama's point of view these are not tshe dbang rituals but gtor ma empowerments (Samuel 1993: 261). The ma ni pills consecrated during a Mani Rimdu ritual involve the deity Avalokiteśvara and his mantra om ma ni padme hung, not the long-life deities and their mantras, and the aim is primarily a spiritual enhancement and only secondarily related to longevity (Samuel 1993: 261). Nevertheless, local Sherpa in Tengboche refer to it as a tshe dbang. Kohn's study of this ritual is very extensive, but mostly describes the 'educated view' from the monastic vantage point. Kohn admits that he hardly interviewed villagers concerning their perspectives on the ritual (Kohn 1988: vii), which is also a shortcoming of Beyer's tshe dbang description (Beyer 1973: 375-398).

Snellgrove briefly describes long-life consecrations in Dolpo, northwestern Nepal, with the emphasis of transferring byin rlabs (Snellgrove 1961: 141-146). His ethnographic account of a Nyingma tshe dbang focuses 
on Amitāyus and describes the perspectives of the villagers of Dolpo, who were little concerned with the actual ritual of consecration and more focused on receiving the byin rlabs and the strengthening of bla tshe, which Snellgrove translated as 'supernal life.' He links the loss of bla with the tshe dbang, which is supposed to nourish bla tshe (Snellgrove 1961: 143). In the Darjeeling Hills, Tibetans did not connect a tshe dbang directly with bla. The loss of bla was diagnosed and treated separately (see chapters 5 and 6.4). Snellgrove's observations on byin rlabs, however, point to the gulf between the meaning of Buddhist technical terms and what people project onto the ritual. His observations also echoe in my ethnographic account of the Sakya tshe dbang in chapter 10.

Kind (2002) presents a detailed ethnographic description of a sman sgrub ritual among a Bonpo community in Tsho, a village in Dolpo. Here, sman sgrub is a way to bless medicinal substances over a several-day-long ritual to benefit the spiritual and physical health of the entire community. It is widely known among Tibetan Buddhist communities, and many different textual versions are in circulation. The sman sgrub is not a tshe dbang, but long life is also one of the benefits of sman sgrub (Kind 2002: 39). The sman sgrub ingredients are numerous and largely medicinal, whereas long-life pills (tshe ril) are made from roasted barley flour (rtsam pa) and butter. Both are seen as carriers of byin rlabs.

In Kalimpong, I participated in a seven-day sman sgrub sgrub chen ${ }^{6}$ linked to the wrathful deity Vajrakillaya, which was concluded with a Vajrakilaya tshe dbang. ${ }^{7}$ Among Tibetans it is considered auspicious to conclude a major cycle of empowerments with a teaching that focuses on longevity, or a tshe dbang "to preserve the health of the students for future practice" (Samuel 1993: 261). In this context it is interesting to note that yogic practitioners also do long-life practices to compensate for the risks involved in 'killing' beings during a ritual - especially if they do this without the motivation of bodhicitta. This was given by a lama as the reason why the 'chi med srog thig (lit. 'life drop of deathlessness'), a longevity practice of the Nyingma tradition of Dudjom Rinpoche, is 'officially' a supplement to a Vajrakilaya practice. ${ }^{8}$

\footnotetext{
${ }^{6}$ A sgrub chen is a sādhana practice undertaken on a regular basis by a monastery or other religious community. During a sman sgrub sgrub chen, blessing pills are consecrated and later distributed to the public for general health and well-being.

7 Boord (1993: 207-214) published the translation of a Vajrakilaya tshe sgrub of the Northern Treasure Tradition (byang gter tshe sgrub).

${ }^{8}$ Geoffrey Samuel, personal communication, October 2007.
} 
The Autobiography of Jamgön Kongtrul (Barron 2003) is a good starting point for a historical study of tshe dbang and longevity practices in general. Translated from the Tibetan, it describes the variety of long-life ritual practices and their social embeddedness from the perspective of a Tibetan lama, Jamgön Kongtrul Rinpoche Lodrö Thaye (1813-1899), during the nineteenth century in Tibet. From this narrative, the reader can understand the importance that longevity practices had throughout the life of a lama in Tibet, including the social and political obligations that surrounded a tshe dbang. I will not review his work here in detail, but use some of his quotes in this chapter, since his account is the only historical example on tshe dbang I came across.

Jamgön Kongtrul illustrates the place of long-life practices in relation to other Tibetan Buddhist practices. Long-life practices are listed under 'Miscellaneous Instructions,' along with the alchemical teachings (Barron 2003: 274) and not under the main headings of the Buddhist lineage practices and empowerments. Longevity sādhana feature under 'Concluding Teachings' (Barron 2003: 520), which points to the place they often hold in larger ritual events.

Childs' Tibetan Diary (2004) offers a few interesting points on tshe dbang from his research in Nubri, Nepal. He gives a few examples of how tshe dbang are used as auspicious time-markers during childhood. He mentions a tshe dbang that took place three days after birth, marking the event when the lama named the child and calculated its natal-chart, including the life-span. Longevity and freedom of illness were the benefits of this tshe dbang mentioned by Childs. He also observed that tshe dbang were held more often for boys than for girls (Childs 2004: 41), a gender distinction I did not come across in my field site. On the child's birthday, a year later, the first hair-cutting ceremony again included a tshe dbang (Childs 2004: 54). Childs' ethnographies show that tshe dbang not only mark but also enhance important life-cycle rites.

The best-known account of a Tārā tshe dbang is in Beyer's The Cult of Tārā, published in 1973. Beyer observed a White Tārā tshe dbang ${ }^{9}$ and a White Tārā empowerment or 'permission ritual' (rjes gnang) $)^{10}$ in Dalhousie, in Himachal Pradesh, India, among exiled Tibetan communities from Kham belonging to the Kagyü lineage. The study was carried out

\footnotetext{
9 This ritual is a Geluk practice performed by Tārā Rinpoche, and was authored by the last regent of Tibet, Tagdrag Ngawang Sungrab Thutop (1874-1952; Beyer 1973: 500, n. 15).

${ }^{10}$ This ritual text was composed by Kongtrul Rinpoche (Beyer 1973: 501, n. 45). The rjes gnang is a preparation for further practice.
} 
in the early 1970 s and offers a good description of both rituals, including the translation of ritual texts, the explanation of their meaning, and the methods of visualisation.

The White Tārā tshe dbang, also summarised by Samuel (1993: 262-263), is too long to be repeated here, but there are important points to be raised concerning ritual efficacy, an issue I take up in the discussions of my ethnographic accounts of tshe dbang. Beyer describes that the effectiveness of the initiation depends entirely upon the spiritual abilities of the master. Ritual efficacy involves more than reading the texts, reciting the mantras, and performing the gestures using the ritual objects. The ritual objects, such as the long-life initiation gtor ma (tshe gtor), ${ }^{11}$ the long-life vase (tshe bum), the longevity pills (tshe ril), and the long-life nectar (tshe chu) are all there to make the power of the visualised deity tangible to the lay person and bestow byin rlabs.

The master's ability to visualise himself as White Tārā is decisive. The people attending a tshe dbang generally do not take part in these visualisations. The bestowing of long life is not thought of as being dependent on their participation. As Beyer puts it,

The initiation into life [i.e. tshe dbang] is an end in itself, a bestowing of the magical attainment of longevity, and the major aim of the recipients is fulfilled by their increase of life; hence we find the use of devices and recipes that function more or less independently of the spiritual state of the disciples (Beyer 1973: 432).

Beyer describes the White Tārā tshe dbang in detail, also presenting a translation of the ritual text (Beyer 1973: 378-398). The master first prepares himself alone in contemplation, visualising himself as White Tārā ('self-generation'). He then visualises the deity in front of him and merges her with the long-life gtor ma ('generation in front'). Finally, he enters the main shrine room and bestows the initiation. The disciples who are receiving the empowerment are instructed to visualise the deity in front of themselves, and then visualise themselves as well as the lama as White Tārā (Beyer 1973: 388-389). During the course of the tshe dbang they are instructed to visualise the power of long life entering their bodies through

${ }^{11}$ Gtor $m a$ are offering cakes in various shapes and colours made from dough. They are used as food offerings for deities or spirits during tantric rituals. A gtor ma can also be an implement used during empowerments, called an initiation gtor ma (see also footnote 5 in chapter 10). Initiation gtor ma used in long-life empowerments are called tshe gtor. 
the ritual implements (e.g. tshe gtor, long-life vase, long-life pills [see plate 9.1], long-life nectar [see plate 9.2]).

My ethnographic account of a tshe dbang in chapter 10 complements Beyer's description and shows that what matters to the laity attending the ritual is different from what matters to the lama. I argue that being removed from the ritual's text and its content, lay Tibetans in the Darjeeling Hills reinterpret tshe dbang in their own terms, which are different from the textual Buddhist ideas the lama is applying in his ritual performance. Consequently, people's inner experiences of the ritual do not necessarily correspond to the 'inner work' prescribed and performed by the lama conducting the ritual.

Remembering that "no one cultural standpoint is central" Jackson (1996: 9), I am well aware that the multidimensional individual experiences in longevity rituals are so rich that no view can be singled out as

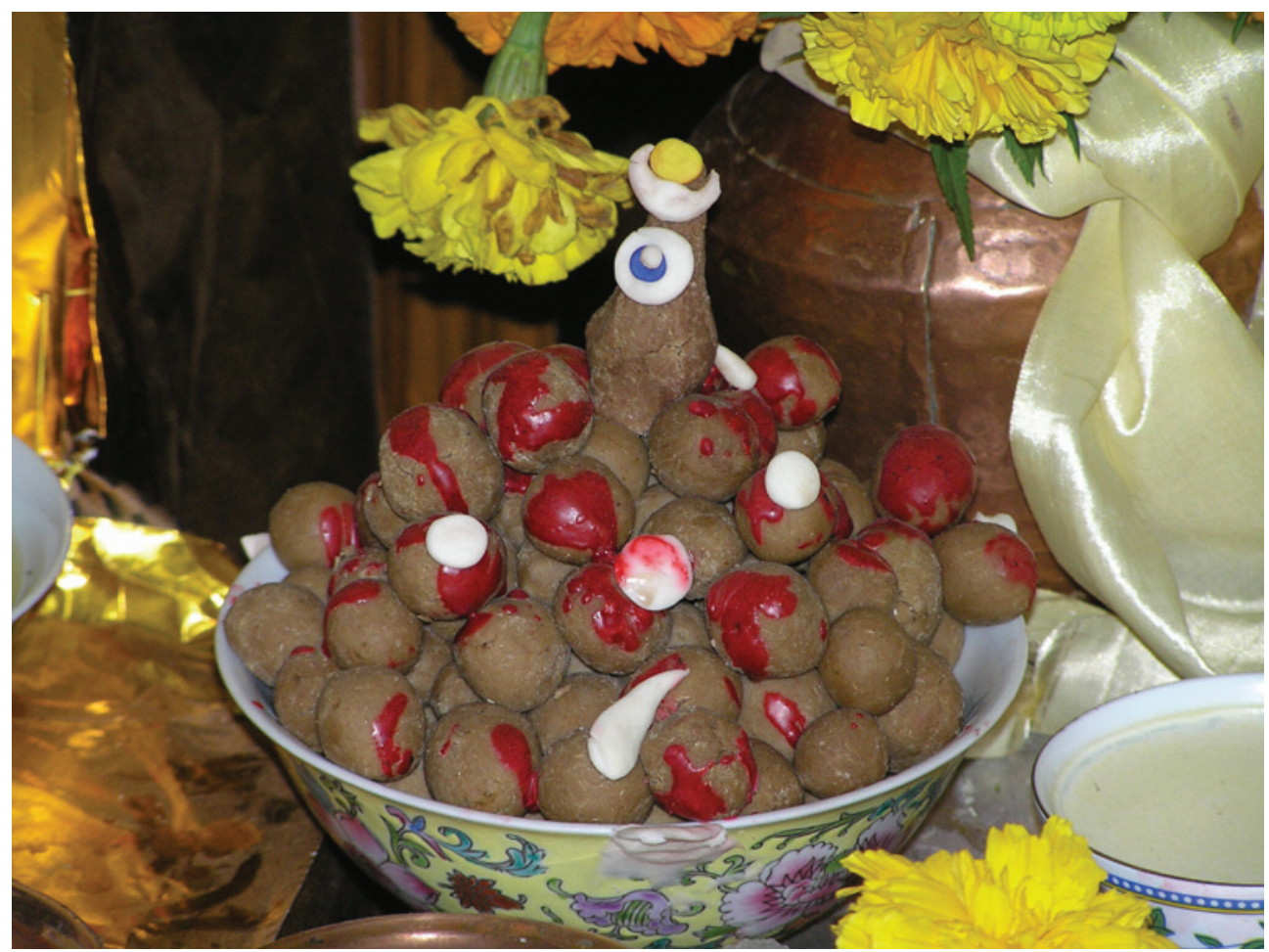

Plate 9.1. Red-coloured long-life pills symbolise the red-coloured Buddha Amitāyus during the tshe dbang at the Mani Nyungne Kidu, Ghum, October 2004. 


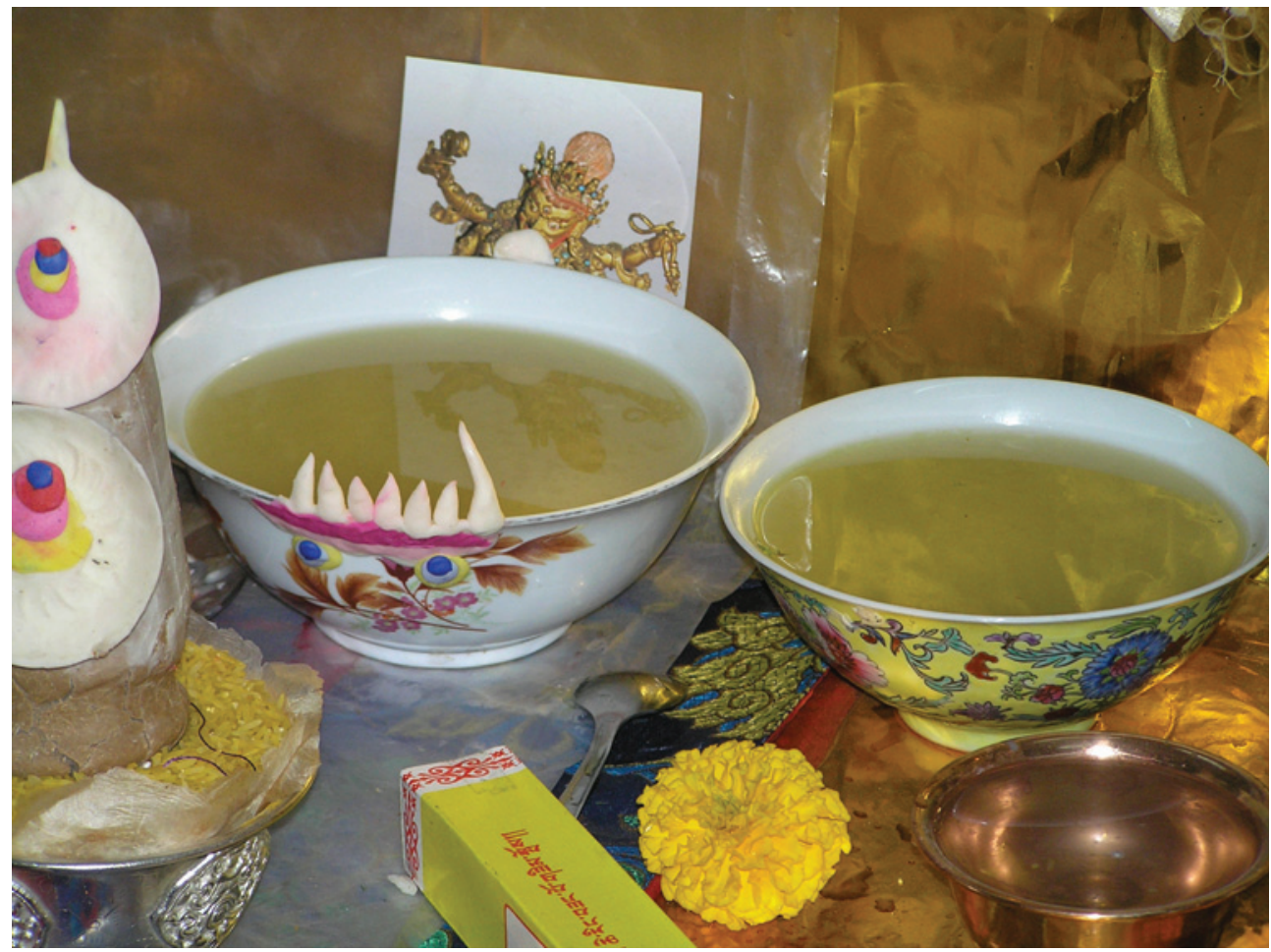

Plate 9.2. Two bowls of long-life nectar and other offerings. To the very left is an offering gtor ma made from roasted barley flour and coloured clarified butter, Ghum, October 2004.

'representing' the attitudes of people attending, conducting, and organising the rituals. Therefore, during fieldwork I kept shifting my ethnographic gaze from the public, to the monks, to the interpreter, lama, and sponsors, etc. In each ritual, I tried to understand another perspective. Before presenting the ethnography of a tshe dbang, I attempt to sketch this wide range of views by introducing the various participants of a tshe dbang.

How are ideas surrounding longevity expressed by lay Tibetans, who for the few hours that the tshe dbang lasts create a collective manifestation of a phenomenon that challenges the purely textual views of tshe dbang rituals?

\section{Ritual Layers and Multiple Voices}

Tibetan Buddhist rituals can be received on various levels. Samuel points out that the basic idea behind a tshe dbang is that 
[t]he lama uses his Tantric powers to confer long-life and health upon those receiving the empowerment. As with any other Tibetan rituals, this process may be interpreted at any of a number of levels, and the participants are free to take the ritual at whichever level they wish (Samuel 1993: 262).

Ways to account for multilevel ritual meanings have been described by anthropologists, for example, in the context of Jain rituals (Humphrey and Laidlaw 1994: 13). With the aim of unravelling the multiple levels on which a tshe dbang ritual takes place, in this section I first sketch the various roles of the people involved in a tshe dbang. The participants in the performance of a tshe dbang are the rinpoche or lama, his close ritual assistants (ordained monks and lamas), the attending monks and nuns, the organisers, the sponsors (sbyin bdag), the interpreter, and the lay public, some of whom are dedicated practitioners. These participants are presented briefly below. To let the people speak for themselves I chose quotes from interviews and informal conversations that took place at various points during the eight tshe dbang I attended.

\section{The Lama}

The role of the lama in a tshe dbang has been portrayed in detail by Beyer (1973: 375-398). Beyer describes the ritual set-up, the ritual instruments used, and their purpose, all from the lama's perspective. Providing the translation of the ritual text, he then describes the visualisations the lama has to perform to fully identify with the deity and to consecrate the tshe gtor, tshe ril, and tshe chu. Unfortunately, we do not directly hear the voice of the lama, nor do we understand how he sees or perceives the tshe dbang. I admit this perspective is extremely difficult to research, since the high lamas are rarely accessible and are well shielded from the public. Moreover, they are not supposed to talk about the inner tantric practices and visualisations, except when passing them on to a disciple. During the eight tshe dbang I attended, I was able to receive only one ten-minute interview with one of the leading rinpoches, who mainly reiterated the expected Buddhist textual view.

My long-term association with Lama Kunzang (see plate 9.3) proved to be more useful in this regard, and he spent many hours over several days with me in Kalimpong after the seven-day sman sgrub sgrub chen with Dudjom Rinpoche, which included three longevity rituals, a tshe sgrub, a brtan bzhugs, and a tshe dbang. Since he himself held a leading role during the sman sgrub sgrub chen and had performed many tshe dbang and tshe sgrub himself, he had a clear insight into the role of the lama and the 


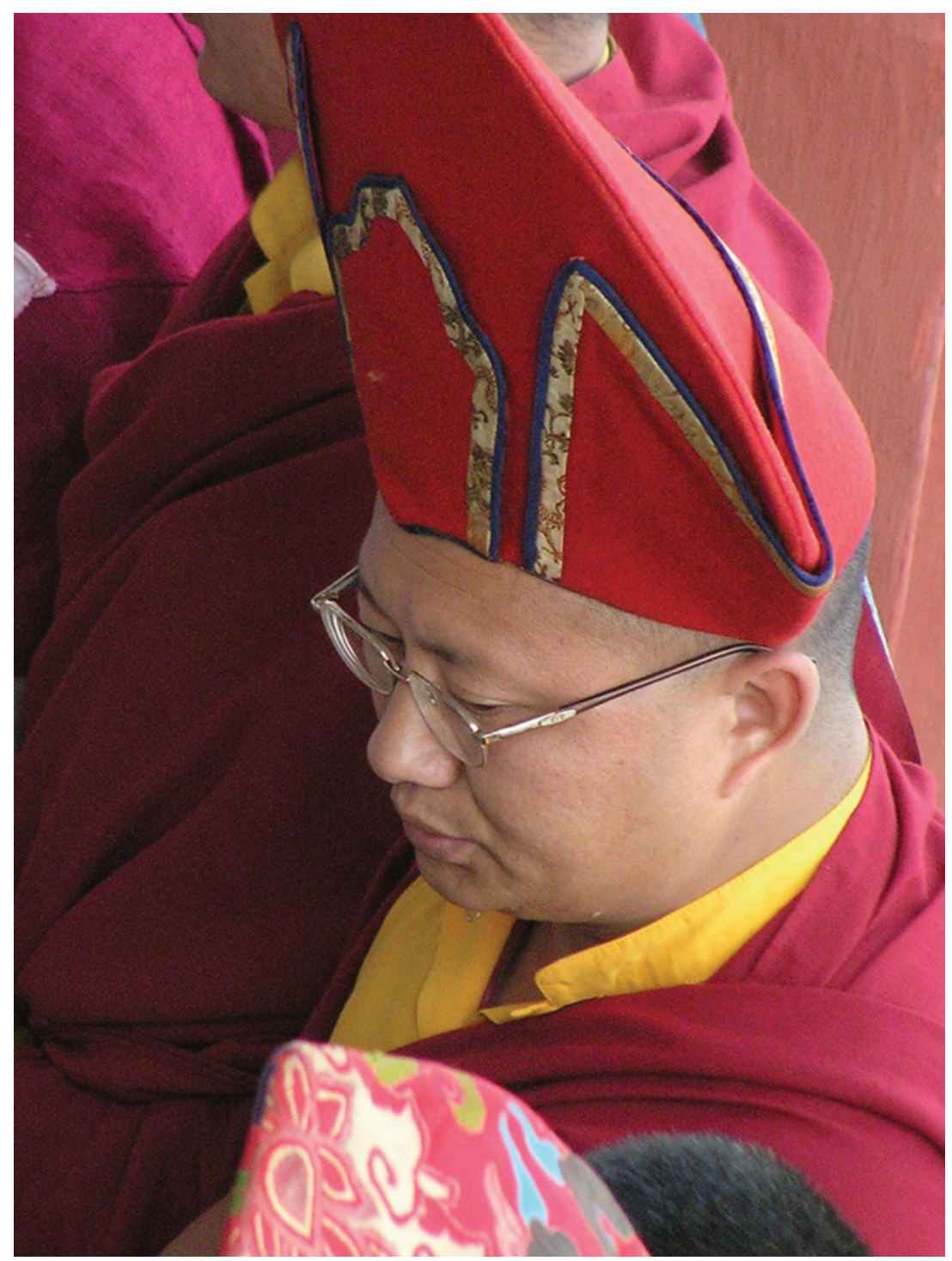

Plate 9.3. Lama Kunzang Dorje at the seven-day sman sgrub sgrub chen ritual, which was concluded with a tshe dbang at Durpin Gompa, Kalimpong, November 2004. 
capacity to express some of his personal views, of which I present a few in this chapter.

The only time the lama is free to add his own views to a tshe dbang is during the speech or sermon. Any other moment of the event is prearranged and fixed in the ritual texts and follows prescribed roles of hierarchy. The sermon can be part of the written ritual text (see, for example, Beyer 1973: 386-388), but in many cases, the lama adds his own material to the speech, or retells stories of people who extended their lives. ${ }^{12}$ One story I heard many times during tshe dbang was of Rechungpa (1084-1161), the disciple of the famous Tibetan yogi Jetsün Milarepa (1040-1123). The story goes as follows:

During his second visit to India, Rechungpa, at that time forty-two years old, met a yogi who told him that he only had seven days to live. His master, who had been aware of Rechungpa's short life-span, sent him to a female yogini called Machig Drupä Gyalmo, who was said to be five hundred years old but had the appearance of a sixteen-year old girl. Rechungpa requested her for the siddhi of long life. She asked if he could stay without sleep for a week and when he agreed gave him a longevity practice to be performed for seven days and nights. After seven days, Rechungpa had a vision of Buddha Amitāyus, who taught him further long-life sädhanas. Machig Drupä Gyalmo asked Rechungpa how long he wanted to live and he replied, "I want to live until I don't want to live anymore." She replied, "You wicked Tibetan with such great desire to live so long. Your teacher Milarepa is now eighty-three and is going to live until his eighty-fourth year, so you can do the same." Rechungpa returned to Tibet with numerous practices that were translated into Tibetan and died at the age of seventy-eight (summarised from Thrangu Rinpoche 2001: 15-16).

Now follows an example from a young Nyingma Lama from Darjeeling who told this story during a tshe dbang to emphasise the need for peoples' own effort in increasing their life-span. He spoke in broken Nepali to the assembly: ${ }^{13}$

\footnotetext{
${ }^{12}$ Beyer mentions the story of a lama whose disciple was told that he had only three years left to live, but who extended his life up to the age of ninety-five through the White Tārā practice (Beyer 1973: 387).

${ }_{13}$ This tshe dbang was organised by the Buddhist Yolmo community and held in October 2004 at the Yolmo Gompa in Aloobari near Darjeeling. I could not attend the tshe dbang, but received a copy of a video recording of the entire ritual, from where the lama's speech was translated. Thanks to Prof. Samten Norbu and his late nephew Pemba of the Yolmo Buddhist Association, Darjeeling, for providing a copy of the video.
} 
[...] Rechungpa got the dbang and the practice, and after this his age increased by about fifty years. Your age increases after you receive the dbang, but only if the rules associated with it are followed properly. If one does not follow the rules, your age can even decrease. But if you receive the dbang today, then reach home, do a lot of your [negative] karma, hit people, and ill-treat the sick, then your age may also decrease. If, however, you don't do this, but act according to the rules, and follow what I have said, then people may have their age increased (video of 24.10.2004, translated from Nepali by Heera Sharma).

In this sermon, the life-span is linked to good and bad actions. The lama points out the effects that ethical or unethical behaviour have on one's life-span. The central message of most of the speeches I heard during longevity empowerments was that there are always possibilities to adjust one's fate, including one's life-span, through dharma practice and good karmic actions. The temporal aspect of it is similar to what I discussed in chapter 8 . The message surrounding tshe is vague. It depends on a person's actions, which can change each day. Thus, especially with a crowd of people, the lama plays it safe; he does his part to increase tshe through his dbang, but makes sure to state that it will only work if people follow the rules. So if it does not work, the fault never lies with the lama or the system, but only with the personal karma of the individual.

On the one hand, it is believed that the lama's spiritual accomplishment is responsible for the efficacy of the tshe dbang. On the other hand, he would never be held responsible if a person died after a tshe dbang. Individual karma is therefore the ultimate regulator of the life-span; the rituals are given credit when successful (see Momola's example in chapter 8.1).

\section{The Monks}

During a tshe dbang, the role of the monks is to assist the lama in the practical aspects of the ritual. They shop for the ingredients in the bazaar and prepare the long-life pills and the offerings for the altar (see plate 9.4). Making long-life pills for hundreds of people takes a few days. Tibetan Buddhist rituals are complex and time-consuming in their preparations and require artistic skills, such as the making and decoration of gtor ma. During the actual tshe dbang, only a few monks are required to recite prayers, play the ritual instruments, and hand the ritual objects to the 


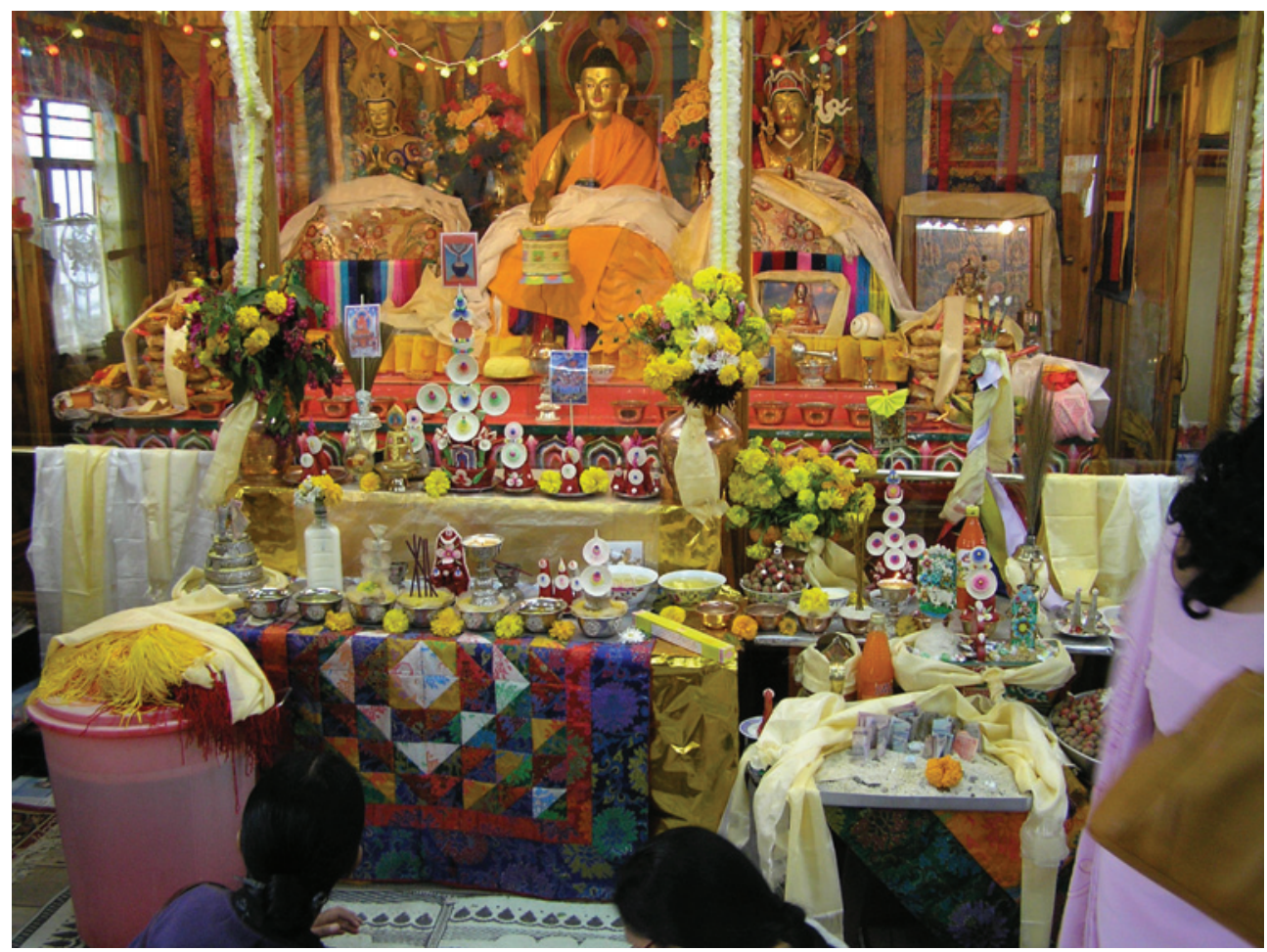

Plate 9.4. Elaborate offerings for a tshe dbang at the Mani Nyungne Kidu, Ghum, October 2004. The large red bucket (left) contains orange-juice coloured long-life water. On the lid are yellow and red protection cords; both are distributed to the public during the tshe dbang.

lama at the right time. Strong monks are usually assigned to handle the crowd and protect the lama from a stampede. ${ }^{14}$

I noticed that the monks, especially when they were young, had a general grasp of the ritual procedure on a practical level, but did not seem to engage in any active visualisation. In November 2005, I attended a tshe sgrub, performed by eight monks on the top floor of the Durpin Gompa in Kalimpong, while downstairs in the main hall the seven-day sman sgrub sgrub chen was carried out by Dudjom Rinpoche. The ritual ended with a tshe dbang on the last day. During the tshe sgrub a small amount of

${ }^{14}$ This is no exaggeration. During a tshe dbang given by the fourteenth Dalai Lama in 2004, which 30,000 people attended, I observed just how close a tshe dbang can come to a stampede. Jerstad describes a "clamor of crushing bodies" among a Sherpa tshe dbang in Tengboche, Nepal (Jerstad 1969: 105). 
long-life pills and long-life nectar were consecrated over six days and then offered to Dudjom Rinpoche for his long life on the last day of the sman sgrub sgrub chen. The idea behind this was that a certain amount of tshe was generated over the six-day tshe sgrub ritual, which was then transferred to Dudjom Rinpoche through the long-life pills, the long-life nectar, the long-life arrow, and the tshe gtor (see plate 9.5). I come back to this idea of accumulating and transferring tshe later in this chapter.

Only two of the eight monks, Lama Karma and Lama Sonam, had actually been trained in leading the ritual and doing the visualisation and had completed a three-year retreat, which gave them the title 'lama.' They were around thirty. The others, who were much younger, participated in the recitations, played the ritual instruments, and assisted with the offerings (see plate 9.6). Most of them were still in training, like the eight-year old

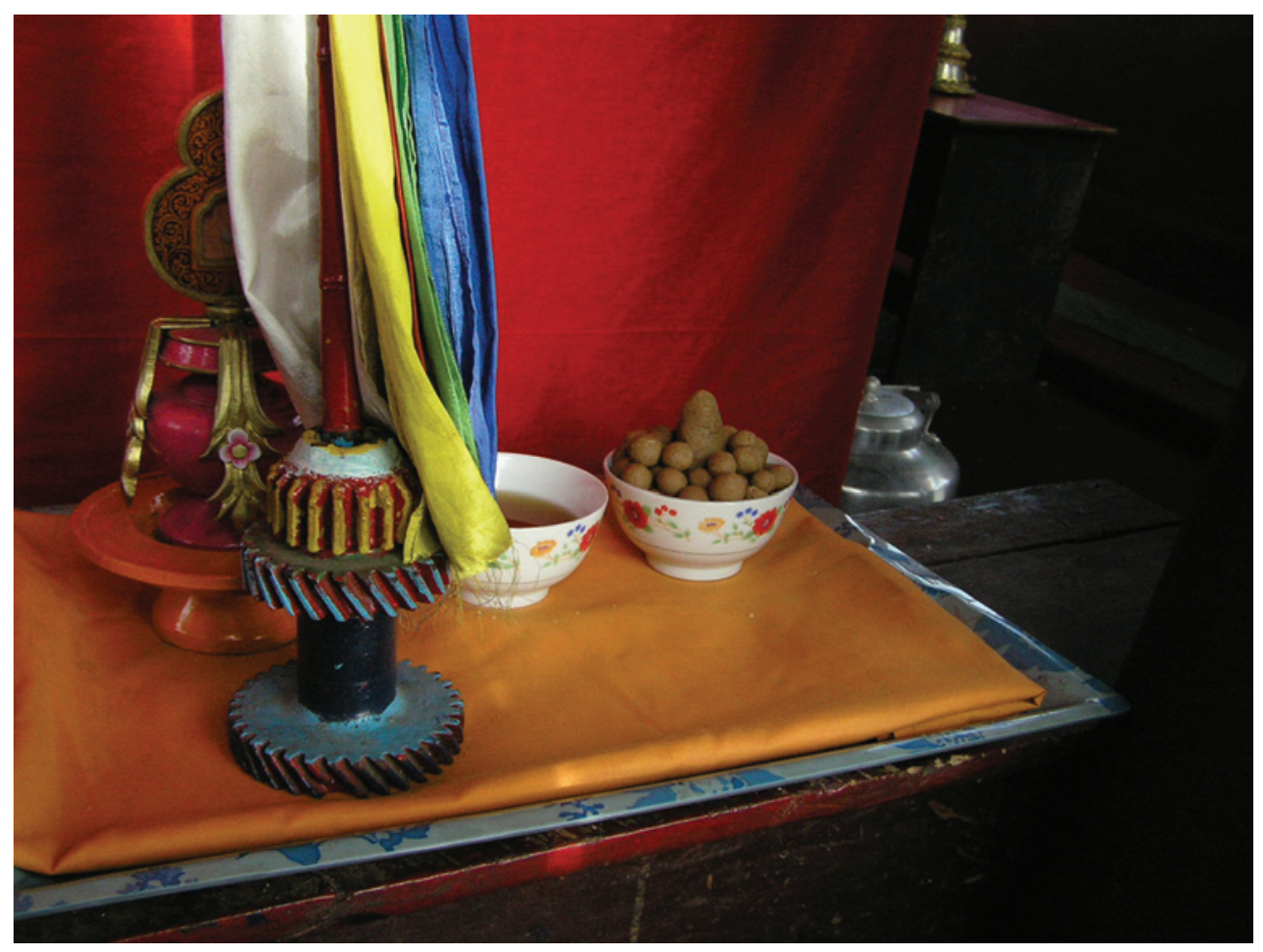

Plate 9.5. A small amount of long-life pills (top right) and long-life nectar (top centre) that were consecrated during a six-day tshe sgrub and then offered to Dudjom Rinpoche for his long life. He also received the byin rlabs, offered to him by the head lama of the monastery, through the long-life arrow (front) and the tshe gtor (top left). Durpin Gompa, Kalimpong, November 2004. 


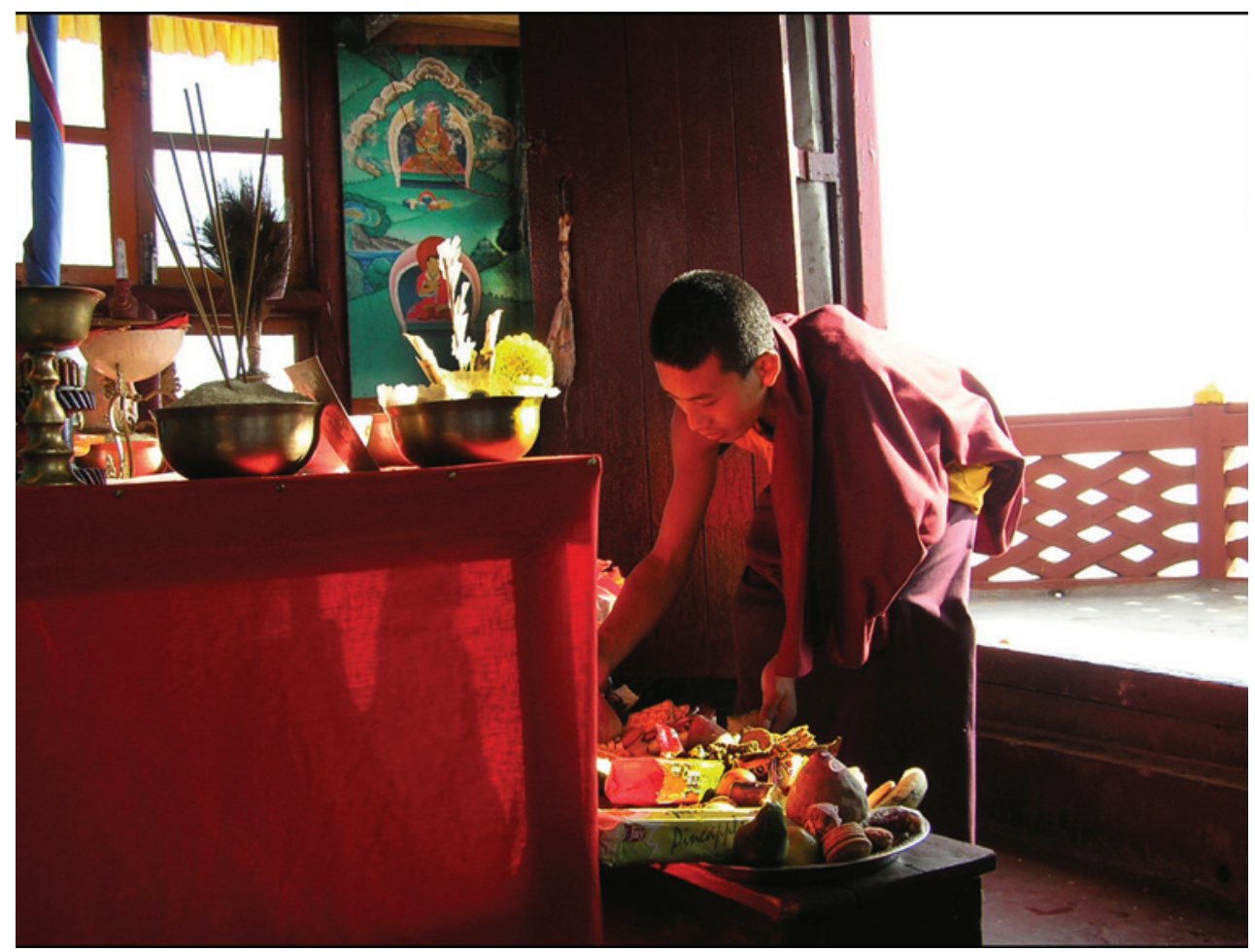

Plate 9.6. A young monk prepares the offerings during the six-day tshe sgrub at the Durpin Gompa, Kalimpong, November 2004.

monk who sat next to me for the entire week blowing a conch shell (see plate 9.7) or learning how to use the ritual implements bell (dril bu) and vajra ( $r$ do rje; see plate 9.8). He was laughed at by the others when he did not blow it at the right time, which was his main concern, because he knew he would be beaten by his teacher afterwards when he made a mistake in the ritual performance. The abbot, who was supposed to lead the ritual, could not come and I had the unusual chance of participating in a tshe sgrub with eight monks without the head lama being present. In the absence of this hierarchical control, the atmosphere was quite relaxed throughout the entire week. Nevertheless, the monks were remarkably disciplined in completing their ritual duties day after day, which lasted from 6 a.m. to about 4 p.m., with only two breaks for breakfast and lunch.

One of the younger monks, Phuntsok, had been a monk for nine years. He was now in his early twenties and responsible for setting up the offerings 


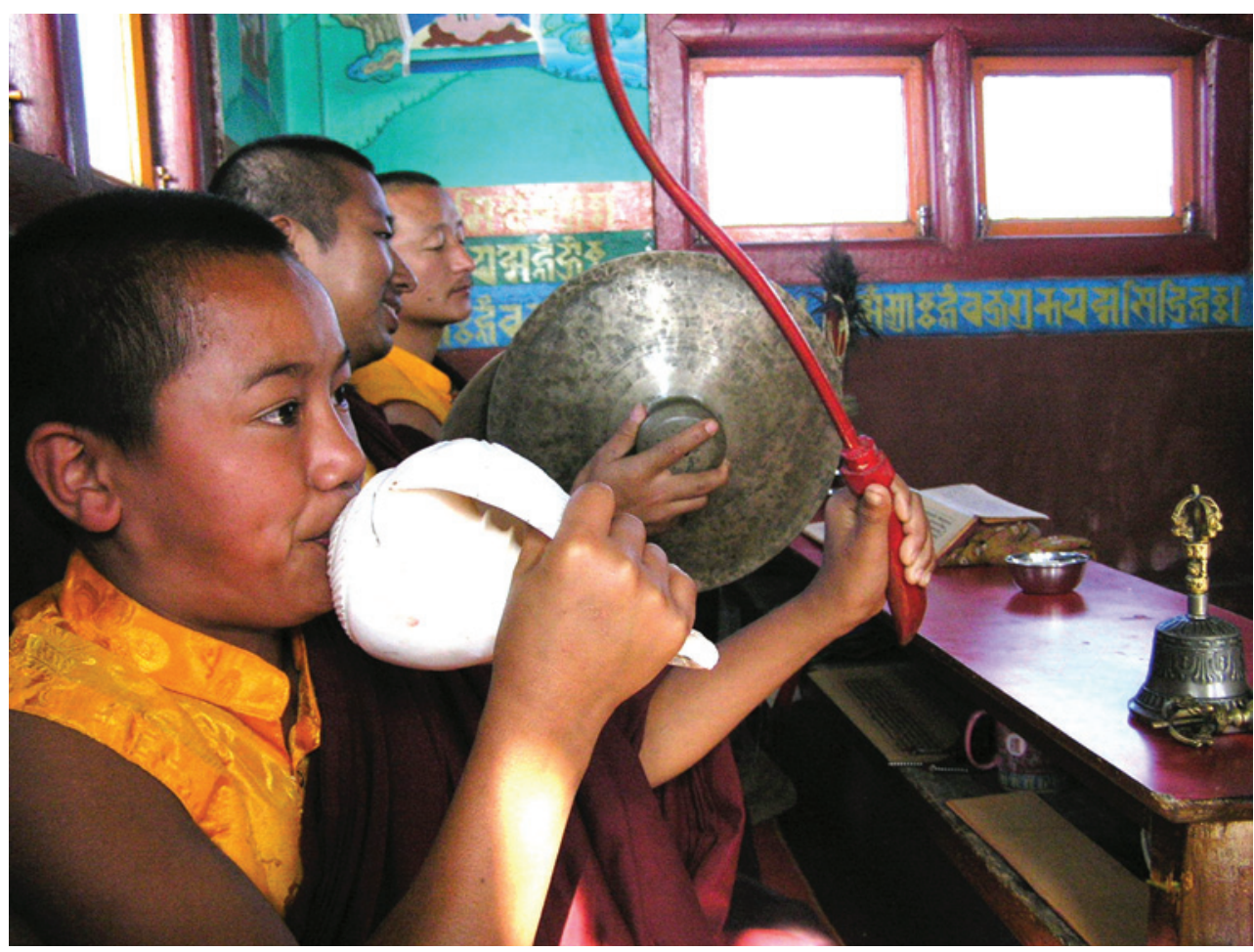

Plate 9.7. Lama Karma (back), Lama Sonam (centre), and a young novice (front) blowing a conch shell during the tshe sgrub at Durpin Gompa, Kalimpong, November 2004.

on the altar and assisting the senior monks with the ritual implements (see plate 9.9). He was able to explain the meaning and location of the various gtor ma offered during a tshe sgrub, but he could not say anything about the mantras. He said,

The mantras are secret and I am not allowed to talk about them. I also do not have the $d b a n g$ and permission to talk about them and you have to ask Lama Chime [the head lama of Durpin Gompa] or another high lama.

During the breaks, when we were drinking tea and discussing long life, one of the two lamas leading the ritual, Lama Sonam, told me:

I do not want to live long; maximum fifty years. Old age is not good; you lose your taste for good food, get diseases, and are not able to walk, read, or talk. I do this tshe sgrub only for Dudjom Rinpoche and for all sentient beings. I myself do not want to live that long. 


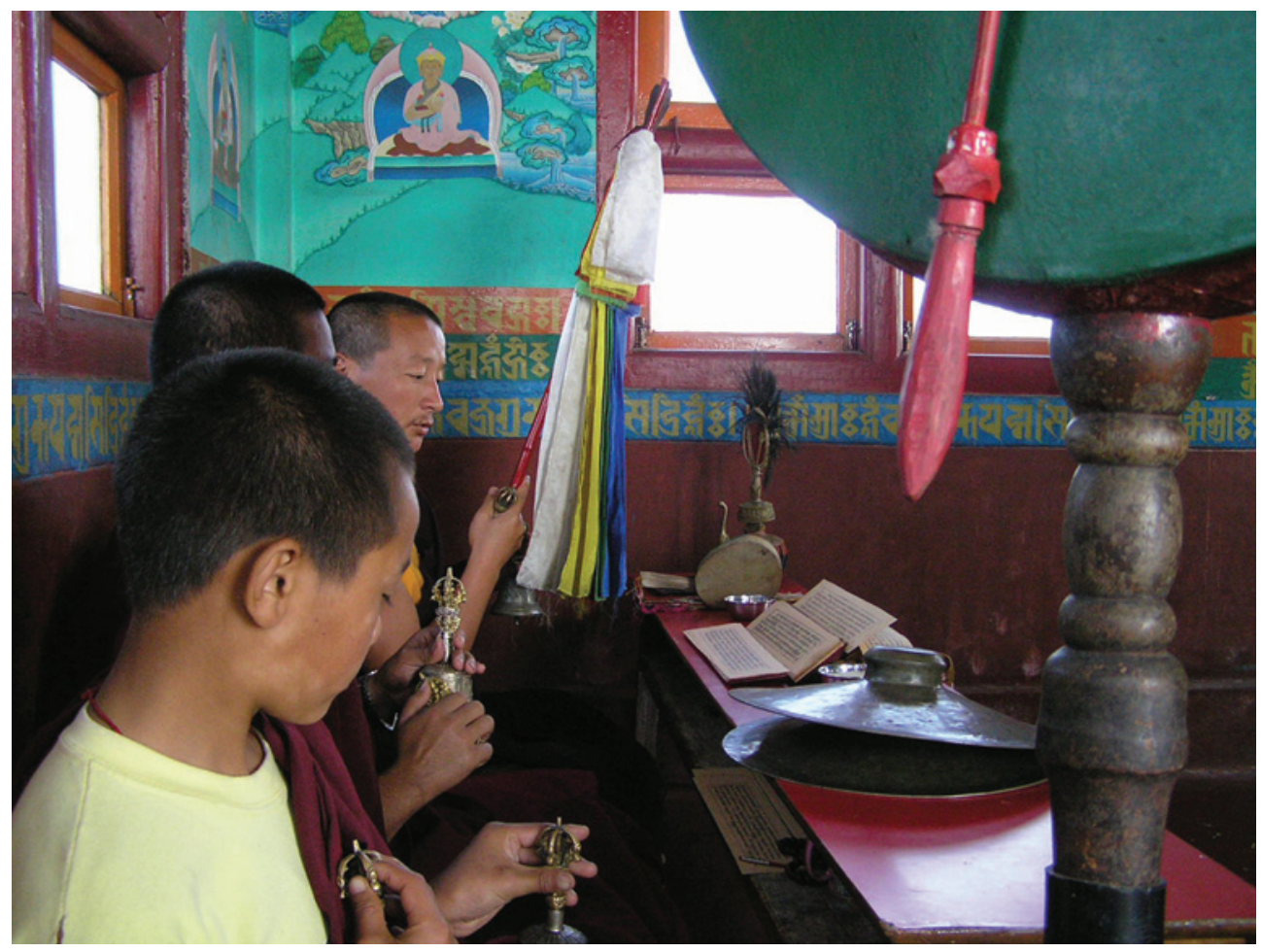

Plate 9.8. Lama Karma (back) circulating the long-life arrow to collect the lost tshe during the tshe sgrub at Durpin Gompa, Kalimpong, November 2004. A young novice (front) learns how to use the ritual implements dril bu and rdo rje.

On the last day of the extensive ritual, after the tshe ril and tshe chu had been offered to Dudjom Rinpoche, and we all had received our share of the blessings, the atmosphere became looser, and the monks started joking with each other. Jokes on long life were cracked in Tibetan. One monk said, "A yogi told me he would live a hundred years if he did not die in between." Everyone burst into laughter and started speculating about the ritual long-life arrow (tshe dar) on the altar. The arrow was a red painted bamboo stick, decorated with five ribbons in the colours of the five elements (yellow, red, green, blue, and white) and a round mirror (me long). The arrow was protruding from a colourful metal base (see plate 9.10). The long-life arrow had been used during the ritual to summon the lost tshe from the elements in the environment. The monks guessed how much longer the arrow stick had grown and whether its three-kilogram metal base had become even heavier, all signs considered a visible proof of a 


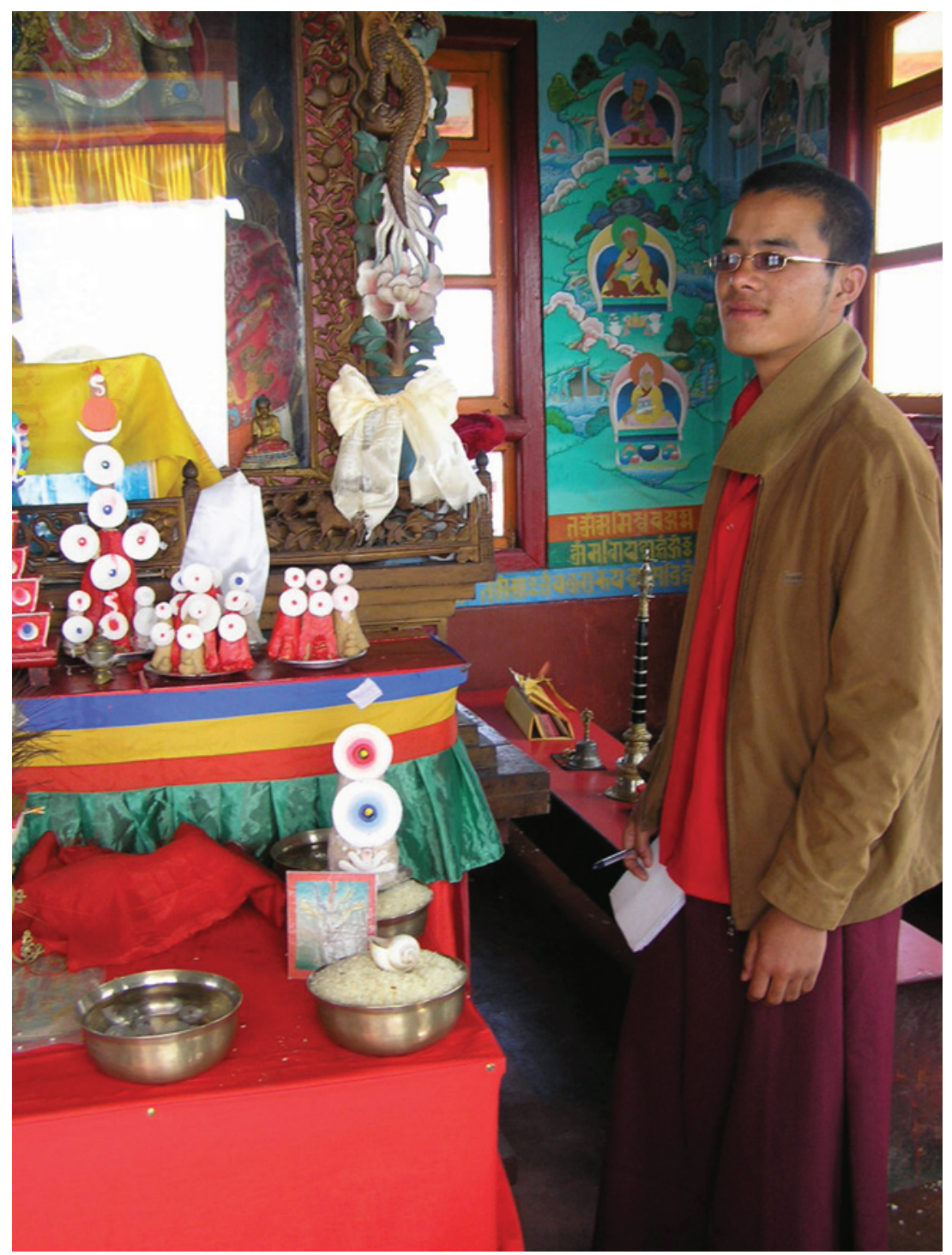

Plate 9.9. The monk Phuntsok explains the various offering gtor ma during the tshe sgrub at Durpin Gompa, Kalimpong, November 2004. 


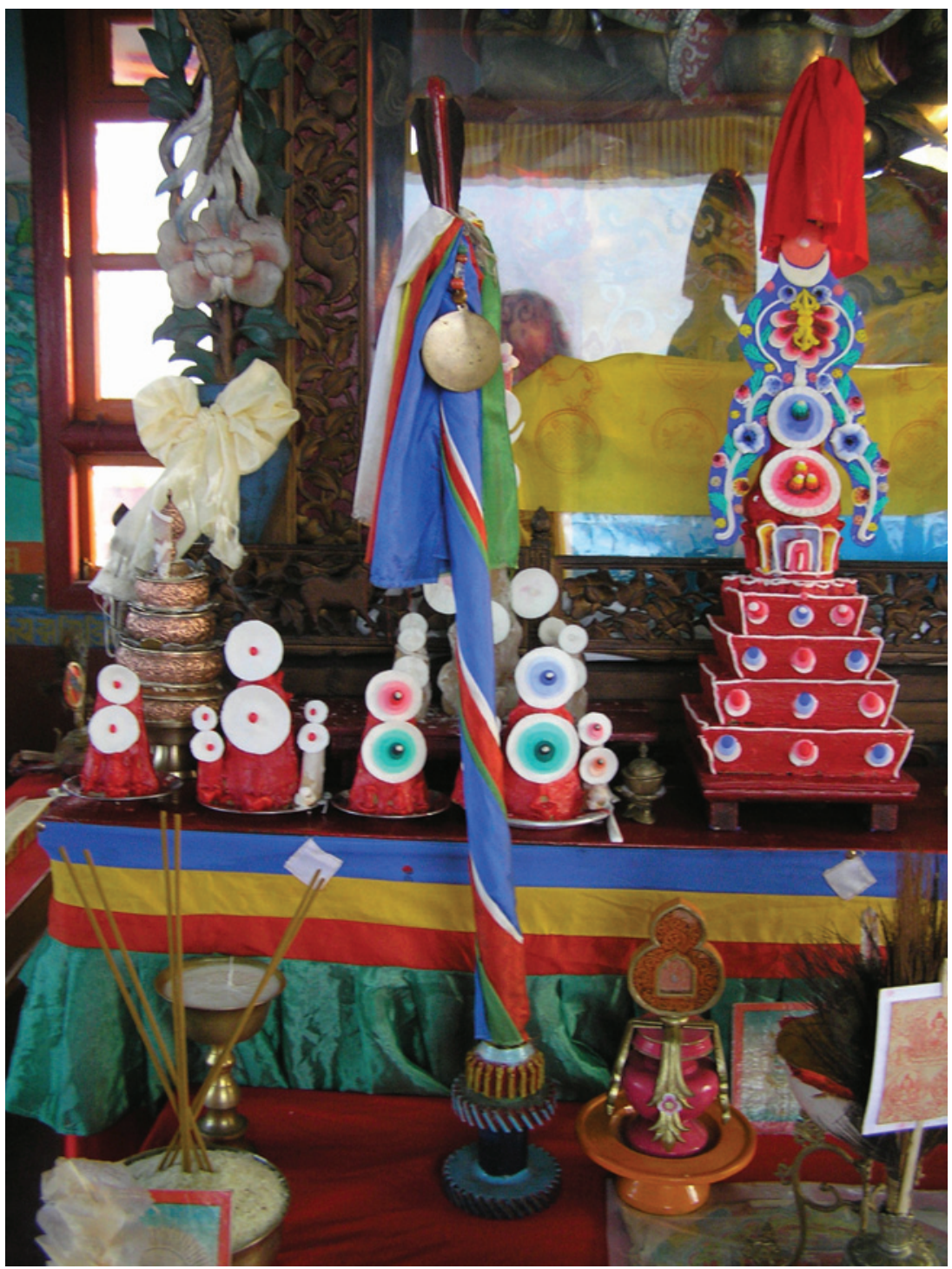

Plate 9.10. The long-life arrow with the round mirror standing in its colourful metal base on the tshe sgrub altar, Durpin Gompa, Kalimpong, November 2004. 
successful tshe sgrub. There were a number of stories told how the arrow had become longer and its base heavier after high lamas had performed this ritual.

Then Sonam asked me if I now believed that my life had been extended. That was a tricky question for an anthropologist. I said that I thought it depended on the ritual and how well we did it. "It does not matter if you do the ritual well or not. It all depends on belief," Sonam replied ('di tshang ma 'belief' red). He used the English term 'belief' in his last sentence. He surprised me with his answer, since they had scolded monks who made mistakes during the ritual.

Sonam himself thought that perhaps one or two years would be added to his life through this tshe sgrub, not more. He could live with that small prolongation of life. "Then why are you attending the tshe dbang tomorrow, if you just added one or two years to your life-span and don't want to live longer than fifty?" I asked him. He responded,

I will attend the tshe dbang tomorrow, because of the dngos grub [Skt. sid$d h i]$, not to live long, but to attain the power of dngos grub, to achieve the rainbow body ('ja lus). ${ }^{5}$ There are many dngos grub, but the one of Amitāyus is the rainbow body.

The monks then invited me to come back the next morning at 4 a.m. and attend the tshe dbang, because the tshe dbang would give the byin rlabs to attain this particular dngos grub. Phuntsok added his own story:

It is one of the aims of the tshe sgrub and tshe dbang practices to pray that everyone will achieve the rainbow body. When everything inside the mind is purified, the physical body will dissolve into light and no remains will be left, only nails and hair. And the quality of that light is like the rainbow in the sky. There was an old lama from Tibet; he practised for so many years. He lived in Namchi, in Sikkim, and attained the rainbow body. He was purified and had attained wisdom (ye shes). He had given up all defilements in his mind and he attained ye shes. He was a dge slong. ${ }^{16}$ He just disappeared.

The aim and wish to come closer to the attainment (dngos grub) of the rainbow body through tshe sgrub practice or a tshe dbang was only

\footnotetext{
15 The rainbow body is described as a supernatural body attained by means of tantric techniques through which the practitioner is able to physically disappear, leaving only hair and nails behind. It is usually associated with Dzogchen ( $r d z o g s$ chen) practices.

${ }^{16}$ A dge slong (Skt. bhikșu) is a fully ordained monk, who has renounced worldly life and has taken the pledge to observe more than two hundred precepts in order to attain liberation from this worldly existence (Skt. saṃsāra).
} 
mentioned to me by these monks, not the public or lay people, who operate with the idea of byin rlabs in a more pragmatic fashion.

\section{The Organisers}

Tshe dbang are institutionalised events that not only mark auspiciousness, but also bring together the community for various purposes. The organisers of these events play an important role when it comes to requesting a lama to give a tshe dbang. On a social level, the lamas have little say in the matter of their ritual performance and time management. The administrators of the monasteries and the communities are quite powerful in deciding on the type of empowerments to be given, even though this decision is made always in the form of a 'request' $(z h u)$, to which the lama consents.

A good example from the literature on historic Tibet is found in Kongtrul Rinpoche's autobiography. In 1871, the governor of Nyarong summoned Kongtrul. Kongtrul writes: "The governor insisted that I should conduct a ritual to ensure his longevity, so I spent a week performing many longevity empowerments" (Barron 2003: 161). The governor set the agenda for what kind of empowerments should be given to a group of a thousand lamas and monks, and Kongtrul had no choice but to honour all requests made of him (Barron 2003: 166).

Socially, the lama often has to let others decide when, where, and for whom dbang take place. During the time of my fieldwork, the reasons for tshe dbang being performed varied. In Kalimpong, the Tibetan welfare officer requested Ratna Vajra Rinpoche during his one-month visit to the region in 2005 to visit Kalimpong and give a tshe dbang. When I asked him why he requested a tshe dbang, he replied,

Everybody wants to live long, so people will all come. If there is no tshe dbang they won't come, because other dbang are more complicated and difficult to understand. Tshe dbang is easy, and the feeling will be there, 'I got tshe dbang' (tshe dbang thob song).

During the tshe dbang, I noticed that the welfare officer allotted a half hour in the programme for his own speech, in which he passed on political messages from the CTA in Dharamsala. He utilised the tshe dbang to draw the largest possible crowd from the Tibetan community; not so many people would come if it would be just to receive a speech by him. He knew longevity was an emotional, human desire felt by almost everyone in the community, which he capitalised on by organising a tshe dbang. 
In Gangtok, in July 2004, the Khampa Social Welfare Organisation (kham pa skyid sdug) organised a tshe dbang following the request of elderly people in the Tibetan community of Sikkim. In Kalimpong, in April 2007, the elderly people of the Tibetan old age home requested a tshe dbang which was then organised and financed by a wealthy local Tibetan family at the Mani Lhakhang. The sponsors requested a senior Geluk lama to give the tshe dbang. He stayed in retreat for most of the year, but came out once a year to give a dbang to the public, which was usually a tshe dbang.

In Pedong, a predominantly Christian township near Kalimpong, in May 2005, a tshe dbang marked the inauguration of the newly renovated Sikkimese monastery, built in 1932. According to the president of the local skyid sdug, "tshe dbang help to attract a large crowd for the opening ceremony," which was scheduled for the last day of a week of reading Buddhist scriptures out loud. Because people had to go to Gangtok (several hours by jeep) for their rituals, the skyid sdug, which was established in 1935 and had about sixty-five members in 2005, wanted to have their own lama in residence. Inviting a young lama from the largest monastery in Darjeeling, the Thupten Sangnag Chöling (locally known as Dali Gompa), who was potentially looking for his own gompa, was a step in that direction. The tshe dbang brought the renewed activities at the renovated gompa to the attention of entire community, including to the head priest of the Christian congregation, who was also invited.

Apart from the president of the skyid sdug, most people were not really sure about the type of dbang that was given that day, but anticipated a tshe dbang. "What kind of dbang will be given," I asked someone in the crowd. "We are not sure, but tshe dbang will be there for certain," I was told. "Tshe dbang must be there because it is for longevity."

In Ghum, in October 2004, at the newly established Mani Nyungne Kidu ( ma ni bsnyung gnas skyid sdug), a tshe dbang marked the inauguration of the new community centre and was performed by a Nyingma Lama from Siliguri, who was invited for the occasion. The Kidu did not have the facilities to have a resident lama at the centre.

Often adjunct to other rituals, tshe dbang are designed to bring together and protect the network of the monastery and the community. With regional variation, lamas have combined the popularity of tshe dbang and ritual mask dances ('cham) into one festival, "in which the welfare of the community is secured and entertainment is offered" (Jerstad 1969: 106). In Kalimpong, in November 2004, at the Durpin Gompa, the tshe dbang concluded the seven-day sman sgrub sgrub chen conducted by Dudjom Rinpoche on the occasion of his first visit to Kalimpong. In Kalimpong, 
every Tibetan New Year (lo gsar), from the third to the eighth day of the first month of the Tibetan calendar, the monks of Jangsa Gompa perform a seven-day longevity ritual, the 'chi med srog thig, which concludes with 'cham dances and a tshe dbang for the public on the ninth and tenth days.

All these events benefited from a tshe dbang, which drew a large crowd, and thus created an audience for the organisers' message, which had to do with other issues apart from long life: Tibetan exile politics (the welfare officer's speech); the strengthening of Buddhist-oriented community practices (for example, the inauguration of the Mani Nyungne Kidu); strengthening a marginalised Buddhist group in a predominantly Christian town (the newly renovated Sikkimese monastery in Pedong); and marking the come-back of the head lama to his old monastery in his current incarnation (Dudjom Rinpoche's first visit back to Kalimpong).

Overall, in the Darjeeling Hills tshe dbang were performed as an integral part of a series of other rituals, such as Dudjom Rinpoche's sman sgrub sgrub chen, where the tshe sgrub and brtan bzhugs were actually done for the long life of the rinpoche himself, and where the tshe dbang marked the end of the main ritual. It is possible for the community to make use of a tshe dbang for its own needs because of the social etiquette attached to the organisation of dbang: they have to be requested on behalf of an individual or a group. Lamas consent and thus offer a platform to play out social needs in a large arena without ever letting the crowd appear as a gathering with a socio-political agenda, something that could draw attention to the local Indian authorities. Tshe dbang are certainly perceived as a safe terrain to gather large crowds and to deliver a message.

Lamas also draw economic benefits from a tshe dbang, since it is also part of the social etiquette not to go empty-handed to a dbang, which the next section shows.

\section{The Sponsor}

Every ritual participant is expected to give a small donation, mostly at the end of a tshe dbang. The main donor, the sbyin bdag, is, however, the official sponsor of the ritual. Acts of giving are considered to raise the social status of the sbyin bdag in the community. They also secure political alliances and social control (Gombo 1985: 240). Sbyin bdag, who are often but not by rule also the organisers of a tshe dbang, are either wealthy and influential families in the community or a local organisation, such as a skyid sdug. Sponsors are actively integrated into the ritual structure, 
making various ritual offerings, and in return receiving their byin rlabs early on from the lama; they do not have to queue for it for hours (see plate 9.11). As Clarke succinctly points out, the sbyin bdag "receives the primary merit of the ritual" (Clarke 1990: 174). The higher social status of the sbyin bdag is publicly choreographed in the way they are seated in the crowd: always in the front and close to the rinpoche's throne. Clarke mentions that the village households take turns in being the sbyin bdag of rituals throughout the year, which gives them a rotational and "institutionalised access to merit" (Clarke 1990: 174). Unfortunately, I was not able to research such rotation sequences among upper class Tibetan families in the Darjeeling Hills.

Tshe dbang always involve economics. Concluding major rituals with a tshe dbang naturally also reaps economic benefits for the monastery.

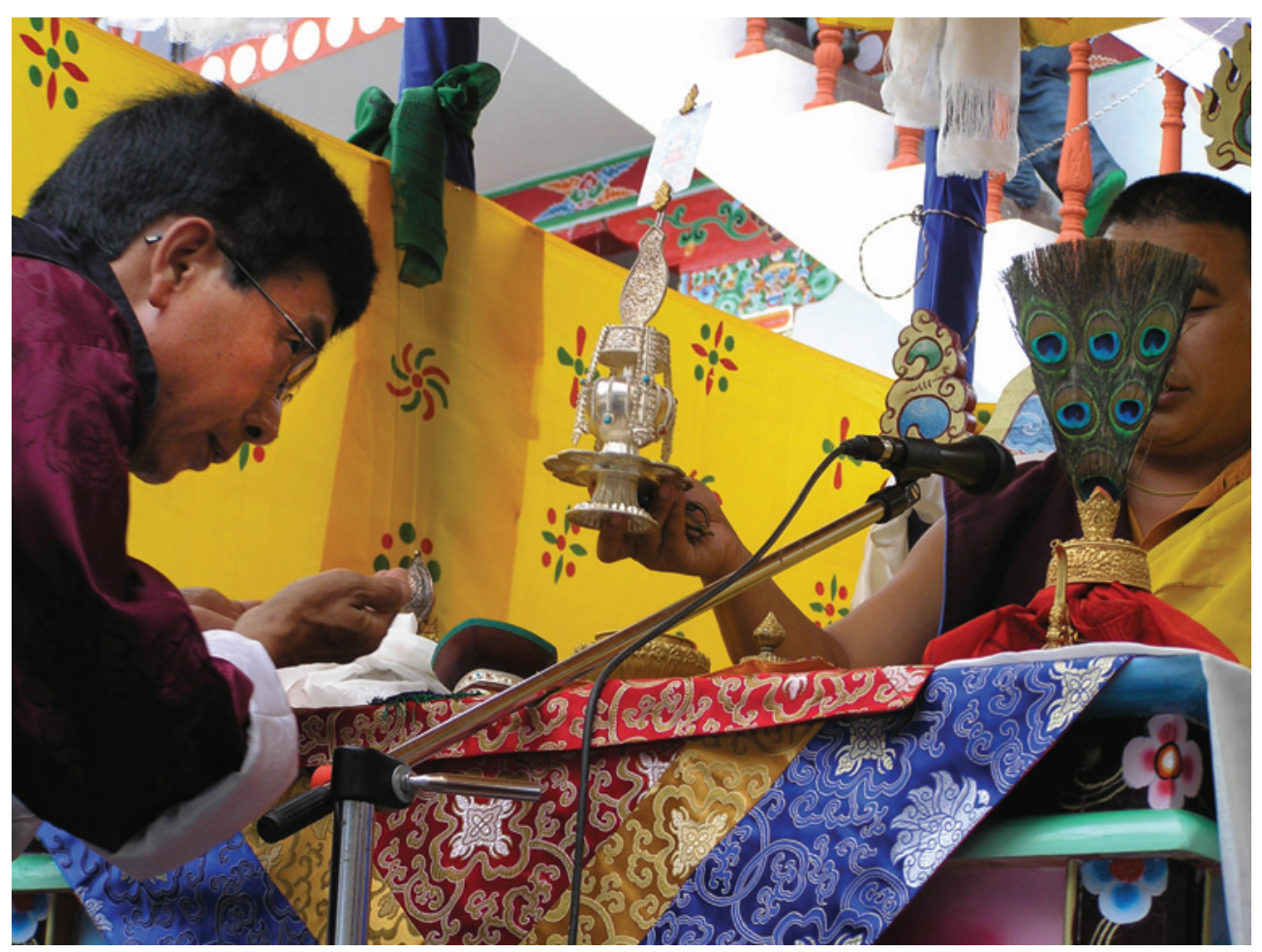

Plate 9.11. The official sponsor of a tshe dbang receives the blessings first and with them the primary merit of the ritual from the lama during a tshe dbang in Pedong, May 2005. A picture of the initiation deity is affixed to the top of the initiation gtor ma. 
Childs mentions that the lamas in Nubri provided long-life rituals in return for labour in their fields (Childs 2004: 29). In another paper he describes how an entire tax system was devised in a Nubri village to fund a particular ritual, which was to bring prosperity to the entire community (Childs 2005: 46-48).

In the Darjeeling Hills, tshe dbang are funded by the community. The lamas are certainly aware of the economic benefits of tshe dbang. One lama told me that travelling into another region and performing five tshe dbang over a period of a few weeks was the easiest way for him to raise a substantial amount of funds to support his monastery and pay major bills, simply because of the large crowds and their individual donations. More difficult rituals demand proper preparation on the part of the lama and are attended by less people. The crowd during a tshe dbang thus becomes an important contributing economic force in an area where hardly any monastery can survive locally without its foreign patrons (see chapter 2.7).

\section{The Interpreter}

Not all tshe dbang engage interpreters. Only half of those I attended had an interpreter who translated the lama's speech from Tibetan into Nepali. The interpreter acted as a verbal communication bridge between the world of the rinpoche and that of the public. These worlds rarely engage in direct verbal communication and any encounter between them is highly ritualised and controlled. This formalised ritual communication involves public dharma teachings and the transmission of dbang through tangible ritual objects infused with byin rlabs.

Being touched by one of these ritual objects becomes the sole communication between the lama and the public, since they do not speak to each other directly, other than during the rare occasions of private interviews. A lay person will also not look straight at the lama but bow his/her head, and byin rlabs is received from the lama through his touching the crown of the head of the devotee. The higher the lama the more carefully he is guarded and shielded from the public through the monastic hierarchical set-up. Likewise, Tibetans believe, the higher the lama the higher is the efficacy of his byin rlabs.

One striking aspect of a tshe dbang - and many other Tibetan Buddhist rituals for that matter - are the large gaps between textual and nontextual participation. Only the monks and sometimes only the rinpoche have the manuscript with the prayers and ritual instructions, especially of the visualisations. The attending public usually does not follow the 
long recitations, the content of which is written in a specialised dharma Tibetan and not understandable to those with only a knowledge of colloquial Tibetan. Although the lamas give some basic information on the lineage of the tshe dbang and instruct the public in the visualisation, only a few people can actually understand and follow these instructions.

The gap between the oral and written world is partly bridged by the interpreter. In the case of the Sakya tshe dbang, the interpreter was a local Tibetan language teacher, who had agreed to translate for Ratna Vajra Rinpoche during most of his visit to the region. He translated almost every day for several hours; the programme was packed with teachings and empowerments, five of them being tshe dbang. His services were entirely voluntary. Interestingly, even the interpreter himself never spoke with the rinpoche directly. When I questioned him about this later, he said,

I never met rinpoche in private and this was the first time I translated for him, almost every day for a month. I felt that only through his byin rlabs I was able to do it. The entire time I felt his blessing was with me and the translations went very smoothly. I had actually never done this before, and Nepali does not have all the words that are needed to translate what rinpoche says. So it was difficult to explain the meanings. I had to keep it simple. But I felt I had the byin rlabs of rinpoche, so I could just do it.

What we would call a 'working relationship' involving discussions and feed-back looks very different in the Tibetan ritual environment. Even the relationship between the interpreter and the lama is marked by the dominance of byin rlabs in the absence of any form of direct communication or practical instruction.

\section{The Public}

Based on his research in Helambu, Nepal, Clarke discusses how conceptions of what a dbang actually means varied considerably (Clarke 1990: 171). Beyer observes that the public attending a tshe dbang "have in mind not so much his [the lama's] bestowing of authorization and capacity for their future practice as the exercise of his magical powers to prolong their lives" (Beyer 1973: 375). Snellgrove confirms this emphasis on byin rlabs (Snellgrove 1961: 142-143), which I think is what Beyer means with 'magical powers.'

Tshe dbang were originally not designed for crowds, but they have been adapted to crowds. Actually, the crowds have appropriated tshe dbang for their own needs. The ritual structure is usually centuries old and conservative, although the ritual texts can be quite recent. How has the 
conservative ritual structure been adapted to ritual performances for large crowds of people, many of whom are not active Buddhist dharma practitioners? What has changed in the interpretation of what is important in a tshe dbang?

During the several large-scale tshe dbang I attended, the collective experience of the dbang in the crowd was mostly marked by the rush for the long-life pills, and the near-stampede conditions when people pushed into the temple to receive the lama's blessing on their heads. These events form the most active and dominant part of the ritual, often taking three times the amount of time of the ritual itself. It can take three to four hours, or more, to distribute the blessed substances to hundreds of people. People queue with empty plastic bottles to collect the long-life nectar in order to take it home (see plate 9.12). They try to grab as many long-life pills and protective cords (tshe srung) as possible to distribute them to their family members. Since the crowd does not fit into the temple and is often removed from the ritual to the extent that people do not even see the lama or understand what he says (background noise, inadequate sound system, language problems), the blessed substances become the essential means of communication between the crowd and the lama. The only time the public comes near the presence of the lama is when he touches the crown of their bowed-down heads with the tshe bum, tshe gtor, or tshe dar. The tshe ril, tshe srung, and tshe chu are usually distributed by the monks (see plates 9.13 and 9.14). One cannot help but be struck by the intense devotion on people's faces during these empowerments, especially among the older generation (see plate 9.15).

While being a part of the crowd, I often asked people when exactly they would receive the dbang and the byin rlabs. Most of them said they received the dbang and the byin rlabs the very moment that the lama touched their head and they received the long-life pill and the long-life nectar, which they believed would extend their life-span. For the crowd and I treat them here as a collective phenomenon, almost institutionalised for duration of the tshe dbang - the temporal idea of life-extension, the adding on to tshe, manifests in substances they can feel and touch, as well as eat and drink and thereby ingest them into their own bodies and make them a part of themselves.

\section{Individual Buddhist Practitioners}

Quite a different picture emerges when we look at how tshe dbang are experienced by dedicated individual Buddhist practitioners, be they lay 


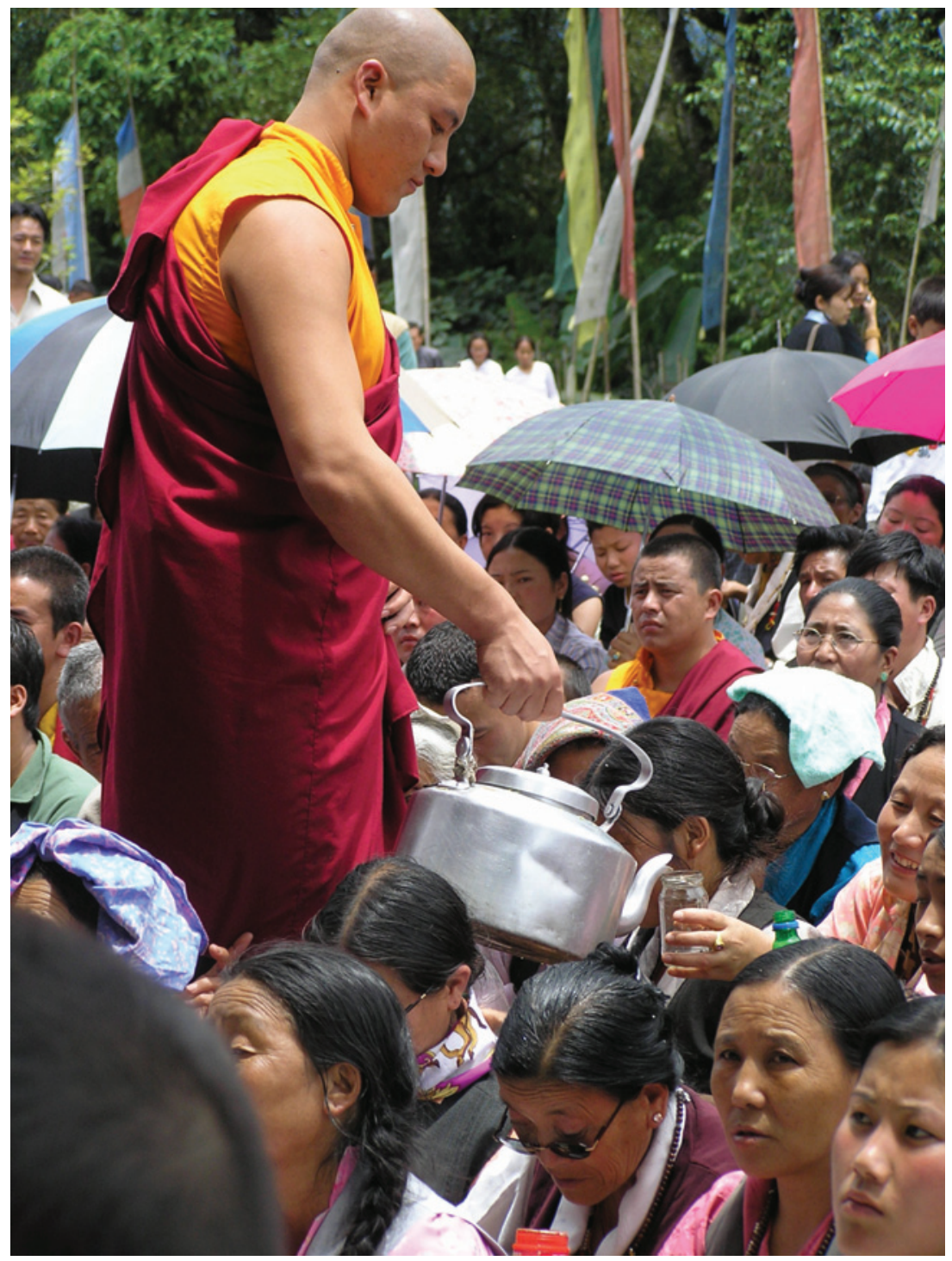

Plate 9.12. A monk distributes long-life water to tshe dbang participants during the tshe dbang in Gangtok, Sikkim, July 2004. The participants collect it in glass bottles and plastic containers to take home and distribute the 'blessing.' 


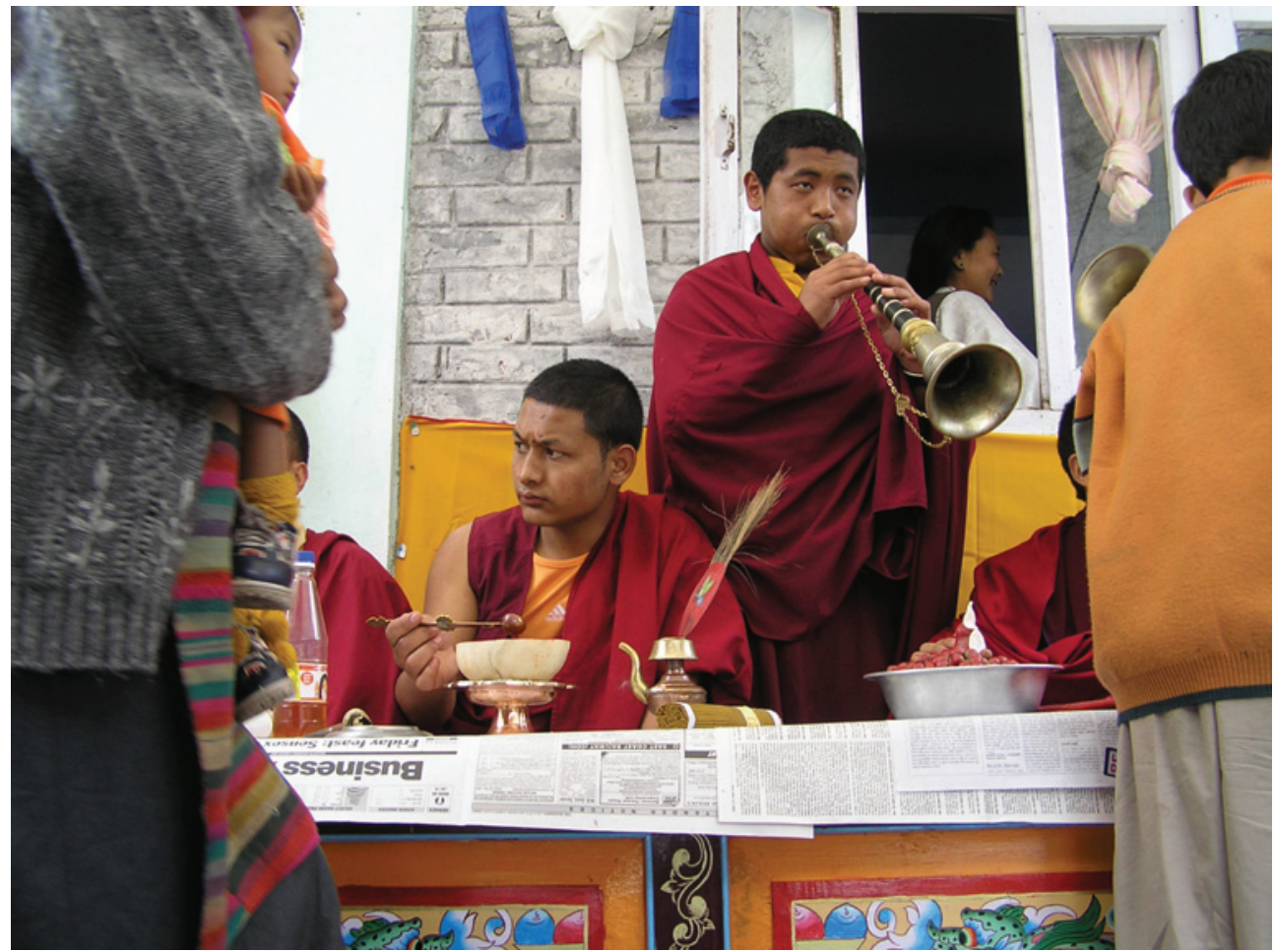

Plate 9.13. Monks distribute long-life nectar from a skull (left) and long-life pills (right) to the crowd during a tshe dbang in Pedong, May 2005.

or ordained. Gyatso, a Tibetan lay practitioner in his fifties and the father of a reincarnate lama (sprul sku), received a tshe dbang in a small group of about fifteen disciples from his own son with detailed explanations. After receiving the dbang, he recited the White Tārā, Amitāyus, and Ușnīịavijayā mantras one hundred thousand times each. He was talking from the perspective of a devoted practitioner.

The mantra and visualisation are much more important than the tshe ril and other blessed substances. The tshe bum is not important. The tshe ril will give a little blessing, but not the real one. The imagination is very important to obtain the real blessing. You have to imagine the lama in front of you as the deity and from his embodiment of the deity you receive the real byin rlabs. The lama is Tārā or Amitāyus, and from there comes the blessing. It depends on your visualisation and devotion. The full byin rlabs comes only if you believe in your guru. 


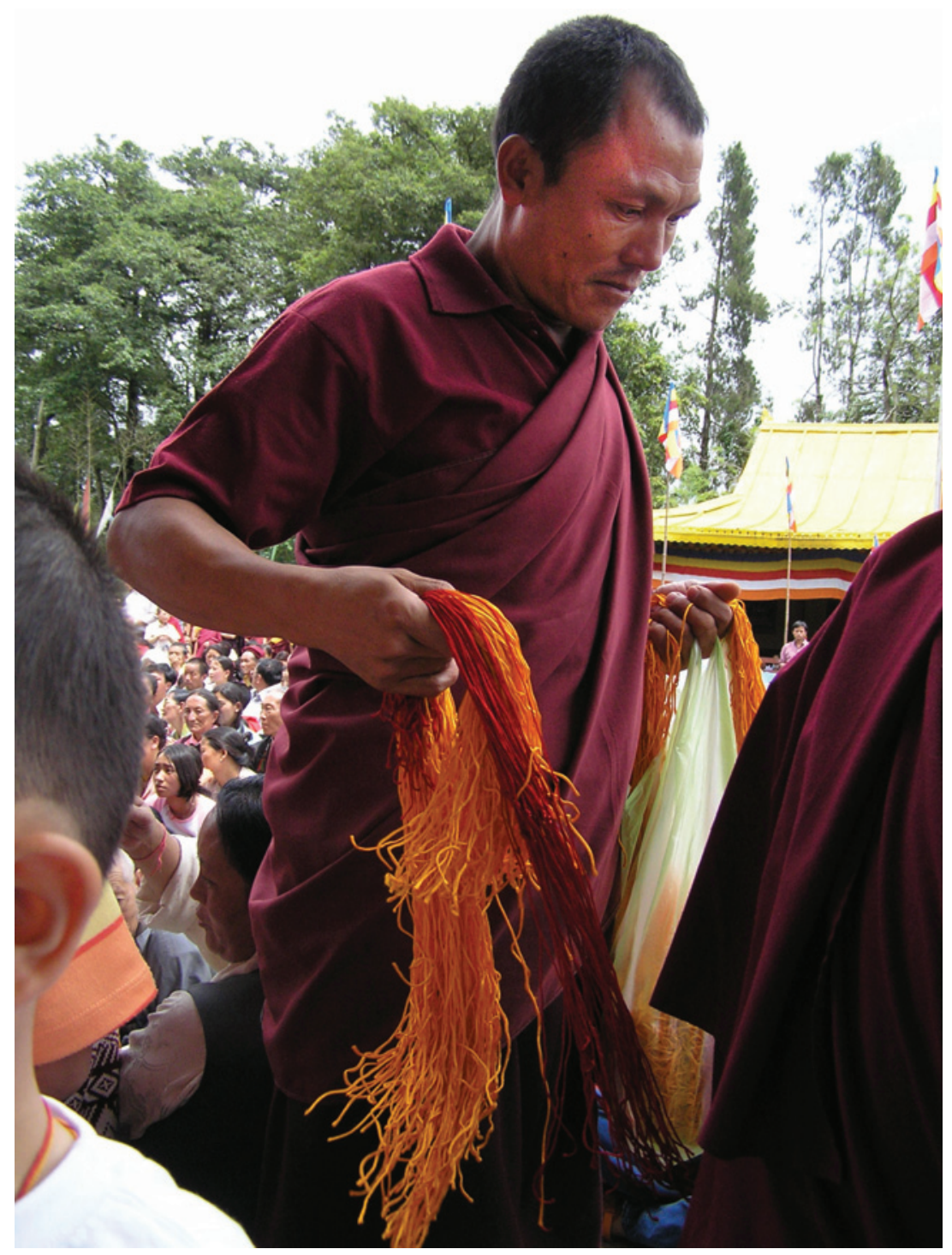

Plate 9.14. A monk distributes protective cords during a tshe dbang in Gangtok, Sikkim, July 2004. 


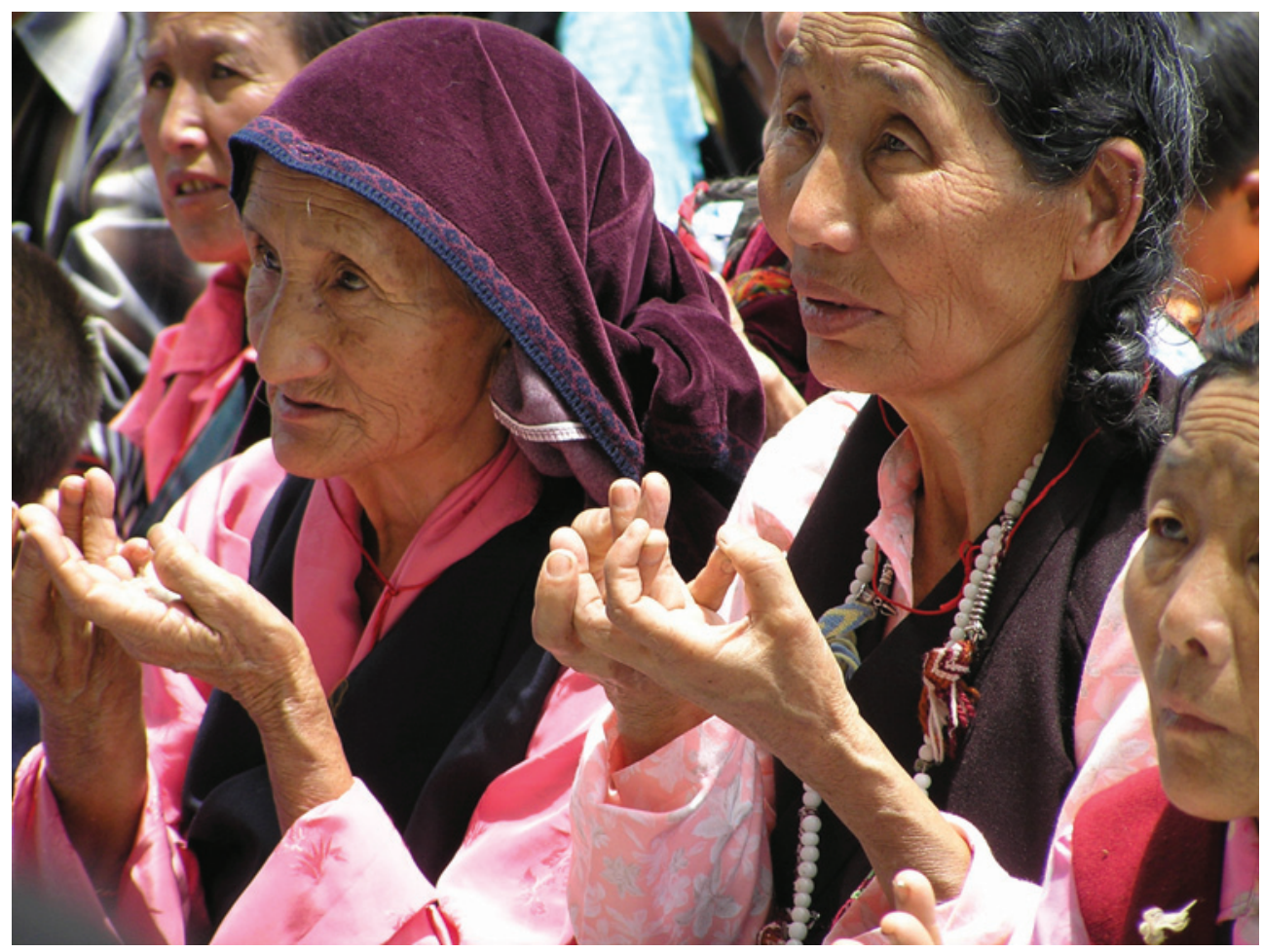

Plate 9.15. Tibetan women pray during a mandala offering at a tshe dbang in Gangtok, Sikkim, July 2004 .

Shortly before we attended the Sakya tshe dbang in Ghum, Sherab, the Nyingma snags pa practitioner from Darjeeling who was introduced in chapter 7.2, told me his ideas concerning tshe dbang from the point of view of a practitioner:

During a tshe dbang the visualisation is most important. When you just sit through the ritual and receive the tshe ril and the tshe chu, you receive a little blessing, but the real blessing will come if you can do the visualisation with single-pointed concentration.

Lama Tsewang at the Tharpa Chöling monastery in Kalimpong was an Amitāyus practitioner. He said Amitāyus was his yi dam, and he practised Amitāyus for one hour every morning at around 4 a.m. He combined his visualisation of Amitāyus with everything he did in daily life. He offered the clothes he wore, the food he ate, everything he did to Amitāyus and in return received his blessings. He said there would be no success in practice without prayer and dedication. 
These individual Buddhist practitioners emphasised visualisation. Before describing the day of the Sakya tshe dbang, a further explanation of the process of visualisation in relation to byin rlabs is pertinent.

\section{The Importance of Visualisation in relation to Byin rlabs}

How is byin rlab generated through visualisation? The theme keeps coming up in ethnographic encounters surrounding longevity rituals, but so far there have been no ethnographic studies on how byin rlabs is generated through visualisation. In this section, I therefore present only a preliminary discussion on the topic. From the point of view of ritual efficacy, the lama clearly has the guiding role in a tshe dbang ritual. The success of the tshe dbang lies in his capacity to generate the deity and byin rlabs through visualisation. Beyer describes the visualisation the lamas undergo during a White Tārā tshe dbang and their role in the ritual in detail. Unfortunately, his description of this event, although accurate and detailed, is entirely text-based (Beyer 1973: 378-398).

The lama's official role during a tshe dbang is to utilise his visualisation skills, in which he has been trained during the traditional three-year and other retreats, and evoke the long-life deity inside the ritual objects, for example, the tshe gtor or the tshe bum, on behalf of the attending disciples. The visualisation is done mentally and is maintained while the text, which describes the visualisation - interspersed with prayers, praises, and offerings to the deity - is recited. The visualisation engages colours, forms, and movements of mantra syllables and light from different body centres of the deity into the lama's and disciples' bodies. From the point of view of the lama, the aim is to visualise the deity first in front and then within himself, within others, and inside the ritual objects. Tshe is visualised in the various colours of the five elements and collected with the long-life arrow (tshe dar) from the surrounding environment and various ritual realms. This practice is accompanied by the recitation of a particular mantra.

It is important to note that Tibetan monks are trained in visualisation relatively late in their monastic education, if at all. It is not part of the general education in the monastery, and monks only start to practise visualising themselves as a deity during their first three-year retreat when they are usually in their early twenties.

How do the lamas themselves feel about these visualisations? In this section I make some tentative steps into unexplored ground; therefore my 
conclusions preliminary. Much more research is needed to understand the visualised world of a Tibetan Buddhist ritual.

Lama Kunzang explained some of the difficulties of visualisation and how he dealt with them:

Even the visualisation is your own rnam rtog [conceptual thoughts and illusory associations], because it can be distorted and not correct, strange and funny. In India, they took only one deity and practised twelve years to visualise it; they were perfected. Tibetans have too many deities; we cannot visualise all of them in detail. ${ }^{17}$ So sometimes we have to think that the deity is there with all the protectors, we think it is there so it is there even though it has not been visualised clearly.

Lama Kunzang clearly perceived a difference between thinking the deity and visualising it, even though he considered both as efficacious. The visualisation itself is influenced by the individual's own thoughts and mental patterns and does not always appear the way the deity is depicted on painted images. In the process of developing the ability to visualise clearly, the practitioner has to face and transform these rnam rtog.

During a tshe dbang, the disciples are instructed to take part in the visualisation process. They basically have to visualise the lama as the longlife deity of the particular tshe dbang they are attending. Most Tibetan practitioners I spoke with, including young monastics, find it very difficult to visualise and do not engage in it. Both monks and lamas consider it enough for a ritual to work if one person present does the visualisation. This is mostly a senior monk, the abbot (mkhan po), or the lama or rinpoche himself. Beyer writes that the efficacy of the initation depends almost exclusively on the contemplative capacities of the lama who bestows the initiation, even though it can be aided by the disciple, especially when he or she is a practitioner (Beyer 1973: 398). However, the lama remains in control of the visualised reality, and it is "basically his control that achieves their generation" (Beyer 1973: 390). In this process the ritual implements hold certain significance, which Lama Kunzang explained to me. I asked him how the visualisation is linked to ritual objects, through which byin rlabs is transmitted to the disciples. He said:

\footnotetext{
${ }_{17}$ The same thought is also expressed in the popular Tibetan proverb: "Indians attain one yi dam and thus accomplish a hundred; Tibetans attain a hundred yi dam and thus accomplish not even one" (rgya lha gcig bsgrubs pas lha brgya grub/bod lha brgya bsgrubs pas lha gcig mi'grub).
} 
Then the lama will explain how to visualise. These instructions are all read out by the lama, but lay people will not understand. Some lamas sometimes explain the visualisation. People, who know dharma, will do the visualisation when the lama will say so [...].

If the lama gives an Amitāyus tshe dbang, he will visualise countless Buddhas and Bodhisattvas as small as mustard seeds and as large as high mountains, filling the students with blessings of light. Students have to think that they have the blessing of the Buddha: 'We got the body blessing of the Buddha.' The Lama will visualise many mantras coming down entering the students through their mouths and throats. Like that they will receive the blessings of the Buddha's speech. Then the blessing of the heart will be received through what the particular Buddha is carrying. If it is Amitāyus, he will carry the long-life vase (tshe bum), if it is Tārā, it is the flower. Padmasambhava holds the vajra ${ }^{18}$ in his hand. Through this, the lama will visualise that the students will attain the mind blessing of the Buddha.

Through the visualisation the byin rlabs is then passed on to the disciples, either through a direct transfer into their bodies ('through their mouths and throats'), or through a transfer of the (visualised) object that the Buddha holds in his or her hand (long-life vase, flower, vajra). From there it is transferred to the tangible objects that are given to the crowd through touch (long-life vase) or for ingestion (long-life pills, long-life nectar).

I want to take the example of one ritual object, the long-life arrow (tshe dar), to show how visualisation is linked to a ritual object and the accumulation of tshe. The arrow itself ( $\left.m d a^{\prime} d a r\right)$ is a sign of auspiciousness and is used by various Tibetan groups on many occasions, not only for long-life rituals. ${ }^{19}$ Buddhism absorbed and assimilated symbols and practices from other traditions and as Kohn has pointed out in his research on Mani Rimdu, "to distinguish a non-Buddhist tradition in Buddhist disguise from a Buddhist tradition with non-Buddhist trappings may be a hopeless task" (Kohn 1988: 955).

Every Tibetan household has an arrow. Sometimes they are adorned with turquoise and other stones. In Kalimpong they are sold in the Tibetan shops in Tenth Mile for about forty Indian rupees each (approximately

${ }_{18}$ A vajra (rdo rje) is a ritual object resembling a thunderbolt that is used during many Tibetan Buddhist rituals (see plate 9.8).

19 The $m d a^{\prime}$ dar is widely used by different Tibetan groups across the Himalayas. Tibetans use it during marriage and death rituals as well as during empowerments. Jampel Kaldhen explained to me that before the dead body is taken from the house they wave the arrow across the corpse so that the body will not take the good luck away from the house. Similarly, when the daughter of the house gets married the arrow is fixed at the back of her wedding dress, so that she does not take the good luck away from her family's home. The same arrow is used in longevity rituals, where it is called tshe dar. 
eighty euro cents). The arrow usually has a round-shaped mirror, which can be made of bronze, copper, or silver (see plate 9.10). Jampel Kaldhen told me that it is meant to reflect all good and auspicious things. The arrow is generally used in rites to summon fortune and long life.

Lama Kunzang offered some interesting explanations on the use of the long-life arrow that extends the idea of tshe into limitless space and time.

LAMA KUNZANG: With the long-life arrow, the lama collects tshe from all directions, from all five elements, and from all the pure lands.

BG: Is he collecting what the people have lost? Sometimes they lose part of their life-force.

LAMA KUNZANG: Yes, they lose it. But the lama collects even the long life of Buddhas and Bodhisattvas, and the tshe from the sages, who live long.

BG: Does the tshe just exist out there freely? Is it not taken away from someone else? Can it be taken from their lives?

LAMA KUNZANG: In Vajrayāna, with the visualisation, these Buddhas and sages do not lose it. It does not affect them. They are enlightened. Even if they are not enlightened they do not lose the tshe that we collect during the tshe dbang.

BG: So it is limitless?

LAMA KUNZANG: Yes it is limitless tshe.

The idea of tshe here expands into other (visualised) dimensions. The entire visualisation opens an access to the 'pure lands' of existence of the sages and Buddhas. The lamas can tap into the life-spans of these enlightened or unenlightened beings and gather tshe to bring it to their disciples to prolong their lives. Not only has the amount of tshe 'out there' no limit, it can also be taken from the Buddhas and transferred to ordinary people. In Tibetan Vajrayāna Buddhism the collection of tshe through visualisation is a ritualised tool to enhance the life-span, health and well-being. ${ }^{20}$

So what is the meaning of the long-life arrow in this ritual context? Ritual symbols in Tibetan Buddhism challenge anthropologists in a different way from Buddhist practitioners. The problem for the anthropologist begins where Tibetans 'explain' the meaning of the ritual object. To explain the association people make between objects and 'explanations' is a more difficult but essential task in the analysis of long-life rituals. Explaining symbols with their Buddhist meanings would be a mere descriptive approach, but discovering what these associations mean to people who

\footnotetext{
${ }^{20}$ See Samuel $2010 \mathrm{~b}$ for a discussion of the 'inner work' involved in the visualisation process during such rituals.
} 
attend the ritual would reveal a deeper level of understanding of Tibetan culture. For the $m d a^{\prime} d a r$, we have such an example in the literature. Kohn mentioned in his thesis on Mani Rimdu that,

Freud is said to have remarked that 'sometimes a cigar is just a cigar.' When Trulshig Rinpoche states that he chooses an arrow to bless the multitudes because of its convenient shape, we must grant him equal courtesy (Kohn 1988: 956).

During a tshe dbang, the arrow can become basically anything from a device that supports the visualisation of collecting lost tshe to a tool that is helpful to touch hundreds of people's heads and convey the byin rlabs. It is also the object for projecting stories and jokes on ritual efficacy, which I mentioned in the section on the role of the monks above.

Visualisation is also linked to faith, which plays a role in receiving the byin rlabs of a tshe dbang and is evaluated higher than actual knowledge of the ritual techniques. This issue came up when I asked Lama Kunzang if the transmission of the byin rlabs depended on whether the disciple is able to visualise the deity:

LAMA KUNZANG: In Vajrayāna, there are sometimes things which have to be kept secret. But even if people hear them, they do not understand them, so it is still secret. They only hear. The Lama will put something on their head and give them something to eat; so they only get the $d b a n g$.

BG: Only the person who can visualise the deity will receive the $d$ bang?

LAMA KUNZANG: He who visualises will get the dbang. But if it is a high lama, even if people cannot do it, they get the dbang. Even pregnant mothers with babies can get the dbang. Babies will get the dbang. It depends on the lama. If he is able to bring the blessing to everyone, they will all get it. Also, you need faith. If you do not know the tshe dbang, but you have faith, you will get it.

What Lama Kunzang is essentially saying here is that the empowerment is passed on to anyone being present at a tshe dbang through the generation of byin rlabs, the power of visualisation done by the lama, and the faith of the recipient. The interface of faith and visualisation in the transmission of byin rlabs is certainly worth more research and has probably deeper links than I can show in this chapter.

In Tibetan texts the visualisation is described in detail, but the degree to which a practitioner can do it and generate the byin rlabs depends on his spiritual power and practice. Beyer writes, "the Tibetan initiation depends almost exclusively upon the contemplative capacities of the bestowing lama" (Beyer 1973: 398). So the ritual does not just work because the text was recited correctly, or because the lama visualised correctly; there is 
another layer of efficacy, which lies within the lama's own realisation, which of course is difficult to research. And, to make things more complex, as we saw above in the section on the monks, Lama Sonam thought that in any case the effect of the longevity ritual all depended on 'belief,' in other words on the meaning he as an individual gave to the ritual.

The late Khen Rinpoche from Darjeeling with his vast knowledge on Tibetan ritual commented on the topic of visualisation in 2004, during an informal discussion on byin rlabs:

The visualisation will not be successful without a proper initiation and lineage. Even a quick dbang will not give the desired support. It is the combination of a good lineage, a powerful dbang, faith of the student, and good visualisation practice that will lead to the desired effect. Faith will link the disciple to the lama's mind, which is like a 'spiritual satellite.' Only then byin rlabs can work.

Khen Rinpoche here linked together the various aspects discussed above, adding the importance of the lineage. He offers an interconnected picture of byin rlabs, which shows that byin rlabs is a more complex issue than carried by the term 'blessing.' The following ethnographic account takes us through a day of a tshe dbang ritual that took place on March 20, 2005, ten kilometres south of Darjeeling at the Sakya Guru Gompa in Ghum. It unravels the different layers of how byin rlabs works for the people who attend a tshe dbang. 


\section{THE SAKYA TSHE DBANG: AN ETHNOGRAPHIC ACCOUNT OF A LONG-LIFE EMPOWERMENT}

The head of the Sakya religious order of Tibetan Buddhism belongs to the famous Khön family which ruled large parts of Tibet from its main Sakya monastery in Tsang, Central Tibet. The Khön family had been installed as rulers by the Mongols in the thirteenth and fourteenth centuries long before the institution of the Dalai Lamas came into being. They do not practise celibacy, which enables them to pass on their lineage within the family and not through recognised reincarnations, as is the case in some other schools of Tibetan Buddhism. In Indian exile, the Sakya Tibetan society settled in Puruwala in Himachal Pradesh in the 1970s, and later shifted to Rajpur, Uttar Pradesh.

Their branch in the Darjeeling Hills is the Sakya Guru Gompa in Ghum, which houses one hundred twenty-five Sakya monks. In March 2005, the young son of Ratna Vajra Trizin and heir to the Sakya throne, Ratna Vajra Rinpoche (1974-), who had recently married Dagmo Kalden from Kham, visited the monastery in Ghum to inaugurate the Sakya Lhadrang Bridge. The new bridge spanned a steep gorge from the main road up to the monastery. Over a period of one month, Ratna Vajra Rinpoche (see plate 10.1) gave teachings and a series of initiations to the public in Ghum, Pashupathi, Rimbik, Kalimpong, and Salugara. The initations were predominantly tshe dbang and the lo ma kyong ma empowerment, which was said to protect from epidemics and infectious diseases. ${ }^{1}$ I attended two of his tshe dbang, in Ghum and in Kalimpong. Unfortunately, it was impossible to obtain a private interview with Ratna Vajra Rinpoche.

At the time, I stayed with Sherab and his father, Könchok Peljor, in Darjeeling. Earlier I had recorded their story of short-lived family members

\footnotetext{
${ }^{1}$ Jampel Kaldhen told me that lo ma kyong ma is a 'mantra for infectious diseases' (rims nad gyi gzungs), which used to be a famous practice in Tibet. At the Geluk Tantric College in Tibet, as a part of the lo ma kyong ma practice a pill was made that contained aconite (bong nga), also called 'deadly poison' (btsan dug). Kaldhen and his family took it for a while to protect themselves from infectious diseases. Amchi Jamyang said that this practice is originally from India, but that the pill could only be made in Tibet because of the ingredients needed.
} 


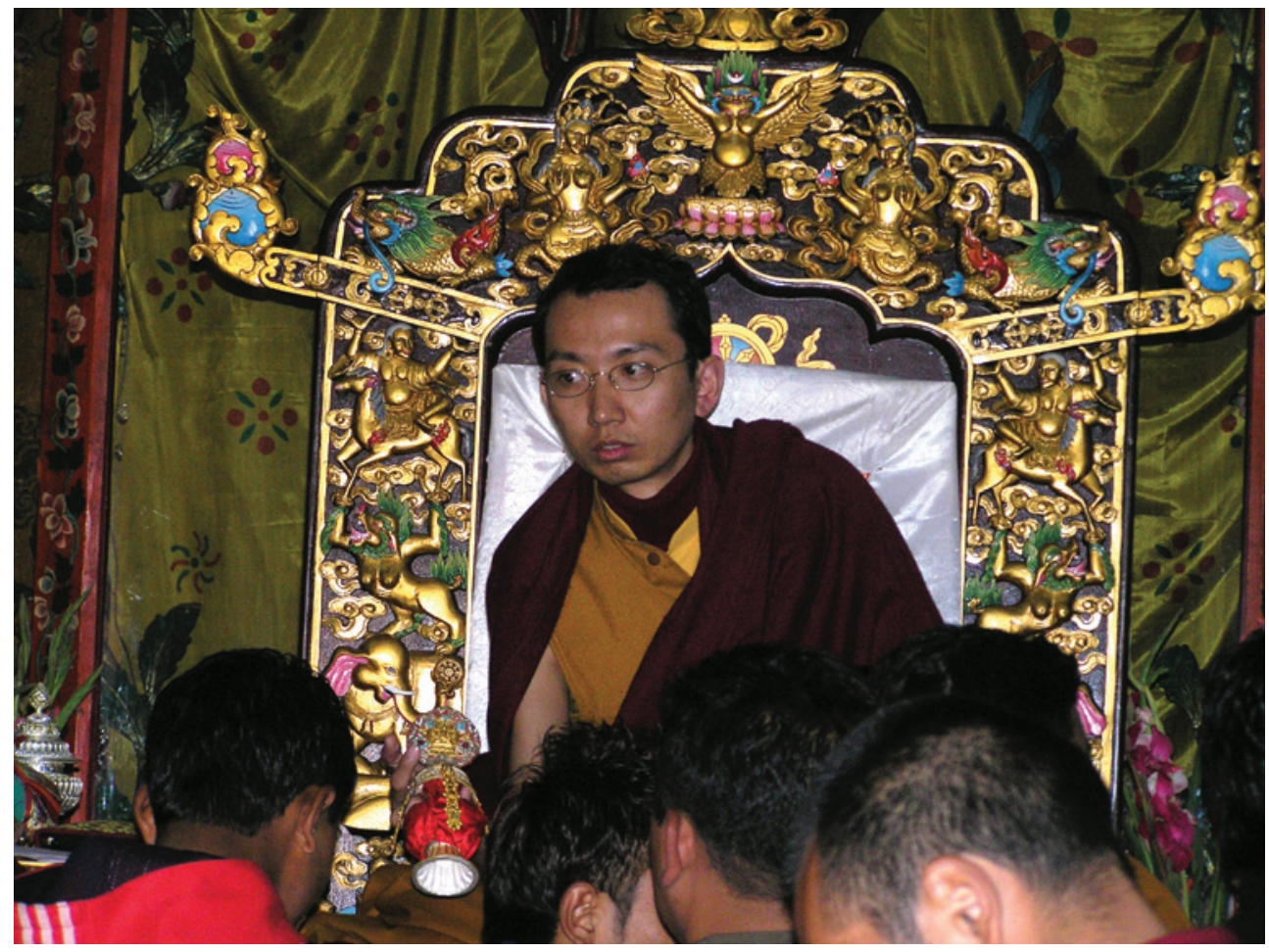

Plate 10.1. Ratna Vajra Rinpoche gives a White Tārā tshe dbang in Ghum, March 2005. In his right hand he holds a tshe gtor with which he touches the crown of the head of each participant to transfer the blessings (byin rlabs).

(see chapter 7.2) and was curious about their attitudes towards the tshe dbang. The night before the empowerment, I talked with Sherab about his understanding of tshe dbang. He said:

I attended many tshe dbang, but never studied the texts. One of the effects of receiving tshe dbang is that you do not even feel like killing animals. The thought does not so easily arise in your mind anymore. Receiving tshe dbang will stop you from taking other beings' lives! The tshe dbang itself is a blessing, but more important is your motivation, visualisation, devotion to the lama, practice, faith, and the blessings of the enlightened beings. All that counts together to make a tshe dbang effective. Then your own life will be prolonged.

We all were excited to attend the dbang in Ghum and rose early the next morning. Könchok and I left the house at 7:30 a.m. Sherab followed later. On the way, we met many Tibetans. Könchok was excited about the fact 
that four empowerments were given on one day. He clearly considered this a good bargain. This meant more potentially difficult areas of life would be covered through the various blessings and he only had to make one trip to the monastery, which meant an expense of about one hundred Indian rupees for the taxi. Local transport was expensive that day, since the public jeeps were already overbooked. While walking to the taxi stand, he explained to me in Tibetan the various $d$ bang we would receive that day.

The first dbang is rta phyag khyung gsum..$^{2}$ It removes obstacles (bar chad). The second one is lo ma kyong ma, which helps in epidemics. The third is a 'pho ba lung, for a good death, and the last will be tshe dbang, for long life. The first one is the most important, more important even than the tshe dbang, because it will protect us from all kinds of evil and disease.

I asked him whether the tshe dbang was only to prolong the life-span or also for a healthy life, remembering previous comments by my Sikkimese Bhutia landlady in Kalimpong that one should not attend too many tshe dbang, because what was the point of a long life if one had a sick body? Könchok replied that tshe dbang was also for health, not only longevity. This answer was repeated by other Tibetans as well. I met several Tibetans who by the time they were in their forties had attended about thirty tshe dbang.

We shared the taxi to Ghum with other Tibetans. In the car, I sat next to a woman who introduced herself as Dölma. She spoke English and was in her forties. She was born in Darjeeling and called herself a Bhutia. Her father was a small boy when he came from Tibet. We talked about the protective cords called tshe srung that are given out during a dbang and that people wear around their neck and about tshe dbang in general.

DöLMA: I wear the tshe srung for three days without washing my head or taking a bath. After that it is your own choice, some wear it for fifteen days, some for a month or longer.

BG: Does the tshe dbang increase the life-span?

Dölma: Yes, by a year or two.

BG: Do you know your actual life-span? Did you have it calculated?

DöLMA: (gesticulating negation with her hands) No, no, I do not want to know. I would not go to an astrologer to find out my life-span. I am happier

${ }^{2}$ This dbang involves three deities - the horse headed Hayagrīva, the wrathful manifestation of Avalokiteśvara; the Garuda bird (khyung), which protects from the serpent spirit $(k l u)$; and Vajrapāni, one of the Buddha's three protective deities. 
knowing that my life-span, whatever it is, is increased by one to two years through receiving the tshe dbang.

When we arrived in Ghum ten minutes later, we found the place already crowded with people. Everyone was dressed in warm jackets and shawls, for the dbang would take many hours and Ghum is notoriously covered in thick fog by early afternoon. The monastery had been decorated with many strings of colourful little flags, hissing in a strong wind. Across the bridge against a whitewashed wall was an oversized photo of Ratna Vajra Rinpoche printed on a huge welcome banner. Prayer flags hung across the newly inaugurated bridge. School children, dressed in their school uniforms, had occupied all the balconies of the three-storied monk residence building next to the temple. Entire families had come with babies and baskets of food and sat in the front yard. As time went by, the roofs of the nearby houses were occupied as well. Mats, cushions, tea flasks, and picnics were spread out. Tea, snacks, and rice were served throughout the day (see plates 10.2, 10.3, 10.4, and 10.5). Due to the crowd it was impossible to enter the temple.

It was difficult to decide where in this crowd I could place myself to observe different levels of participation without being crushed. I had already lost Könchok in the crowd and only saw his head sticking out a few times. I eventually made my way through to a window from where I could see Rinpoche's throne and the monks inside the temple and also talk to passers-by outside. In this way I could observe and record what was happening inside and still communicate with people outside and receive a glimpse of the masses.

Inside the temple were mostly young monks, some senior monks, and the abbot (mkhan po) of the monastery. A senior Tibetan man and a few women dressed in Tibetan attire, apparently the sponsors of the ritual, were the only laity inside the temple. Everyone except the rinpoche, the abbot, and the monks reciting the texts sat on thin carpets that were spread on the floor. Right outside the temple doors nuns sat on mats on the ground. The interpreter sat in front of a microphone on a cushion to the right of Rinpoche's throne, and at the far end left side of the temple two rows of monks were seated at low tables with their ritual instruments and one microphone to guide the prayers, which were all recited by heart. To the right of the throne was also a special arrangement of cushions for Rinpoche's wife, Dagmo Kalden, but on a much lower level than Rinpoche's throne. I could not see the altar behind Rinpoche's throne. 


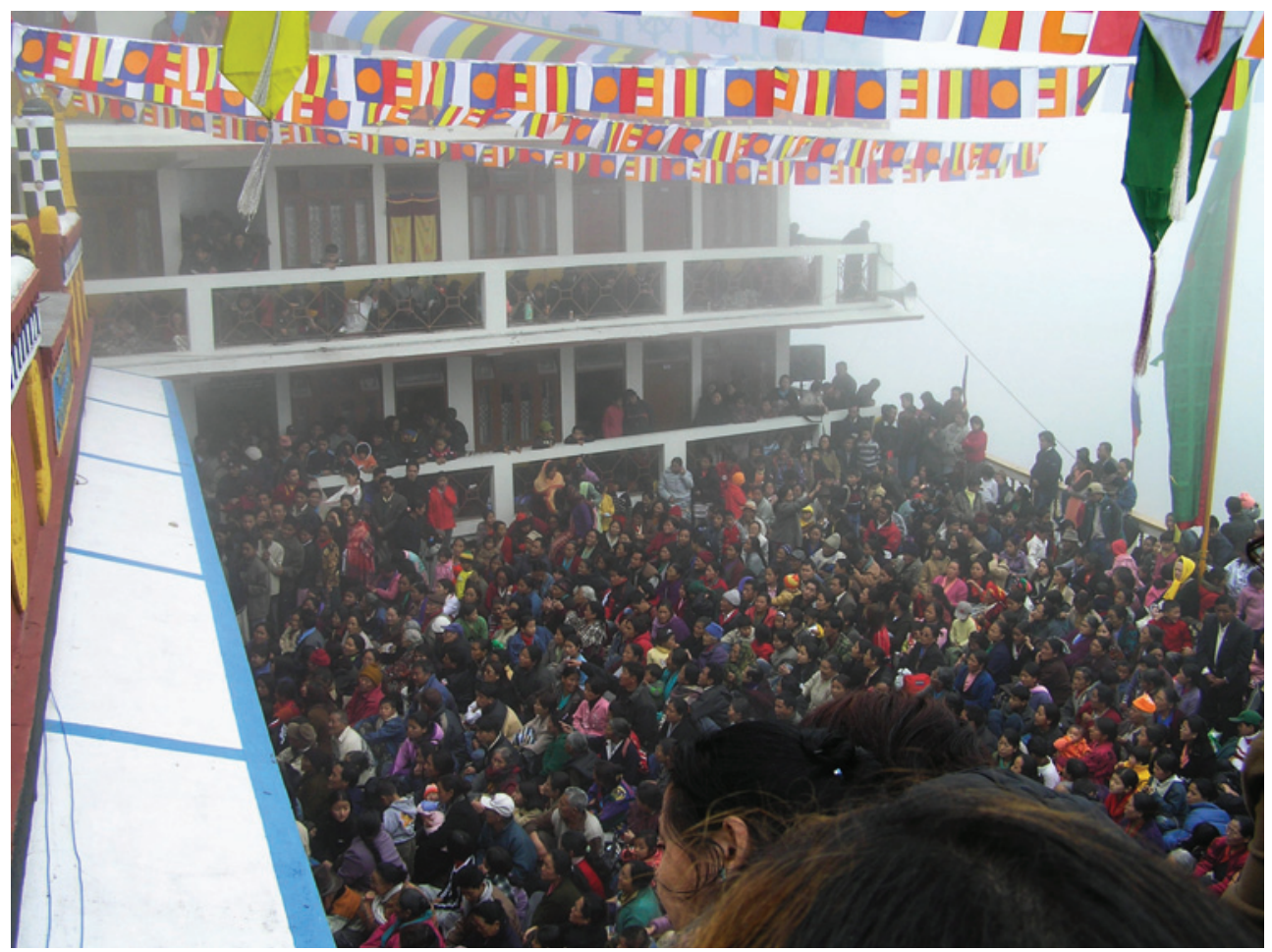

Plate 10.2. The crowd in front of the Sakya monastery and temple during the Sakya tshe dbang in Ghum, March 2005.

Outside, I started talking in English to a Tibetan teenager, who was passing by the window where I stood. I call him Pema.

BG: Why did you come here today?

PEMA: Because of the dbang.

BG: What does the dbang do?

PEMA: If you get this dbang you get long life.

BG: How many years will you live longer with this dbang?

PEMA: It is not really about years, but it helps in accidents. If you have the bad omen of having an accident you will be protected by this dbang. And if you get the 'pho ba lung you do not have to do the death rituals when you die.

By 8:30 a.m. Rinpoche arrived, accompanied by the sound of Tibetan double-reed oboes (rgya gling). Everybody stood up and bowed down, and where there was enough space, prostrated themselves three times. 


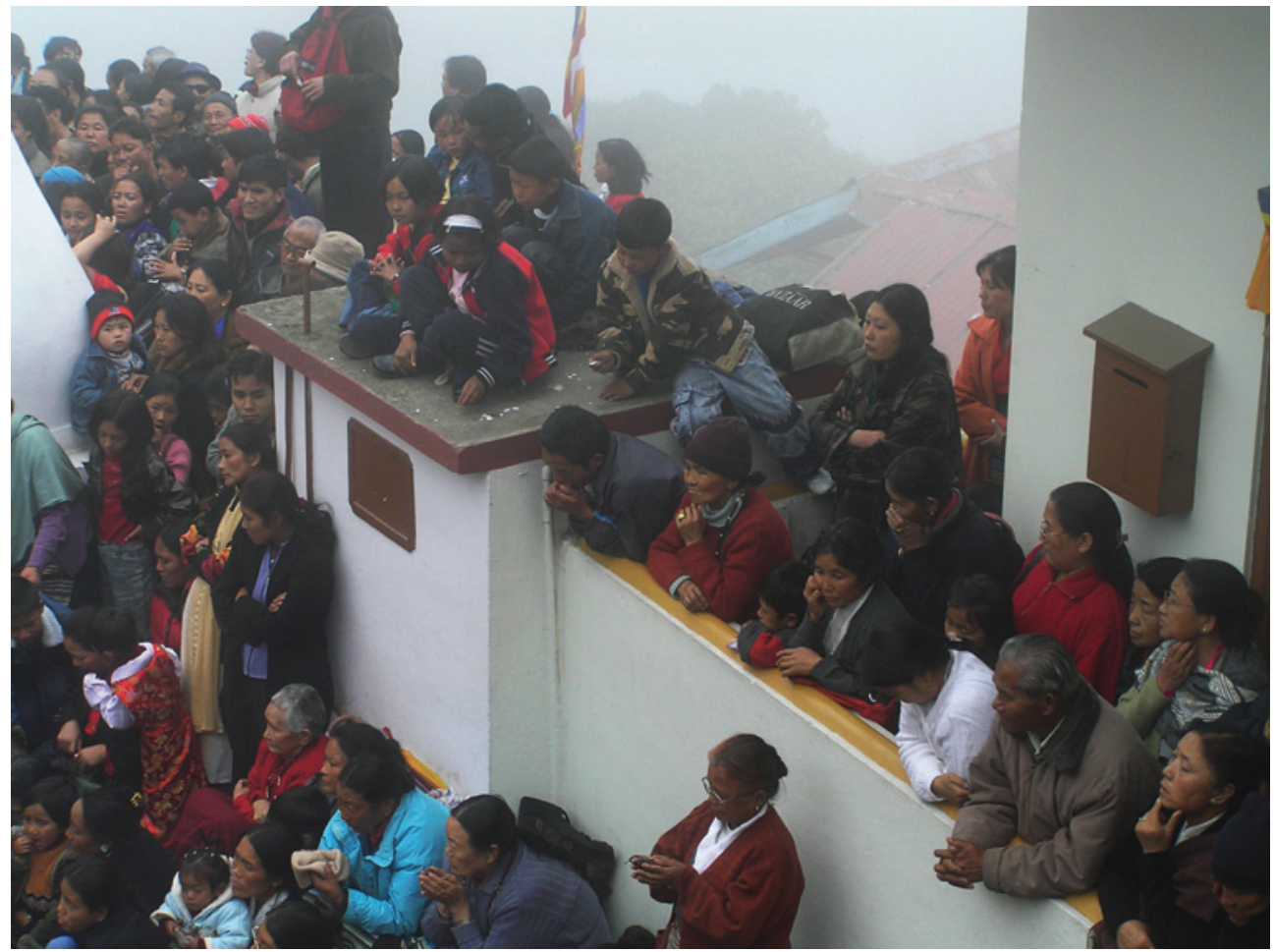

Plate 10.3. The crowd settling on balconies and roof tops during the Sakya tshe dbang in Ghum, March 2005 .

Rinpoche made three prostrations in the centre of the temple and climbed up on his throne where he would be sitting for most of the day to conduct all the initiations. He looked very young with his large glasses and braces on his teeth. He was tall and very thin, unusual in comparison to the hefty and mostly overweight rinpoches I had seen. Monks began to recite prayers. The preliminary prayers took about half an hour. They were all recited by heart. Nobody had a printed text ${ }^{3}$ apart from Rinpoche. His soft voice was transmitted through a microphone system, but the electricity failed several times and the noise level outside was so high that

${ }^{3}$ During all the tshe dbang I attended, apart from an occasional printed programme in Tibetan and English no written materials were distributed. Once, during a tshe dbang in Kalimpong a Xeroxed copy of a long-life prayer was distributed, but since everyone sat on the floor, there was an issue about where to keep the sheets. Religious texts are not supposed to be placed on the floor since they are considered sacred. 


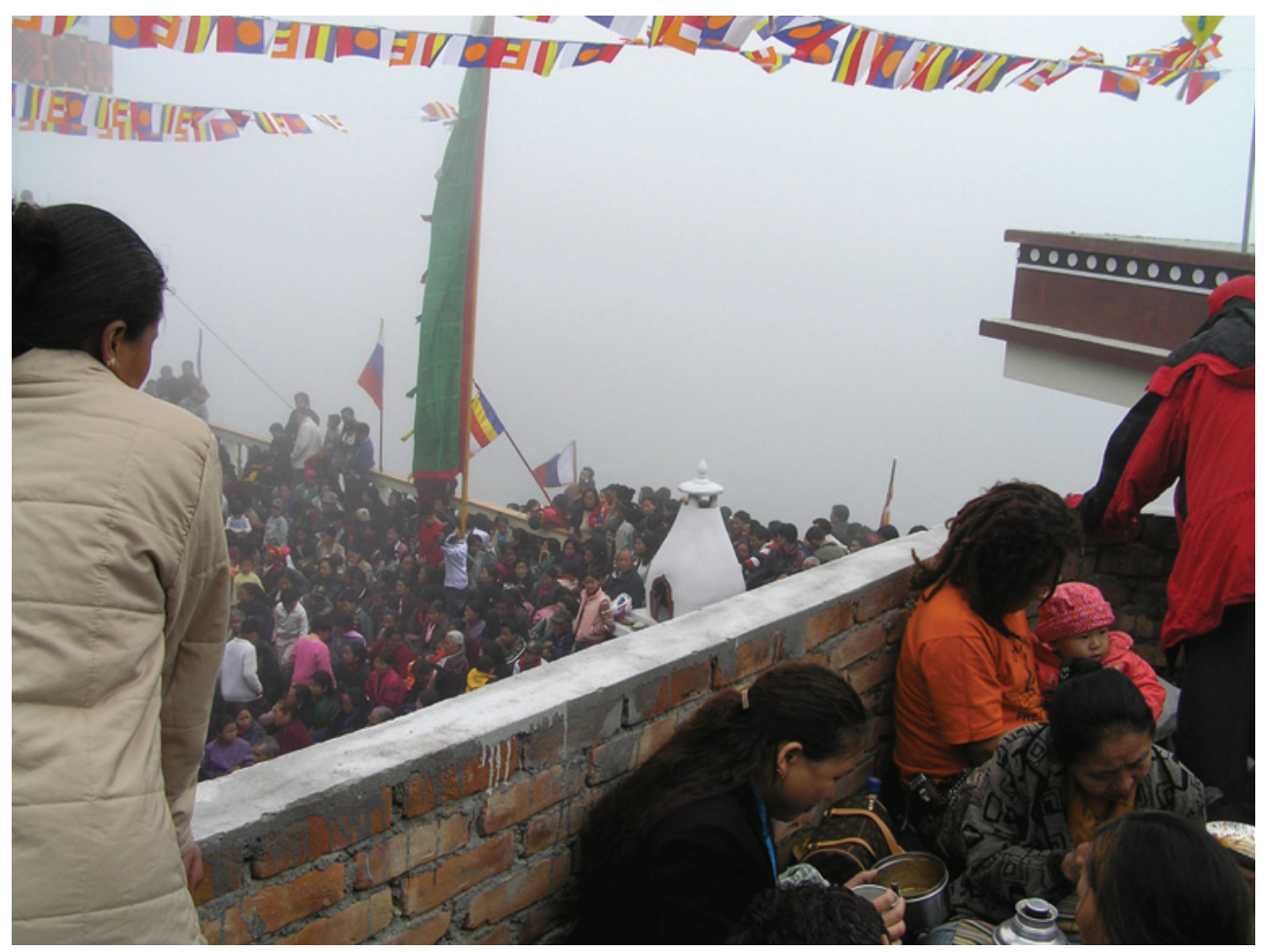

Plate 10.4. Family picnics on roof tops during the Sakya tshe dbang in Ghum, March 2005.

it was impossible to understand him. Only his speech, which he gave in between the initiations, was translated into Nepali. The interpreter's voice was louder and easier to hear.

People told me that it was not important to understand everything; they would still receive the $d b a n g$. If understanding the texts was important, no one would receive the dbang. They said tshe dbang was an 'easy dbang without practice.'

I continued to be squeezed against the window, audio recording the ritual and taking photos and short video clips with my digital camera. Despite the lack of space, there was quite a movement of people around me. Any long conversation was impossible since people kept moving and merged back into the crowd again. But the few small conversations I had at that window were quite enlightening. A fourteen-year old Tibetan girl, whom I call Nyima, born in Darjeeling, stood next to me for a short while. She said her parents were born here, and they spoke Nepali at home. She only knew a little Tibetan; we spoke English. 


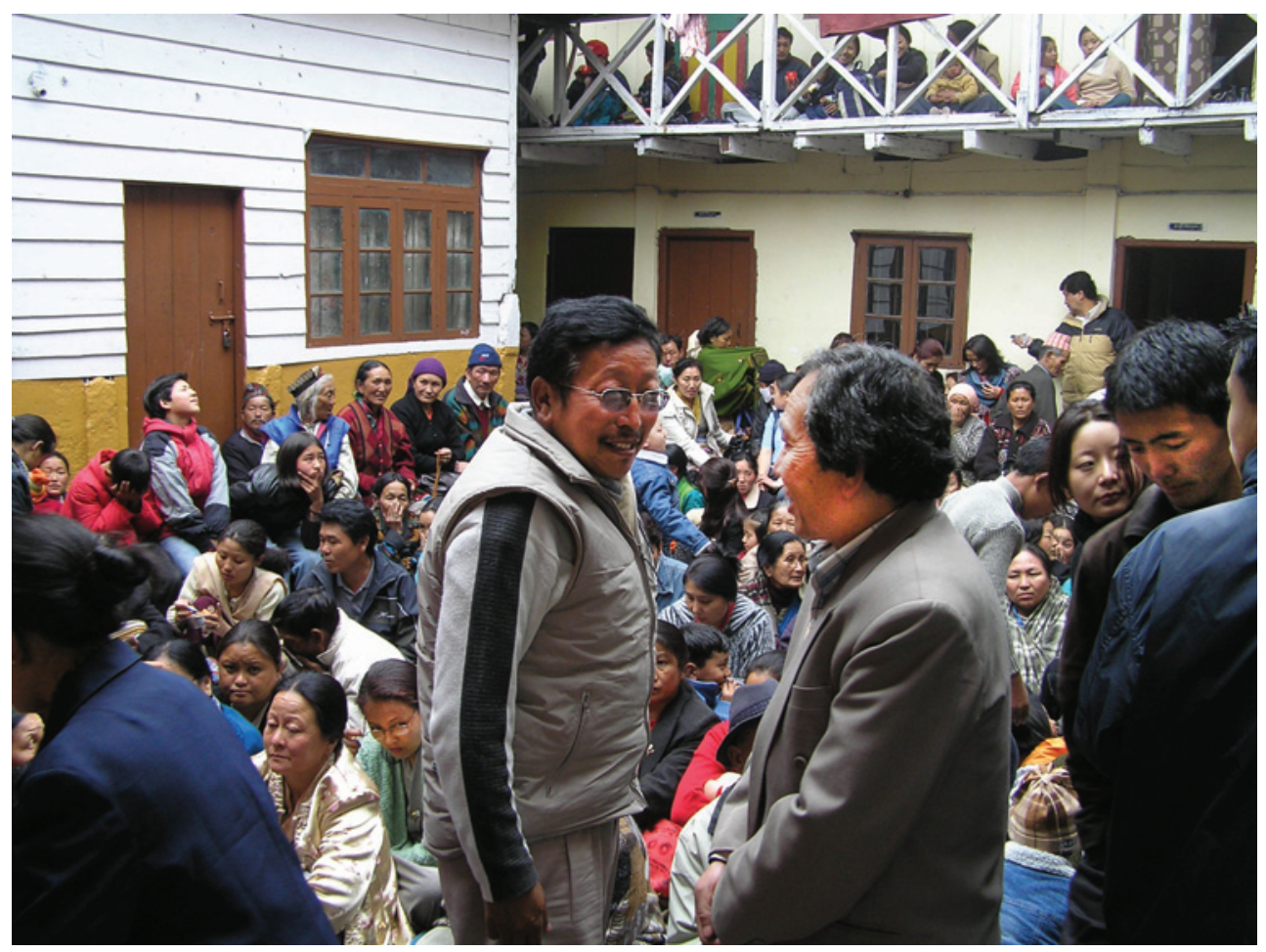

Plate 10.5. A scene behind the temple during the Sakya tshe dbang in Ghum, March 2005.

BG: Why did you come here?

NYIMA: For the dbang.

$\mathrm{BG}$ : What is the dbang good for?

NYIMA: For Aids [She referred to the lo ma kyong ma dbang, which in the English programme was announced as 'anti-epidemic dbang'].

BG: Who told you that?

NYIMA: My sister.

BG: How old is your sister?

NYIMA: Twenty-four.

BG: Are there many of your friends attending the dbang for this purpose?

NYIMA: My sister's friends.

BG: Do you think a lot of people have Aids here in the Hills?

NYIMA: I don't know.

BG: Do you think this $d b a n g$ will really protect you?

NYIMA: I don't know.

Nyima walked off, too shy to talk more and left me with a creeping feeling about local health care; I wondered whether the rinpoche had any idea about how his dbang was interpreted by Tibetan teenagers. 
I wanted to find out what people thought about when and how they would receive the tshe dbang. As the ritual proceeded in Tibetan, people kept moving around, chatting with friends, drinking tea, and queuing at the few toilets behind the temple. It was chilly, and the fog crept up the hills and engulfed the crowd and even moved through the open windows into the temple. The monotony of the hour-long recitations was only interrupted by occasional changes in the rhythm of how the prayers were recited. The most prominent breaks in the monotony occurred when the offerings were made by the sponsors and senior monks, and when Rinpoche recited the few phrases of the actual 'promise' of the dbang, which people were supposed to recite after him. Whoever could hear what was going on recited the words.

For about an hour between the rituals, Rinpoche gave teachings in Tibetan, which were translated into Nepali by a Tibetan interpreter, who I knew was teaching Tibetan in one of the Darjeeling schools. It was clear that many young Tibetans did not understand Tibetan and those Tibetans who knew Tibetan did not necessarily understand dharma Tibetan, and those who did follow the dharma Tibetan may not have followed Ratna Vajra Rinpoche's Sakya dialect. Moreover, the microphone system did not really catch his soft voice. Simple translations into Nepali were required.

At the time of the teaching, two Tibetan college girls, whom I call Tsering and Dölma, stood next to me. They told me that they went to the local Tibetan school until class twelve, but spoke Tibetan only at home and in school. They understood the Nepali better than the Tibetan, but were uncertain with religious terms, such as abishek, and translated it as 'worship' in English or chos in Tibetan, not as 'empowerment.' Several times they said they could not understand anything. They said that Rinpoche repeated the same thing over and over again. A young man joined us and they asked him to translate for me. He said in broken English that he could not understand much Tibetan or Nepali. I asked what his mother tongue was and he said Tibetan. I asked him why he was here, and he said he was driving a lot and heard that the tshe dbang would protect from accidents, which he felt was a necessary protection with the increasing amount of traffic on the dangerous Hill roads.

Language was clearly a problem and created a lot of barriers between Ratna Vajra Rinpoche's elaborate dharma teachings and the people, who understood only a fraction of what was said. The interpreter translated well in the sense that he used simple and colloquial words in Nepali to bring the meaning of the dharma teachings across. The content was kept simple. The teachings were about non-violence, compassion, and religious 
tolerance. Rinpoche promoted vegetarianism, requesting people not to place too much importance on food and materialism. Tsering and Dölma, gave me their version of what they understood:

DÖLMA: We have to pray and worship, so many gods are there, we have to learn how to pray.

TSERING: We should not say we are Christian or Buddhist. All religions are the same. When we are sick, we all take the same medicine. We are not different.

DÖLMA: People should not be short-tempered, should have a cool mind, and should not become angry.

TSERING: We should think about everybody, not just ourselves. Bodhicitta [i.e. an attitude of loving-kindness towards all beings] is important. We should worship. Animals and people are living beings. We should not kill animals. Motivation of compassion is important. We should study, pray to the Buddhas and the three jewels, help others, and animals. Whether rich or poor, we are all the same.

DÖLMA: We have to promise that from today onwards we will not speak lies and will not kill animals.

TSERING: Understanding the text is not important to receive the dbang. Nothing matters. We have to catch only the important thing, like not lying, not killing, from today onwards. We get the dbang anyhow even if we do not understand all what the rinpoche says.

BG: Have you been to a tshe dbang before?

TSERING: Yes, three or four times.

One dbang followed the other, hour after hour. While Rinpoche went through the empowerment rituals inside the temple, packets of crisps were distributed outside to the schoolchildren on the balcony. The noise level increased. In between the empowerments a popular Padmasambhava prayer ${ }^{4}$ was recited for about ten minutes at the time. The recitation of the prayer and the fact that everyone knew it, would give a sudden focus and coherence to the group. It reduced the noise levels and gave a sense of order. The masses could participate in this prayer and the ritual was not longer just 'happening inside.'

Even inside the temple, I noticed that there were only a few monks who were apparently not distracted by what was happening around them and sat in quiet meditation pose. Three younger monks in their teens, who sat just below the window where I stood, were exchanging playing cards of body-builders and chatting with each other. Most people did not have the

${ }^{4}$ Later I was told that the reason for them reciting this prayer during each $d$ bang is that one of Padmasambhava's disciples started a lineage in the Sakya tradition. 
discipline and training to concentrate for three and a half hours on the various dbang. Outside the temple, food was taken at all times; inside tea and oily rice with nuts and raisins were served only during the breaks, and only eaten once Rinpoche had blessed them with a prayer.

At 11:30 a.m., after I had stood with cold feet on the same concrete spot by the window for three hours, the actual tshe dbang ritual finally started. Two monks carried a large brown wooden box to the front of the altar. They opened it and took out a bowl of long-life pills, which had been prepared from roasted barley flour (rtsam pa) and butter. A monk later told me they had been consecrated by Rinpoche during his early morning meditation in his room. At the far end of the temple I saw two large bowls of long-life pills and large plastic containers and metal kettles filled with long-life nectar that had been prepared earlier. Such large amounts of long-life nectar are usually made of water and concentrated coloured orange juice. I had seen smaller amounts made from milk and water, or Tibetan beer (chang). A smaller bowl of long-life nectar was placed on Rinpoche's altar, along with a long-life initiation gtor ma (tshe gtor). ${ }^{5}$ Sometimes they would use a long-life vase (tshe bum). With the tshe gtor Rinpoche would later touch the head of each person to bestow byin rlabs (see plate 10.1).

Rinpoche recited the tshe dbang sādhana alone from his ritual text. Whenever he needed any ritual implements his two monk assistants placed the needed item on his high table which was at the height of their shoulders. While approaching him they always kept the end piece of their robe in their mouths not to 'pollute' the ritual space with their breath. The first offering was a rice mandala generally presented as a 'payment' to the lama for performing the tshe dbang. Senior monks lined up to make various offerings, each wrapped in a long white kha btags (see plate 10.7). The monks sitting in the temple recited prayers from memory during this offering. Then Rinpoche recited the 'promise,' and the monks and the public (whoever could hear and understand) repeated the verses after him three times. The noise levels outside were still very high, but the sound of the rhythmic recitations repeating the verses after Rinpoche were getting even louder and went on for about ten minutes. Each line read from the ritual text was repeated by the crowd with varying

\footnotetext{
5 An initiation gtor $m a$ can be made from wood with the respective deity painted on its top (see plate 10.6), or from metal, which is covered with gold, silver, precious stones, and sometimes pieces of silk cloth (see plate 10.1). A picture of the initiation deity might be affixed to the top (see plate 9.11).
} 


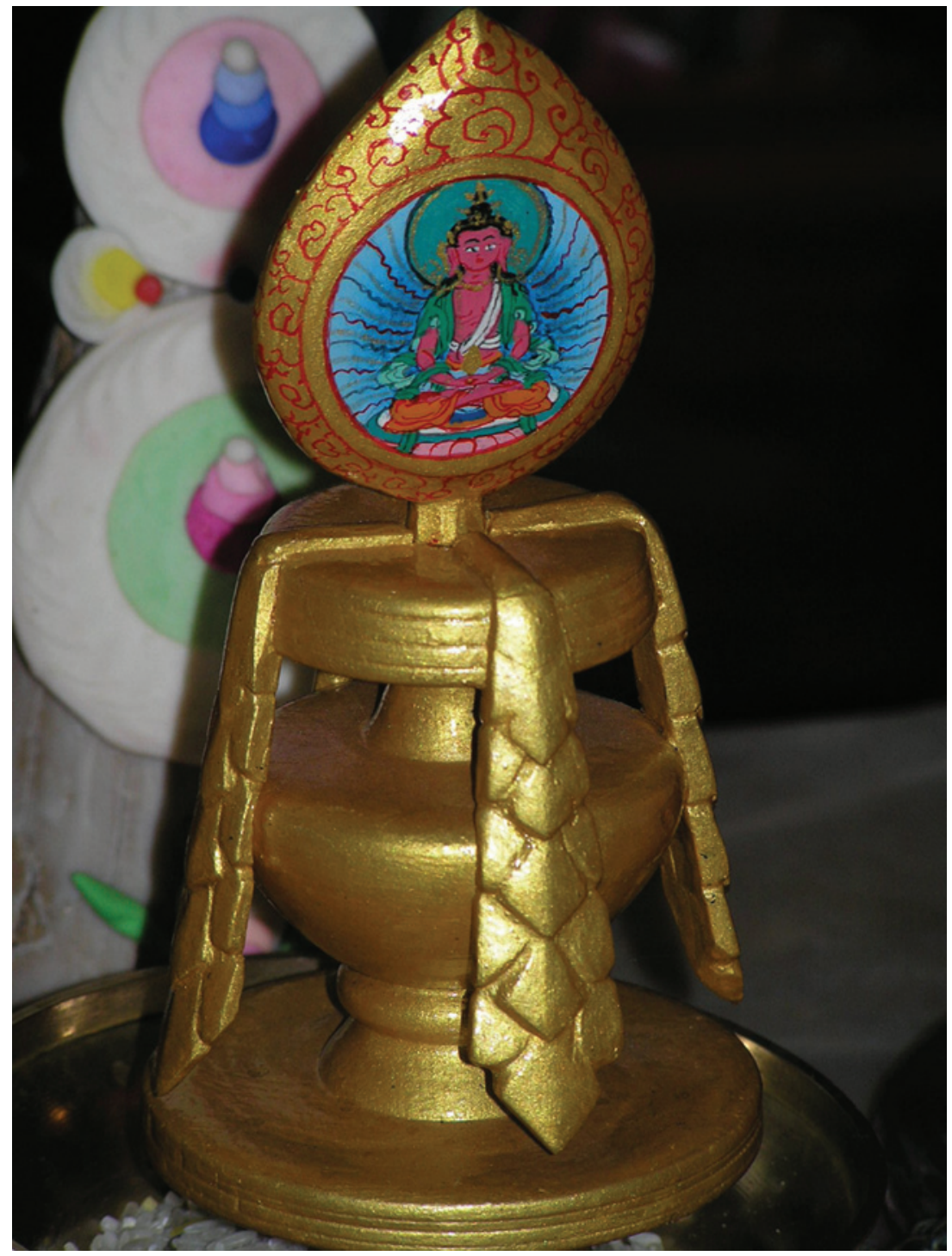

Plate 10.6. A long-life initiation gtor ma with an image of Amitāyus, used to transfer blessings during the Nyingma tshe dbang at the Mani Nyungne Kidu, Ghum, October 2004. 


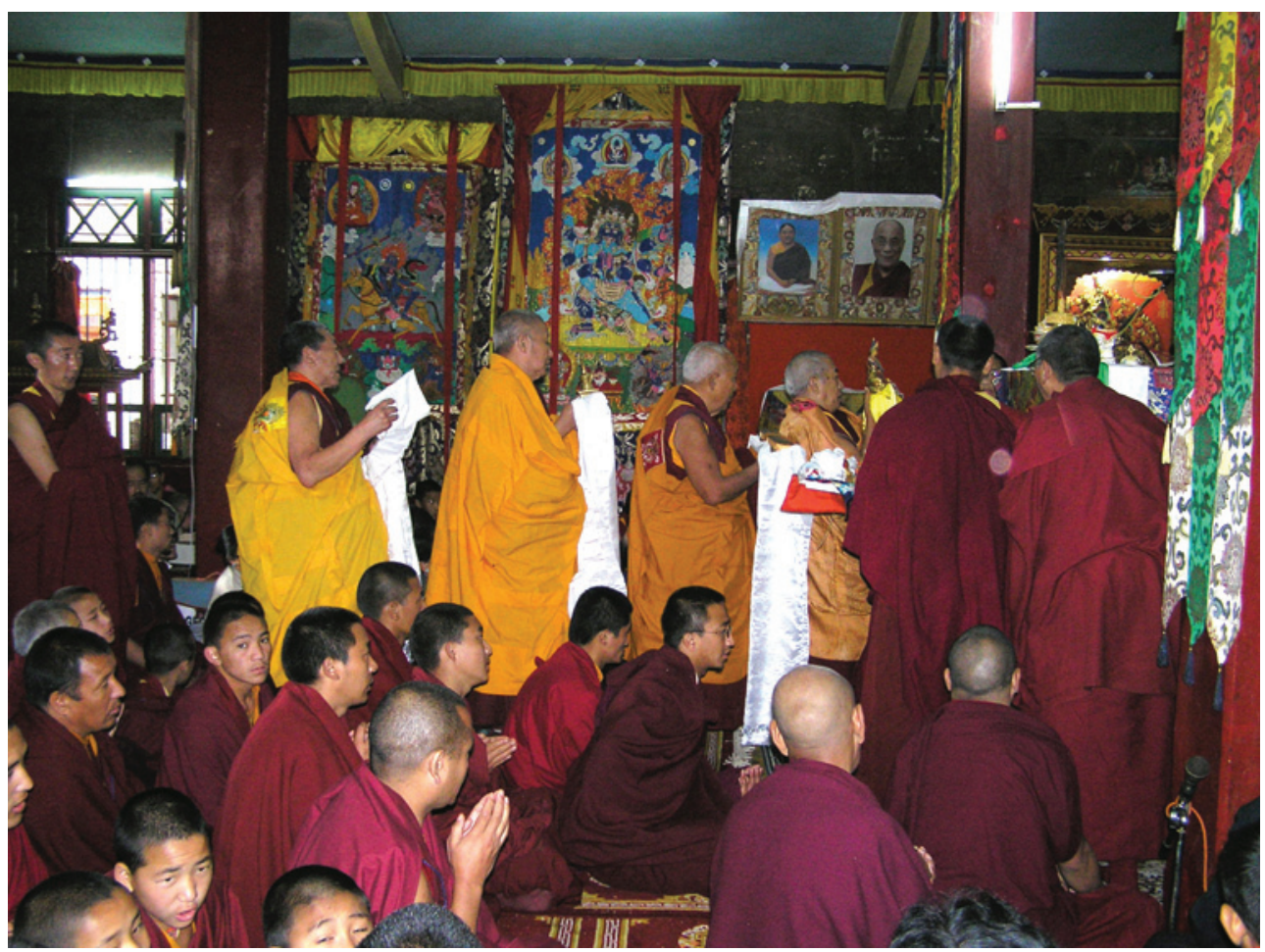

Plate 10.7. A scene inside the temple: senior monks make offerings to Ratna Vajra Rinpoche, during the tshe dbang at the Sakya monastery, Ghum, March 2005.

accuracy. The monks concluded the recitation by playing their cymbals and trumpets, after which the next part of the ritual began; again Rinpoche's recital, the public reciting after him, and the monks playing their cymbals and trumpets.

Then the monk handed Rinpoche the long-life arrow. He circled the arrow three times with his right hand. According to the ritual description, he is supposed to visualise the collection of the lost life-forces from the surrounding elements. This scene was accompanied by the sounds of his ritual bell (dril bu), which he held in his left hand. During the entire time he also held another ritual implement, a vajra ( $r$ do rje) in his right hand, which is meant to protect tshe from getting lost once it has been collected. $^{6}$

${ }^{6}$ A ritual dril bu and $r d o$ rje can be seen on plate 9.8 . 
The assistant monk then placed a bowl with the long-life pills on Rinpoche's high table, along with an offering bowl made from the top of a human skull (ka pa la), which was filled with long-life beer (tshe chang). All offerings were placed on the high table in front of Rinpoche. His food was moved to the side. The long-life vase was placed to the right. $\mathrm{He}$ blessed the crowd by throwing rice into space and recited prayers.

The main sponsor of the ritual, a Tibetan man in his sixties, who was dressed in traditional Tibetan men's attire with long sleeves (pho chas) and a western-style grey hat, got up and offered three prostrations. He was assisted by three monks to make the offerings, which were placed on a tray carried by one monk. The sponsor first offered a large white ceremonial scarf along with a golden mandala that was connected to a large colourful tail of fabric that was draped over his left shoulder by one of the monks. These ritual implements belonged to the monastery and were used in all types of dbang. The sponsor offered the mandala to the rinpoche, who accepted it and placed it on a table next to his throne. The sponsor then offered a statue of Amitāyus, a manuscript, and a mandala, then another ceremonial scarf and a white envelope that contained his donation. The ceremonial scarf was placed in front of Rinpoche's throne. The envelope with another scarf was offered directly to him. Rinpoche in return placed a special white ceremonial scarf and a broad red blessing ribbon around the neck of the sponsor, who then returned to his place. The gift giving was entirely ritualised. There was no conversation and no eye contact. Whoever approached the rinpoche bowed their heads low. During the offerings, all monks in the temple recited their offering prayers from memory. The other sponsors present in the temple, two women and one man, all dressed in Tibetan costumes, lined up in front of the altar to present their ceremonial scarves and boxes of gifts wrapped in shiny plastic gift-wrappings.

Rinpoche then recited prayers, and whoever understood him reciting the phrases through the microphone, repeated them after him. Now the sponsor appeared again and offered another mandala in the same ritualised fashion as before, all accompanied by recitations. With this, the textual part of the ritual was over.

Then, suddenly, a wave of abrupt movement went through the crowd outside and people got to their feet and started pushing towards the main gate of the temple. The interpreter screamed instructions in Nepali and asked people to keep in line, but nobody listened. The temple inside was almost taken by storm and I felt there could be a stampede. Both doors to the temple had iron push doors, which were now closed, held together 
by an iron chain and only a small gate was left open. A small group of strong youths and monks functioned as the gate keepers. Through the left gate people entered the temple, and they left through the right gate. The pushing and shouting was tremendous and, anticipating what was happening, I had moved myself onto a nearby roof to watch the scene. I saw more people streaming in from the village, not only Tibetans, but also many local Nepalis who had come for the blessing. The crowd started moving into the temple at around 1:30 p.m., and it was 4 p.m. when the crowd in the courtyard finally thinned, making it possible to go near the temple gate without being shoved around. Moving with the last crowd towards the gate, I saw that the gate keepers were passing around a large metal kettle, filled with consecrated long-life nectar. Young teenage boys were passing it around and all of them poured the yellowish liquid into their mouths and over their heads and faces (see plate 10.8). I approached a few Tibetan women coming out of the temple and asked them about

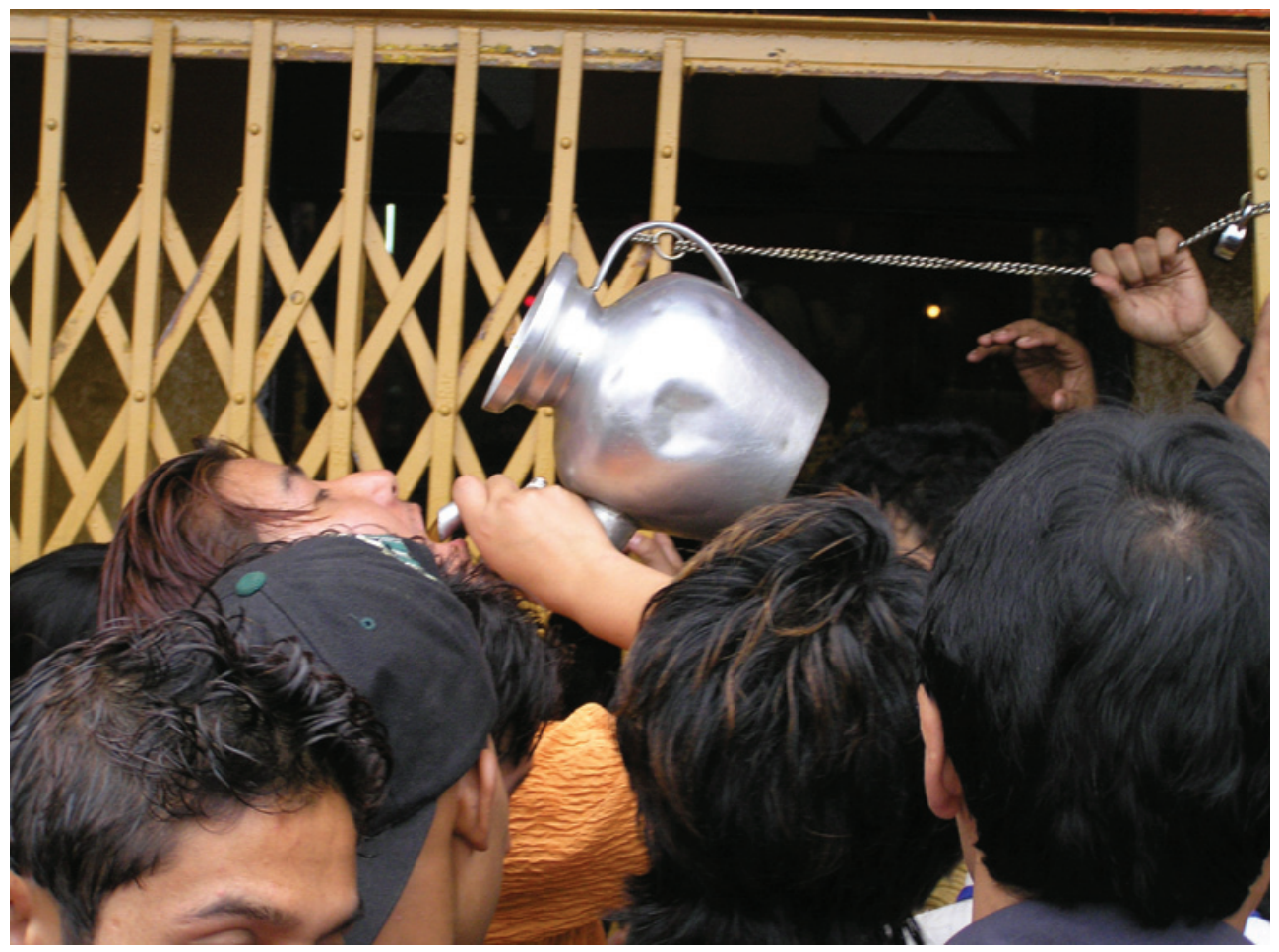

Plate 10.8. Young teenage participants receive byin rlabs in the form of long-life nectar from a kettle at the gate of the temple during the tshe dbang at the Sakya monastery, Ghum, March 2005. 
their impressions of the dbang. A middle-aged woman, whom I call Passang, said in English:

PASSANG: We are doing this to live long. I stood in the crowd for three hours to get in, but I received the dbang.

BG: What does the tshe dbang mean to you?

PASSANG: I will live longer now.

BG: How much longer?

PASSANG: I believe I got about fifteen years more.

Inside the temple, the line of people approached Rinpoche's throne from the left and departed on the right. A film team using bright stage lights lit up the otherwise dim room and videotaped the crowd passing by Rinpoche's throne. Monk assistants controlled the rows of people while others gave out the long-life pills, long-life nectar, and the protective cords. Several monks held large plastic bags to collect donations, and I could see the bags were filled mostly with ten, fifty, and one hundred Indian rupee notes. Rinpoche looked visibly tired. He had been placing the tshe gtor onto each individual head that passed by his throne for the past two and a half hours and had been sitting in a cross-legged position on his throne since 8:30 a.m. with only one twenty minute break. With a monotonous, repetitive movement he placed the tshe gtor with his right hand on each person's head. His lips were moving silently, repetitively, with a soundless mantra. Once in a while, I saw him giving some instructions to his assistants. I followed the crowd and received the blessings. I later gave the long-life pill and protective cord to Momola, who was sitting alone in her hut below the monastery, too weak to climb up the hill. She was not sad about it. "I don't like the crowds," she said.

I passed by the monastery office and saw through the open door about six monks busying themselves with counting the hundreds of currency notes, keeping track of the accounts. The tables were packed with bills.

After the dbang, the crowds dispersed and Rinpoche went to his room. Outside the temple I ran into Tenzin, an old friend of mine from Darjeeling. His family was very close to Ratna Vajra Rinpoche and he had known him for many years. Tenzin had studied at a Sakya monastery for several years before becoming a Tibetan language teacher at an Indian university. I was curious to learn more about the dbang.

BG: What kind of epidemics have Tibetans in mind when they attend a lo ma kyong ma dbang? One girl told me she came to this dbang because it would protect her from Aids. 
TENZIN: (laughs) It would be better if she would know how to protect herself. The dbang won't help. You can't do everything you like and say the dbang will help. It is not like that. As Rinpoche said this morning, motivation is very important. If people come for protection of Aids it is not a correct motivation. The dbang won't be effective.

BG: What makes the dbang effective?

TENZIN: Motivation. First we have to have bodhicitta. I have to take the dbang for the sake of others, not for myself. First, I have to become enlightened to benefit others, not myself. Without that kind of motivation, she may still receive some blessings, but the dbang is not effective.

I spent the next two hours with Tenzin, who took me along with his parents and a small group of Sakya Tibetans for a private blessing to Ratna Vajra Rinpoche's residence, which was on the top-floor of the monastery. The veranda railing had been covered with large printed colourful cloths with auspicious signs and his door was guarded by monk attendants. Still, individual Tibetans tried to enter his room making offerings of packets of tea and noodles, rtsam $p a$, and dried cheese. The monks tried to receive the gifts on behalf of the rinpoche and keep the crowds away from him as much as they could. I witnessed an old Tibetan lady passing the guards and going into Rinpoche's room to make the offering herself. I got a glimpse of the room. Bags of food and gifts were piled up wherever there was free space on the floor, the beds, and chairs.

We waited for about an hour before I could follow the Sakya group into a large room with an exquisite-looking throne placed on a carpet at the end of the room. Rinpoche walked in and sat on the throne. He held a ritual dagger ( $p$ hur ba) from his Sakya family lineage wrapped in dark blue velvet cloth in his hands. The group prostrated and we lined up in front of the throne and he placed the phur ba onto each of our heads, reciting a mantra. Then the group had a private audience, which I was not allowed to attend. I waited for Tenzin outside. He came out after about half an hour and smiled at me.

Now we are OK for a year. We believe that with this special blessing nothing bad can happen for the next year. No untimely deaths, no severe illness. His phur ba blessing is very powerful.

We parted soon after, and I hitched a ride back to Darjeeling. By 8 p.m. I reached Könchok's place. "How was the dbang?" I asked. "Very good. I made it back home here by 4 p.m. I got the $d$ bang very quickly and made it really fast through the crowd," he laughed and gave a lively demonstration of how he had elbowed his way through the crowd. 


\section{SUMMARY AND CONCLUSIONS}

In this book, I presented multiple perspectives on the life-span, tshe, and various life-forces as understood by Tibetans living in the Darjeeling Hills, along with numerous examples of how lay and professional Tibetans deal with these life-forces in medical, astrological, divinatory, and ritual contexts. I brought the various life-forces together, despite their disparate origins, in an attempt to show their pervasiveness in Tibetan culture and to demonstrate through contemporary ethnographic accounts how Tibetans make sense of them today.

I sketched various temporal frameworks and time-markers that Tibetans employ to map out, diagnose, prognosticate, and negotiate their often much-personalised ideas of the life-span in numerous ethnographic contexts. In addition, I translated some relevant Tibetan medical and divinatory written sources to add a textual dimension to the ethnographic data and investigated the ways in which specialists selectively read and interpret such texts.

Following a detailed exposition of the socio-political situation of Tibetans in the Darjeeling Hills in chapter 2 and an outline of the relevant Tibetan areas of knowledge in chapter 3 , the ethnographic material was organised into three main parts (III to V). These main ethnographic chapters of the book focused on longevity practices in medicine, astrology and divination, and Tibetan Buddhist Vajrayāna rituals. I also discussed Tibetans' personal perceptions of the life-span in the context of Tibetan value concepts, considering cosmological ideas of auspiciousness, 'blessing,' karma, and merit. Throughout these chapters, my focus was on practices of temporalisation, which I used as an overarching term to describe diverse activities through which Tibetans mediate between existing temporal frameworks and their personal and collective situations in wideranging, dissimilar contexts.

Throughout this book I showed that the various temporal frameworks found in Tibetan knowledge systems are not only abstract constructs that appear in texts or calendars, but are employed and often (re)interpreted differently by professionals as well as lay people according to situation. Here, people's agency - which I labelled with the more nuanced term 
'situational agency' - plays out in some of the most difficult life situations, such as illness and death. It also plays a role in numerous prophylactic activities such as long-life empowerments and astrological and divinatory prognostications of specific vital factors, which help Tibetans understand and counteract misfortunes.

In this summary, I succinctly draw several conclusions from the data.

Tibetans in the Darjeeling Hills, with only one refugee settlement, are unlike Tibetans who grew up in less stratified areas in Indian exile with more homogenous settlements or close to the Dharamsala-based Tibetan government-in-exile. While I did not attempt any comparative approach to issues of Tibetan identity in India, which would require multi-sited ethnographic research, I noticed that the second and third generations of Tibetans born in the Hills often show a limited knowledge of, interest in, and awareness of Tibetan language and culture. This shows a tendency towards a situation in which - once the generation of Tibetans born in Tibet has passed away - being a Tibetan in the Hills will increasingly mean having Tibetan ancestors, but living a modern Nepali-Indian urban lifestyle in a stratified society in which Tibetans are a marginalised group. With such mounting diffusion of cultures, the inherent experience of 'Tibetaness' is fluid for many Tibetans. The sense of being a Tibetan in the Darjeeling Hills is not necessarily bound to knowing the Tibetan language; it can also be linked to belonging to a category, the Bhutias, which indicates both an ethnic group and a legal status under the Indian government reservation system. This 'Bhutia' status is often just a pragmatic choice that opens the door for a better life in India and also removes Tibetans from their 'refugee' status, which they do not like to identify with. 'Bhutia' can also involve an emotional identification with the ethnic group 'Bhutia,' distinct from those Tibetans who show strong nationalist feelings of 'Tibetanness,' or who only recently arrived in India.

Tibetans in the Darjeeling Hills have shown themselves to be quite flexible, not only in their ways of utilising the 'Bhutia' status, but also in their ways of moving through the Hills, setting up an urban 'camp,' linked with trans-national and international 'trade routes' adopting and changing identities along the way if and when required. I also found this flexible attitude among Tibetans who have permanently settled in the region.

In chapter 2, I also sketched the medical syncretism found among the multi-ethnic communities living in the Darjeeling Hills to show how it influenced treatment choices among Tibetans. Overall, Tibetans in the Darjeeling Hills have a tendency to see medical, astrological and ritual practitioners as 'experts' who provide medical, divinatory, and ritual 
advice, prescribe remedies, and offer practical health solutions. I have shown that Tibetans make medical choices by interpreting diagnostic and divinatory results for their personal circumstances. For the most part they are not concerned with epistemological conflicts and the way these systems theoretically contradict each other. Especially when it comes to expensive Buddhist rituals or costly biomedical treatment schemes, a divination often helps allocate people's resources. Biomedicine and religious practice are deeply interrelated and on the whole do not oppose or compete with each other, but are part of a diverse process of health-seeking behaviour in the pluralistic societies of the Hills. The story of Jigme losing his bla (chapter 6.4) illustrates how numerous Tibetan and 'western' frameworks can be employed to interpret illness events. These frameworks do not necessarily have a clear hierarchical structure. Even within the various Tibetan knowledge systems, interpretations can easily cross the boundaries between the various systems.

In my discussion of the various notions of vitality, a variety of disparate concepts emerged, which I collectively labelled 'life-forces' (summarised in appendix 1). In Tibetan medical contexts, such life-forces - specifically srog (life itself), bla (the subtle life-essence) and mdangs mchog (the supreme vital essence) - are not primarily related to bodily organs, but are often linked to different physiological and anatomical perceptions that lie outside a biomedical understanding of the body. Therefore, any analysis of these life-forces should be placed within the physiological context in which Tibetan physicians themselves understand them. In my analysis of these various notions of vitality I argued that in Tibetan medicine, and also in astrology, they are made more tangible and calculable through temporal frameworks. In Tibetan medicine, they are often interlinked with the three nyes $p a$, which allows amchis to diagnose diseases with seasonal periodicities and conduct treatment at times that are deemed effective.

I showed that calendars and 'vitality tables' help professionals and lay Tibetans negotiate the qualities of srog and bla and draw strength from their peak times. In practice, textual Rgyud bzhi knowledge is not always applied literally but rather adjusted to what is practical, such as administering medication at four specific times of the day. The increasing institutionalisation of the MTK clinics has also led to a more standardised treatment structure, in which it is not possible to take into account the numerous intricacies of seasonality and other temporalities as described in the texts (chapter 4).

In chapter 5 , I showed how bla, a pre-Buddhist notion of vitality, has been mapped out in various ways in the Tibetan scholarly medical tradi- 
tion: the calendar rhythm of the moon cycle is used as a reckoning system; anatomical points in the body are used as a map to locate and protect bla; and the pulse beat of the bla rtsa is used as a temporal framework to prognosticate the life-span. Even mdangs mchog, which is of Āyurvedic origin and marks the radiant complexion of a healthy person, is linked by amchis to the movement of bla on the basis of their common characteristics of vitality, despite it being an integral part of a different set of anatomical and physiological conceptual structures. I argued that this coupling of life-forces into the same temporal framework, which is not necessarily explained in medical texts, can be understood as a practice of temporalisation, which Tibetan medical practitioners themselves engage in based on their own practical experience and medical perception. I conclude from this material that such practices of temporalisation are a useful way for Tibetan doctors to pin down abstract ideas and historically unrelated concepts of vitality into spatial and temporal frameworks that they can relate to and work with in an attempt to strengthen a person's well-being and achieve longevity.

From the ethnographic examples it emerges that there is a difference between the medical, astrological, and popular understanding of bla. We need to be cautious not to conflate them into one single concept of bla, but carefully contextualise any further analysis. Even though I sketched some possible historical links to related Chinese and Indian material, the historical developments from Indian or Chinese contexts, and the ways in which various notions of bla were introduced into the different Tibetan knowledge systems, still remain unclear and open to further research.

With regard to the life-span pulse diagnosis (bla rtsa), I asked how temporal patterns guide notions of Tibetan life-span prognostics. The technique of the bla rtsa correlates the rhythm of the pulse beat to years of life; irregularities in the pulse beat are translated into ill health, obstacles, or chances of dying. I showed that feeling the bla rtsa is both diagnostic and divinatory, requiring the interface of doctor, patient, and the act of touch with an intended focus in a set temporal framework. From exploring temporality in these different contexts, one could single out an emphasis on 'what kind of time' (qualitative, quantitative, circular, linear, etc.) is emphasised in the different contexts, similar to previous anthropological approaches, mentioned in chapter 1.6.

With the aim of enlarging the lens of time beyond some of these temporal dichotomies, I suggest that through the theoretical concept of practices of temporalisation it is possible to come to a deeper understanding of the actual processes of how people use ideological and cosmological frameworks to bring temporal characteristics of medical ideas involving 
vitality to the forefront. Tibetan physicians can make more sense of concepts of life-forces that are difficult to assess - such as bla and mdangs mchog - by linking them to each other and to temporal frameworks they can relate to and that are more easily observable (for example, the moon cycle, the calendar, or the pulse beat). Consequently, medical practitioners empower themselves and their patients to be active agents in the process of strengthening the life-forces, counteracting negative predictions of the life-span, and obviating any obstacles that could potentially cut it short.

In part IV of the book, I sketched ethnographically how Tibetans often seek assistance from astrological calculations and divinations regarding their life-span and obstacles to it. This includes questions whether the lifeforce is exhausted, whether a death is 'timely' or 'untimely,' or whether a 'remaining life-span' will be completed in another lifetime. My discussions on divinations and calculations showed that lamas and diviners have a major influence on people's understanding of the life-span and the ritual activities surrounding it. Here, again, I suggest that it is anthropologically relevant to look at practices of temporalisation in order to understand situational agency of professionals, who often mediate between the existing temporal frameworks and the people who ask for guidance.

For example, in chapter 7.1, I discussed the 'timely' death of Samden (Mumford 1989). From Mumford's material I extracted three main points: first, 'timeliness' as an attribute of death is skilfully employed to place tshe into a temporal framework that extends across lifetimes; second, the 'interpretation of timeliness' is given a important role in the death calculation; and third, the person who performs and interprets the calculations has power and agency over the social interpretation and activities surrounding the death. Calculations were done carefully and taken seriously, but the situational agency of the lama-cum-astrologer was the essential and powerful factor in bridging the gap between the multilayered calculations and the tragic social situation the people found themselves in.

At the beginning of the book, I pointed out recent anthropological approaches of time that focus on "the embodied practices by which people do time," which in Mills' case means the ways in which people use the calendars and "thereby integrate themselves into wider ideologically structured communities" (Mills 2005: 350, 360). With the various examples of practices of temporalisation I expanded this approach to time in order to show how gaps are bridged between individual realities and temporal frameworks in various existing knowledge systems. I argued, for example, that the ways people use astrological time-markers can be understood as practices of temporalisation, in which cosmological ideas are utilised to 
map out auspicious and inauspicious days and years. These can be used situationally to increase the efficacy of medical treatment or to avoid chances of an 'untimely death' during an 'obstacle year.'

When it comes to life-span predictions, their accuracy is highly questionable and the result often 'wrong,' but it is rarely questioned in terms of the system being 'wrong.' The important point here is that we do not need to think of these ways of Tibetan life-span calculation and divination as lacking logic or following erroneous methods. They constitute a mechanism that is vital for keeping the entire system in operation.

In chapter 1.6, I mentioned earlier studies that discussed 'errors' involved in Tibetan calendar calculation (Henning 2007, Hobbs 2006). We need to be clear that we are dealing with two types of errors here. On the one hand, Tibetan calendars have 'errors' because of differences between empirical astronomical observation and mathematical calculations (for example, Henning 2007: chapter 6; see also Yamaguchi 1992: 873-895). On the other hand, astrological calculations or divinations of the life-span turn out to be 'inaccurate' because, for instance, people die at times other than those predicted. It is this second type of error which is significant for my argument. Why has this apparent lack of accuracy not led to a discontinuation of these practices among Tibetans in the Darjeeling Hills? Since accuracy does not seem to be the point in question, perhaps something else is.

Others have resorted to Buddhist doctrine to explain how inaccuracies are tolerated by Tibetans themselves (Berzin 1996 and Hobbs 2006). My fieldwork nevertheless offers another interpretation. While Buddhist ideas of 'voidness' ${ }^{1}$ and of the "Two Truths' ${ }^{2}$ might be quoted in professional Tibetan astrological circles, I doubt that they would be given as a reason for inaccuracies in life-span calculations by lay Tibetans. The example of the illiterate Tibetan female diviner Momola in chapter 8.1 shows that Tibetans can take the predictions at face-value and then validate the effectiveness of longevity practices when people exceed the predicted age. This example hints at an important conclusion.

\footnotetext{
${ }^{1}$ Berzin describes inaccuracies as being helpful to understand that life is not solid and fixed but void of inherent existence, alluding to ideas of samsāra and emptiness (Berzin 1996).

${ }^{2}$ Hobbs argues that "within the Tibetan Buddhist doctrine of the Two Truths, the fact that Tibetan calendars might be empirically 'wrong' simply becomes an 'appearance' and only 'conventional truth"' (Hobbs 2006: 49). Her M.Phil. thesis was based on textual analysis and did not involve ethnographic fieldwork, so further fieldwork might prove her point.
} 
I argue that divinations and calculations of the life-span, even though they might be empirically 'wrong' from a western 'logical' point of view, continue to be practised because they fulfil other needs. Tibetans with their intrinsic desire for a 'good life' (Lichter and Epstein 1983) utilise knowledge systems such as astrology and divination to obtain solutions to life's difficulties and when they believe that they have been struck by obstacles (bar chad). If the various calculations and divinations of the life-forces and the life-span that we have come across in this book were not coupled with detailed instructions on how to counteract negative results, they would be of no use to the people. What makes the predictions valuable for Tibetans is the entire package that they are presented with: Momola's ritual and dharma instructions, the Palden Lhamo mo lists of things to do, Dr. Pema Dorje's advice on longevity practices, or the various practices to counteract weaknesses in the five factors. People want solutions to their problems, preferably even before they occur. In that process, the actual life-span is not as important as the instructions on how to eliminate bar chad, strengthen tshe, bla, srog, rlung rta or the other astrological factors.

Individual and communal needs supersede possible 'errors' and have the power to link the client and the professional lama, astrologer, diviner, or amchi to a larger picture of social practices involving rituals and healthseeking behaviour in an environment which has multiple treatment schemes to offer and in which Tibetans feel it is often difficult to make decisions without guidance.

Part V (chapters 9 and 10) of the book focused on life-prolonging Tibetan Buddhist Vajrayāna rituals, specifically popular long-life empowerments (tshe dbang). These empowerments themselves are used as time-markers to add auspiciousness to events. This usually happens by scheduling a tshe dbang at the end of other ritual events. I want to stress here that tshe dbang become part of a larger temporal framework that sets other events in time and also enhance them with certain qualities, of which auspiciousness is an essential one. In chapter 1.6, I gave the example of the Tibetan New Year celebrations, which show that auspiciousness can link temporal ideas also to political power (Schaeffer 2006).

It would be limiting to focus only on a certain aspect of temporality within longevity rituals, in the manner of previous studies that distinguished 'practical, durational' from 'ritual, non-durational' time (for example, Bloch 1977; see chapter 1.6). Within the multi-layered perspectives of ritual participants, 'practical' and 'ritual' time merge into each other and neither can claim exclusivity. There is also no need to demarcate too 
strongly the differences between these concepts of time, since they are intertwined in different ways for the various participants.

Tibetans in the Darjeeling Hills have utilised longevity rituals to fulfil their contemporary needs without changing the content of the conservative ritual structure or questioning its hierarchical elements. In fact, the hierarchical elements - which themselves lead to the lack of direct verbal communication between the lamas and the ritual participants - make this possible. I showed in the ethnographic account of the Sakya tshe dbang how people themselves transform a tshe dbang into a meaningful ritual by filling the open spaces within the hierarchical structures with their own beliefs of life-extension, accident prevention, and disease protection.

Tshe dbang should be recognised for the temporal significance they hold for the communities. This includes the various beliefs of the participants concerning their own life-span extension, which are part of the larger social settings where the ritual itself is used as an auspicious timemarker and helps support wider community agendas (for example, the strengthening of a Buddhist minority in a Christian-dominated town as during the tshe dbang in Pedong, or the inauguration of the new community centre in Ghum, both mentioned in chapter 9).

Tshe dbang bring together large crowds for the duration of the ritual. The phenomenon of the crowd in relation to receiving the 'blessing' (byin rlabs) of longevity is quite significant. Ramble pointingly charactersises crowds:

The evanescence of crowds scarcely entitles them to qualify as institutions. They are, nevertheless, collective manifestations that have an effect on their component individuals; and even though they may persist for only short periods the recurrence of recognisable varieties of crowd suggests that they are a phenomenon to be taken more seriously than is usually the case in the study of any community (Ramble 2008: 10).

The queuing, pushing, and competing for byin rlabs tend to dominate the external scenes of a tshe dbang event, and make the ritual objects that carry byin rlabs take on more importance than visualisation or internal meditative practice. I argued that the ritual objects here are not only ritual symbols that pertain to textual Buddhist interpretations, but are also active agents in the process of how the various participants of a tshe dbang or tshe sgrub interpret byin rlabs and link it to their own ideas of life-span extension. The crowd tends to intensify the emotional component of a tshe dbang. The feeling of "I got tshe dbang" (tshe dbang thob song) is known to organisers, who use it to promote their own agendas. 
This personal satisfaction of having received a tshe dbang also contributes to the enduring popularity of tshe dbang rituals.

In chapter 9, I analysed the notion of byin rlabs, which, I argue, is fundamental to the transmission of the long-life empowerments. Byin rlabs is a central component of the communication between the lamas and lay Tibetans, who, during the event, appear as hierarchically-structured segregated groups of people. As part of the ritual process lay Tibetans fill ritual spaces that they cannot relate to textually with individual beliefs; byin rlabs plays a significant role in this. For example, people in the crowd felt they received the benefits of the ritual, which they could not understand otherwise, through the byin rlabs. Even the well-educated interpreter of the lama's speech during the tshe dbang in Ghum felt he could accomplish this difficult task only through the byin rlabs of the lama.

My discussions here highlight the perspectives of lay Tibetans in ritual, which have received less emphasis in Tibetan Buddhist studies. I conclude from my data that people's experiences of a tshe dbang do not necessarily correspond to the 'inner work' prescribed and performed by the lama performing the ritual or the few trained Buddhist practitioners attending the ritual, a point worth recognising in the anthropology of Tibetan Buddhist rituals. Tshe dbang remain popular because the structure of the ritual allows and accommodates people's contemporary needs, which can vary widely, but are essentially centred on the prevention of an 'untimely death' and the prolongation of the life-span.

Direct communication between the lama and the crowd is focused on the transmission of byin rlabs. This creates space for personal devotion and interpretation of the efficacy of a tshe dbang, which are believed to make possible the extension of the life-span by several years. This space for personal interpretation seems to be a crucial point for the popularity of tshe dbang. If tshe dbang did not have the flexibility to accommodate ritual meanings that the crowds can engage in with their contemporary concerns, these rituals would probably lose popularity in a short period of time. The collective partaking in the 'auspiciousness' that a tshe dbang represents and which empowers this ritual itself to make other events more auspicious, embraces wider social concerns. Organisers, lamas, and indeed whole communities have certainly taken advantage of these features of tshe dbang for their own agendas.

To conclude, this book has brought together many different aspects of Tibetan life that at first appear to arise in quite separate contexts. I have no doubt that the material presented could have been analysed 
from other anthropological vantage points, for example, in terms of the anthropology of ritual (chapters 9 and 10), or with a more detailed focus on divination (chapter 8), astrology (chapters 6 and 7), or Tibetan medical practice (chapters 4 and 5). My aim, however, has been to trace the central issue of longevity in these various knowledge systems, examining their interconnections and their relationships with the life-forces.

It was a challenge to contextualise this vastly heterogeneous Tibetan material on longevity that appears across Tibetan societies in popular knowledge as well as in sophisticated and extensive bodies of literature. The anthropology of time provided a unifying concern - that of temporality in longevity - which I have worked out in disparate contexts that reveal underlying common patterns of temporal frameworks and which illustrate what I have referred to throughout the book as practices of temporalisation. In focusing on the interrelationships between situational agency, temporal frameworks, and practices of temporalisation, I offer an anthropological approach to explore the tensions between existing knowledge systems and how professionals and lay people selectively utilise temporal frameworks to negotiate their life-spans.

While this approach recognises certain temporal attributes (cyclical, linear, durational, etc.), it is not limited to them. Rather, it allows a broader ethnographic gaze on the diverse practices through which life-forces are being protected, 'untimely deaths' avoided, and the life-span extended. By taking this approach, I hope that this book has made visible the central place longevity holds in Tibetan societies, with its links to 'blessing,' merit, karma, auspiciousness, and 'obstacles,' and has shown its pervasiveness in the lives of Tibetans in the Darjeeling Hills. 
Barbara Gerke - 978-90-04-21748-5 Downloaded from Brill.com๑4/26/2023 $\odot 2: 47: 13 \mathrm{PM}$ via free access 
APPENDICES

Barbara Gerke - 978-90-04-21748-5 Downloaded from Brill.com@4/26/2023 ०2:47:13PM via free access 
Barbara Gerke - 978-90-04-21748-5 Downloaded from Brill.com๑4/26/2023 $\odot 2: 47: 13 \mathrm{PM}$ via free access 


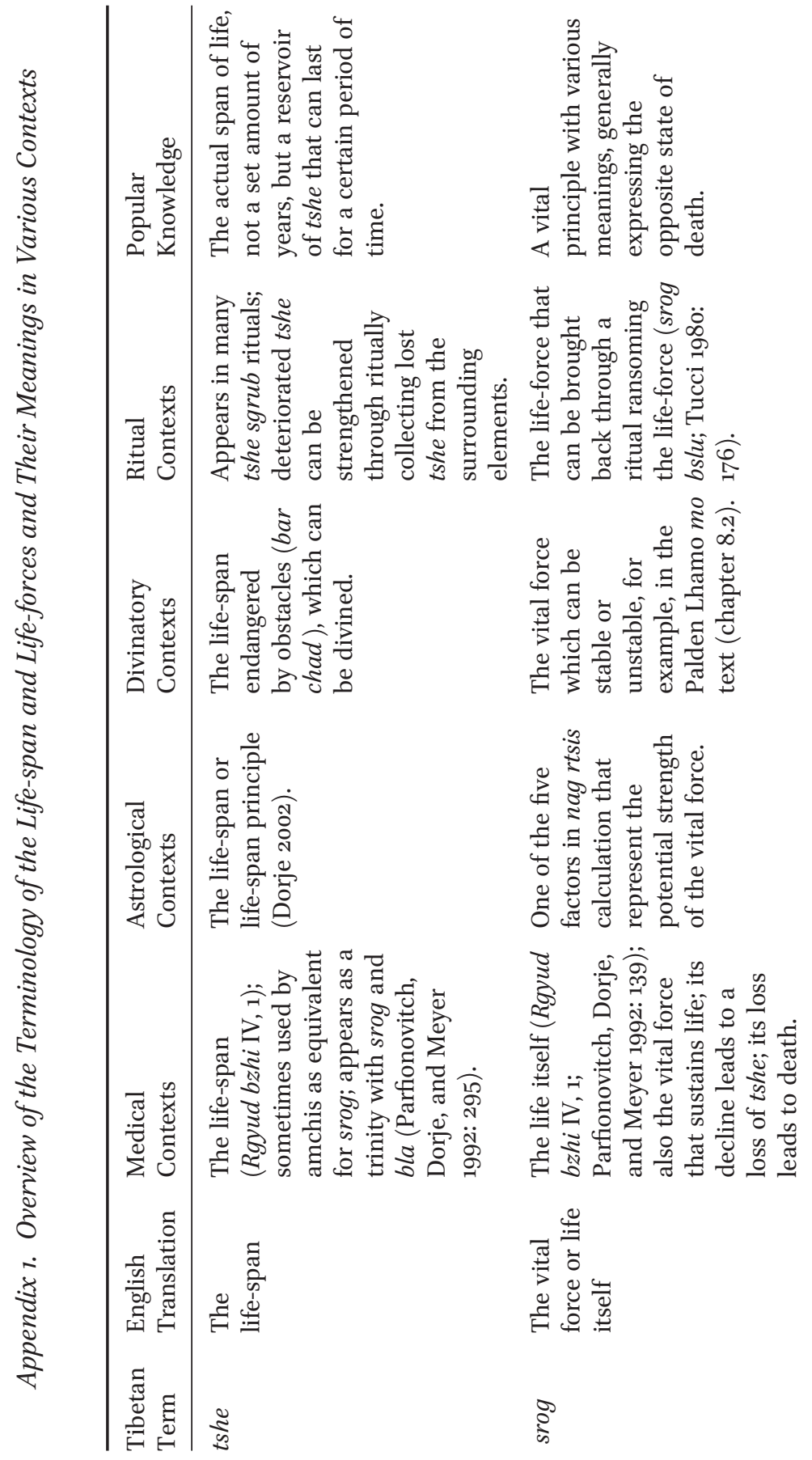




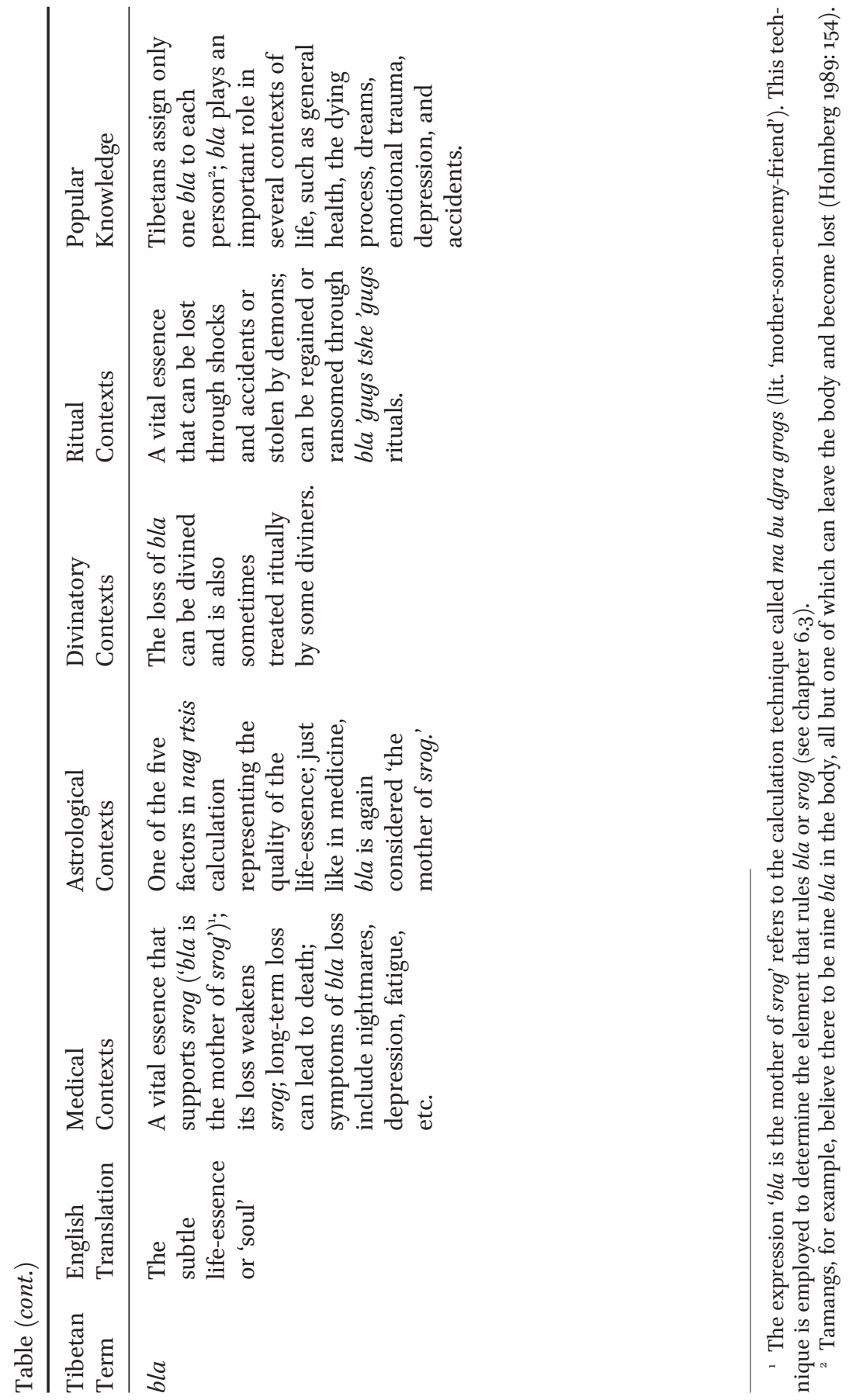




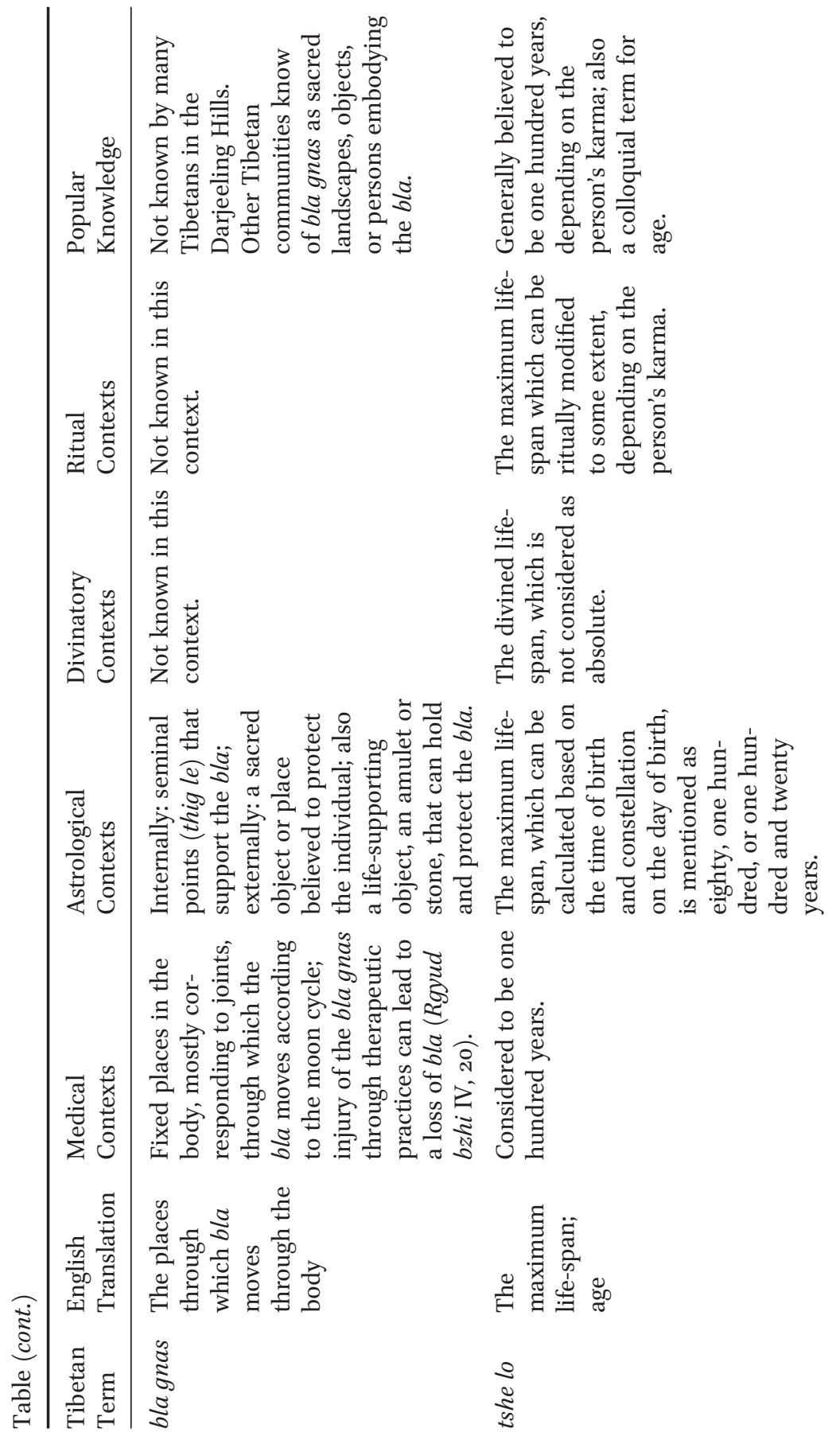




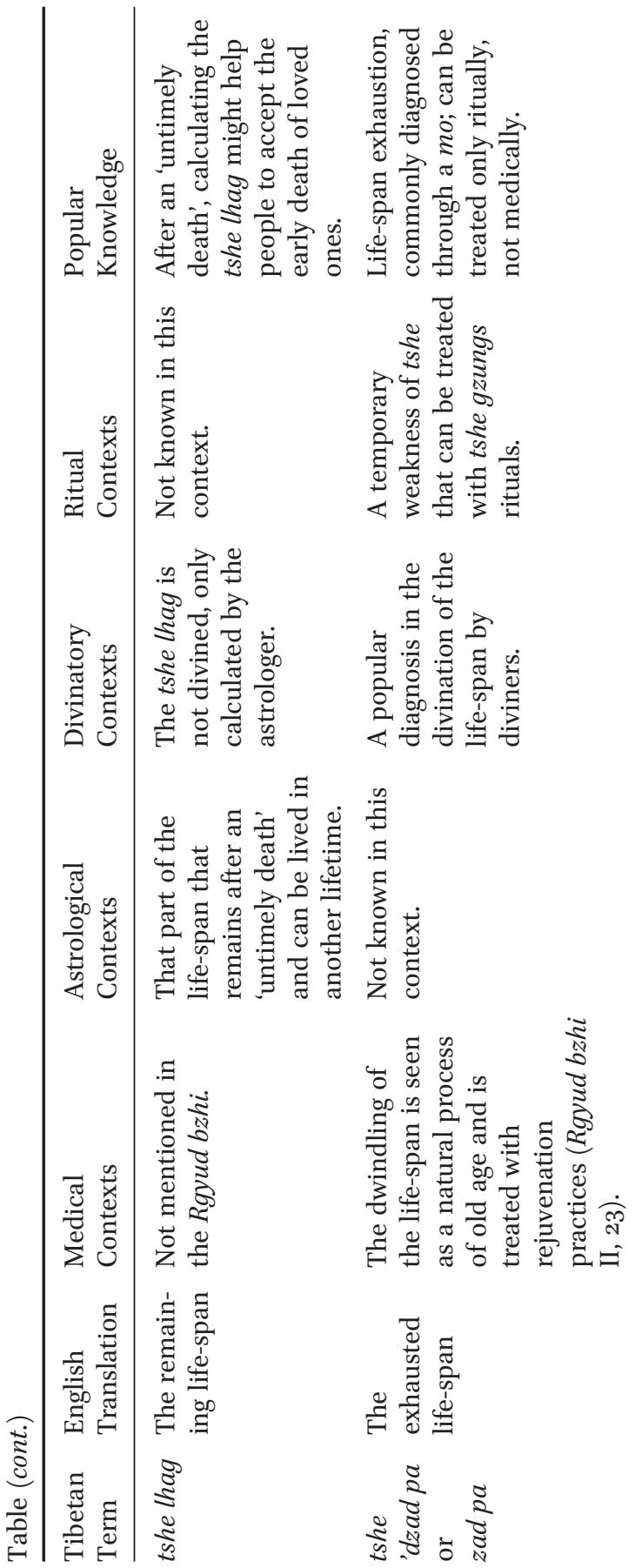




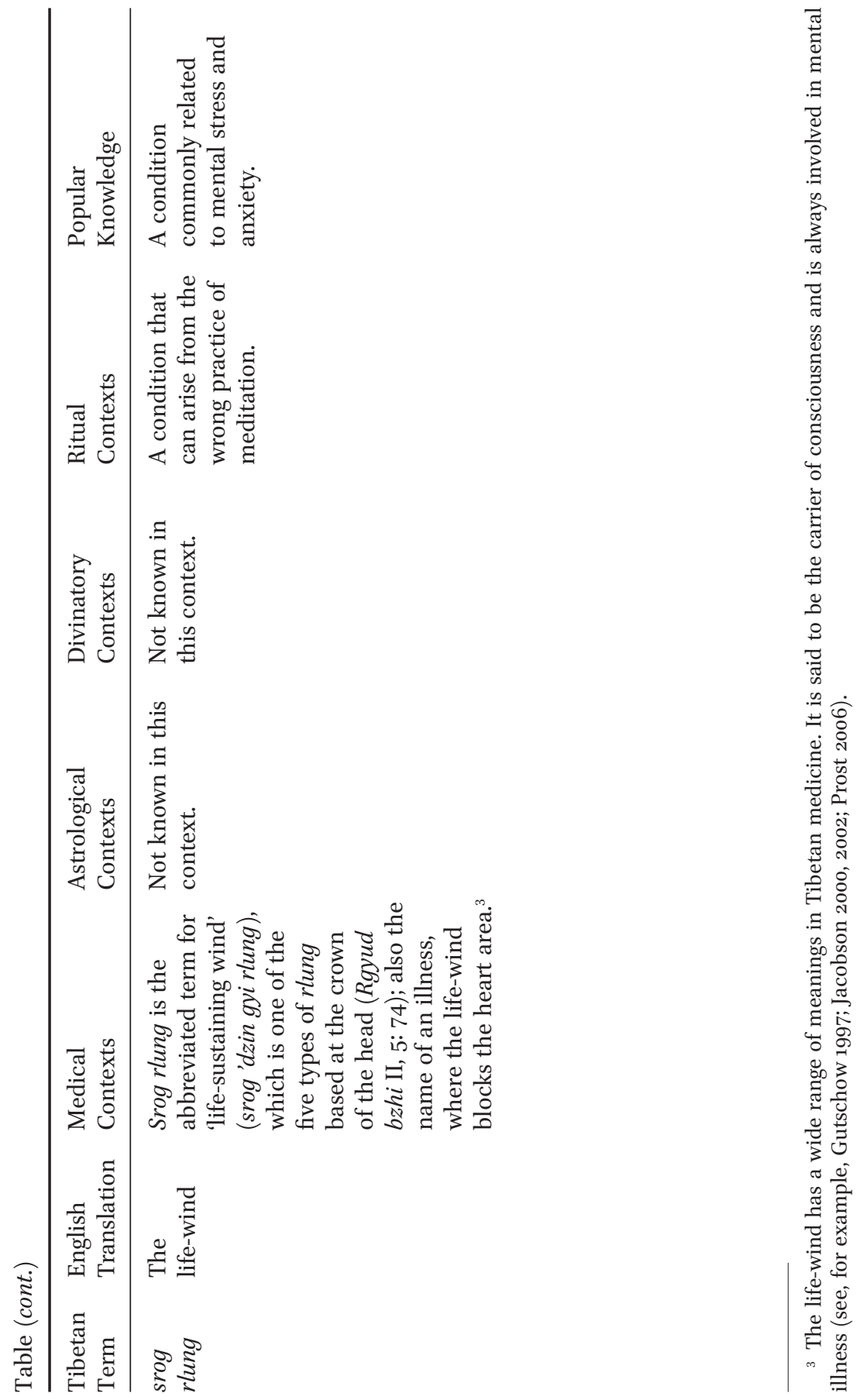




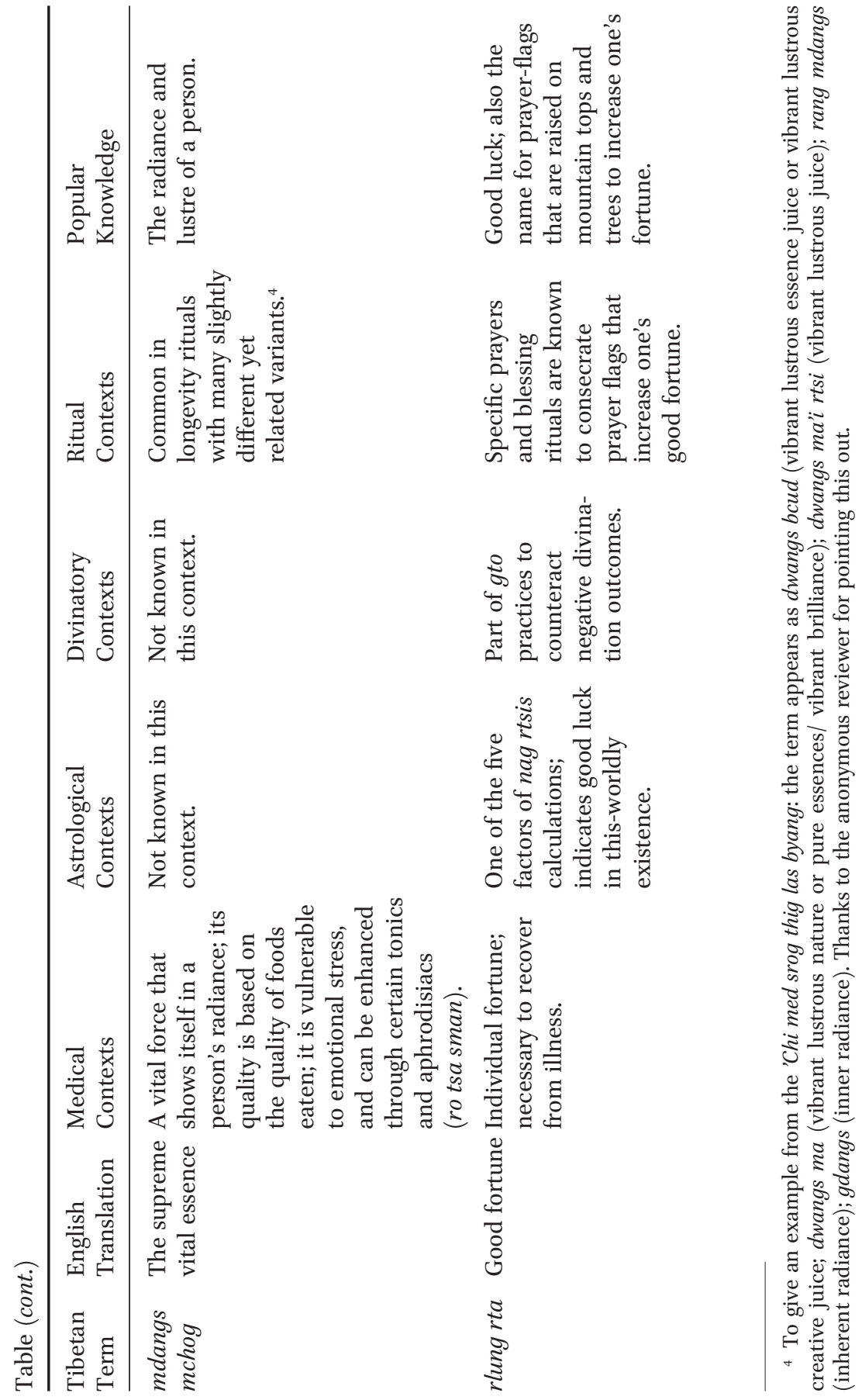




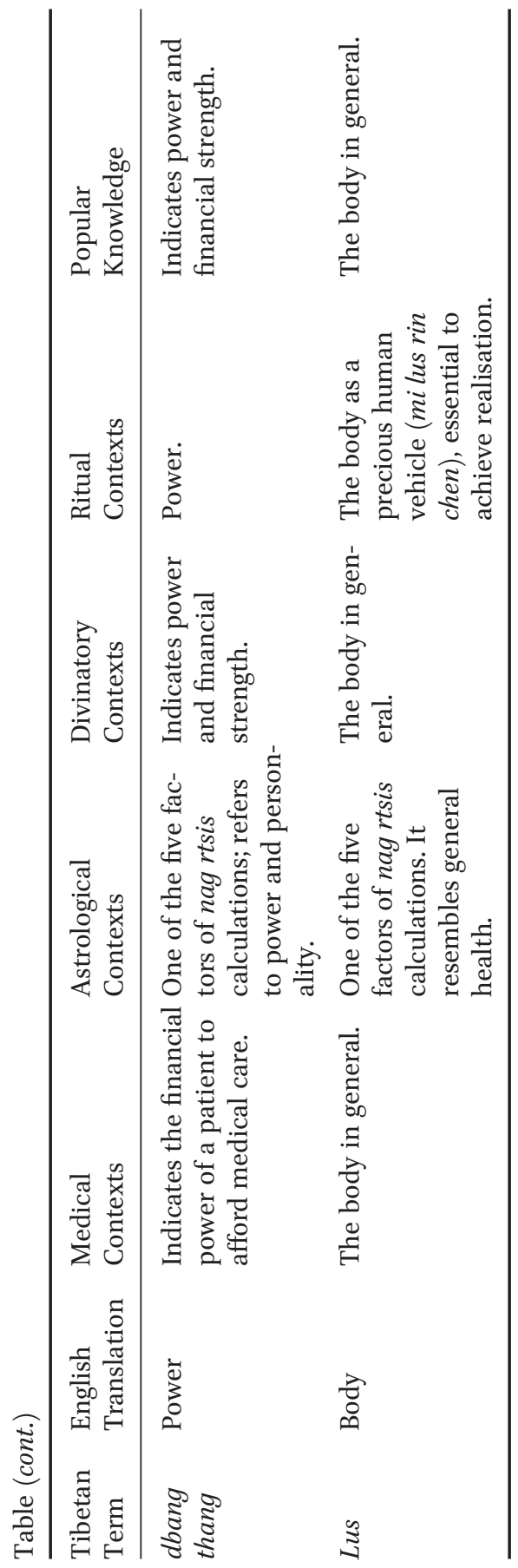


Appendix 2. List of Monasteries Mentioned in the Book

\begin{tabular}{|c|c|}
\hline $\begin{array}{l}\text { Local, Tibetan and Popular } \\
\text { Names }\end{array}$ & Location and Buddhist School \\
\hline \multicolumn{2}{|l|}{ In Kalimpong } \\
\hline $\begin{array}{l}\text { Durpin Gompa, Zangdok } \\
\text { Palri Phodang Tsenpo }\end{array}$ & $\begin{array}{l}\text { The Nyingma monastery (Dudjom gter gsar } \\
\text { tradition) on the top of Durpin Hill, built in } \\
1975 \text {. }\end{array}$ \\
\hline $\begin{array}{l}\text { Jangsa Gompa, Tongsa } \\
\text { Gompa, Jangsa Dechen } \\
\text { Chöling, 'Bhutanese Gompa' }\end{array}$ & $\begin{array}{l}\text { The oldest monastery in Kalimpong, first } \\
\text { consecrated in } 168 \text {, located near the Tenth } \\
\text { Mile area. Originally Drukpa Kagyü, now also } \\
\text { follows the Dudjom gter gsar tradition of the } \\
\text { Nyingma School. }\end{array}$ \\
\hline Mani Lhakhang & $\begin{array}{l}\text { The Geluk temple-cum-community hall in the } \\
\text { centre of Kalimpong, built in the 1970s. }\end{array}$ \\
\hline Segyu Gyumed Datsan & $\begin{array}{l}\text { The Geluk Tantric College in 11th Mile, } \\
\text { renovated in } 1997 .\end{array}$ \\
\hline $\begin{array}{l}\text { Tirpai Gompa, Tharpa } \\
\text { Chöling }\end{array}$ & $\begin{array}{l}\text { The Geluk monastery on Tirpai Hill, built in } \\
\text { 1937. }\end{array}$ \\
\hline \multicolumn{2}{|l|}{ In Pedong } \\
\hline Sikkim Gompa & $\begin{array}{l}\text { The Nyingma gompa of the Sikkim } \\
\text { Buddhist community in Pedong, near } \\
\text { Kalimpong, built in } 1932 \text {. }\end{array}$ \\
\hline \multicolumn{2}{|l|}{ In Darjeeling } \\
\hline $\begin{array}{l}\text { Dali Gompa, Thupten } \\
\text { Sangngag Chöling } \\
\text { Sakya Guru Gompa }\end{array}$ & $\begin{array}{l}\text { The largest monastery in Darjeeling, following } \\
\text { the Drukpa Kagyü School, built in } 1971 . \\
\text { The Sakya monastery in Ghum, near } \\
\text { Darjeeling, built in } 1915 .\end{array}$ \\
\hline $\begin{array}{l}\text { Yolmo Gompa, Makdhog } \\
\text { Monastery }\end{array}$ & $\begin{array}{l}\text { The Nyingma gompa (byang gter tradition) of } \\
\text { the Yolmo community in Aloobari, near } \\
\text { Darjeeling, built in 1914. }\end{array}$ \\
\hline
\end{tabular}




\section{Appendix 3. The Thirty Places of Bla in the Body}

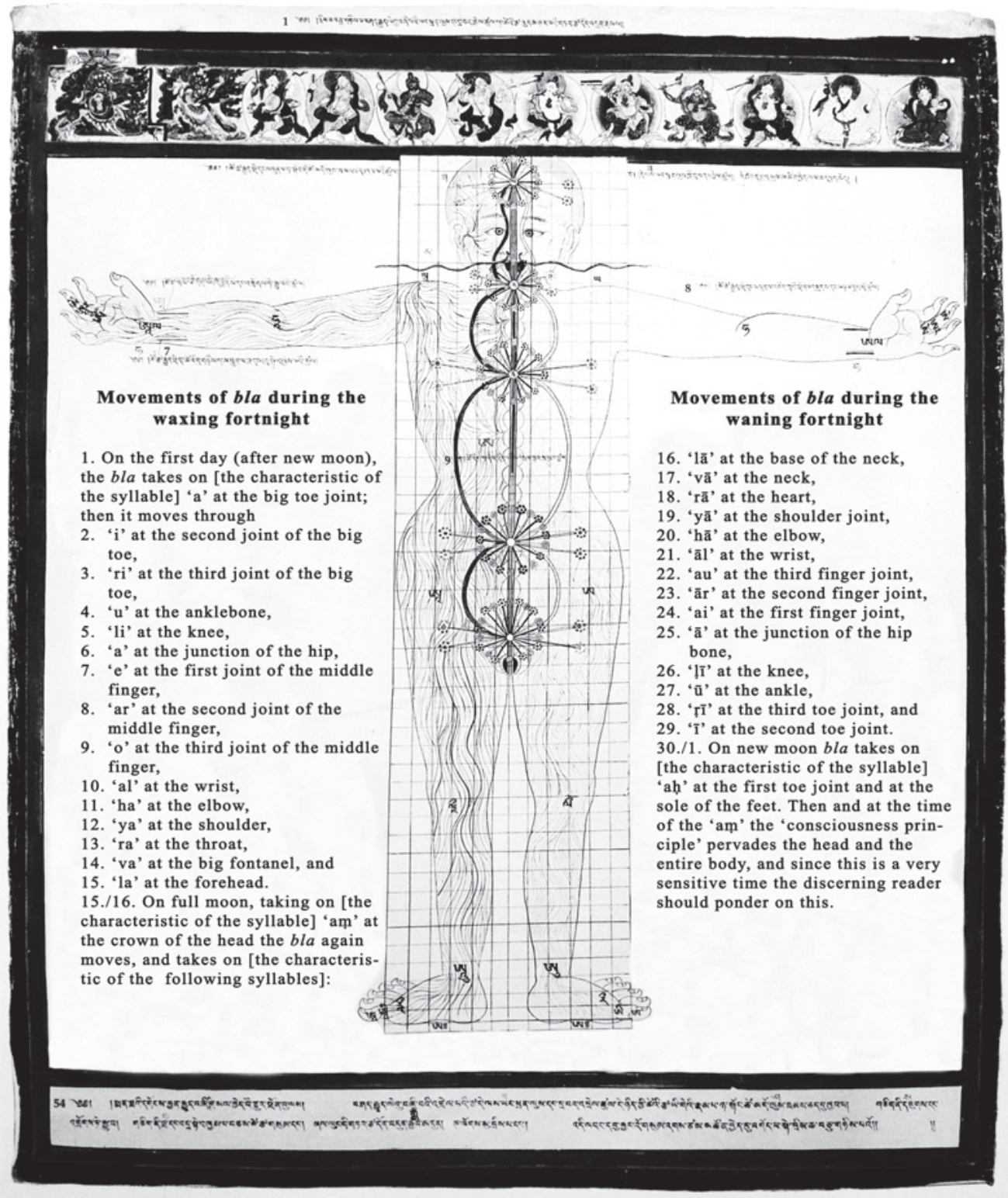

Excerpt of a medical thanka depicting the thirty bla gnas and their syllables through which bla circulates in the body (Parfionovitch, Dorje, and Meyer 1992: 39-40). I translated the list of the syllables and bla gnas from Sangye Gyatso's Baidūrya sngon po (1982: 107) and copied them into this chart. 


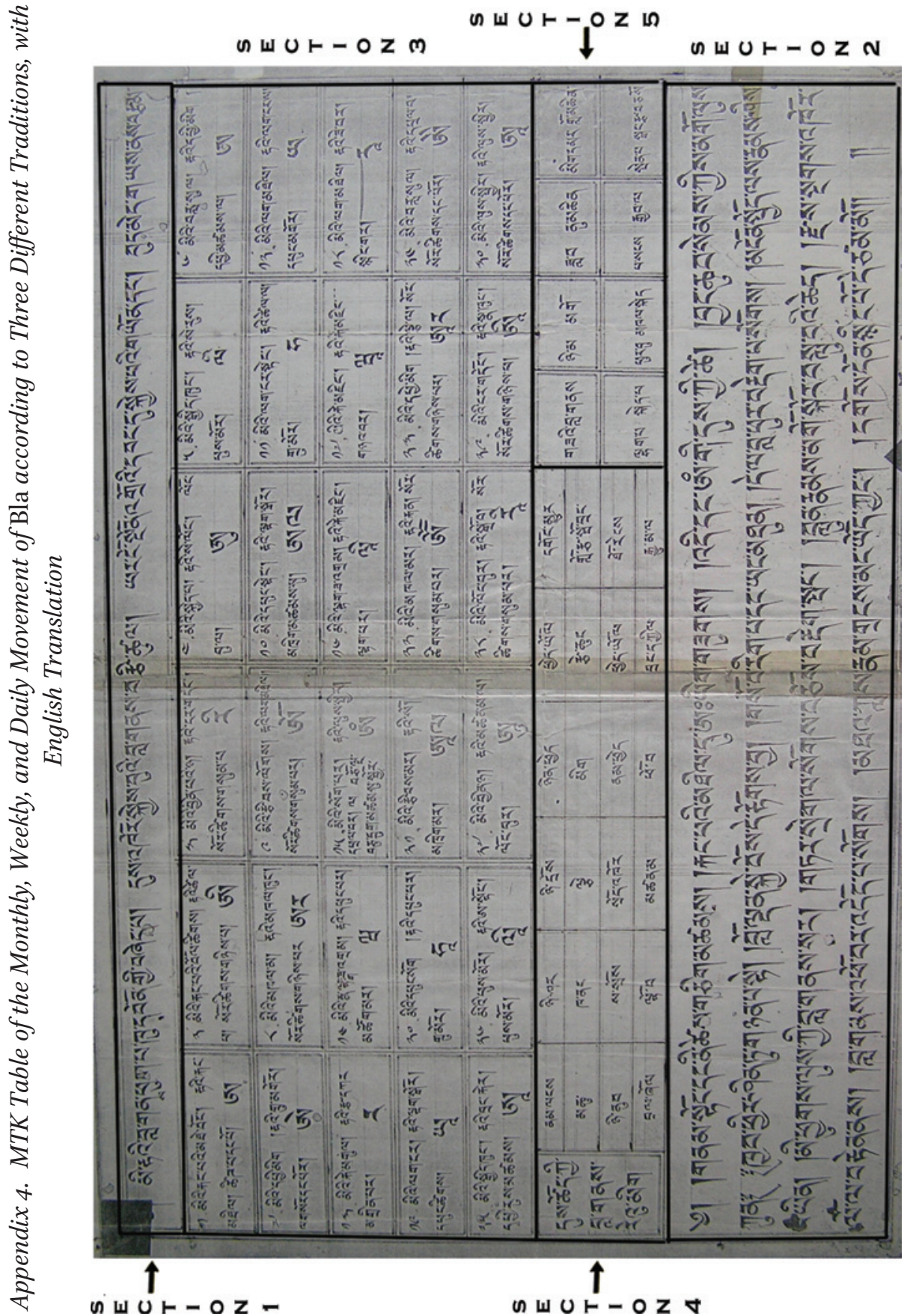




\section{Translation of Section 1: Title}

Tibetan Title:

mi rta'i bla gnas phug pa khu dbon gyi bzhed pa/ / dus 'khor skyes bu'i bla gnas brtsi tshul/ / yar ngo sngon 'gro'i dbang du skyes pa'i g.yon dang/ bud med g.yas nas brtsam

\section{Translation:}

The places of bla in humans and horses according to Phugpa Lhundrup Gyatso. ${ }^{5}$ The way of reckoning the places of bla in man [according to] the Kālacakra; under the influence of the waxing period [first fifteen days of the month including fullmoon] you should begin calculating to the left side [counterclockwise] in men and the right side [clockwise] in women.

\section{Translation of Section 2: Caption}

Tibetan Text:

gnam stong dang ni tshes gcig mtshams/ / rkang pa'i mthil du 'ah' yig gzugs/ /'di dang 'aṃ' gi dus kyi tshe/ byang chub sems kyis mgo lus kun//khyab phyir shin tu gnyan pa ste/ /blo ldan skye bos de rtogs bya/ / gso ba rig pa dang yang mthun/ / de la bla phur brdeg pa sogs//mngon spyod las rnams shis yin/ /mi phyugs lus kyi bla gnas sur/ /gtar sreg la sogs bcos brdeg spang / blun rnams mgo skor bslu ba'i ched/ /rdzas sngags 'khor lo la brten nas//bla gnas 'pho bar 'dod pa sogs/ /mtha' klas rnam grangs mang yod kyang / dgos don snying po de tsam mo/ /

\section{Translation:}

On the day before new moon [3oth day of the Tibetan lunar month] and the day after new moon [the first day of the Tibetan lunar month], [the bla] appears under the foot sole taking the characteristic (lit. 'form') of the letter 'ah.' At this time and at the time of the 'am' [on the 15th day when the bla is on the crown of the head], the 'consciousness principle' [perhaps here a synonym for bla; also a synonym for sperm in tantric practices] pervades the entire head and body. This is a very sensitive time. The intelligent person should realise this.

${ }^{5}$ In the title Phugpa Lhundrup Gyatso is called phug pa khu dbon. Khu dbon refers to his disciples (lit. 'uncle and nephew'). According to Dr. Sonam Rinchen there are two different ways of naming them: the first is Palgon Thinley as 'the uncle' ( khu bo) and Norzang Gyatso and Künga Pel as 'the nephews' (dbon po); the second is Minyak Gyeltsen Pal as 'the uncle' $(k h u b o)$ and Norzang Gyatso and Künga Pel as 'the nephews' (dbon po; Edward Henning, personal communication, December 2007). 
This is also compatible with the science of healing. This [time] is also effective to perform destructive rituals (mngon spyod) such as striking a ritual dagger or (phur ba), and so forth, into the bla. Do not strike or alter the places of bla in the body of humans and cattle through bloodletting and moxibustion. Even though there may be a limitless number of people who maintain that they can change the position of the bla through ritual objects, mantras, or circular magic diagrams (rdzas sngags 'khor $l o)^{6}$ in order to deceive foolish people, the essential issue is merely for practical purposes.

${ }^{6}$ These are particular tantric items, wheel-shaped and printed with mantras. 


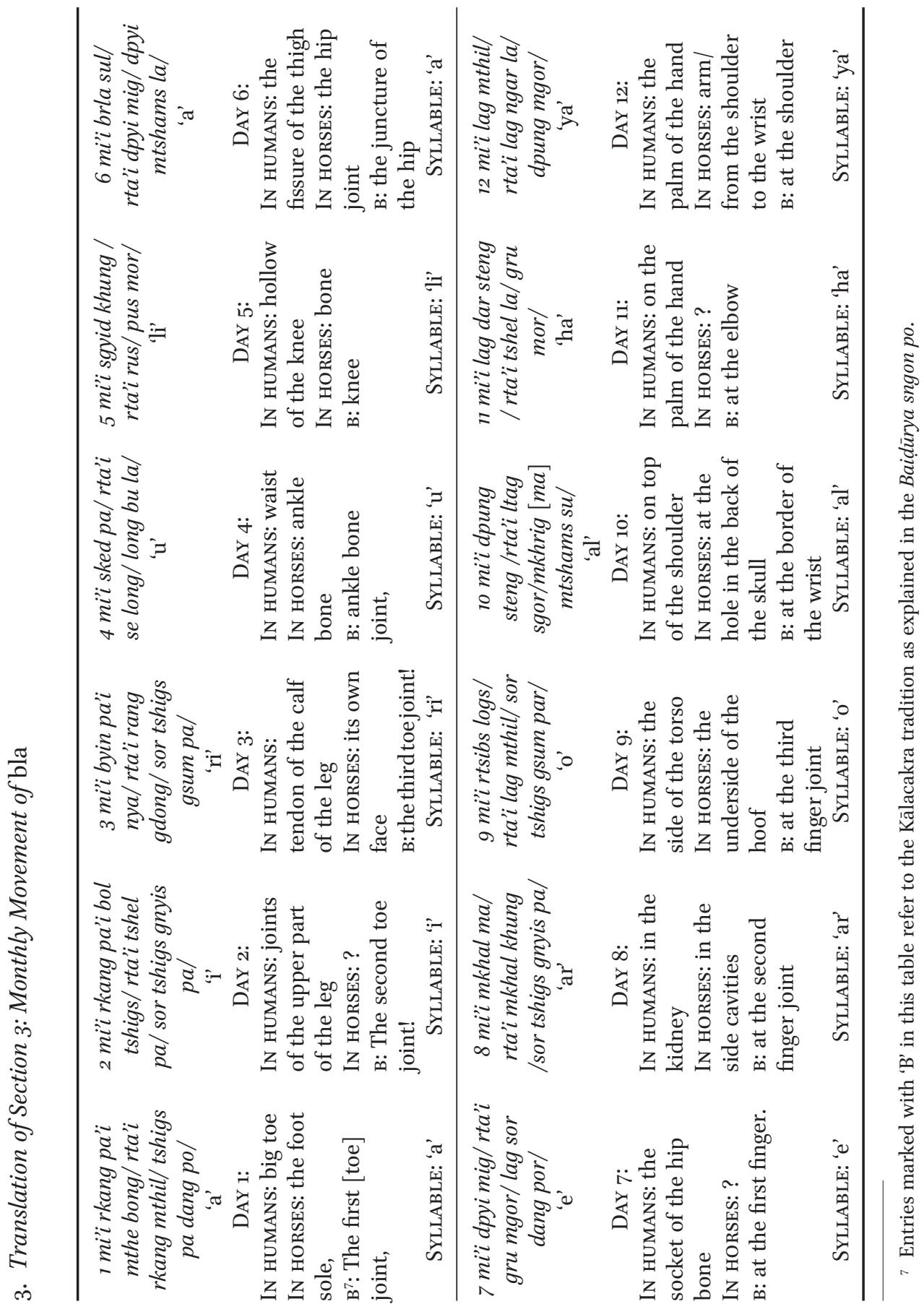




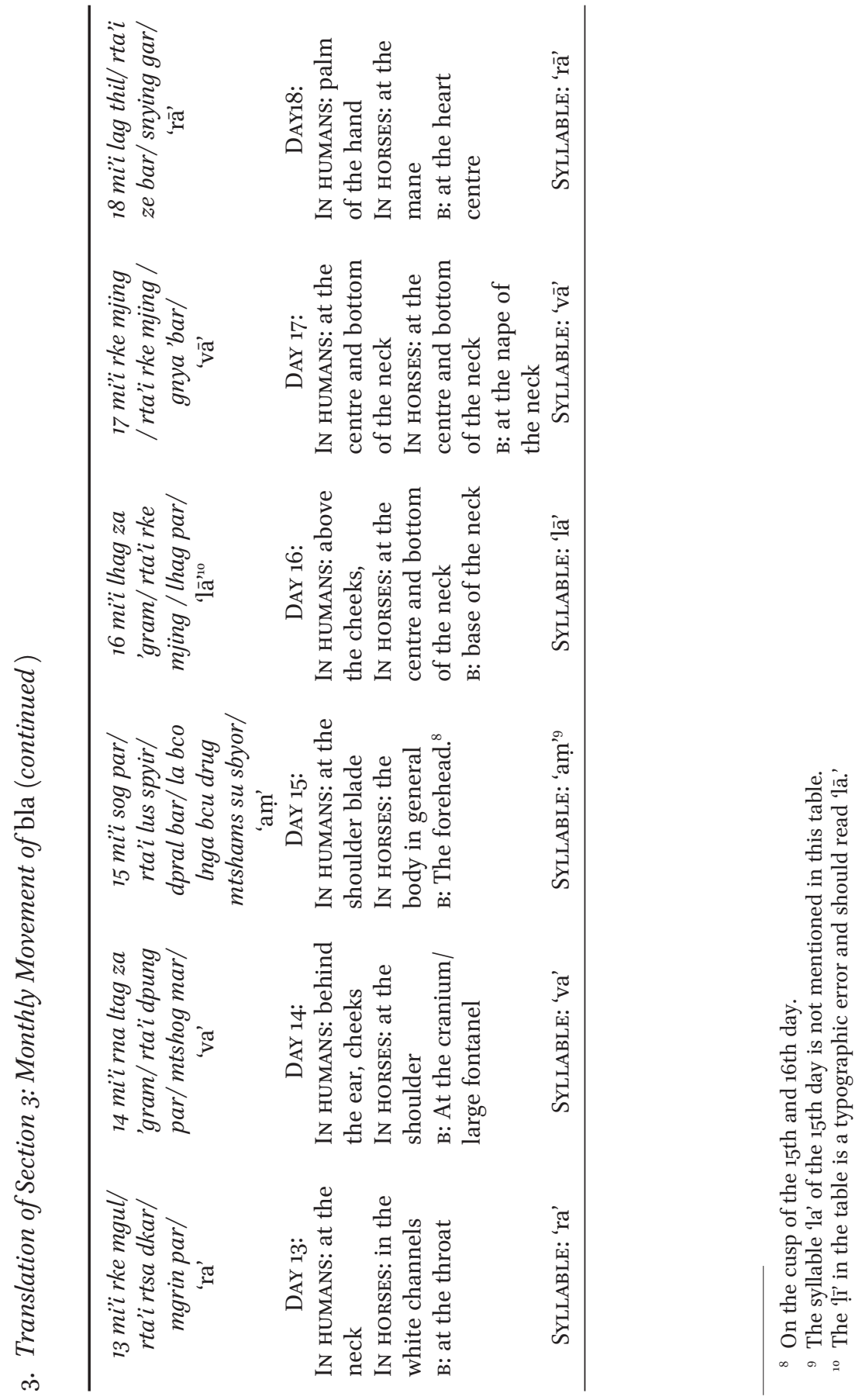




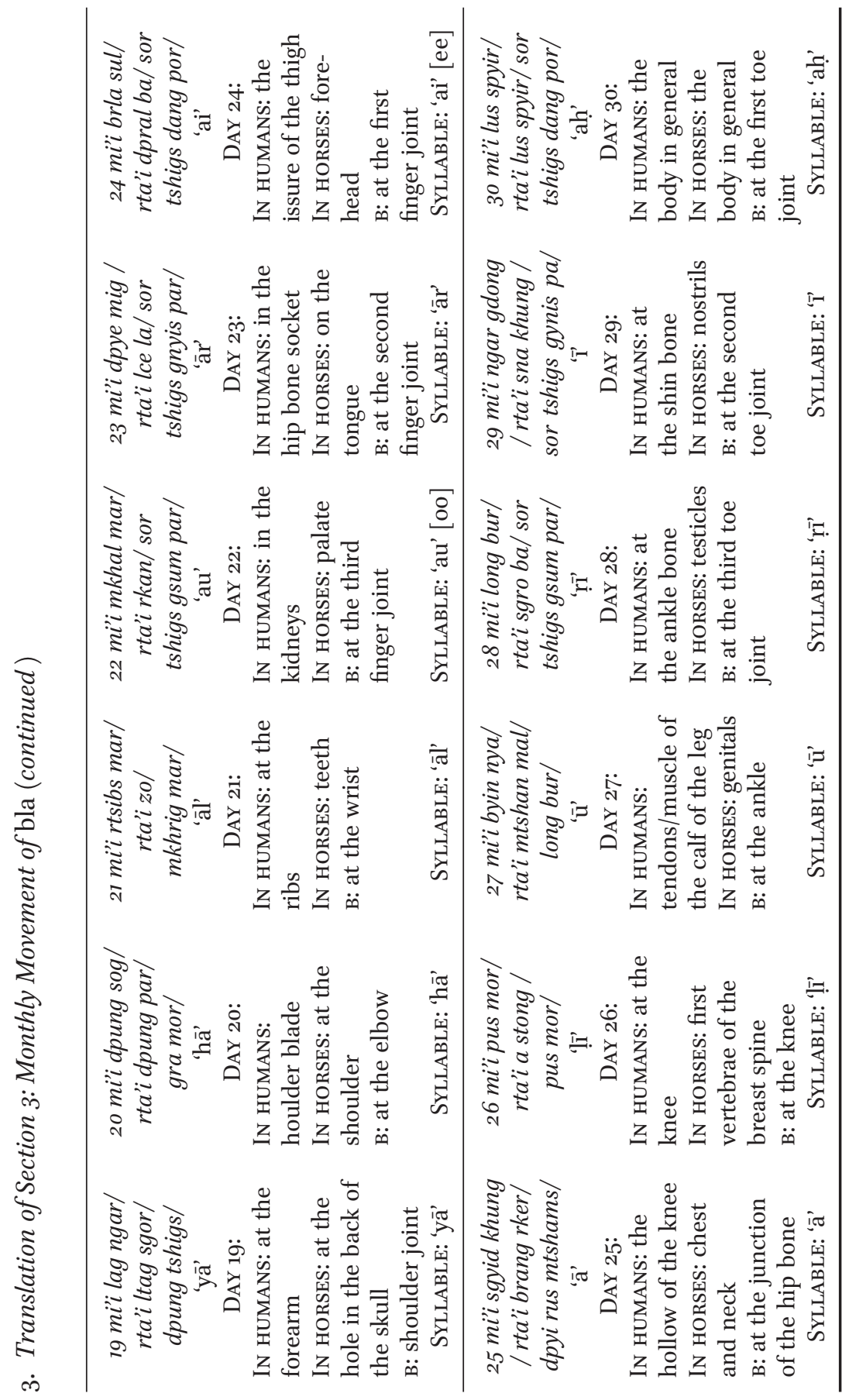




\section{Translation of Section 4: Daily Movement of bla}

A table on the [daily] places of bla and their [twelve two-hour] time periods (dus tshod kyi bla gnas re'u mig) ${ }^{11}$

\begin{tabular}{|c|c|c|c|c|c|}
\hline nam langs & nyi shar & nyi dros & nyin phyed & phyed yol ${ }^{12}$ & dgong myur \\
\hline daybreak & sunrise & mid-morning & noon & mid-noon & late \\
\hline $\begin{array}{l}\text { [time of the } \\
\text { rabbit] }\end{array}$ & $\begin{array}{l}\text { [time of the } \\
\text { dragon] }\end{array}$ & $\begin{array}{l}\text { [time of the } \\
\text { snake] }\end{array}$ & $\begin{array}{l}\text { [time of the } \\
\text { horse] }\end{array}$ & $\begin{array}{l}\text { [time of the } \\
\text { sheep] }\end{array}$ & $\begin{array}{l}\text { [time of the } \\
\text { monkey] }\end{array}$ \\
\hline 5 to 7 o'clock & 7 to 9 & 9 to 11 & 11 to 13 & 13 to 15 & 15 to 17 \\
\hline mchu & kha nang & lce & mig & rtse chung & $\begin{array}{l}\text { glo rtsa sbo } \\
\text { brang }\end{array}$ \\
\hline lips & $\begin{array}{l}\text { inside the } \\
\text { mouth }\end{array}$ & tongue & eyes & $\begin{array}{l}\text { arteries from } \\
\text { the head on } \\
\text { either side of } \\
\text { the neck }\end{array}$ & $\begin{array}{l}\text { lungs, veins, } \\
\text { upper part } \\
\text { of the belly, } \\
\text { chest, }\end{array}$ \\
\hline $\begin{array}{l}\text { nyi nub } \\
\text { sunset }\end{array}$ & $\begin{array}{l}\text { sa sros } \\
\text { twilight }\end{array}$ & $\begin{array}{l}\text { srod 'khor } \\
\text { evening }\end{array}$ & $\begin{array}{l}\text { nam phyed } \\
\text { midnight }\end{array}$ & $\begin{array}{l}\text { phyed yol } \\
\text { mid-noon } \\
\text { after mid- } \\
\text { night }\end{array}$ & $\begin{array}{l}\text { tho rengs } \\
\text { pre-dawn }\end{array}$ \\
\hline $\begin{array}{l}\text { [time of the } \\
\text { bird] }\end{array}$ & $\begin{array}{l}\text { [time of the } \\
\text { dog] }\end{array}$ & $\begin{array}{l}\text { [time of the } \\
\text { pig] }\end{array}$ & $\begin{array}{l}\text { [time of the } \\
\text { bird] }\end{array}$ & $\begin{array}{l}\text { [time of the } \\
\text { ox }]\end{array}$ & $\begin{array}{l}\text { [time of the } \\
\text { tiger] }\end{array}$ \\
\hline $17-19$ & $19-21$ & $21-23$ & $23^{-21}$ & $1-3$ & $3-5$ \\
\hline brang zhol & lto $b a$ & mtshan ma & pho ba & brang dkyil & rgyu ma la \\
\hline lower chest & belly & genitals & stomach & $\begin{array}{l}\text { pit of the } \\
\text { stomach }\end{array}$ & $\begin{array}{l}\text { inside the } \\
\text { small } \\
\text { intestines }\end{array}$ \\
\hline
\end{tabular}

${ }^{11}$ According to the Tibetan calendar one day lasts from 5 a.m. to the following day 5 a.m. (see also Henning 2007: 358-359).

${ }_{12}$ The Tibetan phyed yol appears twice and signifies that a halfway point, noon or midnight, has been passed. The close equivalent to this is the now archaic English midnoon, which indicates either afternoon or the period following midnight (Henning 2007: 358). 
5. Translation of Section 5: Weekly Movement of bla

\begin{tabular}{|c|c|c|c|}
\hline gza’i bla gnas & nyi ma mgo & zla ba nu mchin & mig dmar glo mchin \\
\hline $\begin{array}{l}\text { The places of } b l a \\
\text { on the weekdays }\end{array}$ & $\begin{array}{l}\text { Sunday: } \\
\text { head }\end{array}$ & $\begin{array}{l}\text { Monday: } \\
\text { breast } \\
\text { and liver }\end{array}$ & $\begin{array}{l}\text { Tuesday: } \\
\text { lung and liver }\end{array}$ \\
\hline lhag pa sked pa & $\begin{array}{l}\text { phur bu mkhal } \\
\text { sked }\end{array}$ & $\begin{array}{l}\text { pa sangs rgyab } \\
\text { la }\end{array}$ & $\begin{array}{l}\text { spen pa sgang rtsa } \\
\text { bcas so }\end{array}$ \\
\hline $\begin{array}{l}\text { Wednesday: } \\
\text { waist }\end{array}$ & $\begin{array}{l}\text { Thursday: } \\
\text { kidney waist area }\end{array}$ & $\begin{array}{l}\text { Friday: } \\
\text { at the back }\end{array}$ & $\begin{array}{l}\text { Saturday: } \\
\text { 'bleeding spot' } \\
\text { [name of a vessel } \\
\text { for bloodletting] }\end{array}$ \\
\hline
\end{tabular}


Barbara Gerke - 978-90-04-21748-5 Downloaded from Brill.com๑4/26/2023 $\odot 2: 47: 13 \mathrm{PM}$ via free access 


\title{
GLOSSARY OF RECURRENT TIBETAN AND SANSKRIT TERMS
}

\author{
Glossary of Recurrent Tibetan Terms (Except Proper Names)
}

\begin{tabular}{|c|c|c|}
\hline $\begin{array}{l}\text { Wylie Transliteration } \\
\text { of Tibetan Terms }\end{array}$ & $\begin{array}{l}\text { Phonetic } \\
\text { Transliteration } \\
\text { of Tibetan Terms }\end{array}$ & $\begin{array}{l}\text { English Translation or Definition of } \\
\text { Tibetan Terms }\end{array}$ \\
\hline 'brug pa bka' brgyud & Drukpa Kagyü & $\begin{array}{l}\text { a major branch within the Kagyü } \\
\text { school of Tibetan Buddhism }\end{array}$ \\
\hline 'byung ba & jungwa & $\begin{array}{l}\text { element, mostly referring to the five } \\
\text { elements }\end{array}$ \\
\hline 'byung ba lnga & jungwa nga & $\begin{array}{l}\text { five elements: earth, water, fire, } \\
\text { wind, and space }\end{array}$ \\
\hline 'byung rtsis & jungtsi & $\begin{array}{l}\text { ‘elemental calculation,' also known } \\
\text { as 'Chinese divination' or nag } \\
\text { rtsis }\end{array}$ \\
\hline 'cham & cham & ritual mask dance \\
\hline 'chi ltas & chitä & signs of death, death omens \\
\hline 'chi med & chime & deathlessness \\
\hline 'chi med srog thig & chime sogtik & $\begin{array}{l}\text { 'Life drop of deathlessness,' name } \\
\text { of a longevity practice of the } \\
\text { Nyingma tradition of Dudjom } \\
\text { Rinpoche }\end{array}$ \\
\hline $\begin{array}{l}\text { 'chi med tshe yi dngos } \\
\text { grub }\end{array}$ & $\begin{array}{l}\text { chime tseyi } \\
\text { ngödrup }\end{array}$ & $\begin{array}{l}\text { the siddhi of longevity and } \\
\text { immortality }\end{array}$ \\
\hline 'khyams pa & khyampa & $\begin{array}{l}\text { 'wandering,' a term used to } \\
\text { describe the bla when lost; also } \\
\text { vagrants that wander around } \\
\text { without any fixed seasonal abode }\end{array}$ \\
\hline 'pho ba lung & powa lung & $\begin{array}{l}\text { name of an empowerment and a } \\
\text { practice regarding the transfer- } \\
\text { ence of consciousness at death } \\
\text { to a higher realm of existence }\end{array}$ \\
\hline 'phreng ba & trenga & rosary \\
\hline am chi & amchi & Mongolian-derived word for a \\
\hline or & or & Tibetan medical practitioner, \\
\hline em chi & emchi & $\begin{array}{l}\text { widely used across the Himala- } \\
\text { yas }\end{array}$ \\
\hline bad kan & bekan & $\begin{array}{l}\text { one of the three nyes pa, often } \\
\text { translated as 'phlegm' }\end{array}$ \\
\hline $\begin{array}{l}\text { Baidūrya dkar po } \\
\text { or }\end{array}$ & Baidūrya karpo & $\begin{array}{l}\text { 'White Beryl,' the brief title of Desi } \\
\text { Sangye Gyatso's work on astrol- }\end{array}$ \\
\hline Baidūur dkar po & Baidūr karpo & ogy, completed in 1685 \\
\hline
\end{tabular}


Table (cont.)

\begin{tabular}{|c|c|c|}
\hline $\begin{array}{l}\text { Wylie Transliteration } \\
\text { of Tibetan Terms }\end{array}$ & $\begin{array}{l}\text { Phonetic } \\
\text { Transliteration } \\
\text { of Tibetan Terms }\end{array}$ & $\begin{array}{l}\text { English Translation or Definition of } \\
\text { Tibetan Terms }\end{array}$ \\
\hline $\begin{array}{l}\text { Baidūrya sngon po } \\
\text { or }\end{array}$ & Baidūrya ngonpo & $\begin{array}{l}\text { 'Blue Beryl,' the brief title of a } \\
\text { medical }\end{array}$ \\
\hline Baiḍūr sngon po & Baidūr ngonpo & $\begin{array}{l}\text { commentary of the Rgyud bzhi } \\
\text { by Desi Sangye Gyatso, com- } \\
\text { pleted in } 1688\end{array}$ \\
\hline bar chad & barchä & obstacle, misfortune \\
\hline bar chad lam sel & barchä lamsel & $\begin{array}{l}\text { 'Clearing the obstacles of the path,' } \\
\text { name of a prayer text }\end{array}$ \\
\hline bar do & bardo & $\begin{array}{l}\text { intermediate state (usually, } \\
\text { between death and rebirth) }\end{array}$ \\
\hline $\begin{array}{l}\text { bdud rtsi thun } \\
\quad \text { mtshams }\end{array}$ & dütsi tüntsam & $\begin{array}{l}\text { 'auspicious conjunction of time,' } \\
\text { the astrological calculated } \\
\text { 'nectar-hour' indicating a } \\
\text { favourable time for medical } \\
\text { treatment }\end{array}$ \\
\hline bka' brgyud & Kagyü & $\begin{array}{l}\text { one of the main Tibetan Buddhist } \\
\text { schools }\end{array}$ \\
\hline bla & la & $\begin{array}{l}\text { the subtle life-essence or 'soul,' also } \\
\text { one of the five factors in Tibetan } \\
\text { astrology; see appendix } 1\end{array}$ \\
\hline bla 'gugs tshe 'gugs & lakug tsekug & $\begin{array}{l}\text { name of a ritual to summon lost } \\
\text { life-forces, especially bla }\end{array}$ \\
\hline bla 'khyams pa & la khyampa & $\begin{array}{l}\text { 'wandering bla,' a term used to } \\
\text { describe the loss of bla }\end{array}$ \\
\hline bla g.yu & layu & turquoise stone \\
\hline bla gnas & lanä & $\begin{array}{l}\text { the thirty places in the body where } \\
\text { the bla moves through according } \\
\text { to the moon cycle, also sacred } \\
\text { landscapes, objects, or persons } \\
\text { embodying the bla; see appen- } \\
\text { dix } 1\end{array}$ \\
\hline bla gza' & laza & $\begin{array}{l}\text { 'life-essence day,' a favourable day } \\
\text { in the 'vitality table' }\end{array}$ \\
\hline bla ma & lama & $\begin{array}{l}\text { spiritual teacher and ritual master; } \\
\text { see Sanskrit guru }\end{array}$ \\
\hline bla rtsa & latsa & $\begin{array}{l}\text { special method of pulse analysis to } \\
\text { prognosticate the life-span }\end{array}$ \\
\hline bla tshe & latse & $\begin{array}{l}\text { a term indicating both the subtle } \\
\text { life-essence and the life-span }\end{array}$ \\
\hline bod pa & рӧра & $\begin{array}{l}\text { generally translated as 'Tibetan,' } \\
\text { but actually denotes different } \\
\text { people for different groups of } \\
\text { Tibetans }\end{array}$ \\
\hline
\end{tabular}


Table (cont.)

\begin{tabular}{|c|c|c|}
\hline $\begin{array}{l}\text { Wylie Transliteration } \\
\text { of Tibetan Terms }\end{array}$ & $\begin{array}{l}\text { Phonetic } \\
\text { Transliteration } \\
\text { of Tibetan Terms }\end{array}$ & $\begin{array}{l}\text { English Translation or Definition of } \\
\text { Tibetan Terms }\end{array}$ \\
\hline bod pa gsar pa & pöpa sarpa & $\begin{array}{l}\text { 'new Tibetans,' a local term used } \\
\text { in Darjeeling for refugees who } \\
\text { came after } 1959\end{array}$ \\
\hline bod pa rnying pa & pöpa nyingpa & $\begin{array}{l}\text { 'old Tibetans,' a local term used in } \\
\text { Darjeeling for Tibetans who set- } \\
\text { tled there before the Chinese } \\
\text { occupation of Tibet }\end{array}$ \\
\hline brtan bzhugs & tenshuk & $\begin{array}{l}\text { 'abiding with stability,' longevity } \\
\text { request ritual specifically } \\
\text { performed for a high lama }\end{array}$ \\
\hline brtan pa & tenpa & firm, stable \\
\hline bsang & sang & fumigation ritual \\
\hline bsod nams & sönam & merit \\
\hline bsod nams kyi tshogs & sönam ki tsok & $\begin{array}{l}\text { accumulation of merit through } \\
\text { virtuous actions }\end{array}$ \\
\hline btsan byol pa & tsenjolpa & refugee \\
\hline bum pa can & bumpa chen & $\begin{array}{l}\text { 'holding a vase,' a specific method } \\
\text { of holding the breath within the } \\
\text { body; see Sanskrit kumbhaka }\end{array}$ \\
\hline bya & ja & bird, one of the twelve year signs \\
\hline byang chub sems & jangchub sem & $\begin{array}{l}\text { 'consciousness principle,' } \\
\text { probably a synonym for bla; it } \\
\text { is also a synonym for sperm in } \\
\text { tantric practices; also the Bud- } \\
\text { dhist term for the compassionate } \\
\text { wish to attain enlightenment for } \\
\text { the benefit of all living beings, } \\
\text { the basic Mahāyāna motivation } \\
\text { for dharma practice; see Sanskrit } \\
\text { bodhicitta }\end{array}$ \\
\hline byin & jin & splendour, blessing \\
\hline byin rlabs & jinlab & 'blessing,' bestowing byin \\
\hline chang & chang & $\begin{array}{l}\text { beer, also used in rituals as 'nectar'; } \\
\text { see tshe chang }\end{array}$ \\
\hline chos & chö & $\begin{array}{l}\text { Buddhist teachings, see Sanskrit } \\
\text { dharma }\end{array}$ \\
\hline chu & chu & the element water \\
\hline chu ser & chuser & $\begin{array}{l}\text { 'yellow water,' often translated as } \\
\text { 'lymph,' the waste product of } \\
\text { 'blood,' which is refined in the } \\
\text { gall bladder and eventually chan- } \\
\text { neled throughout the body }\end{array}$ \\
\hline
\end{tabular}


Table (cont.)

\begin{tabular}{|c|c|c|}
\hline $\begin{array}{l}\text { Wylie Transliteration } \\
\text { of Tibetan Terms }\end{array}$ & $\begin{array}{l}\text { Phonetic } \\
\text { Transliteration } \\
\text { of Tibetan Terms }\end{array}$ & $\begin{array}{l}\text { English Translation or Definition of } \\
\text { Tibetan Terms }\end{array}$ \\
\hline dad pa & däpa & faith \\
\hline dam tshig & damtsig & $\begin{array}{l}\text { commitment or vow undertaken by } \\
\text { a disciple during an empower- } \\
\text { ment; see Sanskrit samaya }\end{array}$ \\
\hline dbang & wang & $\begin{array}{l}\text { 'power,' initiation, empowerment } \\
\text { ritual }\end{array}$ \\
\hline dbang thang & wangthang & $\begin{array}{l}\text { power, one of the five factors in } \\
\text { Tibetan astrology which relates } \\
\text { to personal power and peoples' } \\
\text { capacity to achieve goals and } \\
\text { attract money; see appendix } 1\end{array}$ \\
\hline dbyangs 'char gyi rtsis & jangchar gi tsi & $\begin{array}{l}\text { 'calculation of arising vowels,' name } \\
\text { of a Tibetan astrological system }\end{array}$ \\
\hline dbyar dus & yardü & summer \\
\hline dge lugs & Geluk & $\begin{array}{l}\text { one of the main Tibetan Buddhist } \\
\text { schools }\end{array}$ \\
\hline dge lugs pa & Gelukpa & $\begin{array}{l}\text { a person belonging to the Geluk } \\
\text { school }\end{array}$ \\
\hline dge shes lha ram pa & Geshe Lharampa & $\begin{array}{l}\text { the highest monastic degree of a } \\
\text { very learned monk in the Geluk } \\
\text { school }\end{array}$ \\
\hline dgon pa & gompa & $\begin{array}{c}\text { Tibetan term for a monastery or } \\
\text { other religious establishment }\end{array}$ \\
\hline $\begin{array}{l}\text { dkar rtsis or } \\
\text { skar rtsis }\end{array}$ & kartsi & $\begin{array}{l}\text { 'white calculation' or 'star } \\
\text { calculation,' the Indian tradition } \\
\text { of Tibetan astrology }\end{array}$ \\
\hline dngos grub & ngödup & $\begin{array}{l}\text { spiritual accomplishment; see } \\
\text { Sanskrit siddhi }\end{array}$ \\
\hline dpal ldan lha mo & Palden Lhamo & $\begin{array}{l}\text { a wrathful goddess and one of the } \\
\text { principal protectors of Tibet }\end{array}$ \\
\hline $\begin{array}{l}\text { dpal ldan lha mo } \\
\text { dmag zor rgyal mo }\end{array}$ & $\begin{array}{l}\text { Palden Lhamo } \\
\text { Magsor } \\
\text { Gyalmo }\end{array}$ & $\begin{array}{l}\text { one of the forms of the goddess } \\
\text { Palden Lhamo }\end{array}$ \\
\hline dpyid dus & chidü & spring \\
\hline dril bu & dilbu & a bronze bell used in rituals \\
\hline dus & $d \ddot{u}$ & seasons, time \\
\hline dus min 'chi ba & dü min chiwa & 'untimely death' \\
\hline dus tshod & dütsö & $\begin{array}{l}\text { the twelve two-hour periods into } \\
\text { which the day is divided, also } \\
\text { the time it takes to breathe once } \\
\text { in and out }\end{array}$ \\
\hline
\end{tabular}


Table (cont.)

\begin{tabular}{|c|c|c|}
\hline $\begin{array}{l}\text { Wylie Transliteration } \\
\text { of Tibetan Terms }\end{array}$ & $\begin{array}{l}\text { Phonetic } \\
\text { Transliteration } \\
\text { of Tibetan Terms }\end{array}$ & $\begin{array}{l}\text { English Translation or Definition of } \\
\text { Tibetan Terms }\end{array}$ \\
\hline gdon & dön & malevolent spirit(s), spirit affliction \\
\hline grib & drip & $\begin{array}{l}\text { pollution, defilement that can only } \\
\text { be treated ritually }\end{array}$ \\
\hline grwa pa & trapa & ordained, celibate monk \\
\hline gsar'byor ba & sarchorwa & $\begin{array}{l}\text { 'newcomers,' a term for Tibetan } \\
\text { refugees used in Dharamsala and } \\
\text { Kalimpong }\end{array}$ \\
\hline gshed gza' & shedza & $\begin{array}{l}\text { inauspicious day, incompatible } \\
\text { weekday }\end{array}$ \\
\hline gso ba rig pa & sowa rigpa & $\begin{array}{l}\text { 'science of healing,' a term for } \\
\text { Tibetan medicine }\end{array}$ \\
\hline gtar bsreg & tarseg & $\begin{array}{l}\text { a term indicating both bloodletting } \\
\text { and moxibustion }\end{array}$ \\
\hline gter gsar & tersar & $\begin{array}{l}\text { 'new gter ma,' an important } \\
\text { tradition within the Nyingma } \\
\text { school of Tibetan Buddhism }\end{array}$ \\
\hline gter ma & terma & $\begin{array}{l}\text { a revealed treasure, which can be } \\
\text { an object, a text, or a ritual } \\
\text { practice, etc. }\end{array}$ \\
\hline gter ston & terton & $\begin{array}{l}\text { a revealer of gter } m a \text {, treasure } \\
\text { revealer }\end{array}$ \\
\hline gto & to & $\begin{array}{l}\text { rituals that counteract negative } \\
\text { outcomes of divinations }\end{array}$ \\
\hline gtor ma & torma & $\begin{array}{l}\text { offering cakes in various shapes } \\
\text { and colours made from dough } \\
\text { that are ceremonially presented } \\
\text { to deities or spiritual beings for } \\
\text { diverse purposes; a special } \\
\text { initiation gtor ma is used during } \\
\text { empowerments; see also tshe } \\
\text { gtor }\end{array}$ \\
\hline gzungs & zung & $\begin{array}{l}\text { ritual formula, usually consisting } \\
\text { of a long mantra; see Sanskrit } \\
\text { dhāraṇi }\end{array}$ \\
\hline kha btags & khata & Tibetan ceremonial scarf \\
\hline khu ba & kuwa & $\begin{array}{l}\text { regenerative fluid, mentioned in } \\
\text { the Rgyud bzhi as semen }\end{array}$ \\
\hline la & la & $\begin{array}{l}\text { mountain pass, added to pass } \\
\text { names such as in Jelep La, Nathu } \\
\text { La }\end{array}$ \\
\hline la yogs & layok & $\begin{array}{l}\text { 'suffering of change,' Tibetan } \\
\text { concept of retribution }\end{array}$ \\
\hline las & lä & 'action'; see Sanskrit karma \\
\hline
\end{tabular}


Table (cont.)

\begin{tabular}{|c|c|c|}
\hline $\begin{array}{l}\text { Wylie Transliteration } \\
\text { of Tibetan Terms }\end{array}$ & $\begin{array}{l}\text { Phonetic } \\
\text { Transliteration } \\
\text { of Tibetan Terms }\end{array}$ & $\begin{array}{l}\text { English Translation or Definition of } \\
\text { Tibetan Terms }\end{array}$ \\
\hline lcags po ri & Chagpori & $\begin{array}{l}\text { 'Iron mountain,' the name of the } \\
\text { monastic medical college in } \\
\text { Lhasa, founded in 1696; the full } \\
\text { Tibetan name of the college is } \\
\text { Icags po ri rig byed 'gro phan } \\
\text { gling. }\end{array}$ \\
\hline lo gsar & losar & Tibetan New Year \\
\hline lo ma kyong ma & $\begin{array}{l}\text { Loma Kyongma } \\
\text { loma kyongma }\end{array}$ & $\begin{array}{l}\text { name of a female deity linked to } \\
\text { an anti-epidemic empowerment, } \\
\text { also the name of the practice } \\
\text { itself, a 'mantra for infectious } \\
\text { diseases' }\end{array}$ \\
\hline lo rtags & lotak & year sign of one's birth year \\
\hline lo rtags bcu gnyis & lotak chunyi & twelve year signs \\
\hline $\begin{array}{l}\text { lo skag } \\
\quad \text { or lo skeg }\end{array}$ & $\begin{array}{l}\text { lokak } \\
\quad \text { or lokek }\end{array}$ & $\begin{array}{l}\text { 'obstacle year,' which occurs every } \\
\text { twelve years }\end{array}$ \\
\hline lo tho & lotho & popular Tibetan annual almanac \\
\hline lus & $l \ddot{u}$ & $\begin{array}{l}\text { 'body,' one of the five factors in } \\
\text { Tibetan astrology, also the body } \\
\text { as such; see appendix } 1\end{array}$ \\
\hline lus zungs bdun & lüzung dün & $\begin{array}{l}\text { the seven bodily constituents in } \\
\text { Tibetan medicine; see Sanskrit } \\
\text { dhâtu }\end{array}$ \\
\hline ma bu dgra grogs & $m a-b u$-dra-tog & $\begin{array}{l}\text { 'mother-son-enemy-friend' cycle, } \\
\text { an astrological calculation tech- } \\
\text { nique to determine the benefi- } \\
\text { cial or harmful interrelationships } \\
\text { between the elements and year } \\
\text { signs }\end{array}$ \\
\hline ma ni lha khang & Mani Lhakhang & $\begin{array}{l}\text { 'Jewel temple,' name of a Tibetan } \\
\text { temple and a community- } \\
\text { cum-marriage hall in Kalimpong; } \\
\text { also a general term for a house } \\
\text { with a large prayer-wheel }\end{array}$ \\
\hline $\begin{array}{l}\text { ma ni bsnyung gnas } \\
\text { skyid sdug }\end{array}$ & $\begin{array}{l}\text { Mani Nyungne } \\
\text { Kidu }\end{array}$ & $\begin{array}{l}\text { name of a social welfare society } \\
\text { organising rituals and spiritual } \\
\text { practices for the Buddhist } \\
\text { community in Ghum }\end{array}$ \\
\hline$m d a^{\prime} d a r$ & dadar & $\begin{array}{l}\text { ritual arrow decorated with } \\
\text { five-coloured pieces of cloths, } \\
\text { used in various rituals, marriage } \\
\text { and death ceremonies, etc.; see } \\
\text { also tshe dar }\end{array}$ \\
\hline
\end{tabular}


Table (cont.)

\begin{tabular}{|c|c|c|}
\hline $\begin{array}{l}\text { Wylie Transliteration } \\
\text { of Tibetan Terms }\end{array}$ & $\begin{array}{l}\text { Phonetic } \\
\text { Transliteration } \\
\text { of Tibetan Terms }\end{array}$ & $\begin{array}{l}\text { English Translation or Definition of } \\
\text { Tibetan Terms }\end{array}$ \\
\hline mdangs mchog & dangchog & $\begin{array}{l}\text { 'supreme radiance,' a supreme vital } \\
\text { essence, which is a distillate of } \\
\text { the seven bodily constituents; } \\
\text { see Sanskrit ōjas; see appendix } 1\end{array}$ \\
\hline me long & melong & $\begin{array}{l}\text { a round metal mirror used in } \\
\text { rituals }\end{array}$ \\
\hline Mes po'i zhal lung & Mepö Shelung & $\begin{array}{l}\text { short title of Zurkar Lodrö Gyalpo's } \\
\text { commentary of the Rgyud bzhi, } \\
\text { compiled between } 1560 \text { and } 1570\end{array}$ \\
\hline mkhan po & khempo & $\begin{array}{l}\text { abbot of a monastery, but also } \\
\text { someone well-versed in a subject }\end{array}$ \\
\hline mkhris pa & tripa & $\begin{array}{l}\text { one of the three nyes pa often } \\
\text { translated as 'bile' }\end{array}$ \\
\hline mo & mo & divination \\
\hline mo pa & mopa & $\begin{array}{l}\text { common Tibetan name for a } \\
\text { diviner }\end{array}$ \\
\hline mo rtsis & motsi & $\begin{array}{l}\text { divinations that do not involve } \\
\text { calculations, but rely on chance, } \\
\text { such as the throwing of dice }\end{array}$ \\
\hline mtshan nyid & tsenyi & $\begin{array}{l}\text { 'characteristics' that describe the } \\
\text { nyes pa }\end{array}$ \\
\hline nag rtsis & nagtsi & $\begin{array}{l}\text { 'black calculation,' the Chinese- } \\
\text { derived tradition of Tibetan } \\
\text { astrological divination, also } \\
\text { known as 'elemental calculation' } \\
\text { or 'byung rtsis }\end{array}$ \\
\hline nyes pa & nyepa & $\begin{array}{l}\text { 'fault,' the technical term for the } \\
\text { three main principles in Tibetan } \\
\text { medicine; see Sanskrit doṣa }\end{array}$ \\
\hline phug pa & phugpa & $\begin{array}{l}\text { one of the two main lineages of } \\
\text { calendrical calculations in Tibet }\end{array}$ \\
\hline phyu pa & chuba & traditional Tibetan dress for women \\
\hline rang bzhin & rangshin & $\begin{array}{l}\text { individual nature of each person, } \\
\text { which usually appears in single, } \\
\text { dual, or triple combinations of } \\
\text { the nyes pa }\end{array}$ \\
\hline rdo rje & dorje & $\begin{array}{l}\text { 'thunderbolt,' a ritual object; see } \\
\text { Sanskrit vajra }\end{array}$ \\
\hline rgya rtsis & gyatsi & Chinese astrology and astronomy \\
\hline rgyu & gyu & $\begin{array}{l}\text { material or primary cause } \\
\quad \text { (cf. rkyen); see Sanskrit hetu }\end{array}$ \\
\hline rgyud & gyü & lineage \\
\hline
\end{tabular}


Table (cont.)

\begin{tabular}{|c|c|c|}
\hline $\begin{array}{l}\text { Wylie Transliteration } \\
\text { of Tibetan Terms }\end{array}$ & $\begin{array}{l}\text { Phonetic } \\
\text { Transliteration } \\
\text { of Tibetan Terms }\end{array}$ & $\begin{array}{l}\text { English Translation or Definition of } \\
\text { Tibetan Terms }\end{array}$ \\
\hline Rgyud bzhi & Gyüshi & $\begin{array}{l}\text { brief Tibetan title for The Four } \\
\text { Medical Treatises }\end{array}$ \\
\hline rig pa'i gnas bcu & rigpä nä chu & $\begin{array}{l}\text { the ten sciences, which are arts, } \\
\text { grammar, medicine, logic, } \\
\text { Buddhism, astrology, poetics, } \\
\text { prosody (metrical structure of } \\
\text { verse), synonymics, and drama }\end{array}$ \\
\hline rin chen ril bu & rinchen rilbu & $\begin{array}{l}\text { 'precious pills,' multi-compound } \\
\text { Tibetan medicines containing } \\
\text { herbs, minerals, and precious } \\
\text { stones }\end{array}$ \\
\hline rin po che & rinpoche & $\begin{array}{l}\text { 'precious one(s),' additional title for } \\
\text { a leading Buddhist teacher and } \\
\text { high lama }\end{array}$ \\
\hline rkyen & kyen & $\begin{array}{l}\text { secondary cause; conditions, which } \\
\text { might include any misfortune } \\
\text { from a demonic attack to an } \\
\text { accident } \\
\text { (cf. rgyu); see Sanskrit pratyaya }\end{array}$ \\
\hline rlung & lung & $\begin{array}{l}\text { element wind, also one of the } \\
\text { three nyes pa often translated as } \\
\text { 'wind'; see Sanskrit prāna and } \\
\text { vāyu }\end{array}$ \\
\hline rlung rta & lungta & $\begin{array}{l}\text { 'wind horse,' good fortune, one } \\
\text { of the five factors in Tibetan } \\
\text { astrology, also a colloquial term } \\
\text { for 'prayer flags' that are raised } \\
\text { up high to increase good fortune; } \\
\text { see appendix } 1\end{array}$ \\
\hline rnam shes & namshe & $\begin{array}{l}\text { 'consciousness' in Buddhist } \\
\text { philosophy; see Sanskrit vijñanna. } \\
\text { In colloquial contexts the mean- } \\
\text { ings of rnam shes can differ. }\end{array}$ \\
\hline rnying ma & Nyingma & $\begin{array}{l}\text { the oldest of the four main Tibetan } \\
\text { Buddhist schools }\end{array}$ \\
\hline rnying ma pa & Nyingmapa & $\begin{array}{l}\text { a person belonging to the Nyingma } \\
\text { school }\end{array}$ \\
\hline rten'brel & tendrel & $\begin{array}{l}\text { 'arising in mutual connection,' } \\
\text { has many different meanings in } \\
\text { Tibetan contexts, for example, } \\
\text { omen, karmic connection; see } \\
\text { Sanskrit pratītyasamudpāda }\end{array}$ \\
\hline
\end{tabular}


Table (cont.)

\begin{tabular}{|c|c|c|}
\hline $\begin{array}{l}\text { Wylie Transliteration } \\
\text { of Tibetan Terms }\end{array}$ & $\begin{array}{l}\text { Phonetic } \\
\text { Transliteration } \\
\text { of Tibetan Terms }\end{array}$ & $\begin{array}{l}\text { English Translation or Definition of } \\
\text { Tibetan Terms }\end{array}$ \\
\hline rtsam pa & tsampa & $\begin{array}{l}\text { Tibetan staple of roasted barley } \\
\text { flower }\end{array}$ \\
\hline rtsis & $t s i$ & $\begin{array}{l}\text { 'calculation,' a general term for } \\
\text { Tibetan astrology that sums up } \\
\text { Tibetan arithmetic, astronomy, } \\
\text { calendrical calculations, astrol- } \\
\text { ogy, and divinatory calculations } \\
\text { of both Indian and Chinese } \\
\text { origin }\end{array}$ \\
\hline rtsis kyi rig gnas & tsi kyi rignä & $\begin{array}{l}\text { 'science of calculation,' Tibetan } \\
\text { astrological and divinatory } \\
\text { calculations, also called simply } \\
\text { astrology or rtsis }\end{array}$ \\
\hline rtsis pa & tsipa & astrologer \\
\hline sa skya & Sakya & $\begin{array}{l}\text { one of the main Tibetan Buddhist } \\
\text { schools }\end{array}$ \\
\hline sa skya pa & Sakyapa & $\begin{array}{l}\text { a person belonging to the Sakya } \\
\text { school }\end{array}$ \\
\hline sangs rgyas sman bla & Sangye Mänla & $\begin{array}{l}\text { Medicine Buddha; see Sanskrit } \\
\text { Bhaișajyaguru }\end{array}$ \\
\hline sbyin bdag & jinda & sponsor, donor, benefactor \\
\hline sems & sem & mind \\
\hline sgrub chen & drupchen & $\begin{array}{l}\text { short form of sgrub thabs chen po, } \\
\text { an intensive sādhana practice } \\
\text { over seven days, often under- } \\
\text { taken on a regular basis by a } \\
\text { monastery or other religious } \\
\text { community; see Sanskrit sādhana }\end{array}$ \\
\hline sgrub thabs & drupthab & $\begin{array}{l}\text { 'method for attainment,' central } \\
\text { practices in Buddhist Tantra that } \\
\text { involve the evocation of deities } \\
\text { and their entourage; see Sanskrit } \\
\text { sādhana }\end{array}$ \\
\hline sho & sho & dice \\
\hline skyid sdug & kiduk & $\begin{array}{l}\text { 'joy [and] suffering,' general name } \\
\text { for Tibetan mutual aid societies, } \\
\text { also a general term for 'ups and } \\
\text { downs' in life }\end{array}$ \\
\hline smad & $m \ddot{a}$ & $\begin{array}{l}\text { 'lower,' common denominator in } \\
\text { Tibetan that can indicate } \\
\text { temporality as well as verticality }\end{array}$ \\
\hline sman & $m \ddot{a n}$ & medicine \\
\hline
\end{tabular}


Table (cont.)

\begin{tabular}{|c|c|c|}
\hline $\begin{array}{l}\text { Wylie Transliteration } \\
\text { of Tibetan Terms }\end{array}$ & $\begin{array}{l}\text { Phonetic } \\
\text { Transliteration } \\
\text { of Tibetan Terms }\end{array}$ & $\begin{array}{l}\text { English Translation or Definition of } \\
\text { Tibetan Terms }\end{array}$ \\
\hline sman rtsis khang & $\begin{array}{l}\text { Men-Tsee-Khang } \\
\text { (Dharamsala) } \\
\text { or } \\
\text { Mentsikhang } \\
\text { (Lhasa) }\end{array}$ & $\begin{array}{l}\text { 'medicine astrology house,' the } \\
\text { name of the Tibetan medial } \\
\text { institute in Dharamsala, India, } \\
\text { founded in } 1967 \text {, and in Lhasa, } \\
\text { established in } 1916\end{array}$ \\
\hline sman sgrub & mendrup & $\begin{array}{l}\text { empowered medicine, also the } \\
\text { general name of the ritual to } \\
\text { empower medicine }\end{array}$ \\
\hline $\begin{array}{l}\text { sman sgrub sgrub } \\
\text { chen }\end{array}$ & $\begin{array}{l}\text { mendrup drup- } \\
\quad \text { chen }\end{array}$ & $\begin{array}{l}\text { name of a ritual during which } \\
\text { blessing pills are consecrated } \\
\text { and distributed to the public for } \\
\text { general health and well-being }\end{array}$ \\
\hline sme $b a$ & mewa & $\begin{array}{l}\text { nine numeric squares, astrological } \\
\text { parameters, also used to calcu- } \\
\text { late the life-span }\end{array}$ \\
\hline sngags & $n g a g$ & mantra \\
\hline sngags pa & ngagpa & $\begin{array}{l}\text { 'one who practises mantra,' a } \\
\text { tantric lay practitioner, who can } \\
\text { be married }\end{array}$ \\
\hline snron & nön & $\begin{array}{l}\text { the fifth month in the Tibetan } \\
\text { calendar, called Antares, which is } \\
\text { the brightest star in the constel- } \\
\text { lation Scorpio }\end{array}$ \\
\hline spar kha & parka & $\begin{array}{l}\text { eight trigrams, astrological } \\
\text { parameters }\end{array}$ \\
\hline sprul sku & tulku & reincarnate lama \\
\hline srog & $\operatorname{sog}$ & $\begin{array}{l}\text { life itself, vital force, also one of the } \\
\text { five factors in Tibetan astrology; } \\
\text { see appendix } 1\end{array}$ \\
\hline srog bslu & soglu & $\begin{array}{l}\text { name of a ritual to ransom srog, } \\
\text { an animal liberation practice } \\
\text { where the animal is bought from } \\
\text { another person for the purpose } \\
\text { of being set free }\end{array}$ \\
\hline $\operatorname{srog} g z a^{\prime}$ & $\operatorname{sogza}$ & 'life-force day,' a favourable day \\
\hline srog rlung & soglung & $\begin{array}{l}\text { 'life-wind,' one of the five types of } \\
\text { rlung; see appendix } 1\end{array}$ \\
\hline stod & $t \ddot{~}$ & $\begin{array}{l}\text { 'upper,' a common denominator } \\
\text { indicating temporality as well as } \\
\text { verticality }\end{array}$ \\
\hline
\end{tabular}


Table (cont.)

\begin{tabular}{|c|c|c|}
\hline $\begin{array}{l}\text { Wylie Transliteration } \\
\text { of Tibetan Terms }\end{array}$ & $\begin{array}{l}\text { Phonetic } \\
\text { Transliteration } \\
\text { of Tibetan Terms }\end{array}$ & $\begin{array}{l}\text { English Translation or Definition of } \\
\text { Tibetan Terms }\end{array}$ \\
\hline thub & $t u b$ & $\begin{array}{l}\text { 'to last,' the Tibetan verb used to } \\
\text { describe the duration of the } \\
\text { life-span }\end{array}$ \\
\hline tsha tsha & tsatsa & $\begin{array}{l}\text { miniature conical figures made } \\
\text { from clay or plaster filled with } \\
\text { wheat, used as offerings }\end{array}$ \\
\hline tshe & tse & life-span; see appendix 1 \\
\hline $\begin{array}{l}\text { tshe 'dzad pa or zad } \\
\qquad p a\end{array}$ & tse säpa & $\begin{array}{l}\text { 'the life-span is exhausted,' a } \\
\text { popular diagnosis in the divina- } \\
\text { tion of the life-span, a temporary } \\
\text { weakness of tshe that can be } \\
\text { treated with longevity rituals; see } \\
\text { appendix } 1\end{array}$ \\
\hline tshe bum & tsebum & $\begin{array}{l}\text { long-life vase, ritual object used } \\
\text { during tshe dbang to transfer } \\
\text { byin rlabs }\end{array}$ \\
\hline tshe chang & tsechang & long-life beer used in rituals \\
\hline tshe chu & tsechu & long-life nectar used in rituals \\
\hline tshe dar & tsedar & $\begin{array}{l}\text { long-life arrow, ritual object used } \\
\text { during longevity rituals to collect } \\
\text { lost tshe }\end{array}$ \\
\hline tshe dbang & tsewang & long-life empowerment or initiation \\
\hline tshe gtor & tsetor & $\begin{array}{l}\text { long-life initiation gtor ma made of } \\
\text { metal or wood }\end{array}$ \\
\hline tshe gzungs & tsezung & $\begin{array}{l}\text { longevity dhāraṇī, recitations of } \\
\text { prayers and long-life mantras; } \\
\text { see Sanskrit dhāraṇi }\end{array}$ \\
\hline tshe lha rnam gsum & tsela nam sum & $\begin{array}{l}\text { trinity of the 'three long-life } \\
\text { deities': Amitāyus, White Tārā, } \\
\text { and Ușnīṣavijayā }\end{array}$ \\
\hline tshe lhag & tselag & $\begin{array}{l}\text { the remaining life-span; see } \\
\text { appendix } 1\end{array}$ \\
\hline tshe lo & tselo & $\begin{array}{l}\text { the maximum life-span, also a } \\
\text { colloquial term for age; see } \\
\text { appendix } 1\end{array}$ \\
\hline tshe ril & tseril & $\begin{array}{l}\text { long-life pill, which is distributed } \\
\text { during longevity rituals }\end{array}$ \\
\hline tshe ring & tsering & long life-span, also a Tibetan name \\
\hline tshe sgrub & tsedup & $\begin{array}{l}\text { meditative and ritual practice to } \\
\text { strengthen tshe and accomplish } \\
\text { the power of long life; see } \\
\text { also sgrub thabs and Sanskrit } \\
\text { sādhana }\end{array}$ \\
\hline
\end{tabular}


Table (cont.)

\begin{tabular}{|c|c|c|}
\hline $\begin{array}{l}\text { Wylie Transliteration } \\
\text { of Tibetan Terms }\end{array}$ & $\begin{array}{l}\text { Phonetic } \\
\text { Transliteration } \\
\text { of Tibetan Terms }\end{array}$ & $\begin{array}{l}\text { English Translation or Definition of } \\
\text { Tibetan Terms }\end{array}$ \\
\hline tshe smad & tsemä & the latter half of life \\
\hline tshe srung & tsesung & $\begin{array}{l}\text { protective cord given out during } \\
\text { empowerments }\end{array}$ \\
\hline tshe stod & tsetö & the first half of life \\
\hline tshe thar & tsethar & $\begin{array}{l}\text { 'life-liberation,' a practice of freeing } \\
\text { animals where the animal that is } \\
\text { set free belongs to oneself }\end{array}$ \\
\hline tshe thung & tsetung & short life-span \\
\hline tshe tshad & tsetsä & 'duration of life,' the life-span \\
\hline tshe tshar ba & tse tsarwa & full completion of the life-span \\
\hline or & or & \\
\hline tshe mthar phyin pa & tse thar chinpa & \\
\hline ye shes & yeshe & $\begin{array}{l}\text { wisdom, cognition, primordial } \\
\text { wisdom, timeless awareness }\end{array}$ \\
\hline yi dam & yidam & $\begin{array}{l}\text { meditation deity, the personal deity } \\
\text { of a Buddhist practitioner }\end{array}$ \\
\hline zhabs brtan & shabten & $\begin{array}{l}\text { 'firm feet,' poetic prayers for } \\
\text { longevity, also a popular term } \\
\text { for ritual }\end{array}$ \\
\hline
\end{tabular}

Glossary of Recurrent Sanskrit Terms (Including Proper Names)

\begin{tabular}{|c|c|c|}
\hline $\begin{array}{l}\text { Transliteration of } \\
\text { Sanskrit Term }\end{array}$ & $\begin{array}{l}\text { Tibetan Term in } \\
\text { Wylie }\end{array}$ & $\begin{array}{l}\text { English Translation or Definition } \\
\text { of the Term }\end{array}$ \\
\hline adhișţāna & byin rlabs & 'blessing' \\
\hline Amitāyus & tshe dpag med & Buddha of Boundless Life \\
\hline Amitābha & od dpag med & Buddha of Limitless Light \\
\hline Așțāngahrrdayasaṃhitā & $\begin{array}{l}\text { yan lag brgyad pa } \\
\text { snying po bsdus pa }\end{array}$ & $\begin{array}{l}\text { Title of a medical work by } \\
\text { Vāgbhața }\end{array}$ \\
\hline Atiśa & jo bo rje & $\begin{array}{l}\text { Indian master who visited Tibet } \\
\text { in the eleventh century }\end{array}$ \\
\hline Avalokiteśvara & spyan ras gzigs & Buddha of Compassion \\
\hline Āyurveda & tshe yi rig byed & $\begin{array}{l}\text { 'science of long life,' generic term } \\
\text { for the Indian medical tradition }\end{array}$ \\
\hline Bhaișajyaguru & $\begin{array}{l}\text { sangs rgyas sman } \\
\quad \text { bla }\end{array}$ & Medicine Buddha \\
\hline bhikṣu & dge slong & fully ordained monk \\
\hline bhoțah & bod & $\begin{array}{l}\text { Sanskrit rendering of the Tibetan } \\
\text { word for Tibet }\end{array}$ \\
\hline
\end{tabular}


Table (cont.)

\begin{tabular}{|c|c|c|}
\hline $\begin{array}{l}\text { Transliteration of } \\
\text { Sanskrit Term }\end{array}$ & $\begin{array}{l}\text { Tibetan Term in } \\
\text { Wylie }\end{array}$ & $\begin{array}{l}\text { English Translation or Definition } \\
\text { of the Term }\end{array}$ \\
\hline bodhicitta & $\begin{array}{l}\text { byang chub gyi } \\
\text { sems }\end{array}$ & $\begin{array}{l}\text { the compassionate wish to attain } \\
\text { enlightenment for the benefit } \\
\text { of all living beings, the basic } \\
\text { Mahāyāna motivation for } \\
\text { dharma practice }\end{array}$ \\
\hline dhāraṇi & gzungs & $\begin{array}{l}\text { a ritual formula, consisting of } \\
\text { mantras }\end{array}$ \\
\hline dharma & chos & $\begin{array}{l}\text { Buddhist teachings, elemental } \\
\text { constituents, underlying } \\
\text { principles of the universe, etc. }\end{array}$ \\
\hline dhātu & lus zungs bdun & $\begin{array}{l}\text { the seven bodily constituents in } \\
\text { Āyurveda }\end{array}$ \\
\hline doșa & nyes pa & $\begin{array}{l}\text { 'fault,' the three main principles } \\
\text { in Âyurveda }\end{array}$ \\
\hline guru & bla ma & spiritual teacher \\
\hline Hayagrīva & rta mgrin & $\begin{array}{l}\text { horse-headed deity, the wrathful } \\
\text { manifestation of Avalokiteśvara }\end{array}$ \\
\hline hetu & rgyu & $\begin{array}{l}\text { the material or primary cause } \\
\text { (cf. pratyaya) }\end{array}$ \\
\hline Kälacakratantra & dus kyi 'khor lo & $\begin{array}{l}\text { 'Tantra of the wheel of time,' } \\
\text { an Indian tantric text, which } \\
\text { entered Tibet in the eleventh } \\
\text { century }\end{array}$ \\
\hline karma & las & 'action' \\
\hline kumbhaka & bum pa can & $\begin{array}{l}\text { 'holding a vase,' a specific method } \\
\text { of holding the breath within } \\
\text { the body }\end{array}$ \\
\hline Mahāyāna & theg pa chen po & $\begin{array}{l}\text { 'great vehicle,' one of the two } \\
\text { major branches of Buddhism }\end{array}$ \\
\hline Mandarava & man da ra ba & $\begin{array}{l}\text { Mandarava, Princess of Zahor and } \\
\text { one of the main five consorts of } \\
\text { Padmasambhava }\end{array}$ \\
\hline Maratika & 'chi ba mthar byed & $\begin{array}{l}\text { 'to destroy death,' name of a } \\
\text { sacred place in eastern Nepal } \\
\text { where Padmasambhava and } \\
\text { Mandarava were blessed } \\
\text { with immortal life by Buddha } \\
\text { Amitāyus. }\end{array}$ \\
\hline Nāgārjuna & klu sgrub & $\begin{array}{l}\text { Indian Buddhist philosopher of } \\
\text { the second century CE (?) }\end{array}$ \\
\hline ōjas & mdangs mchog & $\begin{array}{l}\text { 'supreme radiance,' a distillate of } \\
\text { seven bodily constituents }\end{array}$ \\
\hline
\end{tabular}


Table (cont.)

\begin{tabular}{|c|c|c|}
\hline $\begin{array}{l}\text { Transliteration of } \\
\text { Sanskrit Term }\end{array}$ & $\begin{array}{l}\text { Tibetan Term in } \\
\text { Wylie }\end{array}$ & $\begin{array}{l}\text { English Translation or Definition } \\
\text { of the Term }\end{array}$ \\
\hline Padmasambhava & gu ru rin po che & $\begin{array}{l}\text { founding figure for the Nyingma } \\
\text { school of Tibetan Buddhism }\end{array}$ \\
\hline prāṇa & rlung & $\begin{array}{l}\text { 'wind,' breath; see also Sanskrit } \\
\quad v \bar{a} y u\end{array}$ \\
\hline pratītyasamudpāda & rten 'brel & 'arising in mutual connection' \\
\hline pratyaya & rkyen & $\begin{array}{l}\text { The cooperating or secondary } \\
\text { cause (cf. hetu) }\end{array}$ \\
\hline pūjā & cho ga, mchod & common term for ritual, offering \\
\hline sädhana & sgrub thabs & $\begin{array}{l}\text { 'method for attainment,' central } \\
\text { practices in Buddhist Tantra } \\
\text { that involve the evocation of } \\
\text { deities and their entourage }\end{array}$ \\
\hline samaya & dam tshig & $\begin{array}{l}\text { vow or commitment undertaken } \\
\text { by a disciple to the lama during } \\
\text { an empowerment }\end{array}$ \\
\hline saṃsāra & 'khor ba & cyclic existence \\
\hline siddhi & dngos grub & spiritual accomplishment \\
\hline Tārā & sgrol dkar & $\begin{array}{l}\text { White Tārā, female goddess of } \\
\text { longevity }\end{array}$ \\
\hline Uș̣̣īṣavijayā & $\begin{array}{l}\text { gtsug tor rnam } \\
\text { rgyal ma }\end{array}$ & female goddess of longevity \\
\hline Vāgbhața & $d p a^{\prime} b o$ & $\begin{array}{l}\text { Ayurvedic physician of the } \\
\text { seventh century, author of the } \\
\text { Aștāingahṛayasamhitā }\end{array}$ \\
\hline Vāgīśvarakīrti & $\begin{array}{l}\text { ngag dbang grags } \\
\quad p a\end{array}$ & $\begin{array}{l}\text { Indian scholar of the tenth/elev- } \\
\text { enth century, author of the } \\
\text { Mrtyuvañcanopadeśa }\end{array}$ \\
\hline Vajrakīlaya or Vajrakīla & rdo rje phur ba & name of a male wrathful deity \\
\hline Vajrapāṇi & phyag na rdo rje & $\begin{array}{l}\text { one of the Buddha's three } \\
\text { protective deities }\end{array}$ \\
\hline Vajrayāna & $\begin{array}{l}\text { gsang sngags rdo } \\
\text { rje theg pa }\end{array}$ & $\begin{array}{l}\text { 'the secret mantra vehicle,' tantric } \\
\text { form of Tibetan Buddhism }\end{array}$ \\
\hline vajra & rdo rje & 'thunderbolt,' a ritual object \\
\hline Vajrayoginī & $\begin{array}{l}\text { rdo rje rnal 'byor } \\
\quad \text { ma }\end{array}$ & name of a female deity \\
\hline vāyu & rlung & $\begin{array}{l}\text { 'wind,' breath; see also Sanskrit } \\
\text { prāṇa }\end{array}$ \\
\hline vijñ̄āna & rnam shes & consciousness \\
\hline Yamāntaka & gshin rje gshed & $\begin{array}{l}\text { 'terminator of death,' name of a } \\
\text { wrathful deity who subdues the } \\
\text { lord of death }\end{array}$ \\
\hline
\end{tabular}




\section{LIST OF TIBETAN PROPER NAMES}

Phonetic Spelling

Note: In numerous cases the phonetic spellings reflect the local spellings used by the people themselves.
Wylie Transliteration

Amchi Jamyang Tashi

Amchi Kartsokyi

Amchi Künga

Amchi Penpa

Amchi Sonam Wangdu

Amchi Tashi

Amchi Tashi Namgyal

Amchi Tsering Wangdue

Amchi Yontan Gyatso

Anila

Chatral Sangye Dorje Rinpoche

Chime Radha Rinpoche

Chögyal Namkhai Norbu Rinpoche

Dagmo Kalden

Desi Sangye Gyatso

Dhardo Tulku Rinpoche

Dharmo Mänrampa Lobsang Chödrak

Dolgyal [Shukden]

Dölma

Dorje Shukden

Dinchen Rinpoche

Dudjom Rinpoche Jigdral Yeshe Dorje

Dumbu Döndrub Wangyal

Dzongsar Jamyang Khyentse Rinpoche

Gergan Dorje Tharchin

Gyalwa Rinpoche [Dalai Lama]

Gyatso

Jamgön Kongtrul Rinpoche Lodrö Thaye

Jamgön Mipham Gyatso

Jampa Kalsang

Jampel Kaldhen am chi 'jam dbyangs bkra shis

am chi dkar mtsho skyid

am chi kun dga'

am chi spen pa

am chi bsod nams dbang 'dus

am chi bkra shis

am chi bkra shis rnam rgyal

am chi tshe ring dbang 'dus

am chi yon tan rgya mtsho

a ne lags

bya bral sangs rgyas rdo rje rin po che 'chi med ra brda rin po che

chos rgyal nam mkha'i nor bu rin po che bdag mo skal ldan

sde srid sangs rgyas rgya mtsho

dar mdo sprul sku rin po che

dar mo sman rams pa blo bzang chos

grags

dol rgyal [shugs ldan]

sgrol ma

rdo rje shugs ldan

drin chen rin po che

bdud 'joms rin po che 'jigs bral ye shes rdo rje

ldum bu don grub dbang rgyal

rdzong gsar 'jam dbyangs mkhyen

brtse rin po che

dge rgan rdo rje mthar phyin

rgyal ba rin po che

rgya mtsho

'jam mgon kong sprul rin po che blo

gros mtha' yas

'jam mgon mi pham rgya mtsho

byams pa skal bzang

'jam dpal skal ldan 
Table (cont.)

Phonetic Spelling

Wylie Transliteration

Note: In numerous cases the phonetic spellings reflect the local spellings used by the people themselves.

\begin{tabular}{ll}
\hline Jetsün Milarepa & rje btsun mi la ras pa \\
Jigme Senge Palbar & 'jigs med seng ge dpal 'bar \\
Kesang Tseten & bskal bzang tshe brtan \\
Khempo Tsündru & mkhan po brtson 'grus \\
Khunu Dhatho Gyespa & khu nu zla tho rgyas pa \\
Könchok Peljor & dkon mchog dpal 'byor \\
Kongtrul Rinpoche & kong sprul rin po che \\
Künga Pel & kun dga'dpal \\
Kyabje Dudjom Yangsi Rinpoche & skyabs rje bdud 'joms yang srid rin \\
& po che \\
Lama Chime & bla ma'chi med \\
Lama Karma & bla ma kar ma \\
Lama Kunzang Dorje & bla ma kun bzang rdo rje \\
Lama Pema Longdrol & bla ma padma klong grol \\
Lama Sonam & bla ma bsod nams \\
Lama Tsewang & bla ma tshe dbang \\
Lang Darma & glang dar ma \\
Lha Totori & lha tho tho ri \\
Lhalung Palgyi Dorje & lha lung dpal gyi rdo rje \\
Lhatsün Namkha Jigme & lha btsun nam mkha' 'jigs med \\
Lobsang Wangyal & blo bzang dbang rgyal \\
Machig Drupä Gyalmo & ma gcig grub pa'i rgyal mo \\
Minyak Gyaltsen Pal & mi nyag rgyal mtshan dpal \\
Ngawang Jinpa, Khen Rinpoche & ngag dbang sbyin pa, mkhan rin po che \\
Ngawang Lobsang Gyatso, the fifth & rgyal ba lnga pa ngag dbang blo bzang \\
Dalai Lama & rgya mtsho \\
Norzang Gyatso & nor bzang rgya mtsho \\
Nyima & nyi ma \\
Palgon Thinley & dpal mgon 'phrin las \\
Passang & pa sangs \\
Pawo Tsuklak Trengwa & dpa' bo gtsug lag phreng ba \\
Pema & padma \\
Pema Dorje & padma rdo rje \\
Pemba & spen pa \\
Penpa Yeshi & spen pa ye shes \\
Phugpa Lhundrup Gyatso & phug pa lhun grub rgya mtsho \\
Phuntsok & phun tshogs \\
Ratna Vajra Rinpoche & rat na vajra rin po che \\
Ratna Vajra Trizin & rat na vajra khri'dzin \\
Rechungpa & ras chung pa \\
& \\
& \\
&
\end{tabular}


Table (cont.)

Phonetic Spelling

Wylie Transliteration

Note: In numerous cases the phonetic spellings reflect the local spellings used by the people themselves.

Rigzin Lhundrub Paljor Nyerongshar

rigs 'dzin lhun grub dpal 'byor nyag rong shar

Rinchen Zangpo

rin chen bzang po

Sakya Trizin Rinpoche Ngawang Künga

Samphel Norbu Trogawa Rinpoche

Samten Norbu

Sangye Gyatso

Sherab

Situ Panchen

Sonam Rinchen

Songtsen Gampo

Tagdrag Ngawang Sungrab Thutop

\section{Tenzin}

Tenzin Gyatso, the fourteenth Dalai Lama

Tenzin Tsewang Jamling

Thangtong Gyalpo

Tri Songdetsen

Tsering

Tsering Dorje

Tsewang Lhamo

Tsongkhapa

Yogini Kachö Deden Wangmo

Yuthok Yönten Gonpo the Elder

Yuthok Yönten Gonpo the Younger

Zurkhar Lodrö Gyalpo

sa skya khri'dzin rin po che ngag

dbang kun dga'

bsam 'phel nor bu khro dga' bo rin po che

bsam gtan nor bu

sangs rgyas rgya mtsho

shes rab

si tu paN chen

bsod nams rin chen

srong btsan sgam po

stag brag ngag dbang gsung rab mthu stobs

bstan 'dzin

rgyal ba bcu bzhi pa bstan 'dzin rgya mtsho

bstan 'dzin tshe dbang 'jam gling

thang stong rgyal po

khri srong lde'u (or lde) btsan

tshe ring

tshe ring rdo rje

tshe dbang tha mo

tsong kha pa

rnal 'byor ma mkha' spyod bde ldan dbang mo

g.yu thog yon tan mgon po rnying ma g.yu thog yon tan mgon po gsar ma zur mkhar blo gros rgyal po 
Barbara Gerke - 978-90-04-21748-5 Downloaded from Brill.com๑4/26/2023 $\odot 2: 47: 13 \mathrm{PM}$ via free access 


\section{BIBLIOGRAPHY}

\section{Sources in European Languages}

Adam B. 1994. Perceptions of time. In Companion Encyclopedia of Anthropology, ed. T. Ingold, pp. 503-526. London: Routledge.

1995. Timewatch: The Social Analysis of Time. Cambridge: Polity Press. 2004. Time. Cambridge: Polity Press.

Adams V. 1996. Karaoke as modern Lhasa, Tibet: Western encounters with cultural politics. Cultural Anthropology 11: 510-546.

- 1998. Suffering the winds of Lhasa: politicized bodies, human rights, cultural difference, and humanism in Tibet. Medical Anthropology Quarterly 12: 74-102.

- 2002a. The sacred in the scientific: ambiguous practices of science in Tibetan medicine. Cultural Anthropology 16: 542-575.

2002b. Establishing proof: translating science and the state in Tibetan medicine. In New Horizons in Medical Anthropology: Essays in Honour of Charles Leslie, eds. M. Nichter, M. Lock, pp. 200-220. London, New York: Routledge.

- 2005. Saving Tibet? An inquiry into modernity, lies, truths, and beliefs. Medical Anthropology 24: 71-110.

Ahearn L. 2001. Language and agency. Annual Review of Anthropology 30: 109-137.

Allen N. 1972. The vertical dimension in Thulung classification. JASO 3: 81-94.

Alter J.S. 1992. The Wrestler's Body: Identity and Ideology in North India. Berkeley and Los Angeles: University of California Press.

. 1999. Heaps of health, metaphysical fitness: Âyurveda and the ontology of good health in medical anthropology. Current Anthropology 40, supplement: 43-66.

Arakeri A.V. 1998. Tibetans in India: The Uprooted People and Their Cultural Transplantation. New Delhi: Reliance Publishing House.

Arora V. 2004. Just a Pile of Stones!: The Politicization of Identity, Indigenous Knowledge, and Sacred Landscapes among the Lepcha and the Bhutia Tribes of Contemporary Sikkim, India. D.Phil. thesis. University of Oxford, Oxford.

- 2006a. "We are the Lhopo of Sikkim. We do not have Tibetan origins. The Tibetans are the refugees": Changes in the perceptions of Tibetan identities in contemporary Sikkim, India. In Tibetan Borderlands. PIATS 2003: Tibetan Studies: Proceedings of the 1oth Seminar of the International Association for Tibetan Studies, Oxford 2003, ed. C. Klieger, pp. 157-180. Leiden, Boston: Brill.

2006b. The forest of symbols embodied in the Tholung sacred landscape of North Sikkim, India. Conservation and Society 4: 55-83.

- 2007. Unheard voices of protest in Sikkim. Economic and Political Weekly 42 (25 Aug 2007): 3451-3455.

Arrault A. 2010. Activités médicales et méthodes hémérologiques dans les calendriers de Dunhuang du $\mathrm{IX}^{\mathrm{e}}$ au $\mathrm{X}^{\mathrm{e}}$ siècle: esprit humain (renshen) et esprit du jour (riyou). In Médecine, Religion et Société dans la Chine Médiévale: Étude de Manuscrits Chinois de Dunhuang et de Turfan, 3 vols., ed. C. Despeux, pp. 285-332. Paris: Collège de France.

Aschoff J.C. 1996. Annotated Bibliography of Tibetan Medicine (1789-1995). Ulm, Dietikon: Fabri-Verlag, Garuda Verlag.

Aschoff J.C., Tashigang T.Y. 1997. On mercury in Tibetan 'precious pills.' Journal of the European Ayurvedic Society 6: 129-135.

- 2001. Tibetan Precious Pills: A Tantric Healing System. Ulm/Donau: Fabri Verlag.

_. 2004. Tibetan Jewel Pills. Ulm/Donau: Fabri Verlag. 
Awasty I. 1978. Between Sikkim and Bhutan: The Lepchas and Bhutias of Pedong. New Delhi: B.R. Publishing Corporation.

Baatz U. 2002. Zeit im Buddhismus. In Zeit und Geschichte: Kulturgeschichtliche Perspektiven, eds. E. Chvojka, A. Schwarcz, K. Thien, pp. 154-161. Vienna, Munich: R.Oldenbourg Verlag.

Badaraev B.D., Bazaron E.G., Dashiev M.D., Aseeva T.A., Batorova S.M. 1981. Glang thabs (Acute diseases of the organs of the abdominal cavity) and their correction in Tibetan medicine: translation into Russian from the third section of the Rgyud bzhi and the Vaidurya sngon po, translated from the Russian by Dr. Stanley Frye. Tibetan Medicine 4: $5^{-116 .}$

Balikci A. 2002. Buddhism and Shamanism in Village Sikkim. PhD thesis. SOAS, London.

. 2008. Lamas, Shamans, and Ancestors: Village Religion in Sikkim. Leiden, Boston: Brill.

Barnes B. 2000. Understanding Agency. London: Sage Publications.

Barron R., transl. and ed., 2003. The Autobiography of Jamgön Kongtrul: A Gem of Many Colors. Ithaca, NY: Snow Lion Publications.

Barth F. 1969. Introduction. In Ethnic Groups and Boundaries: Social Organisation of Cultural Difference, ed. F. Barth, pp. 9-38. Long Grove, Illinois: Waveland Press.

Bassini P. 2006 (unpublished paper). "Traumatic experiences of loss and social change: patients' perspectives on heart distress and other illnesses in Amdo." Paper presented at the nth Seminar of the International Association for Tibetan Studies, Bonn, Aug. 27-Sept. 2, 2006.

-2007. Heart Distress and Other Illnesses on the Sino-Tibetan Frontier: Home-based Tibetan Perspectives from the Qinghai Part of Amdo. D.Phil. thesis. University of Oxford, Oxford.

Bates D. 1995. Knowledge and the Scholarly Medical Traditions. Cambridge: Cambridge University Press.

Bawden C.R. 1962. Calling the soul: a Mongolian litany. Bulletin of the School of Oriental and African Studies 25: 81-103.

Beckwith C.I. 1979. The introduction of Greek medicine into Tibet in the seventh and eighth centuries. Journal of the American Oriental Society 99: 297-313.

Bell C.S. 1992 [1924]. Tibet Past and Present. Delhi: Motilal Banarsidass Publishers.

Bellezza J.V. 2005. Spirit-Mediums, Sacred Mountains and Related Bon Textual Traditions in Upper Tibet: Calling Down the Gods. Leiden, Boston: Brill.

Berg E. 1994. Sherpa Buddhists on a regional pilgrimage: the case of Maratika Cave at Halase. Occasional Papers in Sociology and Anthropology 4: 124-145.

Berglie P.-A. 1976. Preliminary remarks on some Tibetan "spirit mediums" in Nepal. Kailash 4: 87-108.

-1992. Tibetan spirit-mediumship: change and continuity. Some observations from a revisit to Nepal. In Tibetan Studies: Proceedings of the 5 th Seminar of the International Association for Tibetan Studies, Narita 1989, eds. I. Shoren, Y. Zuiho, pp. 361-365. Narita: Naritasan Shinshoji.

Bernstorff D., von Welck H., eds. 2004. Exile as Challenge: The Tibetan Diaspora. Delhi, Orient Longman.

Berzin A. 1991. Tibetan astro sciences. Chö-Yang: The Voice of Tibetan Religion and Culture, Year of Tibet Edition: 181-192.

—. 1996. "Tibetan-Mongolian astrology and karma." URL: <http://www.berzinarchives .com/web/en/archives/study/tibetan_astrology_medicine/astrology/tibeto_mongolian_ astrology_karma.html>. Last date of access 22.12.2010.

Beyer S. 1973. The Cult of Tārā: Magic and Ritual in Tibet. Berkeley and Los Angeles: University of California Press.

Bhasin V. 2007. Medical anthropology: healing practices in contemporary Sikkim. Anthropologist Special Volume 3: 59-94. 
Bhatia S., Dranyi T., Rowley D. 2002. A social and demographic study of Tibetan refugees in India. Social Science and Medicine 54: 411-422.

Bickel B., Gaenszle M., eds. 1999. Himalayan Space: Cultural Horizons and Practices. Zürich: Völkerkundemuseum.

Bloch Marc. 1992. [1954] The Historian's Craft. Manchester: Manchester University Press.

Bloch Maurice. 1977. The past and the present in the present. Man, n.s. 12: 278-292.

Boord M.J. 1993. The Cult of the Deity Vajrakila according to the Texts of the Northern Treasures Tradition of Tibet (Byang-Gter Phur-Ba). Tring, UK: The Institute of Buddhist Studies.

Buffetrille K. 1994. The Halase-Maratika Caves (Eastern Nepal): A Sacred Place Claimed by both Hindus and Buddhists. Pondichéry: Institut Français de Pondichéry.

Cabezón J.I. 1996. Firm feet and long lives: the Zhabs brtan literature of Tibetan Buddhism. In Tibetan Literature, Studies in Genre, eds. J.I. Cabezón, R. Jackson, pp. 344-357. Ithaca, NY: Snow Lion Publications.

- 2010. Introduction. In Tibetan Ritual, ed. J.I. Cabezón, pp. 1-34. New York: Oxford University Press.

Cabezón J.I., Jackson R. 1996. Editor's introduction. In Tibetan Literature, Studies in Genre, eds. J.I. Cabezón, R. Jackson, pp. 11-37. Ithaca, NY: Snow Lion Publications.

Cabinet of the Tibetan Government in Exile. 1996. "Kashag's statement concerning Dolgyal. Dharamsala-May31,1996.” URL:<http://www.dalailama.com/messages/dolgyalshugden/kashags-statement>. Last date of access 09.11.2010.

Calkowski M. 1993. Contesting hierarchy: on gambling as an authoritative resource in Tibetan refugee society. In Anthropology of Tibet and the Himalaya, eds. C. Ramble, M. Brauen, pp. 30-38. Zürich: Ethnological Museum of the University of Zürich.

Cantwell C., Mayer R. 2008 (unpublished paper). "Imagery for creating longevity: artwork used for the 'Chi med srog thig." Paper presented at the panel 'Theory and Practice of Healing, Medicine and Longevity in Buddhism,' XVth Conference of the International Association of Buddhist Studies (IABS), Atlanta, Georgia, June 23-28, 2008.

- 2010. The creation and transmission of a textual corpus in the twentieth century: the 'Chi med srog thig. In Edition, Éditions: L'écrit au Tibet, Évolution et Devenir, eds. A. Chayet, C. Scherrer-Schaub, F. Robin, J.-L. Achard, pp. 65-83. Munich: Indus Verlag.

CCTM (Central Council of Tibetan Medicine) 2010a. "About us." Official Website of the Central Council of Tibetan Medicine. URL: <http://www.tibmedcouncil.org/index. html>. Last date of access 12.10.2010.

- 2010b. "Registered medical colleges." Official Website of the Central Council of Tibetan Medicine. URL: <http://www.tibmedcouncil.org/med_col_n_inst.html>. Last date of access 12.10.2010.

Chatral Sangye Dorje Rinpoche. 20o6. "The benefits of saving the lives of other living beings." URL: <http://www.animalsavingtrust.org/benefit.htm>. Last date of access: 07.08.2010.

Childs G. 2004. Tibetan Diary: From Birth to Death and Beyond in a Himalayan Valley of Nepal. Berkeley and Los Angeles: University of California Press.

- 2005. How to fund a ritual: the social usage of the Kanjur (bka' 'gyur) in a Tibetan village. The Tibet Journal 30: 41-48.

- 2008. Tibetan Transitions: Historical and Contemporary Perspectives on Fertility, Family Planning, and Demographic Change. Leiden, Boston: Brill.

Chime Radha Rinpoche. 1981. Tibet. In Divination and Oracles, eds. M. Loewe, C. Blacker, pp. 3-37. London: George Allen \& Unwin.

Clark B. 1995. The Quintessence Tantras of Tibetan Medicine. Ithaca, NY: Snow Lion Publications.

Clarke G.E. 1990. Ideas of merit (bsod-nams), virtue (dge-ba), blessing (byin-rlabs) and material prosperity (rten-'brel) in highland Nepal. Journal of the Anthropological Society of Oxford 21: 165-184. 
Clifford T. 1984. Tibetan Buddhist Medicine and Psychiatry: The Diamond Healing. Wellingborough: Aquarian.

Comaroff J., Comaroff J. 1992. Ethnography and the Historical Imagination. Boulder: Westview Press.

Connor L., Samuel G., eds. 2001. Healing Powers and Modernity: Traditional Medicine, Shamanism, and Science in Asian Societies. Westport, Connecticut; London: Bergin \& Garvey.

Cornu P. 1997. Tibetan Astrology. Boulder: Shambhala Publications.

Cozort D. 1997. Sādhana (sGrub thabs): means of achievement for deity yoga. In Tibetan Literature: Studies in Genre, eds. J. Cabezón, R. Jackson, pp. 331-343. Ithaca, NY: Snow Lion Publications.

Craig S.R. 2008. Place and professionalization: navigating amchi identity in Nepal. In Tibetan Medicine in the Contemporary World. Global Politics of Medical Knowledge and Practice, ed. L. Pordié, pp. 62-9o. London and New York: Routledge.

CTA (Central Tibetan Administration-in-exile, India), Planning Council 200o. Tibetan Demographic Survey 1998. Dharamsala: Planning Council, Central Tibetan Administration, Gangchen Kyishong.

CTA (Central Tibetan Administration-in-exile, India) 2009. "Issues facing Tibet today." Official Website of the Central Tibetan Administration-in-exile. URL: <http://www.tibet .net $/$ en/index.php?id=7\&rmenuid=8.htm $>$. Last date of access 12.10.2010.

CTMI (Chagpori Tibetan Medical Institute) 2010. "College department." URL: <http://www .chagpori-tibetan-medical-institute.com/college.htm >. Last date of access: 10.10.2010.

CTRC (Central Tibetan Relief Committee) 2010. "Tibetan refugee settlements in India." Official Website of the Department of Home, Central Tibetan Administration-in-exile. URL: <http://www.tibetgov.net/set-ind.html>. Last date of access 12.12.2010.

CTSA (Central Tibetan Schools Administration) 2009. "Central Tibetan Schools Administration." URL: <http://www.ctsa.nic.in/index.aspx>. Last date of access 17.12.2010.

Czaja O. Winter 2005 \& Spring 2006. Zurkharwa Lodro Gyalpo (1509-1579) on the controversy of the Indian origin of the rGyud bzhi. The Tibet Journal Vol. XXX, No. 4 \& Vol. XXXI, No. 1: 131-152.

- 2007. The making of the Blue Beryl - some remarks on the textual sources of the famous commentary of Sangye Gyatsho (1653-1705). In Soundings in Tibetan Medicine. Anthropological and Historical Perspectives. PIATS 2003: Tibetan Studies: Proceedings of the 1oth Seminar of the International Association for Tibetan Studies, Oxford 2003, ed. M. Schrempf, pp. 345-371. Leiden, Boston: Brill.

Daniel E.V. 1984. The pulse as icon in Siddha medicine. Contributions to Asian Studies 18: $115^{-126 .}$

Daniels C. 1994. Defilement and Purification: Tibetan Buddhist Pilgrims at Bodhnath, Nepal. D.Phil. thesis. University of Oxford, Oxford.

Das A.K., Banerjee SK. 1962. The Lepchas of Darjeeling District. Calcutta: Tribal Welfare Dept. Government of West Bengal.

Dash A.J. 1947. Bengal District Gazetteers: Darjeeling. Alipore, Calcutta: Bengal Government Press.

Dash V.B., transl. and ed. 1994-2001. Encyclopaedia of Tibetan Medicine: Being the Tibetan Text of Rgyud Bzhi and Sanskrit Restoration of Amrta Hrdaya Aștānga Guhyopadeśa Tantra and Expository Translation in English, vols. 1-7. Delhi: Sri Satguru Publications.

Davis R. 1976. The northern Thai calendar and its uses. Anthropos 71: 3-32.

Department of AYUSH 2010. "Introduction of Sowa-Rigpa." Website of the Ministry of Health and Family Welfare, Government of India. URL: <http://www.indianmedicine .nic.in/index3.asp?sslid=144\&subsublinkid=20\&lang=1 $>$. Last date of access 12.12.2010.

Desjarlais R.R. 1991. Samsara's Sadness: Sherpa Shamanism and the "Calling of Lost Souls." $\mathrm{PhD}$ thesis. University of California, Los Angeles.

-1992. Body and Emotion: The Aesthetics of Illness and Healing in the Nepal Himalayas. Philadelphia: University of Pennsylvania Press. 
1996. Presence. In The Performance of Healing, eds. C. Laderman, M. Roseman, pp. 143-164. London, New York: Routledge.

Diehl K. 2002. Echoes from Dharamsala: Music in the Life of a Tibetan Refugee Community. Berkeley and Los Angeles: University of California Press.

Diemberger H. 1993. Blood, sperm, soul and the mountain: gender relations, kinship and cosmovision among the Khumbo (N.E. Nepal). In Gendered Anthropology, ed. T. del Valle, pp. 88-127. London, New York: Routledge.

-2005. Female oracles in modern Tibet. In Women in Tibet, eds. J. Gyatso, H. Havnevik, pp. 113-168. London: Hurst \& Company.

Donden Y. 1977. The Ambrosia Heart Tantra - The Secret Oral Teaching on the Eight Branches of the Science of Healing. Dharamsala: Library of Tibetan Works and Archives.

Donden Y., Hopkins J. 1986. Health Through Balance: An Introduction to Tibetan Medicine. Ithaca, NY: Snow Lion Publications.

Dorje G. 2002. Tibetan Elemental Divination Paintings: Illuminated Manuscripts from The White Beryl of Sangs-rgyas rGya-mtsho with the Moonbeams Treatise of Lo-chen Dharmaśrī. London: John Eskenazi Ltd.

Dorje P., Richards E. 1981. Cures and concepts of Tibetan medicine. Tibetan Medicine 2: $1-83$.

Dreyfus G. 1998. The Shuk-Den affair: origins of a controversy. Journal of the International Association of Buddhist Studies 21: 227-270.

-2002. Tibetan religious nationalism: Western fantasy or empowering vision. In Tibet, Self, and the Tibetan Diaspora: Voices of Difference. PIATS 20oo: Tibetan Studies: Proceedings of the gth Seminar of the International Association for Tibetan Studies, Leiden 200o, ed. C. Klieger, pp. 37-56. Leiden, Boston: Brill.

Drungsto T.D. 2002. Tibetan Elemental Astrology: Ancient Tibetan Wisdom to Lighten Our Path of Progress and Guide Our Future. Dharamsala: Drungsto Publications.

Drungsto T.T. 2007. Basic Concepts of Tibetan Medicine: A Guide to Understanding Tibetan Medical Science. Dharamsala: Drungtso Publications.

— 2008. Tibetan Medicine: The Healing Science of Tibet. Dharamsala: Drungtso Publications.

Drungtso T.D., Drungtso T.T. 2005. Tibetan-English Dictionary of Tibetan Medicine and Astrology. Dharamsala: Drungtso Publications.

Durrenberger E.P., Tannenbaum N. 1989. Continuities in highland and lowland regions of Thailand. Journal of the Siam Society 77: 83-90.

Ekvall R.B. 1963. Some aspects of divination in Tibetan society. Ethnology 2: 31-39.

Emmerick R.E. 1975. A chapter from the rGyud-bzhi. Asia Major, Third Series XIX(2): 141162.

—. 1977. Sources of the rGyud-bzhi. Zeitschrift der Deutschen Morgenländischen Gesellschaft sup. 1.III, 2: 1135-1142.

—. 1990. rGas-pa gso-ba. Buddhica Britannica Series Continua II - Indo-Tibetan Studies: 89-99.

Emmerick R.E., Das R.P., eds. 1998. Vāgbhața's Aștāingahrdayasaṃhitā: The Romanised Text Accompanied by Line and Word Indexes. Groningen Oriental Studies. Groningen: Egbert Forsten.

Evans-Pritchard E.E. 1939. Nuer time-reckoning. Africa 12: 189-216.

Fabian J. 2000 [1983]. Time and the Other. New York: Columbia University Press.

Fantin M. 1976. Mani Rimdu, Nepal: The Buddhist Dance Drama of Tengboche. New Delhi: The English Book Store.

Fareedi M., Lepcha P.D., eds. 2002/2003. Area and Issue Profile of Darjeeling and Sikkim, Darjeeling: R.C.D.C. Hayden Hall.

Fenner E.T. 1996. The origin of the rGyud bzhi: a Tibetan medical tantra. In Tibetan Literature, Studies in Genre, eds. J. Cabezón, R. Jackson, pp. 458-469. Ithaca, NY: Snow Lion Publications. 
Frechette A. 2002. Tibetans in Nepal: The Dynamics of International Assistance among a Community in Exile. Oxford, New York: Berghahn Books.

Fürer-Haimendorf C. v. 1964. The Sherpas of Nepal: Buddhist Highlanders. London: John Murray.

—. 1990. The Renaissance of Tibetan Civilisation. Oracle, Arizona: Synergetic Press, Inc.

Garrett F. 2005. Ordering human growth in Tibetan medical and religious embryologies. In Textual Healing: Essays on Medieval and Early Modern Medicine, ed. E.L. Furdell, pp. 31-52. Leiden, Boston: Brill.

2006. Buddhism and the historicizing of medicine in thirteenth century Tibet. Asian Medicine: Tradition and Modernity 2: 204-224.

-2007. Embryology and embodiment in Tibetan literature: narrative epistemology and the rhetoric of identity. In Soundings in Tibetan Medicine: Anthropological and Historical Perspectives. PIATS 2003: Tibetan Studies: Proceedings of the 1oth Seminar of the International Association for Tibetan Studies, Oxford 2003, ed. M. Schrempf, pp. 411-425. Leiden, Boston: Brill.

- 2008. Religion, Medicine and the Human Embryo in Tibet. London, New York: Routledge (Routledge Critical Studies in Buddhism).

—. forthcoming. Mercury, mad dogs and smallpox: medicine in the Si tu paN chen tradition.

Garrett F., Adams V. 2008. The three channels in Tibetan medicine. Traditional South Asian Medicine 8: 86-114.

Geertz C. 1973. The Interpretation of Cultures. New York: Basic Books.

Gell A. 1992. The Anthropology of Time: Cultural Constructions of Temporal Maps and Images. Oxford: Berg.

Gellner D.N. 1992. Monk, Householder, and Tantric Priest: Newar Buddhism and its Hierarchy of Ritual. Cambridge: Cambridge University Press.

Gellner E. 1970. Concepts and society. In Rationality, ed. B.R. Wilson, pp. 18-49. Oxford: Basil Blackwell.

Gerke B. 1999a. On the history of the two Tibetan medical schools Janglug and Zurlug. AyurVijnana 6: 17-25.

-1999b. Mataji Kumari Cintury: Devi healer priestess of Darjeeling. Curare 22: 157-164. . 2007. Engaging the subtle body: re-approaching bla rituals among Himalayan Tibetan societies. In Soundings in Tibetan Medicine. Anthropological and Historical Perspectives. PIATS 2003: Tibetan Studies: Proceedings of the 1oth Seminar of the International Association for Tibetan Studies, Oxford 2003, ed. M. Schrempf, pp. 191-212. Leiden, Boston: Brill.

- 2010a. Tibetan treatment choices in the context of medical pluralism in the Darjeeling Hills, India. In Studies of Medical Pluralism in Tibetan History and Society. PIATS 2006: Proceedings of the 11th Seminar of the International Association for Tibetan Studies, Königswinter 2006, eds. M. Schrempf, S. Craig, F. Garrett, M. Cuomu, pp. 337-376. Andiast, Switzerland: International Institute for Tibetan and Buddhist Studies GmbH.

-2011. Correlating biomedical and Tibetan medical terms in amchi medical practice. In Medicine Between Science and Religion: Explorations on Tibetan Grounds, eds. V. Adams, M. Schrempf, S. Craig, pp. 127-152. Oxford, New York: Berghahn Books.

- in press. "Allegiance to whose community? Effects of Men-Tsee-Khang policies on the role and identity of amchi in the Darjeeling Hills," Healing at the Periphery: Ethnographies of Tibetan Medicine in India, ed. L. Pordié. Durham: Duke University Press.

- forthcoming. What is subtle about the medical body in Tibet? In Between Mind and Body: Subtle Body Practices in Asia and the West, eds. G. Samuel, J. Johnston. London, New York: Routledge (Routledge Studies in Asian Religion).

Gerl R., Aschoff J.C. 2005. Der Tschagpori in Lhasa: Medizinhochschule und Kloster. Ulm/ Donau: Fabri Verlag.

Germano D. 1997. Food, clothes, dreams, and karmic propensities. In Religions of Tibet in Practice, ed. D.S. Lopez, Jr., pp. 293-312. Princeton: Princeton University Press. 
Goldstein M.C. 1978. Ethnogenesis and resource competition among Tibetan refugees in South India. In Himalayan Anthropology: Indo-Tibetan Interface, ed. J.F. Fisher, pp. 395-420. The Hague: Mouton.

Goldstein M.C., Kapstein M.T. 1998. Buddhism in Contemporary Tibet: Religious Revival and Cultural Identity. Berkeley and Los Angeles: University of California Press.

Gombo U. 1985. Belief in karma and its social ramifications in samsāra. In Soundings in Tibetan Civilization. Proceedings of the 1982 Seminar of the International Association for Tibetan Studies, Columbia University, eds. B.N. Aziz, M.T. Kapstein, pp. 233-244. Delhi: Manohar Publications.

Gorer G. 1984 [1938]. Himalayan Village: An Account of the Lepchas of Sikkim. Gloucester: Alan Sutton.

Gutschow K. 1997. A study of 'wind disorder' or madness in Zangskar, northwest India. In Recent Research on Ladakh 7: Proceedings of the Sixth International Colloquium on Ladakh, eds. T. Dodin, H. Raether, pp. 177-202. Ulm: Ulmer Kulturanthropologische Schriften, University of Ulm.

Gyatso J. 2004. The authority of empiricism and the empiricism of authority: medicine and Buddhism in Tibet on the eve of modernity. Comparative Studies of South Asia, Africa and the Middle East Vol. XXX, No. 4 \& Vol. XXXI, No. 1: 83-96.

Gyatso L. 1990. Tibet: a state or a state of mind? Himal: Jan/Feb: 15.

Gyatso Y. Winter 2005 \& Spring 2006. Nyes pa: a brief review of its English translation. The Tibet Journal Vol. XXX, No. 4 \& Vol. XXXI, No. 1: 109-118.

Hastrup K. 1990. The ethnographic present: a reinvention. Cultural Anthropology 5: 45-61.

Henning E. 2004a. "Astrology associated with Kālacakra." URL: <http://www.kalacakra.org/ calendar/tibasto1.htm>. Last date of access: 20.12.2010.

- 2004b. "Natal astrology of the five components." URL: <http://www.kalacakra.org/ calendar/tibasto2.htm > . Last date of access: 20.12.2010.

- 2006. "A modern attempt at reform of the Tibetan calendar." URL: <http://www .kalacakra.org/calendar/calnew.htm>. Last date of access: 20.12.2010.

-2007. Kälacakra and the Tibetan Calendar. New York: American Institute of Buddhist Studies.

Hilgenberg L., Kirfel W. 1941. Vāgbhața's Aștāñgahṛdayasaṃhitā: Ein Altindisches Lehrbuch der Heilkunde. Leiden, Boston: Brill.

Hobbs J. 2006. Are Tibetan Calendars Wrong? An Anthropological Analysis of Tibetan Time-Reckoning Debates. M.Phil. thesis. Cambridge University, Cambridge.

- 2010. "History of the Tibetan calendar: the time-reckoning systems of India, Mongolia, China \& Tibet.” URL:< http://www.jacquelinehobbs28.blogspot.com>. Last date of access: 12.11.2010.

Hofer T. 2007. Preliminary investigations into the oral and textual sources on byangs lugs - the 'northern school' of Tibetan medicine. In Soundings in Tibetan Medicine. Anthropological and Historical Perspectives. PIATS 2003: Tibetan Studies: Proceedings of the 1oth Seminar of the International Association for Tibetan Studies, Oxford 2003, ed. M. Schrempf, pp. 373-410. Leiden, Boston: Brill.

- in press 2011. The Inheritance of Change: The Transmission and Practice of Tibetan Medicine in Ngamring. Vienna: Wiener Studien zur Tibetologie und Buddhismuskunde.

Holler D. 2002. The ritual of freeing lives. In Religion and Secular Culture in Tibet. Tibetan Studies II. PIATS 200o: Tibetan Studies: Proceedings of the gth Seminar of the International Association for Tibetan Studies, Leiden 200o, eds. H. Blezer, A. McKay, C. Ramble, pp. 207-226. Leiden, Boston: Brill.

Holmberg D. 1984. Ritual paradoxes in Nepal: comparative perspectives on Tamang religion. The Journal of Asian Studies 43: 697-722.

1989. Order in Paradox: Myth, Ritual, and Exchange among Nepal's Tamang. Ithaca, NY: Cornell University Press.

Hsu E. 1999. The Transmission of Chinese Medicine. Cambridge: Cambridge University Press. 
2000a. Spirit (shen), styles of knowing, and authority in contemporary Chinese medicine. Culture, Medicine and Psychiatry 24: 197-229.

- 20oob. Towards a science of touch, part II: representations of the tactile experience of the seven Chinese pulses indicating danger of death in early modern Europe. Anthropology and Medicine 7: 3-16.

- 2005a. Time inscribed in space, and the process of diagnosis in African and Chinese medical practices. In The Qualities of Time: Anthropological Approaches, eds. W. James, D. Mills, pp. 155-170. Oxford, New York: Berg.

2005b. Tactility and the body in early Chinese medicine. Science in Context 18: 7-34.

2007. The experience of wind in early and medieval Chinese medicine. Wind, Life, Health: Anthropological and Historical Perspectives. Journal of the Royal Anthropological Institute. Special Issue (eds. E. Hsu and C. Low): 117-134.

Hsu E., Low C., eds. 2007. Wind, Life, Health: Anthropological and Historical Perspectives. Journal of the Royal Anthropological Institute. Special Issue: iii-iv, 1-181.

Huber T. 1999. Putting the gnas back into gnas-skor: rethinking Tibetan pilgrimage practices. In Sacred Spaces and Powerful Places in Tibetan Culture: A Collection of Essays, ed. T. Huber, pp. 78-104. Dharamsala: Library of Tibetan Works and Archives.

Hubert H. 1999 [1905]. Essay on Time: A Brief Study of the Representation of Time in Religion and Magic. Oxford: Durkheim Press.

Humphrey C., Laidlaw J. 1994. The Archetypal Actions of Ritual: A Theory of Ritual Illustrated by the Jain Rite of Worship. Oxford: Clarendon Press.

IDP (International Dunhuang Project) 2010. "The international Dunhuang project: the silk road online." URL: <http://www.idp.bl.uk>. Last date of access: 06.02.2011.

Jackson M. 1996. Things as They Are: New Directions in Phenomenology. Bloomington: Indiana University Press.

Jacobson E.E. 200o. Situated Knowledge in Classical Tibetan Medicine: Psychiatric Aspects. PhD thesis. Harvard University, Cambridge, MA.

- 2002. Panic attack in a context of comorbid anxiety and depression in a Tibetan refugee. Culture, Medicine and Psychiatry 26: 259-279.

- 2007. 'Life-wind illness' in Tibetan medicine: depression, generalised anxiety, and panic attack. In Soundings in Tibetan Medicine. Anthropological and Historical Perspectives. PIATS 2003: Tibetan Studies: Proceedings of the 1oth Seminar of the International Association for Tibetan Studies, Oxford 2003, ed. M. Schrempf, pp. 225-245. Leiden, Boston: Brill.

- 2009. Panic illness in Tibetan refugees. In Culture and Panic Disorder, eds. E.H. Devon, B. Good, pp. 230-261. Stanford: Stanford University Press.

Jäger K. 1999. "Nektar der Unsterblichkeit" Zwei Kapitel aus der Tibetischen Kinderheilkunde: Übersetzung aus dem Tibetischen Originalwerk und Kommentar. Engelsbach, Frankfurt a.M., München, New York: Hänsel-Hohenhausen.

James W., Mills D., eds. 2005. The Qualities of Time: Anthropological Approaches. Oxford, New York: Berg.

Janes C.R. 1995. The transformations of Tibetan medicine. Medical Anthropology Quarterly 9: 6-39.

-1999a. The health transition, global modernity and the crisis of traditional medicine: the Tibetan case. Social Science and Medicine 48: 1803-1820.

-1999b. Imagined lives, suffering, and the work of culture: the embodied discourse of conflict in modern Tibet. Medical Anthropology Quarterly 13: 391-412.

- 2001. Tibetan medicine at the crossroads: radical modernity and the social organisation of traditional medicine in the Tibet Autonomous Region, China. In Healing Powers and Modernity: Traditional Medicine, Shamanism, and Science in Asian Studies, eds. L.H. Connor, G. Samuel, pp. 197-221. Westport, Connecticut and London: Bergin \& Garvey.

Jenkins R. 1997. Rethinking Ethnicity: Arguments and Explorations. London: Sage Publications. 
Jerstad L.G. 1969. Mani Rimdu: Sherpa Dance-Drama. Seattle and London: University of Washington Press.

Jest C. 1975. Dolpo: Communautés de Langue Tibétaine du Népal. Paris: Éditions du Centre National de la Recherche Scientifique.

Kalinowski M., ed. 2003. Divination et Société dans la Chine Médiévale: Étude des Manuscrits de Dunhuang de la Bibliothèque Nationale de France et de la British Library. Paris: Bibliothèque Nationale de France.

Kammerer C.A., Tannenbaum N., eds. 1996. Merit and Blessing in Mainland Southeast Asian Comparative Perspective. New Haven, Connecticut: Yale University.

Kapstein M.T. 200o. The Tibetan Assimilation of Buddhism: Conversion, Contestation, and Memory. Oxford, New York: Oxford University Press.

- 2006. The Tibetans. Oxford: Blackwell Publishing.

Karmay S. 1989. Vairocana and the rGyud-bzhi. Tibetan Medicine 12: 19-31.

- 1993. The wind-horse and the well-being of man. In Anthropology of Tibet and the Himalaya, eds. C. Ramble, M. Brauen, pp. 150-157. Zürich: Ethnological Museum of the University of Zürich.

- 1998. The Arrow and the Spindle: Studies in History, Myth, Rituals and Beliefs in Tibet. Kathmandu: Mandala Book Point.

Kelsang J., transl. 1977. The Ambrosia Heart Tantra: The Secret Oral Teaching on the Eight Branches of the Science of Healing. Dharamsala: Library of Tibetan Works and Archives.

Kennedy D. 1996. The Magic Mountains: Hill Stations and the British Raj. Berkeley and Los Angeles: University of California Press.

Keyes C.F., Daniel V.E., eds. 1983. Karma: An Anthropological Inquiry. Berkeley and Los Angeles: University of California Press.

Kilty G., transl. 2009. Translator's introduction. In A Mirror of Beryl: Historical Introduction to Tibetan Medicine, by Desi Sangye Gyatso, pp. 1-25. Boston: Wisdom Publications.

Kind M. 2002. Mendrub: A Bonpo Ritual for the Benefit of All Living Beings and the Empowerment of Medicine Performed in Tsho, Dolpo. Kathmandu: WWF Nepal Program.

Klieger P.C. 1992. Tibetan Nationalism: The Role of Patronage in the Accomplishment of a National Identity. Berkeley: Folklore Institute.

- 2002. Introduction. The quest for understanding the modern Tibetan self. In Tibet, Self, and the Tibetan Diaspora: Voices of Difference. PIATS 20oo: Tibetan Studies: Proceedings of the gth Seminar of the International Association for Tibetan Studies, Leiden 20oo, ed. P.C. Klieger, pp. 1-9. Leiden, Boston: Brill.

Kloos S. 2008. The history and development of Tibetan medicine in exile. The Tibet Journal 33: $15-49$.

2010. Tibetan Medicine in Exile: The Ethics, Politics, and Science of Cultural Survival. PhD thesis. University of California San Francisco \& Berkeley.

Kohn R.J. 1988. Mani Rimbdu: Text and Tradition in a Tibetan Ritual (Sherpa, Nepal). PhD thesis. University of Wisconsin, Madison.

Korom F.J., ed. 1997. Constructing Tibetan Culture: Contemporary Perspectives. Quebec: World Heritage Press.

Kuriyama S. 1999. The Expressiveness of the Body and the Divergence of Greek and Chinese Medicine. New York: Zone Books.

Lama Kunzang Dorje. 20o6. "The Jangsa Animal Saving Trust and how to save the lives of other living beings." URL: <http://www.animalsavingtrust.org>. Last date of access: 07.08.2007.

Langford J.M. 1995. Āyurvedic interiors: person, space, and episteme in three medical practices. Cultural Anthropology 10: 330-366.

Laufer B. 1914. Bird divination among the Tibetans. T'oung Pao 15: 1-110.

Lepcha D.T., Balikci-Denjongpa A. 2005. Tingvong: A Lepcha Village in Sikkim (Ethnographic Film). Gangtok: Namgyal Institute of Tibetology.

Lessing F.D. 1951. Calling the soul: a Lamaist ritual. Semitic and Oriental Studies 9: 263284 . 
Lichter D., Epstein L. 1983. Irony in Tibetan notions of the good life. In Karma: An Anthropological Inquiry, eds. C.F. Keyes, V.E. Daniel, pp. 223-26o. Berkeley and Los Angeles: University of California Press.

Lo V. 2001. Huangdi hama jing (Yellow Emperor's Toad Canon). Asia Major, Third Series XIV: 61-99.

—. 2005. Quick and easy Chinese medicine. Medieval Chinese Medicine: The Dunhuang Medical Manuscripts, eds. V. Lo, C. Cullen. 227-251. London, New York: Routledge.

—. 2010. Manuscrits de Dunhuang et de Khotan sur la moxibustion. In Médecine, Religion et Société dans la Chine Médiévale: Étude de Manuscrits Chinois de Dunhuang et de Turfan, 3 vols., ed. C. Despeux, pp. 239-284. Paris: Collège de France.

Lopez D.S., Jr. 1997a. "Lamaism" and the disappearance of Tibet. In Constructing Tibetan Culture: Contemporary Perspectives, ed. F.J. Korom, pp. 19-46. Quebec: World Heritage Press.

— 1997b. A prayer flag of Tārā. In Religions of Tibet in Practice, ed. D.S. Lopez, Jr., pp. 548-552. Princeton: Princeton University Press.

Loseries-Leick A. 1997. Psychic sports - a living tradition in contemporary Tibet? In Tibetan Studies. Proceedings of the 7 th Seminar of the International Association for Tibetan Studies, Graz 1995. eds. H. Krasser, M.T. Much, E. Steinkeller, H. Tauscher, pp. 583-592. Vienna: Verlag der Österreichischen Akademie der Wissenschaften.

Macdonald A.W. 1982, ed. Le Sikkim in Les Royaumes de l'Himâlaya. Histoire et Civilisation. Le Ladakh, le Bhoutan, le Sikkim, le Népal. Paris: Imprimerie Nationale.

Malinowski B. 1927. Lunar and seasonal calendar in the Trobriands. Journal of the Royal Anthropological Institute 57: 203-215.

Martin D. 2007. An early Tibetan history of Indian medicine. In Soundings in Tibetan Medicine. Anthropological and Historical Perspectives. PIATS 2003: Tibetan Studies: Proceedings of the 1oth Seminar of the International Association for Tibetan Studies, Oxford 2003, ed. M. Schrempf, pp. 307-325. Leiden, Boston: Brill.

Maurer P.H. 2001. Handschriften zur Tibetischen Hippiatrie und Hippologie. Bonn: VGH Wissenschaftsverlag.

McKay A. 2007a. Himalayan medical encounters: the establishment of biomedicine in Tibet and in Indian exile. In Soundings in Tibetan Medicine. Anthropological and Historical Perspectives. PIATS 2003: Tibetan Studies: Proceedings of the 1oth Seminar of the International Association for Tibetan Studies, Oxford 2003, ed. M. Schrempf, pp. 9-27. Leiden, Boston: Brill.

-2007b. Their Footprints Remain: Biomedical Beginning across the Indo-Tibetan Frontier. Amsterdam: Amsterdam University Press.

Meyer F. 1981. Le Système Médical Tibétain: Gso-ba Rig-pa. Paris: Centre National de la Recherche Scientifique.

—. 1990. Théorie et pratique de l'examen des pouls dans un chapitre du rGyud-bzhi. In Indo-Tibetan Studies: Papers in Honour and Appreciation of Professor David L. Snellgrove's Contribution to Indo-Tibetan Studies, ed. T. Skorupski, pp. 209-256. Tring: The Institute of Buddhist Studies.

— 1992. Introduction. In Tibetan Medical Paintings. Illustrations to the Blue Beryl Treatise of Sangye Gyamtso (1653-1705), eds. Y. Parfionovitch, G. Dorje, F. Meyer, pp. 2-12. London: Serindia Publications.

- 2003. The golden century of Tibetan medicine. In Lhasa in the Seventeenth Century: The Capital of the Dalai Lamas, ed. F. Pommaret, pp. 99-118. Leiden, Boston: Brill.

Middleton C.T. 2010. Beyond Recognition: Ethnoloy, Belonging, and the Refashioning of the Ethnic Subject in Darjeeling, India. PhD thesis. Cornell University, Ithaca, NY.

Millard C. 2002. Learning Processes in a Tibetan Medical School. PhD thesis. University of Edinburgh, Edinburgh.

_ 2007. Tibetan medicine and the classification and treatment of mental illness. In Soundings in Tibetan Medicine. Anthropological and Historical Perspectives. PIATS 2003: 
Tibetan Studies: Proceedings of the 1oth Seminar of the International Association for Tibetan Studies, Oxford 2003, ed. M. Schrempf, pp. 247-283. Leiden, Boston: Brill.

Miller B.D. 1956. Ganye and Kidu: two formalized systems of mutual aid among the Tibetans. Southwestern Journal of Anthropology 12: 157-170.

- 1958. Lamas and Laymen: An Historico-Functional Study of the Secular Integration of Monastery and Community. PhD thesis. University of Washington, Seattle, WA.

Mills M.A. 2003a. Identity, Ritual and State in Tibetan Buddhism: The Foundations of Authority in Gelukpa Monasticism. London, New York: RoutledgeCurzon.

- 2003b. This turbulent priest: contesting religious rights and the state in the Tibetan Shugden controversy. In Human Rights in Global Perspective: Anthropological Studies of Rights, Claims, and Entitlements, eds. R.A. Wilson, J.P. Mitchell, pp. 54-70. London, New York: Routledge.

- 2005. Living in time's shadow: pollution, purification and fractured temporalities in Buddhist Ladakh. In The Qualities of Time: Anthropological Approaches, eds. W. James, D. Mills, pp. 349-366. Oxford, New York: Berg.

Morris J. 1938. Living with Lepchas. London: William Heinemann.

Mortensen E.D. 2003. Raven Augury in Tibet, Northwest Yunnan, Inner Asia, and Circumpolar Regions; A Study in Comparative Folklore and Religion. PhD thesis. Harvard University, Cambridge, MA.

MTK (Men-Tsee-Khang). 2001. Fundamentals of Tibetan Medicine. Dharamsala: Men-TseeKhang.

—. 2006. "Men-Tsee-Khang turns 45." URL: <http://www.men-tsee-khang.org/archives/ 2006/turn45.htm>. Last date of access: 19.08.2010.

— transl. 2008. The Basic Tantra and the Explanatory Tantra from the Secret Quintessential Instructions on the Eight Branches of the Ambrosia Essence Tantra. Dharamsala: Men-Tsee-Khang.

—. 2010a. "Men-Tsee-Khang branch offices." URL: <http://www.men-tsee-khang.org/ branch/>. Last date of access: 10.09.2010.

—. 2010b. "Mission." URL: <http://www.men-tsee-khang.org/mission/index.htm>. Last date of access: 10.09.2010.

_ 2010c. "Rajya Sabha-bill passed to recognize Sowa-Rigpa system of medicine." URL: <http://www.men-tsee-khang.org/new_news/sowa\%2origpa.htm>. Last date of access: 28.09.2010.

_transl. 2011. The Subsequent Tantra from the Four Tantras of Tibetan Medicine. Dharamsala: Men-Tsee-Khang.

Mullin G.H. 1986. Death and Dying: The Tibetan Tradition. Boston, London, Henley: Arkana.

Mumford S. 1989. Himalayan Dialogue: Tibetan Lamas and Gurung Shamans in Nepal. Madison: University of Wisconsin Press.

Munn N.D. 1992. The cultural anthropology of time: a critical essay. Annual Review of Anthropology 21: 93-123.

Murthy S.K.R., transl. and ed. 1996. Vāgbhața's Așțānga Hridayam. Varanasi: Krishnadas Academy.

Nakane C. 1966. A plural society in Sikkim. In Caste and Kin in India, Nepal and Ceylon, ed. C. von Fürer-Haimendorf, pp. 213-263. Bombay: Asia Publishing House.

Norbu D. 2004. The settlements: participation and integration. In Exile as Challenge: The Tibetan Diaspora, eds. D. Bernstorff, H. von Welck, pp. 186-212. Delhi: Orient Longman.

Norbu N. 1995. Drung, Deu and Bön: Narrations, Symbolic Languages and the Bön Tradition in Ancient Tibet. Dharamsala: Library of Tibetan Works and Archives.

Nowak M. 1984. Tibetan Refugees: Youth and the New Generation of Meaning. New Brunswick, NJ: Rutgers University Press.

O’Malley L.S.S. 1989 [1907]. Bengal District Gazetteers: Darjeeling. Delhi: Logos Press. 
Orofino G. 1994. Divination with mirrors: observations on a simile found in the Kālacakra literature. In Tibetan Studies: Proceedings of the 6th Seminar of the International Association for Tibetan Studies, Fagernes 1992, vol. 2, ed. P. Kvaerne. 612-628. Oslo: Institute for Comparative Research in Human Culture.

Ortner S. 1989. High Religion: A Cultural and Political History of Sherpa Buddhism. Princeton: Princeton University Press.

—. 2006. Anthropology and Social Theory: Culture, Power, and the Acting Subject. Durham, NC: Duke University Press.

Parfionovitch Y., Dorje G., Meyer F., eds. 1992. Tibetan Medical Paintings. Illustrations to the Blue Beryl Treatise of Sangye Gyamtso (1653-1705). London: Serindia Publications.

Peek P.M. 1991. The study of divination, present and past. In African Divination Systems: Ways of Knowing, ed. P.M. Peek, pp. 1-22. Bloomington, IN: Indiana University Press.

Plaisier H. 2007. A Grammar of Lepcha. Brill's Tibetan Studies Library, Languages of the Greater Himalayan Region 5. Leiden, Boston: Brill.

—. 2010. "Selected bibliography of works concerning Lepcha language or culture." URL: $<$ http://www.lepcha.info/bibliography.htm>. Last date of access: 22.05.2011.

Ploberger F., transl. forthcoming. Die Vier Tantras der Tibetischen Medizin (1. und 2. Teil): Eine Übersetzung des Buches 'The Basic Tantra and The Explanatory Tantra from the Secret Quintessential Instructions on the Eight Branches of the Ambrosia Essence Tantra' basierend auf der Men-Tsee-Khang Publikation (2008). Schiedlberg, Austria: Bacopa.

Pordié L. 2008. Tibetan medicine today. Neo-traditionalism as an analytical lens and a political tool. In Tibetan Medicine in the Contemporary World. Global Politics of Medical Knowledge and Practice, ed. L. Pordié, pp. 3-32. London, New York: Routledge.

Prost A.G. 2004. Exile, Social Change and Medicine among Tibetans in Dharamsala (Himachal Pradesh), India. PhD thesis. University College London, London.

- 2006. Causation as strategy: interpreting humours among Tibetan refugees. Anthropology and Medicine 13: 119-130.

- 2008. Precious Pills: Medicine and Social Change among Tibetan Refugees in India. Epistemologies of Healing. Oxford, New York: Berghahn Books.

Ramble C. 1984. The Lamas of Lubra: Tibetan Bonpo Householder Priests in Western Nepal. D.Phil. thesis. University of Oxford, Oxford.

- 1996. Patterns of places. In Reflections of the Mountain: Essays on the History and Social Meaning of the Mountain Cult in Tibet and the Himalaya, eds. A.-M. Blondeau, E. Steinkeller, pp. 141-153. Vienna: Verlag der Österreichischen Akademie der Wissenschaften.

1997. Tibetan pride of place: or, why Nepal's Bhotiyas are not an ethnic group. In Nationalism and Ethnicity in a Hindu Kingdom: The Politics of Culture in Contemporary Nepal, eds. D.N. Gellner, J. Pfaff-Czarnecka, J. Whelpton, pp. 379-413. Amsterdam: Harwood Academic.

- 2002. Temporal disjunction and collectivity in Mustang, Nepal. Current Anthropology 43: $75^{-84}$.

2008. The Navel of the Demoness: Tibetan Buddhism and Civil Religion in Highland Nepal. New York: Oxford University Press.

Rauber H. 1980. The Humli-Khyampas of far western Nepal: a study in ethnogenesis. Contributions to Nepalese Studies 8: 57-80.

Risley H.H. 1894. The Gazetteer of Sikkim. Calcutta: Bengal Secretariat Press.

Róna-Tas A. 1956. Tally-stick and divination-dice in the iconography of Lha mo. Acta Orientalia Hungaricae 62: 163-168.

Rucinska A. 2007. Lunged Out in Bodh Gaya: Exploring the Meaning and Perceptions of Sog-lung among Western Participants of a Meditation Course. Master's dissertation. Brunel University, London.

Sagant P. 1996. The Dozing Shaman: The Limbus of Eastern Nepal. New Delhi: Oxford University Press. 
Saklani G. 1984. The Uprooted Tibetans in India: A Sociological Study of Continuity and Change. New Delhi: Cosmo Publishers.

Samuel G. 1993. Civilized Shamans: Buddhism in Tibetan Societies. Washington DC: Smithsonian Institution Press.

- 2001. Tibetan medicine in contemporary India: theory and practice. In Healing Powers and Modernity: Traditional Medicine, Shamanism, and Science in Asian Studies, eds. L.H. Connor, G. Samuel, pp. 247-268. Westport, Connecticut and London: Bergin \& Garvey.

-2005. Tantric Revisionings: New Understandings of Tibetan Buddhism and Indian Religion. Delhi: Motilal Banarsidass Publishers.

- 2008a (unpublished paper). "Tibetan longevity practices: the body in the 'Chi med srog thig tradition." Paper presented at the panel 'Theory and Practice of Healing, Medicine and Longevity in Buddhism,' XVth Conference of the International Association of Buddhist Studies (IABS), Atlanta, Georgia, June 23-28, 2008.

- 2008b (unpublished paper). "Amitayus and the development of tantric practices for longevity and health in Tibet." Paper presented at the International Conference, Transformations and Transfer of Tantra in Asia and Beyond, Freie Universität Berlin, December 1-3, 2008.

- 2010a. Possession and self-possession: towards an integrated mind-body perspective. In Spirit Possession and Trance: New Interdisciplinary Perspectives, eds. B.E. Schmidt, L. Huskinson, pp. $35^{-52}$. London and New York: Continuum (Continuum Advances in Religious Studies Series).

- 2010b. Inner work and the connection between anthropological and psychological analysis. In The Varieties of Ritual Experience. Section IV of Ritual Dynamics and the Science of Ritual. Volume II - Body, Performance, Agency and Experience (eds. A. Michaels et al.) eds. J. Weinhold, G. Samuel, pp. 299-314. Wiesbaden: Harrassowitz.

- 2010c. Healing, efficacy and the spirits. The Efficacy of Rituals Part II. Journal of Ritual Studies. Special Issue (eds. W.S. Sax and J. Quack) 24: 7-20.

- 2010d. A short history of Indo-Tibetan alchemy. In Studies of Medical Pluralism in Tibetan History and Society. PIATS 2006: Proceedings of the 11th Seminar of the International Association for Tibetan Studies, Königswinter 20o6, eds. S. Craig, M. Cuomo, F. Garrett, M. Schrempf, pp. 221-233. Andiast, Switzerland: International Institute for Tibetan and Buddhist Studies GmbH.

Samuel G., Cantwell C. (with contributions from R. Mayer and P. Ogyan Tanzin). forthcoming. The Seed of Immortal Life: Contexts and Meanings of a Tibetan Longevity Practice. Kathmandu: Vajra Books.

Schaeffer K.R. 2003. Textual scholarship, medical tradition, and Mahāyāna Buddhist ideals in Tibet. Journal of Indian Philosophy 31: 621-641.

- 2006. Ritual, festival and authority under the fifth Dalai Lama. In Power, Politics, and the Reinvention of Tradition: Tibetan in the Seventeenth and Eighteenth Centuries. PIATS 2003: Tibetan Studies: Proceedings of the 1oth Seminar of the International Association for Tibetan Studies, Oxford 2003, eds. B.J. Cuevas, K.R. Schaeffer, pp. 187-202. Leiden, Boston: Brill.

Schneider J. 2010. Vāgissvarakïrtis Mrtyuvañcanopadeśa, eine buddhistische Lehrschrift zur Abwehr der Todes. Vienna: Verlag der Österreichischen Akademie der Wissenschaften (Beiträge zur Kultur- und Geistesgeschichte Asiens, 66; Denkschriften der philosophisch-historischen Klasse, 394).

Schrempf M. 2007. Refocusing on Tibetan medicine. In Soundings in Tibetan Medicine. Anthropological and Historical Perspectives. PIATS 2003: Tibetan Studies: Proceedings of the 1oth Seminar of the International Association for Tibetan Studies, Oxford 2003, ed. M. Schrempf, pp. 1-6. Leiden, Boston: Brill.

Schuh D. 1973. Untersuchungen zur Geschichte der Tibetischen Kalenderrechnung. Wiesbaden: F. Steiner. 
2010. "Tibetische Zeitmaße." URL: <http://www.tibet-encyclopaedia.de/zeitmasse .html> . Last date of access: 21.12.2010.

Seitelberger S. 2010. Therapie in der Tibetischen Medizin. Eine Medizingeschichtliche und Sozialanthropologische Studie anhand Ausgewählter Kapitel des TibetischMedizinischen Basiswerkes rGyud bzhi. Mag. phil. thesis (Diplomarbeit). University of Vienna, Vienna.

Shakya T. 1993. Wither the tsampa eaters. Himal 6: 8-11.

Shaw M. 2007. Buddhist Goddesses of India. New Delhi: Munshiram Manoharlal Publishers Pvt.Ltd.

Shneiderman S. 2006. Barbarians at the border and civilising projects: analysing ethnic and national identities in the Tibetan context. In Tibetan Borderlands. PIATS 2003: Tibetan Studies: Proceedings of the 1oth Seminar of the International Association for Tibetan Studies, Oxford 2003, ed. C. Klieger, pp. 9-34. Brill: Leiden, Boston.

Shneiderman S., Turin M. 20o6. Seeking the tribe: ethno-politics in Darjeeling and Sikkim. Himal Southasian 19: 54-58.

Siiger H. 1967. The Lepchas. Culture and Religion of a Himalayan People. Part I. Results of Anthropological Field Work in Sikkim, Kalimpong, and Git. The National Museum of Denmark: Copenhagen.

Sivin N. 1987. Traditional Medicine in Contemporary China. A Partial Translation of Revised Outline of Chinese Medicine (1972) with an Introductory Study on Change in Present-day and Early Medicine. Ann Arbor: Center for Chinese Studies, University of Michigan.

Smith G.E. 2001. Among Tibetan Texts: History and Literature of the Himalayan Plateau. Boston: Wisdom Publications.

Snellgrove D.L. 1961. Himalayan Pilgrimage: A Study of Tibetan Religion. Oxford: B. Cassirer. Sogyal Rinpoche 1993. The Tibetan Book of Living and Dying. New Delhi: Rupa \& Co.

Spengen W. v. 2000. Tibetan Border Worlds: A Geohistorical Analysis of Trade and Traders. London: Kegan Paul International.

Sprigg R.K. 2005. Shedding Some Light on the History, Language and Literature of the Lepchas. Kalimpong: Indigenous Lepcha Tribal Association.

Stearns C., transl. 2007. King of the Empty Plain: The Tibetan Iron-Bridge Builder Tangtong Gyalpo. Ithaca, NY: Snow Lion Publications.

Steinmann B. 1996. Mountain deities, the invisible body of society: a comparative study of the representations of mountains by the Tamang and the Thami of Nepal, the Lepcha and Bothia of Sikkim. In Reflections of the Mountain: Essays on the History and Social Meaning of the Mountain Cult in Tibet and the Himalaya, eds. A.-M. Blondeau, E. Steinkellner, pp. 179-218. Vienna: Verlag der Österreichischen Akademie der Wissenschaften.

—. 2001. Les Enfants du Singe et de la Démone: Mémoires des Tamangs, Récits Himalayens. Nanterre: Société d'Ethnologie.

Strässle S. 2007. Biomedizin im Kontext. Medizin, Glauben und Moderne in den Darjeeling Hills, Indien. Zürich: Argonaut (Züricher Arbeitspapiere zur Ethnologie 17).

STSS (Sambhota Tibetan Schools Society) 2010. URL: < http://www.sambhota.org/index1 .html >. Last date of access: 17.12.2010.

Subba T.B. 1985. Caste and adaptation: the case of the Nepalis in Darjeeling. In The Himalayas: Profile of Modernisation and Adaptation, ed. S.K. Chanbe, pp. 72-90. New Delhi: Sterling.

- 1988a. Social adaptation of the Tibetan refugees in the Darjeeling-Sikkim Himalayas. The Tibet Journal 13: 49-57.

- 1988b. Migration and ethnic relations in Darjeeling and Sikkim. In Social Science and Social Concern: Felicitation Volume in Honour of Professor B.K. Roy Burman, ed. S.B. Chakrabarti, pp. 356-365. Delhi: Mittal Publications.

1989. Dynamics of a Hill Society: The Nepalis in the Darjeeling and Sikkim Himalayas. Delhi: Mittal Publications.

- 1990. Flight and Adaptation: Tibetan Refugees in the Darjeeling Sikkim Himalaya. Dharamsala: Library of Tibetan Works and Archives. 
. 1992a. Ethnicity, State, and Development: A Case Study of the Gorkhaland Movement in Darjeeling. New Delhi: Har-Anand Publications in association with Vikas Publishing House.

- 1992b. Tibetans in exile: economic pursuits and ethnicity. In Ethnicity and Politics in Central Asia, eds. K. Warikoo, D. Norbu, pp. 204-215. New Delhi: South Asian Publishers.

-2002. One or many paths: coping with the Tibetan refugees in India. In Dimensions of Displaced People in North-East India, ed. J.C. Thomas, pp. 131-148. New Delhi: Regency Publications.

Swancutt K. 2006. Representational vs. conjectural divination: innovating out of nothing in Mongolia. Journal of the Royal Anthropological Institute n.s. 12: 331-353.

Tannenbaum N. 1988. The Shan calendrical system and its uses. Mankind 18: 14-26.

Taube M. 1981. Beiträge zur Geschichte der Medizinischen Literatur Tibets. Sankt Augustin: VGH Wissenschaftsverlag.

THL (Tibetan and Himalayan Library) 2009. "The THL Tibetan dictionaries. Tibetan to English translation tool." URL: <http://www.thlib.org/reference/dictionaries/tibetandictionary/translate.php $>$. Last date of access: 22.05.2011.

Thrangu Rinpoche 2001. A Spiritual Biography of Rechungpa. Delhi: Dri Satguru Publications.

Tokar E. 2008. An ancient medicine in a new world: a Tibetan medicine doctor's reflections from 'inside.' In Tibetan Medicine in the Contemporary World. Global Politics of Medical Knowledge and Practice, ed. L. Pordié, pp. 229-248. London, New York: Routledge.

Torri D. 2010. In the shadow of the devil. Traditional patterns of Lepcha culture reinterpreted. In Health and Religious Rituals in South Asia. Disease, Possession and Healing, ed. F. Ferrari, pp. 148-165. London, New York: Routledge.

Tsogyal Y. 1999. The Lotus-Born: The Life Story of Padmasambhava. Boston: Shambala.

Tucci G. 1980. The Religions of Tibet. London: Routledge \& Kegan Paul Ltd.

Turton D, Ruggles C. 1978. Agreeing to disagree: the measurement of duration in a southwestern Ethiopian community. Current Anthropology 19: 589-593.

Vandenhelsken M. 2003. Secularism and the Buddhist monastery of Pemayangtse in Sikkim. Bulletin of Tibetology 39: 55-73.

Volkmann R. 1995. Female stereotypes in Tibetan religion and art: the genitrix/ progenitress as the exponent of the underworld. In Female Stereotypes in Religious Traditions, eds. R. Kloppenborg, W.J. Hanegraaff, pp. 171-212. Leiden, Boston: Brill.

Waddell A.L. 1978 [1895]. Buddhism and Lamaism of Tibet. Delhi: Asian Publishers.

Wallace V.A. 2004. The Kälacakratantra: The Chapter on the Individual Together with the Vimalaprabhā. New York: Columbia University's Centre for Buddhist Studies and Tibet House USA.

- 2008. A convergence of medical and astro-sciences in Indian tantric Buddhism: a case of the Kālacakratantra. In Astro-Medicine: Astrology and Medicine, East and West. Micrologus Library 25, eds. A. Akasoy, C. Burnett, R. Yoeli-Tlalim, pp. 209-222. Florence: Sismel Edzioni del Galluzzo.

- 2009a. The body as a text and the text as the body: A view from the Kālacakratantra's perspective. In As Long as Space Endures: Essays on the Kälacakra Tantra in Honor of H. H. The Dalai Lama, ed. E.A. Arnold, pp. 179-192. Ithaca, NY: Snow Lion Publications.

- 20ogb. Medicine and astrology in the healing arts of the Kālacakratantra. In As Long as Space Endures: Essays on the Kälacakra Tantra in Honor of H. H. The Dalai Lama, ed. E.A. Arnold, pp. 277-30o. Ithaca, NY: Snow Lion Publications.

Wangdu P., Diemberger H., transl. and eds. 2000. $d B a^{\prime}$ bzhed: The Royal Narrative Concerning the Bringing of the Buddha's Doctrine to Tibet. Vienna: Verlag der Österreichischen Akademie der Wissenschaften.

Wangyal S.B. 2002. Sikkim \& Darjeeling: Division \& Deception. Jaigon: Sonam B. Wangyal.

Wehr H. 1979. A Dictionary of Modern Written Arabic (Arabic-English). Wiesbaden: Harrassowitz. 
White D.G. 1996. The Alchemical Body: Siddha Traditions in Medieval India. Chicago and London: The University of Chicago Press.

Winder M. 1981. Tibetan medicine compared with ancient and medieval Western medicine. Bulletin of Tibetology 1: $5^{-22 .}$

Wujastyk D. 1998. The Roots of Āyurveda: Selections from Sanskrit Medical Writings. New Delhi: Penguin Books.

Wylie T. 1959. A standard system of Tibetan transcription. Harvard Journal of Asiatic Studies 22: 261-267.

Yamaguchi Z. 1992. The significance of intercalary constants in the Tibetan calendar and historical tables of intercalary months. In Tibetan Studies: Proceedings of the 5 th Seminar of the International Association for Tibetan Studies, Narita 1989, eds. I. Sho-ren, Y. Zuiho, pp. 873-895. Tokio: Naritasan Shinshoji.

Yan Z., Jingfeng C. 2007. Tibetan and Chinese pulse diagnostics: a comparison - with special reference to locations for pulse taking. In Soundings in Tibetan Medicine. Anthropological and Historical Perspectives. PIATS 2003: Tibetan Studies: Proceedings of the 1oth Seminar of the International Association for Tibetan Studies, Oxford 2003, ed. M. Schrempf, pp. 327-343. Leiden, Boston: Brill.

Yang Ga. 2010. The Sources for the Writing of the Rgyud bzhi, Tibetan Medical Classic. PhD thesis. Harvard University, Cambridge MA.

Yoeli-Tlalim R. 2008. Tibetan medical astrology. In Astro-Medicine: Astrology and Medicine, East and West, eds. A. Akasoy, C. Burnett, R. Yoeli-Tlalim, pp. 223-236. Florence: Micrologus Library.

2010. On urine analysis and Tibetan medicine's connections with the West. In Studies of Medical Pluralism in Tibetan History and Society. PIATS 2006: Proceedings of the 11th Seminar of the International Association for Tibetan Studies, Königswinter 2006, eds. M. Schrempf, S. Craig, F. Garrett, M. Cuomo, pp. 195-211. Andiast, Switzerland: International Institute for Tibetan and Buddhist Studies GmbH.

Yontan P. 1989. A history of the Tibetan medical system. Tibetan Medicine 12: $32-51$.

Zeitlyn D. 2001. Finding meaning in the text: the process of interpretation in text-based divination. The Journal of the Royal Anthropological Institute 7: 225-240.

Zimmermann F. 1987. The Jungle and the Aroma of Meats: An Ecological Theme in Hindu Medicine. Berkeley and Los Angeles: University of California Press.

Zivkovic T.M. 2008. In-Between Bodies: The Biographical Process of Tibetanised Lamas. $\mathrm{PhD}$ thesis. University of Adelaide, South Australia.

Zysk K.G. 1993. The science of respiration and the doctrine of the bodily winds in ancient India. Journal of the American Oriental Society 113: 198-213.

2008. The bodily winds in ancient India revisited. In Wind, Life, Health: Anthropological and Historical Perspectives, eds. E. Hsu, C. Low, pp. 99-109. Oxford: Blackwell Publishing.

\section{Tibetan Sources}

DLLS (Drepung Loseling Library Society) 1994. Tshe lha rnam gsum gyi gzungs. In Chos spyod rab gsal skal bzang skye bo'i mgul rgyan. A Collection of Devotional and Dedicational Prayers Recited in Religious Services in All Gelug Monasteries Including the Three Main Sects of Drepung, Sera and Ganden, pp. 573-577. Mundgod, Karnataka, India: Drepung Loseling Library Society.

Dorji J.N. no date (manuscript). Dpyad gsum 'bras rtsis rat na'i bad mdzod snang ba'i dga' ston. Lhasa. Personal collection Jampel Kaldhen, Kalimpong.

Lobsang Wangyal. no date. Bod kyi gso ba rig pa'i rgyud 'di nyid zab mo nang don rig pa dang 'brel ba'i kun khyab rtsis rig dang ji ltar 'brel tshul snying bsdus su brjod pa. Dharamsala: Bod gzhung sman rtsis khang. 
Nāgārjuna 1989 [translation ninth century?]. Sman dpyad zla ba'i rgyal po: The Somarājabhaisajyasādhanā, an Indian Medical Work by Nāgārjuna in its Tibetan Translation by Hashang Mahāyāna and Vairocana. Sman rtsis shes rig dpe mdzod. v. 135. Sde dge print. Leh: D.L. Tashigang.

NSWC (Nyingmapa Student's Welfare Committee) 2002. Snga 'gyur rnying ma'i chos spyod. Varanasi: Central Institute of Higher Tibetan Studies.

Pawo Tsuklak Trengwa. 1986 edition [sixteenth century]. Dam pa'i chos kyi khor lo bsgyur ba rnams kyi byung ba gsal bar byed pa mkhas pa'i dga' ston. Beijing: Mi rigs dpe skrun khang.

Sangye Gyatso, Desi. 1972 [completed in 1685]. Phug lugs rtsis kyi legs bshad mkhas pa'i mgul rgyan baidūr dkar po'i do shal dpyod ldan snying nor. New Delhi: Reproduced by T. Tsepal Taikhang as: The Vaidurya dkar po of sde-srid sans-rgyas-rgya-mtsho: The Fundamental Treatise on Tibetan Astrology and Calendrical Calculations.

_. 1982 [completed in 1688]. Gso ba rig pa'i bstan bcos sman bla'i dgongs rgyan rgyud bzhi'i gsal byed bai dūr sngon po'i ma lli ka, 2 vols. Lhasa: Bod ljongs mi dmangs dpe skrun khang.

Tsewang Lhamo. 1997. Lo tho'i shes bya rab gsal. Chengdu: Si khron mi rigs dpe skrun khang.

Vāgbhața [seventh century]. no date (manuscript). Yan lag brgyad pa'i snying po bsdus pa. In Gso rig, vol. he pa, pp. 88-669, folio 44b-335a. Dharamsala.

Yogini Kachö Deden Wangmo. no date (manuscript). Dpal ldan lha mo'i blang dor gsal ba'i me long sho mig grangs ldan. Personal collection Jampel Kaldhen, Kalimpong.

Yuthok Yönten Gonpo. 1984 [twelfth century]. Bdud rtsi snying po yan lag brgyad pa gsang ba man ngag gi rgyud. Dharamsala: Bod gzhung sman rtsis khang.

- 1992 [twelfth century]. Bdud rtsi snying po yan lag brgyad pa gsang ba man ngag gi rgyud. Darjeeling: Chagpori Tibetan Medical Institute.

Zurkhar Lodrö Gyalpo. 1991 [sixteenth century]. Rgyud bzhi'i 'grel pa mes po'i zhal lung, 2 vols. Dharamsala: Bod gzhung sman rtsis khang. 
Barbara Gerke - 978-90-04-21748-5 Downloaded from Brill.com๑4/26/2023 $\odot 2: 47: 13 \mathrm{PM}$ via free access 


\section{INDEX}

Adam, B., 34

Adams, V., 15-16, 27, 90, 122, 140n6, 164n25 adhișthāna, 170, 232

Agency, 36n26, 41 in anthropology, 41

situational agency, $3,4-6,10,36-37,39$, $41-42,136,196,287,290,295$

Ahearn, L., 41

almanac, 3, 5-6, 12, 36, 40, 97-98, 131-136 $177-181,186,189$

Alter, J.S., 162

Ama Tsamla, 100, 103, 111

ambrosia, 204

Amchi Jamyang, 26-28, 97, 125, 130, $132-135,147-151,153,156,160,163-164$, 171, 180, 182-183, 187, 193, 269n1

Amchi Kartsokyi, 26, 130, 151-153, 160

Amchi Künga, 26, 150, 155, 159

Amchi Penpa, 85n 5

Amchi Sonam Wangdu, 92n28

Amchi Tashi Namgyal, $85 \mathrm{n}_{5}$

Amchi Tsering Wangdue, 26, 64, 85n4

Amchi Yönten Gyatso, 121

Amitāyus, 29, 109-110, 199-201, 212, 229, $231,235,238,242,251,260,262,265,280$, 282

Amitāyus mantra, 200

Amitāyus mantra of Padmasambhava, 200 amulets, 7n5, 104

anatomy, 90, 91n25, 140, 143, 204

animal liberation practices, 12, 169, 171-172, 174-176, 219. See also srog bslu and tshe thar

Anthropology of time, 4-5, 10, 32-36, 295 cyclical versus linear time, 34

durational time, 34, 292

Fabian, Time and the Other, 34

Gell, The Anthropology of Time, 34, 35, 38

James and Mills, The Qualities of Time, $35^{-36}$

non-durational time, 34, 292

'oecological' and 'structural' time, 33

the quality of time, 33

Arora, V., 45n2, 46n4, 62n25, 229n2

Aschoff, J.C., 82n44, 86n9, $91 \mathrm{n} 20$

Aschoff, J.C. and Tashigang T.Y., 82n44
Asțāngahṛdayasaṃhitā, 89, 123n10, 162 astrology. See Tibetan astrology

Atiśa, 109, 113

auspiciousness, 1, 4, 7, 37, 39-40, 42, 97, $117,131,135,182,213-214,232,252,265$, 286, 292, 294-295

Avalokiteśvara, 108n57, 210, 234, 271n2

Āyurveda, 79n38, 96, 120, 123n10, 161-163

Âyurvedic medical literature, 91, 162, 203

bad kan, 12, 119-120, 125-127, 130-131, 134

Badaraev, B.D. et al., 91

Baidūrya dkar po, 93, 98, 138, 191, 206n17

Baiḍürya sngon po, 11, 29, 32, 90, 93, 122n9, $138-139,143-144,147,156,163,192$, 203-204, 208, 307

Balikci, A., 45n2, 46n4, 62, 229n2

bar chad lam sel prayer, 199-200, 210, 213

bar do, 9, 192

Barnes, B., 41n26

Barron, R., 107n54, 236, $25^{2}$

Barth, F., 61

Bates, D., 142n11

Beckwith, C., 88n11, 120

bell (dril bu), 246, 281

Bell, C., 47-48

Bellezza, J.V., 102

Berzin, A., 6, 93n3o, 178, 225, 291

Beyer, S., 106, 109-110, 191, 234, 236-238, 240, 242, 257, 263-264, 267-268

Bhaissajyaguru, $3^{1}$

Bhutan, 21n15, 46-47, 57, 62, 67, 76

Bhutanese Bhutia, 64

Bhutanese monastery, 22-23, 76, 306

Bhutia. See Tibetans

biomedicine, 79-81, 83, 174, 189, 288

bla, 7-9, 114-115, 119, 219-221, 288, 300. See also life-forces and five factors anthropological studies of, 137 iconographies of, 144, 147 in divination, 219-221 in external places, 138 in pebble calculations, 186-190, 194 in the Baidūrya sngon po, 139 in the Kälacakratantra, 144 in relation to pulse. See life-essence pulse 
in the Rgyud bzhi, 140

loss of bla, 8, 12, 83, 140, 145-146, 148, 151,

$156,160,163,169,186-190,235$

popular knowledge of, 141

possible origins of, 137

wandering around, 140-141, 188

western interpretations of bla loss, 189, 288

bla 'gugs tshe 'gugs, 111, 158, 188-189, 300. See bla rituals

bla g.yu. See turquoise stone

bla gnas, 8, 12, 136-144, 147-148, 151, 153n18, 160, 164, 301, 307

attached syllables of, 94, 139, 307 different versions of circulation, 138

importance for medical practice, 140

in astrological contexts, 138

in horses, 137n2, 176

in medical paintings, 139, 307

in the Baidūrya sngon po, 143, 307

in the Kälacakratantra, 144

in the Rgyud bzhi, 141

bla gza'. See vitality tables

bla rituals, 98, 111, 132, 137, 148, 153

bla rtsa. See life-essence pulse

bla tables, 135, 138-139, 143, 147-154, 308-315

three different traditions in MTK bla table, 147, 308-315

blessing. See byin rlabs

Bloch, Marc, 31

Bloch, Maurice, 34, 292

bloodletting, $85 \mathrm{n} 5,132,137 \mathrm{n} 2,141,15^{2}$, 309, 314

bod sman. See Tibetan medicine

bodhicitta, 4n2, 107n56, 235, 278, 285

breath control practices, 13, 201-205

breath retention, 13, 202, 204

bum pa can, 203-205

exhalation, 13, 128, 156, 202

holding one's breath, 204

inhalation, 13, 128, 156, 202

unrestricted breathing, 203-204

brtan bzhugs, 24-25, 107-108, 240, 254

bsod nams. See merit

byin rlabs, 5, 14, 80, 231-235, 237, 245,

251-252, 255-257, 270, 279, 283, 293-294

and visulalisation, $263-268$

efficacy of, 256, 260

link to merit and karma, 170-171

Cabezón, J.I., 105n51, 108, 210 n1

Cabezón, J.I. and Jackson R., 88

Cantwell, C., 112n63, 192n1

Cantwell, C. and Mayer, R., 107 census data, 56

Central Council of Tibetan Medicine

(CCTM), 84-85, 87

Central School for Tibetans, 25, 65, 67,

74

Central Tibetan Administration-in-exile

(CTA), 57-58, 67n28, 76n37, $25^{2}$

Central Tibetan Relief Committee (CTRC), 67 n29

Chagpori Medical College, Lhasa, 86-87

Chagpori Tibetan Medical Institute, Darjeeling, xxi, 18, 23, 25, 31, 76n 37 , 85-87, 89n14, 91n26, 122n9, 132n20

Chatral Sangye Dorje Rinpoche, 175

cheating death, 109n6o, 112-113, 173, 203

'chi med srog thig, 107, 199n6, 235, 254, $304 n 4$

Childs, G., 57n14, 225, 236, 256

Chime Radha Rinpoche, 100, 195

China, 27, 48, 55, 63, 79n38, 87-88, 93n31, $95,138,155,198$

Chinese 'prohibition literature', 141-142

Chinese medicine, 36n21, 113, 154

Chinese pulse diagnosis, 154

Chögyal Namkhai Norbu Rinpoche, 139

Clark, B., 91, 120n1, 122n9, 162

Clarke, G.E., 99nn45-46, 170, 183, 210, 233, 255,257

Clifford, T., 91

Comaroff, J. and Comaroff, J., 41n26, 42 communication

between lama and public, $25^{6-258}$, 293-294

through byin rlabs, 14, 257

consciousness. See rnam shes

Craig, S.R., 17

Dagmo Kalden, 269, 272

Dalai Lama

fifth Dalai Lama, 39-40, 86-87, 90, 143n12, 175

first Dalai Lama, 109, 191

fourteenth Dalai Lama, 11, 54-55, 62, $65^{-67}, 76,82,96,104 n_{50}, 112,124,171$, 185, 230, 244n14

second Dalai Lama, 109n 58

thirteenth Dalai Lama, 48

dam tshig, 231

Daniels, C., 55n13, 99, 172, 232

Darjeeling history of, 46-56 population, $56-57$

Darjeeling Gorkha Hill Council, 51-52

Darjeeling Hills

historical and political climate, $45^{-56}$ 
migration to, 48-49

Nepali nationalist movement, 10, 51, $53,5^{8}$ reservation system among ethnic groups, $58-59$

The Agitation, 10, 52-54

Tibetan Buddhist monasteries, 75-79

Dash, V.B., 91024

Davis, R., 38, 40

dbang thang. See five factors

death of children, 167, 198, 201

death rituals, 196, 205, 265n19, 273

deathlessness, 203n11, 205, 219, 235

Department of AYUSH, $17 \mathrm{n} 12$

Desi Sangye Gyatso, 39-40, 86, 90-93, 122n9, 137-138, 140, 143-144, 147-148, 163, 203-204, 205n15, 307

Desjarlais, R., 7, 137, 208

Dharamsala, 11, 16, 26-27, 54, 57, 62, 64, 67n28, 69-70, 77, 79n38, 81, 82n43,

84-87, 89n14, 91n26, 92, 96, 112, 124, 147,

151, 154, 16o-161, 179n6, 252, 287

dhäraṇi, 107-108, 200, 212, 219

Dhardo Tulku Rinpoche, 27, 215-216, 218

Dharmo Mänrampa Lobsang Chödrak, 139n 4

dhātu, 162

dice divination, $27,99,100,102,188$, 215-223

Diehl, K., 11, 15, 66n27, 69

Diemberger, H., 9n7, 21n17, 102-103, 137-138, 216n3

Dinchen Rinpoche, 205n16

divination (mo), 7-9, 13-14, 27-28, 8o, $82-83,88,96,99-105,167,171,174$, 176-178, 188-190, 195, 202, 205, 207-226 ambiguity in answers, 221-224 and astrology, 92-99 issues of accuracy, 14, 31, 37-38, 98, 206-207, 221, 226, 291

diviner ( $m o$ pa), 28, 96, 100-104, 208-210 dngos grub. See siddhi

Dolgyal. See Dorje Shukden

Donden, Y., 91, 120, 154-155

Donden, Y. and Hopkins, J., 91

Dorje Shukden, 104, 112

Dorje, G., 92n28, 93-94, 98-99, 137-138, 178, 18on10, 182, 191, 206n17, 299

Dr. Graham's Homes, Kalimpong, 52-53, 74, 75 n 34

Dr. Pema Dorje, 26, 28-29, 155-158, 161, $163^{-165}, 226,292$

Drepung, 24, 86

Dreyfuss, G., 16

Drukpa Kagyü, $21 n 15$
Dudjom gter gsar school, 23, 71n33, 76, 306 Dudjom Rinpoche Jigdral Yeshe Dorje, 22, 230

Dudjom tradition, 107, 235, 254

Dunhuang, 88, 138-139, 141, 144

Durpin Gompa, Kalimpong, 22, 71-73, 186, 188, 231, 241, 244-250, 253, 306

Durrenberger, E.P. and Tannenbaum, N., 170

dus tshod, 95, 128, 135n23, 156, 313

Dzongsar Jamyang Khyentse Rinpoche, 229

efficacy of medical treatment, 11, 79-80

eight trigrams, 94, 189, 191

Ekvall, R.B., 10on48, 178n5

Emmerick, R.E., 89, 91

empowerments (dbang), 5, 106, 108, 112, 161, 170-171, 181, 201, 227, 229-230, 234-236, 237n11, 243, 252, 257, 271 efficacy of, 14, 264, 285 point of receiving, 258 motivation for receiving, 285

Evans-Pritchard, E.E., 33

expert knowledge, 5, 41, 80, 113-114, 133, 287

Fabian, J., 33-34

five Chinese elements, 96,178

five elements, 37, 95-97, 99, 117, 119-120, 122, 127-128, 131, 133, 151, 156, 162, $179,184-185,188,248,263,266$

five factors, $12-13,97-98,167,169$, 176-188, 190-191, 194, 222, 292 bla, 97-98, 177, 186-187, 300 dbang thang, 97, 177, 180, 182-183, 189-190, 194, 305

lus, 97, 177, 181-182, 188-189, 194, 305 rlung rta, 97, 104, 177, 180, 182-186, 188, 194, 292, 304

srog, 97, 177, 181-182, 186, 188-190, 194, 299

five factors, $97 \mathrm{n} 43$

foreign patrons, 256

fumigation ritual, 184

Fürer-Haimendorf, C.v., 66n27, 234

Ganden government, 39, 40, 48, 86-87, 175

Gangtok, Sikkim, 24, 26, 67nn29 and 31, 78, $85,102-103,108,253,259,261-262$

Garrett, F., 84, 89-9o, 91n25, 147, 164n25

Garrett, F. and Adams, V., 90, 140n6, $164 n 25$

Geertz, C., 33

Gell, A., 34-35, 38

Gell. See also Anthropology of time 
Geluk, 21, 40, 76, 78, 104, 108-109, 188, 216, 236ng, 253, 269nı, 306

Gergan Dorje Tharchin, $5^{0}$

Gerke, B., 25nn19-20, 64, 79n39, 8o-81, 86n8, 90, 103, 111n61, 137n1, 140n6, 164n25 Gerl, R. and Aschoff, J.C., 86ng

Ghum, Darjeeling, 8-9, 24-25, 73, 76, 102, 108, 133, 208-211, 227, 234, 238-239, 244, $253,262,268-272,276,280-281,283$, 293-294, 306

Goldstein, M.C., 66n27

Goldstein, M.C. and Kapstein, M.T., 15, 61 good fortune, 97, 99n46, 177, 182, 184-186, 233, 302, see also rlung rta gshed gza'. See vitality tables Gso rig sman gyi khog 'bugs, 91 gtor ma, 234, 237, 239, 243, 247, 249, 255, 279, 280. See also tshe gtor

Gyatso, J., 31, 87, 89n16, 9o, 91n25, 164n25 Gyatso, L., 16, 73

Hastrup, K., 18

Henning, E., 37n22, 94nn34-35, 95, 97, 128n16, 132, 139, 140n $5,144,148 \mathrm{n}_{15}$, 178-179, 181-182, 184, 186, 225n8, 226, 291, 308n5, 313nnio-11

HIV Aids, 276, 284-285

Hobbs, J., 38, 96n40, 291

Hofer, T., 86n8

Holler, D., 174n2, 175

Hsu, E., 36n21, 113-114, 121n6, 126, 138, $142-143,154,159,216$

Huber, T., 138, 232

Hubert, H., 33

immortality, 108, 199, 202, 233 inauspicious day. See vitality tables individual Buddhist practitioners, 233, 258-263

Indo-Tibetan Buddhist Cultural Institute (ITBCI), 24, 27, 74, 215, 218 International Trust for Traditional Medicine (ITTM), 18, 22, 26

Jacobson, E.E., 54, 55n11, 70-71, 122, 303n3 Jäger, K., 91 James, W. and Mills, D., 35-36 Jamgön Mipham Gyatso, 139n4 Jampel Kaldhen, Kalimpong, 24, 27-28, 74, 97, 99n46, 180, 182, 188-189, 193, 213, 215-218, 221, 226, 230, 265n19, 266, 269nı Janes, C.R., 27, 96, 122n7, 124

Jangsa Gompa, Kalimpong, 22-23, 75n36, 101-102, 107, 172, 175, 177, 254, 306
Jelep La, 47-48

Jenkins, R., 73

Kagyü, 21, 76, 108-109, 236, 306

Kälacakratantra, 93-95, 123, 127n14, 128, 140, 143-144, 148, 308

Kalimpong

history of, $45^{-56}$

population, $56-58$

trade route, $47-49,52,55,57,65$, 74, 76

See also Darjeeling Hills

Kammerer, C.A. and Tannenbaum, N., 170

Kapstein, M.T., 21n15, 88, 143, 200n8

karma. See merit

Karmay, S., 88, 89n16, 90, 111n61, 137, 183-185

Kelsang, J., 91

Kesang Tseten, 75n34

Khampa Social Welfare Organisation, Gangtok, 253

Khen Rinpoche, Ngawang Jinpa, Darjeeling, 24, 78, 110, 268

Khön family, Tsang, Central Tibet, 269

'khyams pa, 140-141, 188

Kilty, G., 91

Klieger, P.C., 11, 15, 66n27, 76

Kloos, S., 11, 16n11, 81, 85-86

Kongtrul Rinpoche, 107n54, 236, 252

Korom, F.J., 11

kumbhaka, 203, See also breath control practices, bum pa can

Kyabje Dudjom Yangsi Rinpoche, 22, 28, 230-231, 240, 244-245, 247-248, 253-254

Ladakh, 36, 67, 76n37, 85, 94n32, 136, 214

Lama Chime, Kalimpong, 247

Lama Kunzang Dorje, Kalimpong, 22, $25,28,172,175^{-176}, 231,240-241,264$, 266-267

Lama Tsewang, Kalimpong, 29-30, 76, 262

Lang Darma, 2oon8

Lepchas, 1on1o, 46, 56, $59 n n 17$ and 19, 74, 76,229

Lha Totori, 111

Lhasa, 15-16, 26, 39-40, 47-51, 55, 57, 61, $67,74,85 \mathrm{n}_{5}, 86-87,90,92 \mathrm{n} 28,151,154$, 16o, 175, 198

Lhatsün Namkha Jigme, 229

life channels, 9, 140, 155, 163-164, 181

life extension, 8, 108, 111, 173, 258, 293

in Tibetan royal mythology, 111

life-essence day. See vitality tables 
life-essence pulse (bla rtsa), 4, 12, 26, 93, 140, 144, 146, 154-157, 159-165, 289

life-force day. See vitality tables life-forces. See also bla, five factors bla tshe occuring together, 144-146, 235 control through breath, 201-205 divination of, 219-221 loss of bla and mdangs mchog, 163-165 mdangs mchog, 12, 117, 161-165, 288-290, 204

physical location of, 115, 138-140

popular knowledge of, 98, 114, 141, 147, 295, 299-305

srog, 7-8, 40-41, 119, 131-133, 145, 174, $176-177,180-182,186,188-190,199$, 207, 215-221

srog and tshe interlinked, 181

tshe, srog, and bla as a trinity, 8, 299

life-span (tshe)

accepting the end of, 205-206

as a linear concept, 3

as a reservoir, 3, 8-9, 224, 299

considered fixed, 202

considered flexible, 201-202, 225

correlations to the pulse beat, 12 ,

154-161, 289

divination of, 174, 207-214, 221-226

is completed, $205^{-206}$

is completed (tshe tshar ba), 13, 205-206

is exhausted (tshe 'dzad pa), 13, 174, 207-214

long life-span, 125-126

maximum life-span (tshe lo), 7, 13, 95,

114, 127n14, 157, 167, 191-192, 201-203,

205, 222-223, 301

medium life-span, 125-126

measured by breaths, 203

predictions of, $13,37-38,157-159,161$,

174, 207-214, 221-226, 291

prognosis through pulse diagnosis, 157-159

remaining life-span (tshe lhag), 7,13

$127,170,182,192-193,196-198,201$, 302

short life-span, 125-126, 171, 192-193, 197-201, 242

ups and downs, 219, 221

life-wind (srog rlung), 122, 134-135, 161, 303

lo ma kyong ma empowerment, 269, 271, 276,284

long life. See also life-span

of the Dalai Lama, 82, 171

longevity attainment practices. See tshe sgrub longevity deities. See also three long-life deities

local variants of, 229

longevity pilgrimage, 198-199, 201

longevity practices, 200. See also tshe dbang, tshe sgrub as part of Buddhist retreats, 173 efficacy of, 14, 113, 230, 243, 264, 285 kept secret, 202, 204, 247 motivation for, 173, 227, 270, 278, 285

longevity rituals. See also tshe sgrub, tshe dbang, and brtan bzhugs

'inner work', 238, 266n2o, 294

to ransom srog, 220, 299

longevity sādhana, 107, 236, 242, 279

long-life arrow (tshe dar), 245, 248, 250-251, 258, 263, 265-267, 281

long-life empowerments. See tshe dbang long-life goddesses, 229

long-life gtor ma. See tshe gtor

long-life nectar (tshe chu), 237-240, 245, 248, 258, 26o, 262, 265, 279, 283-284

long-life pills (tshe ril ), 171, 235, 237-238, 240, 243, 245, 248, 258, 260, 262, 265, 279, 282, 284

long-life vase (tshe bum), 237-238, 258, $260,263,265,279,282$

Lopez, D.S. Jr., 7n4, 186n13

Lord of Death. See Yamāntaka

lus. See five factors

ma bu dgra grogs cycle.

See mother-son-enemy-friend cycle

Machig Drupä Gyalmo, 242

Mahāyāna, 4, 87, 92, 109, 111, 191

Malinowski, B., 33

Mani Lhakhang, Kalimpong, 65, 76, 110, 253, 306

Mani Nyungne Kidu, Ghum, 238, 244, 253-254, 280

Mani Rimdu ritual, 229, 234, 265, 267

mantra, 5, 7n $5,9,21,71,78,80,83,94,107$, 108n57, 110, 134, 152-153, 181, 185, 200, 204, 209-214, 217, 221, 231, 234, 237, 247, 26o, 263, 265, 269n1, 284-285, 309

Maratika, halesi, 198- 199, 230

Martin, D., 89

mata, 81, 103-104

mātrās, 204

maximum life-span. See Life-span

McKay, A., 48, 81

Medicine Buddha, 31, 89

Men-Tsee-Khang, Dharamsala, 16-17, 26-27, 29, 64, 80-81, 85, 89n14, 91-92, 
96-97, 12onn1-2, 122ng, 129, 132n2o, 148, 157-16o

amchi rotation scheme, 25,64

annual almanac, 131, 179, 186

bla table, 139, 143, 147, 151-154, 308-315

branch clinic, 26, 64, 80-81, 87, 129-130, 133-134, 149-150, 157, 212, 288

history of, $85^{-86}$

medical camps, 81-82, 157, 171

relationship with CTMI, 87

syllabus, 85,176

Mentsikhang, Lhasa, 26, 86, 151, 154, 160 merit and karma, 8, 12, 167, 169, 171, 174,

191, 199, 201, 233

enhancing social status in community, 171

merit transfer, 82

merit-making activities, 170-172

Mes po'i zhal lung, 143-144

Meyer, F., 86-87, 89n16, 90-91, 143, 154-155

Middleton, C.T., 1ong, 51, 58n15, 59

Milarepa, 242

Millard, C., 9n7, 29, 91n26, 111n61, 122n7, 140n6, 163

Miller, B., 45, 55n13, 74-77

Mills, M.A., 29, 36-37, 40, 94n32, 98, $104 n_{50}, 136,138,171,196,214,232 n_{4}$

mind (sems), 191-192, 199, 251, 265, 268

missionaries, 48, 50, 74

mkhris pa, 12, 119-120, 124-127, 130

Momola, 13, 100, 207-215, 224-226, 243, 284, 291-292

Mongolia, 87

Mongolian divination, 195

mother-son-enemy-friend cycle, 178, 186, 3oon1

Mount Kanchenjunga, 46-47

movement of bla through the body. See blagnas

moxibustion, $85^{\mathrm{n}} 5,13^{2}$

134-136, 141-142, 148, 152, 212-213, 309

Mullin, G., 109, 191, 207

Mumford, S., 39, 137, 186, 192-196, 290

Mungpoo Rinpoche. See Dinchen Rinpoche

Munn, N.D., 34

Nathu La, 48

nectar hour (bdud rtsi thun mtshams), 132-136

Nepal, 17, 25n2o, 46, 48-49, 54, 56, 57, $62 \mathrm{n} 25,85,91 \mathrm{n} 26,99 \mathrm{n} 45,102,104 \mathrm{n}_{50}, 141$, $163,170,192-193,198-200,208,210-211$, 229, 234, 236, 244n14, 257
Nepali Ghorkas, 49

Nepali-Bengali conflict, $5^{1}$

nine numeric squares, 93, 176n4, 189, 191

Norbu, D., 66n27, 67-68

North Bengal, 26

Nyerongshar, Rigzin Lhundrub Paljor, 87

nyes pa. See three nyes pa

Nyingma, 21-23, 71, 76, 108, 199, 229-230, 234-235, 242, 253, 262, 280, 306

obstacle (bar chad), 3-4, 7-8, 37, 40, 96-97, 110, 159-161, 172-175, 180, 184, 199-200, 207, 210-215, 218, 221-222, 224, 231, 271, 289-290, 292, 295, 299

obstacle year (lo skak), 96, 128, 167, 180, 195, 199-201, 213, 291

ōjas, 162, See life-forces, mdangs mchog

om ma ni padme hung, 234

Ortner, S., 41n26, 42, 5on9

Other Backward Classes (OBC), 59

Padmasambhava, 71, 107-108, 111, 199-200, 209-210, 229, 231, 265, 278

Palden Lhamo, 13, 27, 37, 176, 188, 215-217, 221, 224

Palden Lhamo divination, 13, 207, 216-223, 292, 299

Palden Lhamo Magsor Gyalmo, 215

Parfionovitch,Y., Dorje, G. and Meyer, F., 9on18, 93, 115, 122ng, 138-139, 143-146, 154-157, 299, 307

Pawo Tsuklak Trengwa, $111 n 62$

pebble calculations, $178-180,184,186-190$, 194

Pedong, 24, 47, 71, 108, 205, 230, 253-255, 260, 293, 306

Penpa Yeshi, Kalimpong, 52-53

'pho ba lung, 271, 273

Phugpa Lhundrup Gyatso, 147, 148n15, 308

phur ba, 152, 285, 309

Ploberger, F., 91

Pokhriabong, 67

pollution (grib), 36, 97, 171-172, 214

polysemous nature of medical terms, 36 , 120, 138, 143

Pordié, L., 16

practices of temporalisation, 4, 6, 9-10, $33,37,41-42,115,131,154,195,197,286$, 289-290, 295

prāṇa. See rlung

prayer flags, 48, 104, 184-186, 272, 304

precious pills (rin chen ril bu), 82, 131

primary cause (rgyu), 172-173 
Prof. Ngawang Jinpa, Darjeeling. See Khen Rinpoche

Prof. Samten Norbu, Darjeeling, 24, 242n13 Prost, A.G., 11, 62n22, 66n27, 67, 69, 77, 79, $81,82 n_{43}, 122 n 7,124,303 n 3$

protective cords (tshe srung), 258, 261, 271, 284

pulse beat, $6,12,114,136,154,156-160,165,289$ as a temporal framework, 154, 159, 289 synchronicity, 158

pulse diagnosis, $8,93,96,114,120 n 2,117$, $126,154-157,159,160,289$

prognostic methods, $155^{-156,289}$

related to breath, 156

$q i, 142$

rainbow body, 251

Ramble, C., 39, 61-62, 73, 77, 94n32, 111n62, 112, 145n14, 224, 293

Ratna Vajra Rinpoche, 252, 257, 269, 270, 272, 277, 281, 284-285

Ratna Vajra Trizin Rinpoche, 269

Ravangla, Sikkim, 67

Rechungpa, 242

refugee (btsan byol pa), 45, 49, 53, 56-67, $60-71,287$

refugee certificate (RC), 6o, 63, 74

remaining life-span. See life-span

renshen ('human spirit'), 138-139, 142

Rgyud bzhi, 11-12, 29, 31-32, 84, 89-91, 119, 120n2, 121, 122n9, 123nn10-11, 124-127, 129-130, 137n2, 140-141, 143, 154-157, 162-163, 164n24, 172, 181, 192, 204, 208, 288, 299, 301-303

as a religious text, 31

authorship of, 31, $89 n 16$

debates about the origin, 89

history of, 88-90

memorisation of, 29, 32, 91, 155

oral instructions, 32

principles of physiology, 96, 119-122, 162 times for medication, 129-131

translations of, 91

Rinchen Zangpo, 89, 113

ritual arrow (mda' dar), 265-267. See also long-life arrow

ritual efficacy, 14, 81-82, 113, 230, 237, 243, 263-264, 267-268, 285

ritual sheep (bla lug), 189

rjes gnang, 236

rlung, 12, 119-120, 122-127, 130, 132n21, 134, 202, 205n15. See also three nyes pa and life-wind rlung rta. See five factors

rnam shes, 9, 192

Róna-Tas, A., 10onn48-49, 216

rosary divination, 209

rta phyag khyung gsum empowerment, 271

rten 'brel, 98-99, 100n47, 156, 233

sādhana, 107, 235n6, 236, 242, 279

Sakya, 21n15, 108, 227, 230, 235, 257, 262-263, 269, 274-277, 278n4, 284-285, 293

Sakya Guru Gompa, Ghum, 133, 210-211, 268-269, 273, 281, 283-284, 306

Sakya Trizin Rinpoche Ngawang Künga, 230

Salugara, 26, 150, 157-159, 269

samaya. See dam tshig

Sambhota Tibetan Schools Society (STSS), $67 n 31$

Samuel, G., 21n16, 71, 77, 79, 8on40, 81, 86, 88n13, 97, 99, 102, 107, 109, 121, 139n4, 170-171, 174, 177, 186, 199n6, 214, 232, 234-235, 237, 239-240, 266n2o

Samuel, G. and Cantwell, C., 107

sbyin bdag. See sponsor

Schaeffer, K.R., 7, 39-40, 86, 147

Scheduled Castes (SC), 59

Scheduled Tribes (ST), 59-6o, 62-63, $67-68,74-75$

Schneider, J., 109n6o, 111-113, 162, 173, 191, 203-204

scholarly medical traditions, 121n6, 142

Schrempf, M., 6n3, 17, 79n38

Schuh, D., 93n31, 94, 98-99, 128n15

secondary cause (rkyen), 37, 172-173, 223

seven bodily constituents (lus zungs bdun), $134,162,164-165$

sexagenary table, 179-180, 184

Shakya, T., 15, 61

shen ('spirit'), 138, 142

Shigatse, 86

Shneiderman, S., 49n7

Shneiderman, S. and Turin, M., 45n2, 49n7, 59n16 and nn. 19-20

siddhi, 107n54, 199, 233, 242, 251

siddhi of longevity and immortality, 199, 233, 242

signs of death, 112

Sikkim, 10n1o, 26, 45-48, 59n19, 62, 66-67, $70,76-77,85,198,229,251,253,259$, 261-262, 306

Sikkimese Bhutia, 10n10, 62, 64, 181, 205, 230, 271

Siliguri, 26, 51, 205, 253 
Situ Panchen, 89

six tastes, 96, 162

skyid sdug, 45, 55, 227, 230, 253-254

Sman dpyad zla ba'i rgyal po, 155

sman sgrub sgrub chen, 235, 240-241, 244-245, 253-254

Smith, G.E., 89n14, 93n29

Snellgrove, D., 234-235, 257

Snga 'gyur rnying ma'i chos spyod, 199n 5

social welfare network. See skyid sdug

Sonada, 67

Songtsen Gampo, 61, 88n11

South Indian Siddha pulse diagnosis, 154

Sowa Rigpa, $16-17,85$. See Tibetan medicine

spar kha, 94, 189, 191, 94n32

sphygmology. See pulse diagnosis

sponsor (sbyin bdag), 76-77, 171, 181, 183, 239-240, 253-255, 272, 277, 282

srog. See life-forces and five factors

srog bslu, 8, 174

srog gza'. See vitality tables

stod and smad, 224

Strässle, S., 79n39, 8in42, 103

Subba, T., 45-46, 48n6, 5on8, 51, 53, 56, $62 \mathrm{n} 23,63,66,67 \mathrm{n} 30,68-70$

sudden death, 9, 167, 192-193, 196-197

Tagdrag Ngawang Sungrab Thutop, 236ng

Tannenbaum, N., 38, 40-41

Tārā, 109-110, 113, 200, 204, 210, 212-213, 219, 229-231, 236-237, 242n12, 26o, 263, 265,270

Taube, M., $86 \mathrm{n} 8$

temporal frameworks, 3-4, 6-8, 11-13, 33, $35,37,114,117,122-123,131,156,165,167$, $177,197,215,286,288-290,295$

in Tibetan medicine, 131

temporal maps, $35^{-36}$

ten cultural sciences, 88

Tenth Mile, Kalimpong, 24, 48, 53-54, 57, $61,67,69,184,265,306$

Tenzin Tsewang Jamling, Dharamsala, 27, 95nn36-39, 97n42, 179nn6-7, 22on5, $223 n 6$

textual divination, 215-220, 226

Thangtong Gyalpo, 230

Tharpa Chöling monastery, Kalimpong, 24, 29-30, 76-78, 104-105, 110-111, 189n15, 262,306

the first half of life (tshe stod), 222-224

The Four Medical Treatises. See Rgyud bzhi

the latter half of life (tshe smad), 222-224

three long-life deities, 109-110, 212, 229, three nyes $p a, 12,32,80,93,99,117,119-131$, $136,151,156,172,181$

issues of balance, 121

issues of translating these terms, 120 relationship to life-span, $125^{-126}$ seasonal fluctuations, 122-126, 288 sub-types, 120

their characteristics (mtshan nyid), 123-126

Tibet, 11, 15, 17n12, 24, 31, 47-48, 50, 53, 55-56, 6o-62, 66, 67n28, 68-69, 71, 77, 79n38, 84, 86-90, 91n25, 93-94, 96, 102, 106, 109, 112-113, 120n4, 128, 138, 141, 143, $147,155,176,188,198,203,204 n 14,208$, 215-216, 224n7, 234, 236, 242, 251-252, 269,271

Tibet Mirror, ${ }^{0-51}$

Tibetan astrology, 92-99, 128, 159, 180, 186

arising vowels and nine planets

(dbyangs 'char gza' dgu), 95

astrologer (rtsis pa) , 4, 13, 21, 25, 27, 33, 36, 40, 94-97, 131, 133, 147, 16o-161,

174, 177, 180, 182, 187, 192, 194-196, 212-213, 215, 225-227, 271, 290, 292, 302

calculation of arising vowels (dbyangs 'char gyi rtsis), 94-95, 97 elemental divination (nag rtsis), 93, 94-95, 97-98, 178, 299, 300, 304-305 relationship to divination, 93 result calculations ('bras rtsis), 95 white calculation (dkar rtsis), 94-95

Tibetan Autonomous Region (TAR), 49n7, 86n6, 102-103, 124

Tibetan Bhutia, 52-53, 62-63, 74. See also Tibetans

Tibetan Buddhist ritual knowledge, 105-111

Tibetan calendars, 6, 38-39, 82n44, 94, 120n2, 132, 212, 254, 313 and political power, 39-40 auspicious days, 40, 82n 44, 133 errors in, 37n22, 38-39, 291-292 inauspicious days, 6, 40, 131, 133, 179, 186 two main lineages, 93

Tibetan lunar year, 128

Tibetan Medical and Astrological Institute (TMAI). See

Men-Tsee-Khang, Dharamsala

Tibetan medical paintings, 90, 139, 144-145, 147

Tibetan medicine

definition of, 16-17

Graeco-Arabic influence, 88n11, 155 
ideas of efficacy, 81-82, 119, 131,

$$
135^{-136}
$$

institutionalised forms in India, 84-87

lineages, 85-86

link to Buddhism, $87-88$

medical literature, $87-92$

textual knowledge, 32, 84, 89, 114, 126, 147

timings of medication, 129-131

Tibetan New Year, 39-40, 107, 131, 254, 292

Tibetan Refugee Self-Help Centre, Darjeeling, 57, 67-70

Tibetan settlements, 57, 63, 67-70, 287

Tibetan Uprising Day, $55^{-56}$

Tibetanness, 10-11, 15-16, 56, 60-61, 65-66, $73,75,81,83,85 \mathrm{n} 2,287$

\section{Tibetans}

definition of, $15^{-16}$

issues of authority, 29, 31-32, 89, 143, 147,195

refugees, $45,49,53,56-67,60-71,287$

Tibetans in the Darjeeling Hills, $45^{-83}$

affected by the Agitation, $53-54$

Bhutias, 10, 15, 46, 48, 52-53, 55, 59-69, $74,76,102,271,287$

demographic data, $56-58$

healthcare, $79-83$

language issues, $71-75$

March 10 uprising. See Tibetan Uprising Day

Nepali-Tibetan resentments, 54-55

'new' Tibetans, 15, 68-69

newcomers, 10, 15, 24, 52, 60, 65-66, 68-69

'old' Tibetans, $15,56,68-70$

political activities, $52-53,55^{-56}$

refugee status, $60,63,68,70,287$

Tibetan Christians, 50

Tibetan Muslims, $5^{0}$

time

See also anthropology of time

measured in units of inhalation and exhalation, 13, 128, 156, 202

syllables that categorise time, 144, 307

time units of a day, 128

time cycles, $13,34,178,194-197$

timeliness, 184, 192, 196, 290

timeliness of death, 13, 193-197

timely death, 13, 112, 167, 184, 191-194, 201, 205,290

Tri Songdetsen, 111, 216n3

Trogawa Rinpoche, 76 n37, 85, 87, 156 tsha tsha, 104, 219

tshe dbang, 3, 7-9, 14, 24-25, 39, 53, 61, 106, 107-110, 112, 170-171, 173, 181, 192, 199-201, $205,213,225,227,229-245,251-284$,

292-294

accident protection, 8, 108, 192, 229n1, 273, 277, 293

'blessing without practice', 230

ideas of efficacy, 230, 243

in large crowds, 8-9, 39, 108, 227, 229, 231, 254, 256-258, 284-285

in nineteenth century Tibet, 236

interpreters of, $256-257$

lama's speech during, 242

language barriers, 277

literature review, 234-239

one-to-one transmissions, 229

organisers of, 252-254

performed during childhood, 236

stampede, 244, 258, 282

text/s, 274, 278

various roles of participants, 240-263

visualisation, $5,9,14,108,110,170,237$,

240, 244, 256-257, 26o, 262-268, 270,

293

tshe gtor, 237-238, 240, 245, 258, 263, 279, 284

tshe lha rnam gsum. See three long-life deities

tshe sgrub, 8, 22, 25, 78, 106-108, 110, 199, 204, 210, 213, 219, 229, 231, 235n 7, 240, 244-251, 254, 293, 299

byang gter tshe sgrub, $235 \mathrm{n} 7$

tshe sgrub rgyun khyer, 200

tshe thar, 8, 174, 175n3, 219

Tsongkhapa, 39

turquoise stone (bla g.yu), 148, 188, 190

twelve year signs, $58,127-128,13^{2-133}, 178$, 180,194

untimely death, 3, 7-8, 95, 97, 108, 109n6o, 113-114, 180, 183-184, 186, 191-194, 200-201, 208, 285, 291, 294-295, 302 reasons for, 191

Upanișads, 202

urine diagnosis, 93, 96, 124, 155

Uṣnīṣavijayā, 109-110, 212, 229, 26o rnam rgyal stong mchod, 110

Vāgbhața, 89, 123nı, 162

Vāgīśvarakīrti, 109n6o, 113, 203

vajra (rdo rje), 246, 248, 265, 281

Vajrakīlaya, 235

Vajrapāṇi, 27ın2 
Vajrayāna, 3-5, 7, 11, 14, 84, 102, 105-106, 227, 231, 266-267, 286, 292

vāyu. See rlung

vegetarianism, $82,174,201,278$

vitality, 3-9, 93, 97-98, 161, 288-29o

vitality tables, $3,6-8,36,40-41,98,117$, 131-136, 162, 165, 176n4, 18o, 182, 202, 212 inauspicious day (gshed gza'), 132-133 life-essence day (bla gza'), 132-133, 135, 151, 160

life-force day ( $\left.\operatorname{srog} g z a^{\prime}\right), 132-135,212$ use in clinical practice, $131-136$

Wallace, V.A., 92, 93n3o, 95, 99, 123, 127n14, $128,140 n_{5}, 144$

West Bengal, 4, 18, 45-47, 50-51, 57

White Tārā, 109-110, 113, 200, 204, 212, 219, 229-231, 236-237, 242n12, 26o, 263, 265, 270

White, D.J., 110

wind. See rlung
Yamāntaka, 215, 220

yes shes kyi rlung, 203

yi dam, 106, 109, 262, 264n17

Yoeli-Tlalim, R., 88, 92-93, 94n32, 96, 138, 141, 144, 155

yogic breathing exercises, 13, 110-111, 202-204

Yogini Kachö Deden Wangmo, 176, 217

Yolmo Buddhist Association, Darjeeling, 242n13

Yontan, P., 86n8

Younghusband Expedition, 48

Yuthok Yönten Gonpo the Younger, 31, 89,147

Yuthok Yönten Gonpo the Elder, 89

zhabs brtan, 107-108, 210-212

Zimmermann, F., 120n3, 162n2o, 163n23

Zivkovic, T.M., 75

Zurkhar Lodrö Gyalpo, 139n4, 140, 143

Zysk, K.G., 202-203 